\title{
SIGNIFICANCE TESTING OF ARCHEOLOGICAL SITE 41SR242, THE CORNELIO ALVAREZ SR. SITE, STARR COUNTY, TEXAS
}

\section{CSJ: 3632-01-001 PHARR DISTRICT}

\author{
Prepared for \\ Texas Department of Transportation \\ Environmental Affairs Division \\ 118 E. Riverside \\ Austin, Texas 78704
}

Prepared by

Stephen M. Carpenter, M.A., Christopher W. Ringstaff, M.A., Mercedes C. Cody, M.A., James T. Abbott, Ph.D., Ken Lawrence, M.A., Chris Shelton, M.A., Charles D. Frederick, Ph.D., and Christina Nielsen, M.A.

\author{
SWCA Environmental Consultants \\ 4407 Monterey Oaks Boulevard \\ Building 1, Suite 110 \\ Austin, Texas 78749 \\ www.swca.com
}

Principal Investigator

Christopher W. Ringstaff

Texas Antiquities Permit 7912

SWCA Project Number 52105.03

SWCA Cultural Resources Report No. 19-675

Archeological Studies Program Report No. 181

January 2020

ISBN: 978-1-935545-48-4 


\title{
SIGNIFICANCE TESTING OF ARCHEOLOGICAL SITE 41SR242, THE CORNELIO ALVAREZ SR. SITE, STARR COUNTY, TEXAS
}

\author{
Copyright (C) 2020 \\ Texas Department of Transportation (TxDOT)
}

This is a work for hire produced for the Texas Department of Transportation (TxDOT), which owns all rights, title, and interest in and to all data and other information developed for this project under Contract 57903SA004. Brief passages from this publication may be reproduced without permission provided that credit is given to TxDOT and SWCA Environmental Consultants. Permission to reprint an entire chapter, section, figures or tables must be obtained in advance from the Supervisor of the Archeological Studies Program, Environmental Affairs Division, Texas Department of Transportation, 125 East $11^{\text {th }}$ Street, Austin, Texas, 78701. Copies of this publication have been deposited with the Texas State Library in compliance with the State Depository Requirement.

Printed by Sir Speedy

published by:

Texas Department of Transportation

Environmental Affairs Division

Archeological Studies Program

Scott Pletka, Ph.D., Supervisor

Archeological Studies Program Report No. 181

and

SWCA Environmental Consultants

Austin, Texas

SWCA Cultural Resources Report 19-675

ISBN 978-1-935545-48-4 


\section{ABSTRACT}

The Texas Department of Transportation (TxDOT), conducted National Register of Historic Places (NRHP) eligibility testing of the Cornelio Alvarez Sr. site (41SR242) as part of the State Loop (SL) 195 project (Project) (CSJ: 3632-01-001) in Starr County, Texas. Subsequent to the field investigations, SWCA Environmental Consultants (SWCA) conducted artifact analysis, reporting, and curation preparation for the multi-component historic and prehistoric site. Investigations were conducted in compliance with Section 106 of the National Historic Preservation Act (54 United State Code 30601) and the Antiquities Code of Texas (9 Natural Resources Code). The investigations assessed the site's eligibility for listing on the NRHP (36 Code of Federal Regulations 60.4) and for designation as a State Antiquities Landmark (SAL; 13 Texas Administrative Code 26.8, 26.12). Christopher W. Ringstaff served as Principal Investigator under Texas Antiquities Permit Number 7912. TxDOT conducted the field investigations were from February 20-24, 2017, and April 10-14, 2017.

Site 41SR242 is primarily a Middle to Late Archaic site with lesser Late Prehistoric and perhaps earlier components. The open occupational site is located on an upland margin landform in a tributary valley a few miles from the Rio Grande. The investigations revealed material assemblages consisting of diffusely scattered burned rock, debitage, and lithic tools, which were predominantly recovered from a 30- to 50$\mathrm{cm}$-thick stratum of mixed artifacts. However, a few concentrations of artifacts were identified, and each location yielded isolated intact features. Formation and post-depositional processes are generally not conducive to preservation of intact archeological surfaces, patterns, or site structure. Although the overall site lacks integrity and potential data yield, isolated discrete behavioral loci are present. Therefore, site 41SR242 is recommended as eligible for the NRHP and as an SAL. This recommendation pertains to the portions of the site within the APE. The site extends beyond the APE, and the areas outside of the APE have not been evaluated. 


\section{ACKNOWLEDGEMENTS}

The National Register and State Antiquities Landmark testing of 41SR242 was a collaborative effort of Texas Department of Transportation's (TxDOT) Environmental Affairs Division (ENV), TxDOT Pharr District, Cox McClain Environmental Consulting, and SWCA Environmental Consultants. Landowner Cornelio Alvarez, Jr. warrants particular recognition for his hospitality, grilled ribs, and chicken. The Pharr District's logistical support was critical and thanks go out to Edward Paradise Jr., Robin Gelston, Eduardo Garcia Jr., Marisa Ramirez, Dagoberto Salinas, Edelmiro Perez, Esteban Martinez, Antonio Moreno, and Claudio McKee. TxDOT ENV Principal Investigator Christopher W. Ringstaff made it all happen, cradle to grave, with the field assistance of Dr. J. Kevin Hanselka, Dr. Jason Barrett, and Dr. James Abbott. Dr. Abbott's geoarcheological assessment is a principal interpretive basis for understanding the site. As part of the geoarcheological assessment, CT imagery was captured at the High-Resolution CT Scan Facility (UTCT) at the Jackson School of Geosciences, University of Texas at Austin. Analysis of the imagery was greatly facilitated by Dr. Matthew Colbert, who performed the scans and patiently walked Abbott through the ins and outs of the various software packages used for analysis. Thanks are due to him, Dr. Jessie Maisano, Dr. Romy Hanna, David Edley, and Gary Zucker at UTCT for their help and their patience. Consulting Geoarcheologist Dr. Charles Frederick conducted the thin section analysis and the analysis of sediment samples, including granulometry, magnetic susceptibility, CCE, and organic matter. Additionally, Dr. Abbott's analysis benefitted from conversations about the site with a number of individuals, including Charles Frederick, Arlo McKee, Eric Oksanen, Kevin Hanselka, Ken Lawrence, Chris Ringstaff, Matt Colbert, Jason Barrett, Corey Crawford, and Waldo Troell. Special thanks are due to Corey for covering the last field session. Thanks, are in order for the experienced professional staff of Cox McLain for assistance with field efforts, contracting, and initial post-field analyses. Dr. Chris Dayton assembled an "ATeam crew" consisting of Mathew Stotts, Corey Crawford, and Cesario Guerra. The post-field artifact analysis was conducted by Stephen Carpenter, Jessica Ulmer, Ben Morton, Michael Golden, and Mercedes Cody. Chris Shelton conducted the faunal analysis. The report was written and compiled as a group effort by Christopher Ringstaff, Dr. James Abbott, Stephen Carpenter, Ken Lawrence, Chris Shelton, and Mercedes Cody with maps and figures produced by Carole Carpenter and Christopher Ringstaff. Lauri Logan and Kendall Duncan edited, organized, and formatted the report. Finally, Mercedes Cody oversaw the curation preparation. Much appreciation to those who contributed to the effort. To these and others, this author owes a debt of gratitude.

Steve Carpenter

SWCA Project Manager 


\section{CONTENTS}

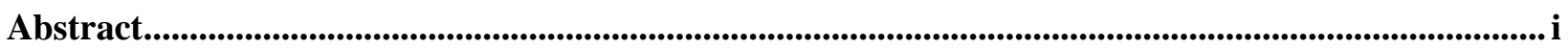

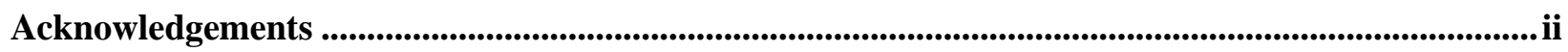

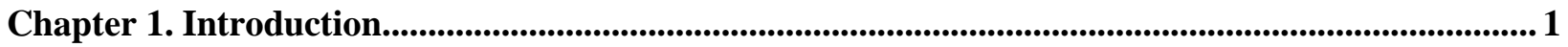

Project Description And Area of Potential Effects (APE) ............................................................ 1

Previous Archeological Investigations .................................................................................... 1

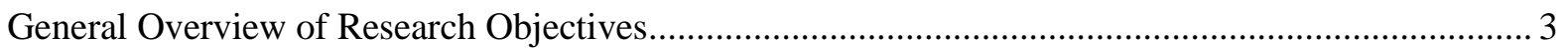

Overview of Investigations and Report Organization .................................................................... 3

Chapter 2. Environmental Setting.............................................................................................................................. 4

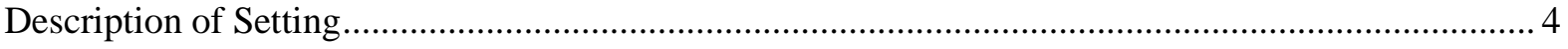

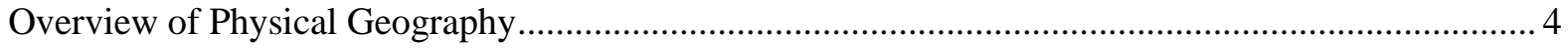

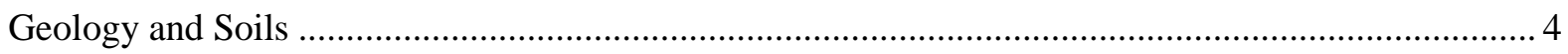

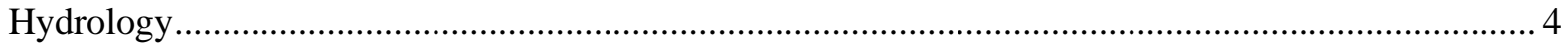

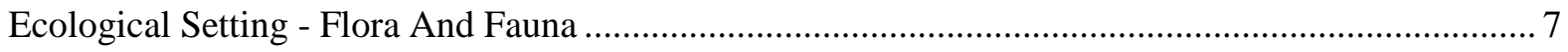

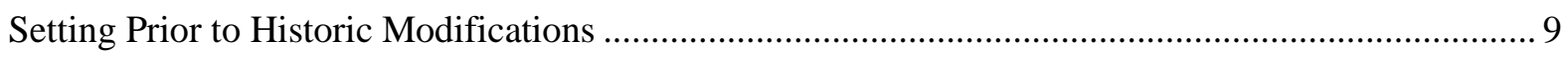

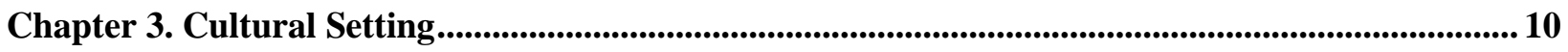

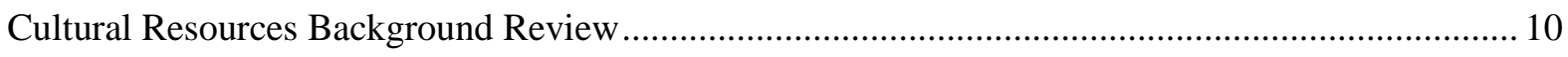

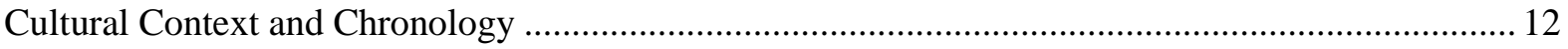

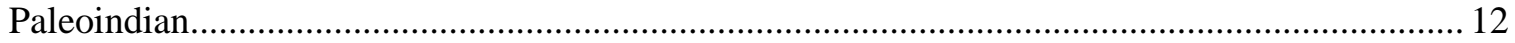

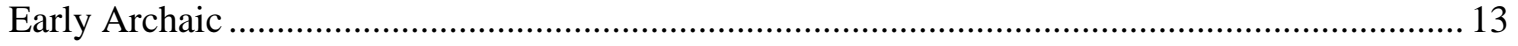

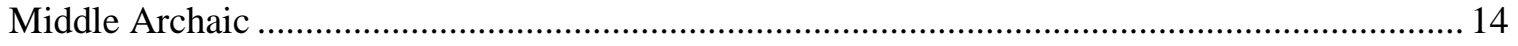

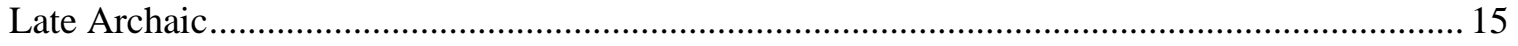

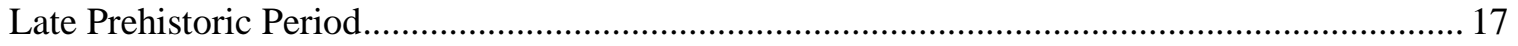

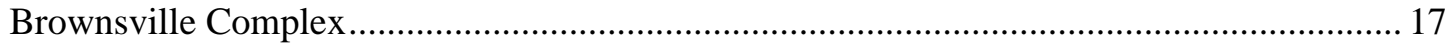

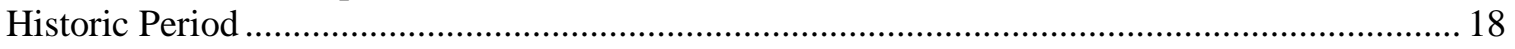

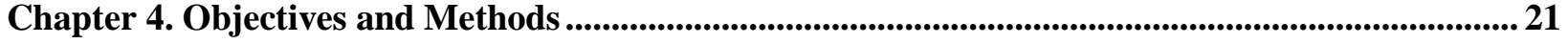

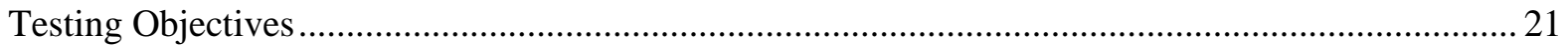

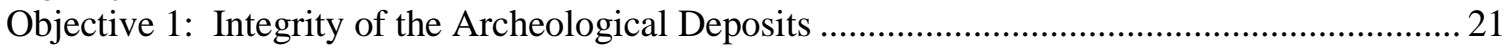

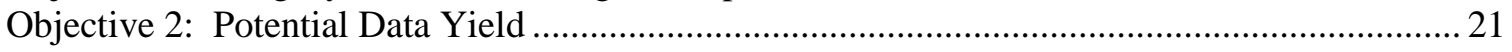

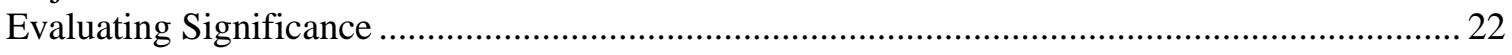

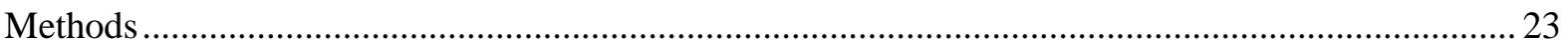

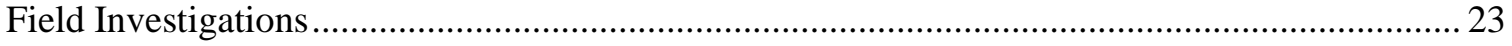

Site Mapping and Provenience Control................................................................................ 25

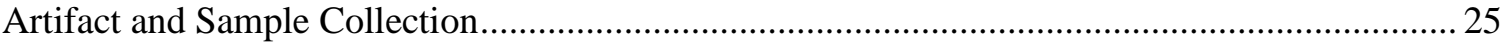

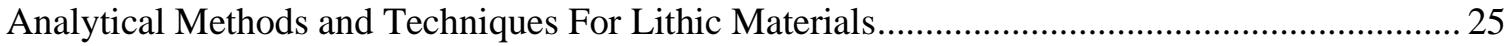

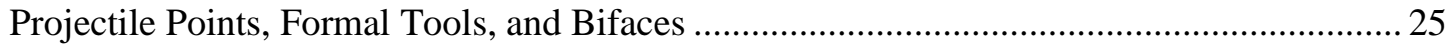

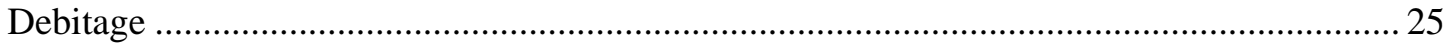

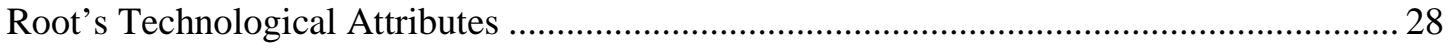

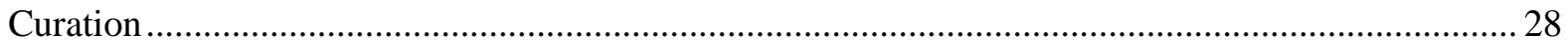

Chapter 5. Results of Field Investigations .................................................................................................... 29

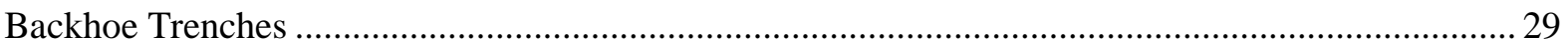

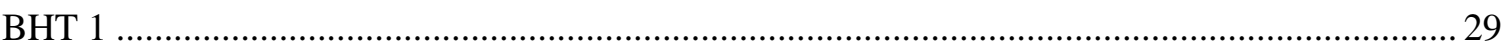

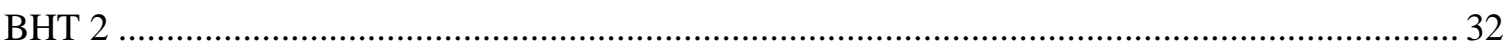

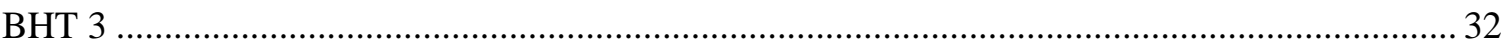




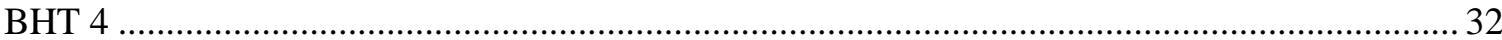

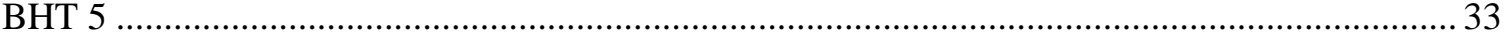

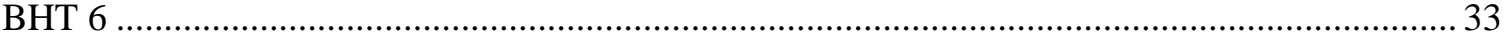

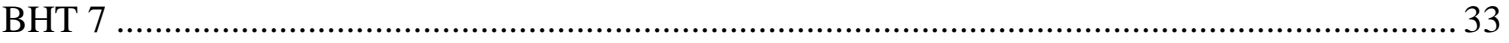

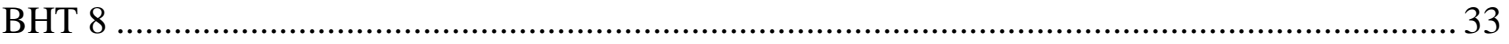

BHT 9

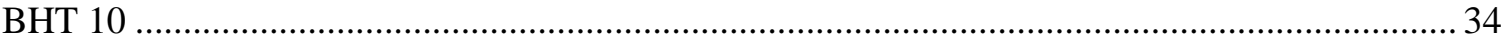

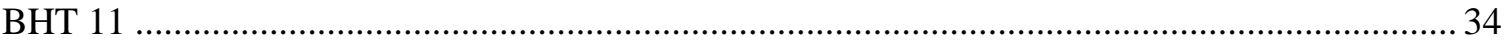

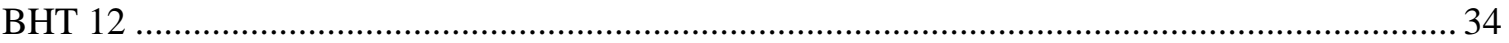

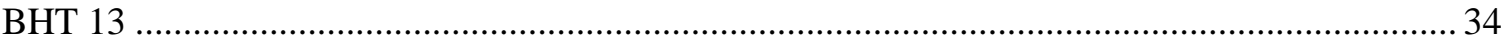

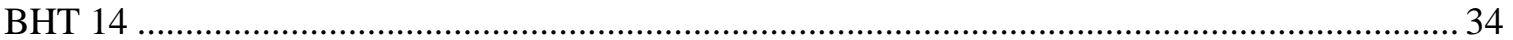

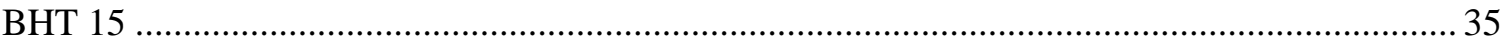

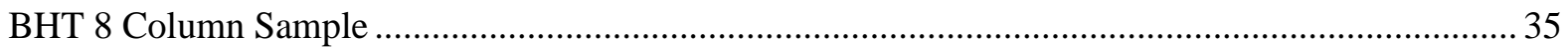

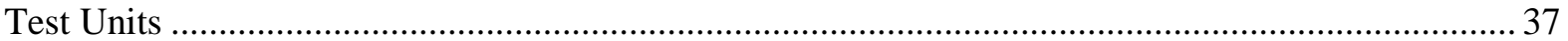

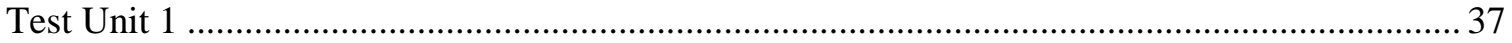

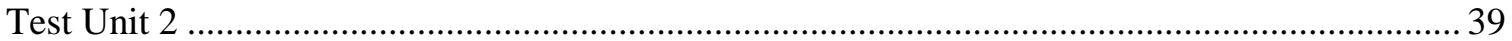

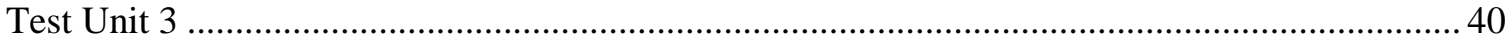

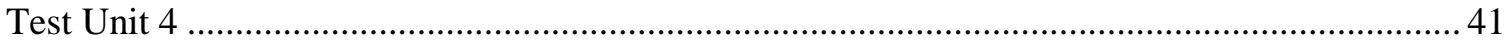

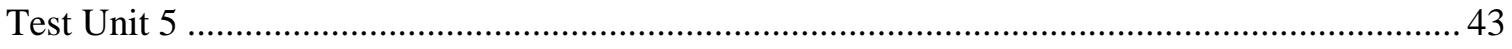

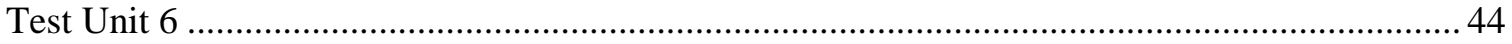

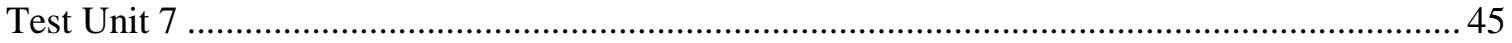

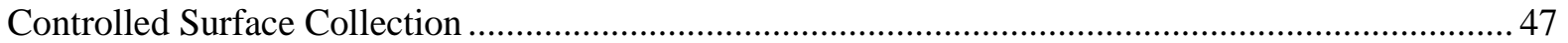

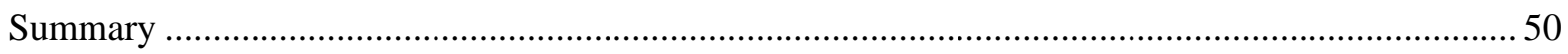

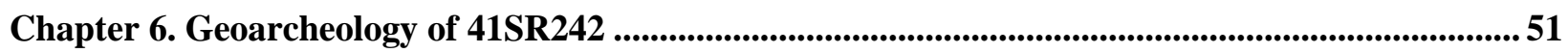

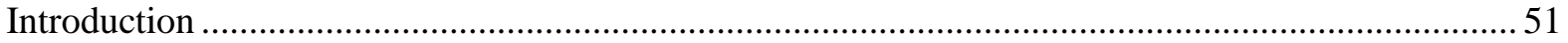

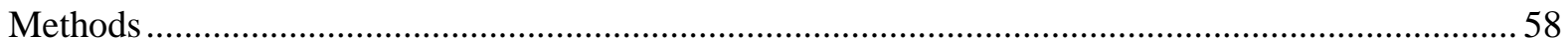

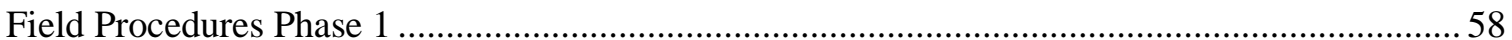

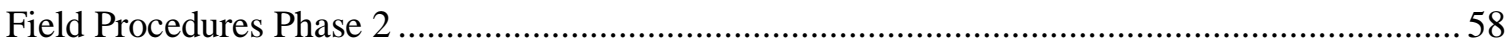

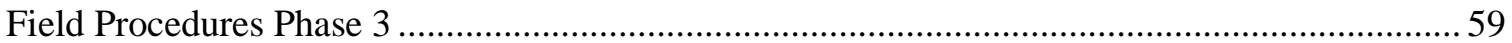

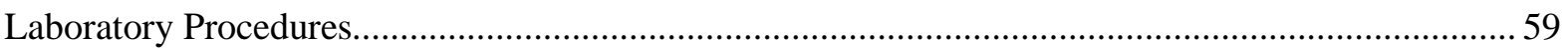

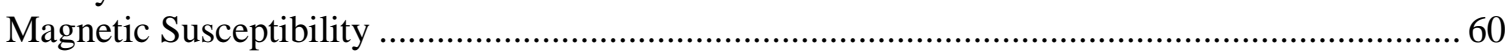

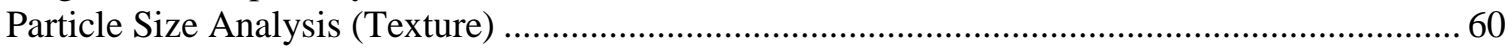

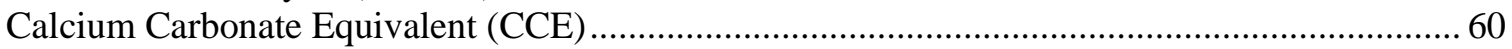

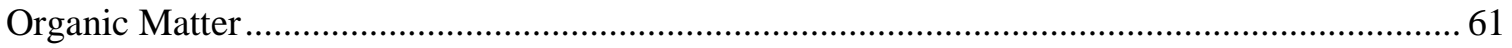

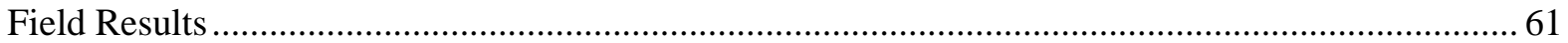

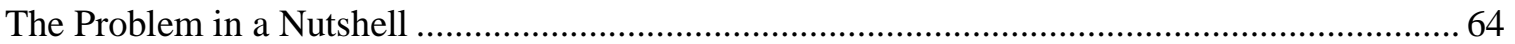

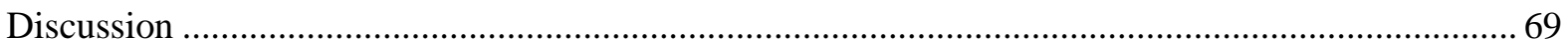

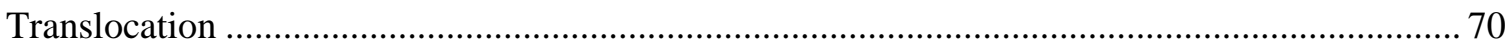

Alluvial and/or Colluvial Transport and Sedimentation .......................................................... 70

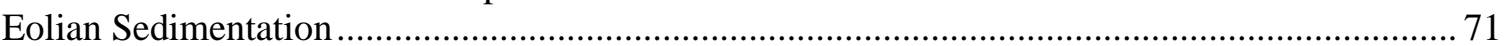

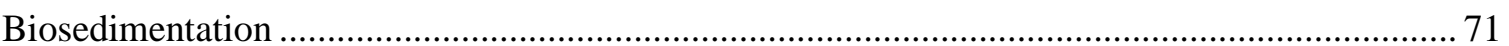

Potential Processes of Artifact Burial at the Cornelio Alvarez Sr. Site .......................................... 72

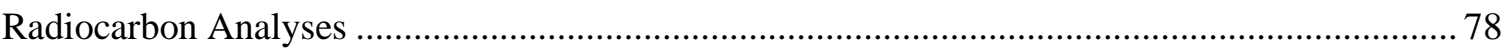

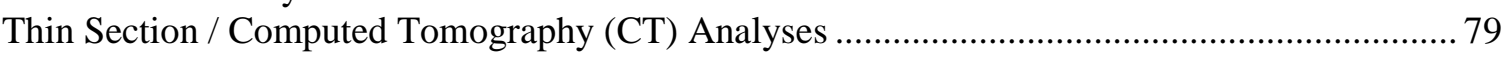

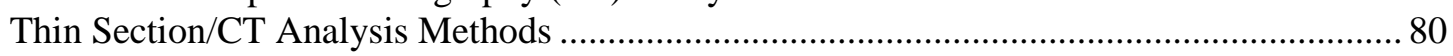

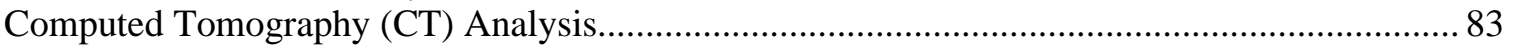

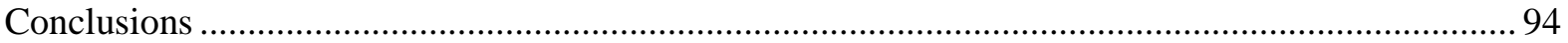




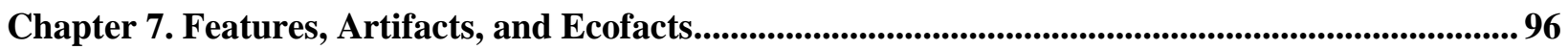

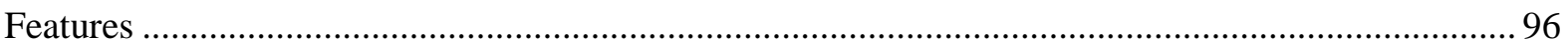

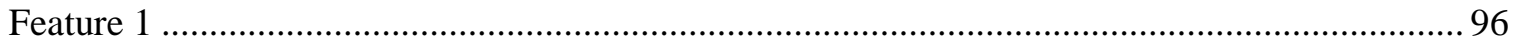

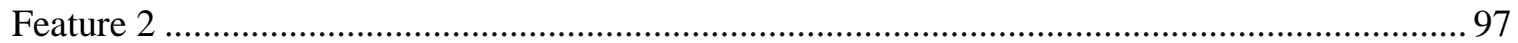

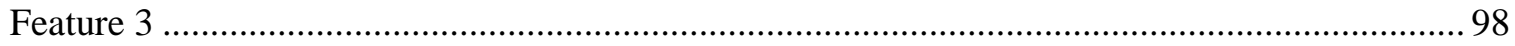

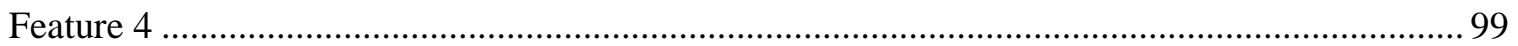

Debitage Analysis of Features 1 and 4 - Biface Production Sequences .................................... 101

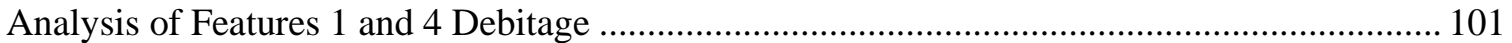

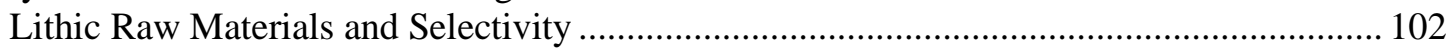

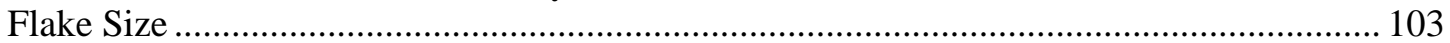

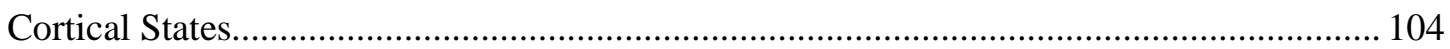

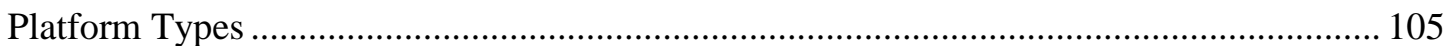

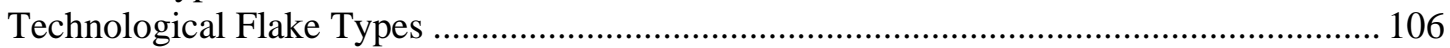

Summary and Interpretations of Features 1 and 4 Debitage ........................................... 107

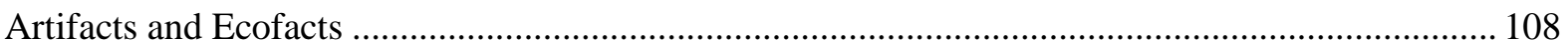

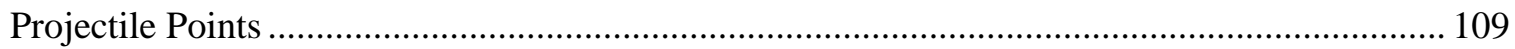

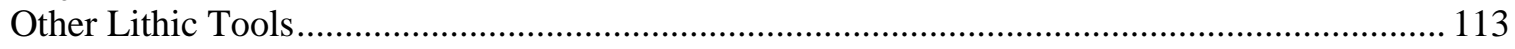

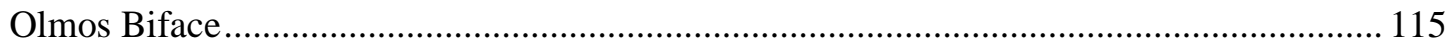

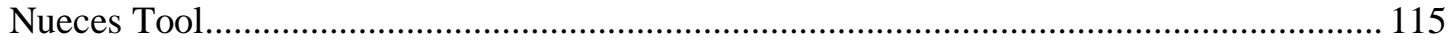

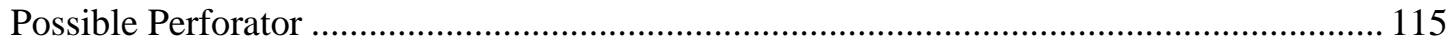

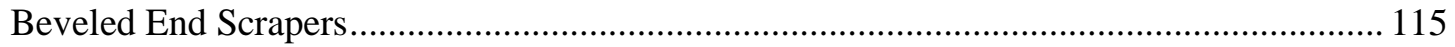

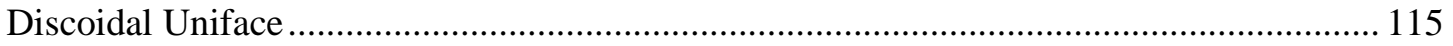

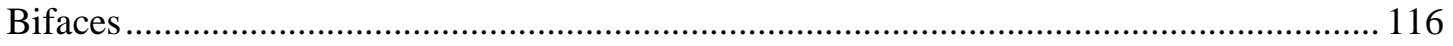

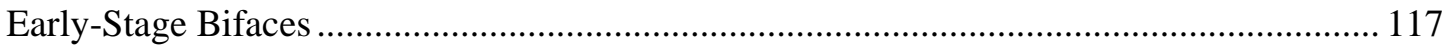

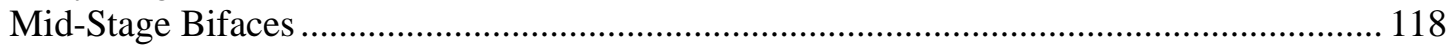

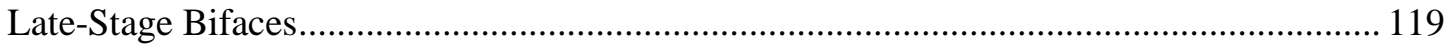

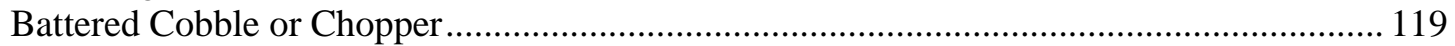

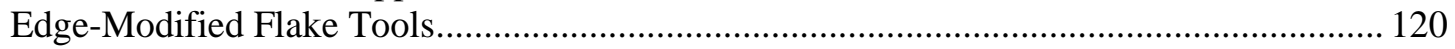

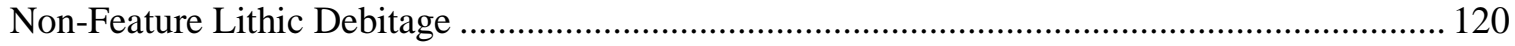

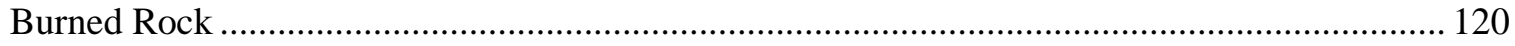

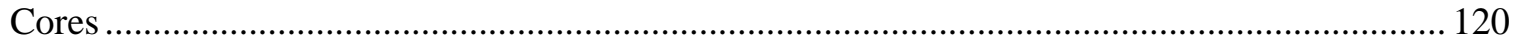

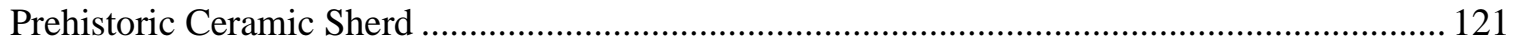

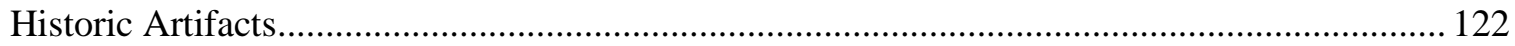

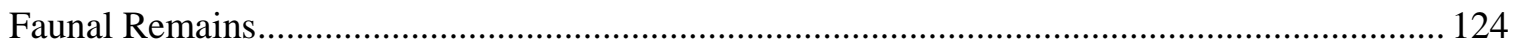

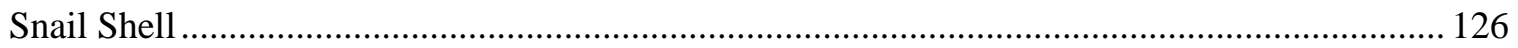

Chapter 8. Summary, Conclusions, and Recommendations .................................................................. 127

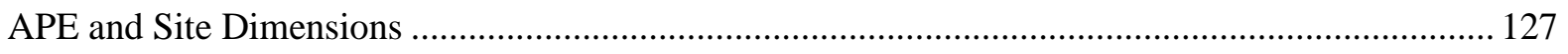

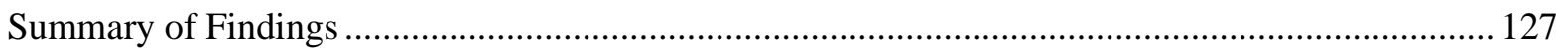

Summary and recommendations of Research directions........................................................... 127

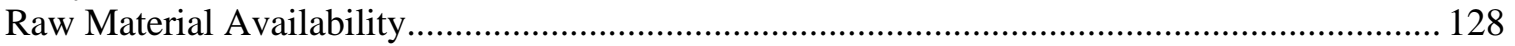

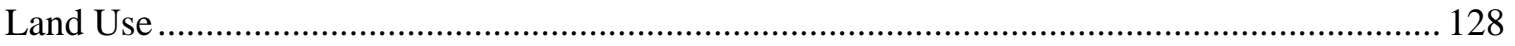

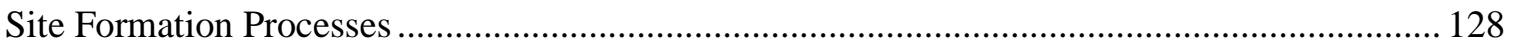

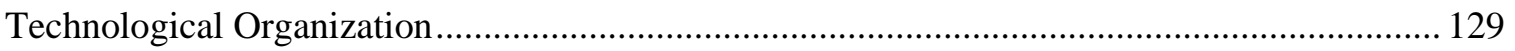

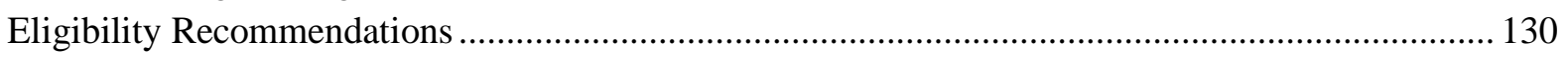

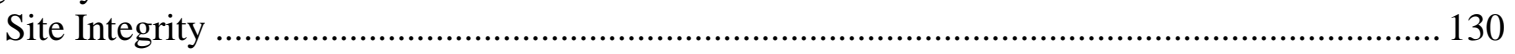

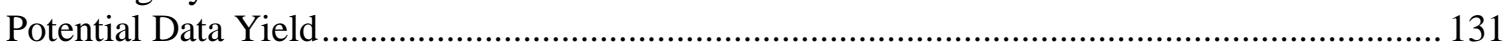

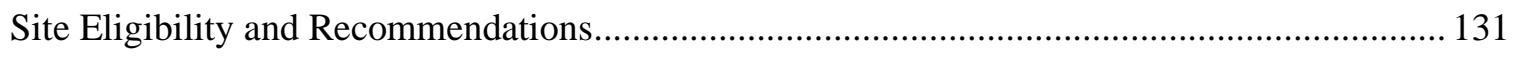

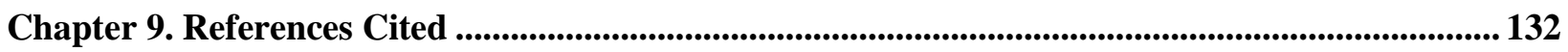




\section{Appendices}

Appendix A. Backhoe Trench Descriptions

Appendix B. Soil Micromorpology

Appendix C. Radiocarbon Data

Appendix D. Lithic Analysis

Appendix E. Faunal Analysis

Appendix F. Historic Artifacts

\section{Figures}

Figure 1.1. Overview of Project area, showing location of site 41SR242 in Starr County. ....................... 2

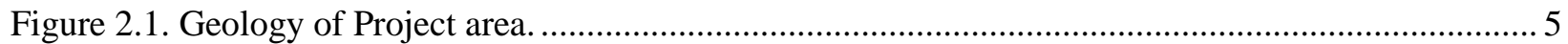

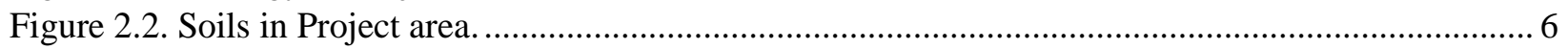

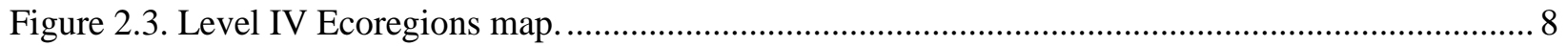

Figure 3.1. Cultural resources background review results map........................................................... 11

Figure 4.1. Backhoe trenching and scraping investigations at the site. ................................................... 24

Figure 4.2. Overview of Corey Crawford conducting geoarcheological investigations at the site............. 24

Figure 4.3. Locations on a flake striking platform for measuring platform width and thickness.............. 27

Figure 4.4. Locations on a flake for measuring axial width and thickness............................................ 27

Figure 5.1. Subsurface testing distribution across area of 41SR242 recommended for NRHP testing...... 30

Figure 5.2. Crew removing overburden during backhoe trench testing, facing east................................. 31

Figure 5.3. Column sample from BHT 8, facing east-southeast............................................................ 35

Figure 5.4. Representative photograph of TU 1, facing north. ........................................................... 37

Figure 5.5. Feature 2 in Test Unit 2 along BHT 4, facing north........................................................... 40

Figure 5.6. Level 2 of TU 4, facing west. Note the Feature 4 on the north side of the test unit............... 42

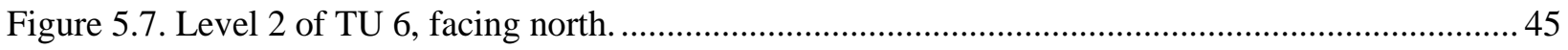

Figure 5.8. Surface artifact distribution across site 41SR242 ............................................................. 49

Figure 6.1. General location of site 41SR242 in Texas. ..................................................................... 51

Figure 6.2. Geology of the area surrounding 41SR242, from McAllen-Brownwood GAT sheet. ............. 52

Figure 6.3. Distribution of gravel-dominated soils and geological formation in Starr County..................54

Figure 6.4. Topography surrounding 41SR242................................................................................5

Figure 6.5. Detail of Web Soil Survey map of the site. ....................................................................56

Figure 6.6. Simulated bird's eye view of 41SR242 and surroundings, facing southwest......................... 57

Figure 6.7. Plot of trench locations through Phase 3. Note north/south-trending scarring from root

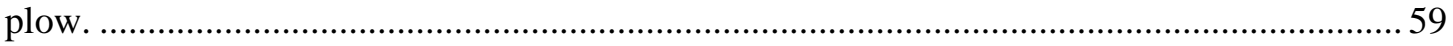

Figure 6.8. Detail of "knobby" texture produced by brushing vertical exposure with a stiff brush........... 62

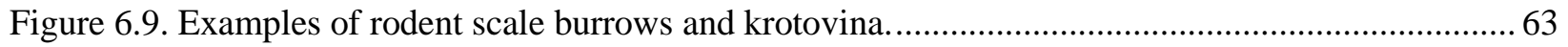

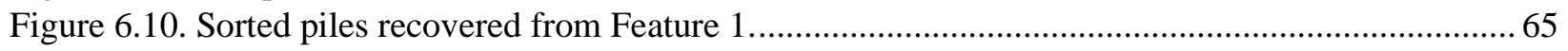

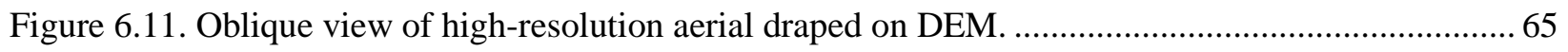

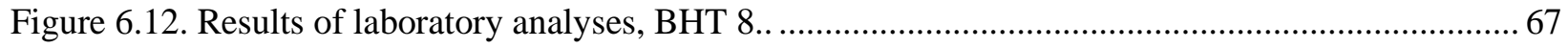

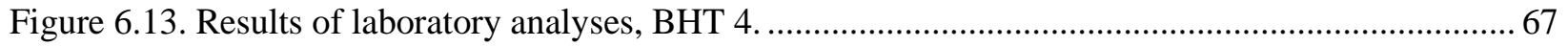

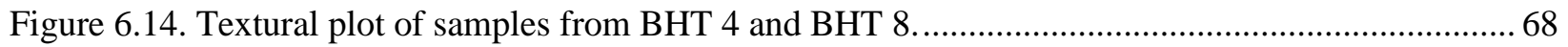

Figure 6.15. Example of brecciated sandstone at the base of the profile of BHT 11............................... 69

Figure 6.16. Lidar-based hillshade showing landforms and modern disturbances in the vicinity of

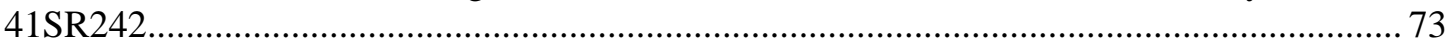


Figure 6.17. Illustrations of root plow equipment, showing the mechanics and impacts of use................. 75

Figure 6.18. Views of the site, showing character of topography and vegetation................................... 76

Figure 6.19. Radiocarbon results arranged by test unit and depth......................................................... 79

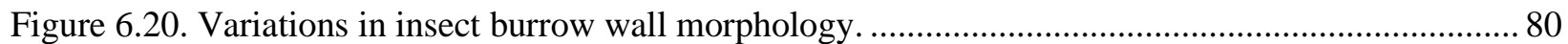

Figure 6.21. Schematic comparison of different macroscopic views of a typical thin section from 41SR242

Figure 6.22. Representative cross section slice of upper $(15-23 \mathrm{~cm})$ block from BHT 8 in normal view and with orange-purple LUT gradient applied.

Figure 6.23. Representative cross section slice of lower $(45-53 \mathrm{~cm})$ block from BHT 8 in normal view and with orange-purple LUT gradient applied.

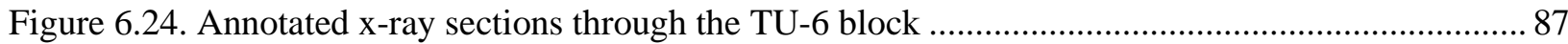

Figure 6.25. Aviso Lite rendering of very low-density segment (voids and very low density fills)........... 88

Figure 6.26. Aviso Lite rendering of the densest material in the TU6 block, ......................................... 89

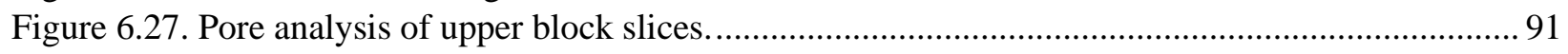

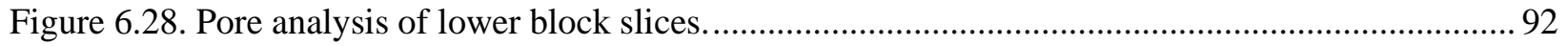

Figure 6.29. Detail of prehistoric and historic materials near BHT 2 …............................................ 95

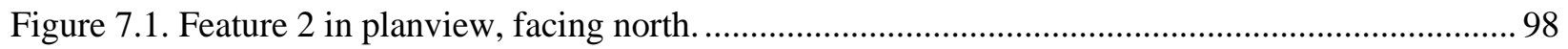

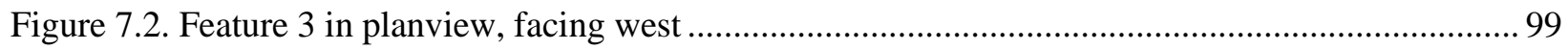

Figure 7.3. Feature 4 after discovery in BHT 15, facing southeast. ..................................................... 100

Figure 7.4. Feature 4 in planview on TU 6 Level 1 and TU 7 Level 2 floors, facing south.................... 100

Figure 7.5. Feature 4 in planview at base of TU 7 Level 2, facing west............................................ 101

Figure 7.6. Small dart and possible arrow point recovered from site 41SR242.. ................................. 110

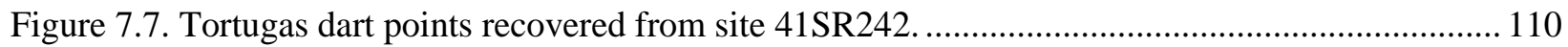

Figure 7.8. Tortugas dart point preforms recovered from site 41SR242 ............................................. 111

Figure 7.9. Refugio dart point recovered from site 41SR242 with possible asphaltum. ........................ 111

Figure 7.10. Lerma-like dart point bases recovered from site 41SR242 ............................................... 112

Figure 7.11. Unidentified dart point bases recovered from site 41SR242 ............................................ 112

Figure 7.12. Unidentified Lanceolate dart point recovered from site 41SR242 ..................................... 112

Figure 7.13. Olmos Biface, Perforator, and Nueces Tool recovered from site 41SR242 ....................... 116

Figure 7.14. Unifaces and scrapers recovered from site 41SR242.................................................... 116

Figure 7.15. Representative sample of late-stage bifaces recovered from Site 41SR242....................... 117

Figure 7.16 Representative sample of mid-stage bifaces recovered from Site 41SR242.. ...................... 118

Figure 7.17. Representative sample of late-stage bifaces recovered from Site 41SR242...................... 119

Figure 7.18. Prehistoric ceramic sherd recovered from site 41SR242. Lot-Specimen No. 170-006........ 122

Figure 7.19. Representative sample of historic ceramics recovered from site 41SR242....................... 124

Figure 7.20. Lot 214-001: Part of a bovid (likely bison) phalange, with the cortical surface

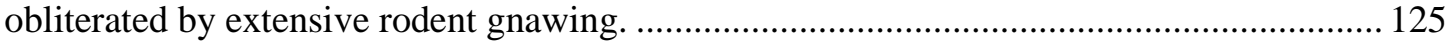

Figure 7.21. Lot 162-045: Trabecular bone fragment exhibiting indications of variable heating. ........... 125

Figure 7.22. Lot 213-001: Javelina mandible with surrounding matrix............................................... 125

Figure 7.23. Lot 213-001: Javelina mandible with surrounding matrix, focus on the occlusal surface

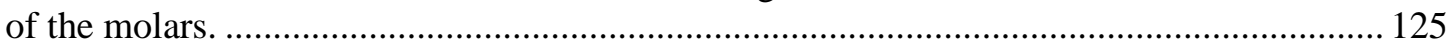




\section{Tables}

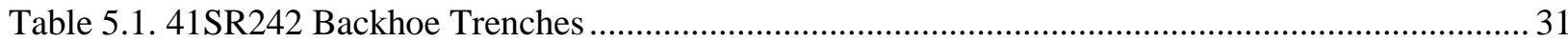

Table 5.2. 41SR242 Artifact Recovery in BHT 8 Column Sample ....................................................... 36

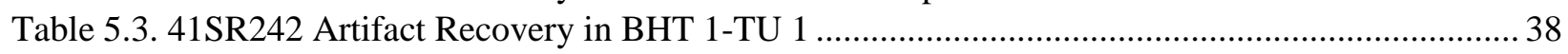

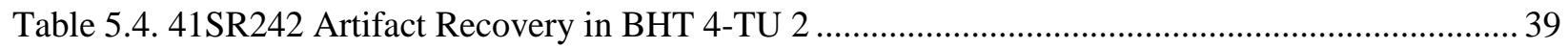

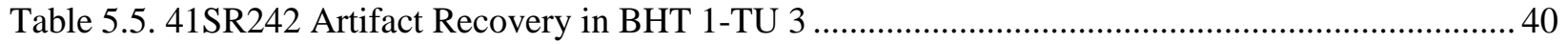

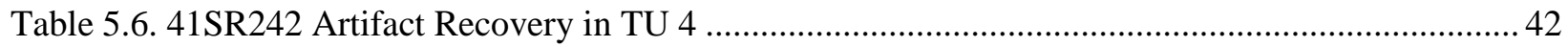

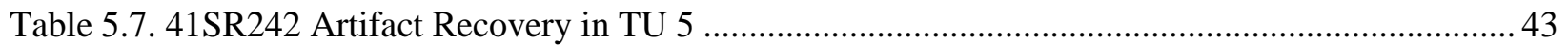

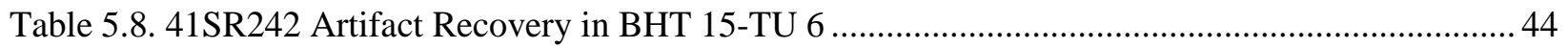

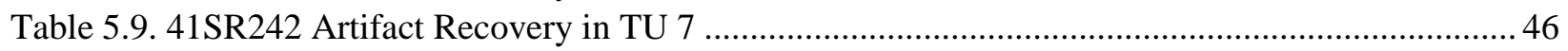

Table 5.10. 41SR242 Prehistoric Controlled Surface Collection ........................................................... 47

Table 6.1. High Gravels Mapped on Various Sheets of the Geologic Atlas of Texas in Central and

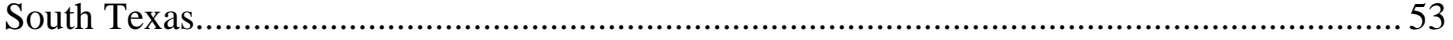

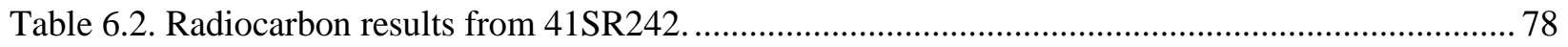

Table 6.3. CT Scan parameters .......................................................................................................... 82

Table 6.4. Comparison of the Relative Frequency of Void Space, Low-density Sediment, and Highdensity Fill (including sediment, rock, and shell) in the "Upper" and "Lower" Block CT

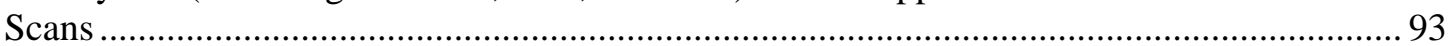

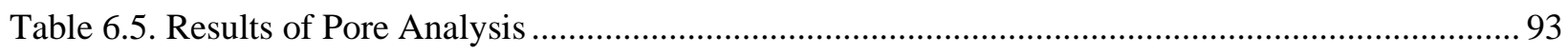

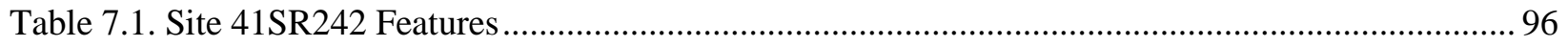

Table 7.2. Lithic Material Types in 41SR242 Feature 1 and Feature 4 Assemblages ............................. 102

Table 7.3. Feature 1 Debitage Size Grades of Five Most Common Raw Material Types ....................... 103

Table 7.4. Feature 4 Debitage Size Grades of Two Most Common Raw Material Types........................ 104

Table 7.5. Feature 1 Debitage Cortical States of Five Most Common Raw Material Types.................... 104

Table 7.6. Feature 4 Debitage Cortical States of Two Most Common Raw Material Types.................... 104

Table 7.7. Feature 1 Debitage Platform Types of Five Most Common Raw Material Types ................... 105

Table 7.8. Feature 4 Debitage Platform Types of Two Most Common Raw Material Types ................... 105

Table 7.9. Feature 1 Debitage Technological Flake Classes of Five Most Common Raw Material

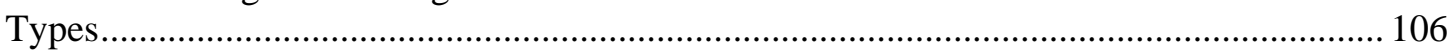

Table 7.10. Feature 4 Debitage Technological Flake Classes of Two Most Common Raw Material

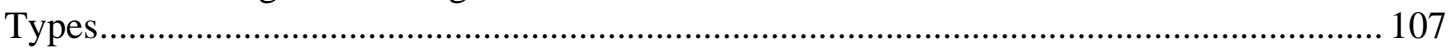

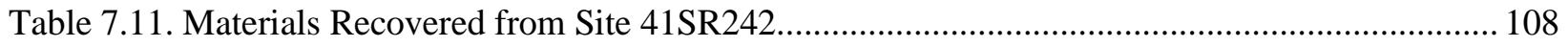

Table 7.12. Projectile Points and Preforms Recovered from Site 41SR242 ........................................ 109

Table 7.13. Other Lithic Tools Not Projectile Points Recovered from Site 41SR242............................ 113

Table 7.14. Cores and Platform Rejuvenation Core Flake Recovered from Site 41SR242.................... 121

Table 7.15. Historic Materials Recovered from Site 41SR242 ............................................................ 122

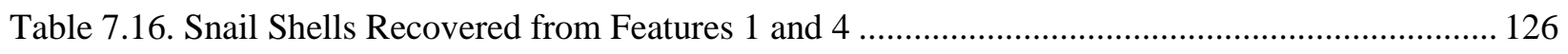

Table 8.1. Comparative Biface:Core Ratio Data from Parry and Kelly (1987)...................................... 130 


\section{CHAPTER 1. INTRODUCTION}

The Texas Department of Transportation (TxDOT), conducted National Register of Historic Places (NRHP) eligibility testing of the Cornelio Alvarez Sr. site (41SR242) as part of the State Loop (SL) 195 project (Project) (CSJ: 3632-01-001) in Starr County, Texas (Figure 1.1). Subsequent to the field investigations, SWCA Environmental Consultants (SWCA) conducted artifact analysis, reporting, and curation preparation for the multi-component historic and prehistoric site. Investigations were conducted in compliance with Section 106 of the National Historic Preservation Act (NHPA; 54 United State Code [USC] 30601) and the Antiquities Code of Texas (ACT; 9 Natural Resources Code [NRC] 191). The investigations assessed the site's eligibility for listing on the NRHP (36 Code of Federal Regulations [CFR] 60.4) and for designation as a State Antiquities Landmark (SAL; 13 Texas Administrative Code [TAC] 26.8, 26.12). Christopher W. Ringstaff served as Principal Investigator under Texas Antiquities Permit Number 7912. The field investigations were conducted on February 20-24, 2017, and April 1014, 2017.

To facilitate the Project schedule, an interim report was submitted in 2017 (Ringstaff and Abbott 2017). Recommendations provided therein were used to coordinate NHPA and ACT obligations. The Texas Historical Commission (THC) concurred with the findings and recommendation provided in the interim report. This report provides the final results of the investigations and analyses to meet the requirements of the antiquities permit and Secretary of Interior guidelines. The additional data and interpretations provided in this report support the previous recommendations.

\section{PROJECT DESCRIPTION AND AREA OF POTENTIAL EFFECTS (APE)}

The tested portion of the site is located within the larger Project area of potential effects (APE). The proposed SL 195 is a new roadway in southwestern Starr County extending from Farm-to-Market (FM) 755 to the intersection of U.S. Highway 83 and Loma Blanca Road. The total project length is 17.21 miles and varies between 300 and 450 feet in width. The entire SL 195 Project covers a total area of approximately 824.5 acres. Existing right-of-way (ROW) composes approximately 24 acres and the remaining 800.5 acres is new ROW. According to typical design sections, the depth of impacts is estimated to be up to 40 feet below the current ground surface for the bridge supports and up to 6 feet in depth for the rest of the project.

\section{PREVIOUS ARCHEOLOGICAL INVESTIGATIONS}

Site 41SR242 was initially recorded in April 1975 as a multi-component historic and prehistoric site. The historic component was described as an artifact scatter associated with an old house foundation disturbed by root plowing. The prehistoric component was simply characterized as cores, flakes, and burned rock. In 2006, Hicks and Company conducted a survey for the initial design of the proposed SL 195 project under Texas Antiquities Permit Number 4199 (King and Feit 2006). The executive summary of the report briefly describes denied right of entry for 41SR242, as well as adjacent site 41SR243. The report further states that site 41SR243 was examined from an adjacent property and bulldozing was observed, but no mention is made of impacts to 41SR242. In May 2016, SWCA conducted additional survey on behalf of TxDOT. Based on shovel test recovery and apparent upland Holocene sedimentation, SWCA recommended additional work in the western portion of the site. The site was re-surveyed in May 2016 by Jim Abbott and Chris Ringstaff of TxDOT to examine the area designated for additional investigation via backhoe trenching. The artifact-bearing Holocene sediments were confirmed and a debitage feature was encountered. The feature was mapped, then covered for systematic excavation later during testing. With confirmation of the upland Holocene soils containing archeological materials, TxDOT recommended NRHP and SAL eligibility testing at 41SR242. 


\section{Restricted Information}

Not for Public Disclosure

Figure 1.1. Overview of Project area, showing location of site 41SR242 in Starr County. 


\section{GENERAL OVERVIEW OF RESEARCH OBJECTIVES}

The Rio Grande delta has long been cited as an archeological region with a rich material record but rife with unresolved issues regarding the prehistoric sequence and adaptive patterns. In part the issues derive from depositional processes that result in mixed assemblages on relatively stable landforms. In alluvial settings, high energy floods often result in lateral scouring of stream terraces. In addition to natural processes, cultural forces have also affected the region's archeological record. Agricultural practices historically relied on gravity flow canal irrigation, which emerged in the early twentieth century. To be effective, the landscape was leveled and the high points removed to fill the low points. Canal irrigation fostered an economic boom, the "Magic Valley," but these agricultural practices significantly disturbed the archeological record.

As a result of these factors, much of the regional archeological record is known from large surface collections and there is a general lack of clarity on cultural and behavioral patterns of the prehistoric sequence extending back to Paleoindian times. Accordingly, in consideration of the regional context, the testing objectives were to assess the site's potential for providing intact and isolable components or activity areas that could redress some of the regional research problems. Site formation processes, both natural and cultural, constituted a central analytical tack in the site assessments. Specifically, the investigations were "feature-focused," directly targeting intact artifact concentrations.

\section{OVERVIEW OF INVESTIGATIONS AND REPORT ORGANIZATION}

To gather sufficient data to make clear determinations of eligibility, the investigation used a two-phased approach, including a geoarcheological study and archeological testing, which were done concurrently. Jim Abbott conducted the geoarcheological study, focusing on the depositional contexts and stratigraphy, site formation processes, and assessing the potential for intact buried surfaces. The second phase entailed archeological investigations using backhoe trenching, mechanical scraping, and hand excavations to assess the potential for intact or substantial cultural deposits. The investigations occurred within select portions of the site, areas defined during previous surveys as having the highest potential for intact deposits (Ringstaff 2014).

Upon completion of the field investigations in April 2017, artifacts were washed, tabulated, and analyzed in accordance with TxDOT and other protocols. The interim report and the artifact and sample analyses were completed in August 2019. Special samples included soil analyses and seven radiocarbon assays obtained from one piece of wood charcoal and six Rabdotus shells. Analyses of artifacts followed TxDOT protocols (TxDOT 2013).

In compliance with requirements of the ACT, and guidelines issued by the Secretary of the Interior and the Council of Texas Archeologists, this report provides details on the environmental setting (Chapter 2), cultural background and contexts (Chapter 3), objectives and methods (Chapter 4), results of investigations (Chapters 5 and 7), and interpretations and recommendations on eligibility and research potential (Chapter 8). Appendices include backhoe trench (BHT) descriptions (Appendix A), soil micromorphology (Appendix B), radiocarbon data (Appendix C), the results of analyses for lithic studies (Appendix D), the faunal assemblage (Appendix E), and the historic artifact assemblage (Appendix F). 


\section{CHAPTER 2. ENVIRONMENTAL SETTING}

\section{DESCRIPTION OF SETTING}

Site 41SR242 is situated on a gradual rise approximately 300 meter (m) east of Arroyo Quiote and approximately $190 \mathrm{~m}$ northeast of a prominent tributary. The site is within the dissected uplands of the Rio Grande Plains physiographic region of Texas. The Rio Grande delta is a region with a distinct set of environmental circumstances that create a unique ecosystem found only in South Texas and Northeastern Mexico (Jahrsdoerfer and Leslie 1988). These environmental conditions, which include suitable soils and climate for agriculture, have attracted human settlement for millennia. The area, referred to by early twentieth land developers as "Magic Valley," currently supports a population of 1.3 million people according to the 2012 U.S. Census Bureau estimates for the four-county area including Starr, Hidalgo, Willacy, and Cameron Counties. As a result of settlement, there have been many environmental changes since the 1920s, including the loss of approximately 95 percent of the original native brushland (Jahrsdoerfer and Leslie 1988). Modern gravel mines and agricultural fields currently border the project area. The practices of both have affected the archeological record of the area, including 41SR242.

\section{OVERVIEW OF PHYSICAL GEOGRAPHY}

A review of the Bureau of Economic Geology and U.S. Geological Survey (USGS) topographic maps reveal the Rio Grande Valley is a wide floodplain delta containing many resacas, oxbow lakes formed from abandoned meanders of the Rio Grande. The Project area is near the northwestern margin of the delta, which fans out to become much wider downstream to the east. Although the region has relatively level topography, the Project area falls on the upland margin overlooking the river floodplain and terraces to the south. Downcutting tributaries create a scalloped upland margin, and archeological sites tend to be common on prominent landforms overlooking the terraces.

\section{GEOLOGY AND SOILS}

The geology of the project area is mapped within the Tertiary-age Jackson Group sandstone and clay, Catahoula and Frio formation mudstone, claystone, sandstone, and clay with occurrences of Pleistocene Uvalde Gravels and Holocene Alluvium (Fisher 1976) (Figure 2.1). Rio Grande gravels composed of chert, chalcedony, sandstone, and quartzite from the Trans-Pecos, Mexico, and New Mexico provide a wide variety of lithic resources available for exploitation by the prehistoric population. However, the area borders the Rio Grande delta, a region in which knappable lithic material is all but absent from the landscape making the project area a suitable area for prehistoric inhabitants to resupply. The mapped soils for site 41SR242 within the ROW are primarily Copita fine sandy loam (Thompson et al. 19724)

(Figure 2.2). The Copita series soils are well drained, moderately deep soils overlaying sandstone that are level to gently sloping (Thompson et al. 1972).

\section{HYDROLOGY}

The Rio Grande, one of North America's major rivers, flows 3,090 kilometers (km) from southeastern Colorado, emptying into the Gulf of Mexico approximately $180 \mathrm{~km}$ east of the project area. Arroyo Quiote flows directly in the Rio Grande. Prior to modern flood and irrigation systems, surface water was much more prevalent in the area (see discussion on modern developments below). 


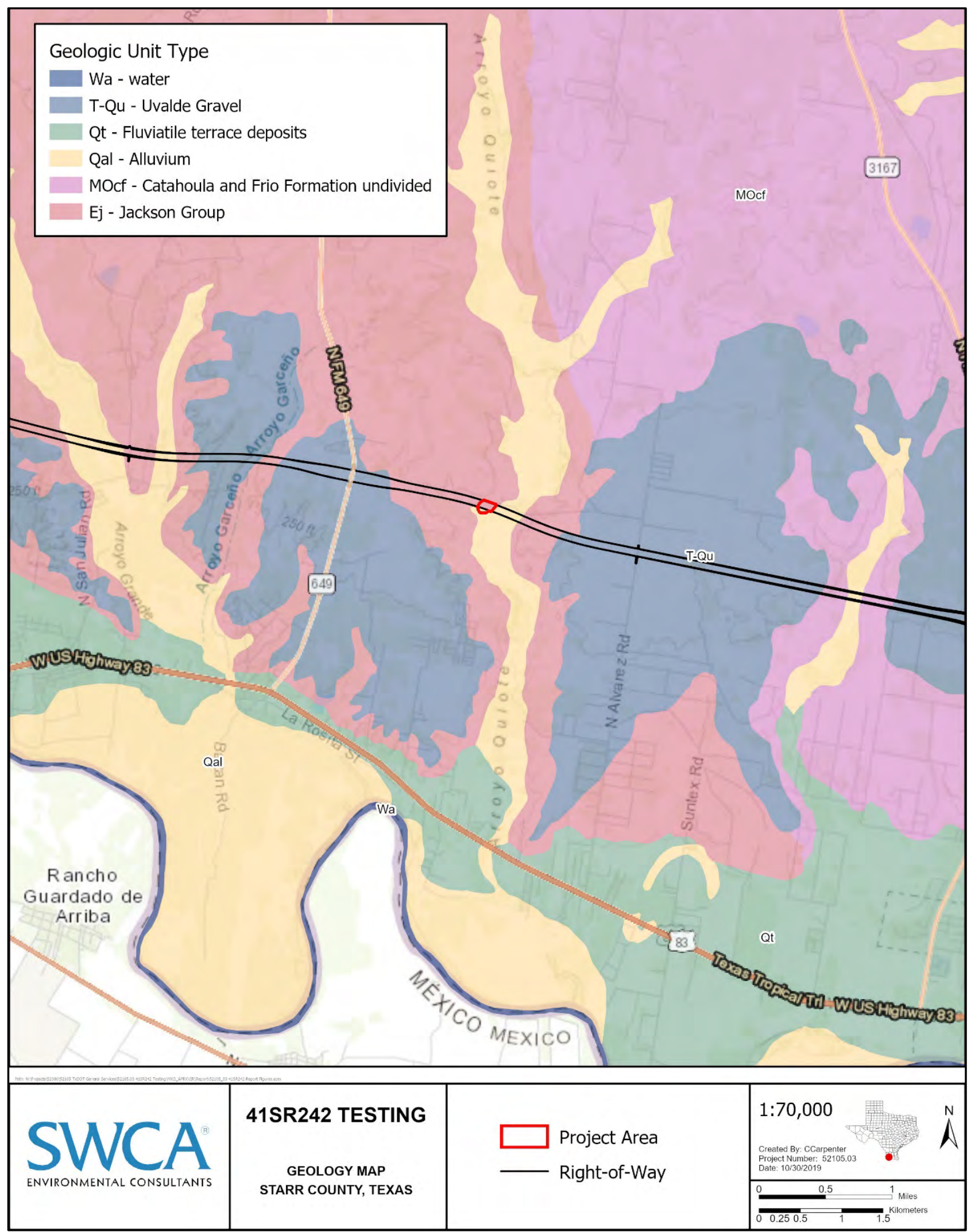

Figure 2.1. Geology of Project area. 


\title{
Restricted Information
}

\author{
Not for Public Disclosure
}

Figure 2.2. Soils in Project area. 
There are several inland lakes, Laguna Madre and Laguna Atascosa are among the largest. Along the western and northern sides of many lakes, clay dunes called lomas create fairly substantial formations up to $9 \mathrm{~m}$ high. Most of the inland lakes are east of the project area in the lower delta, but several lake beds approximately $50 \mathrm{~km}$ to the northeast are notable as historic and prehistoric salt sources. La Sal Vieja and Sal del Rey are shallow salt lakes, dry during parts of the year but seasonally recharged with rainfall, contain millions of tons of 99.0897 percent sodium chloride rock-crystal salt (Campbell 2014).

\section{ECOLOGICAL SETTING - FLORA AND FAUNA}

The Project area falls within the Tamaulipan biotic province as defined by Blair (1950), a province that covers the South Texas Plains geographic region, and more specifically the lower Rio Grande delta ecoregion (Figure 2.3). However, Blair (1950:103) suggests the Lower Rio Grande Valley should be considered a separate biotic district distinct from the rest of South Texas within the Tamaulipan province. Diamond et al. (1987:204) place the area in a subdivision of the South Texas Brush Country called the Subtropical Zone. Many of the 61 mammal species, two land turtles, 36 snakes, 19 lizards, and various species of reptiles, frogs, and toads that occupy, or have historically occupied, this biotic province have adapted to its subtropical, "megathermal” climate (Blair 1950:102-105). Species distribution and densities vary considerably and are mainly dependent upon the local vegetational community and available water resources.

The South Texas Plains region's modern vegetation community has changed quite a bit from prehistoric conditions of the area (Jahrsdoerfer and Leslie 1988). The indigenous flora "would have been composed of riparian lands and bottom lands deciduous forests" (Kibler and Freeman 1993:3). Today, the regional vegetation is brush land dominated by mesquite (Prosopis glandulosa) and acacia (Acacia sp.). Other scrub and brush species found in the region include prickly pear (Opuntia lindheimeri), Barbados cherry or Mexican myrtle (Malpighia glabra), and saw greenbrier (Smilax bona-nox). Vegetation along the Rio Grande is dominated by giant reed (Arundo donax), black willow (Salix nigra), hackberry (Celtis laevigata), and huisache (Acacia farnesiana) trees. The Mexican palm (Sabal Mexicana) is a species the distinguishes the Lower Rio Grande Valley from the rest of south Texas

According to Davis and Schmidly (1994), common small mammals that may occur in the region include the pocket mouse (Perognathus hispidus), white-footed mouse (Peromyscus leucopus), southern plains woodrat (Neotoma micropus), desert cottontail (Sylvilagus audubonii), and black-tailed jackrabbit (Lepus californicus). Large mammal species that occur or have the potential to occur within the project area include white-tailed deer (Odocoileus virginianus), coyote (Canis latrans), bobcat (Lynx rufus), and javelina (Tayassu tajacu).

Bird species present in the area are typical of the brush and scrub vegetational community. Common resident species include the mourning dove (Zenaida macroura), northern mockingbird (Mimus polyglottos), house sparrow (Passer domesticus), olive sparrow (Arremonops rufivirgatus), the northern bobwhite (Colinus virginianus), red-tailed hawk (Buteo jamaicensis), and long-billed thrasher (Toxostoma longirostre). Besides mammals and birds, various snakes and lizards, and occasional toads can also be found. 


\title{
Restricted Information
}

\author{
Not for Public Disclosure
}

Figure 2.3. Level IV Ecoregions map. 


\section{SETTING PRIOR TO HISTORIC MODIFICATIONS}

The current setting of the Rio Grande delta is very different from the landscape occupied by indigenous groups in prehistoric times. The nearly level, treeless coastal plain with little surface water except for irrigation canals is the result of modern development and agricultural practices. Based on a compilation of historical accounts, Salinas (1990:12-13) describes the Rio Grande delta in early historic and prehistoric times as covered with dense woody vegetation, with marshy resacas. Currently, intensive upstream water demand and dams have slowed the Rio Grande flow rate, curtailing deltaic flooding, sapping the recharge of oxbow lakes and marshes. After approximately 1900 to 1920, much of the landscape was cleared and leveled for canal irrigation, removing topographical high points to infill low areas. Based on the accounts, the prehistoric Rio Grande delta likely contained a richer concentration and diversity of biotic resources, both aquatic and terrestrial, prior to historic modifications. 


\section{CHAPTER 3. CULTURAL SETTING}

The project area is within the larger South Texas archeological region, covering the state's southern coastal plain from the margin of Edwards Plateau southward to the Rio Grande delta and thence up the Texas coast to just beyond the mouth of the Guadalupe and San Antonio Rivers (Hester 2004:128). However, the Rio Grande delta is often considered a fairly unique sub-region, one that has many adaptations and traditions not found elsewhere in South Texas. Long-term strategies were likely adapted to the setting at an ecotonal juncture between the southern Texas prairies, inland Brasada with its scrubby, arid setting, and the coastal plain marked by marine and littoral settings along the coast, bays, estuaries, and streams. To provide a context for the archeological sites, this chapter provides data on previous investigations, cultural resources in the area, and the prehistoric sequence.

\section{CULTURAL RESOURCES BACKGROUND REVIEW}

SWCA performed a cultural resources background archival and literature review of the general area surrounding archeological site 41SR242. To conduct this review, an SWCA archeologist reviewed the Roma Los Saenz East USGS 7.5-minute quadrangle maps on the THC's Texas Archeological Sites Atlas online database including searching for pertinent records pertaining to the project area. These sources provided information on the nature and location of previously conducted cultural resources surveys, previously recorded historic and/or prehistoric archeological sites, NRHP districts and/or properties, SALs, Official Texas Historical Markers (OTHMs), Registered Texas Historic Landmarks (RTHLs), cemeteries, and local neighborhood surveys in or near the project area. The results of the review are presented in Figure 3.1.

Site 41SR242 was recorded in April 1975 as a multicomponent historic and prehistoric site. The historic component described an artifact scatter associated with an old house foundation disturbed by root plowing. The prehistoric component is simply characterized as cores, flakes, and burned rock. The form is quite brief, providing minimal information. In 2006, Hicks and Company conducted a survey for the initial design of the proposed SL 195 project under Texas Antiquities Permit 4199. The executive summary of the report briefly describes denied right of entry for 41SR242 and 41SR243 and that site 41SR243 was examined from an adjacent property and bulldozing was observed. There was no mention of impacts to 41SR242.

In May 2016, SWCA conducted additional survey on behalf of TxDOT. Based on shovel test recovery and apparent upland Holocene sedimentation, SWCA recommended additional work in the western portion of the site. The site was re-surveyed in May 2016 by Jim Abbott and Chris Ringstaff of TxDOT to examine the area designated for additional investigation via backhoe trenching. The artifact-bearing Holocene sediments were confirmed and a debitage feature was encountered. The feature was mapped and covered to be excavated properly during testing. With confirmation of the upland Holocene soils containing archeological materials, TxDOT recommended NRHP and SAL eligibility testing at 41SR242.

Four previously recorded sites (i.e., 41SR16, 41SR242, 41SR243, and 41SR419) are within a 1-mile radius of 41SR242 (THC 2019). The sites consist of primarily surface scatters of lithic debris and burned rock. The nearest site, 41SR243, is likely an extension of 41SR242 and was previously recommended for combining by SWCA during the survey investigations (see Figure 3.1). No historical markers, cemeteries, NRHP districts or properties are located within the 1-mile background review area (THC 2019). 


\title{
Restricted Information
}

\author{
Not for Public Disclosure
}

Figure 3.1. Cultural resources background review results map. 


\section{CULTURAL CONTEXT AND CHRONOLOGY}

Site 41SR242 is a multicomponent historic and prehistoric site with possible Paleoindian to Late Prehistoric components. Most of the radiocarbon dates and diagnostic artifacts indicate Middle to Late Archaic occupations were the predominant occupational periods. The cultural chronology provides a wider geographical extent than solely the lower Rio Grande, including the broader South Texas and Coastal regions.

\section{Paleoindian}

The Paleoindian period (11,500 to 8800 B.P. [radiocarbon years]) spans the time of initial settlement to the advent of regional identities that mark the beginnings of the later Archaic period hunter-gatherers. These earliest groups, distinguished in the archaeological record by various lanceolate points, including Clovis, Folsom, Plainview, Golondrina, and Angostura types, are generally inferred to have been small, highly mobile bands relying on large game animals for their basic livelihoods. Although a fairly large number of diagnostic artifacts dating to this period have been recovered from South Texas, no clearly intact sites have been investigated in the region. Consequently, the nature of Paleoindian adaptation to South Texas remains poorly understood, relying largely on inferences from better-studied sites in adjacent areas such as the Southern Plains, Lower Pecos, and Central Texas, but the focus is on the Pharr District in which 41SR242 is located.

Since early Paleoindian sites are rare in far South Texas, the distribution of diagnostic artifacts reveal some important information on settlement patterns. Clovis points mark the earliest identified Paleoindian groups in the region. In a survey of fluted points reported from throughout the state, Meltzer and Bever (1995) identified 49 Clovis points recovered from the counties comprising the South Texas region. Clovis points are rare in the coastal areas, including the Rio Grande Delta. A total of 2 points were reported from the Pharr District counties (see Meltzer and Bever 1995:49-50) and only 4 Clovis points recovered from the counties comprising the Corpus Christi District, further substantiating the rarity of these early sites along the coast and Rio Grande Delta. Interestingly, the vast majority of Clovis points in South Texas have been recovered from the Nueces-Guadalupe Plain, indicating either a focus on the area or uncommonly suitable preservation conditions. Folsom point distributions, both the frequency and spatial patterning, differ from the Clovis patterns, suggesting a shift in settlement patterns (Meltzer and Bever 1995:60, 74). Folsom points appear more frequently in the coastal plain as well as the South Texas plain, most notably the Nueces-Guadalupe Plain. As Folsom points are almost exclusively found in plains settings, the technology perhaps marks a more specialized adaptation, likely to a more intensive reliance on ancient bison.

No intact sites dating to these times have been systematically studied in the vicinity of the Cornelio site. Among the nearest investigated Paleoindian sites is the La Paloma Mammoth site (41KN78) located along the Palo Blanco River in Kenedy County (Suhm 1978, 1980). At this site, a possible fluted lanceolate point and other tools were found in proximity to mammoth and Bison antiquus bones. However, the researchers determined the artifacts were found in secondary context and were not in direct association with the Pleistocene faunal remains. The nearest sites with reasonably good integrity are located in the Lower Pecos (e.g. Baker Cave, Hinds Cave, Devil's Mouth, and Eagle Cave), the coastal plain (e.g. Berger Bluff and several sites in Victoria County), and Central Texas (e.g. Pavo Real, Berclair Terrace, otherwise known as Buckner Ranch). The submerged site at McFaddin Beach on the upper Gulf Coast has produced artifacts spanning the entire spectrum of Texas prehistory, with remarkable numbers of Paleoindian and Early Archaic projectile points having been recovered.

The early lithic technology of the Paleoindians consisted mainly of the fluted projectile points and specialized blade core production (Hester 2004). At the later end of this period, projectile point styles 
change to non-fluted, lanceolate types such as Angostura and Golondrina (Black 1989:49). In addition, the poorly dated Lerma dart point has been tentatively assigned to this period (Epstein 1969; MacNeish 1958; Suhm, Krieger, and Jelks 1954), but the lack of corroborating data makes this style increasingly suspect as a legitimate type (Hester 2004). The important transitional stage between the Paleoindian Period and the subsequent Early Archaic Period is poorly understood in this region. However, it is believed there was a transition from big-game hunting to generalized hunting and gathering strategies at the later part of the Paleoindian Period (Black 1989). An accompanying technological shift from lanceolate points to stemmed dart points appears to have also occurred.

\section{Early Archaic}

The Early Archaic from 8800 to 6000 B.P. is distinguished from the earlier Paleoindian period by increasing adaptation to regional environments, more intensive processing of local resources, and diversification of artifact types and technologies. The temporal division between Paleoindian and Archaic patterns is generally around 8800 B.P. (radiocarbon years) based on several chronologies and well-dated sites (e.g., Thoms and Clabaugh 2011:85), although a number of authors place the advent of Archaic ways later in time. Hester (2004:137) defines the advent of the earliest clearly Archaic technologies as beginning around 8000 B.P. In coastal areas of South Texas, Ricklis (2004:161) begins the Early Archaic at approximately 7500 B.P. when sea level was still well below current levels. The terminus of the South Texas Early Archaic is around 6000 to 5500 B.P., but others have it continuing to 4500 to 4200 B.P. (Hester 2004:137; Ricklis 2004:161). Recent dating of bison bone place of the Calf Creek horizon, which falls within Hester's final horizon of the Early Archaic, from 5955 to 5815 B.P. in calibrated calendrical years or about 5100 to 5200 radiocarbon years (Lohse et al. 2014). Considering the discrepancy between radiocarbon and calendrical years of about 1000 years at this time, the different estimated termini of 5500 and 4500 B.P. may be attributable to conversion factors.

Early Archaic sites are typically located on upland landforms and high terraces, though several components within deep alluvium are known from the Choke Canyon area of Live Oak County. Examples of sites from the coastal bend include 41VT17 (Fox and Hester 1976), the McKenzie site (Ricklis 1988), and the Swan Lake site (Prewitt et al. 1987). Although the Early Archaic components at these sites are ephemeral, they demonstrate early use of the estuarine bayshore environment along coastal areas. During the late part of the Early Archaic, the number of coastal components increased, as did the intensity of the occupations (Ricklis 2004:162, 164). It appears that both shellfish and fish were exploited to the extent that these early components likely functioned as fishing camps (Ricklis 1988:101-102, 2004:161-165).

Few Early Archaic sites have been intensively studied, although there are notable exceptions such as the Richard Beene site (41BX831) (Thoms and Clabaugh 2011; Thoms and Mandel 2007) in Bexar County. It has been suggested that populations and site densities continued to be low on the entire coastal plain during the period (Story 1985:37), but much research is needed to determine whether the lack of sites from the time is a matter of poor preservation or whether the record accurately reflects low population densities.

Early Archaic technology includes projectile points, large bifaces, small informal hearths, Guadalupe tools, and Clear Fork gouges. Projectile points diagnostic of the period include Gower, Wells, Bell, Andice, Martindale, Uvalde, and related forms (Hester 2004:136-137; Weinstein 1992:57). Hester (2004:136-137) has suggested these point styles can be categorized into two sequential horizons, including the early corner-notched, followed by the early basal-notched horizons. The Martindale, Uvalde, Baker, and Bandy points comprise variations on a theme, constituting central diagnostics of the early corner-notched horizon. Some have suggested technological continuity of these forms directly from earlier types such as Hoxie and Early Stemmed Lanceolate (Carpenter and Paquin 2010). If so, the early corner-notched technology could be an in situ technological development. Conversely, the basal-notched 
horizon, which includes Bell and Andice, has strong technological affinities with Calf Creek and other forms found farther to the north, including Oklahoma, suggesting either the diffusion of point-making ways or migration of peoples. Numerous Calf Creek horizon points have been recovered from far south Texas near the project area and southward into northern Mexico (Hester 2004:138).

Hester (2004:136, 138) associates Guadalupe tools, inferred to be wood-working tools (Brown 1985), with the early corner-notched horizon, and unifacial Clear Fork tools with the basal-notched horizon. While the majority of Early Archaic features are small hearths, several larger burned rock features have been noted at sites such as Richard Beene, indicating technological cooking features more common in later times had their origins in the Early Archaic (Thoms and Clabaugh 2011:105).

Evidence of subsistence, although not common, indicates a generalized foraging strategy of exploiting a wide variety of species, including snails, aquatic resources, and many small animals. The association of basal-notched points with bison remains has commonly been noted (e.g., Bement et al. 2005), and Lohse et al. (2014) have shown a prominent increase of bison in the archeological record at the time of the Calf Creek horizon. The implication is that Early Archaic peoples maintained a broad spectrum subsistence, although clearly targeting highly ranked resources when available. They were able to adapt rather quickly to exploit new circumstances.

Early Archaic society is often construed as consisting of a low population density with small mobile, multifamily bands, but evidence from the Early Archaic cemetery at Buckeye Knoll seem to indicate a more diverse picture, one with greater social complexity and widespread supra-regional interaction (Ricklis 2011). A total of 69 burials dating to between 7500 and 6200 B.P. (calibrated years, or about 6600 to 5600 radiocarbon years) yielded evidence of social ranking and "relatively complex cultural expressions" with affinities with cultures in the Lower Mississippi Valley and Eastern Woodlands (Ricklis 2011:70). Sites such as this are paradigm busters, creating cause for a reconsideration of inferences drawn from small occupational sites that may represent only part of the overall picture.

\section{Middle Archaic}

Data from the comparatively brief Middle Archaic are unclear on many aspects, engendering very contradictory interpretations on the nature of cultural adaptations and the climatic setting during this mid- Holocene period. Well-documented sites, such as the Richard Beene site component dating from 4500 to 4,100 years ago, are few and yield sparse remains, often with the inclusion of diagnostic artifacts from other periods. Based on Central Texas data, Johnson and Goode (1994:26) see the period as having mesic but drying conditions, and Thoms and Clabaugh (2011:91) interpret the period as fluctuating between drier conditions but concluding between 4500 and 4100 B.P. with a cooler wetter climate. Data from the adjacent Lower Pecos area show a hot and dry interlude from 5500 to 4100 B.P. (Turpin 2004:270), but whether these patterns are applicable to South Texas remains to be determined. Along the coastal regions, Ricklis identified the period from 5800 to 4200 B.P. as the Middle Holocene stillstand, a period of stable sea levels, before the rapid sea level rise beginning around 4200 B.P. (Ricklis 2004:164). During this stillstand, a period he originally placed within the Early Archaic but would now fall within his Middle Archaic based on his later revised timeframe (e.g., Ricklis 2011:38, see discussion below), Ricklis notes a prominent increase in the number of archeological components. Consequently, in some areas, site frequency appears to increase, and in others the archeological record suggests perhaps a decline, but such a trend is unclear.

Although the Middle Archaic has often been defined as extending from approximately 4,500 to 2,500 years ago (e.g., Hall et al. 1986; Hester 2004; Ricklis 2004), more recent trends in chronological partitioning and better dating techniques have substantially modified not only the timing but also the content of the Middle Archaic (e.g., Lohse et al. 2014; Ricklis 2011:38, 71; Thoms and Clabaugh 2011). 
The differential use of calendrical versus radiocarbon years adds to the confusion and accounts for some of this discrepancy, but there are also substantive differences in chronologies. For instance, as commonly defined, the South Texas Middle Archaic would primarily fall within the Late Archaic of South Texas as defined by Hester (2004). Many of the same diagnostic artifacts are considered Middle Archaic in one region and classified as Late Archaic in the immediately adjacent region. The lack of a common definition of the divisions is partly to blame for such discrepancies. Consistent with these recent data, the Middle Archaic is defined here as dating from 5800 to 4000 B.P. The period begins shortly after the Calf Creek horizon dated by Lohse et al. (2014) to approximately 6000 to 5800 B.P.

While the site distribution patterns remain to be clarified, Story $(1985: 39,1990: 244)$ has suggested that environmental changes may have enhanced coastal resources enough that populations and site densities increased. Ricklis (2004:164) also inferred an increase in population during the period from 5800 to 4200 B.P. If inland sites of the period continue to show small short-term occupations and coastal areas greater concentrations of sites, the period may reflect increased coastal adaptations. However, one aspect that perhaps counters the interpretation of increased population is the lack of cemeteries, often viewed as indicators of increased territoriality and population. Ricklis' (2011:72) review of coastal cemeteries show no cemeteries dating to the time.

Small burned rock features, stemmed and triangular point types, and formal tools such as gouges and scrapers are hallmarks of the Middle Archaic technology. The cooking feature assemblage in the Middle Archaic components at the Richard Beene site comprises mainly small features that do not include burned rock (Thoms and Clabaugh 2011:104). Using data from Central Texas, Johnson and Goode (1994:24, footnote) observe that diagnostic artifacts from the Middle Archaic are typically found below substantial burned rock accumulations. However, they do suggest burned rock midden technology, indicative of more intensive exploitation of vegetal resources, may have been practiced during the Middle Archaic, but perhaps not to the extent as in later times. In coastal areas, shell middens become prominent as evident at sites such as McKinzie (41NU221), Means (41NU184), and 41SP156 (Ricklis 2004:164). Possible baking pit features with associated concentrations of burned rocks also have been identified at coastal shell midden sites. Diagnostic projectile point styles include Early Triangular, Nolan, and Travis points. Pandale points, more common in the Lower Pecos region, are also found in South Texas. There is a difference of opinion on whether the Calf Creek complex with Bell and Andice points are Early or Middle Archaic. Dart points, unifacial scrapers, and preforms found at Middle Archaic sites suggest hunting and manufacturing activities. Gouges are present in artifact assemblages in increased numbers over the preceding period, possibly suggesting increased wood- or hide-working activities (Hester 2004).

Subsistence data from the period are limited. Shell middens, often containing fish otoliths, indicate exploitation of marine resources from the time. As noted, the advent of burned rock middens suggests a more intensive exploitation of plant resources.

The appearance of projectile point types typical of other regions (e.g., Bell, Andice, and Pandale) and marine shell originating from outside the area suggest an expansion of trade/exchange networks in the region, although as previously discussed the Early Archaic Buckeye Knoll site indicates such networks were already well-established.

\section{Late Archaic}

The Late Archaic period from 4000 to 1000 B.P. is far better understood than the preceding periods and is marked by a continuation and intensification of adaptations established in the previous period, but also witnessed the development of new technologies and social identities. There were major environmental fluctuations during the time, but the general trend was towards conditions that roughly equate to the historic setting. The period began with rapid rise in sea level around 4,000 years ago, submerging river 
valleys and reaching the modern stable sea level by about 3,000 years ago (Ricklis 2004:157). In the course of these events, barrier islands developed creating protected bays and extensive estuarine environments with high densities of diverse species. Many models indicate dry conditions in the beginning that gradually ameliorated to increasing mesic conditions. Faunal data from Halls Cave and Bering Sinkhole on the southern margin of Central Texas indicate relative dry conditions until 2700 to 2500 B.P. before the shift to wetter conditions (Toomey et al. 1993:309). Based on the faunal data, inland environments were short-grass grassland or desert grassland, turning to wetter mixed grasslands after circa 2500 to 2000 B.P. (Toomey et al. 1993:309).

The Late Archaic, as defined here, covers a longer span of time than many authors have it, three millennia, beginning earlier than previous chronologies (e.g., Hall et al. 1986; Hester 2004; Ricklis 2004:165). The temporal span and cultural developments in this revised Late Archaic period are consistent with recent revisions and improvements in radiocarbon dating that place the advent around 4000 B.P. (e.g., Lohse 2014; Ricklis 2011:38). Many cultural and temporal subdivisions have been devised to partition the Late Archaic into finer divisions, but there is still much debate on the validity of various phases, complexes, and foci. One of the more enduring divisions is the Aransas focus defined by Campbell $(1947,1952)$, and more recently refined by Weinstein (2002) based on excavations at the Guadalupe Bay site (41CL2). Weinstein (2002) defines the Aransas I (2500 to 2100 B.P.), II (2100 to 1900 B.P.), and III (1900 to 1200/1300 B.P.) as covering the final part of the Archaic period. Ricklis (2011:38) breaks the Late Archaic into sub-periods I (4000 to circa 2700 B.P.), II (2700 to 1900 B.P.), and III (1900 to 1200 B.P.). His Late Archaic II roughly corresponds temporally with Weinstein’s Aransas I and II, and the Late Archaic III corresponds temporally with Aransas III.

Technological hallmarks of the time include hearths, ovens, burned rock middens, ground stone such as manos and metates, bedrock mortars, projectile points, bifaces, bone and shell tools, and various formal types of gouges, scrapers, and adzes. Projectile points from the Late Archaic include Bulverde, Pedernales, Desmuke, Tortugas, Refugio, Marcos, Shumla, Ensor, Frio, Fairland, Montell, Morhiss, Castroville, and Ellis. There is a gradual decrease in point size from the broad-bladed forms that predominate until approximately 2200 B.P. with the advent of the Ensor-Frio-Fairland series.

Coastal sites such as Mustang Lake (41CL3) on San Antonio Bay and 41SP43 along Ingleside Cove on Corpus Christi Bay have yielded evidence to support "a significant intensification of estuarine resource use” in Late Archaic, with an increase in shellfish gathering around 3000 B.P. and a substantial increase in the reliance on fish by around 2000 B.P. (Ricklis 2004:165). In the Aransas Bay area, Campbell (1947, 1952) designated this period of intensive exploitation of estuarine resources as the Aransas Focus. Inland, the presence of grinding implements and large deposits of burned rocks at the Choke Canyon sites suggest continued, intensive exploitation of plant resources in addition to a broad range of animal species (Hester 2004:140).

Burial of the dead in cemeteries appears to be more common in this period as evidenced by excavations at the Loma Sandia Site in Live Oak County (Taylor and Highley 1995), Ernest Witte (Hall 1981), Crestmont (Hall 2002), and numerous other sites.

Distinctive shell tools such as Busycon whorl scrapers and columella gouges mark Aransas sites. Similar tools have been recovered from shell midden sites as far north along the coast as Lavaca Bay and the lower reach of Caney Creek in Matagorda County (Fritz 1975:129). 


\section{Late Prehistoric Period}

The technological innovations of ceramics and the bow and arrow are typically regarded as marking the beginning of the Late Prehistoric (1,150-350 B.P.) (Black 1989b:51; Hester 2004). Prehistoric sites from this period are often the best preserved, most distinctive, and visible of all periods in South Texas. Ceramics dating to this period are generally bone tempered (Black 1989b:52). Late Prehistoric settlement patterns suggest increased mobility, perhaps an effect of greater reliance on bison as a subsistence mainstay. Faunal assemblages dating to the Late Prehistoric show an increased consumption of bison, deer, and antelope (Black 1989b; Hester 2004). At the Hinojosa Site in Jim Wells County, the wellpreserved faunal remains associated with a Toyah occupation showed dependence on deer and antelope, and to a lesser extent, bison (Black 1986). Adoption and use of the bow and arrow may have facilitated the shift in balance between animal and plant foods. In South Texas, common arrow point types include Perdiz, Scallorn, Fresno, Starr, and Zavala. The social and material culture of the period can be inferred to some degree by the ethnohistorical record, as discussed below.

In South Texas coastal areas, around A.D. 1250 to 1300, a distinct archeological assemblage emerges. The Rockport phase is marked by a series of ceramic types that are spatially limited to the central coast, but also a lithic industry that incorporates much of the Toyah assemblage (Ricklis 2004:172-175). Perdiz points, unifacial end scrapers, a prismatic blade-core technology, and thin bifacial knives (occasionally alternately beveled) show a strong overlap between the technologies of both groups. One of the few distinctions between the Rockport and Toyah lithic assemblages is the forms of perforators (Ricklis 2004:175). The former made relatively narrow proximal ends, whereas Toyah drills tend to have a wide proximal portion where it was held or hafted. Rockport subsistence strategies clearly emphasized maritime resources, though perhaps on a seasonal basis. The relationship between Toyah and Rockport is generally inferred to be one of two distinct peoples, with Rockport adopting the Toyah lithic assemblages about the same time bison became relatively abundant on the coastal plain (Ricklis 2004:175). Marine shell, most notably Oliva sayana, are part of the Toyah assemblage, but the extent of mutualistic economic relationships between the inland and coastal groups is not entirely certain.

\section{Brownsville Complex}

In the Rio Grande delta of far south Texas, a distinctive but vaguely understood complex designated the Brownsville Complex is commonly surmised to have emerged around A.D. 1250 to 1300, continuing for a couple centuries until A.D. 1500, although a reanalysis of the long-held construct shows it is not so easily defined (Terneny 2005:1). The "complex," for lack of a better term is primarily defined as a mortuary complex based on several large cemeteries in the region (e.g., Ayala [41HG1] and Floyd Morris [41CF2]) and the extensive use of shell in implements and decorations. The complex is called the Barrill Complex in the coastal areas of Mexico immediately south of Texas, rendering the boundary between the two an arbitrary one (Terneny 2005:212, 214). Additionally, the temporal boundary is arbitrary since there are few dates to clearly define it, and the traits associated with the complex have also been shown to occur in preceding Archaic contexts. Accordingly, Terneny (2005:211) recommends abandoning the construct, but we are still left with an intriguing constellation of archeological traits in need of definition. While the use of cemeteries is often considered evidence of increased social complexity, in this case cemeteries may have evolved as a result of limited territoriality and constrained mobility, not necessarily from increasingly hierarchical society. For example, Hester (1969:163) presents a model of huntergatherer fishers in the area maintaining limited mobility as a result of the rich concentration of estuarine, riverine, and coastal resources - the need for long-range movement to exploit dispersed resources was unnecessary in such a setting. Additional work is needed to address the economic basis of society in the area, not only the subsistence basis but also commerce evident by the high quantity of trade goods going into (e.g., jadeite beads) and out of (e.g., marine shell beads and ornaments). These exotic goods suggest a vibrant trade sphere centered as this critical juncture of environmental and economic contexts. 


\section{Historic Period}

The Historic period in the South Texas Coastal area begins with the first Spanish entradas when the Europeans began to explore and colonize the region. In 1519, Alonso Alvarez de Pineda was the first European to reach the Rio Grande delta, (Scott 1970; Stambaugh and Stambaugh 1954). Álvar Núñez Cabeza de Vaca is cited to have passed through the area in 1528 (Scott 1970), but the evidence that he traveled through the Rio Grande delta is tenuous.

In 1554, a Spanish fleet of four ships laden with treasures from the New World set sail from Veracruz heading home to Spain. The fleet carried over 400 people and a rich cargo. En route to Cuba, its first harbor along the homeward journey, a fierce storm drove three ships aground along the Texas coast off Padre Island a short distance south of Corpus Christi. One captain managed to salvage a crippled ship and tenuously returned to Veracruz, but three hundred passengers were forced ashore, an unknown number drowning in the effort. The survivors began to walk southward along the shoreline hoping to reach the colonial outpost of Tampico thought to be only a short distance away. In, the trek back, however, most survivors were either killed by indigenous groups or drowned while crossing rivers. A few survivors of the "the wreck of the 300" made it to the Rio Grande delta, but only two ultimately made it back to the colonial outpost.

A group under Jacinto García de Sepulveda was sent to explore the area in August 1638. They crossed the Rio Grande near Mier and marched down the north bank of the river as far as the site of present Brownsville (Garza and Long 2015). Also, on February 27, 1747, José de Escandón built a raft to sound the Rio Grande just north of the modern-day Matamoros and Brownsville area. A royal inspection made in 1757 by José Tienda de Cuervo recommended that titles to the land in the area be given to the colonists, and Escandón helped found the colonies of Reynosa (1749), Camargo (1749), Mier (1750), Revilla (1752), and Laredo (1755). Down the Rio Grande to the south of these colonies, San Juan de los Esteros was established in 1765. After 30 years of tenuous existence, San Juan de los Esteros was emboldened by Nuevo León immigrants and renamed Nuestra Señora del Refugio. After Mexico won independence from Spain in 1821, Nuestra Señora del Refugio was renamed Matamoros.

Mexican independence ushered in a prosperous time of settlement for the Rio Grande Delta region and the Lower Coastal region. Most of these early settlers were Mexican ranchers who, in turn, attracted American and European merchants. Matamoros was established as a seaport in 1823, and this significantly increased the economic vitality of the region. This vitality was largely unaffected by the Texas War for Independence, since military campaigns were concentrated further north and west (Webb 1952).

The same cannot be said for the Mexican War, whose formal opening occurred along the Rio Grande at Matamoros. General Zachary Taylor's forces established themselves on the northern side of the Rio Grande opposite Matamoros in March of 1846. Responding to the placement of Mexican artillery, Taylor ordered the construction of a fort, which included defensive works in the form of six-sided, moated earthworks 800 yards in circumference and 9 feet tall (Mahr-Yanez and Perttula 1995). Mexican artillery fired on the fort May 3, 1846, while Taylor and the bulk of his forces had marched downstream to Port Isabel. After several days of heavy fighting, the Mexican troops were turned back. Major Jacob Brown, the interim commander, died during the attack and General Taylor, upon hearing this, ordered the fort to be named Fort Brown (see further discussion below). The Mexican War ended on July 4, 1848, after two years of heavy fighting in Mexico.

Immediately following the war, Starr County was formed from the Nueces Land District and named after James Harper Starr, a Republic of Texas treasurer. Rio Grande City is the county seat. 
Business continued to improve up to the beginning of the Civil War. Confederate forces, under the direction of General H. P. Bee, assumed control of Brownsville in 1861 after the peaceful withdrawal of General Twigg's Union forces. Brownsville returned to Union control in November of 1863 after a sizable Union force landed on Brazos Island, which compelled General Bee to abandon and burn Fort Brown (Pierce 1917). The Confederate forces regained Fort Brown in July of 1864 and held it until the end of the war. The last battle of the Civil War occurred on Palmito Ranch near Brownsville south of the Project area. On May 13, 1865, more than a month after Robert E. Lee's surrender, opposing forces met for the final time as the Confederates pushed back federal troops until reinforcements arrived and a truce was negotiated.

The economy of the Rio Grande Delta suffered after the Civil War, and disorder escalated following the collapsed fortunes of many in the area (Rogers 1996). This prompted Union troops, under the command of General Phillip Sheridan, to restore order to the region immediately after the war (Webb 1952).

The regional economy grew slowly but steadily throughout the rest of the nineteenth century until flood control and irrigation projects contributed to the success of regional agriculture. Shipping and railroads turned Brownsville into a major port during the nineteenth century. In 1837, Charles Morgan established the first steamship line between New Orleans and Galveston, which became the basis for further expansion of the lines throughout Texas into the southern coast by the 1840s (Baughman 2015). Roma and Rio Grande City were both ports for steamboat traffic. After interruption during the Civil War, Morgan began integrating railroad and maritime transport, developing railways that connected to ports. These developments led to the founding of Morgan's Louisiana and Texas Railroad and Steamship Company in 1877.

Rail continued to be a major economic force throughout the nineteenth and twentieth centuries. According to railroad records, the area produced 761 freight car shipments of produce in 1907, when the first flood control project was completed. Shipments totaled 6,307 in 1920, and in 1930 annual shipments reached 28,113 (Watson 1931).

The Project area landscape was transformed by the adjacent ship channel and its history of construction and maintenance. In 1928, residents of the area approved funds to establish the Brownsville Navigation District and construct a ship channel from Brazos Santiago Pass to allow deep-water vessels to dock in Brownsville. The voter-approved $\$ 2$ million provided the initial impetus, but progress was slow. It was not until the Public Works Administration provided additional funds that the 17-mile-long channel, turning basin and Terminal facilities were completed. The port of Brownsville opened on May 15, 1936. The channel connects Brownsville with the Gulf Intracoastal Waterway, and SH 48 runs alongside the channel for most of its length.

The completion of the port made Brownsville the shipping center for the Lower Rio Grande Valley and northeastern Mexico and helped the city to weather the worst effects of the Great Depression.

The Lower Rio Grande Valley, called the Magic Valley for its agricultural productivity, "forms one of the most inviting fields for irrigation on a large scale that can be found in Texas" (Taylor 1902:68). In the delta, the floodplain widens, making it ideal for irrigation agriculture. By 1904 when the St. Louis, Brownsville and Mexico Railway created a suitable mode of export, agriculture become a paramount economic mainstay for the region. Early efforts to irrigate the Lower Rio Grande Valley date back to the 1870s, with the first extensive efforts occurring along the Rio Grande (Knight 2009:13).

George Brulay, "the first irrigator in the Valley and the man who first introduced sugar cane to South Texas” (Knight 2009:13), was a French immigrant who completed a canal system along the Rio Grande south of Brownsville in 1896. Brulay used a large pump with a maximum capacity of 8,000 gallons a 
minute, and a lift of 22 feet (Taylor 1902:68). The pump ran about 14 hours a day and supported 300 acres of sugar cane.

Many canal systems developed throughout the area during the first half of the twentieth century. Knight (2009:31-32) lists 35 irrigation companies that formed in the area from 1896 to 1951.

A review of aerials and maps of the 41SR242 vicinity shows fallow fields and open range. A 2011 aerial clearly shows plowed fields. Sheep, goat, and cattle ranching have long been an important economic mainstay in Starr County, and the current Project area appears to have been previously used as a pasture. 


\section{CHAPTER 4. OBJECTIVES AND METHODS}

\section{TESTING OBJECTIVES}

The main focus of testing was to identify, if present, isolable features that represent discrete activities such as lithic reduction areas. This feature-focused approach acknowledged common disturbances to many of the surficial components, focusing efforts instead on the comparatively intact areas. With so little known of the site prior to testing, the investigations sought to characterize site content and context, to define components, features, or activity areas that could contribute to an understanding of the region's archeological record and cultures. Two main objectives were set forth to define the data needed to address NRHP and SAL criteria within applicable historic contexts. Eligibility requires two fundamental factors, both of which must be present: significance and integrity (Little et al. 2000). The two main objectives, both designed to address these factors, are briefly discussed, followed by the state and federal significance criteria.

\section{Objective 1: Integrity of the Archeological Deposits}

Integrity, according to NRHP guidelines, is the ability of a property to convey its significance. It entails aspects of location, design, setting, materials, workmanship, feeling, and association. Of these aspects, a primary focus of the archeological investigations was on setting and materials, specifically regarding whether the sites retained reasonably intact site assemblages in their original contexts. Accordingly, primary goals of these investigations were:

- To acquire data on depositional context and define any relationships between natural strata and subsurface cultural features/deposits;

- To determine if the integrity of the buried deposits was sufficient to establish relative and/or absolute chronological dates for any subsurface components; and

- To subdivide recovered materials into analytical units relevant to specific research questions.

To address the research issue, excavations were performed with sufficient detail to provide for the identification and documentation of relevant analytical units. The primary means of addressing the issue were the geomorphological assessment and archeological investigations designed to expose broad areas, documenting finds with a survey-grade global positioning system (GPS) unit. Additionally, radiocarbon dating of a cultural feature and paired dates on Rabdotus snail shells provided data on the chronostratigraphy and integrity of deposits.

\section{Objective 2: Potential Data Yield}

Besides integrity, NRHP guidelines define significance as the other necessary quality for eligibility (Little et al. 2000). Significance is the ability of a property to contribute to a meaningful context. In addition to local, state, and national contexts, considerations of significance include:

- Areas of significance;

- Periods of significance; and

- Cultural affiliation.

Consequently, the archeological work sought to establish components that could be assigned to specific timeframes and cultural phases within the Lower Rio Grande Valley and wider region. In considering data yield, the intent was to recover information that could be used to address specific research questions, 
placing the sites in specific spatial, temporal, and cultural contexts. The testing project addressed general questions relevant to the testing archeological investigations, including:

- Depositional/formation processes;

- $\quad$ Site structure;

- Function; and

- Chronology.

Preservation potential for macrobotanical or faunal remains was also a criterion used to evaluate potential data yield. To address the issue of potential data yield, an excavation strategy employed a combination of mechanical stripping and hand excavations. The objective was to expose large areas of the site in the search for isolated contexts with greater archeological potential, then use hand excavations to gather data from these specific contexts. The excavators gathered special samples from appropriate contexts to address aspects of data yield.

\section{Evaluating Significance}

For the site to be found significant and eligible for NRHP listing and SAL designation, the deposits must demonstrate sufficient integrity and data yield potential to contribute to one or more historic contexts. Specifically, the site must provide information that would allow the formulation of specific, detailed research questions that would contribute to the understanding of the regional prehistory.

Specifically, both state and federal eligibility criteria are applicable to the sites. Under the ACT and in accordance with 13 TAC 26.10, criteria used to evaluate the SAL eligibility for archeological sites include:

(1) the site's potential to contribute to a better understanding of the prehistory and/or history of Texas by the addition of new and important information;

(2) the site's archeological deposits and the artifacts within the site are preserved and intact;

(3) the site possesses unique or rare attributes concerning Texas prehistory and/or history;

(4) the study of the site offers the opportunity to test theories and methods of preservation; and

(5) there is a high likelihood that vandalism and relic collecting has occurred or could occur.

Under the purview of Section 106 of the NHPA, criteria for determination of NRHP eligibility stipulate the sites possess integrity of location, design, setting, materials, workmanship, feeling, and association and that sites:

(a) are associated with significant events that have contributed to the broad patterns of our history;

(b) are associated with the lives of persons significant;

(c) embody distinctive characteristics of a type, period, or method of construction, or that represent the work of a master, or that possess high artistic values, or that represent a significant and distinguishable entity whose components may lack individual distinction; or

(d) have yielded, or may be likely to yield, information important in prehistory or history. 
NRHP Criterion D is the primary consideration for a multicomponent site like 41SR242. As such, there are five basic steps in Criterion D evaluation:

(1) identify the property's data set or categories of archeological, historical, or ecological information;

(2) identify the historic context or framework;

(3) identify important research questions that the site can address;

(4) considering integrity, evaluate the site data with regard to addressing questions; and

(5) identify information that archeological study has yielded or would likely yield.

\section{METHODS}

The work involved three primary phases: field investigations, analyses, and curation. Methods for each are detailed below.

\section{Field Investigations}

TxDOT conducted the testing from February 20-24, 2017, and April 10-14, 2017. The work entailed two approaches to assess the eligibility of 41SR242: 1) geoarcheological assessments, and 2) archeological investigations using a combination of mechanical and hand excavations. The geoarcheological investigation of the site determined the depositional contexts and stratigraphy, site formation processes, and the potential for intact buried surfaces. The primary method of this approach was to reopen trenches in or near previously excavated areas tested by TxDOT in 2016 (Figure 4.1). Fifteen BHTs were excavated at 41SR242. Dr. Jim Abbott of TxDOT conducted the geoarcheological investigation (Figure 4.2) and all BHT excavation was monitored by TxDOT personnel. The location of each BHT was recorded with a survey-grade GPS unit. Stratigraphic profile drawings with detailed soil descriptions were made for each BHT. Additional details on the methodology and the results of the geoarcheological investigations are presented in Chapter 6 of this report.

The second approach, overlapping the geoarcheological investigation, was the archeological testing of 41SR242. In lieu of random test units (TUs), which would only give limited understanding at the site, mechanical trenching was used to discover isolated buried features. Where potentially intact features were identified, the backhoe was used to remove the upper disturbed Ap zone, which was typically removed and not screened.

One $50 \times 50$ centimeter $(\mathrm{cm})$ column sample was excavated to quantify artifact density and vertical distribution within the Holocene sediments. The column sample extended from the ground surface to the base of the BHT. The soils from the column sample were excavated in 10-cm levels and screened through $1 / 8$-inch hardware screen mesh to assess the presence of micro-debitage.

Upon identification of subsurface features through mechanical trenching, TUs were placed over the features. TUs were typically $1 \times 1-\mathrm{m}$ in size and excavated in 10-cm arbitrary levels. All matrix excavated was screened through $1 / 8$-inch mesh and, where deemed appropriate, water screen samples were collected. Units used standard archeological methods, the TUs were documented using standardized field forms and photographs. All artifacts and pertinent special samples were collected for analysis. 


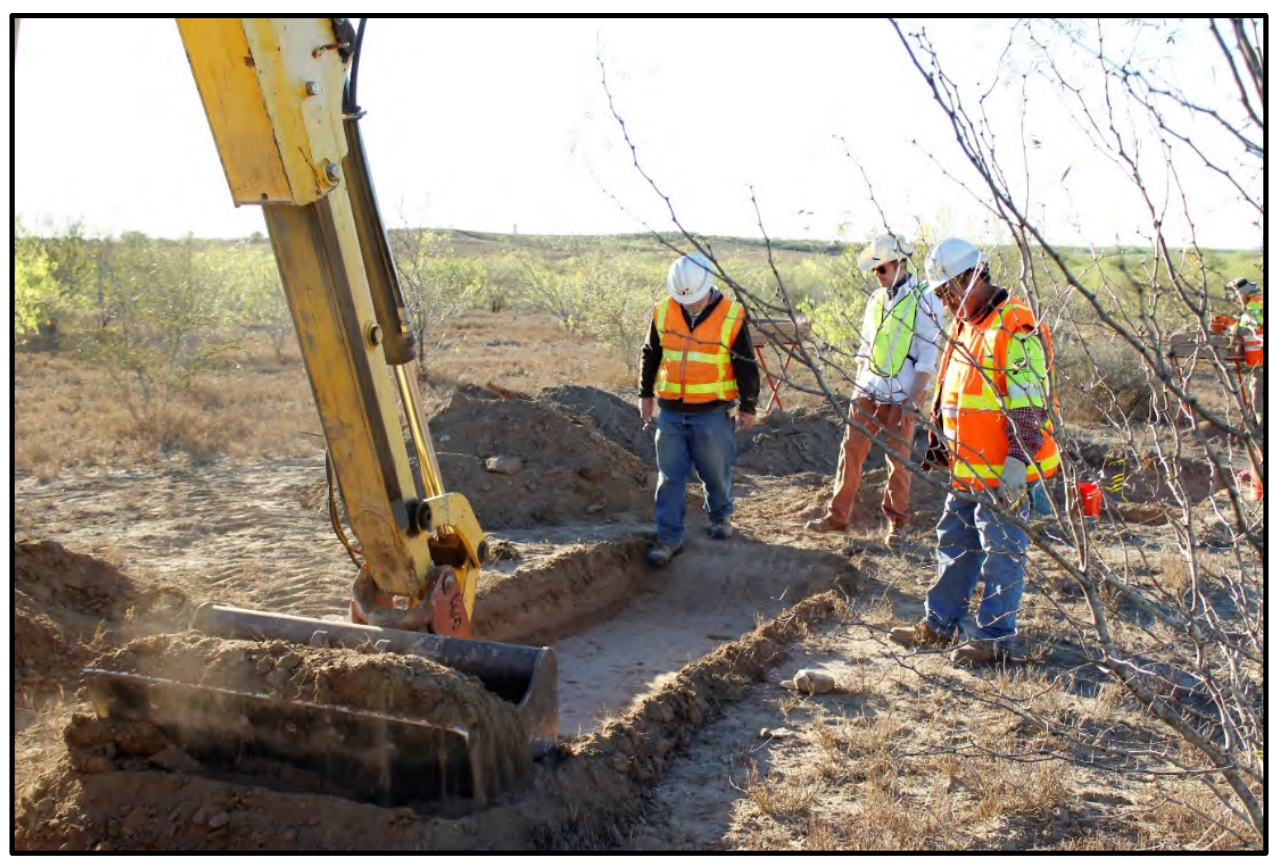

Figure 4.1. Backhoe trenching and scraping investigations at the site.

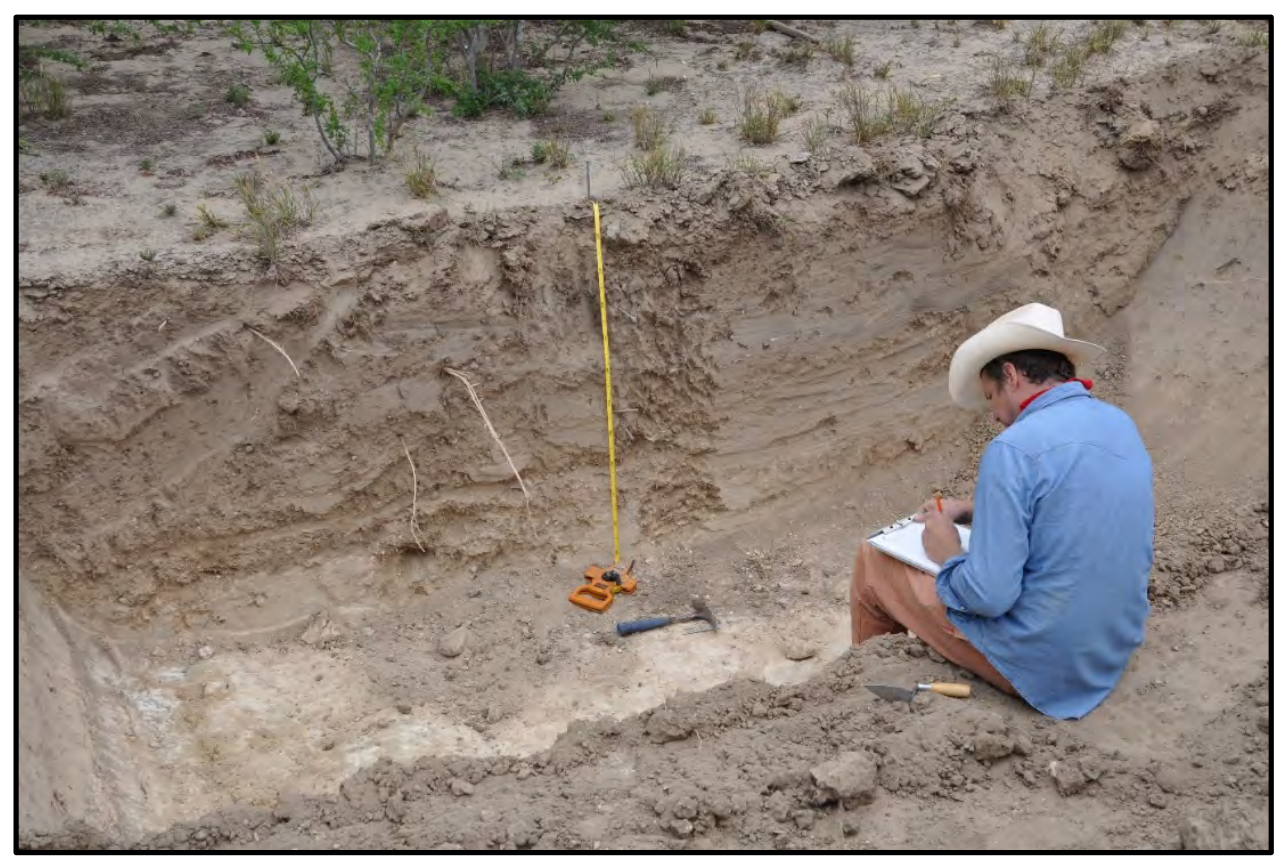

Figure 4.2. Overview of Corey Crawford conducting geoarcheological investigations at the site. 


\section{Site Mapping and Provenience Control}

Satellite Based Augmentation System (SBAS) and Real Time Kinematic Global Navigation Satellite System (RTK GNSS) was used for recording spatial data across the site. Surface artifact collection was plotted using SBAS GNSS which provides sub-meter accuracy. Given the history of root plowing at the site, this level of accuracy was deemed appropriate. RTK GNSS, which provides centimeter accuracy, was used for spatial data collection of BHTs, TUs, and datums across the site. The GPS data are collected in meters above mean sea level (amsl) but can be converted to other scales.

\section{Artifact and Sample Collection}

The field archeologists recovered all artifacts from each excavation unit (e.g., TU levels and column samples). In addition to the subsurface testing, a controlled surface collection was conducted given the quantity of surface materials across the site. Two phases of collection were conducted, with the first focused on prehistoric diagnostics, tools, and staged bifaces. The second focused on the historic artifacts scattered across the site. All artifacts were point provenienced using the GPS unit, collected, bagged, and labeled accordingly.

A suite of special samples was collected from appropriate contexts for subsequent analyses. Snail samples, faunal remains, and radiocarbon samples were routinely collected if present (see discussion of geoarcheological sampling in Chapter 6). Charcoal or other charred organic materials associated with cultural materials were collected, although this was observed in few areas. However, the investigations recovered and submitted seven charcoal radiocarbon samples and four Rabdotus shells were submitted for dating. Radiocarbon and snail samples were submitted to Beta Analytic for analysis. To assist in the geoarcheological analysis, the collection of soil profiles and column samples from the BHT wall profile exposures were the primary field method for determining the depth, extent, and integrity of Holocene sediments with archeological deposits.

\section{Analytical Methods and Techniques For Lithic Materials}

Basic analyses followed TxDOT protocols for lithic artifacts, specifically Version 2.4b (dated March 2013) of the TxDOT Debitage Analysis Protocol, and the Chipped Stone Analytical Protocol (TxDOT 2013). The terms and quantified attributes are defined therein. Additionally, to address specific research issues related to the sites and the Rio Grande delta, certain analyses not covered by the protocols were also conducted. The following section briefly addresses the main analytical aspects of the protocols and on additional analyses that are not covered in those protocols.

\section{Projectile Points, Formal Tools, and Bifaces}

The analysis of points, formal tools, and bifaces followed the TxDOT protocols, which include all the usual aspects such as weight, length, width, and thickness (TxDOT 2013). The analyses of the dart points focused on the few stylistic aspects that are hypothesized to have sociotechnical information. Stem shape, morphology of lateral margin, and barb shape are all hypothesized to be attributes with isochrestic variation, meaning their variation is stylistic (a way of doing things) without affecting function. Certain asymmetries are perhaps related to handedness of the maker, a form of isochrestic variation.

\section{Debitage}

Debitage analysis is designed to identify lithic reduction processes that occur at a particular locale. Such reduction typically includes tool production, maintenance, and core reduction. To address these issues, the analysis of debitage employed a complementary approach using TxDOT lithic protocols (TxDOT 2013) 
augmented by individual flake analysis methods devised by Root (2004). Although there was substantive overlap in the two methods, the main difference is Root's use of a technological flake typology in addition to elements of the mass analysis and individual flake analysis. Additionally, flake and platform dimensions were measured. To define the terms and methods used, the following is an abbreviated version of TxDOT protocols and Root's technological flake criteria. These protocols were applied to all debitage recovered from Features 1 and 4.

\section{MINIMUM NUMBER OF NODULES (MNN)}

An assessment of minimum number of nodules (MNN) is designed to record the minimum number of individual raw material nodules that contributed to a specific analytical assemblage. The sort by raw material was based on visual characteristics of raw material type and properties, augmented with the use of ultraviolet fluorescence. SWCA analysts considered effects of obscuring factors such as calcium carbonate encrustation, patination, and thermal alteration of raw material features when assessing MNN. Analysts should favor lumping over splitting in determining MNN.

\section{SIZE-GRADE ANALYSIS}

In the field, lithic reduction features were screened with nested $1 / 4$-inch and $1 / 8$-inch mesh. For the analysis, all debitage was further size graded using standard grade sizes, including 1 -inch, $3 / 4$-inch, $1 / 2$-inch, and the two smaller screen sizes.

\section{CORTEX PERCENT}

The presence of cortex is an indicator of stage of manufacture. Although many analyses use the "triple cortex" breakdown (primary, secondary, and tertiary cortical states), researchers such as Sullivan and Rozen (1985:756-757) have pointed out that there is little standardization in such approach. In particular, the triple cortex criteria are poorly quantified. Accordingly, the debitage analysis relied upon percentage of cortex on the dorsal surface based on percentages, including the following categories 0 percent, 1 to 25 percent, 26 to 50 percent, 51 to 75 percent, and 76 to 100 percent.

\section{PLATFORM TYPE}

The platform of a flake is the point where the percussor strikes the parent material, initiating flake detachment. The morphology of the platform yields information on the stage of manufacture and reduction methods. These data in turn, when considered in concert with other data, inform on the overall organization of technology. SWCA recorded these data for all complete and proximal flakes from Features 1 and 4.

\section{THERMAL ALTERATION}

Thermal alteration, as defined in the TxDOT protocols, is the use of heat to increase the knappability of lithic materials (TxDOT 2013). The process of heating, recorded in ethnographic cases and experimentally replicated, is thought to homogenize the internal structure of siliceous materials, increase brittleness, and thereby allow better flake propagation. There is a fine line between heat treatment and heat damage. Too much heat or rapid temperature changes create damage that decreases knappability. Thermal alteration was recorded on the debitage from Features 1 and 4.

\section{MEASUREMENTS}

Although measurements of individual flakes are typically not part of the TxDOT lithic protocols, to acquire data for specific research objectives, the analysis obtained four measurements on each analyzed 
flake from Features 1 and 4. The analysts measured the platform width and thickness (Figure 4.3) and the overall flake width and length. While there are multiple ways of measuring flakes, the analysis used axial length and width when the orientation could be discerned (Figure 4.4). Where the orientation could not be discerned, maximum measurements were taken.

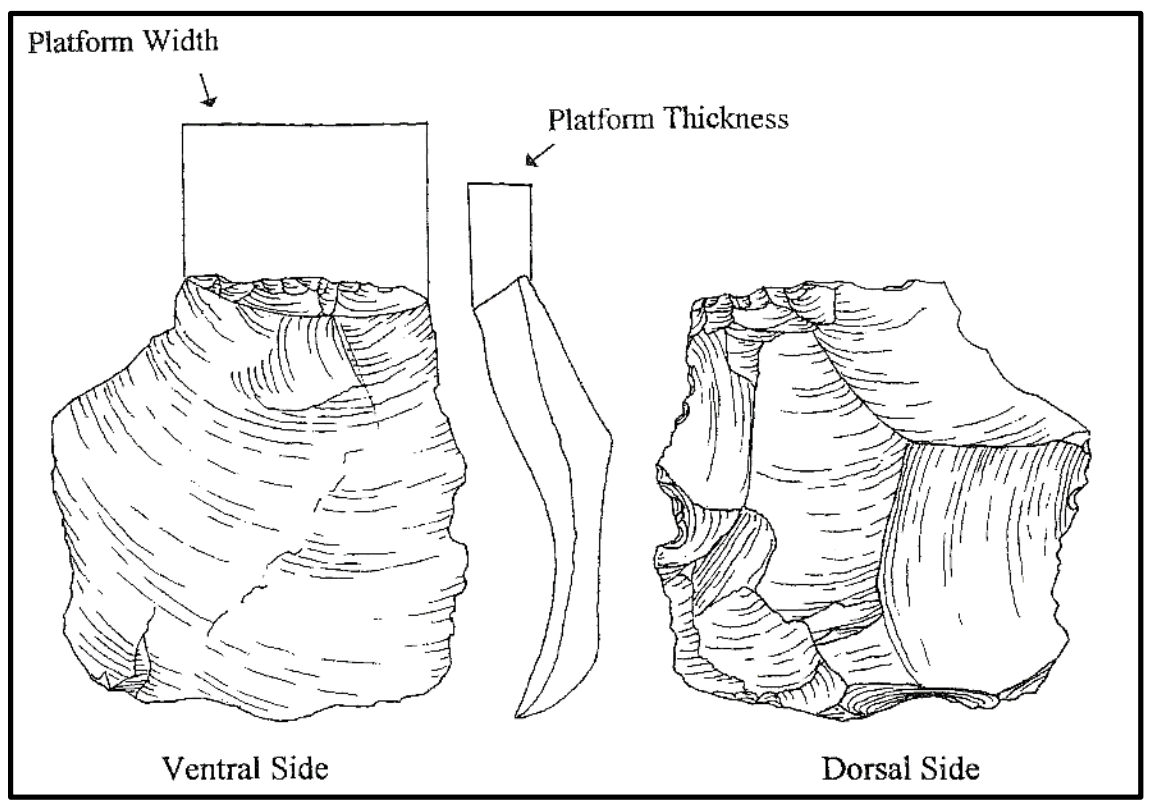

Figure 4.3. Locations on a flake striking platform for measuring platform width and thickness (Andrefsky 2014:95, Figure 5.5).

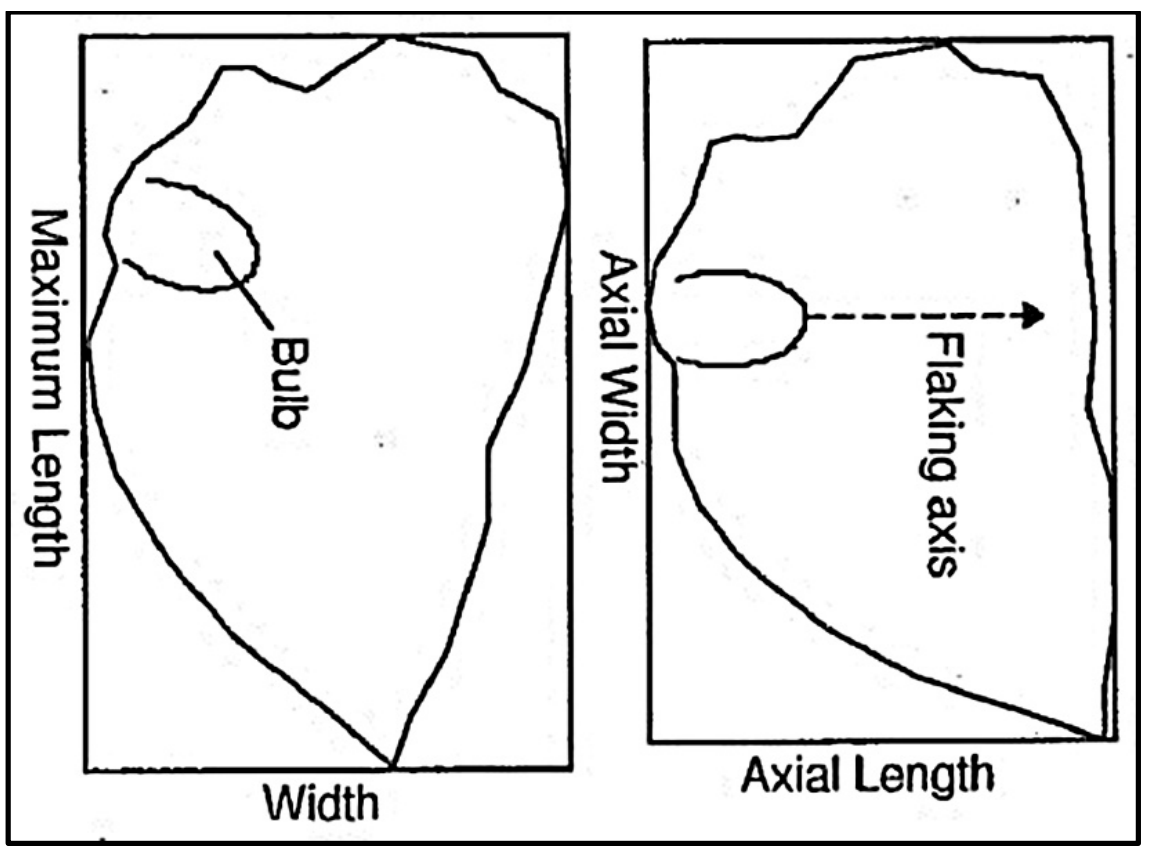

Figure 4.4. Locations on a flake for measuring axial width and thickness. 


\section{Root's Technological Attributes}

In addition to TxDOT protocols, Root's (2004) approach codes for three extra attributes including technological class, detachment scar, and resharpening. Technological class is perhaps the most useful of his attributes, including 13 types:

1. primary decortication - entirely cortical dorsal surfaces.

2. shatter - irregularly shaped fragments lacking platforms, bulbs of percussion, or discernible alignment of flake scars.

3. bifacial thinning flakes - multifaceted and acortical platforms, diffuse bulb of percussion, minimal body cortex, thin and curved long sections, and expanding shape in planview.

4. bifacial shaping or pressure flakes - usually small (less than $5.6 \mathrm{~mm}$ ), thin, with multifaceted and ground platforms.

5. notching flakes - produced by notching points or other tools, these have a circular planview with a concave platform. The appearance looking at the platform is often called "gull-wing" after its semblance to a bird approaching with wings raised.

6. alternate flakes - thick relative to length and width, triangular in cross section, and singlefaceted platforms, these flakes are produced during early stages of bifacial reducing squared off edges.

7. wedging or bipolar flakes - shattered platforms, and evidence of pressure exerted from both ends. Often used in initial stages of pebble reduction.

8. blades - specialized flakes with parallel or subparallel dorsal arises, parallel or subparallel lateral margins, length-to-width ration of 2 to 1, and plano-convex, triangular, rectangular, or trapezoidal cross sections.

9. unifacial retouch - small, single-faceted flakes, often straight to slightly curved long sections, and a near-90 degree platform angle.

10. radial-break flakes - often triangular shaped fragments resulting from transverse fractures radiating outward from a central point of impact.

11. simple flakes - flakes larger than $5.66 \mathrm{~mm}$ that do not have defining characteristics of those above, have cortex on 0 to 99 percent of dorsal surface, and relatively thick cross sections. These flakes typically derive from early stage core and biface reduction.

12. complex flakes - flakes with no cortex and lack attributes that place them in the above-defined categories. These typically are associated with later stages of biface reduction, but can also occur in more formal core reduction.

13. undiagnostic size grade 4 (2.54-mm) flakes - flakes that are too small to technologically attribute to one of the other classes.

\section{CURATION}

All artifacts and records will be curated at the Center for Archeological Studies at Texas State University in San Marcos. Burned rock and snail shell have been quantified and analyzed, but will not be submitted for permanent curation. 


\section{CHAPTER 5. RESULTS OF FIELD INVESTIGATIONS}

Over the course of three phases in 2016 and 2017, TxDOT conducted geoarcheological and testing investigations at archeological site 41SR242. Phase 1 investigations consisted of a preliminary geoarcheological and archeological assessment with mechanical trenching excavations to assist in planning for NRHP eligibility testing performed on December 14, 2016. Phases 2 and 3 investigations consisted of NRHP eligibility testing performed on February 20-24 and April 10-14, 2017. Field crew at the site included Dr. Jim Abbott, Dr. Jason Barrett, Dr. J. Kevin Hanselka, Corey Crawford, Mathew Stotts, and Cesario Guerra. Christopher Ringstaff served as Principal Investigator, participating in all field work.

This chapter provides the findings of the field investigations including the results of the excavations of BHTs, a column sample, and TUs. Results of the geoarcheological investigations are provided in Chapter 6. Detailed descriptions of the features, artifacts, and ecofacts follow in Chapter 7.

The interpretations of the findings are provided in Chapter 8.

The tested area of the site is in a semi-open, broad, flat area of mesquite and acacia shrub. Most of the mesquite is fairly young, less than 6 inches in trunk diameter. A review of recent aerial photographs indicates the site area was an active agricultural field until sometime around 2011 and appears to have subsequently lain fallow or was used as a pasture.

\section{BACKHOE TRENCHES}

TxDOT excavated a total of 15 BHTs across 41SR242 within an approximately $100 \mathrm{~m}^{2}$ area in the northwestern/western portion of the site (Figure 5.1 and Table 5.1). This portion of the site within the proposed ROW was previously recommended for further investigations by SWCA during survey level investigations in May 2016, as discussed in the earlier background review results section of this report. The 15 TxDOT BHTs included the initial excavation of three BHTs (i.e., BHTs 1-3) during the Phase 1 preliminary geoarcheological and archeological assessment investigations, and the subsequent reopening of these three BHTs during the Phases 2 and 3 eligibility testing investigations. Furthermore, TxDOT newly excavated an additional 12 BHTs (i.e., BHTs 4-15) during the Phases 2 and 3 eligibility testing investigations. The distribution of all the BHTs was designed to provide systematic coverage but also explore the more intact and densest portions of the site.

TxDOT encountered a total of four features (i.e., Features 1-4) during the BHT excavations. The features encountered were identified as clusters of chipped stone flaking debris, burned rock, dense land snails (cf Rabdotus sp.), or a combination of the three. The features and cultural materials recovered are further discussed below and in Chapter 7.

\section{BHT 1}

BHT 1 was excavated within the northwestern quadrant of the site area recommended for further investigations during survey level investigations. The trench was approximately $4.5 \mathrm{~m}$ long and excavated to a depth of approximately $65 \mathrm{~cm}$ below surface (cmbs). Intact deposits were encountered at approximately 13 cmbs at the top of Zone 2 (A horizon) and was situated beneath Zone 1 (Ap1 horizon / Ap plow zone). This is followed by Zone 3 (Bk1 horizon), then Zone 4 (Bk2 horizon). 


\section{Restricted Information}

\section{Not for Public Disclosure}

Figure 5.1. Subsurface testing distribution across area of $41 \mathrm{SR242}$ recommended for NRHP testing. 
Table 5.1. 41SR242 Backhoe Trenches

\begin{tabular}{lcc}
\hline Trench & Length $(\mathbf{m})$ & Depth (cmbs) \\
\hline BHT 1 & 4.5 & 65 \\
\hline BHT 2 & 4.5 & 120 \\
\hline BHT 3 & 4.5 & 95 \\
\hline BHT 4 & 6.0 & 160 \\
\hline BHT 5 & 9.0 & 68 \\
\hline BHT 6 & 7.0 & 70 \\
\hline BHT 7 & 4.0 & 50 \\
\hline BHT 8 & 7.0 & 80 \\
\hline BHT 9 & 5.0 & 90 \\
\hline BHT 10 & 4.5 & 100 \\
\hline BHT 11 & 5.0 & 82 \\
\hline BHT 12 & 5.0 & 100 \\
\hline BHT 13 & 5.0 & 120 \\
\hline BHT 14 & 4.5 & 125 \\
\hline BHT 15 & 6.0 & 125 \\
\hline
\end{tabular}

Based on combined archeological and geoarcheological considerations, the upper 25 to $35 \mathrm{~cm}$ of the ground surface was removed (Figure 5.2). The overburden showed little integrity. This layer was likely repeatedly disturbed by agriculture, root plowing, bioturbation, and other processes. This identifiable Ap Horizon (plow zone) was scraped off to the contact with the underlying intact sediments. From there, backhoe scraping was slowed considerably and removed in 3-5 cm increments stopping and hand scraping frequently looking for artifacts and features.

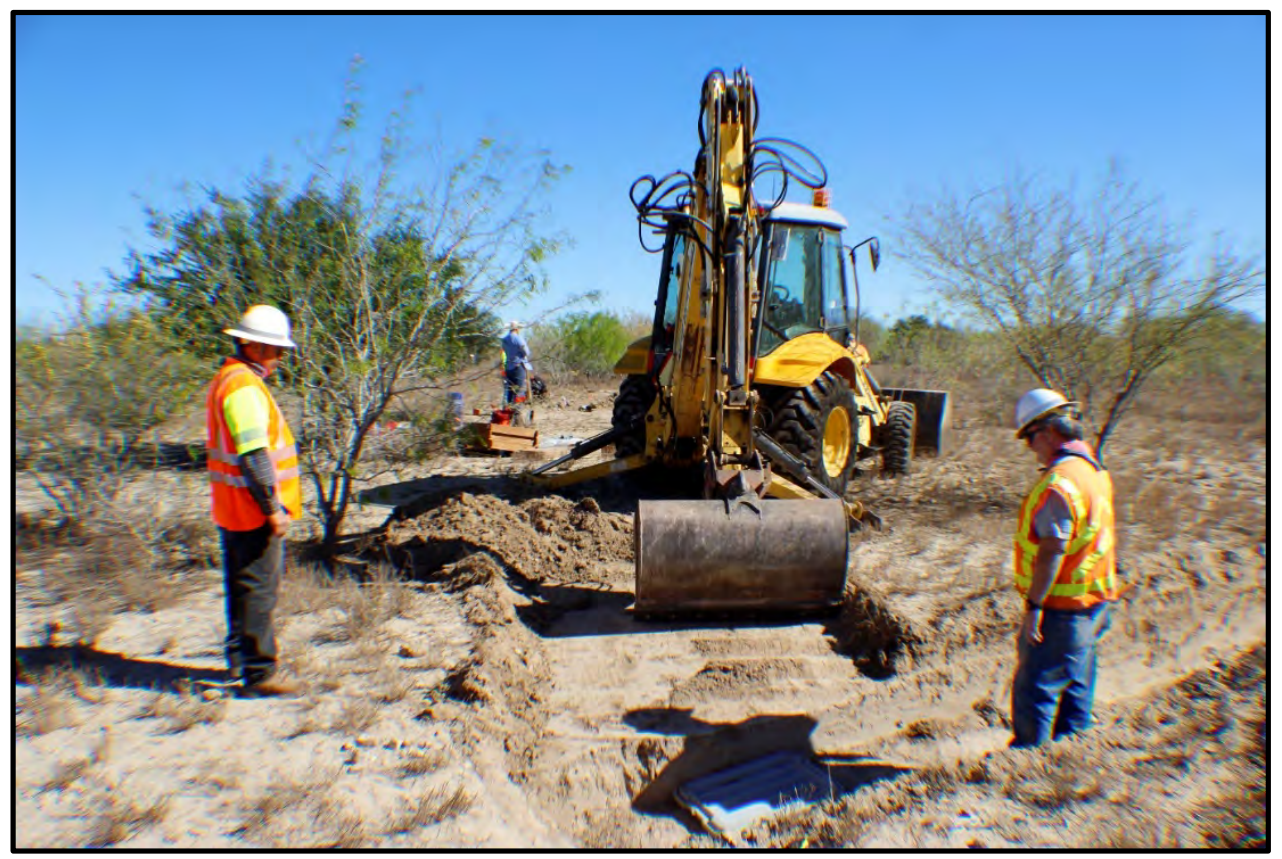

Figure 5.2. Crew removing overburden during backhoe trench testing, facing east. 
The BHT excavation revealed Feature 1 within intact Holocene deposits at a depth of 50-60 cmbs within a relatively small area that measured approximately $50 \times 50 \mathrm{~cm}$. The feature was encountered during trowel scraping of the trench walls and floor. Feature 1 consisted of a dense concentration of chipped stone flaking debris with considerable quantities of land snail (Rabdotus). The BHT excavation yielded 151 pieces of debitage, nine faunal bone fragments, and 71 land snail (Rabdotus), all in association with the feature. The cultural feature and materials were observed within Zone 4 (Bk2 horizon).

In addition, TxDOT excavated four TUs (i.e., TU 1, TU 3, TU 4, and TU 5) to expand the BHT 1 excavation area and further investigate Feature 1 . An additional feature, designated as Feature 3, that consisted of a small scatter of thermally altered rock was revealed during the excavation of TU 4 and TU 5. The TUs and features are further discussed in their respective sections below.

\section{BHT 2}

BHT 2 was placed within the southeastern quadrant of the site area recommended for further investigations during survey level investigations. The trench was approximately $4.5 \mathrm{~m}$ long and excavated to a depth of approximately $120 \mathrm{cmbs}$. Intact deposits were encountered at approximately $22 \mathrm{cmbs}$ at the top of Zone 3 (Bk1 horizon), immediately followed by Zone 4 (Bk2 horizon). Both are situated beneath Zone 1 (Ap1) and Zone 2 (Ap2 horizon / Ap plow zone). Zone 5 (BC horizon), is situated beneath all of the above. No cultural features were observed during the BHT excavations; however, a small area of wellpreserved land snail (Rabdotus) with some flakes was observed within Zone 3 ranging from 22 to 60 cmbs. No cultural materials were collected from BHT 2.

\section{BHT 3}

BHT 3 was located within the northeastern quadrant of the site area recommended for further investigations during survey level investigations. The trench was approximately $4.5 \mathrm{~m}$ long and excavated to a depth of approximately $95 \mathrm{cmbs}$. Intact deposits were encountered at approximately $40 \mathrm{cmbs}$ at the top of Zone 3 (ABk horizon) composed of abundant fine gravels situated beneath Zone 1 (Ap1 horizon) and Zone 2 (Ap2 horizon / Ap plow zone). This is followed by Zone 4 (Bk1 horizon) then Zone 5 (Bk2 horizon). No cultural features or materials were observed during the BHT excavations.

\section{BHT 4}

BHT 4 was positioned within the southwestern quadrant of the site area recommended for further investigations during survey level investigations. The trench was approximately $6.0 \mathrm{~m}$ long and excavated to a depth of approximately $160 \mathrm{cmbs}$. Intact deposits were encountered at approximately $40 \mathrm{cmbs}$ at the top of Zone 3 (ABk1 horizon) situated beneath Zone 1 (Ap1 horizon) and Zone 2 (Ap2 horizon / Ap plow zone). This is followed by Zone 4 (Bk1 horizon) then Zone 5 (2BC horizon).

The BHT excavation revealed Feature 2 relatively high in the profile at a depth of 20-50 cmbs, situated at the contact between the Ap and ABk1 horizons. The feature consisted of a small concentration/cluster of thermally altered rock. The BHT excavation yielded 158 pieces of debitage, 44 burned rock fragments, and sparse mussel shell, all in association with the feature. The cultural feature and materials were observed within Zone 2 (Ap2 horizon) and Zone 3 (ABk1 horizon).

In addition, TxDOT excavated one TU (TU 2) over Feature 2 discovered in this BHT to further investigate the feature. The TU and feature are further discussed in the Test Unit 2 section below. 


\section{BHT 5}

BHT 5 was excavated within the southeastern quadrant of the site area recommended for further investigations during survey level investigations. The trench was approximately $9.0 \mathrm{~m}$ long and excavated to a depth of approximately $68 \mathrm{cmbs}$. A zone of large cobbles was observed at approximately $20 \mathrm{cmbs}$ within Zone 2 (AC horizon). Intact deposits were encountered at approximately $50 \mathrm{cmbs}$ at the top of Zone 3 (Bk horizon) situated beneath Zone 1 (Ap horizon /plow zone) followed by Zone 2 (AC horizon). No cultural features or materials were observed during the BHT excavations.

\section{BHT 6}

BHT 6 was placed within the northwestern quadrant of the site area recommended for further investigations during survey level investigations. The trench stratigraphy was similar to BHT 1. The trench was approximately $7.0 \mathrm{~m}$ long and excavated to a depth of approximately $70 \mathrm{cmbs}$. Intact deposits were encountered at approximately $13 \mathrm{cmbs}$ at the top of Zone 2 (A horizon) situated beneath Zone 1 (Ap1 horizon / Ap plow zone). This is followed by Zone 3 (Bk1 horizon) then Zone 4 (Bk2 horizon). No cultural features or materials were observed during the BHT excavations.

\section{BHT 7}

BHT 7 was located within the southwestern quadrant of the site area recommended for further investigations during survey level investigations. The trench stratigraphy was similar to BHT 1. The trench was approximately $4.0 \mathrm{~m}$ long and excavated to a depth of approximately $50 \mathrm{cmbs}$. Intact deposits were encountered at approximately $13 \mathrm{cmbs}$ at the top of Zone 2 (A horizon) situated beneath Zone 1 (Ap1 horizon / Ap plow zone). This is followed by Zone 3 (Bk1 horizon) then Zone 4 (Bk2 horizon). No cultural features or materials were observed during the BHT excavations.

\section{BHT 8}

BHT 8 was positioned within the northwestern quadrant of the site area recommended for further investigations during survey level investigations. The trench was approximately $7.0 \mathrm{~m}$ long and excavated to a depth of approximately $80 \mathrm{cmbs}$. Intact deposits were encountered at approximately $20 \mathrm{cmbs}$ at the top of Zone 3 (Bk1 horizon) immediately followed by Zone 4 (Bk2 horizon) both situated beneath Zone 1 (Ap1 horizon ) and Zone 2 (Ap2 horizon / Ap plow zone).

The BHT did not reveal any cultural features, but cultural materials were observed during the excavations. TxDOT excavated one column sample along BHT 8 to quantify artifact density and vertical distribution within the Holocene sediments. The column sample is further discussed in its respective section below. No further excavation was performed at BHT 8.

\section{BHT 9}

BHT 9 was excavated just beyond the northwestern site boundary and site area recommended for further investigations during survey level investigations. The trench was approximately $5.0 \mathrm{~m}$ long and excavated to a depth of approximately $90 \mathrm{cmbs}$. Intact deposits were encountered at approximately $25 \mathrm{cmbs}$ at the top of Zone 2 (Ak horizon) and immediately followed by Zone 3 (Bk horizon) both situated beneath Zone 1 (Ap horizon / plow zone). The BHT contains a possible pit feature within the Ak and Bk horizons; however, no cultural materials were observed during the BHT excavations. 


\section{BHT 10}

BHT 10 was placed within the northeastern quadrant of the site area recommended for further investigations during survey level investigations. The trench was approximately $4.5 \mathrm{~m}$ long and excavated to a depth of approximately 100 cmbs. The BHT excavation encountered Zone 1 (Ap1 horizon) and Zone 2 (Ap2 horizon / Ap plow zone) at the top. This is followed by Zone 3 (C1 horizon) composed of channel gravels then Zone 4 (2Bk horizon) composed of highly weathered bedrock. No cultural features were observed during the BHT excavations. Sparse cultural materials observed included occasional crumbs of burned rock within the Ap plow zone. No cultural materials were collected from BHT 10.

\section{BHT 11}

BHT 11 was located within the southeastern quadrant of the site area recommended for further investigations during survey level investigations. The trench was approximately $5.0 \mathrm{~m}$ long and excavated to a depth of approximately 82 cmbs. The BHT excavation encountered Zone 1 (Ap1 horizon) and Zone 2 (Ap2 or Apk horizons / Ap plow zone) composed of colluvial alluvium, followed by Zone 3 (BCk horizon) composed of weathered sandstone bedrock. No cultural features or materials were observed during the BHT excavations with the exception of sparse cultural materials at the surface. No cultural materials were collected from BHT 11.

\section{BHT 12}

BHT 12 was positioned within the southeastern quadrant of the site area recommended for further investigations during survey level investigations. The trench was approximately $5.0 \mathrm{~m}$ long and excavated to a depth of approximately $100 \mathrm{cmbs}$. Intact deposits were encountered at approximately $40 \mathrm{cmbs}$ at the top of Zone 3 (Bk horizon) situated beneath Zone 1 (Ap1 horizon) and Zone 2 (Ap2 horizon / Ap plow zone). This is followed by Zone 4 (C horizon). No cultural features or materials were observed during the BHT excavations. However, it was notes that lots of crushed land snail (Rabdotus) was observed within the Zone 2 (Ap2 horizon) and Zone 3 (Bk horizon) deposits. Very low density gravels were observed within BHT 12.

\section{BHT 13}

BHT 13 was excavated within the southwestern quadrant of the site area recommended for further investigations during survey level investigations. The trench was approximately $5.0 \mathrm{~m}$ long and excavated to a depth of approximately $120 \mathrm{cmbs}$. The trench stratigraphy was similar to BHT 1. Intact deposits were encountered at approximately $13 \mathrm{cmbs}$ at the top of Zone 2 (A horizon) situated beneath Zone 1 (Ap1 horizon / Ap plow zone). This is followed by Zone 3 (Bk1 horizon) then Zone 4 (Bk2 horizon). No cultural features or materials were observed during the BHT excavations.

\section{BHT 14}

BHT 14 was placed within the northwestern quadrant of the site area recommended for further investigations during survey level investigations. The trench was approximately $4.5 \mathrm{~m}$ long and excavated to a depth of approximately $125 \mathrm{cmbs}$. Intact deposits were encountered at approximately $42 \mathrm{cmbs}$ at the top of Zone 2 (B1 horizon) immediately followed by Zone 3 (B2 horizon), both situated beneath Zone 1 (Ap horizon / Ap plow zone). This is followed by Zone 4 (C horizon) composed of weathered sandstone parent material.

The BHT excavations did not encounter any cultural features; however, cultural materials were observed primarily within Zone 2 (B1 horizon) with some disturbed cultural material observed within Zone 1 
(Ap horizon / Ap plow zone). This included two early- to mid-stage bifaces and lightly scattered lithic debitage and burned rock frags. No further excavation was performed at BHT 14.

\section{BHT 15}

BHT 15 was located within the northwestern quadrant of the site area recommended for further investigations during survey level investigations. The trench was approximately $6 \mathrm{~m}$ long and excavated to a depth of approximately $125 \mathrm{cmbs}$. Intact deposits were encountered at approximately $43 \mathrm{cmbs}$ at the top of Zone 2 (B horizon) immediately followed by Zone 3 (Bk horizon), both situated beneath Zone 1 (Ap horizon / Ap plow zone). This is followed by Zone 4 (C horizon) composed of weathered sandstone parent material.

The BHT excavation revealed Feature 4 relatively high in the profile at a depth of $20-50 \mathrm{cmbs}$ at the contact between the Ap and B horizons. The feature consisted of a dense concentration of chipped stone flaking debris, burned rock, and land snail (Rabdotus). The cultural feature and materials were observed within Zone 2 (B horizon).

In addition, TxDOT excavated two TUs (TU 6 and TU 7) over Feature 4 discovered in this trench to further investigate the feature. The results of the TUs are discussed in their respective sections below.

\section{BHT 8 COLUMN SAMPLE}

TxDOT excavated a $50 \times 50$-cm column sample along BHT 8 to the substrate calcic horizon to quantify artifact density and vertical distribution within the Holocene sediments (Figure 5.3). The column sample recovered high quantities of cultural materials (Table 5.2). This included one Tortugas dart point, four bifaces, 204 pieces of debitage, eight burned rock fragments, three faunal bone fragments, one ochre fragment, one charcoal sample, and one historic-age undecorated whiteware ceramic fragment. The Tortugas dart point was recovered in Level 6 between 50 and 60 cmbs and was the only prehistoric temporally diagnostic artifact encountered.

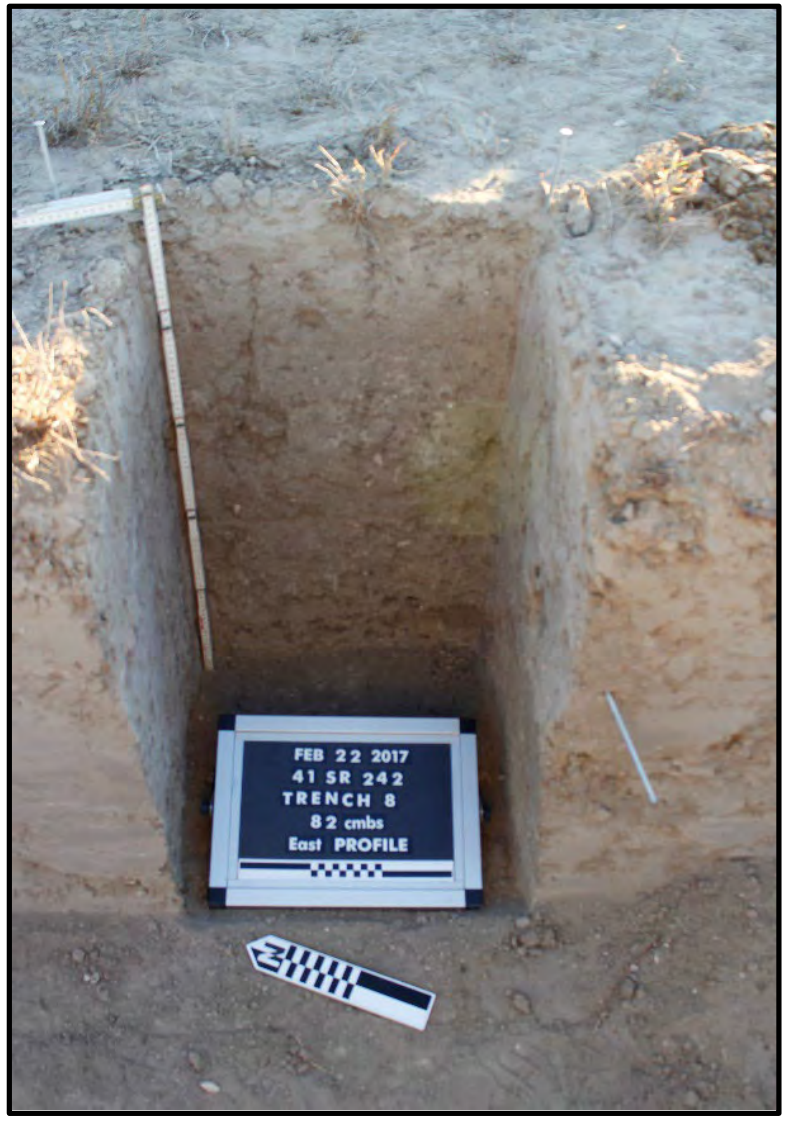

Figure 5.3. Column sample from BHT 8, facing east-southeast. 
Table 5.2. 41SR242 Artifact Recovery in BHT 8 Column Sample

\begin{tabular}{|c|c|c|}
\hline Level & Artifact Description & $\begin{array}{c}\text { Artifact } \\
\text { Total }\end{array}$ \\
\hline \multirow{3}{*}{1} & Size-Graded Debitage & 7 \\
\hline & Burned Rock & 4 \\
\hline & Artifact Total & 11 \\
\hline \multirow{5}{*}{2} & Size-Graded Debitage & 22 \\
\hline & Bone & 2 \\
\hline & Burned Rock & 0 \\
\hline & Undecorated Whiteware Ceramic & 2 \\
\hline & Artifact Total & 26 \\
\hline \multirow{4}{*}{3} & Size-Graded Debitage & 11 \\
\hline & Charcoal Sample & 1 \\
\hline & Burned Rock & 4 \\
\hline & Artifact Total & 16 \\
\hline \multirow{2}{*}{4} & Size-Graded Debitage & 35 \\
\hline & Artifact Total & 35 \\
\hline \multirow{2}{*}{5} & Size-Graded Debitage & 28 \\
\hline & Artifact Total & 28 \\
\hline \multirow{7}{*}{6} & Size-Graded Debitage & 38 \\
\hline & Tortugas Dart Point & 1 \\
\hline & Early-Stage Biface & 1 \\
\hline & Mid-Stage Biface & 2 \\
\hline & Late-Stage Biface & 1 \\
\hline & Ochre & 1 \\
\hline & Artifact Total & 44 \\
\hline \multirow{3}{*}{7} & Size-Graded Debitage & 20 \\
\hline & Bone & 1 \\
\hline & Artifact Total & 21 \\
\hline \multirow{2}{*}{8} & Size-Graded Debitage & 43 \\
\hline & Artifact Total & 43 \\
\hline \multicolumn{2}{|c|}{ Grand Artifact Total } & 224 \\
\hline
\end{tabular}




\section{TEST UNITS}

TxDOT excavated a total of seven $1 \times 1$-m TUs placed over Features $1-4$ encountered during BHT excavations. All TUs were excavated in 10-cm arbitrary levels and the overlying plow zone (Ap) was removed and not screened. All matrix excavated from beneath the plow zone was screened through $1 / 8$ - inch mesh and water screen samples were collected from Features 1,3 , and 4 . The unit corners were recorded using a sub-centimeter GPS unit. All materials and samples were documented with photographs and drawings; provenience was maintained using the GPS for point plotting. Please refer to Tables 5.3 through 5.10 for a detailed accounting of cultural materials recovered in the TUs by level. The features and cultural materials recovered are further discussed below and in Chapter 7.

\section{Test Unit 1}

Although standard $1 \times 1$-m TUs were used for feature recovery, TU 1 is the only exemption (Figure 5.4). After reopening the previously excavated BHT 1 to recover Feature 1, TU 1 was expanded to better expose the feature and the surrounding occupational surface (see Table 5.3).

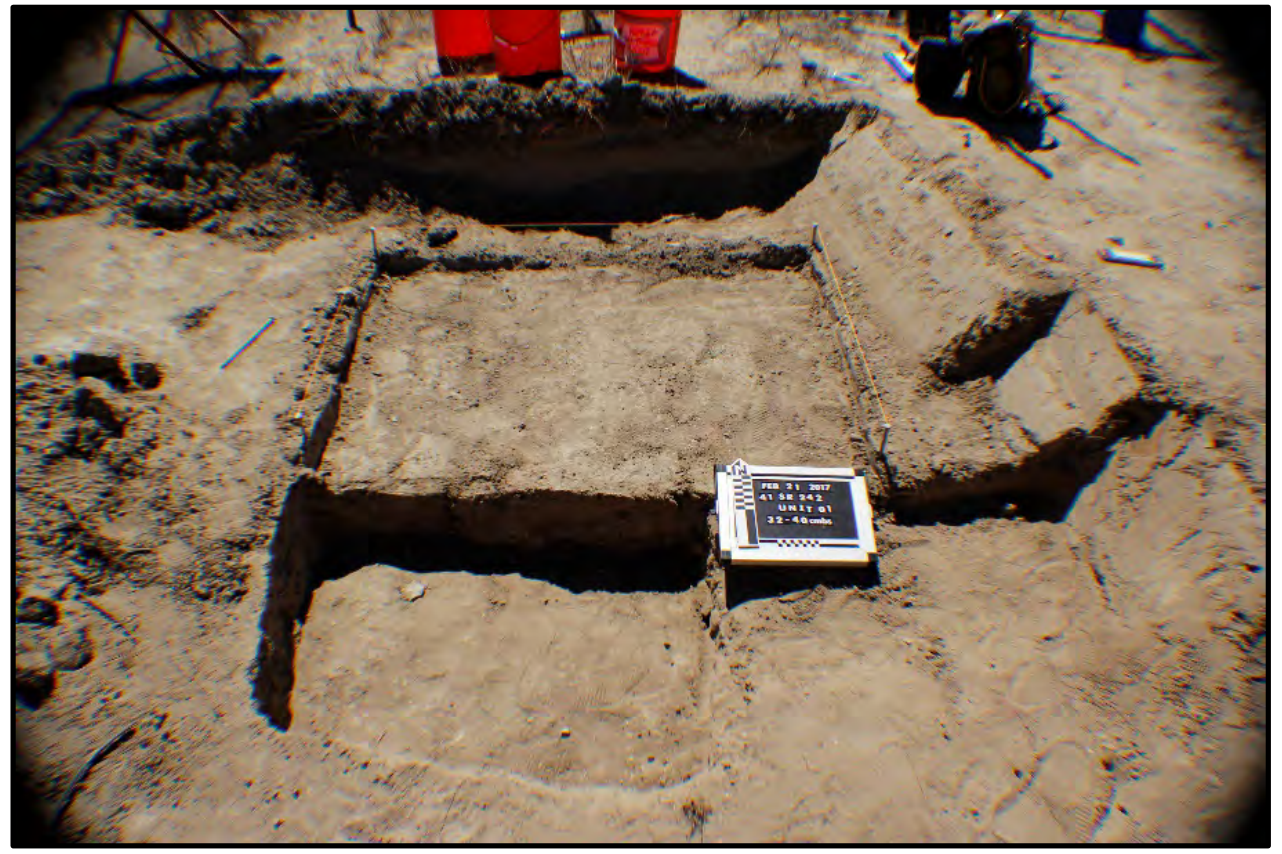

Figure 5.4. Representative photograph of TU 1, facing north. 
Table 5.3. 41SR242 Artifact Recovery in BHT 1-TU 1

\begin{tabular}{|c|c|c|}
\hline Level & Artifact Description & Artifact Total \\
\hline \multirow{5}{*}{1} & Analyzed Debitage & 65 \\
\hline & Charcoal Sample & 1 \\
\hline & Rabdotus Shell & 52 \\
\hline & Burned Rock & 2 \\
\hline & Artifact Total & 120 \\
\hline \multirow{8}{*}{2} & Analyzed Debitage & 196 \\
\hline & Charcoal Sample & 1 \\
\hline & Mussel Shell & 1 \\
\hline & Rabdotus Shell & 24 \\
\hline & Burned Rock & 2 \\
\hline & Undecorated Whiteware Ceramic & 2 \\
\hline & Metal Buckle & 1 \\
\hline & Artifact Total & 227 \\
\hline \multirow{9}{*}{3} & Analyzed Debitage & 505 \\
\hline & Core & 1 \\
\hline & Late-Stage Biface & 1 \\
\hline & Edge-Modified Utilized Flake & 1 \\
\hline & Bone & 25 \\
\hline & Mussel Shell & 3 \\
\hline & Rabdotus Shell & 596 \\
\hline & Burned Rock & 72 \\
\hline & Artifact Total & 1,204 \\
\hline \multirow{5}{*}{4} & Analyzed Debitage & 181 \\
\hline & Mussel Shell & 1 \\
\hline & Rabdotus Shell & 102 \\
\hline & Burned Rock & 19 \\
\hline & Artifact Total & 303 \\
\hline \multicolumn{2}{|c|}{ Grand Artifact Total } & 1,854 \\
\hline
\end{tabular}

Level 1 of TU 1 was excavated between approximately $29 \mathrm{cmbs}$ and $40 \mathrm{cmbs}$. The level is not associated with Feature 1, which begins with Level 3. Excavations of Level 1 recovered primarily lithic debitage ( $\mathrm{n}=65)$ and land snail (Rabdotus) shells ( $\mathrm{n}=52$ ), as well as one charcoal sample and two burned rocks.

Level 2 of TU 1 was excavated between $40 \mathrm{cmbs}$ and $50 \mathrm{cmbs}$. The level is located just above Feature 1 and shows an increase in artifacts as compared to Level 1. Artifacts recovered from Level 2 include primarily lithic debitage $(\mathrm{n}=196)$, as well as two burned rock fragments and a charcoal sample. In addition to the prehistoric artifacts, historic artifacts were also recovered from Level 2 and consist of a metal buckle and two undecorated whiteware ceramic sherds. Recovered ecofacts include one mussel shell and 24 land snail (Rabdotus) shells.

Level 3 of TU 1 was excavated between $50 \mathrm{cmbs}$ and $60 \mathrm{cmbs}$, and contains Feature 1, which consists of a dense concentration of chipped stone flaking debris with considerable quantities of land snail (Rabdotus sp.). The feature is located between approximately $50 \mathrm{cmbs}$ and $62 \mathrm{cmbs}$, and artifacts appear to have been concentrated towards the northwest of the TU. Adjacent TUs (i.e., TU 3, TU 4, and TU 5) 
were excavated to the north, northeast, and east, and TU 1 was expanded to the south to test the extent of the artifact concentration.

Artifacts recovered from TU 1 Level 3 include primarily lithic debitage ( $n=505)$, as well as 72 burned rock fragments, a core, a late-stage biface, and a utilized flake. Ecofacts recovered from Level 3 include primarily land snail (Rabdotus) shell $(\mathrm{n}=596)$, as well as mussel shell $(\mathrm{n}=3)$ and vertebrate remains $(n=25)$.

Level 4 of TU 1 was excavated between $60 \mathrm{cmbs}$ and $70 \mathrm{cmbs}$ and contains considerably fewer artifacts/ecofacts in relation to Level 3. The Feature 1 concentration terminates at approximately $62 \mathrm{cmbs}$. Artifacts below this depth are probably due to disturbances, such as bioturbation. Artifacts recovered from Level 4 include lithic debitage $(n=181)$ and burned rock fragments $(n=19)$. Ecofacts recovered from the level include land snail (Rabdotus) shells ( $\mathrm{n}=102)$ and mussel shell $(\mathrm{n}=1)$.

\section{Test Unit 2}

TU 2 was excavated within BHT 4 after the top of a small concentration of burned rock was encountered relatively high in the profile (approximately $20 \mathrm{cmbs}$ ) (see Table 5.4). This concentration was designated as Feature 2, and the floor of BHT 4 was excavated down to the bottom of Feature 2, approximately 40 cmbs. Levels 1 and 2 of TU 2 consist of the north half of the TU alone and were excavated to bring the rest of TU 2 down to the feature.

Table 5.4. 41SR242 Artifact Recovery in BHT 4-TU 2

\begin{tabular}{|c|c|c|}
\hline Level & Artifact Description & Artifact Total \\
\hline \multirow{3}{*}{1} & Size-Graded Debitage & 42 \\
\hline & Burned Rock & 12 \\
\hline & Artifact Total & 54 \\
\hline \multirow{7}{*}{2} & Size-Graded Debitage & 63 \\
\hline & Mid-Stage Biface & 1 \\
\hline & Late-Stage Biface & 1 \\
\hline & Mussel Shell & 6 \\
\hline & Burned Rock & 9 \\
\hline & Earthenware Slip Glazed-Brown Ceramic & 1 \\
\hline & Artifact Total & 81 \\
\hline \multirow{5}{*}{3} & Prehistoric Ceramic Plain Body Sherd & 1 \\
\hline & Size-Graded Debitage & 53 \\
\hline & Burned Rock & 23 \\
\hline & Miscellaneous Metal Fragments & 2 \\
\hline & Artifact Total & 79 \\
\hline \multicolumn{2}{|c|}{ Grand Artifact Total } & 214 \\
\hline
\end{tabular}


Level 1 of TU 2 consists of only the northern half of the TU and was excavated between $18 \mathrm{cmbs}$ and 30 cmbs. Recovered artifacts include 42 pieces of lithic debitage and 12 burned rock fragments.

Level 2 of TU 2 consists of only the north half the TU and was excavated between $30 \mathrm{cmbs}$ and $40 \mathrm{cmbs}$. The bottom of level two is level with the floor of BHT 4. Recovered artifacts include 63 pieces of lithic debitage, a mid-stage biface, a late-stage biface, a historic ceramic sherd, and nine burned rock fragments.

Level 3 of TU 2 was excavated between $40 \mathrm{cmbs}$ and $50 \mathrm{cmbs}$ and includes the recovery of Feature 2 (Figure 5.5). Artifacts recovered from Level 3 include 53 pieces of lithic debitage, 23 burned rock fragments, two unidentifiable metal fragments, and one prehistoric ceramic sherd.

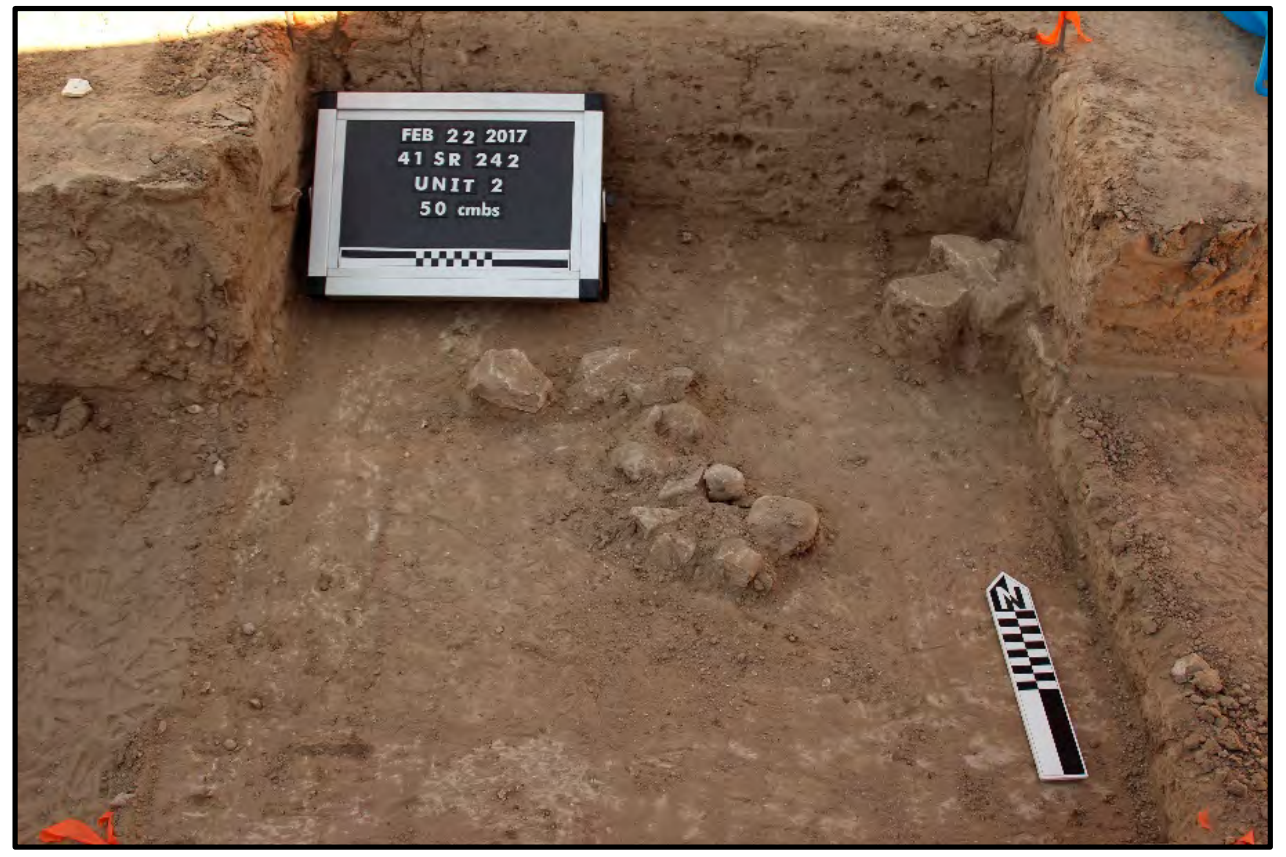

Figure 5.5. Feature 2 in Test Unit 2 along BHT 4, facing north.

\section{Test Unit 3}

TU 3 was excavated to the north of TU 1 and was designed to test the extent of Feature 1 . The southern portion of TU 3 (approximately $40 \mathrm{~cm}$ north to south by $1 \mathrm{~m}$ east to west) was disturbed by previous trenching efforts to a depth of approximately $50 \mathrm{cmbs}$. Although artifacts were found in each level, the Feature 1 concentration was only present in the southeast corner of Levels 3 and 4 (see Table 5.5).

Table 5.5. 41SR242 Artifact Recovery in BHT 1-TU 3

\begin{tabular}{llc}
\hline \multirow{2}{*}{ Level } & Artifact Description & Artifact Total \\
\hline \multirow{2}{*}{1} & Analyzed Debitage & 69 \\
\cline { 2 - 3 } & Rabdotus Shell & 13 \\
\cline { 2 - 3 } & Artifact Total & $\mathbf{8 2}$ \\
\hline
\end{tabular}




\begin{tabular}{|c|c|c|}
\hline Level & Artifact Description & Artifact Total \\
\hline \multirow{5}{*}{2} & Analyzed Debitage & 205 \\
\hline & Multidirectional Core & 1 \\
\hline & Late-Stage Biface & 1 \\
\hline & Burned Rock & 1 \\
\hline & Artifact Total & 208 \\
\hline \multirow{5}{*}{3} & Analyzed Debitage & 243 \\
\hline & Bone & 6 \\
\hline & Mussel Shell & 1 \\
\hline & Rabdotus Shell & 10 \\
\hline & Artifact Total & 260 \\
\hline \multirow{4}{*}{4} & Analyzed Debitage & 65 \\
\hline & Unidentified Dart Point Base & 1 \\
\hline & Bone & 2 \\
\hline & Artifact Total & 68 \\
\hline \multicolumn{2}{|c|}{ Grand Artifact Total } & 618 \\
\hline
\end{tabular}

Level 1 of TU 3 was excavated from $30 \mathrm{cmbs}$ to $40 \mathrm{cmbs}$ in the northern approximately two-thirds of the TU. Artifacts recovered are exclusively lithic debitage $(n=69)$, while recovered ecofacts consist of 13 land snail (Rabdotus) shells.

Level 2 of TU 3 was excavated between $40 \mathrm{cmbs}$ and $50 \mathrm{cmbs}$ in the northern approximately two-thirds of the TU. Although artifact density notably increases, there were no discernable artifact concentrations. Artifacts recovered from Level 2 include 205 pieces of lithic debitage, a multidirectional core, a late-stage biface, and a single burned rock fragment. No ecofacts were recovered from the level.

Level 3 of TU 3 was excavated between $50 \mathrm{cmbs}$ and $60 \mathrm{cmbs}$ and contained a small continuation of Feature 1 in the southeast corner. Artifacts recovered from the level consist exclusively of lithic debitage ( $\mathrm{n}=243$ ), while recovered ecofacts include 10 land snail (Rabdotus) shells, six vertebrate bone fragments, and a mussel shell.

Artifacts continued to be recovered in the first few centimeters of Level 4, which was excavated from 60 cmbs to sterility. Artifacts recovered from the level include 65 pieces of lithic debitage and a single dart point base. Recovered ecofacts include two faunal bone fragments.

\section{Test Unit 4}

TU 4 was excavated to the northeast of TU 1 and was designed to test the extent of Feature 1. Feature 3, a burned rock scatter, was identified in TU 4 and TU 5 at approximately the same depth as Feature 1 (50 cmbs to $60 \mathrm{cmbs}$ ) (Figure 5.6). Although the artifact content of Feature 3 is not as dense as Feature 1, given the proximity and the similarity of depth, the two features are likely related (see Table 5.6). 


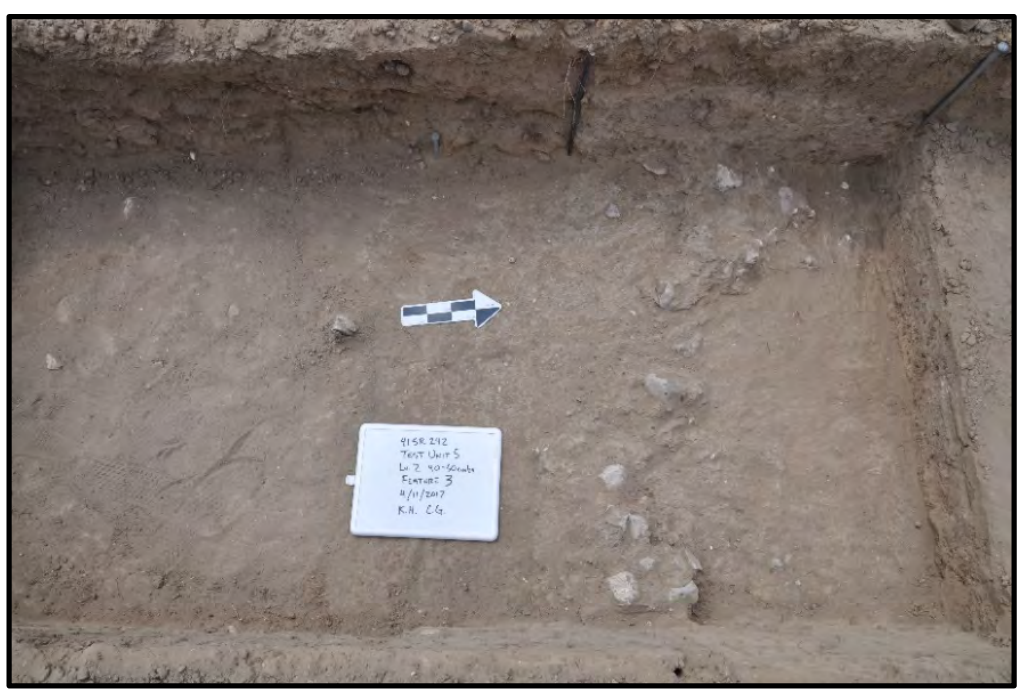

Figure 5.6. Level 2 of TU 4, facing west. Note the Feature 4 on the north side of the test unit.

Table 5.6. 41SR242 Artifact Recovery in TU 4

\begin{tabular}{|c|c|c|}
\hline Level & Artifact Description & Artifact Tota \\
\hline \multirow{2}{*}{ South Wall } & Bone & 1 \\
\hline & Artifact Total & 1 \\
\hline \multirow{6}{*}{1} & Size-Graded Debitage & 108 \\
\hline & Charcoal Sample & 1 \\
\hline & Bone & 4 \\
\hline & Burned Rock & 14 \\
\hline & Earthenware Slip Glazed-Brown Ceramic & 1 \\
\hline & Artifact Total & 128 \\
\hline \multirow{5}{*}{2} & Size-Graded Debitage & 61 \\
\hline & Bone & 3 \\
\hline & Burned Rock & 1 \\
\hline & Colorless Glass & 1 \\
\hline & Artifact Total & 66 \\
\hline \multirow{5}{*}{3} & Size-Graded Debitage & 101 \\
\hline & Multidirectional Core & 1 \\
\hline & Late-Stage Biface & 1 \\
\hline & Mussel Shell & 1 \\
\hline & Artifact Total & 104 \\
\hline \multirow{4}{*}{4} & Size-Graded Debitage & 50 \\
\hline & Early-Stage Biface & 1 \\
\hline & Burned Rock & 21 \\
\hline & Artifact Total & 72 \\
\hline \multicolumn{2}{|c|}{ Grand Artifact Total } & 371 \\
\hline
\end{tabular}


Level 1 of TU 4 was excavated between $30 \mathrm{cmbs}$ and $40 \mathrm{cmbs}$. Both the southern and western edges of the TU consisted of fill from previous trenching efforts. Artifacts include 108 lithic debitage pieces, 14 burned rock fragments, and one historic ceramic sherd. Ecofacts recovered from the level include four faunal bone fragments and one charcoal sample.

Level 2 of TU 4 was excavated between $40 \mathrm{cmbs}$ and $50 \mathrm{cmbs}$. Both the southern and western edges of the TU consisted of fill and embedded modern trash from previous backhoe trenching efforts. Artifacts recovered from the level include 61 lithic debitage pieces, one burned rock fragment, and one shard of colorless glass. Recovered ecofacts consist of three faunal bone fragments.

Level 3 of TU 4 was excavated between $50 \mathrm{cmbs}$ and $60 \mathrm{cmbs}$ and contained a scatter of lithic debitage and burned rock fragments throughout the level. Only a small portion in the southwest corner of the unit consisted of fill from previous backhoe trenching efforts. Artifacts recovered from the level include 101 lithic debitage pieces, one multidirectional core, and one late-stage biface. Only one ecofact, a mussel shell, was recovered from Level 3.

Level 4 of TU 4 was excavated between $60 \mathrm{cmbs}$ and $70 \mathrm{cmbs}$. An increase in presence of large flakes in this level, as compared to the overlying levels, could indicate an association with Feature 1. Artifacts recovered from this level include 50 lithic debitage pieces, 21 burned rock fragments, and one early-stage biface.

\section{Test Unit 5}

TU 5 was excavated to the east of TU 1 and was designed to test the extent of Feature 1 . As mentioned above, Feature 3, a burned rock scatter, was identified in TU 4 and TU 5 at approximately the same depth as Feature 1 ( $50 \mathrm{cmbs}$ to $60 \mathrm{cmbs}$ ). Although the artifact content of Feature 3 is not as dense as Feature 1, given the proximity and the similarity of depth, the two features are likely related (see Table 5.7).

Table 5.7. 41SR242 Artifact Recovery in TU 5

\begin{tabular}{|c|c|c|}
\hline Level & Artifact Description & Artifact Total \\
\hline \multirow{4}{*}{1} & Size-Graded Debitage & 72 \\
\hline & Late-Stage Biface & 1 \\
\hline & Burned Rock & 3 \\
\hline & Artifact Total & 76 \\
\hline \multirow{6}{*}{2} & Size-Graded Debitage & 147 \\
\hline & Edge-Modified Utilized Flake & 1 \\
\hline & Burned Clay & 1 \\
\hline & Charcoal Sample & 1 \\
\hline & Burned Rock & 116 \\
\hline & Artifact Total & 266 \\
\hline \multirow{6}{*}{3} & Size-Graded Debitage & 159 \\
\hline & Edge-Modified Utilized Flake & 2 \\
\hline & Charcoal Sample & 1 \\
\hline & Bone & 1 \\
\hline & Burned Rock & 31 \\
\hline & Artifact Total & 194 \\
\hline \multicolumn{2}{|c|}{ Grand Artifact Total } & 536 \\
\hline
\end{tabular}


Level 1 of TU 5 was excavated between $30 \mathrm{cmbs}$ and $40 \mathrm{cmbs}$. Although artifacts were found scattered throughout the level, no artifact concentration could be discerned. The artifacts recovered from level 1 include 72 lithic debitage pieces, three burned rock fragments, and one late-stage biface. No ecofacts were recovered from Level 1.

Level 2 of TU 5 was excavated between $40 \mathrm{cmbs}$ and $50 \mathrm{cmbs}$ and includes an increase in artifact presence, as well as a continuation of Feature 3, a burned rock cluster. Artifacts within this level include 147 lithic debitage pieces, 116 burned rock fragments, and a utilized flake. In addition to the artifacts, one charcoal sample was collected, and a piece of burned clay was recorded in Level 2.

Level 3 of TU 5 was excavated between $50 \mathrm{cmbs}$ and $60 \mathrm{cmbs}$. Although lithic material remains abundant, the burned rocks are fewer and less concentrated than the overlying level. Artifacts within the level include 159 lithic debitage pieces, 31 burned rock fragments, two modified flakes. In addition to the artifacts found in the level, a charcoal sample and a faunal bone fragment were recovered.

\section{Test Unit 6}

TU 6 was excavated due to a concentration of lithic debitage, burned rock, and land snail (Rabdotus) shell which was uncovered during the excavation of BHT 15 (see Table 5.8). The feature (i.e., Feature 4) was encountered just below the plow zone and begins just below $20 \mathrm{cmbs}$.

Table 5.8. 41SR242 Artifact Recovery in BHT 15-TU 6

\begin{tabular}{|c|c|c|}
\hline Level & Artifact Description & Artifact Total \\
\hline \multirow{5}{*}{1} & Analyzed Debitage & 152 \\
\hline & Rabdotus Shell & 433 \\
\hline & Burned Rock & 36 \\
\hline & Mussel Shell & 1 \\
\hline & Artifact Total & 622 \\
\hline \multirow{6}{*}{2} & Analyzed Debitage & 131 \\
\hline & Tortugas Dart Point Preform & 1 \\
\hline & Charcoal Sample & 1 \\
\hline & Rabdotus Shell & 929 \\
\hline & Burned Rock & 36 \\
\hline & Artifact Total & 1,098 \\
\hline \multirow{6}{*}{3} & Analyzed Debitage & 158 \\
\hline & Mid-Stage Biface & 2 \\
\hline & Unidentified Dart Point Base & 1 \\
\hline & Rabdotus Shell & 491 \\
\hline & Burned Rock & 26 \\
\hline & Artifact Total & 678 \\
\hline \multicolumn{2}{|c|}{ Grand Artifact Total } & 2,398 \\
\hline
\end{tabular}


Level 1 of TU 6 was excavated between $29 \mathrm{cmbs}$ and $40 \mathrm{cmbs}$ and is the first level into Feature 4. Both artifacts and ecofacts within the level were heavily concentrated towards the north and west of the TU. Artifacts recovered from the level include 152 lithic debitage pieces and 36 burned rock fragments. Ecofacts recovered from the level include 433 land snail (Rabdotus) shells and one mussel shell.

Level 2 of TU 6 was excavated between 40 cmbs and 50 cmbs. As Feature 4 was excavated, the highdensity land snail shell concentration was located towards the center of the TU and terminated at approximately 46 cmbs. Artifacts recovered from this level include 131 lithic debitage pieces, 36 burned rock fragments, and a triangular dart point preform. Land snail (Rabdotus) shells were the most prevalent in this level, with 929 shells recovered. In addition, one charcoal sample was recovered from Level 2.

Level 3 of TU 6 was excavated between $50 \mathrm{cmbs}$ and $60 \mathrm{cmbs}$. Although artifacts and ecofacts were not concentrated in this level, they remain prevalent. Artifacts recovered from Level 3 include 158 lithic debitage pieces, 26 burned rock fragments, two mid-stage bifaces, and a dart point base. Ecofacts recovered from the level consist of 491 land snail (Rabdotus) shells.

\section{Test Unit 7}

TU 7 was excavated to the west of TU 6 and was designed to recover and expose the extent of the Feature 4 (Figure 5.7). Feature 4 was exposed during the excavation of BHT 15 and was uncovered just below 20 cmbs. The feature consists of a concentration of land snail (Rabdotus) shells and lithic debitage and is concentrated toward the south wall of the TU (see Table 5.9).

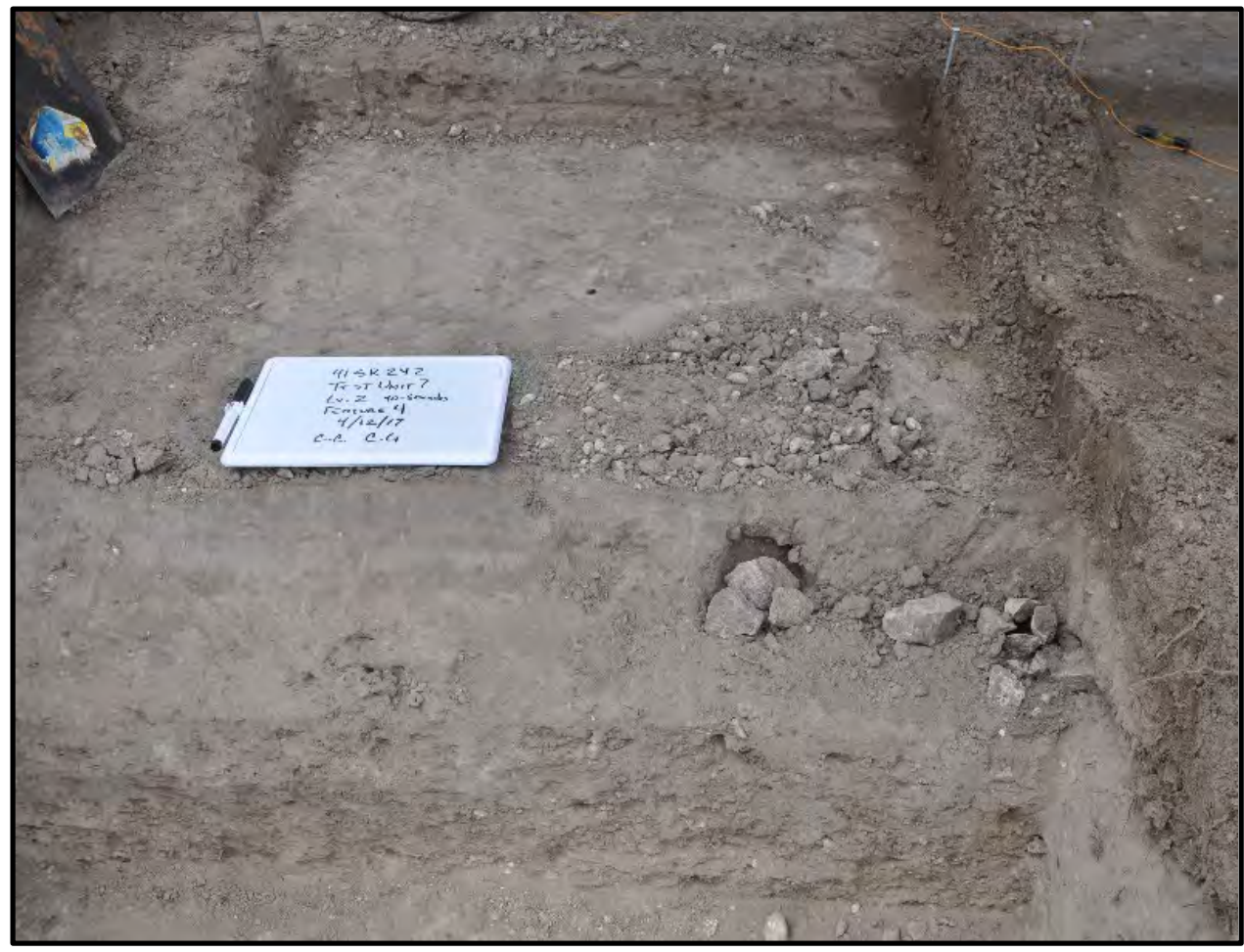

Figure 5.7. Level 2 of TU 6, facing north. 
Table 5.9. 41SR242 Artifact Recovery in TU 7

\begin{tabular}{|c|c|c|}
\hline Level & Artifact Description & $\begin{array}{c}\text { Artifact } \\
\text { Total }\end{array}$ \\
\hline \multirow{5}{*}{1} & Analyzed Debitage & 68 \\
\hline & Early-Stage Biface & 1 \\
\hline & Rabdotus Shell & 69 \\
\hline & Burned Rock & 16 \\
\hline & Artifact Total & 154 \\
\hline \multirow{4}{*}{2} & Analyzed Debitage & 192 \\
\hline & Rabdotus Shell & 532 \\
\hline & Burned Rock & 71 \\
\hline & Artifact Total & 795 \\
\hline \multirow{7}{*}{3} & Analyzed Debitage & 137 \\
\hline & Fresno Arrow Point & 1 \\
\hline & Early-Stage Biface & 2 \\
\hline & Edge-Modified Utilized Flake & 1 \\
\hline & Rabdotus Shell & 315 \\
\hline & Burned Rock & 61 \\
\hline & Artifact Total & 517 \\
\hline \multicolumn{2}{|c|}{ Grand Artifact Total } & 1,466 \\
\hline
\end{tabular}

Level 1 of TU 7 was excavated beginning at the floor of BHT 15, approximately 29 cmbs, to a depth of $40 \mathrm{cmbs}$. Both artifacts and ecofacts were concentrated toward the south wall of the TU. Recovered artifacts consist of 68 lithic debitage pieces, 16 burned rock fragments, and an early-stage biface. Recovered ecofacts consist of 69 land snail (Rabdotus) shells.

Level 2 of TU 7 was excavated between $40 \mathrm{cmbs}$ and $50 \mathrm{cmbs}$ and contained an increase of artifacts compared to the overlying level. Feature 4 continues from the overlying level and terminates just above 50 cmbs. Artifacts from the level include 192 lithic debitage pieces and 71 burned rock fragments. A total of 532 land snail (Rabdotus) shells were recovered from the level.

Level 3 of TU 7 was excavated between $50 \mathrm{cmbs}$ and $60 \mathrm{cmbs}$. Artifacts and ecofacts continue to be present within the level but are fewer in number and are more diffuse as compared to the overlying level. Artifacts recovered from Level 3 include 137 lithic debitage pieces, 61 burned rock fragments, two earlystage bifaces, a Fresno arrow point, and a utilized flake. In addition, 315 land snail (Rabdotus) shells were recovered from the level.

A more detailed discussion of the TU recovered cultural materials and feature investigations and findings is provided in Chapter 7. 


\section{CONTROLLED SURFACE COLLECTION}

As mentioned in the Methods section in Chapter 4, a controlled surface collection was conducted.

The collection targeted both prehistoric and historic-age materials across the site. Cornelio Alvarez Jr.

(the landowner) provided details on soil disturbance at the property. In particular, root plowing conducted by his family in the 1980s and 1990s. These disturbances are clearly visible in trench profiles and even in aerial imagery. It is probable that once shallowly buried archeological materials in the upper $30 \mathrm{~cm}$ of the profile were exposed by these practices and account for the high density of surface chipped stone artifacts across the site (Figure 5.8).

Discussed in more detail in Chapter 7, chipped stone artifacts collected at the site consisted of projectile points, identifiable tools, staged bifaces and cores. The purpose of the collection was, despite compromised context, to gain a better understanding of site chronology, function, and broad temporal technological organization.

In addition to the chipped stone artifacts, a number of twentieth century artifacts were also collected. The historic surface assemblage is dominated by ceramics sherds and glass with various metal artifacts, the majority of which are oxidized. A thorough accounting and analysis of the historic artifact assemblage is presented in Chapter 7.

Table 5.10. 41SR242 Prehistoric Controlled Surface Collection

\begin{tabular}{|c|c|c|c|c|c|}
\hline Designation & Class & Completeness & Type* & Material & Break Type \\
\hline SD1 & Biface & Basal-medial & Dart Point & Chert & Impact \\
\hline SD2 & Biface & Basal-medial & Dart Point & Chert & Compound \\
\hline SD3 & Biface & Basal & Dart Point & Chert & $\mathrm{N} / \mathrm{A}$ \\
\hline SD4 & Late-Stage Biface & Distal & $\mathrm{N} / \mathrm{A}$ & Chert & Snap \\
\hline SD5 & Late-Stage Biface & Basal & Preform & Metamorposed Schist & Bending \\
\hline SD6 & Mid-Stage Biface & Complete & Preform & Chert & $\mathrm{N} / \mathrm{A}$ \\
\hline SD7 & Biface & Basal-medial & Dart Point & Siltstone & Snap \\
\hline SD8 & Late-Stage Biface & Distal & $\mathrm{N} / \mathrm{A}$ & Chert & Compound \\
\hline SD9 & Biface & Basal-Medial & Dart Point & Slate & Compound \\
\hline SD10 & Biface & Complete & Dart Point & Chert & $\mathrm{N} / \mathrm{A}$ \\
\hline SB1 & Mid-Stage Biface & Base & $\mathrm{N} / \mathrm{A}$ & Chert & Oblique Bending \\
\hline SB2 & Biface & Indet & $\mathrm{N} / \mathrm{A}$ & Chert & Bending \\
\hline SB3 & Mid-Stage Biface & Complete & $\mathrm{N} / \mathrm{A}$ & Chert & $\mathrm{N} / \mathrm{A}$ \\
\hline SB4 & Uniface & Complete & Discoid & Chert & $\mathrm{N} / \mathrm{A}$ \\
\hline SB5 & Late-Stage Biface & Indet & $\mathrm{N} / \mathrm{A}$ & Chert & Compound \\
\hline SB6 & Mid-Stage Biface & Distal & $\mathrm{N} / \mathrm{A}$ & Petrified Wood (?) & Oblique Bending \\
\hline SB7 & Mid-Stage Biface & Basal & $\mathrm{N} / \mathrm{A}$ & Chalcedony & Snap \\
\hline SB8 & Mid-Stage Biface & Medial-Distal & $\mathrm{N} / \mathrm{A}$ & Chert & Compound \\
\hline SB9 & Early-Stage Biface & Complete & $\mathrm{N} / \mathrm{A}$ & Chert & $\mathrm{N} / \mathrm{A}$ \\
\hline SB10 & Early-Stage Biface & Complete & $\mathrm{N} / \mathrm{A}$ & Chert & $\mathrm{N} / \mathrm{A}$ \\
\hline SB11 & Uniface & Complete & DBT & Mudstone & $\mathrm{N} / \mathrm{A}$ \\
\hline SB12 & Biface & Complete & Core & Chert & N/A \\
\hline
\end{tabular}




\begin{tabular}{|c|c|c|c|c|c|}
\hline Designation & Class & Completeness & Type* & Material & Break Type \\
\hline SB13 & Late-Stage Biface & Lateral & N/A & Chalcedony & Radial \\
\hline SB14 & Mid-Stage Biface & Basal & N/A & Chalcedony & Overshot \\
\hline SB15 & Biface & Basal & Dart Point & Chert & N/A \\
\hline SB16 & Late-Stage Biface & Distal & $\mathrm{N} / \mathrm{A}$ & Chert & Oblique Snap \\
\hline SB17 & Late-Stage Biface & Basal & $\mathrm{N} / \mathrm{A}$ & Chert & Oblique Bending \\
\hline SB18 & Late-Stage Biface & Basal & N/A & Chert & Oblique Snap \\
\hline SB19 & Biface & Complete & Chopper & Chalcedony & N/A \\
\hline SD201 & Biface & Complete & Dart Point & Chert & N/A \\
\hline SD202 & Biface & Complete & Dart Point & Chert & N/A \\
\hline SD203 & Biface & Base & Dart Point & Chert & Thermal? \\
\hline SD204 & Biface & Complete & Dart Point & Chert & N/A \\
\hline SD205 & Biface & Complete & Dart Point & Siltstone & N/A \\
\hline SD206 & Biface & Basal-medial & Dart Point & Chert & Impact \\
\hline SD207 & Mid-Stage Biface & Complete & Dart Point & Chert & N/A \\
\hline SB201 & Biface & Basal & Dart Point & Metamorphic & Snap \\
\hline SB202 & Late-Stage Biface & Complete & $\mathrm{N} / \mathrm{A}$ & Chalcedony & N/A \\
\hline SB203 & Late-Stage Biface & Distal & N/A & Chert & Snap \\
\hline SB204 & Late-Stage Biface & Basal & N/A & Chalcedony & Oblique Snap \\
\hline SB205 & Late-Stage Biface & Basal-medial & N/A & Chert & Oblique Bending \\
\hline SB206 & Mid-Stage Biface & Basal & N/A & Chert & Snap \\
\hline SB207 & Mid-Stage Biface & Distal & $\mathrm{N} / \mathrm{A}$ & Chert & Bending \\
\hline SB208 & Mid-Stage Biface & Basal & $\mathrm{N} / \mathrm{A}$ & Chalcedony & Oblique Snap \\
\hline SB209 & Early-Stage Biface & Complete & N/A & Chert & N/A \\
\hline SB210 & Biface & Basal & Dart Point & Chert & Snap \\
\hline SB211 & Early-Stage Biface & Basal & $\mathrm{N} / \mathrm{A}$ & Chert & Bending \\
\hline SB212 & Mid-Stage Biface & Complete & N/A & Metamorphic & N/A \\
\hline SB213 & Biface & Indet & Utilized Frag & Chert & N/A \\
\hline SB214 & Early-Stage Biface & Distal & $\mathrm{N} / \mathrm{A}$ & Chert & Snap \\
\hline SB215 & Mid-Stage Biface & Complete & N/A & Chert & N/A \\
\hline SB216 & Late-Stage Biface & Distal & N/A & Chert & Snap \\
\hline SB217 & Mid-Stage Biface & Basal & Dart Point & Chert & Bending \\
\hline SB218 & Mid-Stage Biface & Basal & N/A & cf Petrified Palm & Compound \\
\hline SB219 & Biface & Complete & Olmos Biface & Chert & N/A \\
\hline SB220 & Early-Stage Biface & Complete & N/A & Rhyolite & N/A \\
\hline
\end{tabular}

*see typological classification in Chapter 7 for more detailed analysis. 


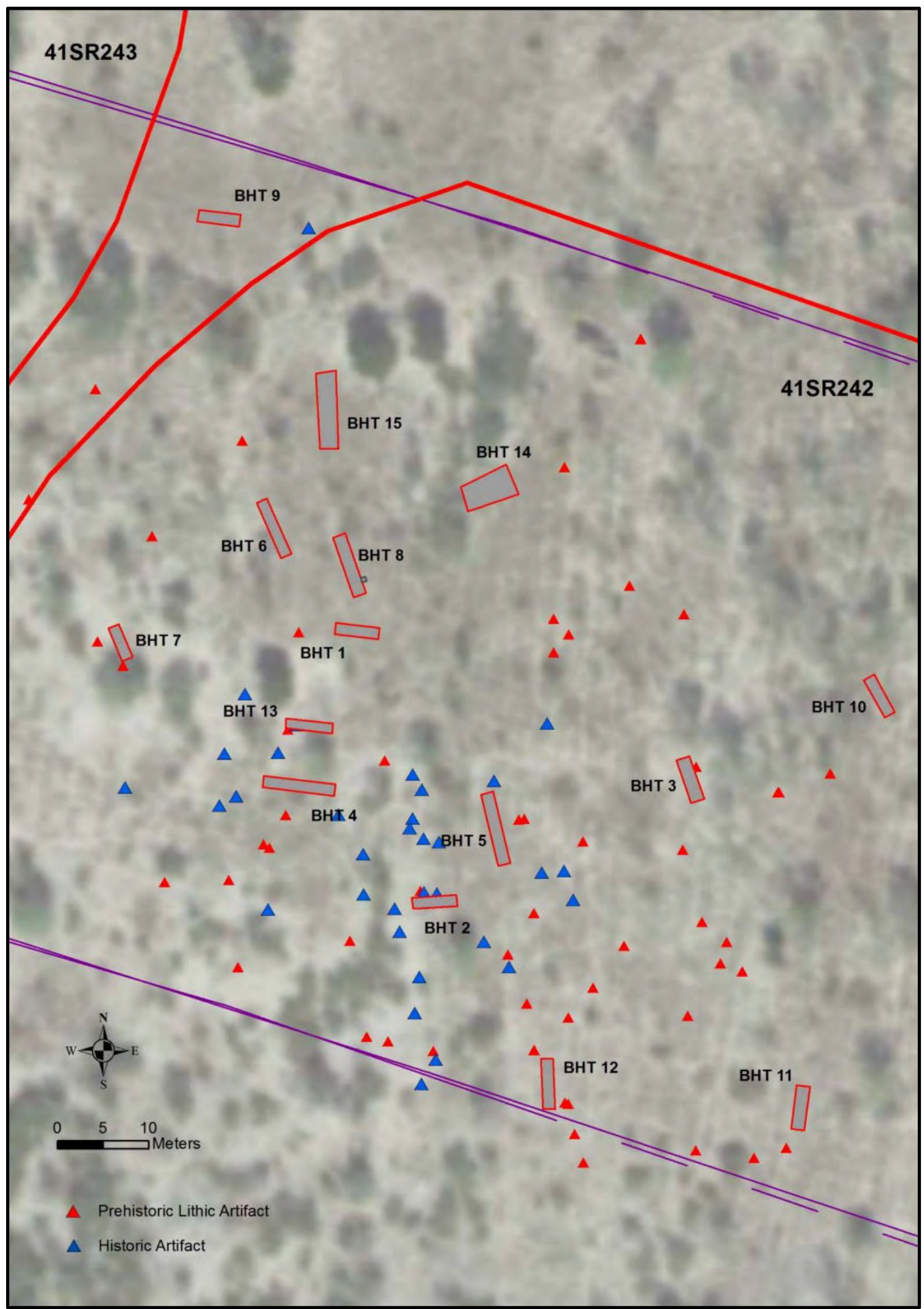

Figure 5.8. Surface artifact distribution across site 41SR242 


\section{SUMMARY}

41SR242 is a Late Archaic to Late Prehistoric open camp on the upland margins of the Lower Rio Grande Valley. Based on the geoarcheological assessment, the site formed within in situ soils (i.e., residuum) that developed in the Goliad formation. At some point, likely in the 1980s and 1990s according to the landowner and a review of aerial photographs, that landform appears to have been root plowed, resulting in an upper Ap zone with minimal integrity. Below the Ap, archeological materials are found within a 30- to 40-cm cultural zone that closely correlates with the A/Bk soil horizon. With very few exceptions, cultural material is absent from the lower Bk horizons.

The spatial distribution of artifacts reveals some trends. The horizontal patterning indicates a sparse, widespread distribution of materials punctuated by locales of higher concentration, such as around Feature 1. The vertical distribution consistently showed all cultural materials within 20 to $60 \mathrm{~cm}$ of the original ground surface, although modern activities may have truncated this surface.

A total of 15 BHTs, seven TUs, and a column sample were excavated during the eligibility testing of 41SR242, revealing the presence of four prehistoric cultural features. Each of the four features consisted of distinct concentrations of artifacts and ecofacts and were completely recovered during testing. A thorough discussion of the geologic analysis, artifact analysis, feature analysis, and chronological data are presented in Chapters 6 and 7. 


\section{CHAPTER 6. GEOARCHEOLOGY OF 41SR242 by James T. Abbott}

\section{INTRODUCTION}

This chapter describes geoarcheological observations made as a result of mechanical trenching and subsequent eligibility testing of site 41SR242, a multicomponent site in the planned ROW of SL 195 around Rio Grande City in Starr County. Figure 6.1 illustrates the general location of the site in Texas. TxDOT conducted the initial work on December 14, 2016 (for convenience sake, Phase 1) to gather preliminary data to assist in planning for eligibility testing of the site in advance of construction on SL 195, while the subsequent phases of fieldwork (Phases 2 and 3) represented NRHP eligibility testing. Fieldwork for Phases 2 and 3 occurred on February 20-23, 2017, and April 10-14, 2017. The current author did not participate in the Phase 3 field effort; geoarcheological observations were made by Corey Crawford (Cox-McClain), and samples taken by the field crew were incorporated into the analysis.

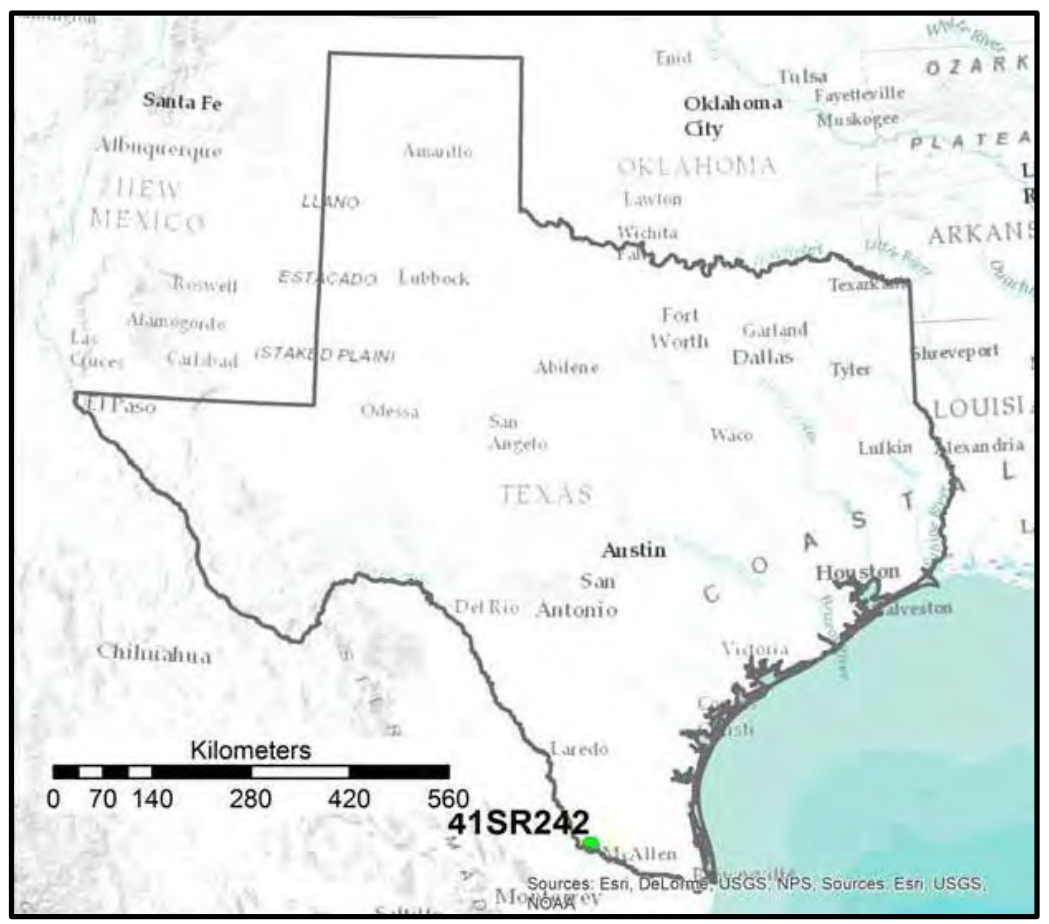

Figure 6.1. General location of site 41SR242 in Texas.

Site 41SR242 occupies mildly dissected uplands on the northern margin of the Rio Grande Valley. The project area is situated in the South Texas Brush Country natural region, and the Western Gulf Coastal Plain physiographic province. The uplands are underlain by the Eocene Jackson Group (Barnes, 1976; Figure 6.2), which outcrops locally in a roughly north-south oriented band approximately 10 miles wide but extends in a coast-parallel arc eastward into Louisiana. Overall, the Jackson Group consists of sandstone and clay that was deposited primarily in deltaic and littoral environments. Fisher et al. (1970) identify five principal depositional systems making up the Jackson Group: 1) a fluvial-deltaic system termed the Fayette system in the eastern part of the outcrop (from Lavaca County east to San Augustine); 2) a shelf (offshore) system east of this delta complex in Louisiana, termed the YazooMoodys Branch system; and, in south Texas, a 3) strandplain-barrier bar system, 4) lagoonal-coastal plain system, and 5) shelf system that are arrayed parallel to the modern coast. The site rests astride thick sandy deposits associated with the barrier bar-strandplain. Older Eocene rocks, including the Yegua and Laredo 
Groups, crop out upstream, while Miocene, Pliocene, and Pleistocene deposits compose the younger coastal plain sediments downstream.

Between Falcón Reservoir (Zapata County) and the head of the Holocene Rio Grande delta in extreme western Hidalgo County, a series of large Pleistocene terraces and discontinuous segments of Holocene floodplain are inset into the older rocks. Holocene deposits are also mapped in a series of large arroyos that drain south into the Rio Grande, including Arroyo Quiote, which flows just east of the site. Finally, the dissected upland margins are mantled with a variable and discontinuous drape of siliceous gravels that are mapped as the Uvalde Gravel by the Bureau of Economic Geology (Barnes 1976). This latter identification is somewhat problematic and merits additional discussion.

Uvalde gravel is an unconformable late Tertiary to Quaternary deposit that occurs primarily on the downthrown side of the Balcones Escarpment, which trends south-southwest from Dallas to San Antonio, then west to Del Rio (Byrd 1971). The designation was first proposed by Hill (1891) to describe upland gravel deposits of central and south Texas, but as Byrd (1971) documents, the definition and usage of the unit has been inconsistent and is somewhat confusing (e.g., Table 6.1). This is probably because Uvalde Gravel rests as an unconformable mantle on uplands and not as a confined stratigraphic unit, so broadly similar deposits of a variety of ages are conflated under a common rubric.

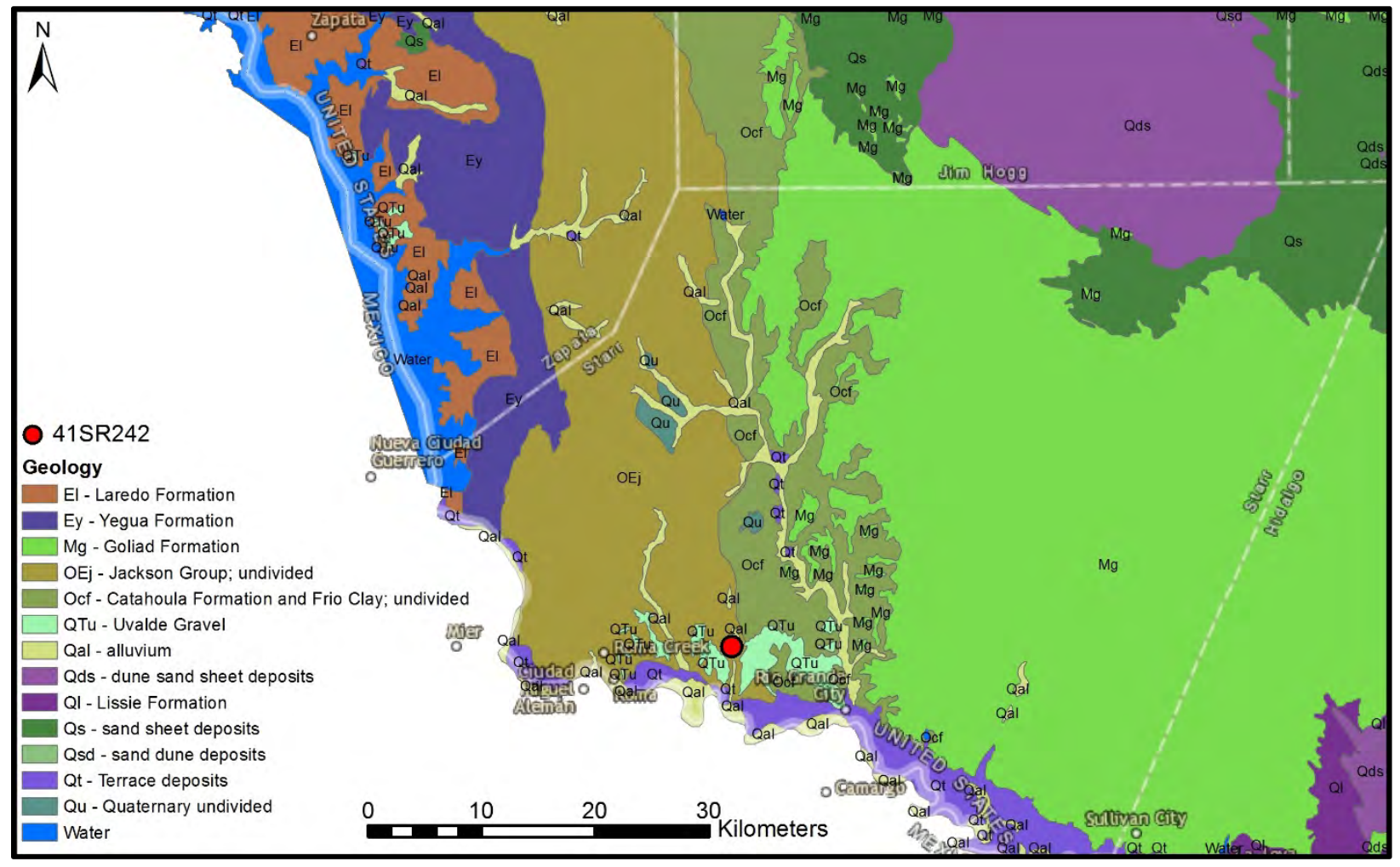

Figure 6.2. Geology of the area surrounding 41SR242, from McAllen-Brownwood GAT sheet.

Key to main stratigraphic units discussed in text: Qal=Holocene alluvium; Qs=Holocene sand sheet deposits; Qt = Pleistocene fluviatile terrace; TQu=Pliocene or Pleistocene Uvalde Gravel; Pg= Pliocene Goliad Fm.; MФcf=Catahoula and Frio Fm (undivided); Ej=Eocene Jackson Gp.; Ey=Eocene Yegua Fm; El=Eocene Laredo Fm. 
Table 6.1. High Gravels Mapped on Various Sheets of the Geologic Atlas of Texas in Central and South Texas

\begin{tabular}{|c|c|c|c|c|c|c|}
\hline GAT Sheet & Year & $\begin{array}{l}\text { Uvalde } \\
\text { Gravel } \\
\text { Listed? }\end{array}$ & $\begin{array}{l}\text { Equivalent } \\
\text { Unit }\end{array}$ & Composition / Description & Inferred Age & Comments \\
\hline Abilene & 1972 & no & Qs1/Qs2 & $\begin{array}{l}\text { Chert, quartz, sandstone, limestone, igneous, and } \\
\text { metamorphic rocks; Qs1 are }<10 \text { feet thick, while } \\
\text { Qs2 are 10-80 feet }\end{array}$ & Pleistocene & $\begin{array}{l}\text { Seymour Fm; Unit Qs3 of the Seymour } \\
\text { Fm is all limestone gravel and therefore } \\
\text { probably distinct; interpreted as ancient } \\
\text { deposits of Clear Fork of Brazos }\end{array}$ \\
\hline Austin & 1974 & no & QHg & $\begin{array}{l}\text { In the southeastern part of the map commonly } \\
\text { exposed at the surface; northwestward, composed of } \\
\text { an upper silty clay good for crop production and a } \\
\text { lower coarse unit that yields some water }\end{array}$ & Pleistocene & $\begin{array}{l}\text { Description speculates that unit possibly } \\
\text { correlates with Onion Creek Marl }\end{array}$ \\
\hline Beeville-Bay City & 1975 & no & - & - & $\begin{array}{l}\text { Pliocene and Miocene, } \\
\text { respectively }\end{array}$ & $\begin{array}{l}\text { Probable equivalents are Willis and Goliad } \\
\text { Fm }\end{array}$ \\
\hline Brownwood & 1976 & no & Qhg & $\begin{array}{l}\text { Caliche cemented gravel, pebbles, and cobbles of } \\
\text { chert and limestone up to } 4 \text { inches long; occupies } \\
\text { topographically high areas not necessarily associated } \\
\text { with present drainage or divides }\end{array}$ & Recent or Pleistocene & $\begin{array}{l}\text { It is unclear how recent deposits could } \\
\text { possibly be associated with high gravels } \\
\text { unrelated to modern drainages }\end{array}$ \\
\hline Corpus Christi & 1975 & no & - & - & & $\begin{array}{l}\text { Nothing mapped older than Pleistocene } \\
\text { Lissie }\end{array}$ \\
\hline $\begin{array}{l}\text { Crystal City-Eagle } \\
\text { Pass }\end{array}$ & 1976 & yes & - & $\begin{array}{l}\text { Caliche cemented gravel; well-rounded pebbles and } \\
\text { cobbles of chert, some pebbles and cobbles of quartz } \\
\text { and igneous rocks }\end{array}$ & Pliocene or Pleistocene & - \\
\hline Dallas & 1972 & no & - & - & & No high gravels mapped \\
\hline Del Rio & 1977 & yes & - & $\begin{array}{l}\text { Caliche cemented gravel; some boulders up to } 1 \text { foot } \\
\text { in diameter; well-rounded cobbles of chert; some } \\
\text { cobbles of quartz, limestone, and igneous rock }\end{array}$ & Pliocene or Pleistocene & - \\
\hline Laredo & 1976 & yes & 一 & Chert; well-rounded pebbles and cobbles & Pliocene or Pleistocene & - \\
\hline Llano & 1981 & no & 一 & - & & - \\
\hline San Angelo & 1974 & no & $\begin{array}{l}\text { Qu and/or } \\
\text { Qs3/Qao }\end{array}$ & - & Pleistocene & $\begin{array}{l}\text { Probable equivalents are Pleistocene } \\
\text { surficial deposits (undivided) and Seymour } \\
\text { Fm and other Quaternary deposits (all } \\
\text { Pleistocene) }\end{array}$ \\
\hline San Antonio & $\begin{array}{l}1974(\mathrm{rev} \\
1981)\end{array}$ & yes & - & $\begin{array}{l}\text { Caliche cemented gravel; well-rounded cobbles of } \\
\text { chert; some quartz, limestone, and igneous rock; } \\
\text { forms extensive deposits in Medina and Uvalde } \\
\text { Counties }\end{array}$ & Pliocene or Pleistocene & - \\
\hline Seguin & 1974 & no & Qhg & - & $\begin{array}{l}\text { Pleistocene and Pliocene, } \\
\text { respectively }\end{array}$ & $\begin{array}{l}\text { Probable equivalents are lower Pleistocene } \\
\text { Willis and Pliocene Goliad Fm }\end{array}$ \\
\hline Waco & 1970 & no & Qhg & $\begin{array}{l}\text { Caliche cemented gravel; cobbles of well-rounded } \\
\text { chert up to } 5 \text { inches in size; pebbles of variegated } \\
\text { quartzite, limestone, chert, and quartz }\end{array}$ & & - \\
\hline
\end{tabular}


In their purest form, Uvalde gravels consist of stream-worn siliceous gravels that occupy uplands of the Texas Coastal Plain (e.g., Byrd 1971). The gravels are dominated by chert but include occasional limestone and igneous rocks. An important component of most descriptions is location on divides, or in locations unrelated to modern drainages. This is generally interpreted as evidence of topographic inversion of the inner Texas Coastal Plain (that is, the ridge-top masses of gravel are believed to represent ancient valley-bottoms where these gravels originally accumulated, and which armored them from erosion so that the surrounding uplands were eventually eroded to form the modern lowlands). However, few of these characteristics are defining, and the term "Uvalde Gravel” is often applied to any upland siliceous gravel in central and south Texas. While a full discussion of the issue is beyond the scope of this document, it is worth noting that the deposits mapped in Starr County are restricted to areas close to the modern Rio Grande (Figure 6.3), and therefore appear unlikely to be "unrelated to modern drainages." Rather, it is considered likely that the deposits mapped as "Uvalde" gravels in the vicinity of 41SR242 actually represent diverse fluvial gravels, including cherts, petrified wood, limestone, and myriad igneous and metamorphic rocks reflecting, and delivered by, the vast ancestral Rio Grande drainage system during the middle to late Pleistocene.

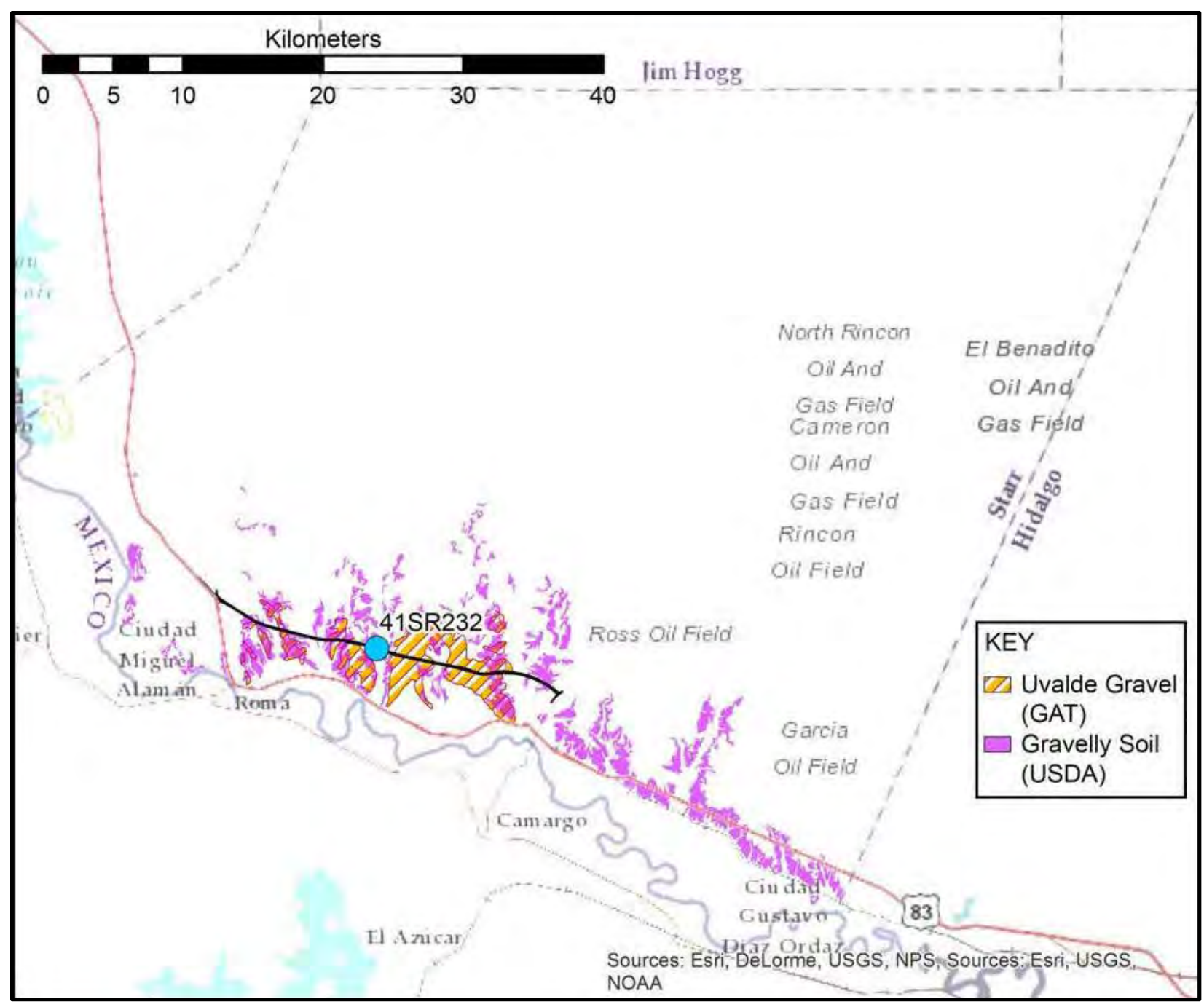

Figure 6.3. Distribution of gravel-dominated soils and geological formation in Starr County. 
The site, as currently defined, measures approximately $175 \mathrm{~m}$ east/west by $75 \mathrm{~m}$ north/south in the proposed ROW but extends an unknown distance to the south. In addition, a separate site (41SR243) is mapped immediately to the northwest of the site (distance from centroid to centroid is approximately $180 \mathrm{~m}$ ), and the most recent surveyors (SWCA) recommended that the two sites be combined. However, the current work focused on 41SR242 as currently defined.

The site is situated at an elevation of approximately 240 feet $(73 \mathrm{~m})$ amsl, on the northern margin of the Rio Grande Valley. A relatively small Rio Grande tributary, Arroyo Quiote, passes east of the site, and a small unnamed tributary of this arroyo passes to the south and west. The site sits on a convex, gently sloping interfluve between these two arroyos, which meet at a confluence approximately $0.5 \mathrm{~km}$ south of the site (Figure 6.4).

\title{
Restricted Information
}

\author{
Not for Public Disclosure
}

Figure 6.4. Topography surrounding 41SR242. 
Soils mapped in the vicinity are illustrated in Figure 6.5. The site proper is entirely within the "Copita fine sandy loam, 0 to 3 percent slopes” mapping unit. Copita soils are classified as Aridic Calciustepts (Inceptisols) and exhibit a typical A1-A2-Bk1-Bk2-Ckr-R profile 37 inches thick. These nearly level to gently sloping upland soils formed in calcareous loamy residuum derived from sandstone predominantly of the Claiborne and Jackson Groups. The underlying bedrock is typically pale brown or gray calcareous sandstone. The Copita fine sandy loam soil mapping unit also includes areas of McAllen fine sandy loam and small areas of Zapata soils (Thompson et al. 1972). McAllen soils are also Aridic Calciustepts and exhibit a typical deep Ap-A-Bw-BCk profile developed in calcareous loamy sediments. Zapata soils are classified as Petrocalcic Calciustepts (Inceptisols) and exhibit a typical A1-A2-Bkkm1-Bkkm2 profile developed in older loamy calcareous alluvium. The other soils mapped in the vicinity are Ramadero loam, which is mapped downslope near the ephemeral arroyo flowing in from the west, and Matamoros silty clay, which is mapped in Arroyo Quiote to the east. Ramadero soils are Cumulic Haplustolls formed in alkaline alluvium, and exhibit a typical A1-A2-A3-Bw- Bk1-Bk2-BCk profile formed in sandy clay loam. Matamoros soils are Vertic Ustifluvents, and exhibit an Ap-C1-C2-2Ab-2Cb profile formed in silty clay alluvium.

\title{
Restricted Information
}

\author{
Not for Public Disclosure
}

Figure 6.5. Detail of Web Soil Survey map of the site, with the current boundary and Phase 1 trench locations added.

Key to mapping units: $\mathrm{Cp}=$ Copita fine sandy loam, 0 to 3 percent slopes; $\mathrm{Mm}=$ Matamoros silty clay; $\mathrm{Ra}$ = Ramadero loam. 
According to generalized Texas Parks and Wildlife Department vegetation mapping (McMahan et al 1984), vegetation in the vicinity of the site is classified as Mesquite-Blackbrush Brush. This assemblage includes lotebush, ceniza, guajillo, desert olive, allthorn, whitebrush, bluewood, granjeno, guayacan, leatherstem, Texas pricklypear, tasajillo, kidneywood, yucca, desert yaupon, goatbush, purple three-awn, pink pappusgrass, hairy tridens, slim tridens, hairy grama, mat euphorbia, coldenia, dogweed, knotweed leafflower, and two-leaved senna (McMahan et al. 1984). However, the landowner reported that the property had been previously root plowed and cultivated, and the locale was relatively open shrubland during testing. Figure 6.6 is a Google Earth-derived birds-eye view of the site, facing southwest and showing the two arroyos and the general character of vegetation.

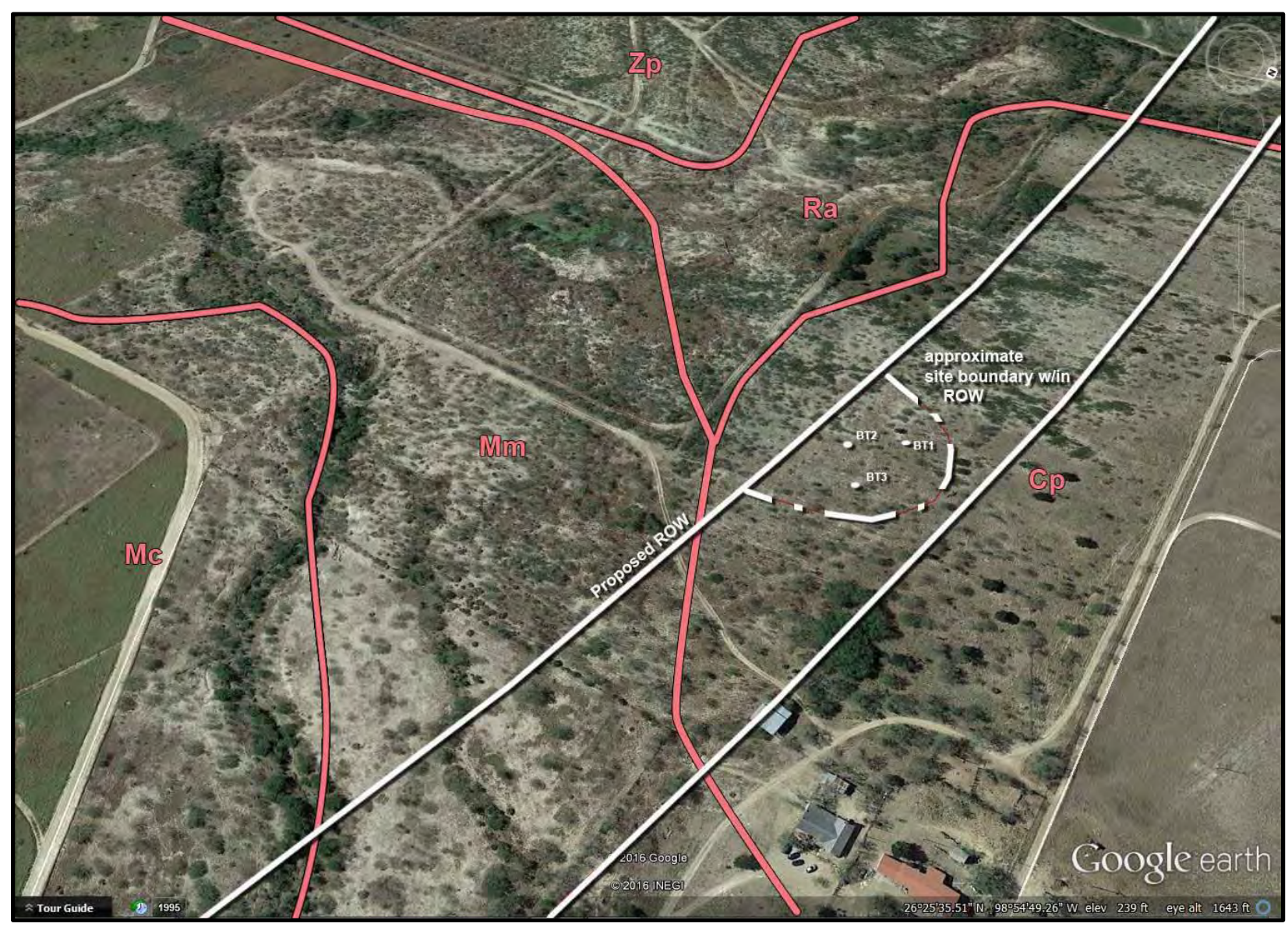

Figure 6.6. Simulated bird's eye view of 41SR242 and surroundings, facing southwest. Only Phase 1 trench locations are illustrated. 


\section{METHODS}

\section{Field Procedures Phase 1}

For logistical reasons, we conducted Phase 1 relatively rapidly, and field recording was rapid and basic. Three BHTs (BHTs $1-3$ ) were excavated in the boundary of the site to examine the stratigraphy and prospect for buried cultural material (see Figures 6.5 and 6.6). All BHTs were situated on a low-gradient upland surface situated a short distance upslope of the alluvial fills flanking Arroyo Quiote and its tributary. Two TxDOT archeologists (Ringstaff and Abbott) were present on site, and all trenching was actively monitored by at least one archeologist and a TxDOT district environmental staff member (Edd Paradise).

Each BHT was excavated with a backhoe equipped with a smooth-bladed, 3-foot bucket. Excavation was periodically paused where appropriate so that the walls and floor of each trench could be troweled and assessed. When a trench exposed obvious pre-Holocene deposits or reached a depth of approximately $150 \mathrm{cmbs}$, an archeologist entered the trench and scraped, examined, and recorded a section of each wall. No profiles were prepared in an archeological sense, but a section of sidewall of each trench was cleaned, photographed, and described using criteria outlined by Olson (1976) and Schoeneberger et al. (2012).

Excavation depth ranged between $75 \mathrm{cmbs}$ and $140 \mathrm{cmbs}$ in the three trenches. Archeological materials were noted and collected opportunistically with minimal control, but the location of each trench corner and of the single feature identified was taken with a survey-grade GPS unit.

\section{Field Procedures Phase 2}

During Phase 2, an additional 10 BHTs (BHT 4 - 13) were excavated across the site (Figure 6.7), and a small block and a few isolated hand TUs were excavated to evaluate cultural materials noted in the BHTs. The following discussion is primarily concerned with the trenches; see Chapter 5 for specific discussion of the hand excavations (note that BHTs were situated adjacent to each hand unit, so generalized contextual information is available). Methods employed were generally as described above. In addition, witness sections were recorded in BHT 8, situated a few meters north of the excavation block centered on BHT 1, and in BHT 4, situated approximately $30 \mathrm{~m}$ to the south of the block (see Figure 6.7). In BHT 8, documentation was accomplished with a $50 \times 50$-cm unit excavated in 10 -cm levels to quantify artifact return by level, flanked by a stacked series of small soil samples taken at approximately 10 -cm levels, and two large blocks were taken at depths of approximately $25 \mathrm{~cm}$ and $50 \mathrm{~cm}$ for micromorphological analysis. In BHT 4, a series of small soil samples were collected from the profile of BHT 4. At the suggestion of geoarcheologist Charles Frederick (who did the micromorphological analysis), these blocks were submitted for computed tomography (CT) analysis at The University of Texas High Resolution Computed Tomography Scan Facility (UTCT) in the Jackson School of Geosciences at The University of Texas at Austin before they were processed for thin sections. 


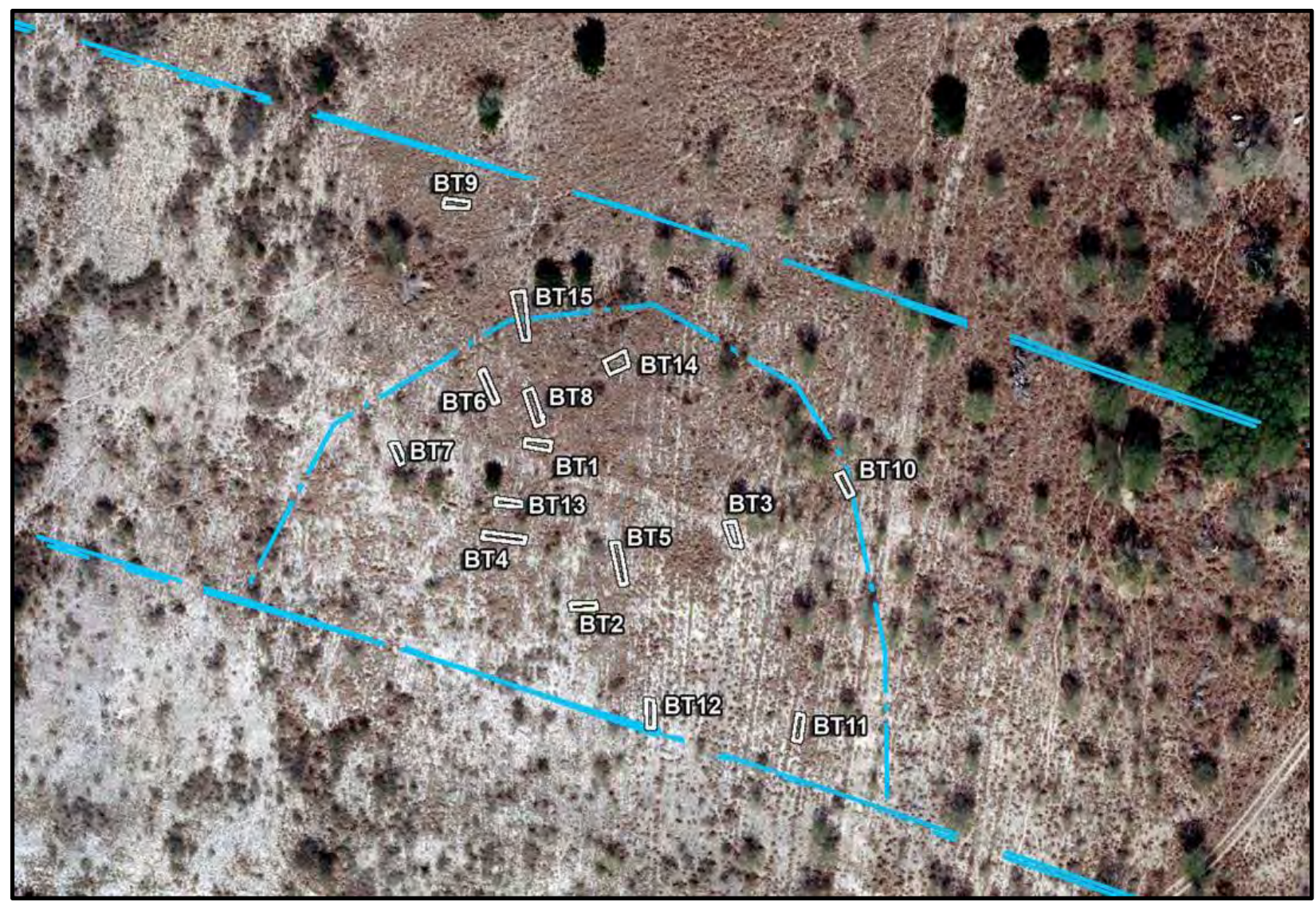

Figure 6.7. Plot of trench locations through Phase 3. Note north/south-trending scarring from root plow.

\section{Field Procedures Phase 3}

Phase 3 consisted of additional machine and hand excavations conducted by TxDOT archeologist Chris Ringstaff and a crew from Cox-McLain Environmental Consultants. Two additional BHTs, BHT 14 and BHT 15, were excavated during this phase. The author did not participate in this field phase; geoarcheological recording of trenches was performed by geoarcheologist (and Cox-McLain crew member) Corey Crawford.

\section{LABORATORY PROCEDURES}

The physical properties of the site were documented primarily through analysis of the two columns of magnetic susceptibility cube samples from BHT 4 and BHT 8, and micromorphology samples from BHT 8. Analyses conducted on the cube samples included magnetic susceptibility, particle size analysis, organic carbon content, calcium carbonate content, iron content, soil $\mathrm{pH}$, and stable carbon isotope analysis. Magnetic susceptibility was determined using 2-cm cubes collected and packed in the field. All sample analyses were on the gravel-free fraction; the size of the samples was inadequate to provide a statistically-relevant gravel sample, so their presence was noted but not quantified. 


\section{Magnetic Susceptibility}

Magnetic susceptibility is a general measure of the degree to which a sample may be magnetized, and provides basic information on the magnetic mineralogy of the sample, which may vary owing to a variety of factors, such as depositional processes, soil development, and human occupation. The general application of magnetic susceptibility in archeological studies has been discussed in detail by Dalan (2008) and Dalan and Bannerjee (1998). Frequency dependent magnetic susceptibility was calculated on cube samples to detect the concentration of ultrafine $(<0.03 \mu \mathrm{m})$ superparamagnetic ferromagnetic minerals occurring as crystals produced by biochemical processes in soil (Dearing 1999). Each cube was weighed, and the low frequency $(470 \mathrm{~Hz} ; \chi$ lf $)$ and high frequency $(4700 \mathrm{~Hz} ; \chi$ hf) magnetic susceptibility was measured at the 0.1 setting on a Bartington MS2 meter using an MS2b sensor. The mass-corrected magnetic susceptibility $(\chi 1 \mathrm{f})$ and coefficient of frequency dependency (Cfd) were then calculated. The coefficient of frequency dependency $(\chi \mathrm{fd})$ is the percentage difference in magnetic susceptibility measured at low and high frequency:

$$
\chi \mathrm{fd}=((\chi \mathrm{lf}-\chi \mathrm{hf}) / \chi \mathrm{lf}) \times 100(1)
$$

Elevated values of $\chi$ fd (greater than approximately 10 percent [Gale and Hoare 1991:213]) are indicative of increased concentrations of fine-grained ferromagnetic minerals such as maghemite and magnetite in topsoils (Dearing et al. 1996).

\section{Particle Size Analysis (Texture)}

The particle size distribution (or texture) of the gravel-free portion of each sample was determined on a Beckman-Coulter LS 13-320 multi-wavelength laser sizer. Samples were first subsampled, and then placed in a small beaker on a hot plate to which concentrated (30 percent) hydrogen peroxide was added in order to remove organic matter, and a 5 percent solution of sodium hexametaphosphate was added to disperse the fine fraction. Samples were brought to a boil and left on the hot plate until the visible reaction (effervescence) had ceased or the color of the sediment had changed, at which point they were removed from the hot plate, cooled, and then measured on the LS-13-320. The results of these analyses are presented as percentages of sand, silt and clay, as well as in the form of descriptive statistics that are presented in phi units (a negative log base 2 conversion of millimeters). In the phi system, sands exhibit phi values between 0 and 4, silts between 4 and 9, and clay $>9$ phi. The U.S. Department of Agriculture soil texture class for each sample was determined using the Soil Texture calculator provided by the Natural Resources Conservation Service (NRCS) website (NRCS n.d.).

\section{Calcium Carbonate Equivalent (CCE)}

Calcium carbonate equivalent percentage (\%CCE) was calculated using a Chittick apparatus. A small split (either 1.7 gram or 0.85 gram, depending on the apparent carbonate content) of each sample was finely ground and passed through a $0.075-\mathrm{mm}$ sieve, weighed, placed into a $250-\mathrm{ml}$ Erlenmayer flask, and connected to the Chittick apparatus. The liquid level in the measuring burette was then set to $-10 \mathrm{ml}$, the stopcock was closed so no gas could leave the system, and the leveling bulb was dropped to establish a vacuum inside the flask. At this point, the temperature and barometric pressure in the room were recorded. Then, $10 \mathrm{ml}$ of 50 percent strength (approximately $6 \mathrm{~N}$ ) hydrochloric acid was introduced into the flask, which was agitated intermittently until the reaction had ceased. At this point, the leveling bulb was raised until the liquid levels in the bulb and burette were equal, the volume of gas evolved was measured, and the calcium carbonate equivalent was calculated according to the method of Dreimanis (1962). 


\section{Organic Matter}

The organic matter was estimated by percent loss-on-ignition at $500^{\circ} \mathrm{C}$. Samples were placed in preweighed crucibles and then dried for 12 hours at $105^{\circ} \mathrm{C}$, after which they were weighed, and then ignited in a muffle furnace for 2 hours at $500^{\circ} \mathrm{C}$. Upon removal from the furnace samples were allowed to cool in a desiccator and then weighed. The organic matter content is calculated as the percentage weight loss between the dry weight and the post $-500^{\circ} \mathrm{C}$ weight.

\section{FIELD RESULTS}

The BHTs at 41SR242 exposed broadly similar slope profiles consisting of brown to pale brown, sandy to silty loam with variable amounts of siliceous gravel. Shallow, ephemeral channels filled with poorly sorted gravel and sand demonstrate that some alluviation has occurred on site. In general, however, the profiles resemble the weathered upland profiles formed in silty sandstone bedrock that are mapped at the site by the NRCS (i.e., Copita soils). In several BHTs, the profile penetrated through this soil into weathered sandstone bedrock ( $\mathrm{C}$ or $\mathrm{Cr}$ horizon). The individual BHT profiles are described in Appendix A. The most obvious unifying features among these profiles were relatively low-chroma colors in the 10YR range, the dominant loamy texture, and the character of soil structure, particularly in that portion between the base of the plow zone and the top of the subsoil.

This structure, which varied considerably in its degree of expression between trenches and within individual profiles, is difficult to describe using traditional nomenclature (e.g., Schoeneberger et al. 2012). It varies intermittently between granular and fine subangular blocky, albeit often with very abundant open pores and fine (insect-scale) krotovina. It is relatively soft in hand section, yet slightly hard to hard in place, and includes clasts that are weakly consolidated, yet prone to abrupt failure (i.e., collapse into loose single grains and fine aggregates) under slight to moderate compression when in hand sample. The pores vary in size from less than a millimeter to more than a centimeter in diameter, and most of them clearly represent insect burrows. Brushing of a cut sidewall with a stiff brush produces an irregular, knobby surface (Figure 6.8). 


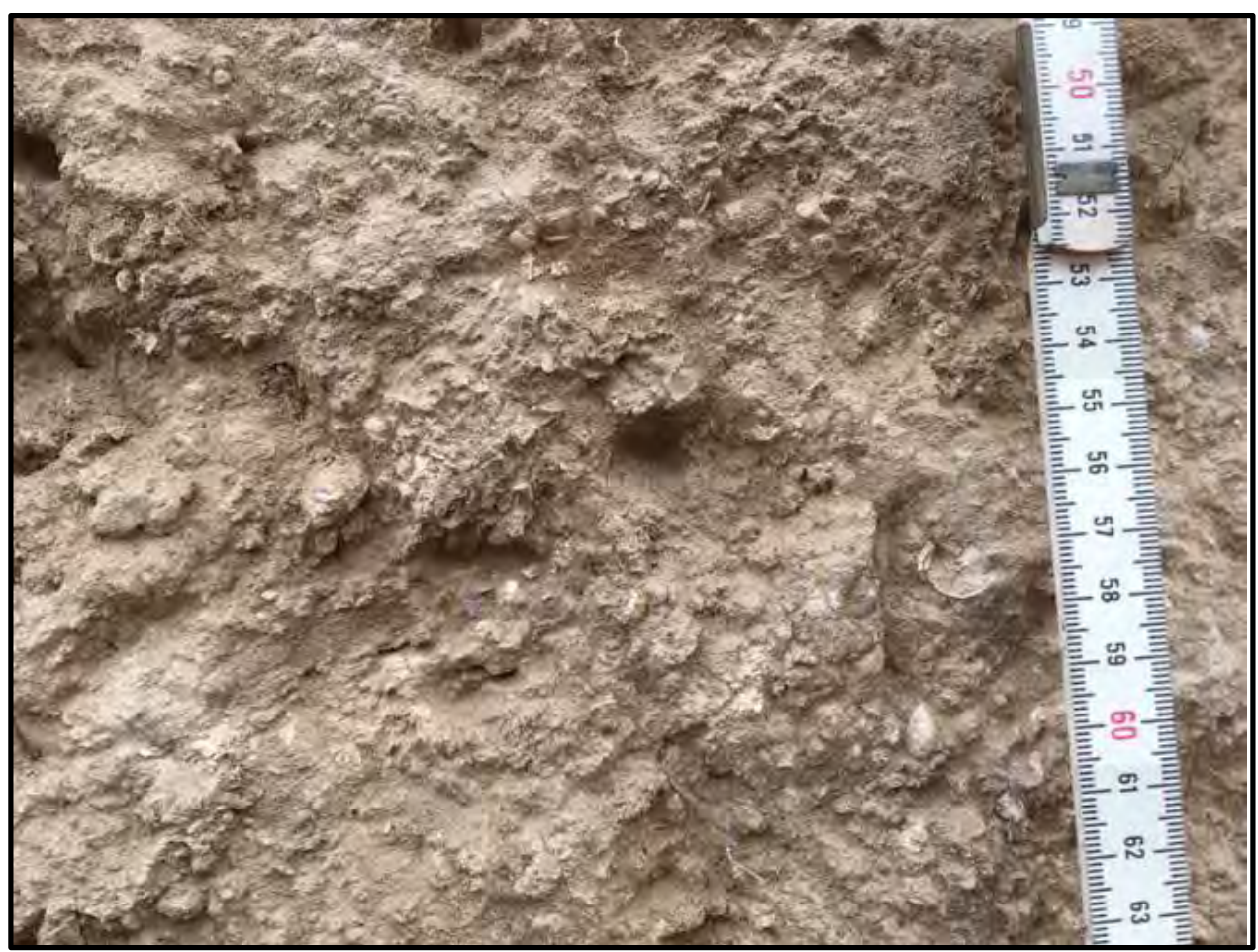

Figure 6.8. Detail of "knobby" texture produced by brushing vertical exposure with a stiff brush. Note snail shells, carbonate masses, charcoal flecks, and hollows formed as large Rabdotus shells were released and fell out.

My field judgment was that the structure is a direct consequence of pervasive bioturbation by insect-scale biota, including localized packing and cementing of pore walls; construction of biocoatings; and pelletal, loose, fibrous, and laminar backfilling of voids. The description of the soil structure I used in the field varied a little between trenches, but was always some variant of "biogenic granular structure." However, it is important to stress that this is not intended as a synonym for a typical granular structure produced (primarily by earthworms) in the upper A horizon of a subhumid to subarid soil profile, because it is not dominated by the pelletal shape typical of worm excreta. While this "knobby" type of soil structure is apparent throughout the profiles, it appears particularly pronounced in the lower B horizon, above the weathered sandstone of the BC and Cr horizons. My initial field impression was that larger (rodent-scale) krotovina were nearly absent—only one was noted on the profiles drawn — but subsequent review of trench photographs indicates that while relatively rare, rodent-scale burrows and krotovina are present in several BHTs and units (Figure 6.9). 

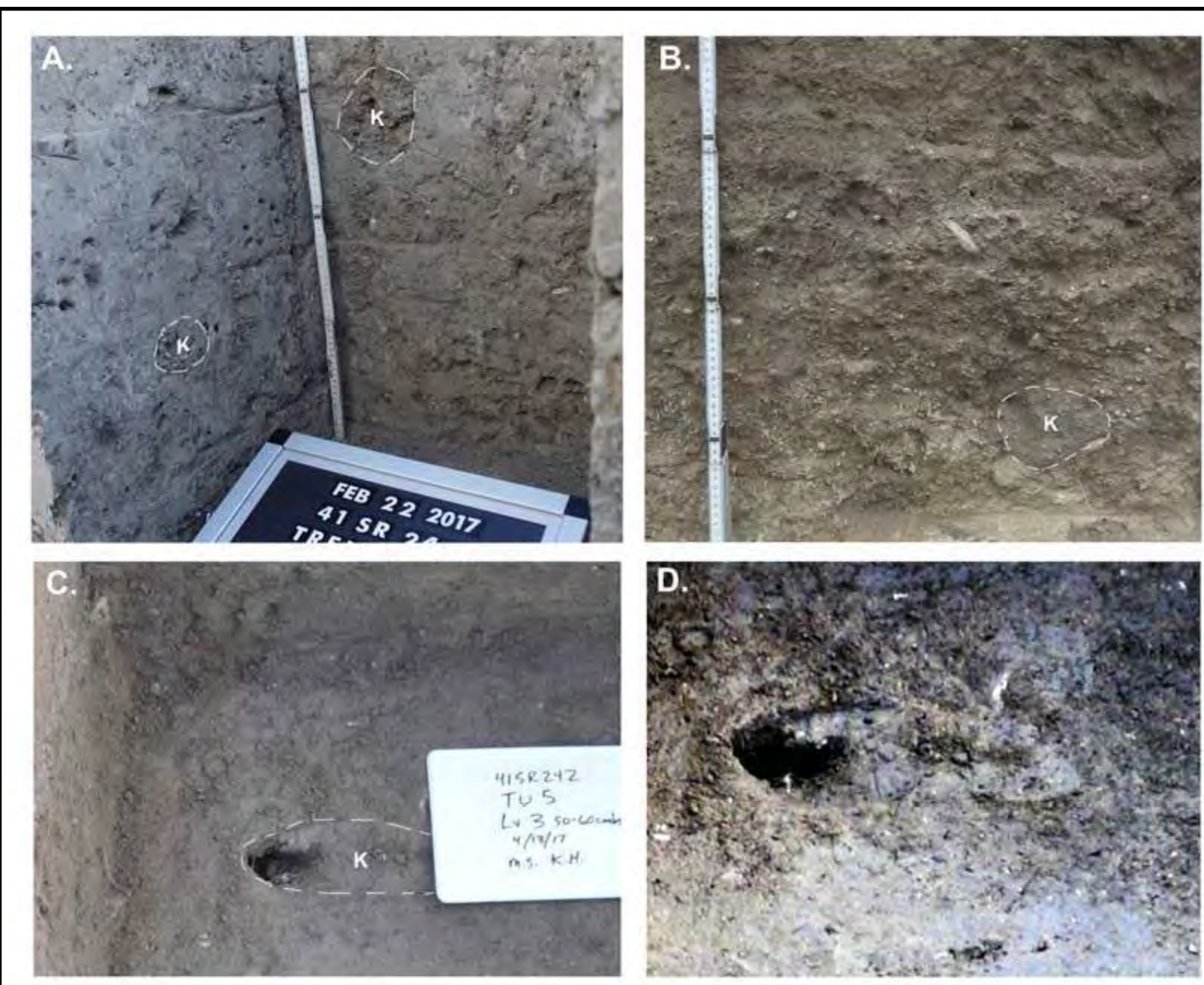

Figure 6.9. Examples of rodent scale burrows and krotovina. A: Profile of $50 \times 50$ off wall of BHT 8; B: BHT 3 profile; C: Partially filled burrow in TU 5 floor; D: photo-enhanced image of the same feature shown in $\mathrm{C}$, showing boundary.

Other than variation in soil structure and cultural material abundance, the most obvious difference within and between profiles was in the frequency and habit of gravels. In the western part of the site, gravels were relatively uncommon, dispersed through the profile, and typically relatively small $(1-2 \mathrm{~cm}$ and smaller). However, there were two exceptions to this latter trend, both situated on the northwestern periphery of the site. In BHT 9, an apparent pit feature contained a number of larger gravels, at least two of which appeared burned (thermally fractured) (see Appendix A). Also, a gravelly zone including a number of large clasts was recorded at depth in BHT 15. In the eastern part of the site, several BHTs (e.g., BHT 5, BHT 10, and BHT 11) exhibited shallow, broad ephemeral channel facies containing a mix of loamy sands and gravels as large as 15-20 cm diameter. These gravels mantled irregular, abrupt scoured surfaces, and were clearly water-lain. However, the encasing matrix was very poorly sorted, ranging from sandy loam to fine gravel, suggesting minimal opportunity for hydraulic sorting of the sediment. Field observations suggest that these gravels derive from "Uvalde" gravel outcrops no more than a few hundred meters upslope and were delivered to the site by sheet flow and broad, ephemeral channelized flow. 


\section{The Problem in a Nutshell}

In essence, the trajectory of geoarcheological investigations at 41SR242 was dictated by questions raised by BHT 1 . The recorded profile of BHT 1 is abbreviated because we discontinued excavation of the BHT after encountering a feature (Feature 1) consisting of lithic flakes and Rabdotus snail shells at around $50 \mathrm{cmbs}$. The final recorded profile of BHT 1 was $65 \mathrm{~cm}$ thick, but the lower $10 \mathrm{~cm}$ of this was based on extrapolation from exposure around Feature 1; the actual documented section was $55 \mathrm{~cm}$ deep (see Appendix A). It revealed an Ap-A-Bk1-Bk2 profile developed in a calcareous sandy loam. The Ap horizon was $13 \mathrm{~cm}$ thick and consisted of somewhat gravelly, grayish brown silty to sandy loam. The gravels were pebble and granule-sized clasts of mixed siliceous lithology. As with all soils on the site, organic matter content was very low. The Ap horizon graded into a thin, discontinuous A horizon that was $5 \mathrm{~cm}$ thick at the measured section. It was similar to the Ap horizon, but slightly darker in color and somewhat more consolidated. Both horizons exhibited a weak biogenic granular structure with many open pores, but this structure was superimposed on a weak platy (i.e., weakly laminated) structure in the Ap horizon. The Bk1 horizon was $22 \mathrm{~cm}$ thick, and the much more structured B2k horizon extended to the base of the trench at approximately $65 \mathrm{~cm}$.

It was this B2k horizon that yielded the concentration of cultural material (Feature 1), which we discovered while scraping the floor of the trench. We noted several snail shells after one particular backhoe "cut," so per procedure we stopped the machine, entered the shallow trench, and began to clean the area with trowels. Immediately, flakes and whole Rabdotus shells began to pop up from the floor. The flakes were particularly striking because they were predominantly flat-lying and in part resting directly on top of each other in a distinct pile, so that dislodging one tended to expose several more. We crudely scraped an area about twice the size of a large dinner plate, recovering dozens of flakes and snail shells (Figure 6.10). I admit I was very puzzled by this feature, as I had already decided based on my initial observations that the profile probably represented a weathered upland soil, and the potential for significant burial of archeological components with reasonable integrity was very limited. Yet here we were, in a dense pocket of flakes (some quite large) and intact snail shells that appeared likely to retain considerable integrity even though it was buried more than half a meter below the surface, with little indication of how that burial occurred.

Although I could not rule out colluvial accumulation, and some limited sheet aggradation was actually considered quite likely, the setting of the site is not particularly conducive to significant colluvial or alluvial aggradation. Figure 6.11 is an oblique view of a relatively high-resolution aerial photograph (0.3 m nominal pixel resolution) draped on a digital elevation model that has been vertically exaggerated to emphasize the landform setting in relation to the proposed alignment and the site boundary. Note that the site occupies a convex portion of the foot of a relatively short upland slope, where significant accumulation of low-energy sediment is not very likely.

Once we recognized the potential significance of the deposit, we elected to record the profile as it was, collect the loose artifacts, mark the location carefully, and backfill the trench pending additional excavations at the location. We excavated two other BHTs during that initial field session, one of which (BHT 2) contained a number of buried (albeit vertically and laterally dispersed) artifacts, and one of which (BHT 3) contained only a few of them (neither trench contained much gravel). Coming out of the field from the first phase of work, my primary working hypothesis was that burial of the flake and snail concentration that we dubbed Feature 1 was a consequence of biosedimentation by insects and annelids, and that it was preserved because disruptive bioturbation of the site deposits by larger fauna (e.g., rodents, reptiles) was rare. We designed subsequent geoarcheological investigations (in part) to test the viability of this hypothesis. 


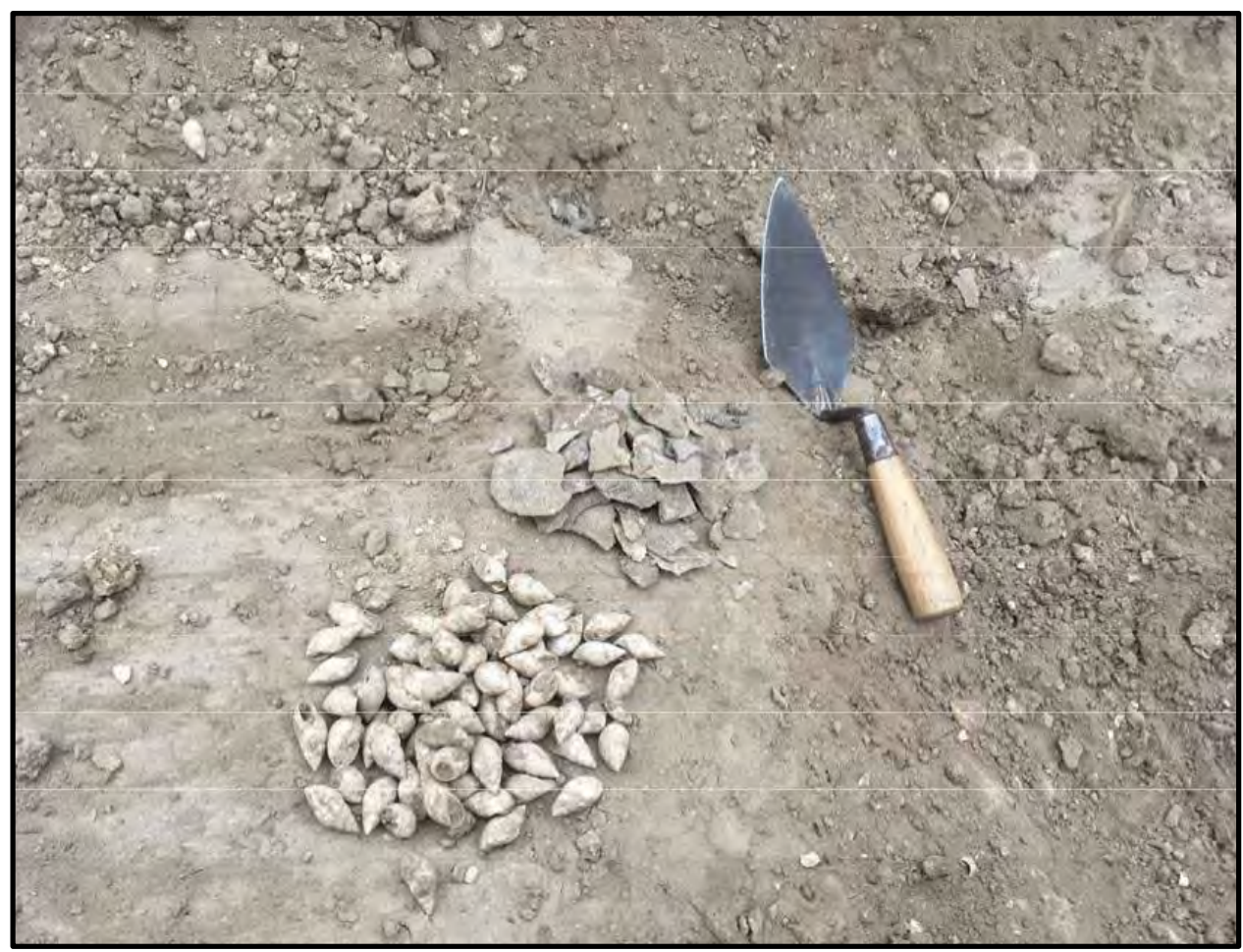

Figure 6.10. Sorted piles recovered from Feature 1, a cluster of lithic debitage and intact snail shells discovered at a depth of approximately 50$60 \mathrm{cmbs}$ in BHT 1.

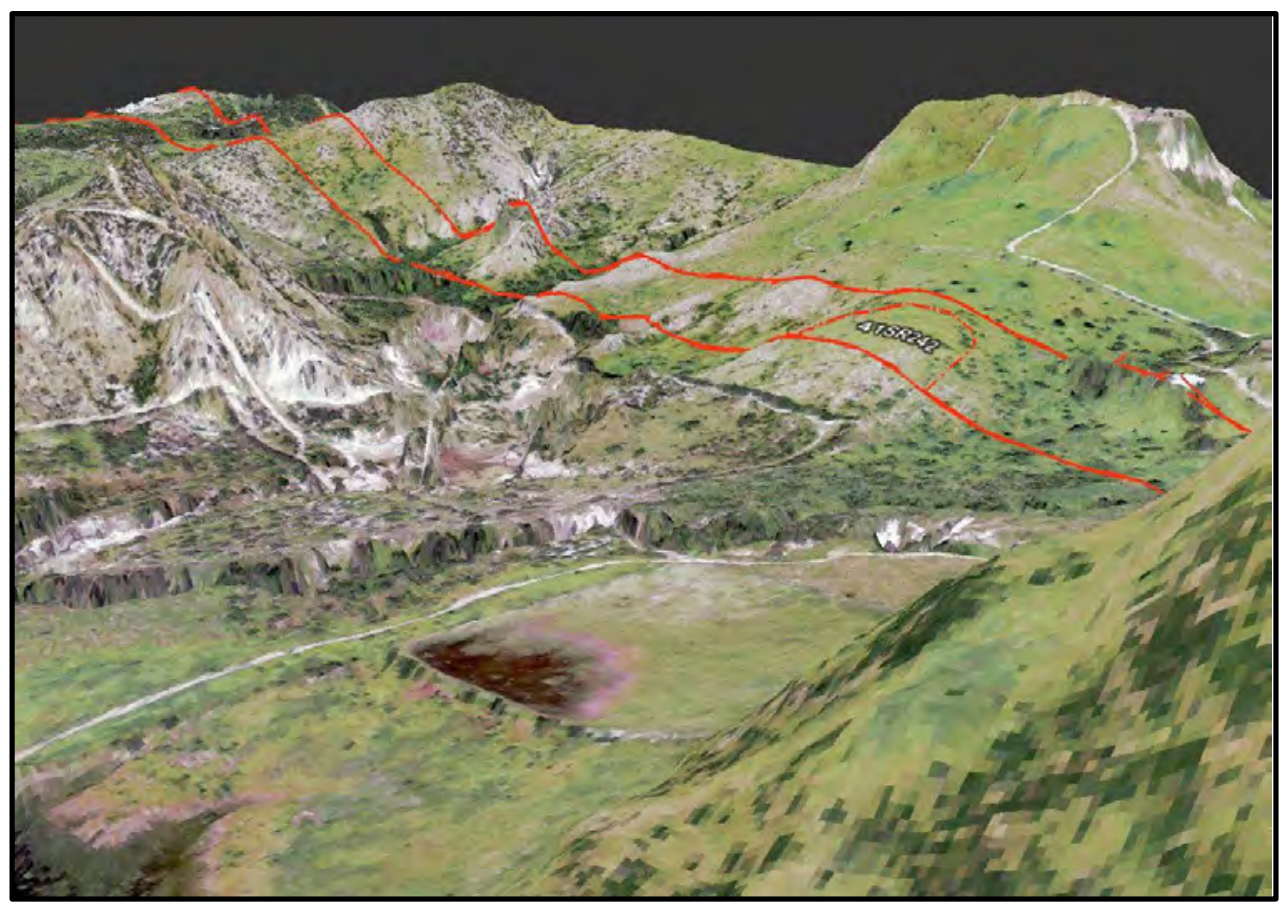

Figure 6.11. Oblique view of high-resolution aerial draped on DEM, showing the landscape setting of the site (convex footslope). 
Phase 2 investigations occurred in February 2017, followed by Phase 3 in April 2017. These excavations involved 12 additional BHTs and a number of test pits. Two profiles were selected for additional documentation and sampling. BHT 8 was selected because it was both physically closest to and very similar in character to the previous exposure in BHT 1, while BHT 4 was selected because it exposed a relatively deep $(1.5 \mathrm{~m})$ profile that appeared among the most complete and clearly horizontal profiles on site. The remaining trenches were described and photo-documented but were not sampled for laboratory analysis.

BHT 8 was excavated immediately (approximately $3 \mathrm{~m}$ ) upslope from BHT 1 and exposed an Ap1-Ap2ABk profile developed in loam and sandy loam. Although the sediment appeared slightly grayer in color (hence the field designation of the thick lower horizon as an Abk rather than a Bk horizon), it was broadly similar to that exposed in the initial trench. The BHT 8 profile was sampled for textural and chemical characterization at an interval of $10 \mathrm{~cm}$ using plastic susceptibility cubes, and bulk samples for thin section characterization were taken from 15-23 cmbs (A and upper Bk1 horizon) and 45-53 cmbs (Bk2 horizon). The results of laboratory studies suggest a uniform profile marked by minor differences in texture (Figure 6.12). The only trend worth noting is a subtle trend of decreasing organic matter content through the Ap sequence (from 10-30 cmbs), and again through the Abk Horizon (40-80 cmbs). However, overall organic content is low, and none of the samples exceeds 1.2 percent OM based on loss on ignition. Calcium carbonate content is also relatively uniform, varying from around 10 percent in the Ap horizon to 16 percent at $50 \mathrm{cmbs}$ in the Abk horizon. Overall magnetic susceptibility (as expressed by $\chi$ lf) trends very slightly down with depth, while frequency-dependent susceptibility ( $\chi$ fd\%) trends very slightly up. The magnitude of these measurements suggests that magnetic minerals are relatively rare overall, and that very fine, superparamagnetic (SP) grains are not present in any concentration (Dearing et al. 1996; Barker 2002).

BHT 4 was excavated approximately $20 \mathrm{~m}$ downslope of BHT 1 . Although it also appears to represent an upland profile, it is far more heterogeneous than BHT 8 (Figure 6.13). Part of the reason for this is that it is simply a more complete profile, which extends into weathered bedrock. BHT 4 grades down through an Ap1-Ap2-Abk-Bk-BC-Cr profile, with soil textures ranging from loamy sand to clay loam (in contrast, all eight samples from BHT 8 are loam; see Figure 6.14). However, this variability does not appear to represent reorganization of the profile by traditional soil processes (e.g., eluviation and illuviation of clay, carbonate, and organic matter) and instead probably represents textural characteristics inherited from the parent material, possibly with additional biases imposed by soil fauna and additions of colluvium and sheetwash. 


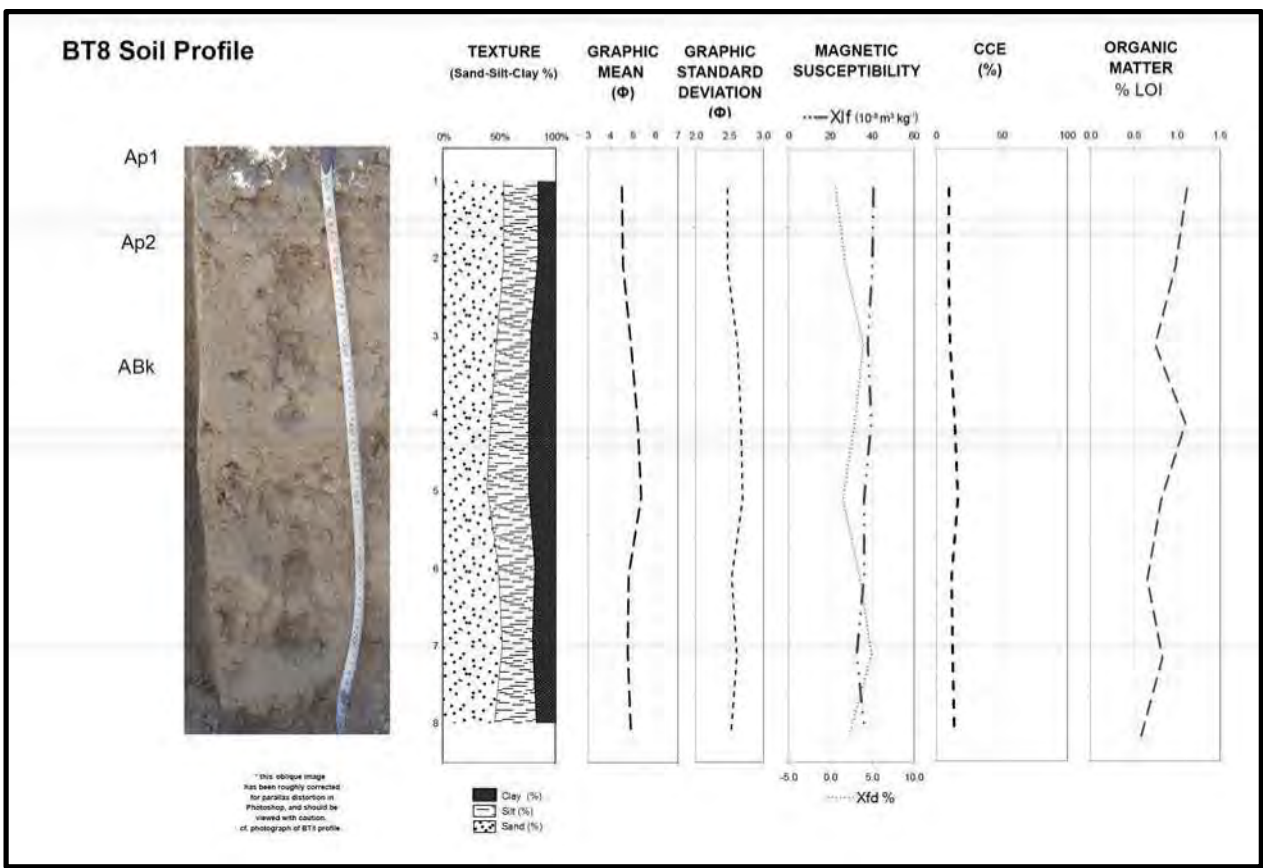

Figure 6.12. Results of laboratory analyses, BHT 8. Note that, to facilitate comparison, the scales of individual graphs in this figure conform with the scales of graphs in Figure 6.13.

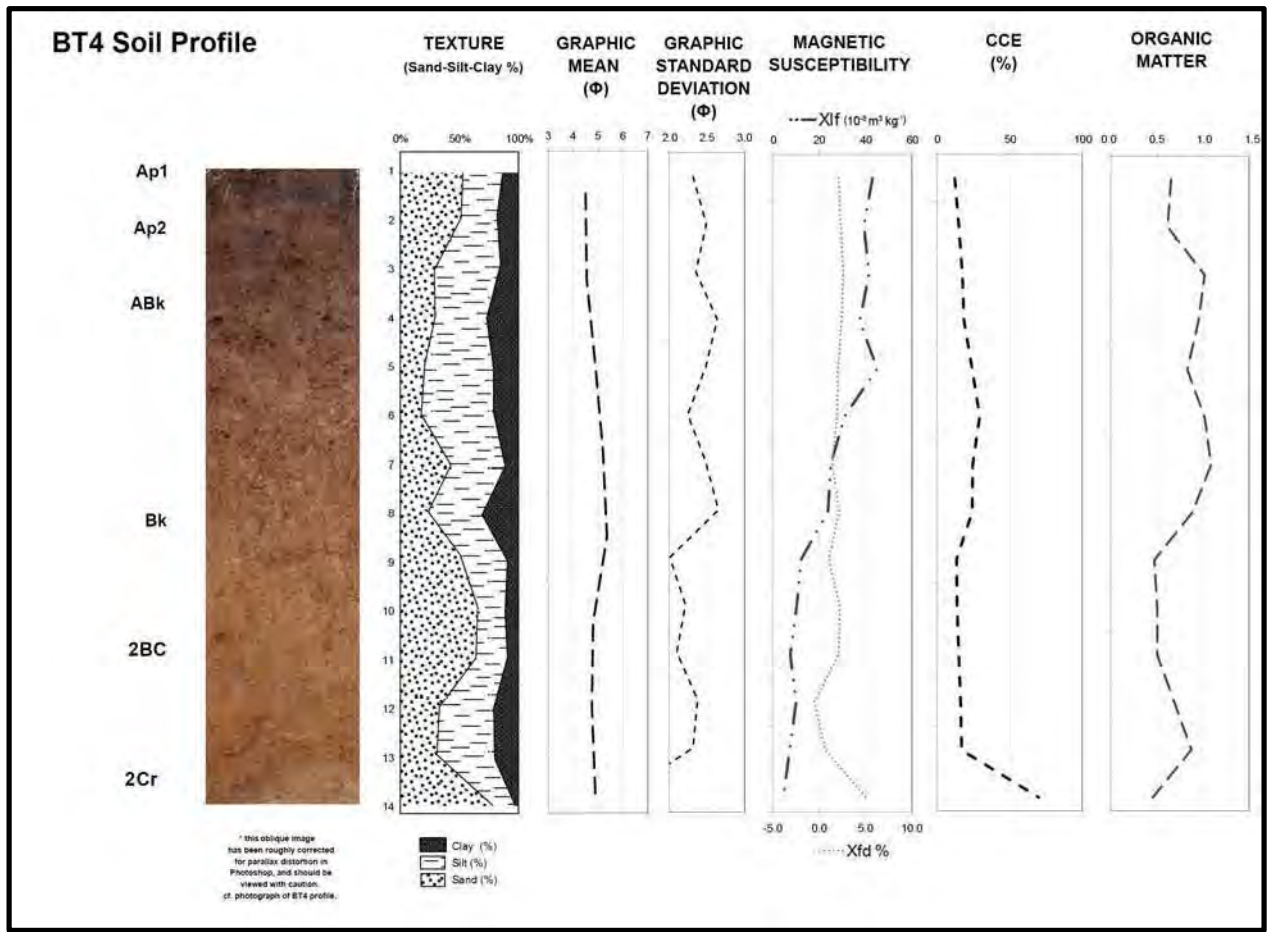

Figure 6.13. Results of laboratory analyses, BHT 4. 


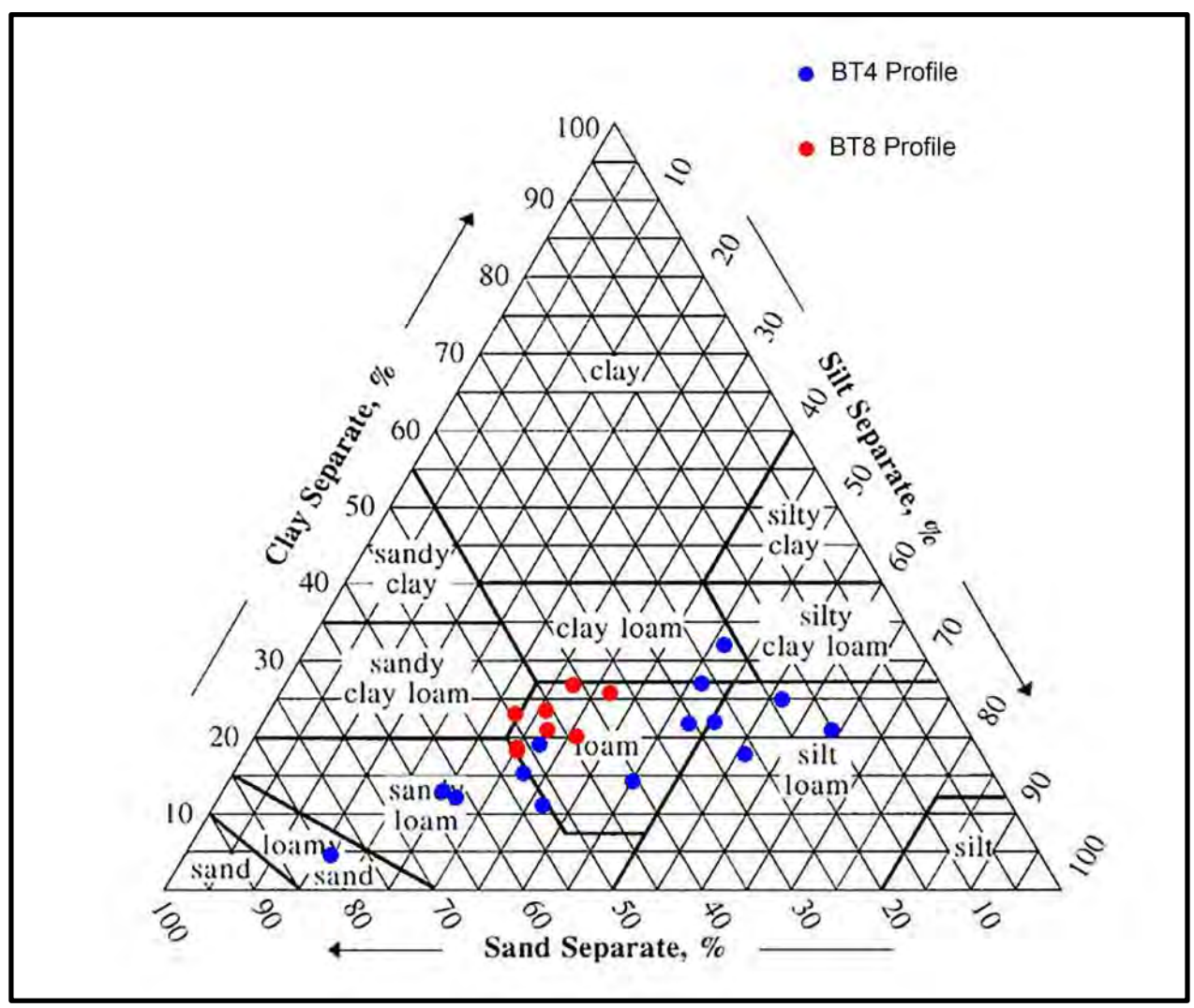

Figure 6.14. Textural plot of samples from BHT 4 and BHT 8.

Organic matter and carbonate content also vary in unexpected ways in BHT 4. The amount of organic matter is limited overall, and never exceeds 1.1 percent. However, the Ap1 and Ap2 horizons have an unexpectedly low organic content compared to the underlying horizons; noticeable enrichment does not occur until the upper Abk horizon. Similarly, there is a noticeable increase in organic content at the base of the profile in the lower 2BC horizon. Both of these trends defy ready explanation, but given the low overall concentration of organic matter, they are probably not particularly telling. The results of measurements of carbonate content (CCE\%) are more puzzling, as the deeper horizons where pedogenic carbonate would be expected to accumulate (here designated the Bk and 2BC) have lower measured carbonate content than the overlying Abk. Although most of the carbonate accumulation observed in these horizons was segregated in masses and soft nodules, and may therefore be under-represented in the very small (8 cc) samples, it is very surprising that the measured $\mathrm{CaCO} 3$ content of the Bk horizon is lower than in the overlying Abk. The low carbonate content of the underlying BC horizon is at odds with the bedrock (Cr horizon), which is a highly calcareous, carbonate-cemented sandstone with a CCE of $>70$ percent. Because the horizon does not appear unconformable based on the character of the contact (Figure 6.15), this suggests that the BC horizon has been substantially decalcified. The sharp decrease in sand content in the lower profile is also difficult to explain, as are the prominent gypsum crystals along the weathered contact. The most likely explanations are that the textural change represents inheritance from the parent material or a consequence of long-term textural segregation and sorting by insects, while the crystalline gypsum represents dissolution and re-precipitation of calcium sulfate cements in the underlying sandstone. 


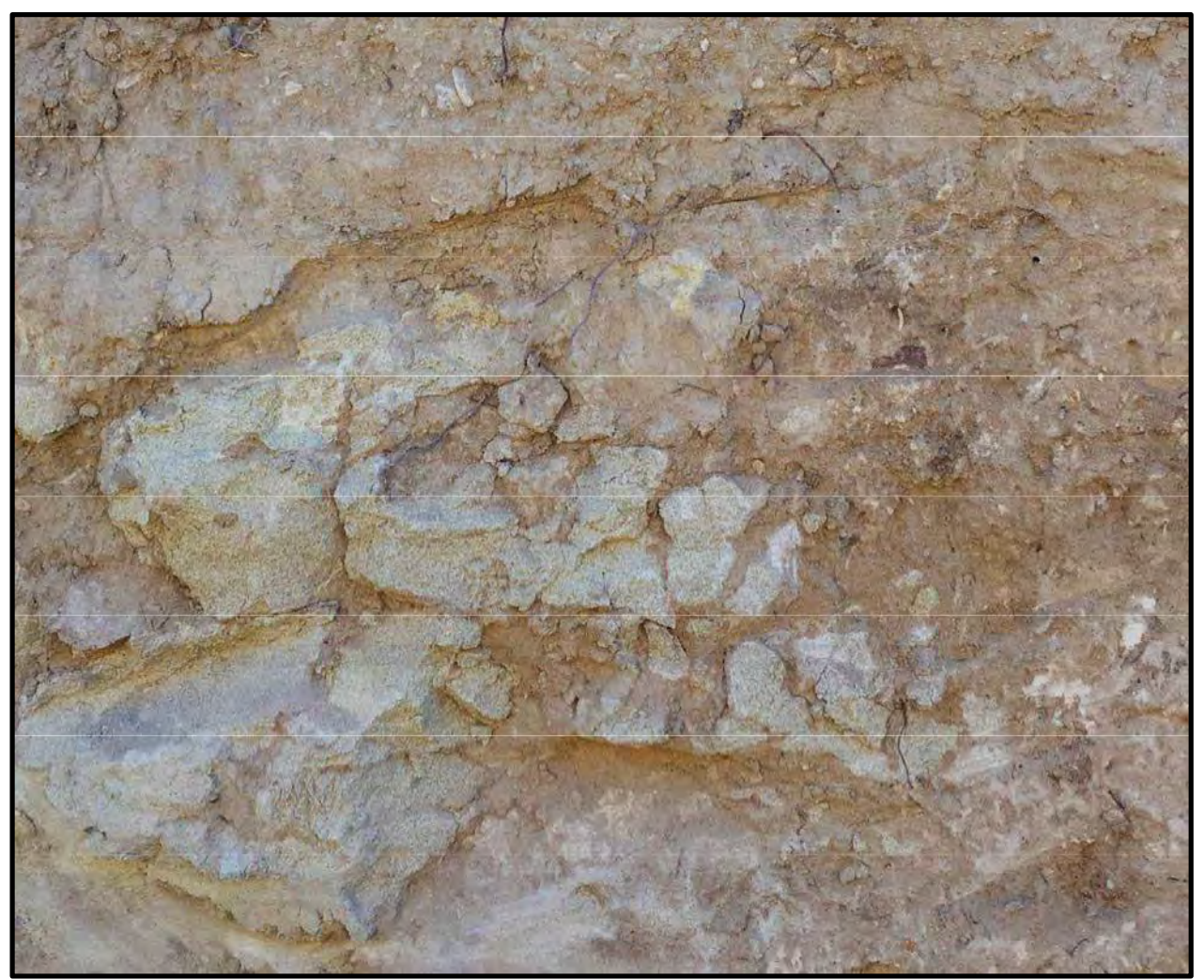

Figure 6.15. Example of brecciated sandstone at the base of the profile of BHT 11. This type of irregular contact, where oriented fragments of bedrock are brecciated and infilled with weathered sediment, is indicative of weathering in place.

The remaining BHTs varied from approximately 50 to $125 \mathrm{~cm}$ in depth. All of them terminated in or at the contact with weathered bedrock (BC or Cr horizon). The broad, shallow gravelly channels exposed in BHTs in the eastern part of the site (see Appendix A) clearly demonstrate that alluvial deposition has occurred on the site during the late Holocene. Nevertheless, as previously stated, I do not believe that there has been sufficient alluvial deposition to account for the burial and preservation of Feature 1. The following discussion further develops this argument and provides alternative theories for the burial of Feature 1, and by extension, the other buried cultural materials encountered at 41SR242.

\section{DISCUSSION}

The question of site burial is not merely of academic interest. The mechanism of burial relates to the potential for the deposits to have sufficient integrity to be eligible for the NRHP. While various members of the lay public, and even a few archeologists I have worked with over the years, have stated the belief that artifacts in sites "work themselves down" into soil, this is not the case. Artifacts do not act, they are acted upon by external forces. In the absence of cultural agency (i.e., intentional or unintentional burial), there is always some physical or biological mechanism (or suite of mechanisms) responsible for moving an artifact from the surface, where they are originally deposited, into the subsurface where they are found. In the case of the Cornelio Alvarez Sr. site (41SR242), there are four classes of mechanisms that I considered as potential preservation agents: 1) translocation downward from the living surface into the subsurface by an agent or by natural processes; 2) living surface burial by alluvial and/or colluvial sedimentation; 3) living surface burial by eolian sedimentation; and 4) living surface burial by biosedimentary processes. Each of these (non-mutually exclusive) alternatives is discussed in turn below. 


\section{Translocation}

Many mechanisms are capable of moving artifacts down (or up) through a soil profile, but they can be subdivided into two broad categories: biological processes, where movement is attributable to the activity of organisms (animals and/or plants), and physical processes, where organisms play no direct role. What these mechanisms share is stratigraphic translocation; the artifacts have been moved through strata, so they are no longer associated with the original living surface, whether that be the modern surface (typical in the uplands) or a buried paleosurface.

Examples of physical displacement processes include vertic soil processes affecting expansive clay soils (including heave, which can lift artifacts by displacing the matrix they inhabit, and soil cracking, which can open conduits for materials to fall or slide deeper into a profile), frost heave, salt growth, and relatively rare events like earthquake-related liquefaction (Schiffer 1983; Waters 1992; Abbott 2001). Some types of slope failure can laterally displace artifacts as the encasing sediment moves as a unit or undergoes plastic deformation, making them intermediate between translocation and sedimentation processes.

Biological displacement occurs when the actions of organisms dislodge and move cultural material. Materials may move up or down the stratigraphic column, and accompanying lateral displacement is common (Schiffer 1983; Armour-Chelu and Andrews 1994). Plant root growth can lift and disrupt overlying deposits, disrupt and spread features, or lead to settling that displaces artifacts downward as plant roots decay. Burrowing animals can exhume buried artifacts, or provide conduits for artifacts to fall, slide, or wash more deeply into the profile. However, the size of the burrower generally dictates the size threshold of artifacts subject to movement, as burrowing mammals and reptiles can readily displace materials that could be caught by $1 / 4$-inch mesh, while invertebrates rarely do. Although both plants and animals can disrupt and translocate sediment, the speed with which animals operate is generally several orders of magnitude faster than plants.

\section{Alluvial and/or Colluvial Transport and Sedimentation}

From a technical perspective, alluvial sedimentation refers to deposition from flowing water, while colluvial sedimentation refers to slope-focused processes that are primarily gravity-driven (Bates and Jackson 1984; Whittow 1984). However, the boundaries of these processes are not as clear-cut as they first seem, and there is lack of sound agreement on the term "colluvium," which differs in usage between continents, disciplines, and even individuals (Miller and Juilleret 2015; 2016). In particular, investigators who are focused on process would tend to consider deposits laid down by unconfined overland flow alluvium, while those focused on resulting deposits would recognize the difficulty separating intimately associated wash-driven and gravity-driven deposits, and be more likely to include wash deposits under the broader rubric of colluvium. In either case, artifact burial occurs because fresh sediment derived from somewhere else on the landscape is introduced and accumulates on the site, burying the living surface and associated artifacts. If water is the agent of transport, it will exert tractive forces on the artifacts that vary depending on the speed and depth of the water column and can disrupt the spatial relationships between artifacts and sort them according to shape and weight.

Water can also erode unconsolidated sediments in a variety of ways, ranging from rapid loss of floodplain and terrace sediments by lateral erosion on the margin of a migrating stream, to shallow surface stripping by overland flow. In semi-arid to arid environments like Starr County, this work tends to be performed during short periods associated with rainfall events, and it is common on semi-arid archeological sites in fine-grained settings to see artifacts resting on short pedestals because the surrounding surface has been stripped by sheet erosion. Over time, episodes of aggradation and erosion can affect the same area 
repeatedly, whether at a large scale (e.g., a river valley) or small scale (e.g., an individual slope segment). Thus, artifacts may have a burial history that is complex and difficult to unravel.

\section{Eolian Sedimentation}

Wind also erodes, transports, and deposits sediment, and like water and gravity is capable of burying or exhuming surfaces. However, because air is much less dense than water, the grain size of materials affected by wind transport is much narrower, ranging roughly from medium sand to fine silt. Coarser materials are generally too massive to be entrained, while finer materials are more difficult to entrain, both because wind velocity drops precipitously in immediate proximity to the ground surface, and because silts and clays are typically bound together by various forms of interparticular attraction (Derbeyshire et al. 1979; Lancaster and Nickling 1994). However, finer sediments may be transported short distances as sand- or silt-sized soil aggregates, or once entrained, as suspended dust which can travel great distances. The impacts of saltating grains are important in dislodging coarser and finer particles (Bagnold 1941; Kok et al. 2012), so the wind speed necessary to initiate eolian erosion is greater than that needed to maintain it once it is initiated.

Eolian deposits are generally better sorted (i.e., more uniformly sized) than alluvial deposits, and far better sorted than colluvium. This means that eolian deposits are relatively easy to recognize, even in the absence of preserved bedding, but care must be taken because the character of the sediment supply can also dictate the texture of deposits - thus, alluvial and colluvial processes reworking older eolian sediment can create deposits that mimic the texture profile of an eolian deposit. While eolian processes will never transport gravel-sized clasts, silts and clays can be transported in suspension or as aggregate particles in the traction load.

\section{Biosedimentation}

Biosedimentation occurs because burrowing animals remove sediment at depth, carry it upwards, and eject it at the surface (Crossley 1986; Frederick 1996; Bagyaraj et al. 2016). Over the long term, this can result in the burial of materials on the surface as burrow ejecta accumulates and is remodeled by wind, rainsplash, overland flow, and similar processes.

However, there is an important difference between biosedimentation and other forms of deposition. Viewed in isolation, biosedimentation is essentially a closed system-any sediment burying a living surface represents material removed from the substrate beneath that living surface, while alluvium, colluvium, and eolian sediments are largely transported to the site from elsewhere. As a consequence, a purely biosedimentary sequence can only aggrade (thicken) an amount equivalent to the volume of pore spaces created in the subsurface; the overall thickness will remain relatively constant, but a given paleosurface associated with the profile will be both progressively buried, and progressively destroyed as it is increasingly riddled with fresh burrows. Thus, all things being equal, one would expect a paleosurface 5,000 years old to be buried approximately five times as deeply as one 1,000 years old.

Of course, things are never equal. In actuality, this “closed system” model probably never happens, because nothing is truly isolated in nature. Exhumed sediment is available for eolian deflation, rainsplash, and sheet erosion, and material from upslope is introduced by the same processes. Weathering of the profile, facilitated in no small part by burrowing, can add to the thickness of the soil column over time. Changes in porosity attributable to progressive burrowing will alter the volume of sediment, as can biotic additions. The intensity of biological activity in any given spot and at any given depth can wax and wane in response to seasonal or climatic shifts, competition from new species, or pure chance. 
Nevertheless, in the absence of significant sediment influx or erosion, the net result of a bioturbationdominated soil will be gradual burial and progressive destruction of any associated occupation surfaces without substantial net gain in soil thickness.

The nature of that destruction, however, will depend on the characteristics of the organisms involved. Although there are burrowing organisms capable of destroying and displacing a cobble- to boulder-sized feature like a burned rock hearth or an intact pot (e.g., bears, alligators, armadillos), most burrowing vertebrates are too small, and will simply work around large clasts rather than go to the trouble to exhume them (Butler 1995). Similarly, smaller burrowing vertebrates can readily disturb and displace pebblesized artifacts like ceramic sherds, lithic tools, and lithic debitage, but burrowing arthropods are far more likely to leave such artifacts in place. Therefore, it may be possible to recover meaningful spatial data from such an assemblage. This does not mean that the site is intact, because smaller components of the assemblage (including microdebitage, pollen, phytoliths, and charcoal) may be in modified spatial and stratigraphic positions or removed entirely. In settings with more advanced turbation effects such as a termite nest, however, sediment may be reworked to the extent that formerly dispersed materials are concentrated at the base of activities (McBrearty 1990).

Moreover, the dynamics of burrowing behavior will vary significantly with depth depending on the specific behavior and level of activity of species involved. In most case, one would expect the intensity of burrowing behavior to decrease with depth, but the character of that change is likely non-linear (Wilkinson et al. 2009; Johnson et al. 2014). In addition, the behavior of individual species active at a given location may affect the trend, as different species occupy different depth ranges, or segregate their activities so that the character of the burrow varies with depth (Butler 1995; Bastardie et al. 2003; Reynolds and Wakkinen 1987).

\section{Potential Processes of Artifact Burial at the Cornelio Alvarez Sr. Site}

The current site is situated in the eroding margin of the Rio Grande Valley, on a subtly convex footslope segment approximately $300 \mathrm{~m}$ from an isolated upland remnant that is the primary source of the gravel. As Figure 6.16 shows (also see Figure 6.11), there is little opportunity for the type of protracted flooding that would be necessary for large volumes of fine-grained sediment to accumulate on this convex toeslope. The gravel lenses almost certainly represent ephemeral channels formed during extreme highmagnitude rain events, which seems the only way that clasts of that size (up to $15 \mathrm{~cm}$ diameter) could be mobilized and moved downslope. Given that the catchment only extends a few hundred meters upslope, the opportunity to entrain sediment is clearly limited. However, intense rainfall (such as provided by tropical storms) can do a great deal of geomorphic work on the type of under-vegetated slopes common in the region in a brief timespan. Therefore, I would expect significant overland transport of fine-grained sediment to occur during such an event.

Sediment yield would be further enhanced if the storm were to occur after an artificial disruption of the surface (e.g., plowing) or drought had limited cover vegetation. However, except where localized sediment traps like the lee side of microtopographic features (e.g., shrubs, burrow spoil) disrupt flow, the majority of this entrained fine-grained sediment would probably sheet across the site and accumulate downslope on the floodplain. That said, overland flow has clearly affected the site, and almost certainly contributed to both adding and removing sediment. The channelized gravels noted in BHT 5, BHT 10, BHT 11, and BHT 15 represent the product of concentrated, torrential slope runoff, with flow concentrating enough to both transport large gravels and incise small ephemeral channels (gullies). Given the setting, such high magnitude events are almost certainly the result of tropical storms making landfall and would occur with relatively low frequency. 


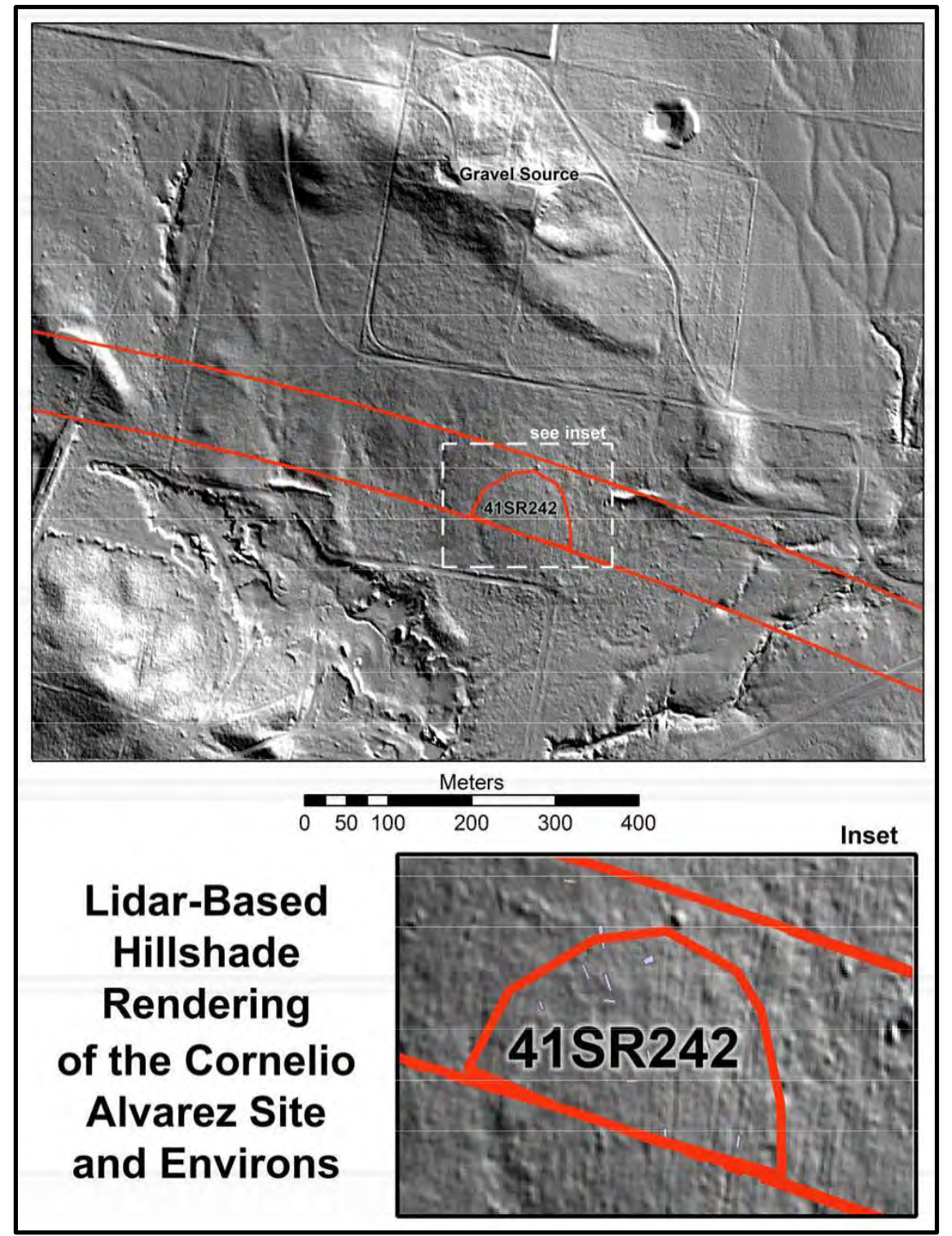

Figure 6.16. Lidar-based hillshade showing landforms and modern disturbances in the vicinity of 41SR242. Note prominent root plow scars visible in inset. 
I therefore argue that traditional alluvial and colluvial processes of deposition are unlikely to have buried the Feature 1 assemblage. Even if fine-grained sediments did happen to accumulate sufficiently to bury an archeological assemblage, one would expect significant hydraulic sorting of materials buried by an intense flow, so the dense assemblage of whole snail shells and flakes represented by Feature 1 would be very unlikely to be preserved through such a mechanism.

Similarly, I cannot imagine a scenario where a dense assemblage of flakes and snail shells could be translocated deeply into the site matrix (i.e., intruded through existing strata) without destroying the associations between artifacts. It is true that pockets of snail shell can be concentrated in rodent burrows in the subsurface as a result of rodent behavior, but there is no reason to expect that lithic debitage would be concentrated in this manner.

Moreover, neither I nor the archeologists excavating the TUs observed any indication that the materials in Feature 1 were associated with a burrow feature during the initial trenching or the subsequent excavations, and the frequency of observable rodent-scale burrows in the site trenches was very low. In contrast, the frequency of fine burrows was very high, and the sediment was overprinted with a soil texture that appeared to be the result of pervasive pedoturbation by insect-scale organisms.

Consideration of bioturbative mechanisms of site burial (e.g., Frederick 1996; Leigh 1998) and site pedoturbation (e.g., Bateman et al. 2003; 2007) is most common in thick, sandy upland soils where macroscopic evidence of depositional and pedogenic process is limited (e.g., the Texas Sandy Mantle). Thus, much of the effort of these investigations is directed at documenting the presence of bioturbation in the first place, and only then estimating its effects on site integrity and dating. At the Cornelio Alvarez Sr. site (41SR242), the loamy nature of the sediment made macroscopic evidence of insect-scale turbation abundant-so abundant, in fact, that there was a danger that overprinting could conceal or have destroyed sedimentary evidence of other processes. For the reasons listed above, it appeared that the most likely scenario was that burial occurred primarily through the accumulation of ejecta produced by burrowing invertebrates over the long term. However, I also considered the possibility that sheetwash aggradation had occurred, or that historic land use practices had buried the material relatively recently. This latter possibility was considered because the site showed evidence of clearing, and the landowner, Cornelio (Cone) Alvarez, informed us that the entire area had been root plowed several decades before.

There are a number of methods to control brush used in south Texas, including controlled burning, mechanical methods, biological methods (e.g., goats), and chemical treatment (Hoffman 1975; NRCS 2012). Of these, mechanical methods are most disruptive to the soil (and the most effective). These methods include chaining, grubbing, chopping, shredding, raking, disking, and root plowing. According to Mr. Alvarez, the site was cleared using a bulldozer-mounted root plow, presumably like that illustrated in Figure 6.17. Even decades later, evidence of that plowing is clearly visible as north/south-oriented scars in the lidar-based hillshade (see inset, Figure 6.16), but is far from obvious on the ground (Figure 6.18) or in profile (see various photographs, Appendix A). Unlike a plow used for cultivation, root plows are not designed to overturn the soil surface. In standard configuration (as in Figure 6.17), they simply slice the roots off underground, disrupting only the area around the blade supports. 


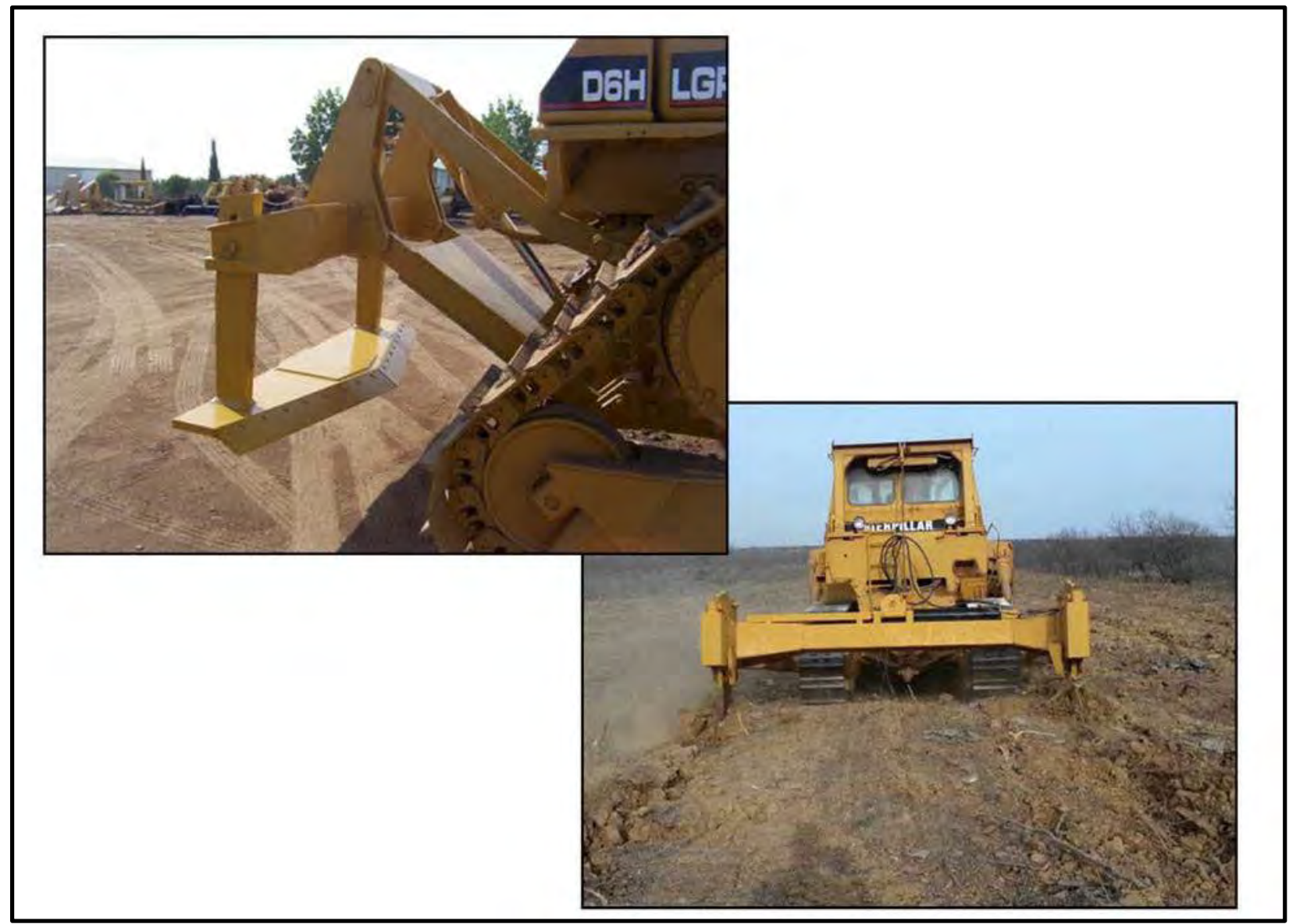

Figure 6.17. Illustrations of root plow equipment, showing the mechanics and impacts of use. Photographs from the internet (top left:

http://www.industrialbuckets.com/English/Attachments/RootPlows/RootPlows.html; bottom right: https://www.youtube.com/watch?v=m-7MboQ6_QM. 


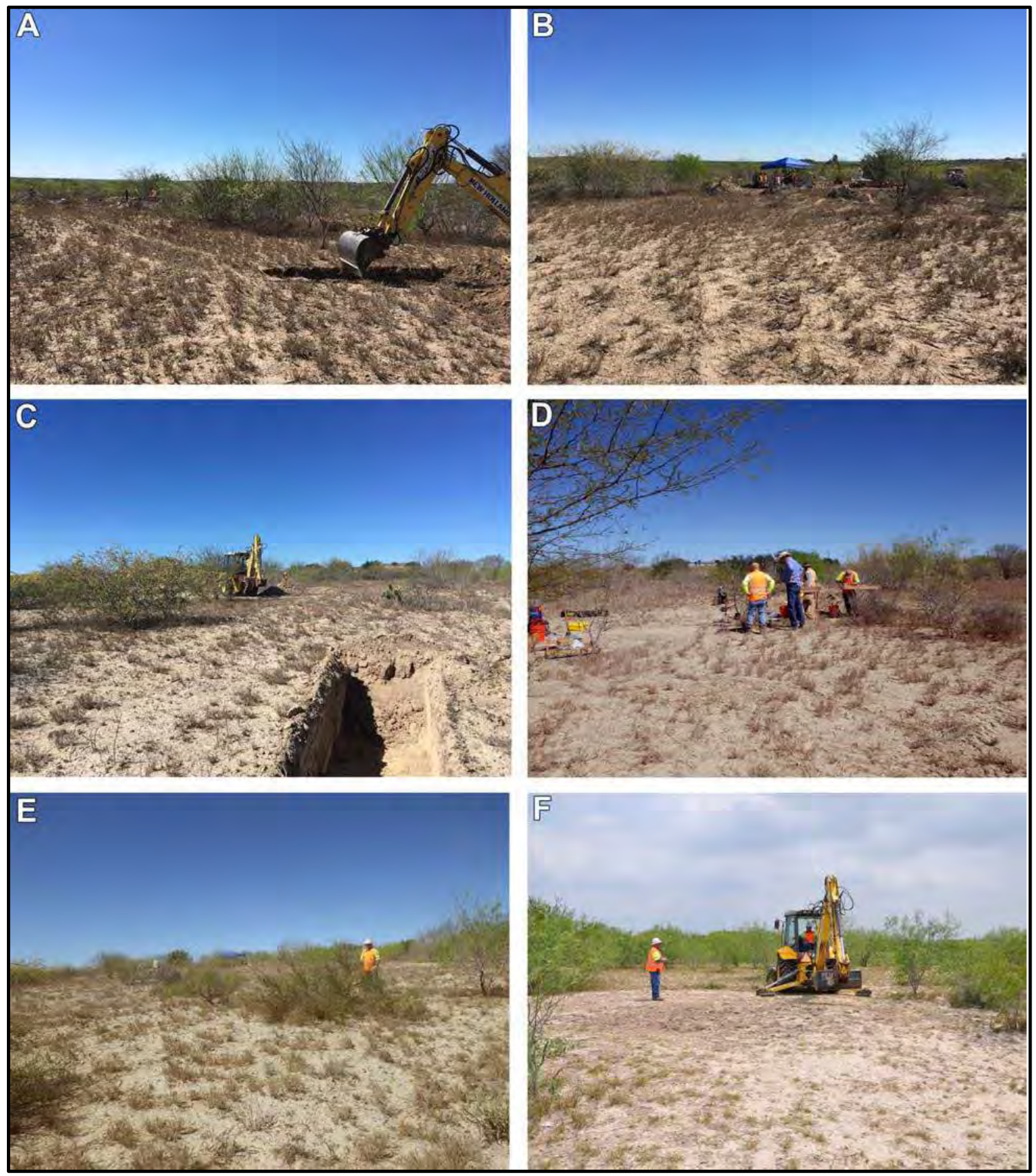

Figure 6.18. Views of the site, showing character of topography and vegetation. A: facing south across center of site from vicinity of BHT 9. B: facing southwest at excavation. C: facing north from BHT 5. Note subtle ridge to west of trench and house in background, which sits on upland remnant. D: facing north toward excavation from general area of BHT 13. E: facing west-northwest across eastern part of site toward main excavation block. Note vague indication of north/south lineaments in vegetation in middle ground, particularly on left side of photograph. F: facing northeast from area of BHT 1, prior to reopening the area in April 2017. Note size of mesquite. 
Root plows may also be fitted with accessory vanes designed to bring severed roots to the surface, which cause considerable disruption of the surface horizons (Hoffman 1975); however, the distinct plow lines visible in the lidar image suggest that these rakes were probably not used. Associated disturbances can also occur as a function of raking, piling, and burning the cut vegetation, not to mention the compression and churning damage imparted by a heavy tracked bulldozer.

It is telling that no evidence of the smooth cut across the profile made by a root plow was noted in the field. With the exception of the knife-like vertical struts, which cause localized disruption to the depth of plowing (usually 11-14 inches), soil damage from a root plow should be visible as a smooth, horizontal contact at the base of the plow zone. If no rake vanes are installed, soil above the cut would be lifted by the wing-shaped plow, then allowed to settle back down en masse as the plow passes, while the presence of low-angle rake vanes would thoroughly break up the soil, bringing the cut roots to the surface. In either case, the diagnostic feature should be a distinct, smooth, horizontal line marking the base of root plowing. The fact that no such feature was noted in any of the trenches, even though there is ample lidar-based evidence to support Mr. Alvarez's account, suggests that the contact has been largely obliterated by insect turbation in the past few decades. Therefore, this lack of a clear root plow cut is very instructive about the overall rate of profile turbation.

The cultural material at 41SR242 is both strewn across the surface, particularly in the southeast portion of the site, and stratified throughout the soil column. However, the uppermost solum was largely ignored during testing because of relatively sparse artifact content and perceived plow disturbance, and the majority of the materials were recovered from below $40 \mathrm{cmbs}$. Eleven radiocarbon ages, including four ages on Rabdotus snail shells and seven on charcoal, were determined on samples recovered from the site (Table 6.2). The first four samples dated were Rabdotus shells. They were run after the initial field session to get a broad idea of the age and integrity of the assemblage, even though Rabdotus shells often exhibit an age anomaly due to incorporation of dead carbon from limestone and soil carbonate (Goodfriend 1992; Goodfriend et al. 1999). Our purpose in dating the snail shells was not to arrive at an accurate estimate of the age of the site, but rather to obtain general insights into the age and integrity of Feature 1 before returning to the field (we had recovered no charcoal to that point). The remaining samples addressed wood charcoal, including mesquite (Prosopis sp.), acacia (Acacia sp.), and snakewood (Condalia sp.). All samples were from units in immediate proximity to each other surrounding Feature 1, and wood identifications were made by TxDOT ethnobotanist/archeologist Dr. Kevin Hanselka.

We pursued several lines of evidence related to the character of turbation processes and resulting morphological features during the analysis phase. Two bulk sample blocks, one from the presumed plow zone (15-23 cmbs) and one from below it (45-53 cmbs), were collected from the documented soil column in BHT 8. Each block was hand carried to the CT lab at the Jackson School of Geosciences, University of Texas at Austin, for CT scanning, then submitted to Dr. Charles Frederick for soil thin section analysis. I then examined and compared the results of these analyses, with particular emphasis placed on evidence of turbation and depositional mechanisms. In addition, radiocarbon dating of samples from the vicinity of Block 1 allowed for calculation of a crude minimum rate of soil turnover, and two additional sediment blocks - one containing a preserved bone fragment and one believed to capture the primary cultural stratum - were collected during the April field session and submitted for CT scanning. All of these analyses are discussed below. 
Table 6.2. Radiocarbon results from 41SR242.

\begin{tabular}{|c|c|c|c|c|c|c|c|}
\hline Sample & Context & Material & Beta Number & $\begin{array}{l}\text { Corrected } \\
\text { Age }\end{array}$ & Error & del $13 C$ & $\begin{array}{l}\text { Calibrated Age } \\
\text { (2 Sigma) }\end{array}$ \\
\hline SR242-1s & $\begin{array}{l}\text { BHT 1, Feature 1, } \\
50-60 \mathrm{cmbs} \\
(1 \text { of } 4)\end{array}$ & $\begin{array}{l}\text { Rabdotus spp. } \\
\text { Snail shell }\end{array}$ & Beta 456114 & 6200 & 30 & -8.1 & BC 5225 to 5055 \\
\hline SR242-2s & $\begin{array}{l}\text { BHT 1, Feature 1, } \\
50-60 \mathrm{cmbs} \\
(2 \text { of } 4)\end{array}$ & $\begin{array}{l}\text { Rabdotus spp. } \\
\text { Snail shell }\end{array}$ & Beta 456115 & 5010 & 30 & -3.9 & $\begin{array}{l}\text { BC } 3935 \text { to } 3860 \\
\text { BC } 3810 \text { to } 3705\end{array}$ \\
\hline SR242-3s & $\begin{array}{l}\text { BHT 1, Feature 1, } \\
50-60 \mathrm{cmbs} \\
(3 \text { of } 4)\end{array}$ & $\begin{array}{l}\text { Rabdotus spp. } \\
\text { Snail shell }\end{array}$ & Beta 456116 & 4640 & 30 & -6.9 & $\begin{array}{l}\text { BC } 3515 \text { to } 3395 \\
\text { BC } 3385 \text { to } 33360\end{array}$ \\
\hline SR242-4s & $\begin{array}{l}\text { BHT 1, Feature 1, } \\
50-60 \mathrm{cmbs} \\
(4 \text { of } 4)\end{array}$ & $\begin{array}{l}\text { Rabdotus spp. } \\
\text { Snail shell }\end{array}$ & Beta 456117 & 5130 & 30 & -7.2 & $\begin{array}{l}\text { BC } 3980 \text { to } 3935 \\
\text { BC } 3870 \text { to } 3810\end{array}$ \\
\hline SR242-5C & $\begin{array}{l}\text { TU 3, Level 3, } \\
55 \text { cmbs }\end{array}$ & $\begin{array}{l}\text { Prosopis sp. } \\
\text { (carbonized) }\end{array}$ & Beta 468117 & 3260 & 30 & -24.1 & $\begin{array}{l}\text { BC } 1616 \text { to } 1493 \\
\text { BC } 1481 \text { to } 1454\end{array}$ \\
\hline SR242-6C & $\begin{array}{l}\text { TU 3, Level 3, } \\
56 \text { cmbs }\end{array}$ & $\begin{array}{l}\text { Prosopis sp. } \\
\text { (carbonized) }\end{array}$ & Beta 468115 & 2420 & 30 & -23.1 & $\begin{array}{l}\text { BC } 748 \text { to } 685 \\
\text { BC } 666 \text { to } 642 \\
\text { BC } 587 \text { to } 581 \\
\text { BC } 556 \text { to } 402\end{array}$ \\
\hline SR242-7C & $\begin{array}{l}\text { TU } 1 \mathrm{~N} \text {, Level } 4 \text {, } \\
56 \mathrm{cmbs}\end{array}$ & $\begin{array}{l}\text { Prosopis sp. } \\
\text { (carbonized) }\end{array}$ & Beta 468116 & 2250 & 30 & -24.1 & $\begin{array}{l}\text { BC } 395 \text { to } 347 \\
\text { BC } 321 \text { to } 206\end{array}$ \\
\hline SR242-8C & $\begin{array}{l}\text { TU 5, Level 3, } \\
57 \text { cmbs }\end{array}$ & $\begin{array}{l}\text { Prosopis sp. } \\
\text { (carbonized) }\end{array}$ & Beta 468118 & 2160 & 30 & -23.4 & $\begin{array}{l}\text { BC } 358 \text { to } 279 \\
\text { BC } 259 \text { to } 108\end{array}$ \\
\hline SR242-9C & $\begin{array}{l}\text { TU 5, Level } 3 \text {, } \\
60 \mathrm{cmbs}\end{array}$ & $\begin{array}{l}\text { Prosopis sp. } \\
\text { (carbonized) }\end{array}$ & Beta 468119 & 3260 & 30 & -22.5 & $\begin{array}{l}\text { BC } 1616 \text { to } 1493 \\
\text { BC } 1481 \text { to } 1454\end{array}$ \\
\hline SR242-10C & $\begin{array}{l}\text { TU 3, Level } 1 \text {, } \\
30-40 \mathrm{cmbs}\end{array}$ & $\begin{array}{l}\text { Condalia sp. } \\
\text { (carbonized) }\end{array}$ & Beta 468120 & 2450 & 30 & -23.6 & $\begin{array}{l}\text { BC } 754 \text { to } 681 \\
\text { BC } 670 \text { to } 609 \\
\text { BC } 595 \text { to } \mathbf{4 1 1}\end{array}$ \\
\hline SR242-11C & $\begin{array}{l}\text { TU 5, Level } 2 \text {, } \\
50 \text { cmbs }\end{array}$ & $\begin{array}{l}\text { Acacia sp. } \\
\text { (carbonized) }\end{array}$ & Beta• 468121 & 3020 & 30 & -23 & $\begin{array}{l}\text { BC } 1391 \text { to } 1337 \\
\text { BC } 1322 \text { to } 1191 \\
\text { BC } 1177 \text { to } 1164 \\
\text { BC } 1144 \text { to } 1131\end{array}$ \\
\hline
\end{tabular}

The bolded range in the calibrated age of each charcoal sample represents the timespan with the highest probability (greatest area under the curve). Sample Context Material Beta Number Corrected Age Error del 13C Calibrated Age (2 Sigma)

\section{Radiocarbon Analyses}

Figure 6.19 (see also Table 6.2) illustrates the calibrated probability curves of dated radiocarbon samples from the site by TU and depth. Two conclusions are immediately apparent from this figure. First, the Rabdotus shells date substantially (as much as 5,000 years) older than charcoal from the same setting. Second, the charcoal ages are themselves relatively widespread and not in stratigraphic order. Scott Pletka with TxDOT conducted a brief Bayesian analysis of these ages in OxCal (see Figure 6.19). This analysis suggested the charcoal resulted from repeated occupation over a timespan of no less than 1,196 and no more than 2,853 years at $20^{\circ}$ (95.4 percent) probability. Based on the probability curves, the most likely scenario is that the charcoal (and associated artifacts) began to accumulate episodically beginning around 1600 B.C. and ending approximately 100 B.C., a period of 1,500 years. However, the 20 range of the "start" boundary extends as far back as 2474 B.C., while that of the "end" boundary extends as late as A.D. 730. In short, little can be said about the age and integrity of the assemblage other than it appears to represent repeated activity over more than a thousand years during the Late Archaic. Given these ages, the rate of burial of the material in Feature 1 appears to be between $0.038 \mathrm{~cm} / \mathrm{yr}-1$ and $0.011 \mathrm{~cm} / \mathrm{yr}-1$, which is lower than the rate of $1.89 \mathrm{~cm} / \mathrm{yr}-1$ to $0.158 \mathrm{~cm} / \mathrm{yr}-1$ calculated by Frederick (1996) for burial by earthworms on a test plot at Fort Hood. 


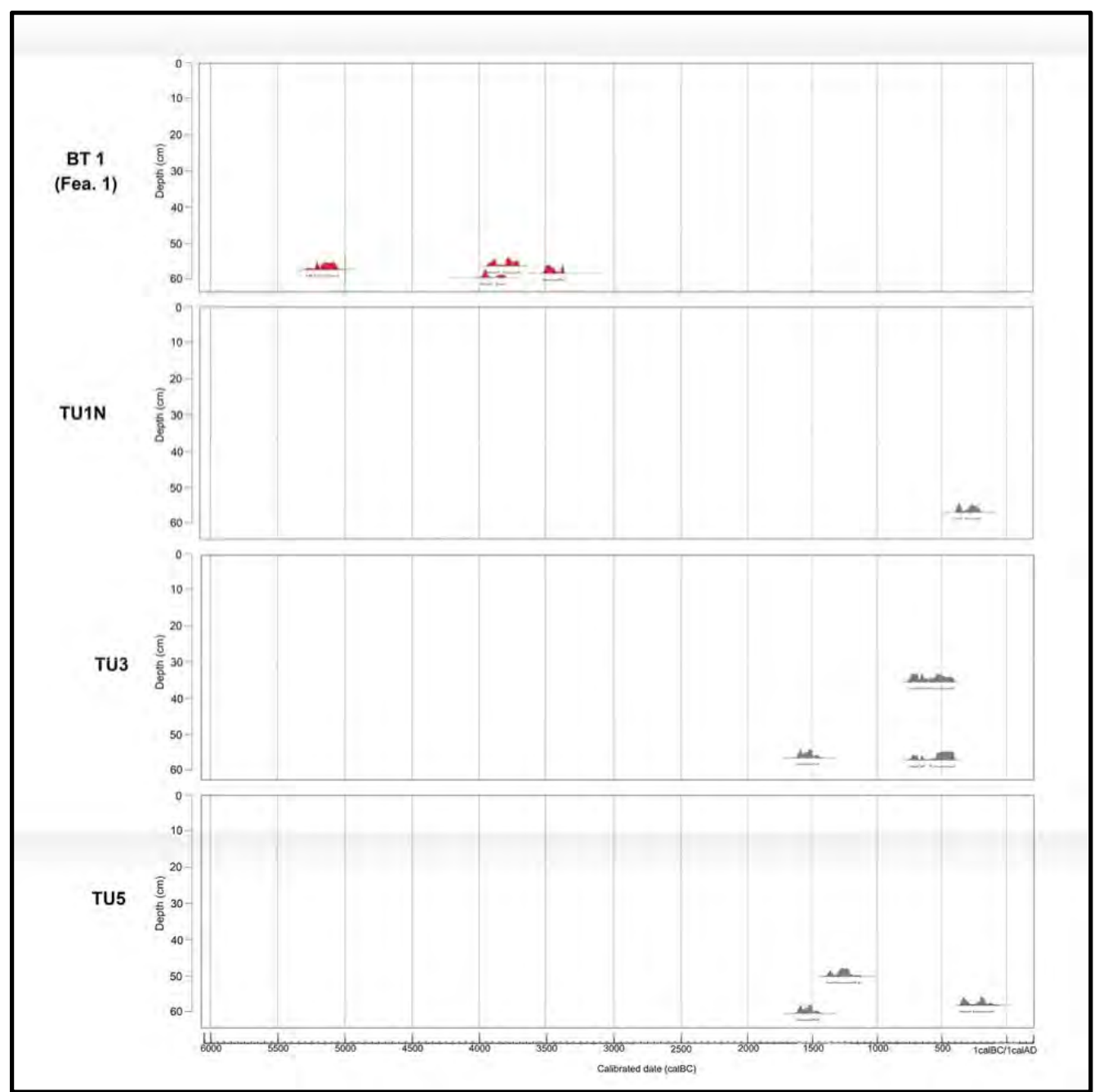

Figure 6.19. Radiocarbon results arranged by test unit and depth. Each sample is represented by the calibration curve for that sample, where the height of the curve at each year represents the relative probability that the sample dates to that year.

\section{Thin Section / Computed Tomography (CT) Analyses}

We conducted the thin section and CT analyses to look for vestiges of both depositional bedding and/or burrowing by microtene mammals, and to characterize the effects of burrowing by invertebrates like annelids, insects, and spiders. The relatively obscure discipline of ichnology is the study of trace fossils, which are sediment disruptions caused by living organisms - burrows, trackways, trails, and the like (Bates and Jackson 1984). It is often divided into two subfields: paleoichnology, the study of trace fossils in the rock record, and neoichnology, the study of modern trace fossils. Recently, a massive tome by Genise (2017) lays out ichnological observations specific to insects, a subfield termed ichnoentomology. He identifies insects with four variations in digging behavior, which he terms rakers, pullers, pushers, and carriers. Each of these burrowers produce burrows with different habits (size, inclination, pattern, etc.), some of which can be extremely large and elaborate architectural structures containing passages, brood chambers, living chambers, and other diverse structures. Insects also prepare the walls of burrows in different ways, including packing, lining, and coating, using ambient moisture and their own biological fluids and excreta to shape, mold, and stabilize burrow walls (Figure 6.20). Termites, in particular, combine excavated sediment with their own excrement to construct tube-like burrows that can not only 
represent below-ground labyrinths, but can extend far above the ground surface, rising up the sides of trees (or houses) to above-ground feeding sites, or, in the case of tropical termites, coalesced into immense freestanding mounds containing tons of excavated sediment (McBrearty 1990; Butler 1995). Earthworms also riddle the soil with burrows and eject copious amounts of sediment (relative to their size) at the surface (Frederick 1996; Zaller et al. 1997). Like many insects, they model burrow walls using a combination of pressure and mucous fluid, stabilizing burrow structures (Jégou et al. 2001). Unlike insects, many earthworms actually ingest and then excrete large volumes of soil material and can fundamentally affect the character of soil structure (Lee and Foster 1991; Jongmans et al. 2003). The role of earthworms in propagating soil fertility and soil structure has been recognized since Darwin (1881), and remains a focus of soil studies (e.g., Schrader and Zhang 1997; Resner et al. 2011). In general, the burrowing and associated biological activity (e.g., feeding, casting) of arthropods and earthworms serves to mix and aerate soil, aid decomposition, and promote infiltration and cycling of humus in soils. More to the point in the present context, this activity can both bury archeological sites and reorganize them in the subsurface, either dispersing buried occupations or collapsing dispersed materials into pseudooccupations (McBrearty 1990; Armour-Chelu and Andrews 1994).

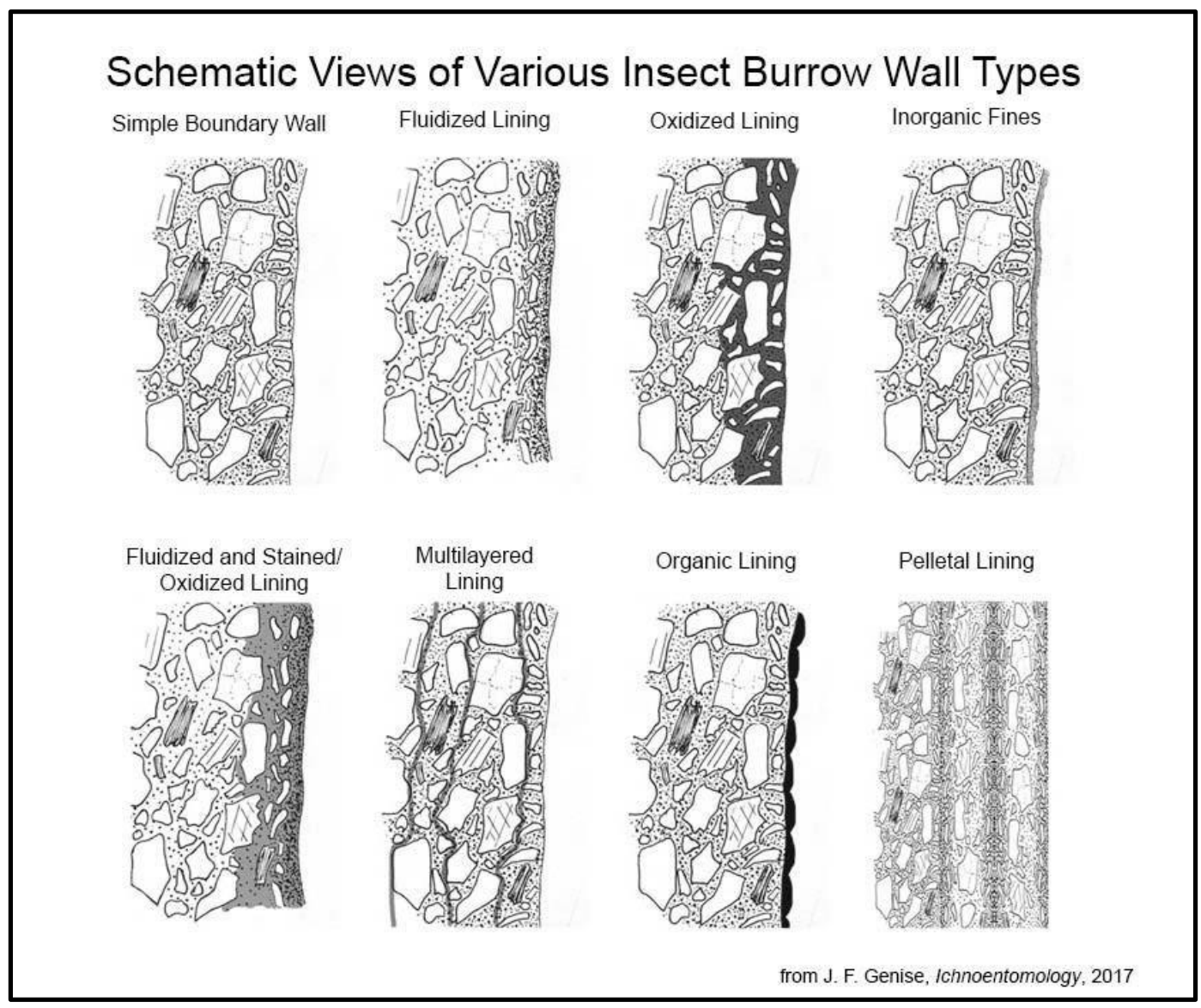

Figure 6.20. Variations in insect burrow wall morphology.

\section{Thin Section/CT Analysis Methods}

We collected bulk samples for thin section analysis from depths of 15-23 cm and 45-53 cm in the documented profile of BHT 8. Each sample was removed as an oriented block and carefully wrapped in heavy gauge aluminum foil, which was then wrapped with duct tape to secure the sample and placed in a padded box for transport. These samples were submitted to The University of Texas High Resolution 
X- Ray CT Facility (UTCT), where they were scanned by Dr. Matthew Colbert on April 12, 2017 using the NSI scanner. The specific parameters of each scan are provided in Table 6.3. The individual scans were captured as 16 bit TIFF and 8 bit JPG images. Processing of the image stacks and analysis of the pore fabric was performed in ImageJ software (National Institute of Health), a powerful open-source image processing application, while 3D manipulation, volume calculation, and segmentation were performed with Aviso Lite (Thermo Fischer Scientific). The latter analysis involved expensive, specialized software, and was performed at UTCT. Several freeware options designed for medical use were employed in an attempt to further this analysis away from UTCT, but none of these attempts were particularly successful.

The scanned blocks were then provided to Dr. Charles Frederick, who carefully opened them, embedded them in polyester resin, and sliced them into slabs on a rock saw. Three slabs were selected for thin section preparation based on review of the slab faces, and submitted to National Petrographic for preparation of $2 \times 3$-inch thin sections. Initial review of the blocks was based on review of the slab faces, with particular attention paid to presumed biogenic structures. This was supplemented by comparison with flatbed-scanned images of each slide using backlit and "pseudo-dark field" illumination (Figure 6.21), and CT radiograph cross sections re-sliced in ImageJ software to align as closely as possible with the slab face. Thin section preparation and analysis is discussed in greater detail in Appendix B.

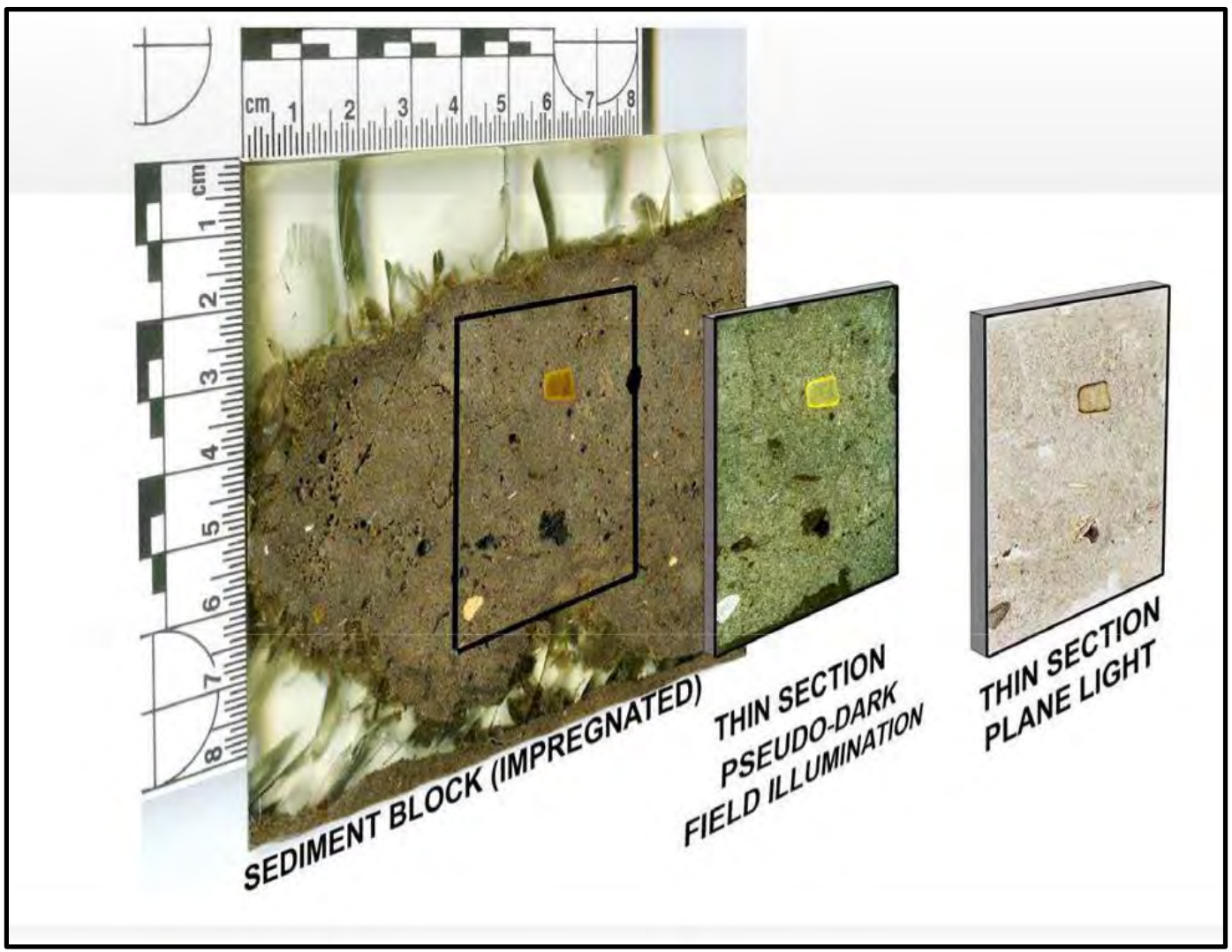

Figure 6.21. Schematic comparison of different macroscopic views of a typical thin section from 41SR242. 
Table 6.3. CT Scan parameters

\begin{tabular}{|c|c|c|c|c|c|c|c|c|}
\hline Sample & Facility & Scanner & $\begin{array}{l}\text { Power } \\
\text { Source }\end{array}$ & Detector & Scan Parameters & $\begin{array}{l}\text { Voxel } \\
\text { Size }\end{array}$ & $\begin{array}{l}\text { Total } \\
\text { Slices }\end{array}$ & Format \\
\hline $\begin{array}{l}\text { Upper } \\
\text { (BHT 8, } 15 \text { to } \\
23 \mathrm{cmbs} \text { ) }\end{array}$ & $\begin{array}{l}\text { UTCT, } \\
\text { Matthew } \\
\text { Colbert, } \\
\text { April 12, } \\
2017\end{array}$ & $\mathrm{NSI}$ & $\begin{array}{l}\text { Fein Focus } \\
\text { High Power } \\
\text { Source, } 190 \\
\text { kV, } 0.07 \mathrm{~mA}\end{array}$ & $\begin{array}{l}\text { Perkin Elmer } \\
\text { detector, } \\
\text { aluminum } \\
\text { filter }\end{array}$ & $\begin{array}{l}0.25 \mathrm{pF} \text { gain, } 1 \mathrm{fps}, 2 \times 2 \text { binning, no flip, source } \\
\text { to object } 553.0 \mathrm{~mm} \text {, source to detector } 1316.806 \\
\mathrm{~mm} \text {, continuous CT scan, } 2 \text { frames averaged, } 0 \\
\text { skip frames, } 1200 \text { projections, } 5 \text { gain } \\
\text { calibrations, } 15 \mathrm{~mm} \text { calibration phantom, data } \\
\text { range }[-1.0,25.0] \text { (grayscale adjusted from NSI } \\
\text { defaults), beam-hardening correction }=0.3 \text {. }\end{array}$ & $209.6 \mu \mathrm{m}$ & 796 & $\begin{array}{l}\text { 16-bit } \\
\text { TIFF, } \\
\text { 8-bit JPG }\end{array}$ \\
\hline $\begin{array}{l}\text { Lower } \\
\text { (BHT 8, } 45 \text { to } \\
53 \mathrm{cmbs} \text { ) }\end{array}$ & $\begin{array}{l}\text { UTCT, } \\
\text { Matthew } \\
\text { Colbert, } \\
\text { April 12, } \\
2017\end{array}$ & $\mathrm{NSI}$ & $\begin{array}{l}\text { Fein Focus } \\
\text { High Power } \\
\text { Source, } 190 \\
\text { kV, } 0.07 \mathrm{~mA}\end{array}$ & $\begin{array}{l}\text { Perkin Elmer } \\
\text { detector, } \\
\text { aluminum } \\
\text { filter }\end{array}$ & $\begin{array}{l}0.25 \mathrm{pF} \text { gain, } 1 \mathrm{fps}, 2 \times 2 \text { binning, no flip, source } \\
\text { to object } 553.0 \mathrm{~mm} \text {, source to detector } 1316.806 \\
\mathrm{~mm} \text {, continuous CT scan, } 2 \text { frames averaged, } 0 \\
\text { skip frames, } 1200 \text { projections, } 5 \text { gain } \\
\text { calibrations, } 15 \mathrm{~mm} \text { calibration phantom, data } \\
\text { range }[-1.0,25.0] \text { (grayscale adjusted from NSI } \\
\text { defaults), beam-hardening correction }=0.3 \text {. }\end{array}$ & $209.6 \mu \mathrm{m}$ & 932 & $\begin{array}{l}\text { 16-bit } \\
\text { TIFF, } \\
\text { 8-bit JPG }\end{array}$ \\
\hline $\begin{array}{l}\text { BALK } 6 \\
\text { (south balk of } \\
\text { TU 6, 35-50 } \\
\text { cmbs) }\end{array}$ & $\begin{array}{l}\text { UTCT, } \\
\text { Matthew } \\
\text { Colbert, } \\
\text { June 28, } \\
2017\end{array}$ & $\mathrm{NSI}$ & $\begin{array}{l}\text { GE Small } \\
\text { Spot source, } \\
250 \mathrm{kV}, 0.7 \\
\mathrm{~mA}\end{array}$ & $\begin{array}{l}\text { Perkin Elmer } \\
\text { detector, } \\
\text { brass filter }\end{array}$ & $\begin{array}{l}0.5 \mathrm{pF} \text { gain, } 1 \mathrm{fps}, 2 \times 2 \text { binning, no flip, source to } \\
\text { object } 910.928 \mathrm{~mm} \text {, source to detector } 1486.33 \\
\text { mm, continuous CT scan, } 2 \text { frames averaged, } 0 \\
\text { skip frames, } 1200 \text { projections, } 4 \text { gain } \\
\text { calibrations, } 15 \mathrm{~mm} \text { calibration phantom, data } \\
\text { range }[-0.2,4.7] \text { (grayscale adjusted from NSI } \\
\text { defaults), beam-hardening correction }=0.25 \text {. }\end{array}$ & $266.5 \mu \mathrm{m}$ & 846 & $\begin{array}{l}\text { 16-bit } \\
\text { TIFF, } \\
\text { 8-bit JPG }\end{array}$ \\
\hline $\begin{array}{l}\text { TU4 } \\
(\sim 50 \text { cmbs, } \\
\text { block containing } \\
\text { skeletal } \\
\text { material })\end{array}$ & $\begin{array}{l}\text { UTCT, } \\
\text { Matthew } \\
\text { Colbert, } \\
\text { June 28, } \\
2017\end{array}$ & $\mathrm{NSI}$ & $\begin{array}{l}\text { GE Small } \\
\text { Spot source, } \\
250 \mathrm{kV}, 0.7 \\
\mathrm{~mA}\end{array}$ & $\begin{array}{l}\text { Perkin Elmer } \\
\text { detector, } \\
\text { brass filter }\end{array}$ & $\begin{array}{l}0.5 \mathrm{pF} \text { gain, } 1 \mathrm{fps}, 2 \times 2 \text { binning, no flip, source to } \\
\text { object } 660.0 \mathrm{~mm} \text {, source to detector } 1486.33 \\
\text { mm, continuous CT scan, } 2 \text { frames averaged, } 0 \\
\text { skip frames, } 1200 \text { projections, } 4 \text { gain } \\
\text { calibrations, } 15 \mathrm{~mm} \text { calibration phantom, data } \\
\text { range }[-0.1,4.0] \text { (grayscale adjusted from NSI } \\
\text { defaults), beam-hardening correction }=0.1 .\end{array}$ & $168.4 \mu \mathrm{m}$ & 851 & $\begin{array}{l}\text { 16-bit TIFF, } \\
\text { 8-bit JPG }\end{array}$ \\
\hline
\end{tabular}


Finally, on June 28, 2017, Dr. Colbert scanned two additional sediment blocks collected by Mr. Ringstaff during the third field session in April. These blocks were collected by the field crew during the April 2017 field session. Collection methodology was similar to the initial two blocks, but these samples were designed to highlight specific archeological features (one block was collected to capture the primary artifact-bearing stratum between 50 and $60 \mathrm{cmbs}$, while the other contained a fragment of faunal bone [mandible] embedded in matrix). Neither of these samples was submitted for thin section analysis.

\section{Computed Tomography (CT) Analysis}

The four CT scans provide a remarkable picture of the character of the site deposits. The history and physics behind CT analysis and its application to geological materials have been summarized in detail many times before (e.g., Ketchum and Carlson 2001; Carlson et al. 2003; Taina et al. 2008), and will only be briefly addressed here. CT was developed for medical applications in the 1970s, and soon caught the interest of soil scientists (e.g., Petrovic et al. 1982; Hainsworth and Aylmore 1983). CT uses the power of computer image processing to distill a series of successive $\mathrm{x}$-ray images taken of the same target from different vantage points into a virtual 3D model of the internal structures. This can be accomplished either by rotating the equipment around the target (as is typical in medical applications) or by turning the target itself on a turntable (which is typical of industrial applications and is how the current study was performed). X-ray imagery results when focused $\mathrm{x}$-ray radiation is directed through the target to a receiver (which was originally film, but in CT and all other modern x-ray applications is a digital sensor). As the x-rays pass through the target to the sensor, they are attenuated by scatter and absorption in the target. The degree of attenuation depends on a variety of factors, including the density of the target material, its elemental composition and moisture content, and the overall thickness of material that the beam must pass through. This latter property leads to a phenomenon called beam hardening, which is a difficult problem to address; see http://www.ctlab.geo.utexas.edu/about-ct/artifacts-and-partial-volumeeffects/ for a good discussion of this phenomenon and other complications.

With an old-fashioned film-based x-ray, the result is a film negative. The more attenuated the $x$-ray beam is, the less exposure that portion of the film receives, and the lighter it appears on the resulting $\mathrm{x}$-ray. Thus, relatively dense structures are bright, while low-density structures are dark. Digital sensors generally follow this convention, producing images that are initially shades of gray, with denser (and therefore more attenuated) objects represented by lighter tones. In processing a CT scan, the computer uses the values from all the images to construct a three-dimensional matrix of attenuation values for each location in the object.

Much as a gray-scale photograph is represented digitally by two-dimensional pixels with different gray values, a CT dataset is composed of volumetric pixels or voxels. These are typically stored in an image stack, which is simply a series of gray-scale images representing successive slices through the threedimensional space. Because they are not designed to image living tissue, the CT sensors used at UTCT are more energetic and capable of far better penetration and much higher resolution than medical scanners. The NSI scanner used for this study can image specimens at a resolution as fine as $10 \mathrm{um}$, but because the pixel resolution of the sensor is fixed, the resolution of the scan is limited by the size of the object (in other words, smaller objects can be scanned at higher resolution). Due to the relatively large size of the current samples, scanning was performed at a spatial resolutions between approximately 170 and 270 ųm, or 35 to 55 voxels per linear centimeter (equivalent to 42,875 to 166,375 voxels per cubic centimeter).

CT imagery can be further processed to highlight or isolate (segment) many aspects of the data, provided that the materials being imaged exhibit sufficient contrast in their x-ray response. Depending on the software involved, the voxel volume can either be virtually re-sliced to yield successive stacked images 
along any axis; processed to accentuate or isolate value differences; and used to calculate and display feature sizes, volumes, and spatial relationships. Isolation of individual features captured in the scan is a process termed segmentation. If the contrast between features and background is strong (e.g., between the skeleton and surrounding soft tissue in a medical CT scan), it is relatively easy to segment materials of interest using response thresholds. In contrast, segmentation of more subtle, low-contrast features requires user intervention to highlight the feature slice by slice and is a relatively labor-intensive process.

Most of the analysis of CT imagery collected during this study focused on the first two samples, which were taken from the same witness profile (BHT 8) sampled for textural and chemical analysis. Sample 1 was taken from the upper part of the profile of BHT 8, from 15-23 cmbs, while Sample 2 was from directly beneath it at $45-53$ cmbs. Typical features visible in slices of these two samples are illustrated in Figures 6.22 and 6.23. The lower image in each figure represents a contrast-optimized gray-scale version of an individual image slice, while the upper images represent the same data slice with a purple-to-orange gradient LUT (lookup table) applied to it. Both images clearly show a history of long-term burrowing by insect-scale fauna, and no evidence of either larger (rodent-scale) burrowing (i.e., burrows with diameters of $5 \mathrm{~cm}$ or more) or preserved remnants of primary (depositional) bedding. There are many open or recently infilled pores ranging from less than a millimeter to more than a centimeter in size in both samples. These may represent insect burrows or root passages; however, very little root matter is recognizable in the imagery. Pore fills are generally less dense than the matrix, but there are many gradations in the density of these fills that probably reflect the age of the features, and there are so many overlapping burrow fills that intact expanses of matrix are difficult to identify. There are also several different types of burrows apparent, including simple burrows with no apparent wall modifications, burrows surrounded by matrix with a quasi-uniform increase in apparent density (which I term compression packing), and occasional burrows with organic lining. Similar features are apparent in the scan of the TU-6 balk, which is stratigraphically equivalent to the lower sample in TU 8 (Figure 6.24). The burrows with packing may represent either insect activity or root channels (or both); insect activity can result in packing/smoothing of tunnel walls (Genise 2017), and expansive growth of plant roots will necessarily displace and compress surrounding matrix. 


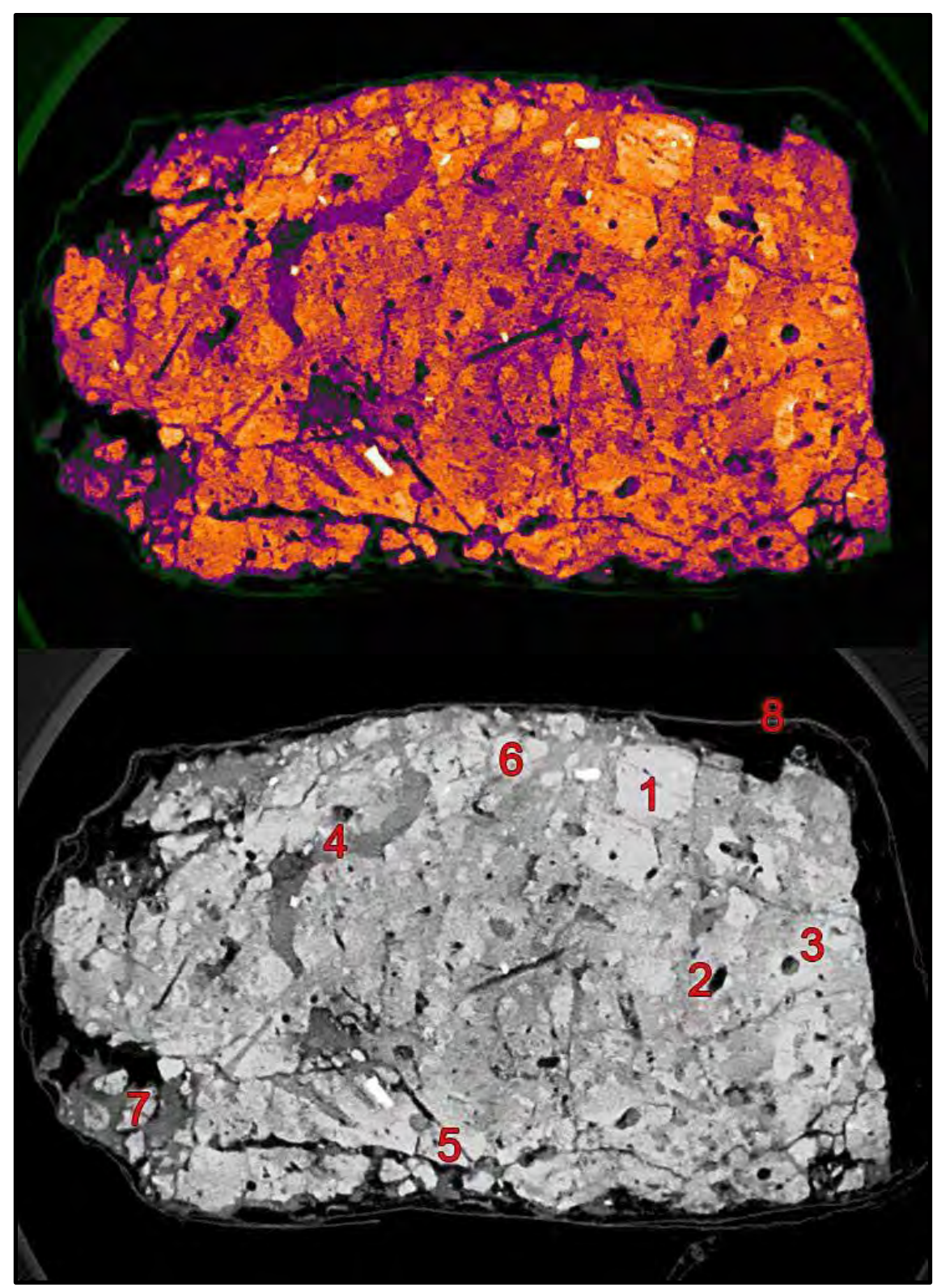

Figure 6.22. Representative cross section slice of upper $(15-23 \mathrm{~cm})$ block from BHT 8 in normal view and with orange-purple LUT gradient applied.

Figure shows examples of typical features (Images prepared in ImageJ):

1) angular fragments of dense sediment, presumably broken by root plowing, embedded in lower density matrix;

2) open channel in 2-3 $\mathrm{mm}$ range; minimal packing or wall modification apparent;

3) partially open channel in $2-3 \mathrm{~mm}$ range, significant wall compression extending several $\mathrm{mm}$ into matrix;

4) elongate channel in 3-5 $\mathrm{mm}$ range, mostly backfilled with low density sediment;

5) fractured dense sediment with no infilling matrix, probably resulting from removal of sediment block;

6) multiple small fractured clasts of relatively dense matrix embedded in lower density matrix, presumably attributable to root plowing;

7) fractured dense sediment with very low density infilling matrix, probably resulting from

removal of sediment block; and

8) aluminum foil wrap. 


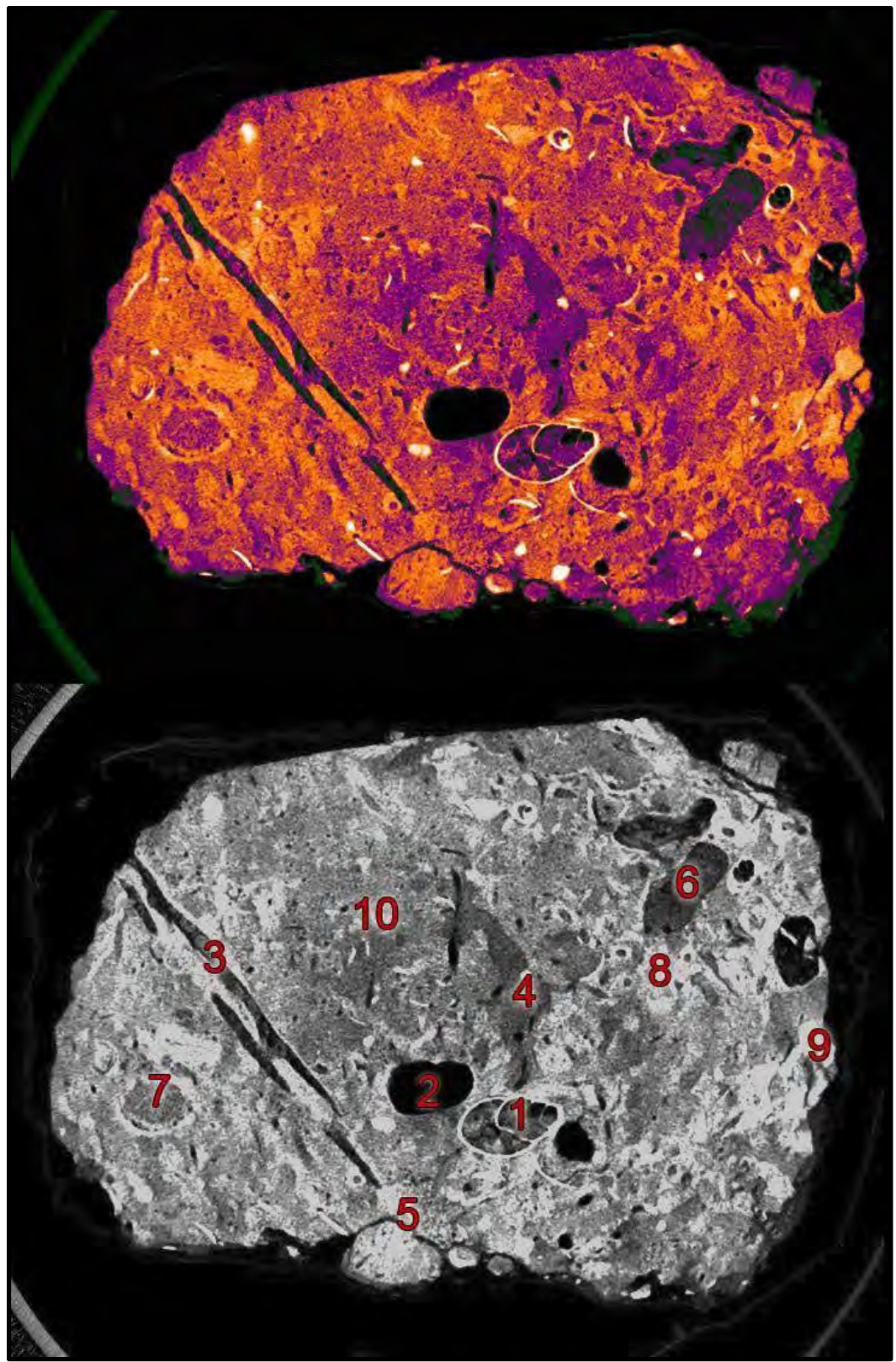

Figure 6.23. Representative cross section slice of lower $(45-53 \mathrm{~cm})$ block from BHT 8 in normal view and with orange-purple LUT gradient applied.

Figure shows examples of typical features (Images prepared in ImageJ):

1) partially infilled Rabdotus sp. Snail shell;

2) open pore in $10-15 \mathrm{~mm}$ size range, showing minimal packing;

3) two parallel burrows, probably produced by termites, showing 1-2 mm of wall packing;

4) network of large burrow galleries infilled with low density sediment;

5) fracture presumably attributable to sample recovery;

6) network of large burrow/galleries with very low density matrix infill;

7) old burrow/gallery with thin packing and organic lining, infilled with relatively dense matrix;

8) network of small $(0.5-2 \mathrm{~mm})$ burrows with $1-2 \mathrm{~mm}$ of compression packing [beneath and to left of number];

9) marginal fractures probably attributable to sample collection; and

10) area showing relatively low-density matrix with many fine pores and variable degrees of wall packing. 

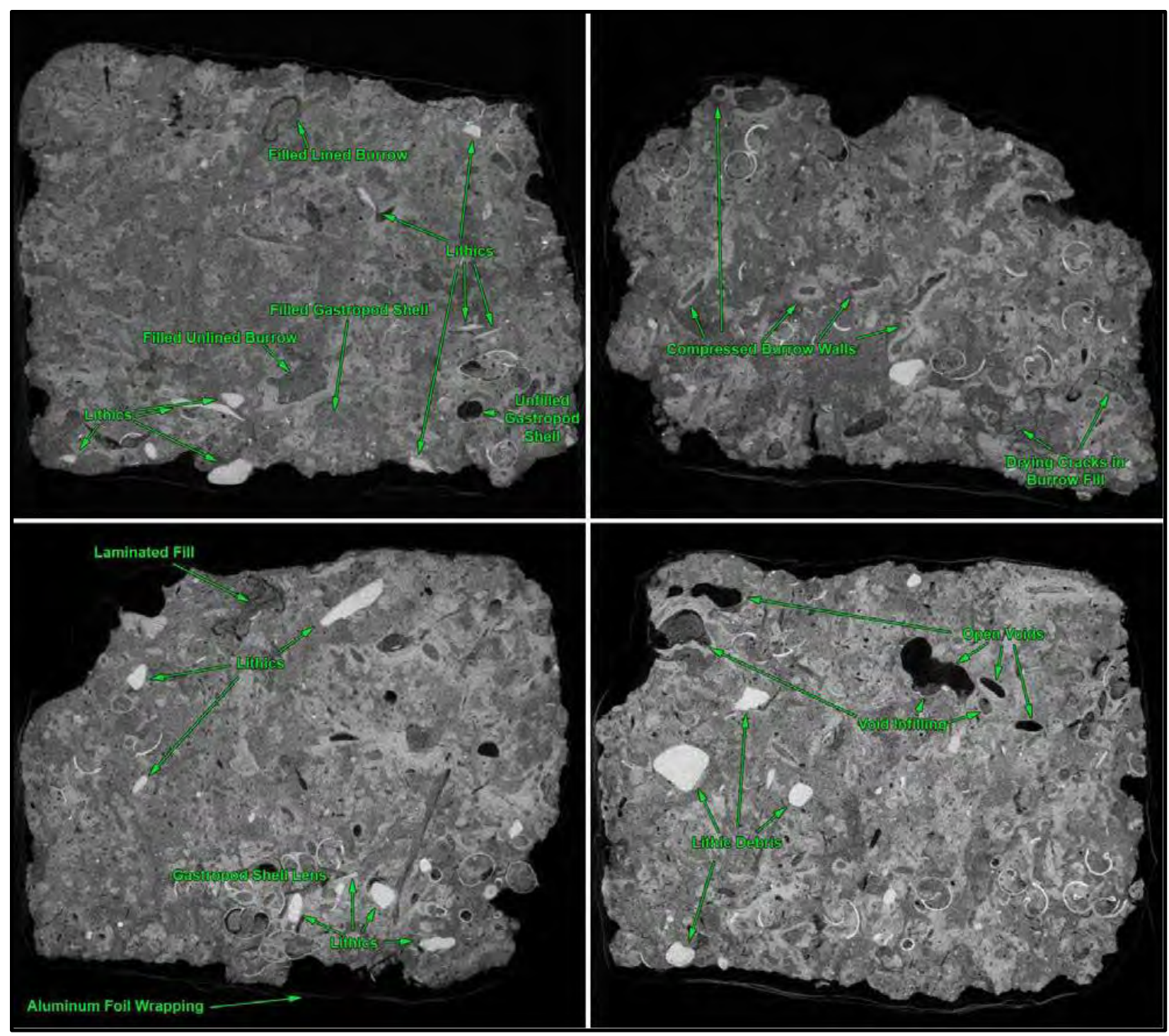

Figure 6.24. Annotated X-ray sections through the TU-6 block, prepared in ImageJ and annotated in Photoshop.

Visually, the principal distinction between the upper and lower samples is that the upper sample exhibits a number of linear/angular fractures and encased angular clasts, while the lower sample exhibit larger $(>0.5$ $\mathrm{mm}$ ) pores and seems to lack the angular clasts entirely. These angular clasts are interpreted as the result of root plowing damage in the upper profile. The same may be true of the absence of large pores, but it is more likely that this reflects behavioral differences, with the relatively large pores representing galleries (rooms) and brooding chambers that are concentrated in the deeper parts of the profile. 3D modelling of the voids and low-density fills in the "upper" sample (Figure 6.25) suggests that these large voids are chambers and galleries rather than continuous burrows; although no comparable model was prepared from the "lower" sample for reasons of time (Aviso Lite is only available to us at UTCT), I was able to confirm that impression using sequential slice animations made in ImageJ. Figure 6.26 illustrates the distribution of the densest material in the TU 6 balk sample, and illustrates how specific features (in this case, fragments of lithic debitage) can be individually segmented out and highlighted. Note that this sample, which was collected to provide a sample of the densest cultural zone, shows only dispersed cultural material rather than a well-defined paleosurface. 


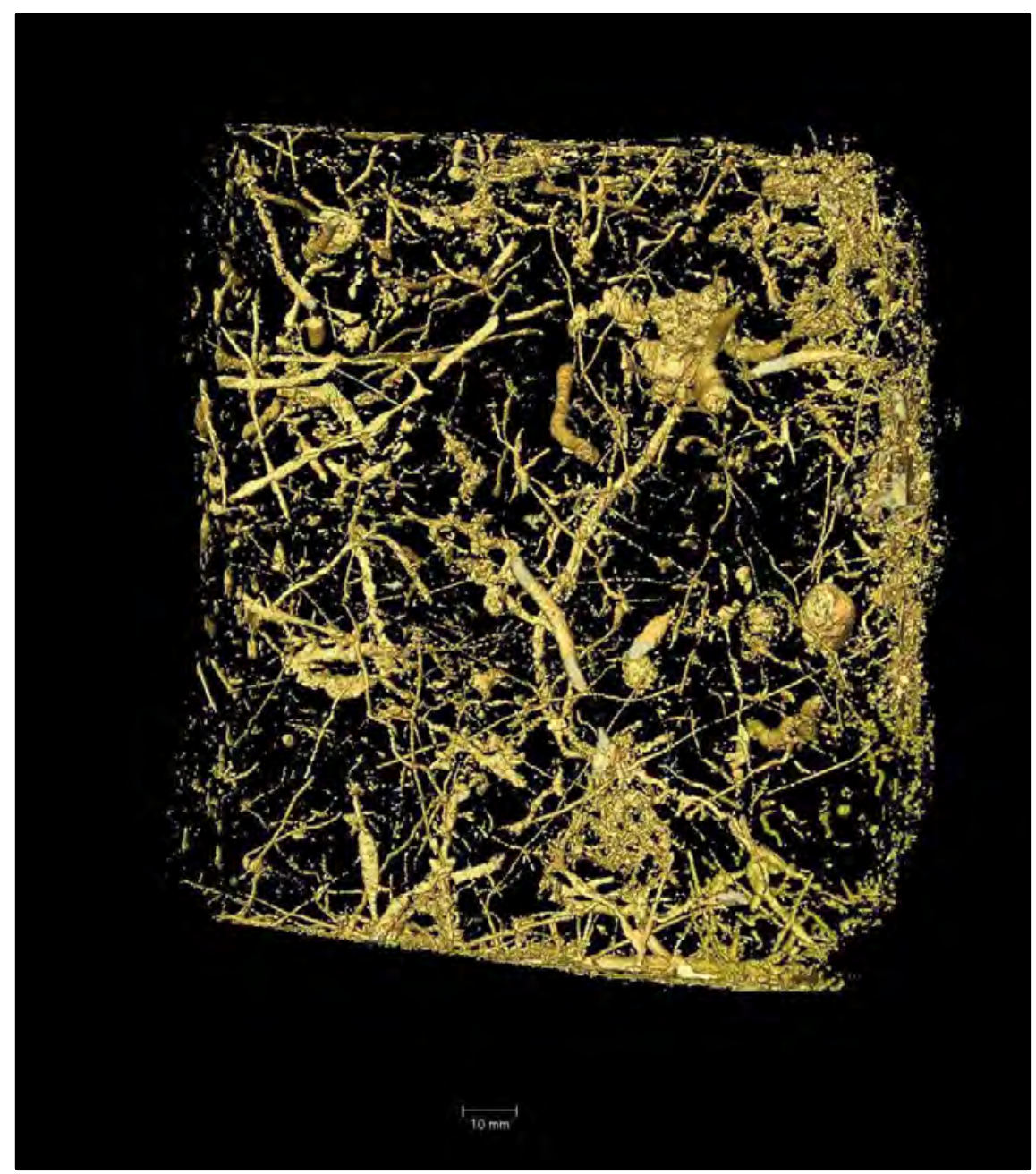

Figure 6.25. Aviso Lite rendering of very low-density segment (voids and very low density fills), showing the frequency and scale of internal voids in the "upper" sample. The image shows a 1-cm vertical slice through the block, which was necessary as the same view of the entire 15-cm-thick block is too densely packed to see through. Note that most voids are relatively continuous. 


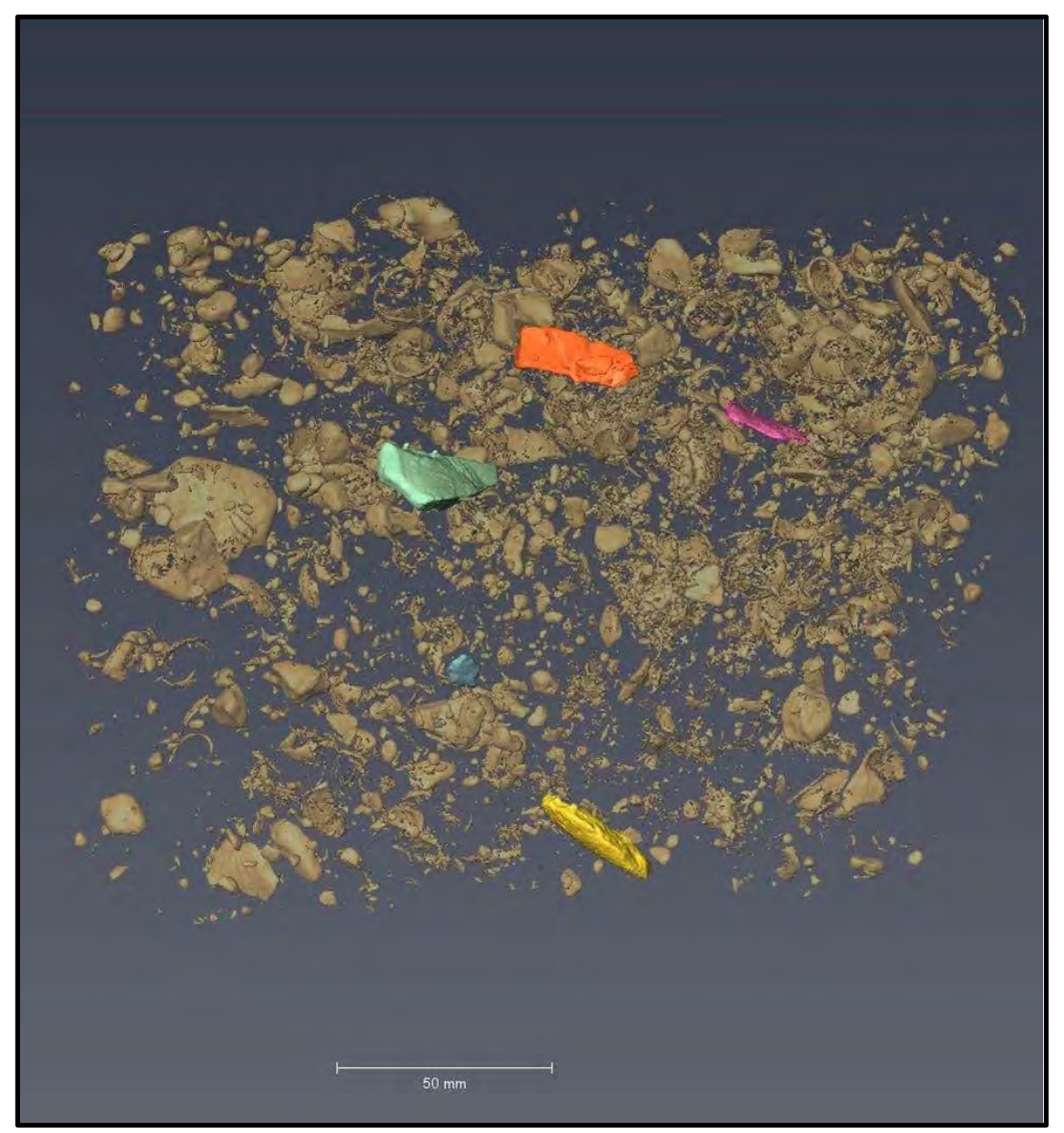

Figure 6.26. Aviso Lite rendering of the densest material in the TU6 block, which consists of pebbles and granules, abundant whole and crushed snail shells, lithic debitage, and probable fragments of burned sandstone. A few of the pieces of lithic debitage have been manually segmented to highlight them, but this process is incomplete.

To quantify the character of the soil, Aviso Lite was used to segment one of the block images into four segments - an "exterior" segment encompassing the airspace and wrapping (foil and tape), a very low density segment representing primarily interior void space, and "low density" and "high density" segments. I first defined the exterior using manual segmentation, and then segmented the interior space by shifting the 16-bit gray-scale thresholds and observing the results until the division matched my intuitive sense of the most natural division. The process was then repeated with the other sample, except that segmentation of the interior space was performed by using the same numerical boundaries used in the first sample. For this reason, the threshold between the interior boundaries, and particularly between the "low density" and "high density" segments, is completely arbitrary and does not represent any directly observable break point, but because the same thresholds were used, it does allow for direct comparison of the volume occupied by each of these segments in the two samples (Table 6.4). This analysis demonstrated that the upper sample had less than half the void space present in the lower sample, and a much higher ratio of high-density to low-density sediment. Although some of this difference may represent the nature of burrowing behavior at different depths (that is, the characteristic depths at which access tunnels transition into warrens of chambers used for living, storing food, raising young, etc.), some of the difference probably reflects compression and loss of pore space during the root plow process. 
However, it is worth noting that the nature of root plowing will not necessarily cause such disruption (see above), and most of the void spaces scanned from the "upper" sample do not appear highly disrupted (see Figure 6.25). At the same time, the base of the root plow is not particularly evident, suggesting that much of the visible turbation (and open passages) may date to the last few decades.

To further explore the issue, I selected four representative cross sections from each sample for analysis of the pore structure. For comparability, I fit a $300 \times 300$ pixel window to each of these cross sections so that the entire field (or as much as possible) was occupied by matrix and internal pores. I then adjusted the threshold value in ImageJ until the binary image isolated the open pores as effectively as possible without including too much obvious matrix. This was sometimes very difficult, and a few of the samples include "pores" that are simply areas of very low density fill within a larger infilling feature. When the best approximation of open pore space was isolated, I then filled the pores so that interior fill fragments in large pores were minimized. I then used ImageJ to index the resulting images, count each pore, a number of "pores" appear to actually represent very low-density fill, particularly inside snail shells Image 773134 261.308 1.956 .609 the one large pore is actually a section of the block exterior and calculate its area. Figures 6.27 and 6.28 show the character of pore analysis, and Table 6.5 shows statistical summaries of the data. The discrimination provided by this method is far from perfect, but the results are clearly in line with the Aviso-based analysis described previously. Pores in the upper sample are no less numerous than in the lower sample, but they are far smaller in size, and the overall area occupied by pores is markedly reduced.

It is unclear to which degree this relates to differences in the insect taxa represented versus to the behavior of the same suite of insects at different depths in the profile. However, thin section analysis by Frederick (Appendix B) clearly indicates the presence of burrows with a variety of different morphologies, not only in form, but in the character and thickness of wall treatments and infillings. This alone implies that a number of different taxa are involved. Like the CT scans, it also shows evidence of many generations of overprinted burrows and of substantial disruption of the upper sample, presumably by plowing.

Unfortunately, there is no real basis for judging the time depth represented by these features. It is tempting to view them as the result of insect activity over the last three or four millennia, but the likelihood is actually that all visible burrow remnants represent a much shorter time depth. One indication of this is the absence of a recognizable cut associated with root plowing of the site, which Mr. Alvarez assured us occurred 20 to 30 years ago. This suggests that burrowing activity is intense enough to blur this contact in a very short span of time and raises significant questions about how long burrow features can persist before they are overprinted and destroyed. Of course, this also implies that evidence of other types of formation processes such as sheetwash deposition and rodent burrowing might have also be destroyed by insect overprinting. While there is clear evidence of water-lain deposits in the form of gravel lenses on some parts of the site, I have previously argued that this mechanism is unlikely to have buried Feature 1 without disrupting it. Unfortunately, given the unknown rate of turbation activity, it is not possible to use the absence of depositional strata to either support or contradict that argument.

In summary, I believe that insect and annelid surface casting is the most likely explanation for burial and preservation of Feature 1 at 41SR242. It may be responsible for the preservation of some other material clusters, but the only CT scan that addressed a comparable stratigraphic zone revealed deposits that contain dispersed artifacts, not an assemblage resting on a paleosurface, as Feature 1 appeared to be. I suspect that the density of the flake and snail shell cluster in Feature 1 contributed to its preservation by inhibiting insect passage. While thin section and CT analysis demonstrate that the deposits are consistent with such an explanation, they do not demonstrate it. Rather, the cumulative evidence suggests that several processes are in play. In particular, the fact that there are prehistoric artifacts littering the surface demonstrates that insect casting cannot be the only process operating, because all artifacts would be buried if that were the case. 

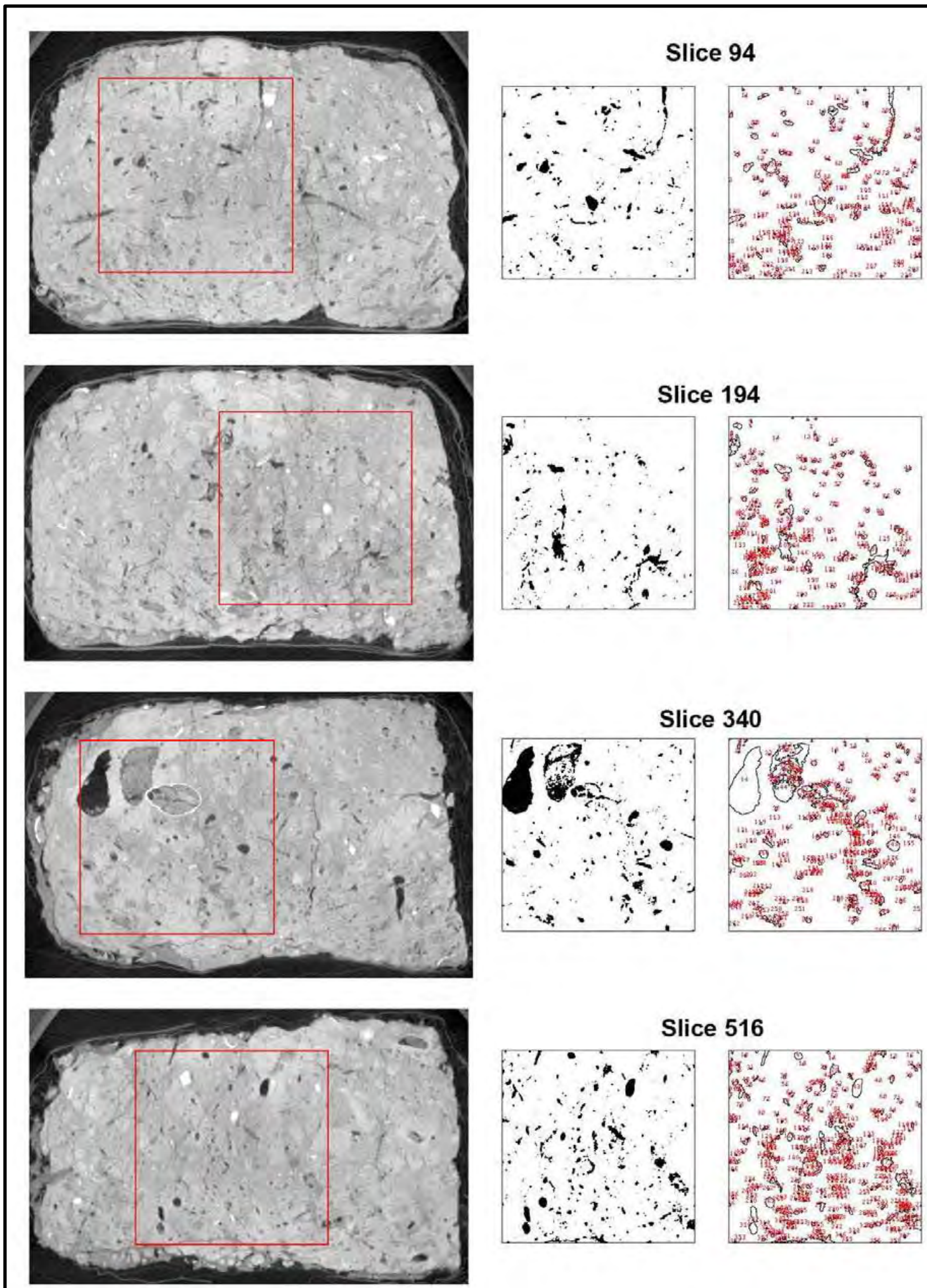

Figure 6.27. Pore analysis of upper block slices. 


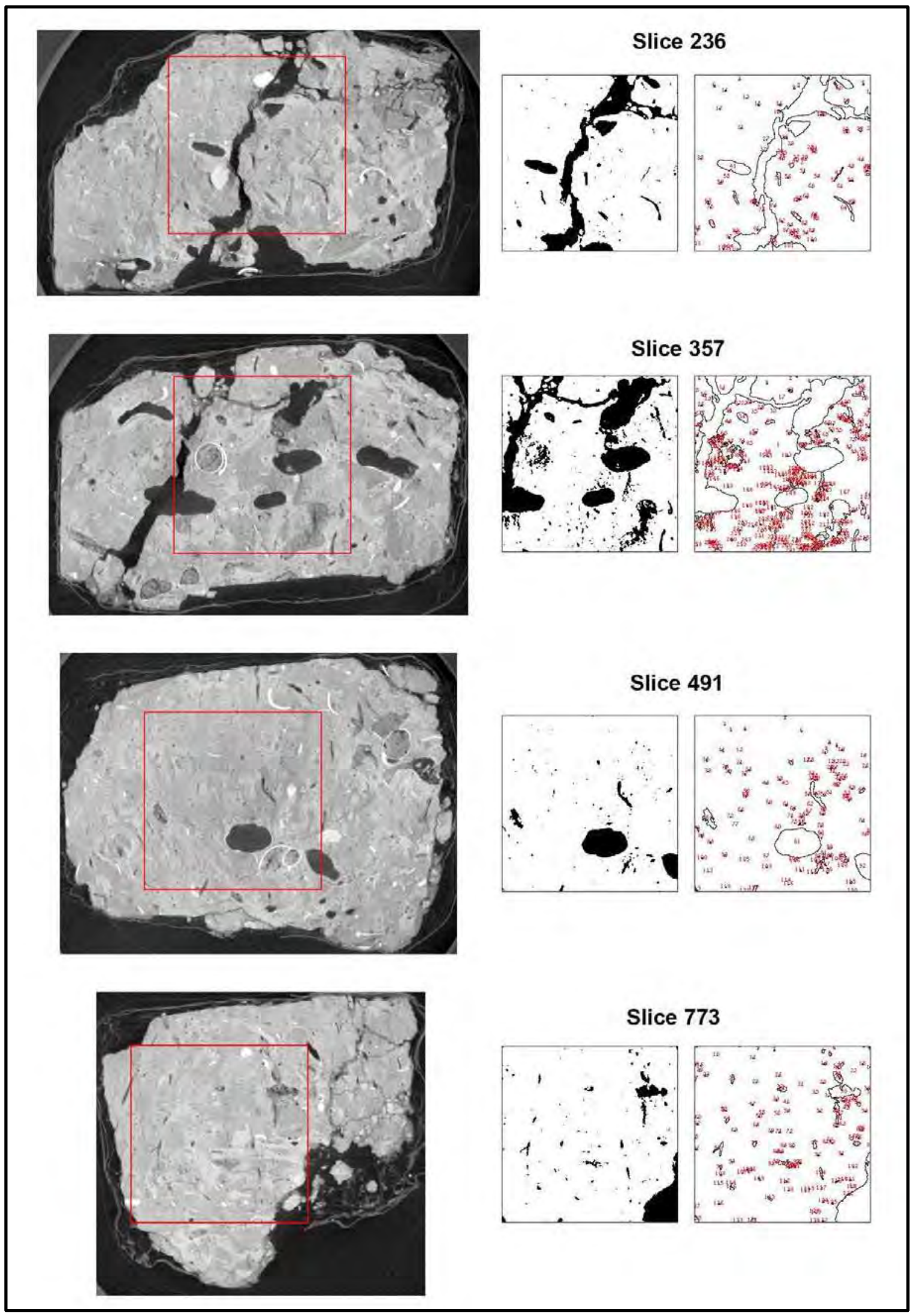

Figure 6.28. Pore analysis of lower block slices. 
Table 6.4. Comparison of the Relative Frequency of Void Space, Low-density Sediment, and Highdensity Fill (including sediment, rock, and shell) in the "Upper" and "Lower" Block CT Scans

\begin{tabular}{lccc}
\hline Segment & Voxel Count & Volume (cubic mm) & Relative Percentage \\
\hline Upper (15-23 cmbs) Block CT Scan & & & (EXCLUDED) \\
\hline Exterior Voxels & 116268265 & 1070619.98 & $29.20 \%$ \\
\hline Low Density Voxels & 52401968 & 482527.145 & $2.00 \%$ \\
\hline Internal Voids and Very Low Density Voxels & 3668530 & 33780.512 & $68.80 \%$ \\
\hline High Density Voxels & 123658613 & 1138671.69 & $($ EXCLUDED) \\
\hline Lower (45-53 cmbs) Block CT Scan & & & $35.00 \%$ \\
\hline Exterior Voxels & 212269731 & 1954617.89 & $4.50 \%$ \\
\hline Low Density Voxels & 63393104 & 583735.113 & $60.60 \%$ \\
\hline Internal Voids and Very Low Density Voxels & 8086173 & 74458.9366 & 1010861.77 \\
\hline High Density Voxels & 109778672 & & \\
\hline
\end{tabular}

Table 6.5. Results of Pore Analysis

\begin{tabular}{|c|c|c|c|c|c|}
\hline $\begin{array}{l}\text { Image } \\
\text { (Slice) } \\
\text { Number }\end{array}$ & $\begin{array}{l}\text { Pore } \\
\text { Count }\end{array}$ & $\begin{array}{l}\text { Total Area } \\
\left(\mathbf{m m}^{2}\right)\end{array}$ & $\begin{array}{c}\text { Average } \\
\text { Area }\left(\mathrm{mm}^{2}\right)\end{array}$ & $\begin{array}{c}\text { Percentage } \\
\text { of Total } \\
\text { Area }\end{array}$ & Comments \\
\hline Image 94 & 224 & 177.345 & 0.792 & 4.511 & - \\
\hline Image 194 & 227 & 179.99 & 0.793 & 4.552 & - \\
\hline Image 340 & 266 & 409.052 & 1.538 & 10.346 & $\begin{array}{l}\text { Many areas registering as small pores are actually } \\
\text { gaps in the low-density fill of a few large pores }\end{array}$ \\
\hline Image 516 & 358 & 282.396 & 0.789 & 7.142 & - \\
\hline \multicolumn{6}{|c|}{ Lower Block (45-53 cmbs) } \\
\hline Image 236 & 106 & 553.282 & 5.22 & 13.993 & $\begin{array}{l}\text { One large pore is actually a section of the Block } \\
\text { exterior }\end{array}$ \\
\hline Image 357 & 284 & 999.764 & 3.52 & 25.286 & $\begin{array}{l}\text { A number of "pores" appear to actually represent } \\
\text { very low density fill, particularly inside snail shells }\end{array}$ \\
\hline Image 491 & 121 & 238.42 & 1.97 & 6.03 & $\begin{array}{l}\text { A number of "pores" appear to actually represent } \\
\text { very low density fill, particularly inside snail shells }\end{array}$ \\
\hline Image 773 & 134 & 261.308 & 1.95 & 6.609 & $\begin{array}{l}\text { The one large pore is actually a section of the } \\
\text { block exterior }\end{array}$ \\
\hline
\end{tabular}




\section{CONCLUSIONS}

The following geoarcheological conclusions are possible regarding the Cornelio Alvarez Sr. site (41SR242):

- The site consists of lithic tools and debris, burned sandstone, limited bone and shell, and some historic artifacts. These artifacts are strewn across the surface and buried in the profile of a location on the convex footslope of a low-gradient upland adjacent to a low-order tributary of the Rio Grande River.

- Buried cultural material is present throughout the profile, but dense clusters that appear to represent cultural activity loci are present at depths of approximately $40-65 \mathrm{~cm}$. Preliminary minimum analytic nodule (MAN) analysis of the lithic debris in Feature 1 suggests that the feature includes multiple biface thinning flakes from about a dozen analytic nodules. Given the diversity of the Rio Grande gravels, this supports the notion that the Feature 1 assemblage reflects a discrete behavioral event. However, the same cannot be said of the site as a whole. Bayesian analysis of radiocarbon ages from the site (see Figure 6.19) suggests that it spans at least 1,000 years, and possibly much longer.

- The site matrix is dominated by loams, but also includes sandy loams, silt loams, clay loams, and loamy gravel. The soil profile exhibits a pronounced and distinctive biogenic structure that gives a cut, brushed face a fine "knobby" appearance. This structure is present throughout the soil column, but most pronounced in a 30-50-cm-thick zone immediately above the transition to bedrock (BC and Cr horizon).

- Micromorphological and CT analyses document that this structure represents the cumulative result of intense turbation by insect-scale organisms (e.g., arthropods and earthworms). Because the diameter of intact burrows vary from less than a millimeter to more than a centimeter in maximum dimension, it is clear that several different faunal taxa are represented, and it is believed to represent the activity of a variety of insects and annelids such as termites, ants, ground wasps, earthworms, and various grubs (e.g., June bugs).

- There is also evidence of shallow, gravelly channels that represent ephemeral drainages flowing off higher portions of the landscape. However, that evidence consists of interbedded lenticular gravels representing shallow channels; there is no remnant bedding preserved in the fine-grained sediment. Given that these channel deposits are located only a few hundred meters downslope of the drainage divide, they are believed to represent very rare mobilization of upland gravels during very intense rain events generated by landfall of tropical storms.

- There is meager evidence of burrowing by rodents or other larger taxa capable of displacing and exhuming artifacts large enough to be caught in a $1 / 4$-inch screen mesh, but a few possible rodent krotovina were noted. It is possible that additional rodent-scale krotovina have been destroyed by subsequent insect/annelid burrowing.

- The absence of a clear-cut line at the depth of root plowing done only a few decades ago (per the landowner) suggests that reworking of the fine matrix is quite rapid. The poor understanding of the rates involved in this process limit interpretation, but because only a limited amount of sediment affected by a given burrow is actually exhumed, it is likely that the rate of subsurface mixing far exceeds that of surface casting.

- Surface casting by insects and annelids is proposed as the most likely mechanism of burial of Feature 1. Deposition from sheet flow may have also played a role, but is unlikely to have buried the feature at the depth and condition in which it was found. Although some limited silt may have been introduced and removed by wind, eolian deposition does not appear to have been an appreciable factor in a volumetric sense. Insect-exhumed sediment was certainly redistributed on 
the surface by rainsplash, sheetflow, and probably wind. Micromorphological and CT data are consistent with such an explanation, but because the rates of insect disturbance and surface casting are so poorly understood, it does not demonstrate causality.

- The presence of artifacts of different ages at the surface (Figure 6.29) and lenses of gravel in the subsurface demonstrate that processes besides insect casting are also active, and it is likely that insect turbation is merely masking evidence of the importance of these other processes to site formation at 41SR242.

- There is no evidence of a buried paleosurface per se in this upland setting. Although Feature 1 appears largely intact based on examination of the debitage (see Chapter 7), most material appears to be distributed through the profile, particularly the B horizon of the soil, and radiocarbon data suggests that the material accumulated over a timespan of at least a thousand years. Accordingly, overall archeological integrity is considered relatively poor.

- Finally, regarding the methodology, we believe that the combination of traditional textural and chemical analysis, thin section analysis, and CT analysis provides for the potential to gain unprecedented insights into many pedological questions in a wide range of environments.

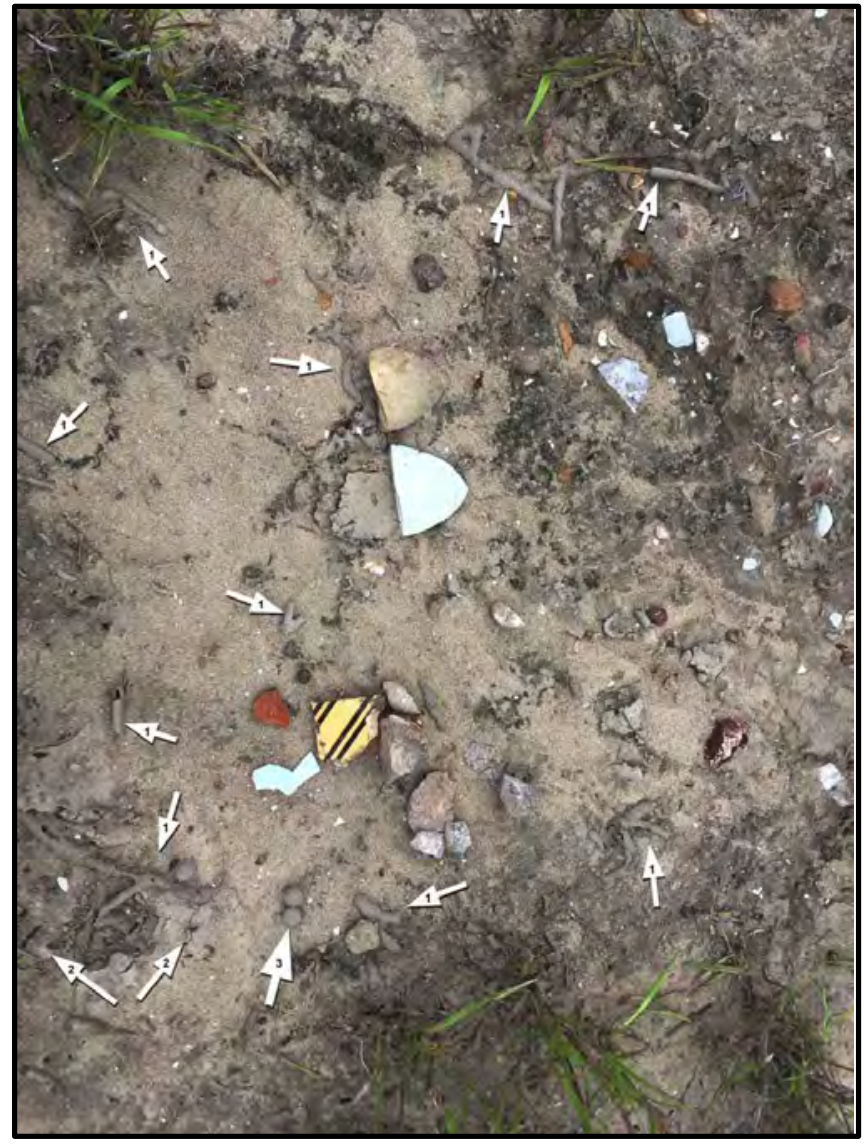

Figure 6.29. Detail of prehistoric and historic materials near BHT 2 (note that most materials are not in the position where they were found). Although the photograph was taken to illustrate the artifacts, it is also instructive because it documents the presence of remnant termite tubes (1) open burrows (2) and possible dung beetle balls (3). 


\section{CHAPTER 7. FEATURES, ARTIFACTS, AND ECOFACTS}

The investigations at 41SR242 identified a dense cluster of cultural materials in surficial and buried contexts. The assemblage is the remains of intermittent prehistoric occupations on a gradually sloping upland margin, an ecotonal juncture between valley and upland settings. This chapter presents basic descriptive data of the features, artifacts, and ecofacts that were investigated or recovered during TxDOT's significance testing excavations on 41SR242. The materials are arranged by basic descriptive categories, and a few low-level interpretations are provided in this chapter, mainly regarding function and formation processes. Subsequently, Chapter 8 ties the findings into broader patterns.

\section{FEATURES}

A total of four prehistoric features were exposed through trench scraping and recovered or sampled through the hand excavation of TUs (Table 7.1). All four features were prehistoric and included a dense debitage concentration, two small clusters/concentrations of thermally altered rock, and an area of densely concentrated Rabdotus with burned rock and debitage.

Table 7.1. Site 41SR242 Features

\begin{tabular}{|c|c|c|c|c|c|}
\hline $\begin{array}{l}\text { Feature } \\
\text { No. }\end{array}$ & Type & Provenience & Corrected Age (B.P.) & Dated Material & $\begin{array}{l}\text { Associated } \\
\text { Diagnostic Artifacts } \\
\text { (Lot-Specimen No.) }\end{array}$ \\
\hline 1 & $\begin{array}{l}\text { Dense concentration of } \\
\text { lithic debitage and land } \\
\text { snails (Rabdotus) }\end{array}$ & $\begin{array}{l}\text { BHT 1, TU 1, } \\
\text { and TU } 3\end{array}$ & $\begin{array}{l}6200 \text { (Beta 456114); } \\
5010 \text { (Beta 456115); } \\
4640 \text { (Beta 456116); } \\
5130 \text { (Beta 456117); } \\
2250 \text { (Beta 468116); } \\
2450 \text { (Beta 468120); } \\
3260 \text { (Beta 468117); } \\
2420 \text { (Beta 468115) }\end{array}$ & $\begin{array}{l}\text { Rabdotus spp. } \\
\text { snail shell; } \\
\text { Prosopis sp. } \\
\text { (carbonized); } \\
\text { Condalia sp. } \\
\text { (carbonized) }\end{array}$ & $\begin{array}{l}\text { Unidentified Dart Point } \\
\text { Base (175-065) }\end{array}$ \\
\hline 2 & $\begin{array}{l}\text { Small cluster of burned } \\
\text { rock }\end{array}$ & TU 2 & None & & $\begin{array}{l}\text { Prehistoric Ceramic } \\
\text { Plain Body Sherd } \\
(170-006)\end{array}$ \\
\hline 3 & $\begin{array}{l}\text { Scatter of burned rock } \\
\text { likely representing a } \\
\text { displaced hearth }\end{array}$ & TU 4 and TU 5 & $\begin{array}{l}3020 \text { (Beta 468121); } \\
2160 \text { (Beta 468118); } \\
3260 \text { (Beta 468119) }\end{array}$ & $\begin{array}{l}\text { Acacia sp. } \\
\text { (carbonized); } \\
\text { Prosopis sp. } \\
\text { (carbonized) }\end{array}$ & None \\
\hline 4 & $\begin{array}{l}\text { Dense concentration of } \\
\text { lithic debitage and land } \\
\text { snails (Rabdotus), and } \\
\text { burned rock }\end{array}$ & $\begin{array}{l}\text { BHT 15, TU 6, } \\
\text { and TU } 7\end{array}$ & None & None & $\begin{array}{l}\text { Tortugas Dart Point } \\
\text { Preform (196-001); } \\
\text { Unidentified Dart Point } \\
\text { Base (199-159); } \\
\text { Fresno Arrow Point } \\
\text { (200-001) }\end{array}$ \\
\hline
\end{tabular}

\section{Feature 1}

Feature 1 was discovered during the excavation of BHT 1. It was encountered during trowel scraping of the trench walls and floor of BHT 1. The feature consisted of a dense concentration of lithic debitage and snails (Rabdotus) at a depth of approximately $50-60 \mathrm{cmbs}$ in a relatively small area measuring approximately $50 \times 50 \mathrm{~cm}$. TU 1 was later expanded off the trench to recover any remaining portion of the debitage cluster. Based on the quantity of debitage recovered, adjacent TU 3 was opened. The Feature 1 cluster may also extend into TUs 4 and 5 . No diagnostic artifacts were recovered in association with the feature. 
During field investigations, the excavators observed flakes lying predominantly flat and often resting directly on top of each other in a distinct pile. The dense pocket of flakes occurred with intact snail shells that appeared likely to retain considerable integrity in a buried context. As discussed in Chapter 6, burial processes of the feature likely included insect turbation with lesser inputs by other processes such as deposition from sheet flow. Micromorphological and CT analyses document a soil structure that is the result of cumulative activity of intense turbation by insect-scale organisms (e.g., arthropods and earthworms).

A total of 1,069 pieces of debitage were recovered from TU 1 and 519 pieces of debitage were recovered from TU 3. Total debitage counts in TUs 4 and 5 are 306 and 403, respectively. The analysis focused on whether all this closely spaced debitage is the result of a single knapping event, secondary dump, or an overprinted palimpsest of multiple overlapping reduction events, as well as the geoarcheological assessment (e.g., formation processes).

After the initial trenching at 41SR242, four Rabdotus shells were submitted to Beta Analytic for radiocarbon analysis to get a broad idea of the age and integrity of the assemblage despite known issues with incorporation of dead carbon from limestone and soil carbonate (Goodfriend 1992; Goodfriend et al. 1999). Corrected ages on the shell ranged from $6200 \pm 30$ yrs BP to $4640 \pm 30$ yrs BP (Appendix C). During test excavations, three wood charcoal samples were recovered from TUs 1 and 3 (see Appendix C). The samples were identified by Dr. J. Kevin Hanselka as mesquite ( $n=3)$ and snakewood $(\mathrm{n}=1)$ and submitted to Beta Analytic for radiocarbon dating. The corrected ages ranged from $3260+/ 30$ yrs BP to $2250 \pm 30$ yrs BP (see Appendix C; see also Chapter 6 discussion of radiocarbon dating).

Based on the analytic nodule analysis, the dense accumulation of debitage in a relatively discrete stratum, and the disposition of the flakes (stacked, lying flat), the feature is inferred to be a relatively intact behavioral event, a lithic reduction area or dump. Radiocarbon dating suggests the sediments in which Feature 1 was found likely accumulated over a millennium or more. Buried cultural material is present throughout the profile, but dense clusters that appear to represent cultural activity loci are present at depths of approximately 40 to 65 cmbs. Minimum analytical nodule analysis (MANA) (discussed below) identified biface thinning flakes from about a dozen analytic nodules. Although the Feature 1 assemblage is inferred to be a discrete behavioral event, isolable activity areas are uncommon on the site. Radiocarbon ages and temporal diagnostic data from the site suggests intermittent occupations over millennia.

\section{Feature 2}

Feature 2 consists of a small cluster of burned rock encountered during the excavation of BHT 4. Observed in profile, TU 2 was placed in a position to fully recover the cluster. Found relatively high in the profile at the contact with the Ap horizon, the first level began at approximately $20 \mathrm{cmbs}$. The feature consisted of a main cluster of approximately 13 large rocks consisting of angular sandstone fragments and stream-rolled cobbles weighing approximately 2.9 kilograms (Figure 7.1).

An additional 31 smaller pieces of burned rock weighing a total of $0.4 \mathrm{~kg}$ was recovered along with one biface, a modified flake, one small prehistoric ceramic sherd, and 165 pieces of debitage. Except for the sherd, no other diagnostic artifacts were associated with the feature and no carbon was recovered from the feature during the excavations. A soil sample was collected from the matrix removed from the main cluster, but additional analysis including flotation yielded no carbonized botanical remains for identification and radiocarbon dating. 


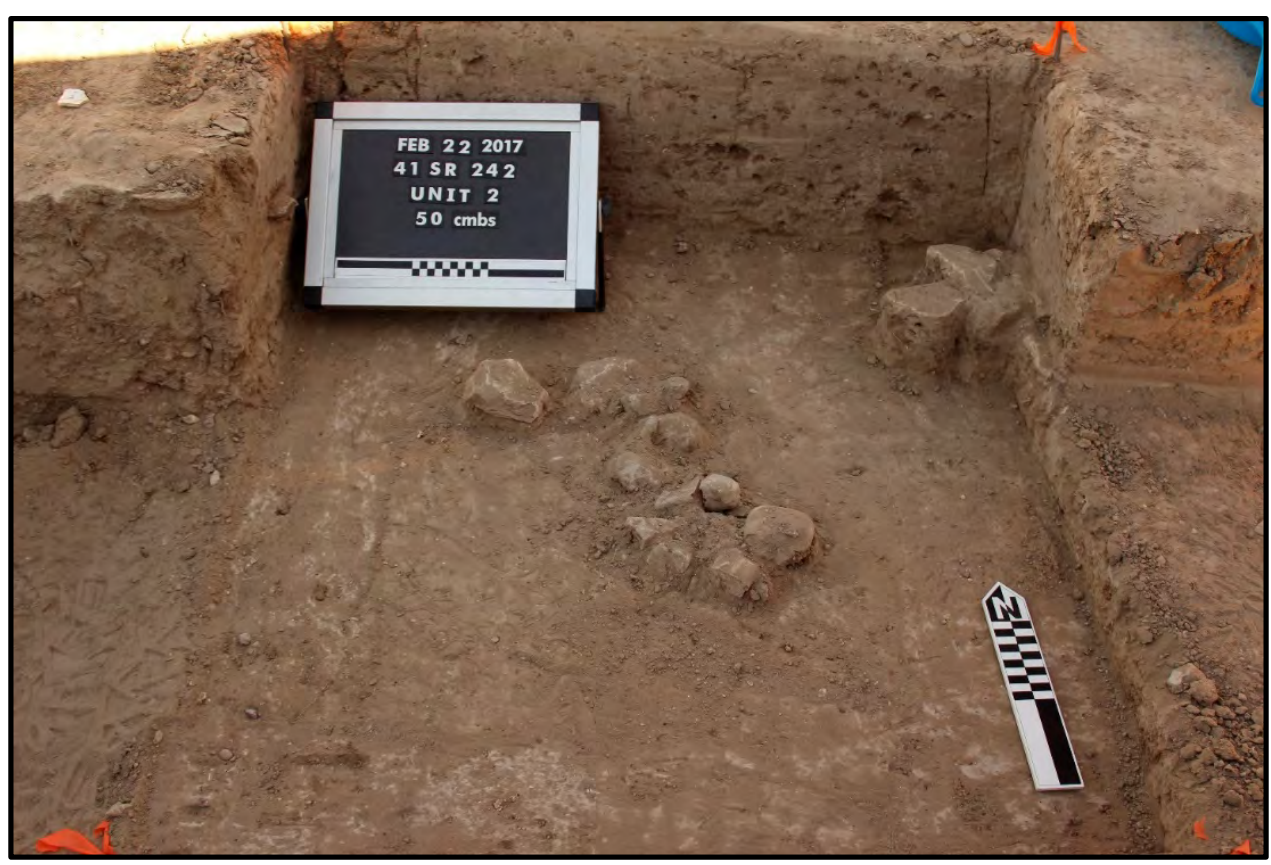

Figure 7.1. Feature 2 in planview, facing north.

Six fragments of freshwater mussel shell were also recovered but are likely portions of the same specimen that was damaged during excavation. Four historic items consisting of two small ceramic sherds and two small pieces of thin oxidized metal were recovered from TU 2. Given the prior land-use impacts at the site (root plowing), the presence of a few historic artifacts is expected in and near the Ap zone contact.

\section{Feature 3}

Feature 3 was encountered during the expansion of the BHT 1 excavation area into a $2 \times 2-m$ unit (Figure 7.2). The feature consists of a scatter of burned rock likely representing a displaced hearth. Feature 3 consisted of a scatter of highly fragmented and mostly small $(<5 \mathrm{~cm})$ burned rock across TUs 4 and 5 (see Figure 7.2). The feature yielded 190 burned rocks, mostly small fragments but including some larger pieces including angular sandstone fragments and stream-rolled cobbles weighing approximately $5.2 \mathrm{~kg}$.

TUs 4 and 5 also yielded 709 pieces of debitage (306 and 403, respectively). As mentioned in the Feature 1 discussion, given the proximity of TU 4 to the adjacent debitage cluster, there may be overlap and association.

Within the scatter, four wood charcoal samples were recovered from TU 5. The samples were identified by Dr. J. Kevin Hanselka as mesquite $(n=2)$ and acacia $(n=1)$. The samples were submitted for radiocarbon dating range from $3260 \pm 30$ yrs BP to $2160 \pm 30$ yrs BP (see Chapter 6 for discussion of radiocarbon dates). 


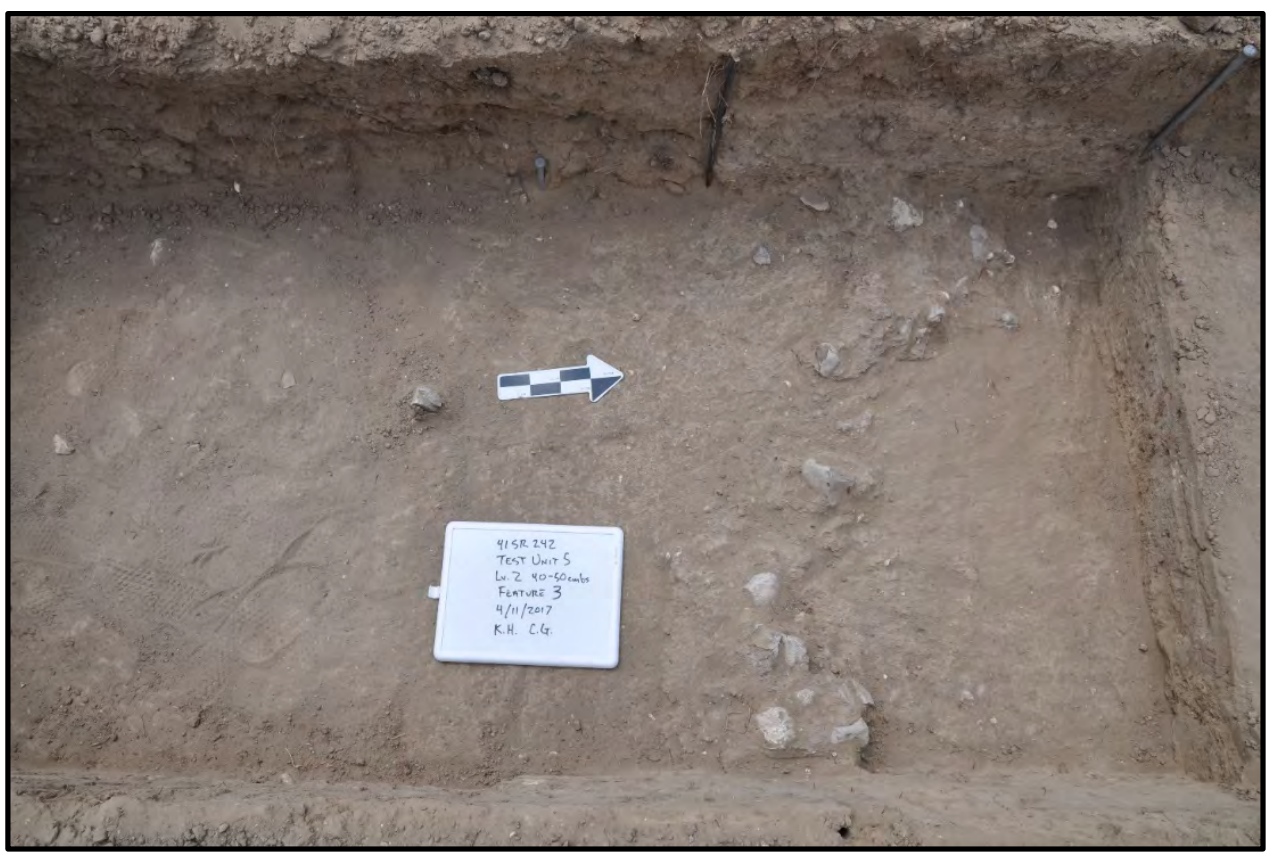

Figure 7.2. Feature 3 in planview, facing west

\section{Feature 4}

Feature 4 was discovered during the excavation of BHT 15 and consists of a dense concentration of Rabdotus, debitage, and burned rock (Figures 7.3, 7.4, and 7.5). TUs 6 and 7 were placed to recover the extent of Feature 4 as exposed in BHT 15. Like Feature 2, it was encountered just below the contact with the Ap horizon, the first level beginning at approximately $20 \mathrm{cmbs}$. The most curious aspect of the feature is the unusual density of Rabdotus snail shells, 2,769 complete shells and an unquantified number of fragmentary shells. Inspection of the shell showed no clear evidence of modification, but consumption of snail may not have left any indicators. Although there is some uncertainty as to whether the shell was naturally occurring or culturally introduced, the intensive clustering in association with cultural material is difficult to explain as a natural phenomenon. Frequent observations of high Rabdotus counts in central Texas burned rock middens has often been explained by the natural behavior of snails, namely the attraction to high organic content of midden contexts. But the small feature in this xeric setting does not seem to harbor sufficient organic content to explain such a concentration. A small cluster of 21 whole and fragmented burned rock was recovered in TU 7 weighing a total of $2.6 \mathrm{~kg}$, along with 198 additional pieces weighing 5.7 kilograms.

Chipped stone recovery included one Tortugas point, three cores, four bifaces, a modified flake, and 854 pieces of debitage. Although this was the only feature to yield a diagnostic artifact, no carbon was recovered from the feature during the excavations. Flotation of a soil sample was collected from the matrix removed from the main cluster. 


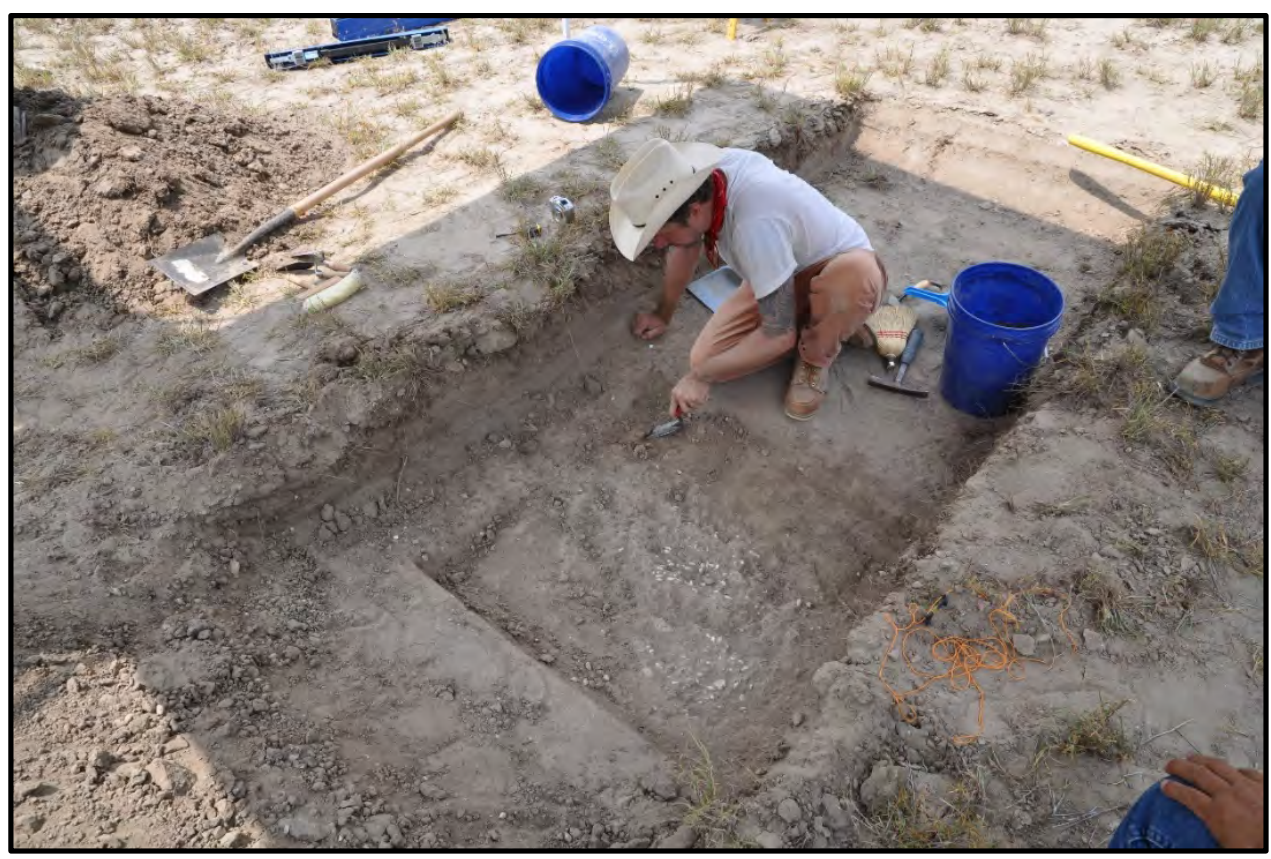

Figure 7.3. Feature 4 after discovery in BHT 15, facing southeast.

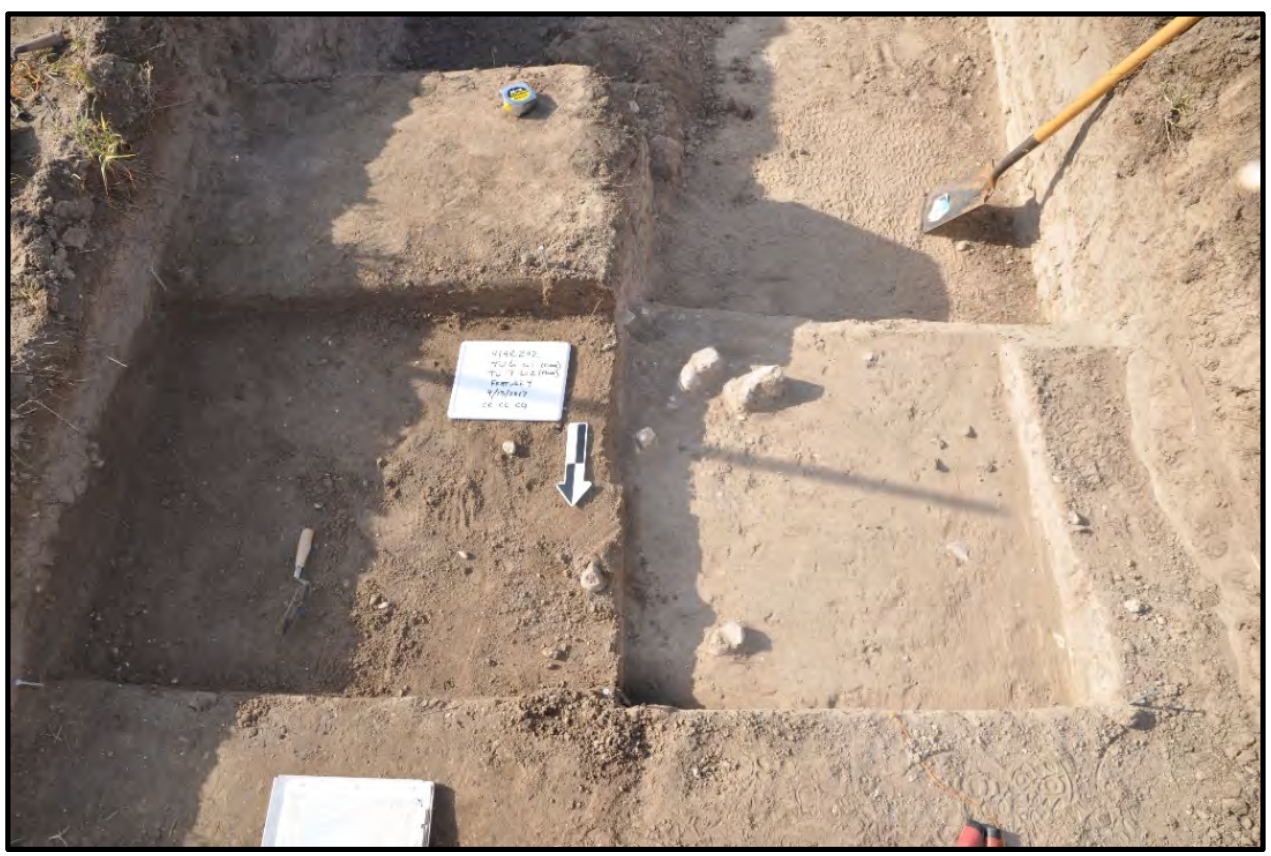

Figure 7.4. Feature 4 in planview on TU 6 Level 1 and TU 7 Level 2 floors, facing south. 


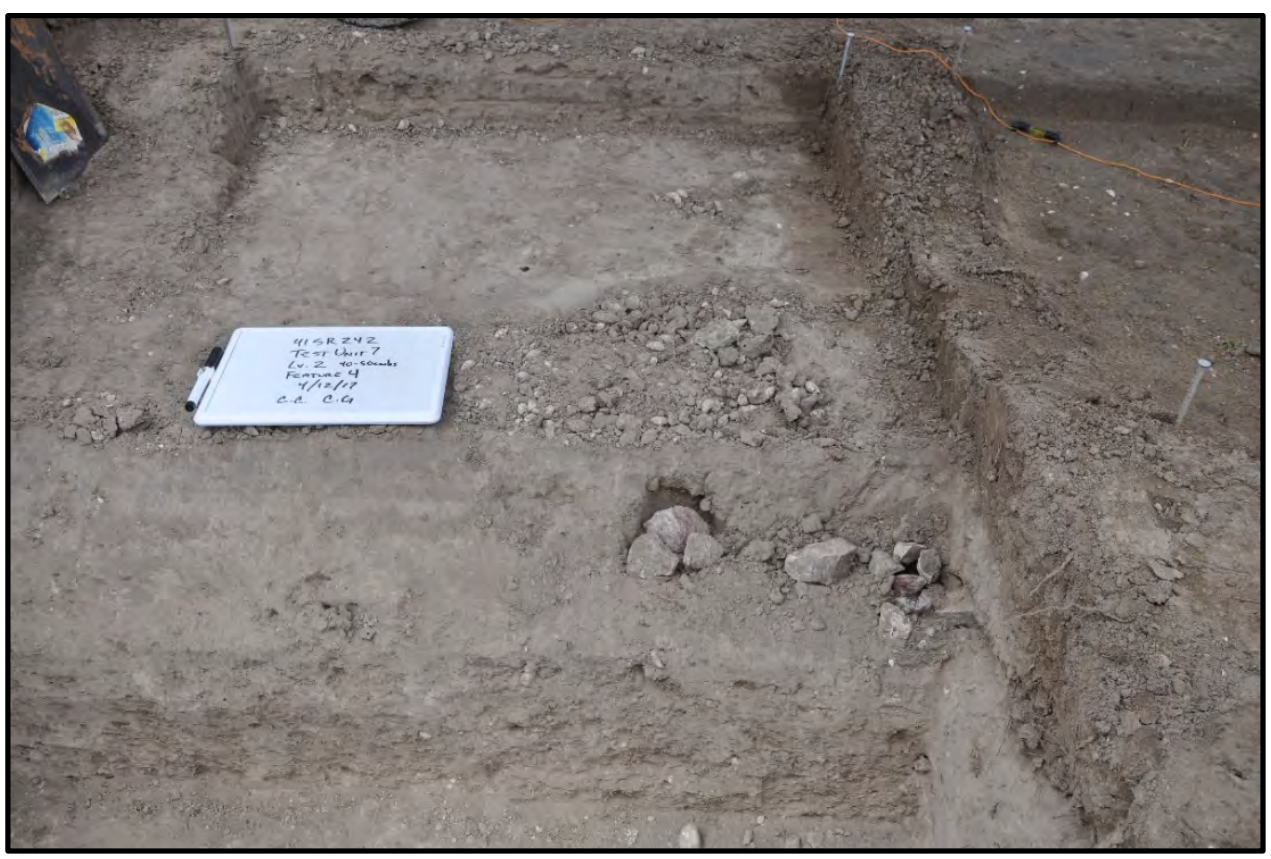

Figure 7.5. Feature 4 in planview at base of TU 7 Level 2, facing west.

\section{Debitage Analysis of Features 1 and 4 - Biface Production Sequences}

Features 1 and 4 are distinct concentrations of debitage along BHT 1 and BHT 15, respectively (see Figure 5.1). Both features are isolable lithic reduction areas, or perhaps secondary discard loci. Feature 1 yielded two Late Archaic dates a millennium apart (3200 and 2200 BP, approximately) and Feature 4 is apparently associated with a Tortugas point, which falls within the temporal range of the Feature 1 radiocarbon dates. Based on characteristics of the debitage, both features are interpreted as comprising multiple segments of bifacial reduction sequences utilizing locally available materials. The knappers were clearly selecting high-grade silicon dioxide-based materials (agate, chert, quartzite, chalcedony, jasper) but to a far lesser extent were also using intrusive igneous (rhyolite or andesite) or metamorphosed sedimentary (siltstone, mudstone).

The features are stratigraphically discrete, but materials have likely been displaced both vertically and horizontally to varying extents. Nevertheless, the geomorphic and in-field archeological assessment of each feature seemed to indicate relatively good integrity. The total debitage recovered from the four levels of TU 1 was 1,195 flakes. The column sample yielded an additional 266 flakes, for a total of 1,461 pieces of debitage.

\section{Analysis of Features 1 and 4 Debitage}

Debitage analysis is designed to identify lithic reduction processes that occur at the particular locales, in this case Features 1 and 4, which are surmised to be isolable behavioral loci, whether activity areas where knapping occurred or secondary discard of debitage. Such reduction typically includes tool production, maintenance, and core reduction. To address these issues, the analysis of debitage from Features 1 and 4 used a complementary approach using TxDOT (2013) lithic protocols augmented by individual flake analysis methods devised by Root (2004). While there was substantive overlap in the two methods, the main difference is Root's use of a technological flake typology in addition to elements of the mass analysis and individual flake analysis. As a first step in the study, MANA was conducted of the feature debitage. This approach, first described by Kelly (1985) and later more formally defined by Larson (1990; 1994; Larson and Kornfield 1997), begins by sorting the mixed assemblage into raw material types. These types are "analytical nodules,” the least common denominator for statistical 
populations. The results of the lithic debitage analyses for Features 1 and 4 are presented in Appendices D.1 and D.2)

\section{Lithic Raw Materials and Selectivity}

The MANA approach is most effective in assemblages with raw materials that are distinctive and internally homogenous, meaning they do not exhibit great variability within a single nodule. In general, the 41SR242 raw materials are highly variable in this regard. Some nodules of chert range from dark gray to tan to dark olive green. Consequently, the certainty of the raw material sort is inversely proportional to flake size - the larger flakes are relatively easy to confidently sort, but the smaller flakes represent only a small portion of the overall variability within any particular nodules. Accordingly, as a general caveat, there are inherent limitations to certainty in the raw material sort. SWCA tried to minimize the uncertainty by using visual characteristics coupled with long- and short-wave ultraviolet fluorescence.

The analysis identified 22 types of raw material composing Feature 1 and at least nine raw material types composing Feature 4 (Table 7.2). The vast majority of the materials are chert (19 of the 31 identified raw material types. This includes a small quantity of the distinctive regional El Sauz chert that was tentatively identified in both tool assemblage and debitage. Two types each of rhyolite, agate, quartzite, and chalcedony were differentiated, as well as one type of jasper, siltstone/mudstone, and petrified wood. Although 31 different raw material types were identified, the following analysis focuses on the five most common raw material types in Features 1 and 4. Many of the raw material types consist of only a flake or two or comprise mainly small, unanalyzable flakes.

Table 7.2. Lithic Material Types in 41SR242 Feature 1 and Feature 4 Assemblages

\begin{tabular}{|c|c|c|c|}
\hline $\begin{array}{l}\text { Lithic } \\
\text { Material }\end{array}$ & Material Description & Munsell Colors & $\begin{array}{c}\text { Nodule } \\
\text { No. }\end{array}$ \\
\hline CA1 & Very pale brown speckled grainy chert & $10 Y R 7 / 3$ & 152.12 \\
\hline CA2 & Brownish yellow chert & 10YR6/6 & 199.57 \\
\hline CA3 & Red ferruginous mudstone or siltstone & $2.5 \mathrm{YR} 4 / 2$ & 173.8 \\
\hline CA4 & Banded very pale brown and grayish brown chert & $\begin{array}{l}\text { 10YR7/3; } \\
\text { 10YR5/2 }\end{array}$ & 152.8 \\
\hline CA5 & Light gray to pale yellow chert & $\begin{array}{c}\text { 10YR7/2; } \\
2.5 \mathrm{Y} 8 / 2\end{array}$ & $\begin{array}{l}152.1 \\
152.7\end{array}$ \\
\hline CA6 & Yellowish brown chert & 10YR5/4 & 194.7 \\
\hline CA7 & Pale brown chert & 10YR6/3 & 199.46 \\
\hline CA8 & Heat-treated reddish brown chert & $5 Y R 4 / 4$ & $\begin{array}{l}152.11 ; \\
153.13 ; \\
152.14\end{array}$ \\
\hline CA9 & Heat-treated (?) gray chert & 10YR6/1 & 198.25 \\
\hline CA10 & Gray to light brown chert & $\begin{array}{l}\text { 10YR5/1; } \\
\text { 10YR6/2 }\end{array}$ & 155.2 \\
\hline CA11 & Semi-translucent dark grayish brown chert & 10YR4/2 & 173.12 \\
\hline CA12 & Very dark gray to brown chert & $\begin{array}{l}\text { 10YR3/1; } \\
\text { 10YR4/3 }\end{array}$ & 156.6 \\
\hline CA13 & Light yellowish brown chert & 10YR6/4 & 199.49 \\
\hline CA14 & Translucent speckled white and strong brown agate & 10YR8/1 & 202.58 \\
\hline CA15 & Coarse-grained yellow chert & 10YR7/6 & 160.2 \\
\hline CA16 & Strong brown and dark brown mottled chert & $\begin{array}{c}\text { 7.5YR5/8; } \\
\text { 10YR3/2 }\end{array}$ & 167.2 \\
\hline CA17 & Very dark brown to black rhyolite & $\begin{array}{l}\text { 10YR2/2; } \\
\text { 10YR2/1 }\end{array}$ & 198.6 \\
\hline
\end{tabular}




\begin{tabular}{|c|c|c|c|}
\hline $\begin{array}{l}\text { Lithic } \\
\text { Material }\end{array}$ & Material Description & Munsell Colors & $\begin{array}{l}\text { Nodule } \\
\text { No. }\end{array}$ \\
\hline CA18 & Dark red agate & $2.5 \mathrm{YR} 3 / 6$ & 171.1 \\
\hline CA19 & Dark brown chert & $5 Y R 3 / 4$ & 174.41 \\
\hline CA20 & Brown chert & 10YR4/3 & 199.43 \\
\hline CA21 & Gray chert & 10YR5/1 & 195.8 \\
\hline CA22 & Heat-treated (?) grayish brown chert & 10YR5/2 & 163.1 \\
\hline CA23 & $\begin{array}{l}\text { Semi-translucent light gray to reddish yellow } \\
\text { chalcedony }\end{array}$ & $\begin{array}{l}\text { 10YR7/1; } \\
5 Y R 6 / 8\end{array}$ & 152.6 \\
\hline CA24 & Dark grayish brown petrified palm wood & 10YR3/2 & 159.34 \\
\hline CA25 & Black chert & 10YR2/1 & 152.9 \\
\hline CA26 & Black quartzite & 10YR2/1 & 152.2 \\
\hline CA27 & Dark reddish brown jasper & $2.5 \mathrm{YR} 3 / 4$ & 152.3 \\
\hline CA28 & Grayish brown mottled quartzite & 10YR5/2 & 152.1 \\
\hline CA29 & White mottled chalcedony & $\begin{array}{l}\text { 10YR8/1; } \\
\text { 10YR7/4 }\end{array}$ & 152.5 \\
\hline CA30 & Dark brown rhyolite & 7.5YR3/3 & 152.4 \\
\hline CA31 & El Sauz chert (?) & $\begin{array}{l}\text { 10YR8/1; } \\
\text { 10YR2/2 }\end{array}$ & 173.7 \\
\hline
\end{tabular}

\section{Flake Size}

All debitage was sorted according to the size grades presented in Tables 7.3 and 7.4. There may be some bias in the less than 0.25-inch size grade, since most smaller flakes would have fallen through the most common-used screen size. Discounting the lowest size-grade, there is generally an inverse relationship between size and quantity; with one exception, the counts decline for each successive increase in size grade. Of the 236 analyzed flakes from the five most common raw material types in Feature 1, there is a slight bimodal distribution with 0.25 to 0.5 inch in maximum diameter being most common (see Table 7.3). Feature 4 counts show a more equitable distribution, with the majority of flakes between 0.5 and 1 inch (see Table 7.4). In general, flake size is an indicator of stage of reduction and/or parent material size. However, small flakes typically derive from all types and stages of reduction. They consist of complete and fragmentary debitage. Flake size is further considered in relation to other aspects discussed below.

Table 7.3. Feature 1 Debitage Size Grades of Five Most Common Raw Material Types

\begin{tabular}{|c|c|c|c|c|c|c|c|c|c|c|c|c|}
\hline \multirow{2}{*}{ Flake Size } & \multicolumn{2}{|c|}{ Material CA1 } & \multicolumn{2}{|c|}{ Material CA5 } & \multicolumn{2}{|c|}{ Material CA8 } & \multicolumn{2}{|c|}{ Material CA25 } & \multicolumn{2}{|c|}{ Material CA 28} & \multicolumn{2}{|c|}{ Totals } \\
\hline & Count & $\%$ & Count & $\%$ & Count & $\%$ & Count & $\%$ & Count & $\%$ & Count & $\%$ \\
\hline less than 0.25 inch & 0 & $0.00 \%$ & 6 & $8.96 \%$ & 1 & $2.50 \%$ & 3 & $6.38 \%$ & 1 & $1.67 \%$ & 11 & $4.66 \%$ \\
\hline 0.25 to 0.5 inch & 4 & $18.18 \%$ & 27 & $40.30 \%$ & 10 & $25.00 \%$ & 21 & $44.68 \%$ & 18 & $30.00 \%$ & 80 & $33.90 \%$ \\
\hline 0.5 to 0.75 inch & 9 & $40.91 \%$ & 11 & $16.42 \%$ & 11 & $27.50 \%$ & 13 & $27.66 \%$ & 19 & $31.67 \%$ & 63 & $26.69 \%$ \\
\hline $3 / 4$ to 1 inch & 2 & $9.09 \%$ & 7 & $10.45 \%$ & 10 & $25.00 \%$ & 9 & $19.15 \%$ & 7 & $11.67 \%$ & 35 & $14.83 \%$ \\
\hline greater than 1 inch & 7 & $31.82 \%$ & 16 & $23.88 \%$ & 8 & $20.00 \%$ & 1 & $2.13 \%$ & 15 & $25.00 \%$ & 47 & $19.92 \%$ \\
\hline Totals & 22 & & 67 & & 40 & & 47 & & 60 & & 236 & \\
\hline
\end{tabular}


Table 7.4. Feature 4 Debitage Size Grades of Two Most Common Raw Material Types

\begin{tabular}{lcccccc}
\hline \multirow{2}{*}{ Flake Size } & \multicolumn{2}{c}{ Material CA7 } & \multicolumn{2}{c}{ Material CA20 } & \multicolumn{2}{c}{ Totals } \\
\cline { 2 - 7 } & Count & $\%$ & Count & $\%$ & Count & \% \\
\hline less than 0.25 inch & 5 & $5.62 \%$ & 0 & $0.00 \%$ & $\mathbf{5}$ & $\mathbf{4 . 1 0 \%}$ \\
\hline 0.25 to 0.5 inch & 21 & $23.60 \%$ & 4 & $12.12 \%$ & $\mathbf{2 5}$ & $\mathbf{2 0 . 4 9 \%}$ \\
\hline 0.5 to 0.75 inch & 26 & $29.21 \%$ & 10 & $30.30 \%$ & $\mathbf{3 6}$ & $\mathbf{2 9 . 5 1 \%}$ \\
\hline 0.75 to 1 inch & 21 & $23.60 \%$ & 10 & $30.30 \%$ & $\mathbf{3 1}$ & $\mathbf{2 5 . 4 1 \%}$ \\
\hline greater than 1 inch & 16 & $17.98 \%$ & 9 & $27.27 \%$ & $\mathbf{2 5}$ & $\mathbf{2 0 . 4 9 \%}$ \\
\hline Totals & $\mathbf{8 9}$ & & $\mathbf{3 3}$ & & $\mathbf{1 2 2}$ & \\
\hline
\end{tabular}

\section{Cortical States}

Cortex is an indicator of several aspects, most notably stage of reduction and proximity to raw material outcrop. Although cortex can be present on fairly late stage reduction pieces, as a general principle, decortication occurs early in the process and decreases through the reductive stages. As an indicator of proximity to raw materials, cortex decreases as distance from sources increases. The premise is that rocks are heavy, and mass reduction occurs near outcrops in order to decrease transport costs (energy expended).

Of the 236 flakes from the three most common material types in Feature 1, cortex is present on 19.07 percent of debitage, a fairly high percentage consistently across all five materials in Feature 1 (Table 7.5). Cortex is present on 33.3 percent of the debitage from Feature 4 materials (Table 7.6). Compared to assemblages of strictly late stage activities such as edge rejuvenation and late stage bifacial reduction in which 0 percent cortex is a common expectation, this high amount of cortex implies use of locally available raw materials being brought to the site without too much prior off-site mass reduction and reduced on site from early through late stages of manufacture.

Table 7.5. Feature 1 Debitage Cortical States of Five Most Common Raw Material Types

\begin{tabular}{|c|c|c|c|c|c|c|c|c|c|c|c|c|}
\hline \multirow{2}{*}{$\begin{array}{l}\% \text { of } \\
\text { Cortex on } \\
\text { Flake }\end{array}$} & \multicolumn{2}{|c|}{ Material CA1 } & \multicolumn{2}{|c|}{ Material CA5 } & \multicolumn{2}{|c|}{ Material CA8 } & \multicolumn{2}{|c|}{ Material CA25 } & \multicolumn{2}{|c|}{ Material CA 28} & \multicolumn{2}{|c|}{ Totals } \\
\hline & Count & $\%$ & Count & $\%$ & Count & $\%$ & Count & $\%$ & Count & $\%$ & Count & $\%$ \\
\hline $0 \%$ & 18 & 81.82 & 60 & 89.55 & 22 & 55.00 & 35 & 74.47 & 56 & 93.33 & 191 & 80.93 \\
\hline $1 \%-25 \%$ & 3 & 13.64 & 3 & 4.48 & 8 & 20.00 & 5 & 10.64 & 3 & 5.00 & 22 & 9.32 \\
\hline $25 \%-50 \%$ & 0 & 0.00 & 2 & 2.99 & 4 & 10.00 & 4 & 8.51 & 0 & 0.00 & 10 & 4.24 \\
\hline $50 \%-75 \%$ & 0 & 0.00 & 0 & 0.00 & 2 & 5.00 & 1 & 2.13 & 0 & 0.00 & 3 & 1.27 \\
\hline $75 \%-100 \%$ & 1 & 4.55 & 2 & 2.99 & 4 & 10.00 & 2 & 4.26 & 1 & 1.67 & 10 & 4.24 \\
\hline Totals & 22 & & 67 & & 40 & & 47 & & 60 & & 236 & \\
\hline
\end{tabular}

Table 7.6. Feature 4 Debitage Cortical States of Two Most Common Raw Material Types

\begin{tabular}{|c|c|c|c|c|c|c|}
\hline \multirow{2}{*}{$\%$ of Cortex on Flake } & \multicolumn{2}{|c|}{ Material CA7 } & \multicolumn{2}{|c|}{ Material CA20 } & \multicolumn{2}{|c|}{ Totals } \\
\hline & Count & $\%$ & Count & $\%$ & Count & $\%$ \\
\hline $0 \%$ & 102 & $86.44 \%$ & 22 & $66.67 \%$ & 124 & $82.12 \%$ \\
\hline $1 \%-25 \%$ & 10 & $8.47 \%$ & 2 & $6.06 \%$ & 12 & $7.95 \%$ \\
\hline $25 \%-50 \%$ & 2 & $1.69 \%$ & 3 & $9.09 \%$ & 5 & $3.31 \%$ \\
\hline
\end{tabular}




\begin{tabular}{lcccccc}
\hline \multirow{2}{*}{$\%$ of Cortex on Flake } & \multicolumn{2}{c}{ Material CA7 } & \multicolumn{2}{c}{ Material CA20 } & \multicolumn{2}{c}{ Totals } \\
\cline { 2 - 7 } & Count & $\%$ & Count & $\%$ & Count & \% \\
\hline $50 \%-75 \%$ & 1 & $0.85 \%$ & 2 & $6.06 \%$ & $\mathbf{3}$ & $\mathbf{1 . 9 9 \%}$ \\
\hline $75 \%-100 \%$ & 3 & $2.54 \%$ & 4 & $12.12 \%$ & $\mathbf{7}$ & $\mathbf{4 . 6 4 \%}$ \\
\hline Totals & $\mathbf{1 1 8}$ & & 33 & & $\mathbf{1 5 1}$ & \\
\hline
\end{tabular}

\section{Platform Types}

Striking platforms, like cortical states, indicate not only stage of reduction but also technological processes (e.g., unifacial, bifacial reduction). Excluding the missing and indeterminate platforms, which constitute the majority of the flakes, multi-faceted platforms predominate in all but one of the five most common raw Feature 1 materials types (Table 7.7). Likewise, multi-faceted flakes are most common in the Feature 4 materials (Table 7.8). This platform type is typically associated with bifacial reduction. Of equal importance is the amount of cortical and single-faceted (flat) platforms, which indicate earlier stages of reduction. The implication is that Features 1 and 4 represents biface production as a primary activity, and the majority of the reduction sequence from early through late stages is represented in the debitage.

Table 7.7. Feature 1 Debitage Platform Types of Five Most Common Raw Material Types

\begin{tabular}{|c|c|c|c|c|c|c|c|c|c|c|c|c|}
\hline \multirow{2}{*}{ Platform Description } & \multicolumn{2}{|c|}{ Material CA1 } & \multicolumn{2}{|c|}{ Material CA5 } & \multicolumn{2}{|c|}{ Material CA8 } & \multicolumn{2}{|c|}{ Material CA25 } & \multicolumn{2}{|c|}{ Material CA28 } & \multicolumn{2}{|c|}{ Totals } \\
\hline & Count & $\%$ & Count & $\%$ & Count & $\%$ & Count & $\%$ & Count & $\%$ & Count & $\%$ \\
\hline Indeterminate & 1 & $4.55 \%$ & 1 & $1.49 \%$ & 0 & $0.00 \%$ & 2 & $4.26 \%$ & 2 & $3.33 \%$ & 2 & $0.85 \%$ \\
\hline Cortical & 2 & $9.09 \%$ & 7 & $10.45 \%$ & 3 & $7.50 \%$ & 3 & $6.38 \%$ & 1 & $1.67 \%$ & 12 & $5.08 \%$ \\
\hline Flat & 1 & $4.55 \%$ & 3 & $4.48 \%$ & 2 & $5.00 \%$ & 1 & $2.13 \%$ & 1 & $1.67 \%$ & 6 & $2.54 \%$ \\
\hline Faceted & 1 & $4.55 \%$ & 3 & $4.48 \%$ & 2 & $5.00 \%$ & 0 & $0.00 \%$ & 4 & $6.67 \%$ & 6 & $2.54 \%$ \\
\hline Multi-faceted & 7 & $31.82 \%$ & 13 & $19.40 \%$ & 3 & $7.50 \%$ & 10 & $21.28 \%$ & 12 & $20.00 \%$ & 23 & $9.75 \%$ \\
\hline Abraded & 0 & $0.00 \%$ & 0 & $0.00 \%$ & 0 & $0.00 \%$ & 0 & $0.00 \%$ & 0 & $0.00 \%$ & 0 & $0.00 \%$ \\
\hline Missing & 10 & $45.45 \%$ & 40 & $59.70 \%$ & 30 & $75.00 \%$ & 31 & $65.96 \%$ & 40 & $66.67 \%$ & 80 & $33.90 \%$ \\
\hline Totals & 22 & & 67 & & 40 & & 47 & & 60 & & 236 & \\
\hline
\end{tabular}

Table 7.8. Feature 4 Debitage Platform Types of Two Most Common Raw Material Types

\begin{tabular}{lcccccc}
\hline \multirow{2}{*}{ Platform Description } & \multicolumn{2}{c}{ Material CA7 } & \multicolumn{2}{c}{ Material CA20 } & \multicolumn{2}{c}{ Totals } \\
\cline { 2 - 7 } Indeterminate & Count & $\%$ & Count & \% & Count & \% \\
\hline Cortical & 7 & $5.88 \%$ & 2 & $6.06 \%$ & $\mathbf{9}$ & $\mathbf{5 . 9 2 \%}$ \\
\hline Flat & 5 & $4.20 \%$ & 3 & $9.09 \%$ & $\mathbf{8}$ & $\mathbf{5 . 2 6 \%}$ \\
\hline Faceted & 3 & $2.52 \%$ & 1 & $3.03 \%$ & $\mathbf{4}$ & $\mathbf{2 . 6 3} \%$ \\
\hline Multi-faceted & 7 & $5.88 \%$ & 2 & $6.06 \%$ & $\mathbf{9}$ & $\mathbf{5 . 9 2} \%$ \\
\hline Abraded & 17 & $21.25 \%$ & 8 & $47.06 \%$ & $\mathbf{2 5}$ & $\mathbf{1 6 . 4 5 \%}$ \\
\hline Missing & 0 & $0.00 \%$ & 0 & $0.00 \%$ & $\mathbf{0}$ & $\mathbf{0 . 0 0} \%$ \\
\hline Totals & 80 & $67.23 \%$ & 17 & $51.52 \%$ & $\mathbf{9 7}$ & $\mathbf{6 3 . 8 2} \%$ \\
\hline
\end{tabular}




\section{Technological Flake Types}

Technological flake classification directly addressing type of reduction and, to some extent, stage of reduction. Using Root's (2004) typology (see definitions in Chapter 4), six flake types are identified in the Features 1 and 4 assemblages, each type being a technological indicator of a step in the reduction sequence. Primary decortication and simple flakes predominate the early stages with complex and bifacial thinning flakes indicative of the mid- to later stages, and bifacial retouch in the final stages of shaping and rejuvenation. The complex flake is the most common type, representing a catchall category that contains many of the attributes of all technologies, including bifacial manufacture and prepared core reduction but is missing certain attributes (such as platforms) that allow positive identification in one of the other categories (Root 2004:76). Like simple flakes, these are not highly distinctive of any particular reduction process.

So excluding the non-diagnostic categories (i.e., shatter), bifacial thinning flakes are the most common in material types, followed complex and simple (Tables 7.9 and 7.10). This profile of everything from primary decortication through bifacial thinning reinforce the interpretation that all stages, early through late, are represented in the assemblage.

In addition to the flake types that are present, several flake types were not identified, indicating the lack of certain techniques. Blades, unifacial retouch, radial-break, notching, bipolar, and alternate flakes were not identified. Blade technology has not been recorded in the regional techno-complexes (early Paleoindian, Toyah, and other techno-complexes in which blade production is common are poorly defined in the Rio Grande delta). Unifaces are quite common in the area, but do not appear to be part of the Features 1 and 4 reduction activities. Radial breakage and bipolar reduction are uncommon strategies in the region and the sites. The Late Archaic and Late Prehistoric projectile points of the area are typically unnotched triangular, sub-triangular, or ovate types, and so the "gull-winged" notching flakes would not be expected. Alternate flakes are early reduction stage flakes to remove right-angle edges on blocky, squared-off nodules. Most of the locally available materials are rounded, heavily stream rolled, but these flake types may be incidental in reduction of all types of raw material. None were clearly identified in Features 1 and 4.

Table 7.9. Feature 1 Debitage Technological Flake Classes of Five Most Common Raw Material Types

\begin{tabular}{|c|c|c|c|c|c|c|c|c|c|c|c|c|}
\hline \multirow{2}{*}{ Flake Class* } & \multicolumn{2}{|c|}{ Material CA1 } & \multicolumn{2}{|c|}{ Material CA5 } & \multicolumn{2}{|c|}{ Material CA8 } & \multicolumn{2}{|c|}{ Material CA25 } & \multicolumn{2}{|c|}{ Material CA28 } & \multicolumn{2}{|c|}{ Totals } \\
\hline & Count & $\%$ & Count & $\%$ & Count & $\%$ & Count & $\%$ & Count & $\%$ & Count & $\%$ \\
\hline $\begin{array}{l}\text { Primary } \\
\text { Decortication }\end{array}$ & 1 & 4.55 & 2 & 2.99 & 3 & 7.50 & 0 & 0.00 & 1 & 1.67 & 6 & 4.65 \\
\hline Shatter & 0 & 0.00 & 12 & 17.91 & 5 & 12.50 & 3 & 5.88 & 7 & 11.67 & 17 & 13.18 \\
\hline Biface Thinning & 4 & 18.18 & 8 & 11.94 & 3 & 7.50 & 5 & 9.80 & 5 & 8.33 & 15 & 11.63 \\
\hline Bifacial Pressure & 0 & 0.00 & 1 & 1.49 & 0 & 0.00 & 0 & 0.00 & 0 & 0.00 & 1 & 0.78 \\
\hline Simple & 3 & 13.64 & 5 & 7.46 & 10 & 25.00 & 9 & 17.65 & 9 & 15.00 & 18 & 13.95 \\
\hline Complex & 14 & 63.64 & 39 & 58.21 & 19 & 47.50 & 34 & 66.67 & 38 & 63.33 & 72 & 55.81 \\
\hline Totals & 22 & & 67 & & 40 & & 51 & & 60 & & 129 & \\
\hline
\end{tabular}

*Technological flake classes defined by Root (2004) 
Table 7.10. Feature 4 Debitage Technological Flake Classes of Two Most Common Raw Material Types

\begin{tabular}{lcccccc}
\hline \multirow{2}{*}{ Flake Class* } & \multicolumn{2}{c}{ Material CA7 } & \multicolumn{2}{c}{ Material CA20 } & \multicolumn{2}{c}{ Totals } \\
\cline { 2 - 7 } & Count & $\%$ & Count & \% & Count & $\%$ \\
\hline Primary Decortication & 3 & $3.70 \%$ & 4 & $12.12 \%$ & $\mathbf{7}$ & $\mathbf{6 . 1 4 \%}$ \\
\hline Shatter & 0 & $0.00 \%$ & 0 & $0.00 \%$ & $\mathbf{0}$ & $\mathbf{0 . 0 0 \%}$ \\
\hline Biface Thinning & 10 & $12.35 \%$ & 7 & $21.21 \%$ & $\mathbf{1 7}$ & $\mathbf{1 4 . 9 1 \%}$ \\
\hline Bifacial Pressure & 1 & $1.23 \%$ & 0 & $0.00 \%$ & $\mathbf{1}$ & $\mathbf{0 . 8 8 \%}$ \\
\hline Simple & 26 & $32.10 \%$ & 12 & $36.36 \%$ & $\mathbf{3 8}$ & $\mathbf{3 3 . 3 3 \%}$ \\
\hline Complex & 41 & $50.62 \%$ & 10 & $30.30 \%$ & $\mathbf{5 1}$ & $\mathbf{4 4 . 7 4 \%}$ \\
\hline Totals & $\mathbf{8 1}$ & & $\mathbf{3 3}$ & & $\mathbf{1 1 4}$ & \\
\hline
\end{tabular}

*Technological flake classes defined by Root (2004)

\section{Summary and Interpretations of Features 1 and 4 Debitage}

Features 1 and 4 represent isolable lithic reduction features, representing either in situ activities or secondary discard. For both, the testing likely captured a fairly robust representative sample, but not the entire population. The MANA study identified a minimum of 31 raw material types composing the features, although two factors warrant interpretive caution: 1) variability within raw material cobbles may introduce erroneous additional types, and 2) there are probably some introduced types, part of the sitewide background noise, that are not directly associated with the features. Nevertheless, there is reasonable confidence that the major material types represent individual reduction sequences in tool production. Many of the material types are statistically inviable, represented by only one or two flakes. Some of these small samples could represent background noise unassociated with the features. A number of methods, most using chemical or trace element analyses, can further assess the validity of the sort.

The feature debitage primarily represents distinct reduction sequences in which locally available raw materials - mainly select, high-grade cherts — were bifacially reduced from early to late stages. In most biface reduction models (e.g., Callahan 1979), mid-stage reduction often entails flakes that travel well beyond the mid-point of the biface. Consequently, the largest thinning flakes provide an approximate indication of maximum biface width (assuming all stages of reduction are represented, which is the case for both features). Considering the lack of large bifacial reduction flakes (few greater than 1 inch in maximum length), the items produced were small, less than 1 inch in maximum dimension. The flake size data warrants qualification, namely in considering the possibility that larger flakes were broken and are consequently not represented in the data. Such a scenario cannot be ruled out but is predicated on the notion that there were biases in breakage patterns, in which all larger flakes were subject to breakage, whereas only proportions of other size grades were subject to breakage. Notwithstanding the caveats, the maximum observed size of the debitage is typical of most of the regional projectile points, which are relatively narrow compared to many of the broad-bladed types in earlier periods and adjacent areas. The feature debitage is consistent with the expected manufacturing debris from the production of the point found within the feature.

Placing the feature within the larger context, the prevailing hypothesis posits a strategy of retooling on the sites whereby the inhabitants would target the local gravel outcrops during short-term occupations. The pattern is expected to yield discarded, exhausted items and a relatively complete reduction sequence from decortication to final pressure flaking. Initial cobble testing was expected to have occurred offsite at the source, but early-stage decortication is expected to have occurred on site. As noted, sorting the collection by raw material type will be the primary analytical tack to get specific isolable reduction sequences. 


\section{ARTIFACTS AND ECOFACTS}

The cultural materials recovered during testing investigations include a total of 105 lithic tools, 3,567 pieces of debitage, and various ecofacts, such as faunal remains, snail shell, and macrofloral samples (Table 7.11). Subsequent to the fieldwork, all materials collected during the testing project were washed, sorted, and tabulated; pertinent samples were processed.

By and large, the analytical categories presented in this chapter follow those defined by TxDOT protocols (TxDOT 2013). These consist of standard artifact classes that are well defined and grounded in the literature and in practice. The specific types, such as for projectile points, rely on standard typologies, for example, Turner et al. (2011). No microscopic use-wear analysis was conducted on the artifact assemblage, hence categorization is based on morphology of the specimens.

Table 7.11. Materials Recovered from Site 41SR242

\begin{tabular}{|c|c|}
\hline Materials Recovered & Count \\
\hline Historic artifacts & 100 \\
\hline Debitage & 3,567 \\
\hline Bone & 54 \\
\hline Burned Clay & 1 \\
\hline Burned Rock & 580 \\
\hline Projectile Points & 21 \\
\hline Charcoal Sample & 7 \\
\hline Discoid Uniface & 1 \\
\hline Distally Beveled Scraper & 2 \\
\hline Edge-Modified Utilized Flake & 7 \\
\hline Bifaces & 61 \\
\hline Mussel Shell & 14 \\
\hline Nueces Tool & 1 \\
\hline Ochre & 1 \\
\hline Olmos Biface & 1 \\
\hline Platform Rejuvenation Core Flake & 1 \\
\hline Prehistoric Ceramic Plain Body Sherd & 1 \\
\hline Rabdotus Shell & 3,637 \\
\hline Refined Multidirectional Core & 3 \\
\hline Side Scraper & 1 \\
\hline Tortugas Dart Point Preform & 5 \\
\hline Uniface & 1 \\
\hline Grand Total & 8,067 \\
\hline
\end{tabular}




\section{Projectile Points}

The investigations recovered one Fresno, five Tortugas preforms, two Matamoros, one Refugio, nine Tortugas, three Desmuke, one Catan, two untyped stemmed points, and an untyped lanceolate point from various contexts, mostly surficial, across the site (Table 7.12). The known temporal range of these diagnostic artifacts indicates Late Archaic to Late Prehistoric occupations, with the untyped lanceolate perhaps representing an earlier component. Lerma points are poorly dated but generally considered Archaic. Quigg et al. (2000) date Refugio points to about 3400 B.P. based on findings at the Lino site, which showed them to be stratigraphically below Tortugas points. Based on sites such as Loma Sandia and Lino, Tortugas points dates to approximately 3200 to 2000 B.P. but more likely from about 2400 to 2700 B.P. based on direct dates of these points in funerary contexts. The Desmuke points date to the Late Archaic period beginning ca. 2400 to 1200 B.P. (Hester 2004). Matamoros points have a poorly dated temporal range. A date of 1000 B.P. was obtained in association with a Matamoros point at 41SP120 in nearby San Patrice County (Turner et al. 2011:133). However, the temporal range may be more extensive, as some have suggested Matamoros developed from the earlier Tortugas points. The radiocarbon dates from 41SR242 range from approximately 3400 to 2200 B.P., consistent with the timeframe of the most common diagnostic artifacts: Tortugas, Desmuke, and Refugio. Minor earlier and later components are suggested by the untyped lanceolate, Matamoros, and Fresno points.

Table 7.12. Projectile Points and Preforms Recovered from Site $41 S R 242$

\begin{tabular}{|c|c|c|c|c|c|c|c|}
\hline $\begin{array}{l}\text { Lot } \\
\text { No. }\end{array}$ & $\begin{array}{l}\text { Specimen } \\
\text { No. }\end{array}$ & FS No. & Artifact Description & $\begin{array}{l}\text { Max. Length } \\
(\mathrm{mm})\end{array}$ & $\begin{array}{l}\text { Max. Width } \\
(\mathrm{mm})\end{array}$ & $\begin{array}{l}\text { Max. Thickness } \\
(\mathrm{mm})\end{array}$ & $\begin{array}{l}\text { Weight } \\
\text { (g) }\end{array}$ \\
\hline 004 & 002 & SC 04.02 & Lerma-like Dart Point Base & 43.22 & 29.83 & 8.52 & 9.9 \\
\hline 005 & 001 & SC 05.01 & Tortugas Dart Point & 29.67 & 35.66 & 8.96 & 11.2 \\
\hline 006 & 001 & SC 06.01 & Tortugas Dart Point & 60.99 & 28.75 & 8.37 & 11.6 \\
\hline 007 & 001 & SD 1 & Tortugas Dart Point & 38.90 & 24.37 & 7.97 & 8.6 \\
\hline 008 & 001 & SD 2 & Tortugas Dart Point & 39.75 & 33.12 & 7.44 & 10.7 \\
\hline 011 & 001 & SD 5 & Tortugas Dart Point Preform & 36.82 & 36.42 & 8.49 & 13.1 \\
\hline 012 & 001 & SD 6 & Tortugas Dart Point Preform & 68.20 & 34.16 & 18.52 & 37.0 \\
\hline 013 & 001 & SD 7 & Tortugas Dart Point & 40.90 & 26.26 & 5.64 & 7.7 \\
\hline 015 & 001 & SD 9 & Unidentified Lanceolate Dart Point & 41.01 & 27.94 & 6.20 & 6.9 \\
\hline 016 & 001 & SD 10 & Catan Dart Point & 35.77 & 24.50 & 5.85 & 5.3 \\
\hline 036 & 001 & SD2 01 & Matamoros Dart/Arrow Point & 32.61 & 20.31 & 5.58 & 4.0 \\
\hline 037 & 001 & SD2 02 & Tortugas Dart Point & 49.70 & 25.50 & 8.73 & 10.1 \\
\hline 038 & 001 & SD2 03 & Tortugas Dart Point & 24.11 & 26.03 & 5.85 & 4.9 \\
\hline 039 & 001 & SD2 04 & Matamoros Dart/Arrow Point & 35.26 & 26.06 & 4.87 & 4.0 \\
\hline 040 & 001 & SD2 05 & Refugio Dart Point & 70.00 & 23.57 & 10.24 & 19.6 \\
\hline 041 & 001 & SD2 06 & Tortugas Dart Point & 39.62 & 27.79 & 6.93 & 8.8 \\
\hline 042 & 001 & SD2 07 & Tortugas Dart Point Preform & 73.38 & 30.95 & 17.51 & 34.3 \\
\hline 043 & 001 & SB2 01 & Lerma-like Dart Point Base & 33.47 & 30.83 & 7.16 & 7.5 \\
\hline 052 & 001 & SB2 10 & Lerma-like Dart Point Base & 32.53 & 28.06 & 6.13 & 5.7 \\
\hline 059 & 001 & SB2 17 & Tortugas Dart Point Preform & 34.64 & 34.02 & 11.23 & 14.6 \\
\hline 175 & 065 & 25.001 & Unidentified Dart Point Base & 17.12 & 25.40 & 5.96 & 2.8 \\
\hline 196 & 001 & 40.001 & Tortugas Dart Point Preform & 44.37 & 35.20 & 8.75 & 15.7 \\
\hline 199 & 159 & 43.002 & Unidentified Dart Point Base & 28.46 & 21.78 & 9.50 & 5.4 \\
\hline 200 & 001 & 45.001 & Fresno Arrow Point & 28.80 & 23.59 & 6.45 & 5.4 \\
\hline 210 & 005 & 54.001 & Tortugas Dart Point & 58.27 & 27.13 & 9.81 & 12.9 \\
\hline
\end{tabular}


One tentatively identified Fresno point was recovered from Feature 4 in TU 7, Level 3 (Figure 7.6). The point is a straight-based triangular point missing the distal end with a transverse medial fracture. The point is roughly equivalent in size with Matamoros points, but the high width to thickness ratio and serration on the lateral margin are more consistent with Fresno than Matamoros points, which typically have a more robust bi-convex or beveled cross section. The raw material is a fine-grained, lusterless siltstone or mudstone.

The two Matamoros dart points were recovered from surface collection units (see Figure 7.6). The points are triangular, relatively thick compared to arrow points of roughly the same size, such as Zapata and Fresno points. Both specimens are complete, with one exhibiting bifacial beveling on the lateral margins indicative of resharpening. Both are made of fine-grained tan chert.

The complete, exhausted Catan, is small, heavily reduced by unifacial beveling on the lateral margins (see Figure 7.6). Its base is rounded to sub-trapezoidal and well-thinned. It is made of a grayish, fine-grained chert and a heavily reworked but complete point.

Eight of the Tortugas dart points were recovered from the surface, one was recovered in a subsurface context from BHT 8 (Figure 7.7). Six are made from a similar drab olive green chert, one is of agate, one of a dark black and gray banded chert, and one of yellowish mudstone. Three are proximal fragments truncated by medial-proximal transverse fractures, three are complete, and three are nearly complete, lacking only the distal tips. Only one (Specimen 037-001) shows alternate beveling from resharpening, with the beveling serving as an indicator of the hafting limits. The specimen is relatively narrow for the type and could conceivably be a Matamoros, although its length dimension makes it more consistent with the Tortugas (see Turner et. al 2011:133).

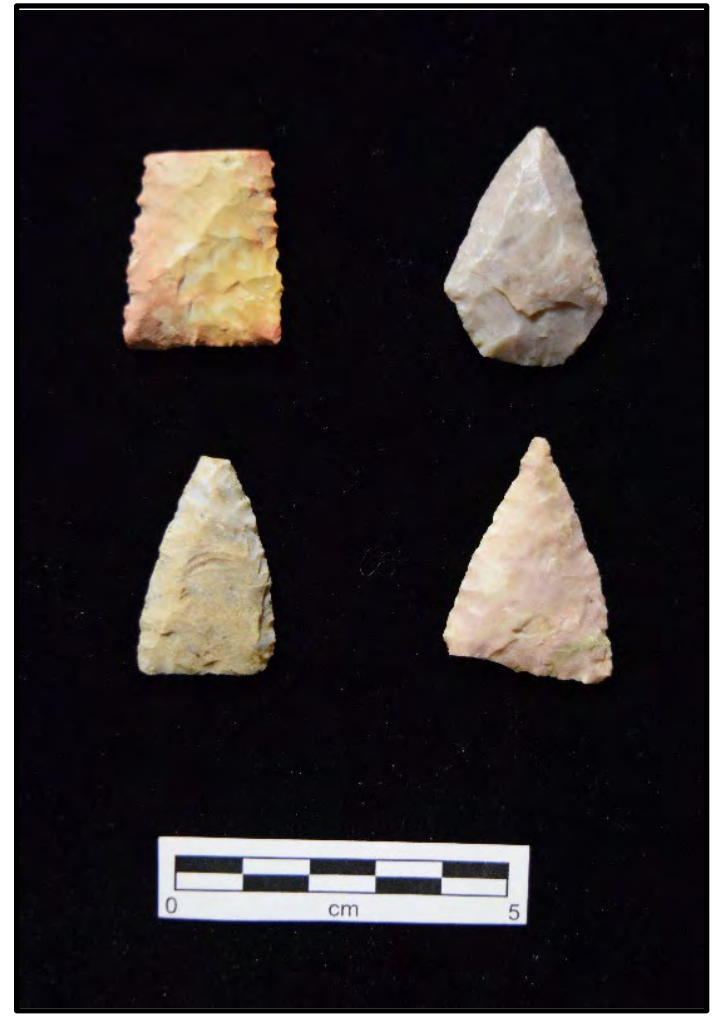

Figure 7.6. Small dart and possible arrow point recovered from site 41SR242. Left to right Lot-Specimen Nos. are: top row 200-001 and 016-001; bottom row 036-001 and 039-001.

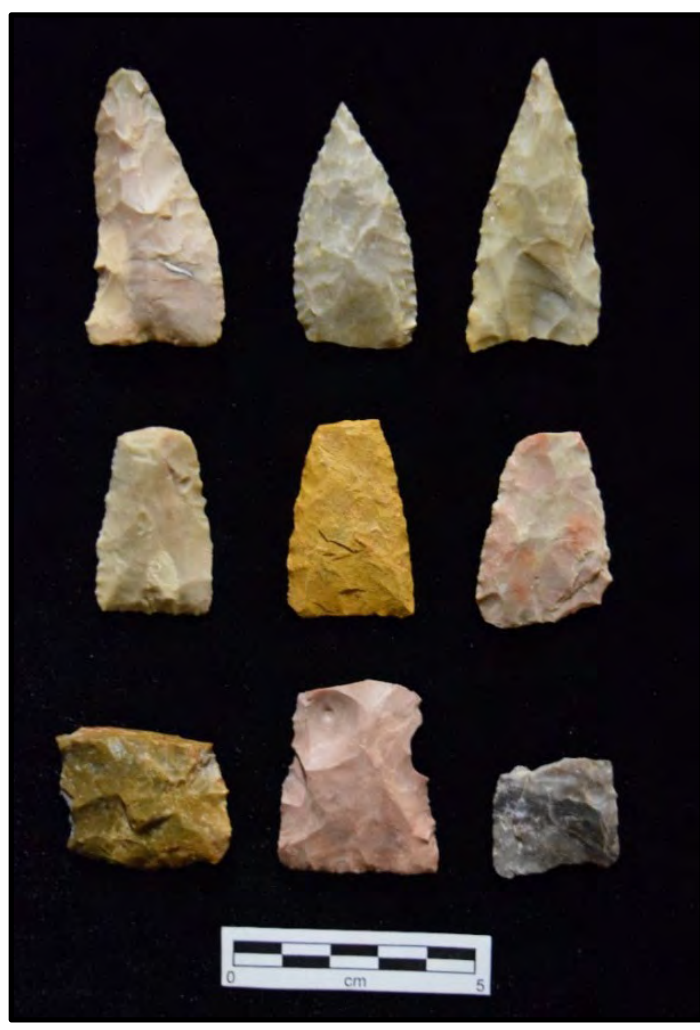

Figure 7.7. Tortugas dart points recovered from site 41SR242. Left to right Lot-Specimen Nos. are: top row 006-001, 037-001 and 210-005; middle row 007-001, 013-001 and 041-001; bottom row 005-001, 008-001 and 038-001. 
The five Tortugas preforms are all late-stage bifaces sufficiently shaped to distinguish the basic form and technological characteristics of the Tortugas type (Figure 7.8). Four of the preforms were recovered from the site surface and one came from Feature 4 in TU 6. Four are made from high-quality, finegrained tan to pale brown chert and one is a black grainy chert or siltstone with distinctive tan bands. Three were discarded after medial transverse fracture and two were discarded after failure to thin from cumulative step fractures on one face.

The Refugio point, collected from the site surface, is a long, narrow point that is crudely made of a tannish, low-quality siltstone (Figure 7.9). One surface contains a black substance that could possibly be asphaltum, but this has not been tested. The point has a convex base, a low width to thickness ratio (2.5- 2:1), and relatively steep edge angles on the lateral margins.

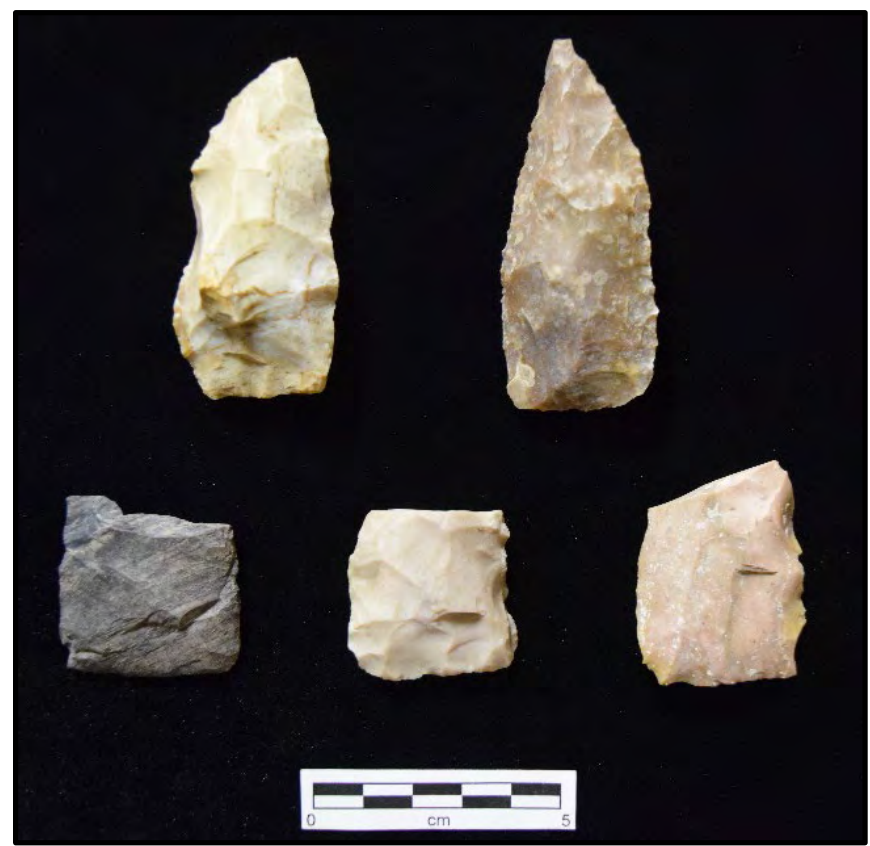

Figure 7.8. Tortugas dart point preforms recovered from site 41SR242. Left to right Lot-Specimen Nos. are: top row 012-001 and 042-001; bottom row 011001, 059-001, and 196-001

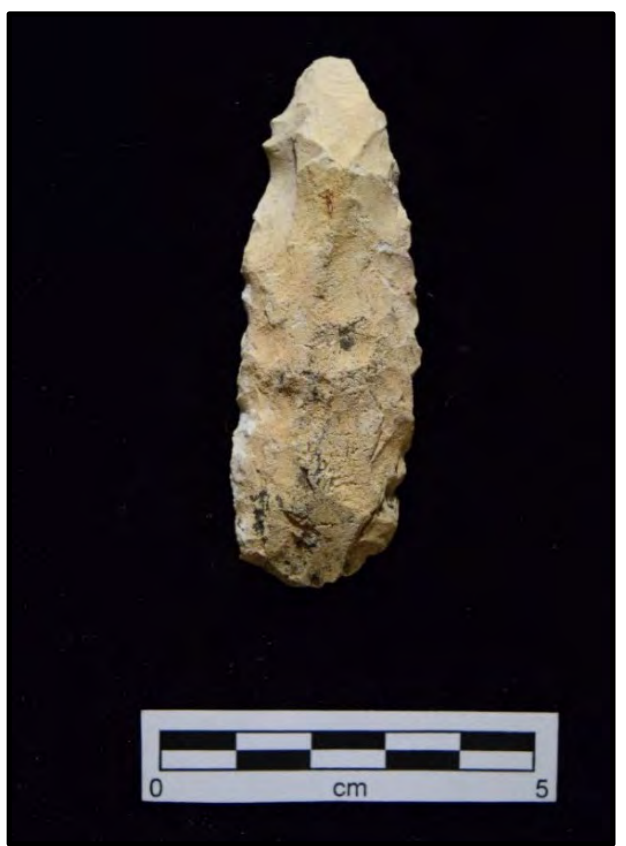

Figure 7.9. Refugio dart point recovered from site 41SR242 with possible asphaltum: Lot-Specimen No. 040-001.

Three Lerma-like dart points, all proximal fragments, were recovered from surface collection units (Figure 7.10). All three proximal fragments are very similar in shape, form, and technology, and all three were broken at about the same place with medial transverse fractures. They are sharply contracting bases, coming to a dull point. One is made of El Sauz chert, one of chalcedony, and one of a reddish siltstone. The chalcedony appears to be a late-stage manufacturing failure. Despite the sinuosity of the lateral edges, the heavy lateral grinding is either for hafting or platform preparation. The latter is suspected. Use through the life of the tool type often results in beveling and slight shoulders where the lateral margins are reworked. None of these indicators of use are present, but they could have been broken off with the distal ends. Although these points are found in a large region of South Texas Plains region (Turner et al. 2011:121), typological ambiguities create some uncertainty as to both the validity of the type and regional distribution. Lerma points were first identified by MacNeish (1958) in southern Tamaulipas, extending into southern, western, and coastal areas of Texas. He surmised the points to be Archaic, but similar points are also known from Paleoindian contexts. For example, the Iztapan Mammoth site in the Valley of Mexico yielded one point, associated with Pleistocene megafauna (Aveleyra A. de Anda 1956:21) that resembles those found on site 41SR242. The type tends to be a catchall grouping for all bi-pointed dart points, within which there might be typological valid sub-types. 
Two fragmentary bases are too small to type (Figure 7.11). Found in Feature 1 in TU 3, the first base is a well-made contracting stem with a straight to slightly concave base reminiscent of possibly a Val Verde or maybe a wide Langtry, but it is too fragmentary to conclusively determine. The second point has a sub-rectangular base and weak shoulders although the distal end is broken and it is difficult to determine whether there may have originally been barbs. It is made of a black lusterless chert that appears heat damaged. The point does not clearly fit into a recognized type, but resembles the Palmillas type.

The untyped lanceolate point, collected from the site surface, is made of a peculiar black opaque and lusterless material, possibly metamorphosed shale (Figure 7.12). It is a material that is not identified in the site's debitage, suggesting possible exotic origins. The point is missing its distal end and one proximal corner. The one remaining lateral margin is heavily ground and the high width to thickness ratio is more suggestive of early technology rather than the Archaic triangular types.

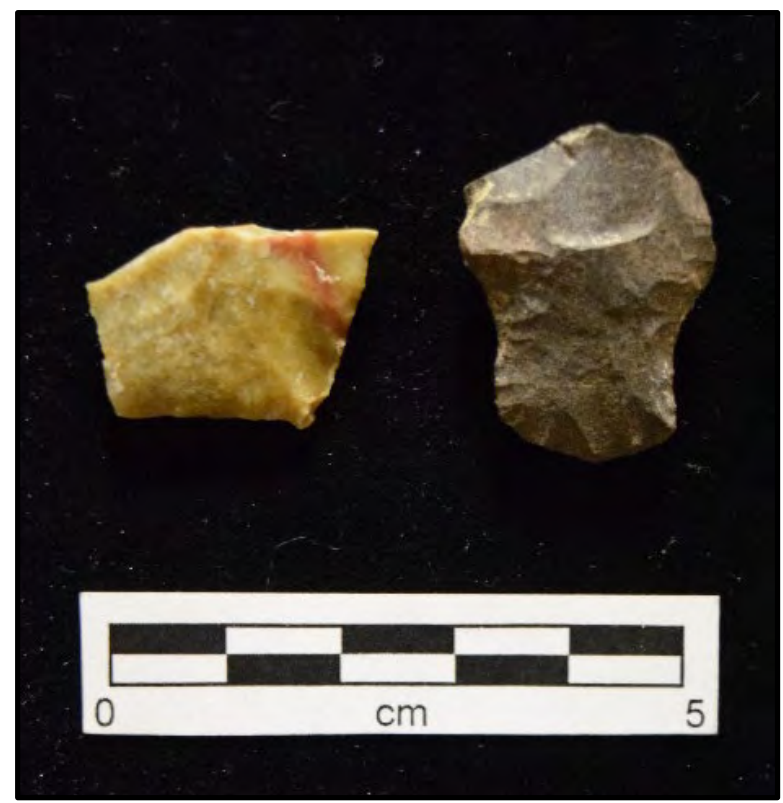

Figure 7.11. Unidentified dart point bases recovered from site 41SR242. Left to right LotSpecimen Nos. are: 175-005 and 199-159

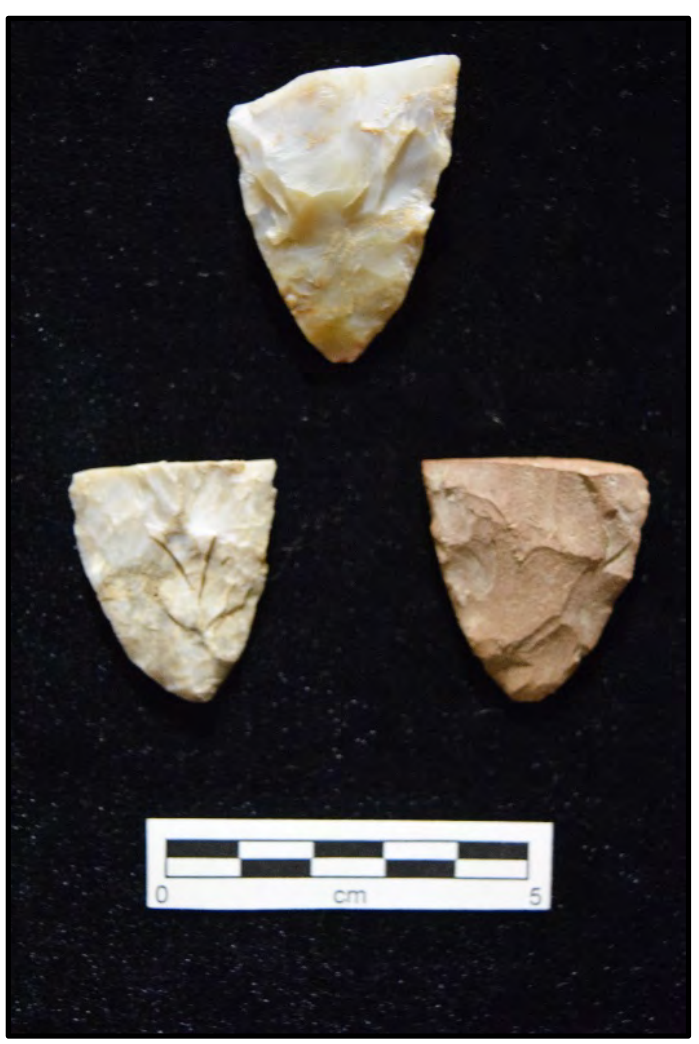

Figure 7.10. Lerma-like dart point bases recovered from site 41SR242. Left to right Lot-Specimen Nos. are: top row 004-002; bottom row 052-001 and 043-001.

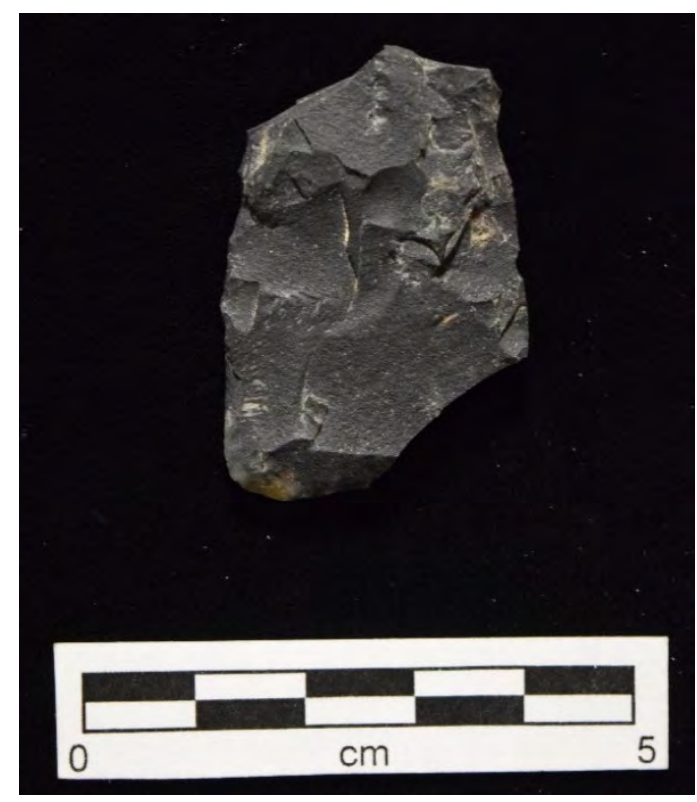

Figure 7.12. Unidentified Lanceolate dart point recovered from site 41SR242. LotSpecimen No. 015-001. 


\section{Other Lithic Tools}

The sites yielded various other lithic tools during the excavations, including 61 bifaces, one Olmos tool, Nueces tool, two beveled end scrapers, edge modified flakes, one possible chopper, cores and debitage (Table 7.13). The assemblages indicate a diverse range of activities.

Table 7.13. Other Lithic Tools Not Projectile Points Recovered from Site 41SR242

\begin{tabular}{|c|c|c|c|c|c|c|c|}
\hline $\begin{array}{l}\text { Lot } \\
\text { No. }\end{array}$ & $\begin{array}{l}\text { Specimen } \\
\text { No. }\end{array}$ & $\begin{array}{l}\text { Field } \\
\text { No. }\end{array}$ & Artifact Description & $\begin{array}{l}\text { Max. Length } \\
(\mathrm{mm})\end{array}$ & $\begin{array}{l}\text { Max. Width } \\
\quad(\mathrm{mm})\end{array}$ & $\begin{array}{l}\text { Max. Thickness } \\
(\mathrm{mm})\end{array}$ & $\begin{array}{l}\text { Weight } \\
\text { (g) }\end{array}$ \\
\hline 001 & 001 & SC 01.01 & Early-Stage Biface & 39.11 & 22.84 & 21.05 & 42.2 \\
\hline 001 & 002 & SC 01.02 & Late-Stage Biface & 20.69 & 13.31 & 7.06 & 9.6 \\
\hline 001 & 003 & SC 01.03 & Early-Stage Biface & 32.99 & 29.40 & 10.62 & 10.8 \\
\hline 001 & 004 & SC 01.04 & Edge-Modified Utilized Flake & 37.87 & 63.28 & 15.74 & 18.9 \\
\hline 001 & 005 & SC 01.05 & Edge-Modified Utilized Flake & 52.78 & 58.94 & 15.74 & 20.5 \\
\hline 002 & 001 & SC 02.01 & Late-Stage Biface & 60.18 & 38.09 & 7.80 & 15.2 \\
\hline 002 & 002 & SC 02.02 & Early-Stage Biface & 73.83 & 50.66 & 27.99 & 106.9 \\
\hline 002 & 003 & SC 02.03 & Early-Stage Biface & 66.77 & 53.28 & 22.59 & 73.9 \\
\hline 003 & 001 & SC 03.01 & Mid-Stage Biface & 61.77 & 42.34 & 15.34 & 41.9 \\
\hline 003 & 002 & SC 03.02 & Late-Stage Biface & 40.70 & 39.93 & 9.43 & 15.3 \\
\hline 004 & 001 & SC 04.01 & Mid-Stage Biface & 64.08 & 49.92 & 17.52 & 52.5 \\
\hline 005 & 002 & SC 05.02 & Late-Stage Biface & 43.18 & 35.57 & 7.86 & 11.4 \\
\hline 005 & 003 & SC 05.03 & Early-Stage Biface & 68.55 & 43.22 & 22.51 & 61.7 \\
\hline 006 & 002 & SC 06.02 & Early-Stage Biface & 63.34 & 56.71 & 26.89 & 85.9 \\
\hline 009 & 001 & SD 3 & Distally Beveled Scraper & 39.40 & 29.52 & 6.67 & 10.1 \\
\hline 010 & 001 & SD 4 & Late-Stage Biface & 36.15 & 26.99 & 7.54 & 6.8 \\
\hline 014 & 001 & SD 8 & Late-Stage Biface & 36.45 & 25.54 & 6.84 & 4.9 \\
\hline 017 & 001 & SB 1 & Mid-Stage Biface & 49.43 & 56.76 & 11.77 & 33.9 \\
\hline 018 & 001 & SB 2 & Perforator & 38.75 & 20.53 & 9.40 & 7.6 \\
\hline 019 & 001 & SB 3 & Mid-Stage Biface & 58.60 & 46.23 & 15.45 & 39.0 \\
\hline 020 & 001 & SB 4 & Discoid Uniface & 38.52 & 34.21 & 14.91 & 17.6 \\
\hline 021 & 001 & SB 5 & Late-Stage Biface & 36.16 & 31.66 & 7.69 & 8.8 \\
\hline 022 & 001 & SB 6 & Mid-Stage Biface & 49.67 & 41.07 & 9.70 & 16.8 \\
\hline 023 & 001 & SB 7 & Mid-Stage Biface & 33.51 & 44.11 & 9.57 & 15.8 \\
\hline 024 & 001 & SB 8 & Mid-Stage Biface & 74.81 & 45.97 & 14.87 & 48.2 \\
\hline 025 & 001 & SB 9 & Early-Stage Biface & 75.49 & 51.43 & 22.65 & 84.9 \\
\hline 026 & 001 & SB 10 & Early-Stage Biface & 86.31 & 62.99 & 30.63 & 147.5 \\
\hline 027 & 001 & SB 11 & Nueces Tool & 54.89 & 46.91 & 12.62 & 39.4 \\
\hline 028 & 001 & SB 12 & Early-Stage Biface & 65.13 & 59.06 & 30.80 & 111.9 \\
\hline 029 & 001 & SB 13 & Late-Stage Biface & 59.77 & 42.24 & 8.55 & 19.5 \\
\hline 030 & 001 & SB 14 & Mid-Stage Biface & 29.22 & 54.60 & 11.34 & 20.5 \\
\hline 031 & 001 & SB 15 & Distally Beveled Scraper & 40.74 & 35.08 & 7.05 & 12.9 \\
\hline 032 & 001 & SB 16 & Late-Stage Biface & 35.69 & 23.62 & 7.99 & 4.3 \\
\hline 033 & 001 & SB 17 & Late-Stage Biface & 34.67 & 41.22 & 8.27 & 12.6 \\
\hline 034 & 001 & SB 18 & Late-Stage Biface & 33.82 & 29.95 & 8.22 & 9.4 \\
\hline 035 & 001 & SB 19 & Side Scraper & 111.80 & 82.55 & 40.97 & 408.3 \\
\hline 044 & 001 & SB2 02 & Late-Stage Biface & 52.65 & 31.65 & 9.74 & 12.5 \\
\hline 045 & 001 & SB2 03 & Late-Stage Biface & 38.64 & 29.59 & 8.72 & 8.5 \\
\hline
\end{tabular}




\begin{tabular}{|c|c|c|c|c|c|c|c|}
\hline $\begin{array}{l}\text { Lot } \\
\text { No. }\end{array}$ & $\begin{array}{l}\text { Specimen } \\
\text { No. }\end{array}$ & $\begin{array}{l}\text { Field } \\
\text { No. }\end{array}$ & Artifact Description & $\begin{array}{l}\text { Max. Length } \\
\quad(\mathrm{mm})\end{array}$ & $\begin{array}{l}\text { Max. Width } \\
(\mathrm{mm})\end{array}$ & $\begin{array}{l}\text { Max. Thickness } \\
(\mathrm{mm})\end{array}$ & $\begin{array}{l}\text { Weight } \\
\text { (g) }\end{array}$ \\
\hline 046 & 001 & SB2 04 & Late-Stage Biface & 36.82 & 34.82 & 8.88 & 13.5 \\
\hline 047 & 001 & SB2 05 & Late-Stage Biface & 50.37 & 39.22 & 7.06 & 11.6 \\
\hline 048 & 001 & SB2 06 & Mid-Stage Biface & 36.90 & 45.69 & 9.77 & 21.1 \\
\hline 049 & 001 & SB2 07 & Mid-Stage Biface & 49.51 & 50.93 & 13.42 & 32.4 \\
\hline 050 & 001 & SB2 08 & Mid-Stage Biface & 44.18 & 49.44 & 10.77 & 30.0 \\
\hline 051 & 001 & SB2 09 & Early-Stage Biface & 77.36 & 45.06 & 20.72 & 59.5 \\
\hline 053 & 001 & SB2 11 & Early-Stage Biface & 71.62 & 75.22 & 27.42 & 114.8 \\
\hline 054 & 001 & SB2 12 & Mid-Stage Biface & 68.32 & 32.29 & 16.78 & 34.8 \\
\hline 055 & 001 & SB2 13 & Uniface & 60.84 & 31.73 & 11.21 & 21.8 \\
\hline 056 & 001 & SB2 14 & Early-Stage Biface & 48.63 & 59.03 & 19.30 & 45.6 \\
\hline 057 & 001 & SB2 15 & Mid-Stage Biface & 70.29 & 40.41 & 18.60 & 45.4 \\
\hline 058 & 001 & SB2 16 & Late-Stage Biface & 43.45 & 27.82 & 6.62 & 8.1 \\
\hline 060 & 001 & SB2 18 & Mid-Stage Biface & 41.97 & 35.96 & 12.26 & 20.5 \\
\hline 061 & 001 & SB2 19 & Olmos Biface & 35.30 & 28.61 & 8.02 & 7.9 \\
\hline 062 & 001 & SB2 20 & Early-Stage Biface & 94.61 & 78.01 & 24.18 & 152.9 \\
\hline 159 & 102 & 8.001 & Edge-Modified Utilized Flake & 38.29 & 23.67 & 13.01 & 8.3 \\
\hline 167 & 016 & 16.001 & Late-Stage Biface & 39.39 & 41.65 & 9.40 & 18.7 \\
\hline 169 & 005 & 19.001 & Mid-Stage Biface & 29.91 & 33.98 & 13.16 & 14.4 \\
\hline 169 & 006 & 19.002 & Late-Stage Biface & 27.36 & 32.53 & 7.85 & 9.0 \\
\hline 171 & 014 & 21.001 & Late-Stage Biface & 35.10 & 25.11 & 8.78 & 10.7 \\
\hline 178 & 001 & 28.001 & Late-Stage Biface & 46.28 & 43.71 & 9.75 & 14.5 \\
\hline 180 & 001 & 29.002 & Early-Stage Biface & 60.53 & 49.86 & 21.41 & 53.0 \\
\hline 189 & 005 & 32.001 & Late-Stage Biface & 48.77 & 25.42 & 10.18 & 13.1 \\
\hline 190 & 006 & 33.001 & Edge-Modified Utilized Flake & 25.43 & 20.75 & 7.59 & 3.3 \\
\hline 197 & 001 & 41.001 & Mid-Stage Biface & 82.40 & 50.30 & 19.49 & 71.1 \\
\hline 199 & 158 & 43.001 & Mid-Stage Biface & 31.19 & 41.80 & 12.31 & 16.0 \\
\hline 201 & 069 & 46.001 & Early-Stage Biface & 38.29 & 42.72 & 14.21 & 27.1 \\
\hline 203 & 138 & 48.001 & Early-Stage Biface & 45.36 & 44.93 & 15.44 & 31.8 \\
\hline 203 & 139 & 48.002 & Early-Stage Biface & 54.10 & 52.32 & 27.65 & 64.8 \\
\hline 203 & 140 & 48.003 & Edge-Modified Utilized Flake & 83.77 & 69.82 & 23.38 & 182.3 \\
\hline 210 & 006 & 54.002 & Late-Stage Biface & 36.20 & 38.43 & 9.12 & 13.0 \\
\hline 210 & 007 & 54.003 & Mid-Stage Biface & 31.46 & 46.83 & 15.55 & 21.4 \\
\hline 210 & 008 & 54.004 & Mid-Stage Biface & 62.02 & 37.62 & 16.31 & 33.6 \\
\hline 210 & 009 & 54.005 & Early-Stage Biface & 80.52 & 43.92 & 30.69 & 100.7 \\
\hline 215 & 001 & 59 & Mid-Stage Biface & 79.36 & 44.05 & 19.75 & 48.0 \\
\hline 216 & 001 & 60 & Early-Stage Biface & 90.91 & 45.10 & 21.92 & 100.8 \\
\hline 219 & 001 & 63 & Edge-Modified Utilized Flake & 39.77 & 32.37 & 7.91 & 10.2 \\
\hline 220 & 001 & 64 & Edge-Modified Utilized Flake & 52.30 & 26.50 & 23.39 & 21.7 \\
\hline
\end{tabular}




\section{Olmos Biface}

One Olmos biface was recovered from the site surface. The tool is finely made and bifacially reduced from high-quality, two-toned tan and brown chert (Figure 7.13). The dorsal side has moderately steep beveling on the lateral sides and steeper beveling (circa 65 to 75 degrees) in the distal bit end. No clear evidence of hafting is noted. No burin spalls, which are commonly found on Olmos bifaces, are present along the distal lateral margins.

\section{Nueces Tool}

The Nueces tool, or scraper, was first defined from specimens recovered from the Oulline site (41LS3) and others in LaSalle County (Hester et al. 1969). The tools were defined as:

...having a distinctive trapezoidal outline. The edges of the specimens are usually straight to convex; the widest side is steeply beveled....[and] are plano-convex in cross section (Hester et al. 1968:148).

One Nueces tool was recovered from the surface of 41SR242. Made from a yellowish grainy siltstone, the tool is unifacially worked with a steeply beveled (circa 75 degrees), convex distal (bit) end (see Figure 7.13).

\section{Possible Perforator}

One possible perforator was recovered from the site surface. The informal, bifacially reduced chert artifact appears to be retouched at its distal end to form a slight diamond-shaped cross section (see Figure 7.13). Use-wear is not clear at low-powered magnification. Given the informality of the tool and lack of clear use-wear, the function of this artifact is tentative.

\section{Beveled End Scrapers}

TxDOT recovered two very similar beveled end scrapers from the site surface. Both are well-thinned bifacial tools made from fine-grained chert with rectangular to sub-rectangular, slightly convex, tapered bases (Figure 7.14). The distal ends are unifacially beveled to about a 45-degree angle. It is possible both tools were made from recycled broken late-stage bifaces.

\section{Discoidal Uniface}

One curious specimen of undetermined function is a discoidal uniface recovered from the site surface. Made of a tan chert with stream-rolled cortex on the unworked side (see Figure 7.14). About $2.5 \mathrm{~cm}$ in diameter, the circular tool has small unifacial flaking originating completely around the margins.

Two small flakes are removed from the cortical side, making it slightly bifacial. No use wear is evident and cortex is typically not used as a working edge. Consequently, the objective of the piece is undetermined. 


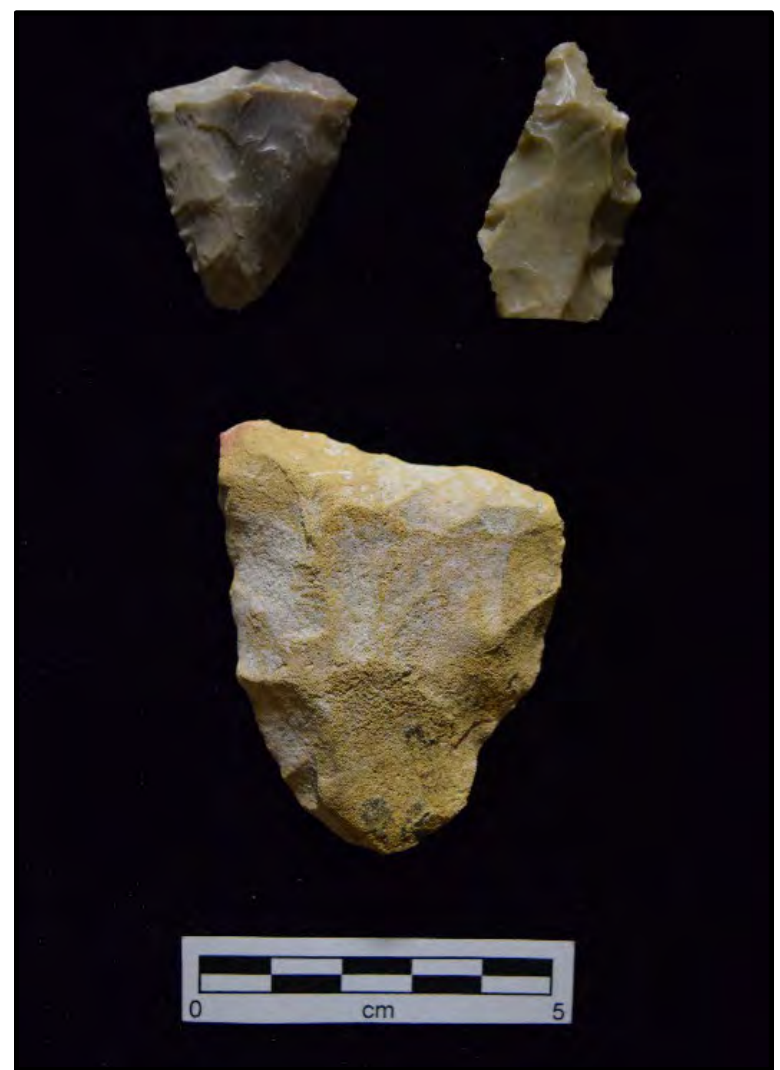

Figure 7.13. Olmos Biface, Perforator, and Nueces Tool recovered from site 41SR242. Left to right Lot-Specimen Nos. are: top row Olmos biface 061-001, perforator 018-001; bottom row Nueces tool 027-001.

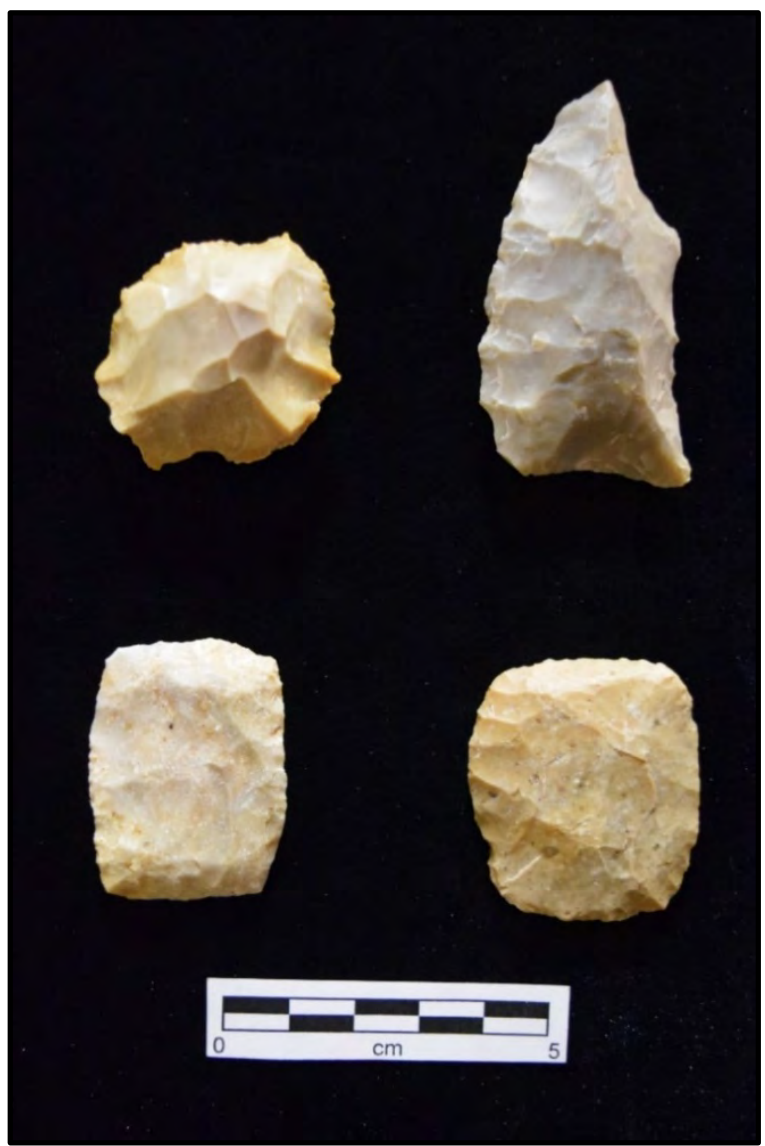

Figure 7.14. Unifaces and scrapers recovered from site 41SR242. Left to right Lot-Specimen Nos. are: top row discoidal uniface 020-001, uniface 055-001; bottom row beveled bifacial end scrapers 009-001 and 031-001.

\section{Bifaces}

This section discusses bifacially reduced tools that do not fit into any of the previously discussed categories such as points or preforms. A total of 61 bifaces were collected from 41SR242. As discussed in TxDOT protocols, the sequence of lithic bifacial reduction has been consistently viewed as a stage or step-like production process along a trajectory, from raw material to finished tool (Callahan 1974; Patterson 1977:60; Whittaker 1994). As the systematic reduction of the biface occurs, it goes through various sequential stages or steps distinguished by the manufacturing implement utilized, as well as the size, thickness, and form of the biface. Differentiation between the sequence and nature of these stages or steps is attributed to a host of variables including the form and quality of the parent raw material, the desired end product of the reduction process, and the flint knapping style or technique employed. Furthermore, previously completed tools may be reintroduced into the production trajectory to be repaired, rejuvenated, or recycle into a different form.

Previously completed tools, such as the beveled end scrapers discussed above, may be reintroduced into the production trajectory and can be repaired, rejuvenated or recycled into a different form. Although projectile points are bifaces, they are their own analytical category and are not included in the biface totals. 
Although Callahan (1979) identified nine stages in biface production, these are condensed into three main stages for the purposes of the current study. In Callahan's analysis, stages 6 through 9 are related to the creation of hafting elements and notching. Callahan's Stage 1 is a cobble, flake, or shatter blank that has not been further modified - none of the specimens described here are unmodified, notched, or otherwise have hafting elements. Accordingly, we divide the assemblage into early, middle, and late stages. A primary variable used to define the stages of the reduction sequence were the width to thickness ratio, with consideration of edge sinuosity and edge angles. The edge angle and width to thickness ratios can vary between sites and within assemblages based upon the parent source being either flakes or cobbles and the desired finished product (Callahan 1979; Andrefsky 1998), biface cross section, and flaking patterns are also used to characterize each reduction stage. Breakage occurs during manufacture, use, discard, and taphonomic factors; the following uses breakage terms provided in the TxDOT protocols.

\section{Early-Stage Bifaces}

Nineteen early-stage bifaces were recovered, 14 of which were collected from surficial contexts (Figure 7.15). These specimens typically have an average width to thickness ratio between 2 and 3 and an average (mean) edge angle between 50 and 80 degrees. These artifacts are preliminary stages of reduction where there is little modification, such as prepared platforms. Flake scars are typically deep and short resulting in a scalloped or sinuous edge. These deep scars are characteristic of hard hammer percussion, which can leave a pronounced negative bulb. The profile is strongly biconvex when blanks are from thick, blocky, flakes or cobbles. Cortex is common, found on 14 of the 19 early-stage bifaces (73.7 percent). Discard was often the result of either breakage, material flaw, failure to thin, or exhaustion of utility (if used for flake production). Early-stage bifaces were likely being reduced for different tool forms; one specimen (Lot 025, Specimen 001) appears to have been intended as a gouge but was not completed.

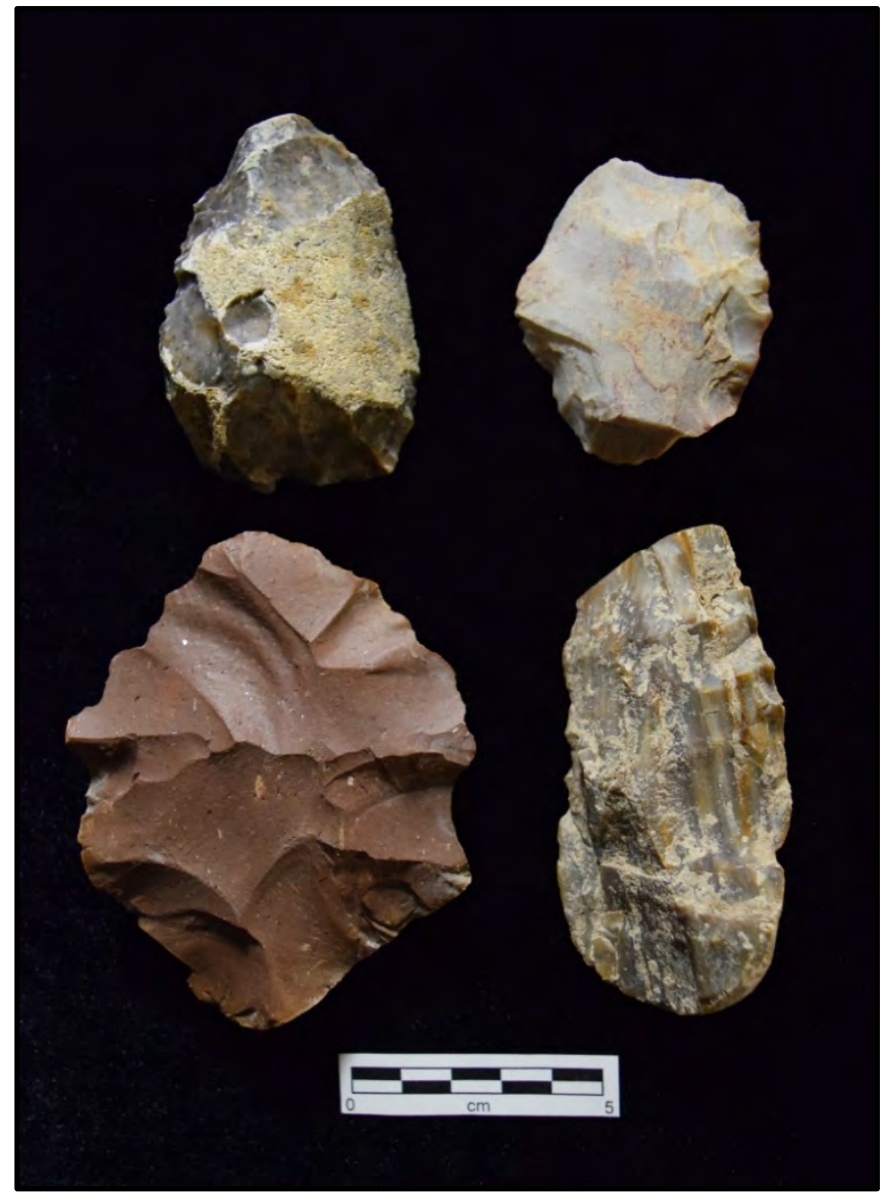

Figure 7.15. Representative sample of late-stage bifaces recovered from Site 41SR242. Left to right Lot-Specimen Nos. are: top row 044-001, 047-001, 058-001 and 178-001; bottom row 005-002, 167-016 and 046-001. 
There is roughly an equitable distribution in the counts of early, middle, and late stage bifaces on the site, which indicates the complete array of bifacial reduction was occurring and the site is close to the lithic raw material source. The occupants primarily were not conducting initial reduction off site, at a farremoved source, and solely bringing in later stage bifaces for further reduction. Conversely, they were exploiting local resources and early reduction occurred at the procurement locale as part of the selection process. The shape of the early-stage bifaces is generally amorphous or ovate, and likely resembling the shape of the parent lithic source.

\section{Mid-Stage Bifaces}

Twenty mid-stage bifaces were recovered, 14 from the site surface and six from buried contexts (Figure 7.16). Mid-stage bifaces typically have a width to thickness ratio between 3 and 4. Longer flakes are removed and flake scars continue to the center of the biface, especially on bifaces produced from cobble blanks. Edge angles are from 40 to 50 degrees. Cortex is significantly less common, found on only one of the 20 mid-stage bifaces. During the transition from early stage, mass reduction is statistically significant as cortex removal continues. The average weight of mid-stage bifaces (32.86 grams) is less than half the weight of early-stage bifaces (71.83 grams). The shapes become more regular and generic like ovate to oval pointed.

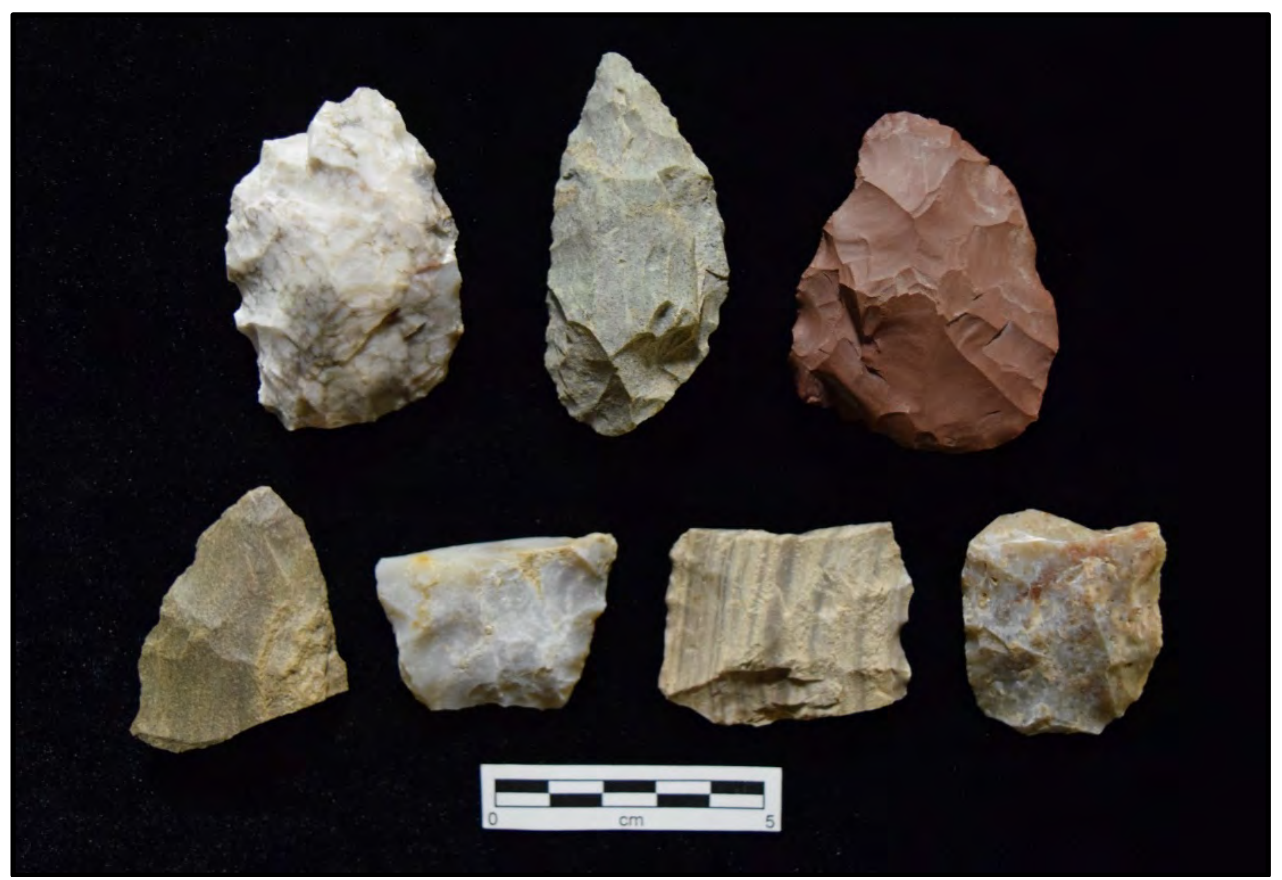

Figure 7.16 Representative sample of mid-stage bifaces recovered from Site 41SR242. Left to right Lot-Specimen Nos. are: top row 003-001, 054-001 and 019-001; bottom row 022-001, 023-001, 048-001 and 060-001.

Discard patterns appear equally divided between breakage and failure to thin. Ten of the 20 mid-stage bifaces are broken, usually transverse medial fractures, and 10 are complete but have various issues, such as stacked hinge fractures that preclude further thinning. Flake scars are large and shallow and cross the medial centerline of the biface and the biconvex profile is less pronounced. The edge is less sinuous, and the outline of the biface is defined. The number of shapes becomes increasingly diversified, with oval pointed or teardrop shapes being the highest. As an intermediate stage, a variety of percussive techniques that may have been used on the more-robust earlier stages may expose previously hidden flaws in the 
material, and the consequence of misplaced blows becomes more damaging. The trend is accelerated in the final stages, when the affects from material flaws or knapping mistakes results in catastrophic fracture.

\section{Late-Stage Bifaces}

A total of 22 late-stage biface were recovered, 16 from surficial contexts and six from subsurface contexts (Figure 7.17). These specimens have an average width to thickness ratio of about 4 to 5 and an edge angle of approximately 30 degrees. The biconvex cross section profile is less pronounced and the edge profile is straighter. The outline of the biface may be further shaped or refined at this stage. The trends in breakage patterns between early and mid-stage bifaces increases dramatically during late-stage reduction; 20 of the 22 late-stage bifaces (91 percent) are broken, usually with transverse medial fractures, compared to 50 percent breakage in the mid-stage bifaces. Oval pointed is the predominant shape, followed by subtriangular.

Since late-stage bifaces are the final stage of reduction without a formal tool designation, the category may nevertheless include some final tool forms, such as distal tips that cannot be clearly classified as a type. Consequently, some breakage may be the result of use as well as manufacturing.

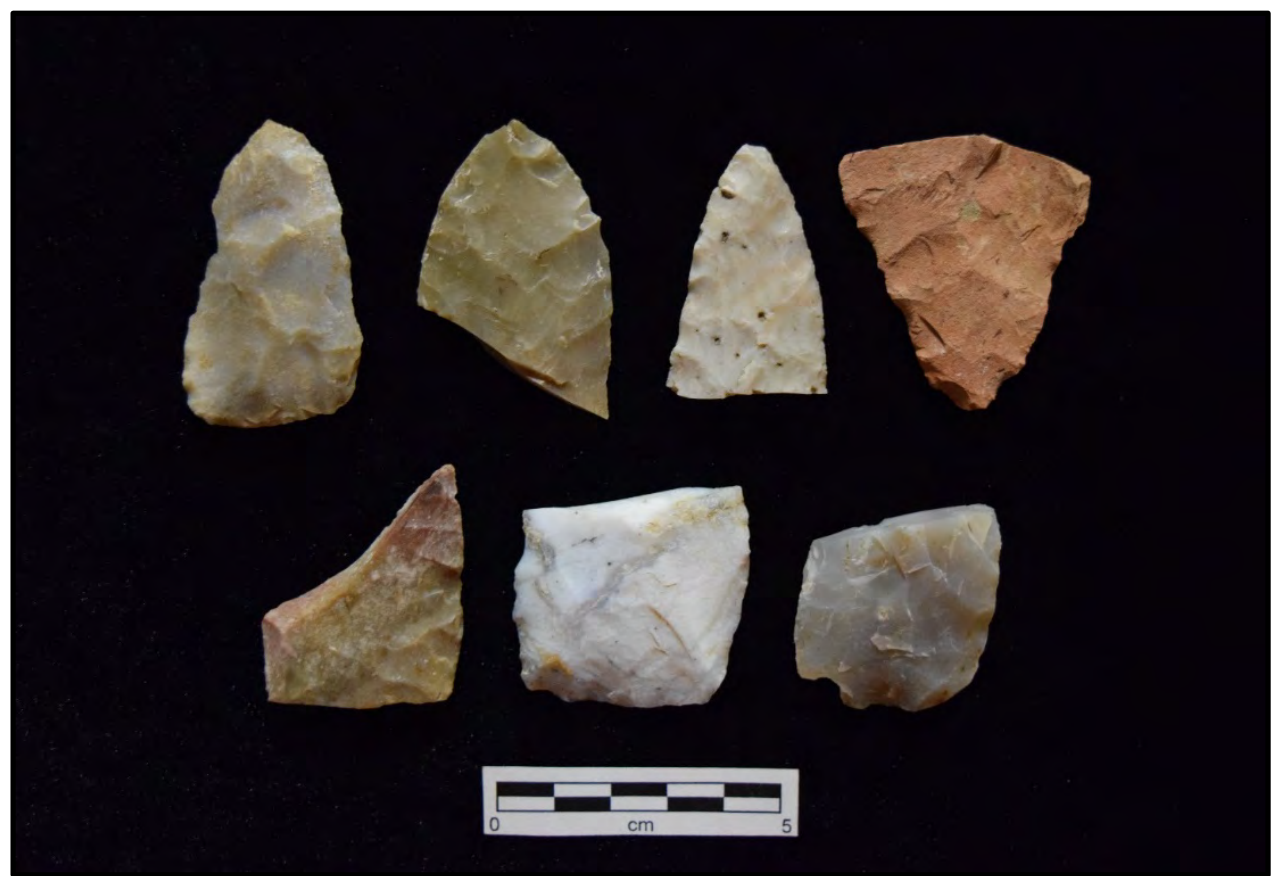

Figure 7.17. Representative sample of late-stage bifaces recovered from Site 41SR242. Left to right Lot-Specimen Nos. are: top row 044-001, 047001, 058-001 and 178-001; bottom row 005-002, 167-016 and 046-001.

\section{Battered Cobble or Chopper}

Choppers are a more expedient tool manufacturing technique and are typically more chunky specimens. One possible chopper was recovered from Feature 4 in TU 7. Stream-rolled cortex remain on one side and a single large flake was removed from the other side, possibly during its use. Battering on one end is evident by numerous short, stacked hinge fractures. Intensive heat damage has caused crazing and potlids on the other end. The artifact is made of a reddish-brown chert. 


\section{Edge-Modified Flake Tools}

Edge-modified flake tools, frequently referred to as modified flakes, are flakes with deliberately retouched edges that lack standardized formal characteristics (Odell 2003). Utilized flakes, defined as unretouched flakes that have been modified as a result of use as tools, are included in this category as well. Both forms having been minimally shaped through use or retouch and are consequently considered informal or expedient tools. Normally, flaking scars are confined to less than $10 \mathrm{~mm}$ of the lateral margins and do not extend into the interior surface of the flake. The modification on these tools may be unifacial or bifacial, and they may have served multiple functional purposes, such as expedient knives, scrapers, or gravers. Utilized flakes can be the most problematic to identify accurately since edge damage through use is created through intensity, duration, and type of use. Additionally, edge damage can likewise occur through post-depositional processes that mimic use wear such as crushing and trampling.

Six modified flakes were recovered, three from surface collections, two from TU 5, and one from Feature 1 in TU 1. Except for one made of black rhyolite, all are chert flakes. None of the specimens are intensively retouched or edge damaged, only having subtle continuous nibbling along some margins. Given the many disturbances in the area (e.g., bulldozing and root plowing), some of the observed damage could be the result of modern activities.

\section{Non-Feature Lithic Debitage}

Detailed debitage analysis was conducted on the lithic reduction features, Features 1 and 4 . SWCA conducted a much more limited analysis on the remainder of the debitage. There were 1,061 pieces of debitage recovered from the backhoe trenches, scrapes, column samples, and TUs on site 41SR242. Generally speaking, the debitage exhibits all stages of lithic reduction, including early through late reduction stages. The raw material consists of diverse materials reflecting the myriad locally available materials, but most is fine-grained chert made available through local sources. Additionally, some of the debitage exhibited evidence of heat treatment and/or burning.

Size-sorting showed the most common size grade (399 flakes) was between 0.5 and 0.75 inch in maximum dimension with 0.75 to 1 inch (296 debitage) and greater than 1 inch (210 pieces) the next highest grades. Less than 0.25 inch is the smallest category and largely attributable to screen size sampling bias. Between 0.25 and 0.5 inch grade yielded 142 pieces of debitage. The median size grade of 0.5 to 0.75 is likely more of a reflection of raw material size than stage of reduction, since all stages of reduction are reflected in the previously discussed biface assemblage.

\section{Burned Rock}

On site 41SR242, there were 628 pieces of burned rock weighing 18,105.0 grams, recovered from the backhoe trenches, scrapes, column samples, and TU during the testing excavations. The majority of these were associated with features. The average rock size was 28.82 grams. These materials will be discarded and not curated.

\section{Cores}

Two cores, a core fragment, and one core platform rejuvenation flake were recovered from 41SR242 (Table 7.14). Cores are objective pieces of lithic material from which another piece is detached (Andrefsky 1998). They exhibit negative flake scars created by fracturing, a reductive process that involves the removal of flakes from the core by striking it with a percussor, such as a billet or hammerstone. Flakes may also be detached through indirect percussion using a punch and through 
pressure. The primary purpose of cores is a source of flakes, which may be utilized or further reduced into stone tools. In some scenarios, a sharp margin of the core itself may be utilized as a stone tool.

Table 7.14. Cores and Platform Rejuvenation Core Flake Recovered from Site 41SR242

\begin{tabular}{ccclcccc}
\hline $\begin{array}{c}\text { Lot } \\
\text { No. }\end{array}$ & $\begin{array}{c}\text { Specimen } \\
\text { No. }\end{array}$ & $\begin{array}{c}\text { Field } \\
\text { No. }\end{array}$ & Artifact Description & $\begin{array}{c}\text { Max. Length } \\
(\mathbf{m m})\end{array}$ & $\begin{array}{c}\text { Max. Width } \\
(\mathbf{m m})\end{array}$ & $\begin{array}{c}\text { Max. Thickness } \\
(\mathbf{m m})\end{array}$ & $\begin{array}{c}\text { Weight } \\
(\mathbf{g})\end{array}$ \\
\hline 003 & 003 & SC 03.03 & Platform Rejuvenation Core Flake & 67.12 & 62.17 & 25.38 & 81.3 \\
\hline 164 & 036 & 13.001 & Multidirectional Core & 86.95 & 53.85 & 46.22 & 239.4 \\
\hline 173 & 182 & 23.001 & Multidirectional Core & 69.26 & 49.68 & 22.53 & 59.2 \\
\hline 187 & 005 & 30.001 & Multidirectional Core & 55.21 & 35.70 & 32.79 & 57.4 \\
\hline
\end{tabular}

The two cores are informal, lightly used, and multidirectional with striking platforms on different axis and flakes removed in numerous directions. Both are made from locally available chert gravels. From Feature 1 in Level 3 of TU 1, one core is made of stream-rolled chert gravel with at least five flake scars from two faces; cortex remains on approximately 60 percent of the artifact. The second core is from TU 4, Level 3 and is a small fine-grained chert with multidirectional flake scars. No use wear, evidence of use as a core tool, is evident on either core.

The platform rejuvenation flake, recovered from the site surface, is a light-colored chalcedony. Multiple stacked hinge fractures are present on one side, which the knapper circumvented by knocking off the entire face to provide a more workable platform.

Finally, one core fragment is a coarse-grained rhyolitic angular fragment with several flake scars. The platform from which several flake scars originated has broken off. The piece is too fragmentary to discern its original form.

\section{Prehistoric Ceramic Sherd}

One small, thin undecorated prehistoric plainware ceramic sherd was recovered from Feature 2 in TU 2, Level 3 (Figure 7.18). Viewed under 200× magnification, the temper is coarse sand; no bone, shell, grog, or other tempering agent were noted. The sherd is untyped but is consistent with lower Gulf Coastal ceramics, which are thin-walled pots (e.g., Rockport Plain). The ceramic indicates a Late Prehistoric component. 


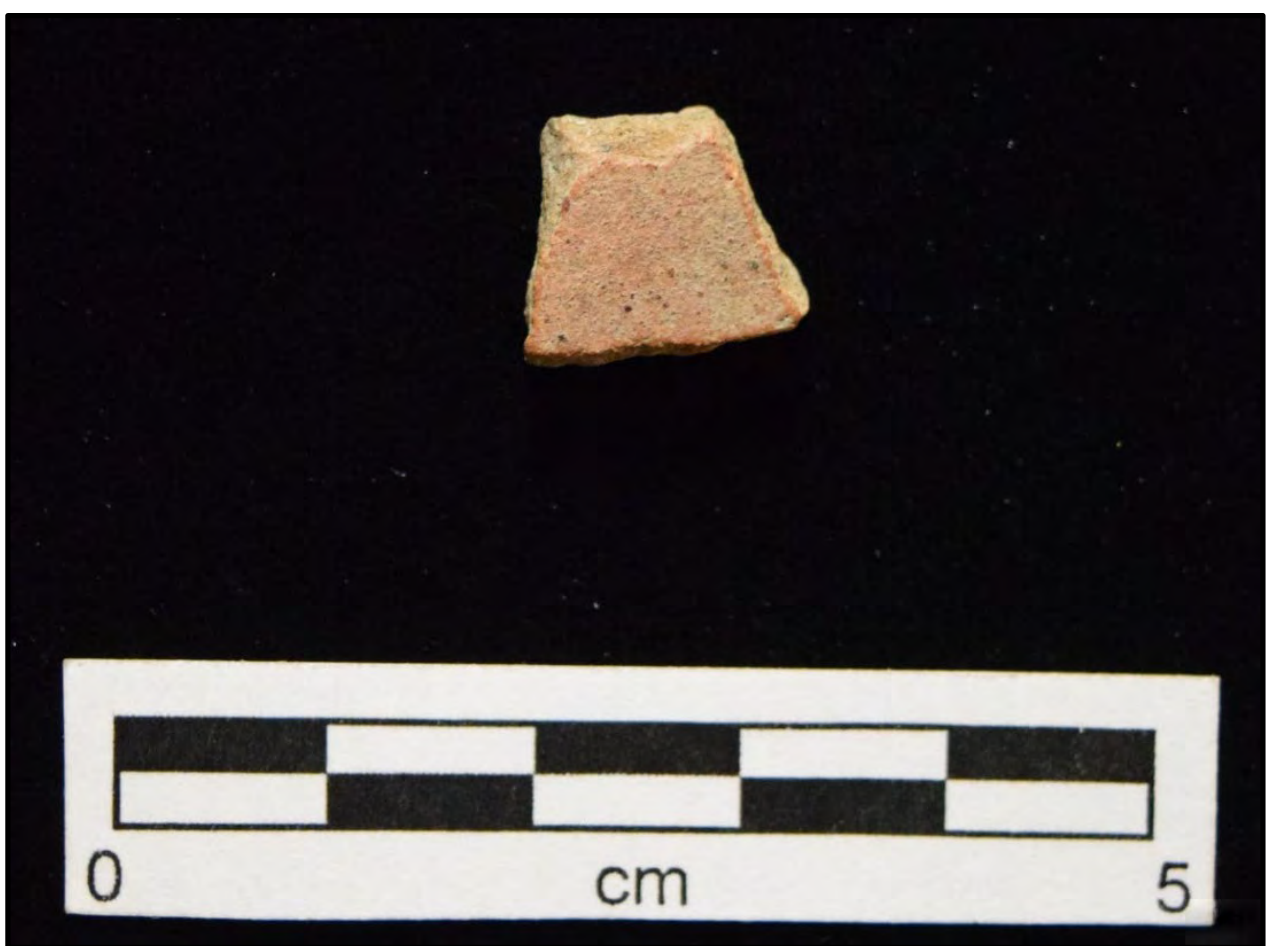

Figure 7.18. Prehistoric ceramic sherd recovered from site 41SR242. LotSpecimen No. 170-006.

\section{Historic Artifacts}

In addition to the prehistoric artifacts, the site also contains a historic component identified by a relatively diffuse scatter of glass, ceramics, metal, and a few miscellaneous items such as a spark plug and bullet cartridge. A total of 101 historic artifacts were recovered, 10 from subsurface contexts and the remainder from the site surface (Table 7.15).

Table 7.15. Historic Materials Recovered from Site 41SR242

\begin{tabular}{lc}
\hline Materials Recovered & Count \\
\hline AC Sparkplug & 1 \\
\hline Aqua Glass & 7 \\
\hline Bailing Wire & 2 \\
\hline Blue Transfer Ware Ceramic & 1 \\
\hline Brown Glass & 1 \\
\hline Colorless Glass & 19 \\
\hline Iron Pipe & 1 \\
\hline Earthenware Slip Glazed-Brown Ceramic & 10 \\
\hline Earthenware Slip Glazed-Green Ceramic & 1 \\
\hline Earthenware Slip Glazed-Tan Ceramic & 1 \\
\hline Fence Staple & 1 \\
\hline Heavy Gauge Wire & 2 \\
\hline Manganese Glass & 18 \\
\hline
\end{tabular}




\begin{tabular}{lc}
\hline Materials Recovered & Count \\
\hline Metal Bracket & 1 \\
\hline Metal Buckle & 1 \\
\hline Metal Perforated Strap & 3 \\
\hline Miscellaneous Metal Fragments & 2 \\
\hline Pistol Cartridge & 1 \\
\hline Platform Rejuvenation Core Flake & 1 \\
\hline Porcelain Ceramic Figurine Fragment & 1 \\
\hline Sheet Metal & 1 \\
\hline Undecorated Ironstone & 1 \\
\hline Undecorated Whiteware Ceramic & 23 \\
\hline Wire & 1 \\
\hline Total & 101 \\
\hline
\end{tabular}

Forty-five of the artifacts (47.4 percent) are glass fragments, including 19 pieces of colorless glass, 18 pieces of manganese (purple) glass, seven aqua shards, and one brown shard. The colorless glass methods indicate a twentieth century (post-World War I) date, whereas the manganese glass suggest a pre-World War I date, since the use of manganese was discontinued during the war. All of the glass fragments are relatively small and have few diagnostic elements such a maker's marks, finishes, bases, stippling (post-dating 1940), seams or other or distinct manufacturing elements. Except one piece of window glass, which suggests an architectural feature, all of the glass are bottle fragments. Most items appear sand etched like beach glass, an indicator of long surface exposure. In general, the available diagnostic attributes indicate an early- to mid-twentieth-century occupation.

Thirteen metal artifacts include one iron sewer pipe fragment, one clothing clasp (like for overalls), four rusty wire fragments, two pieces of strap metal, an unidentified tool or machine part, a fencing nail, an ammunition cartridge, and three unidentified pieces of rusty iron. The ammunition cartridge appears to be a .44 to .50 caliber (the artifact is crushed making dimensions imprecise) with an " $\mathrm{H}$ " headstamp from the Winchester Repeating Arms Co in New Haven, Connecticut (International Ammunition Association 2019). Winchester produced the rim-fired bullet for use in Henry rifles for nearly a century beginning in the 1860s. None of the other metal fragments are temporally diagnostic.

One rusty, old spark plug was recovered from the site surface. It is an AC 44-5 plug with a Coralox ceramic insulator. The plug was made by AC Spark Plug Company before it merged with United Delco to form AC-Delco in 1974. The Coralox insulator appears on AC spark plug advertising in the 1940s and 1950s.

Finally, 36 fragments of historic ceramics were collected, 30 were from the site surface and three were from shallowly buried contexts in TUs 2 and 4 and BHT 8 (Figure 7.19). These include 21 undecorated whiteware sherds, a porcelain figurine fragment, 12 earthenware slip glazed brown ceramic fragments, one blue transfer ware, an undecorated ironstone. One whiteware sherd contained the margins of a black maker's mark, but it was too fragmentary to identify.

Overall, the historic artifact assemblage indicates an early- to mid-twentieth-century occupation. Most of the assemblage is domestic debris, such as ceramics, glass, porcelain figure, and window glass. It is unclear whether the assemblage is from primary discard from an occupation in or near the site or whether it derives from secondary discard (dumping) from nearby residences. 


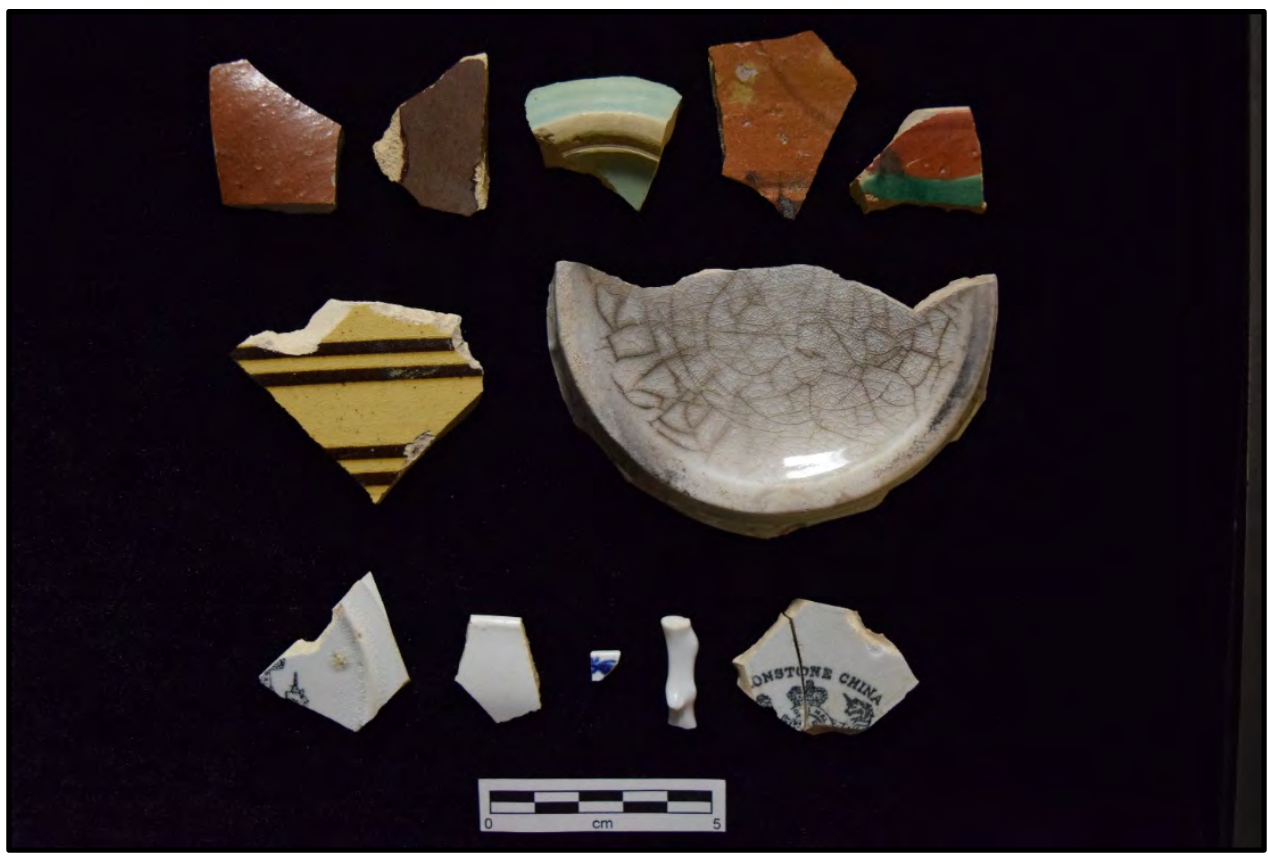

Figure 7.19. Representative sample of historic ceramics recovered from site 41SR242. Left to right Lot-Specimen Nos. are: top row 063-001, 071001, 075-001, 126-001 and 150-001; middle row 142-001 and 064-001; bottom row 069-001, 104-001, 119-001, 143-001 and 147-001.

\section{Faunal Remains}

TxDOT and SWCA recovered and analyzed 52 vertebrate faunal remains from the excavation of archeological site 41SR242. Each element within the assemblage was thoroughly analyzed by Christopher Shelton, M.A., both macroscopically, and with the aid of a 10× microscope combined with an oblique angle light source. SWCA attempted to identify each specimen within the assemblage to skeletal element, as well as to the lowest possible level of taxonomic classification. A full accounting of the faunal analysis can be found in Appendix E.

The most prevalent taphonomic processes identified during the analysis are general weathering, geogenic acid etching, rodent gnawing, and/or burning (Figure 7.20; Appendix E). Anthropogenic taphonomy is biased against in the assemblage due to the prevalence of natural taphonomic processes; however, a total of eight (15.4 percent) specimens were found to exhibit signs of having been burned (Figure 7.21; Appendix E). Although burning can occur naturally, the specimens in the assemblage show variable degrees of burning on single elements. More specifically, single elements may have small portions of the element burned to black in color, while the rest of the element appears unaffected. This pattern of variable evidence of heating can indicate cooking/roasting. The burned potions of the bone may have been exposed during the butchery processes, while the rest of the element were protected from the direct flame by the remaining tissue (meat).

As a result of the high degree of fragmentation, poor preservational environment, and other taphonomic factors, few of the fragments could be attributed to specific elements and/or specific taxa (Appendix E). From the vertebrate assemblage, 10 (23.1 percent) specimens could not be defined beyond class Mammalia, seven (13.5 percent) specimens could be attributed to microfauna and/or biological order Rodentia, and five (9.6 percent) specimens could be contributed to the biological order Testudines (turtle/tortoise). Three specimen could be accurately attributed to the genus level. One specimen is a Pecari tajacu, more commonly known as a peccary or a javelina (Figures 7.22 and 7.23). Additionally, 
two fragments (specimens 214-001 [Figure 7.20] and 214-002) fit together and are part of a cow or bison phalange. Given the subsurface context with prehistoric artifacts, the bones are surmised to be bison.

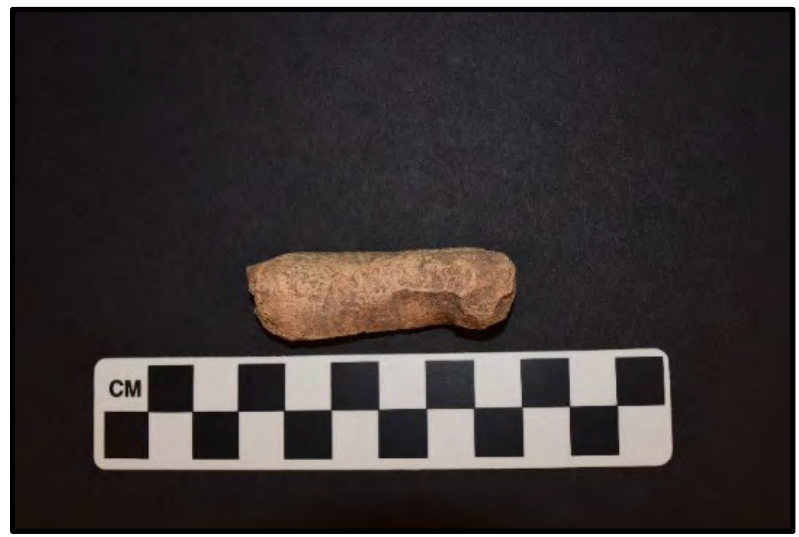

Figure 7.20. Lot 214-001: Part of a bovid (likely bison) phalange, with the cortical surface obliterated by extensive rodent gnawing.

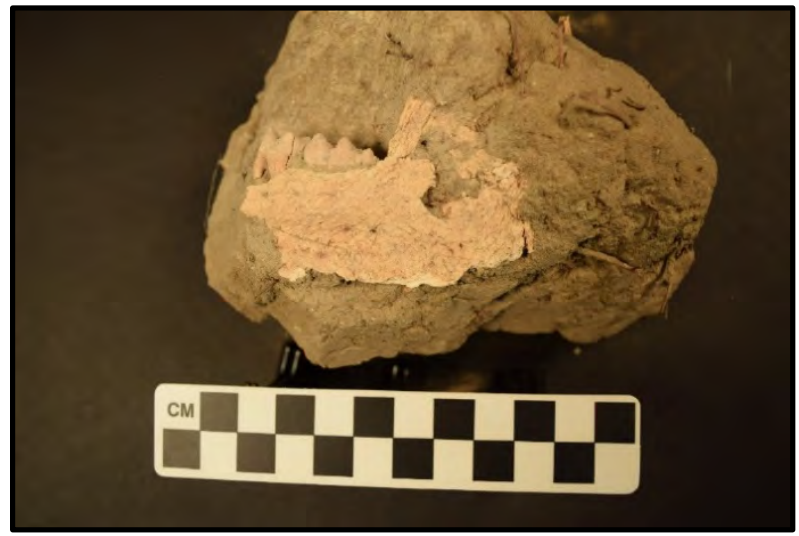

Figure 7.22. Lot 213-001: Javelina mandible with surrounding matrix.

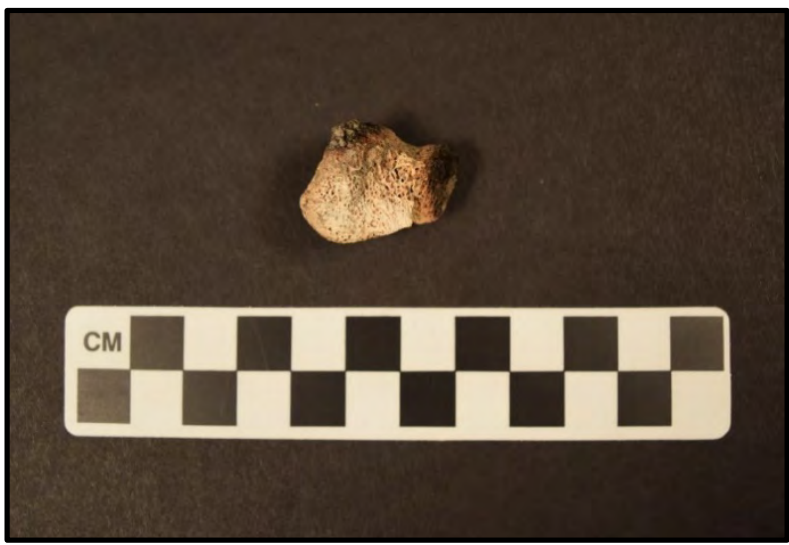

Figure 7.21. Lot 162-045: Trabecular bone fragment exhibiting indications of variable heating.

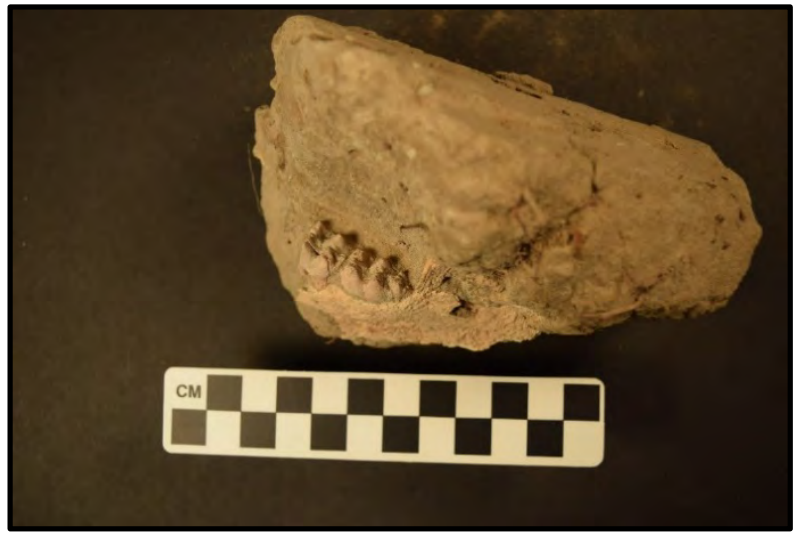

Figure 7.23. Lot 213-001: Javelina mandible with surrounding matrix, focus on the occlusal surface of the molars.

Although anthropogenic surface modification is biased against in the assemblage due to natural taphonomy, anthropogenic processes can be inferred through variable burning, and to a lesser degree, fragmentation and fracture margins. As stated above, a total of eight elements exhibit evidence of variable burning, which could indicate a form of cooking. These elements, although unidentifiable to genus/species level, seem to seem to be associated with medium to large size mammals. In addition, the assemblage is highly fragmented. Of the fracture margins which can be observed, eight (33 percent) are recent breaks, which could have occurred during excavation, four (17 percent) are right angle (dry) breaks, and 12 (50 percent) are oblique or spiral (green) fractures. Although the assemblage could have been fragmented through numerous non-anthropogenic processes, the majority are green (oblique or spiral) fractures, which suggests the elements were broken perimortem. The presence of perimortem fracturing by itself is not evidence of anthropogenic processes. However, when a high degree of green fracture presence is combined with the presence of variable burning and associated artifacts, butchering and/or marrow processing may be inferred. 


\section{Snail Shell}

There has been a long-running debate in Texas archeology on whether snail shells commonly found on prehistoric sites were collected and discarded as a food source or were naturally occurring, perhaps attracted to occupational sites because of a higher abundance of organic materials discarded by humans. Although 41SR242 does not provide conclusive evidence either way, it is noteworthy to document remarkably high quantities of snail shell, almost exclusively Rabdotus, in Features 1 and 4 (Table 7.16). A total of 868 snail shells were recovered from Feature 1; although these were found from 30 to $70 \mathrm{cmbs}$ in TUs 1 and 3, the vertical distribution peaked between 50 and $60 \mathrm{cmbs}$. From Feature 4, a total of 2,769 snail shells were recovered from TUs 6 and 7. In both units, there is a clear spike in the Feature 4 vertical distribution between 40 and 50 cmbs.

Table 7.16. Snail Shells Recovered from Features 1 and 4

\begin{tabular}{|c|c|c|c|c|}
\hline Feature No. & Provenience & Level & $\begin{array}{c}\text { Elevation } \\
\text { (cmbs) }\end{array}$ & Snail Shell Count \\
\hline 1 & BHT1 & - & $50 \mathrm{~cm}$ & 71 \\
\hline 1 & BHT1/ TU1 & - & $50 \mathrm{~cm}$ & 117 \\
\hline 1 & TU1 & Lv1 & $30-40 \mathrm{~cm}$ & 52 \\
\hline 1 & TU1 & Lv2 & $40-50 \mathrm{~cm}$ & 24 \\
\hline 1 & TU1 S & Lv3 & $50-60 \mathrm{~cm}$ & 303 \\
\hline 1 & TU1 NW & Lv3 & $50-60 \mathrm{~cm}$ & 108 \\
\hline 1 & TU1 NE & Lv4 & $60-70 \mathrm{~cm}$ & 102 \\
\hline 1 & TU1 NE & Lv4 & $60-70 \mathrm{~cm}$ & 68 \\
\hline 1 & TU3 & LV1 & $30-40 \mathrm{~cm}$ & 13 \\
\hline 1 & TU3 & Lv3 & $50-60 \mathrm{~cm}$ & 10 \\
\hline \multicolumn{2}{|c|}{ Feature 1 Total } & & & 868 \\
\hline 4 & BHT15/ TU6 & Lv1 & $30-40 \mathrm{~cm}$ & 2 \\
\hline 4 & TU6 & Lv1 & $30-40 \mathrm{~cm}$ & 431 \\
\hline 4 & TU6 & Lv2 & $40-50 \mathrm{~cm}$ & 929 \\
\hline 4 & TU6 & Lv3 & $50-60 \mathrm{~cm}$ & 491 \\
\hline 4 & TU7 & Lv1 & $30-40 \mathrm{~cm}$ & 69 \\
\hline 4 & TU7 & Lv2 & $40-50 \mathrm{~cm}$ & 532 \\
\hline 4 & TU7 & Lv3 & $50-60 \mathrm{~cm}$ & 315 \\
\hline \multicolumn{2}{|c|}{ Feature 4 Total } & & & 2,769 \\
\hline \multicolumn{2}{|c|}{ Feature 1 and 4 Grand Total } & & & 3,637 \\
\hline
\end{tabular}




\section{CHAPTER 8. SUMMARY, CONCLUSIONS, AND RECOMMENDATIONS}

As part of the SL 195 project (CSJ: 3632-01-001), TxDOT conducted NRHP eligibility testing of the Cornelio Alvarez site (41SR242) in Starr County, Texas. Subsequent to the field investigations that occurred in February 2017, and April 2017, SWCA conducted artifact analysis, reporting, and curation preparation for the multi-component historic and prehistoric site. Investigations were conducted in compliance with Section 106 of the NHPA (54 USC 30601) and the ACT (9 NRC 191). The investigations assessed the site's eligibility for listing on the NRHP (36 CFR 60.4) and for designation as an SAL (13 TAC 26.8, 26.12). Christopher W. Ringstaff served as Principal Investigator under Texas Antiquities Permit Number 7912. This document provides the final results of the investigations and analyses to meet the requirements of the antiquities permit and Secretary of Interior guidelines. The additional data and interpretations provided in this report support the previous recommendations.

\section{APE AND SITE DIMENSIONS}

The tested portion of 41SR242 is located within the larger Project APE. The proposed SL 195 is a new roadway in southwestern Starr County extending from FM 755 to the intersection of U.S. Highway 83 and Loma Blanca Road. The total project length is 17.21 miles and varies between 300 and 450 feet in width. The entire SL 195 Project covers a total area of approximately 824.5 acres. Existing ROW composes approximately 24 acres and the remaining 800.5 acres is new ROW. No testing was done outside the APE. According to typical design sections, the depth of impacts is estimated to be up to 40 feet below the current ground surface for the bridge supports and up to 6 feet in depth for the rest of the project.

\section{SUMMARY OF FINDINGS}

The Cornelio Alvarez site (41SR242) is on a subtly convex footslope of a low-gradient upland adjacent to a low-order tributary of the Rio Grande River. Soils at the site have formed in calcareous loamy residuum derived from sandstone predominantly of the Jackson group. Accordingly, most of the cultural materials were on or near the current surface, and burial occurred through various pedogenic and bioturbation processes. Site 41SR242 has buried cultural materials present throughout the site's profile, but dense clusters appear to represent cultural activity loci at depths of approximately 40-65 cmbs.

With the exception of Features 1 and 4, no intact features were identified at 41SR242. Features 1 and 4 were discrete clusters of lithic debitage and intact Rabdotus snail shells discovered at a depth of approximately 50-60 cmbs in BHT 1 and 20-50 cmbs in BHT 15, respectively. The preliminary MAN analysis of the lithic debris in both features suggest that the feature includes multiple biface thinning flakes from about a dozens of analytic nodules. Given the diversity of the Rio Grande gravels, this supports the notion that the Features 1 and 4 assemblages reflected discrete behavioral events.

\section{SUMMARY AND RECOMMENDATIONS OF RESEARCH DIRECTIONS}

The Cornelio Alvarez site (41SR242) is recommended as eligible for the NRHP and as an SAL. Despite some of the mixed contexts at the site, there are feasible research directions that have been pursued and can be further studied in future archeological investigations. These directions include raw material availability, geoarcheological site formation model, and technological organization. 


\section{Raw Material Availability}

The Rio Grande Delta is a region of stark contrasts between lithic-rich and lithic-poor areas.

Understanding how indigenous groups responded to differential availability (such as through trade or mobility) is important to modeling technological organization. As lithic artifacts tend to be among the only classes that endure on many sites, the economic patterns in lithic production/acquisition, use, and discard provide one of the more viable research avenues.

However, lithic material distribution more importantly contributes to the broader topic of overall resource availability, which is the real question to better understanding upland sites like 41SR242 and others. Characterizing, stone, water, floral, and faunal resources (the latter two likely relying on proxy data) will be important in formulating future research questions.

\section{Land Use}

In regard to Archaic foraging, land use in the uplands of the Lower Rio Grande Plains is poorly understood and is closely tied to, as mentioned above, resource availability. Forays into these areas are certainly tied to acquiring resources other than lithic raw materials. Given the meager yet unusual presence of vertebrate remains at the site as well as the high-density land snail features (Features 1 and 4) provides some initial data to develop future research questions. The potential for additional faunal material suggests this line of inquiry may be further developed. With documented carbonized flora recovered from 41SR242, the potential for better understanding acquisition and use of upland floral resources may be possible.

\section{Site Formation Processes}

As discussed in Chapter 6, the regional archeological record forms within two primary depositional settings: 1) aggrading landforms such as alluvial terraces, and 2) non-aggrading or slowly-aggrading, stable landforms such as the upland landform on which 41SR242 occupies. Although non-aggrading landforms may have less potential for preservation, the tested site shows that there are burial processes, such as insects displacing sediments to the surface, that can provide conditions for preservation on a caseby-case basis. This, in part, appears to be the case at 41SR242, where insect and annelid surface casting is the most likely explanation for burial and preservation of Features 1 and 4 . These two features suggest the biomantle phenomena recently documented at 41SR242 as well as in western Hidalgo County (Carpenter et al 2015), Particular attributes of both features (i.e., density of artifacts) supported its preservation by hindering insect passage. However, the overall analyses suggest that other processes have operated on the site. The fact that prehistoric artifacts litter the surface demonstrates that insect casting cannot be the only process operating since all artifacts would be buried if that were the case. The investigations at 41SR242 demonstrate that the combination of traditional textural and chemical analysis, thin section analysis, and CT analysis provides for the potential to gain unprecedented insights into many pedological questions in a wide range of environments. Considering that archeological sites in the region likely have similarly been affected by multiple factors, a variety of related analyses can provide the most informative approach for future research.

In terms of site formation and research directions, the salient point is that an understanding of site formation can help us better understand preservation limitations of the site and help in the development of the data recovery field methodology. In the instance of 41SR242, the geoarcheological understanding of the site, presence of single component living surfaces is unlikely. However, the potential for intact features within the site has been demonstrated. 


\section{Technological Organization}

Lithic technological organization refers to the ways in which people procured, transported, manufactured, and used stone tools (Andrefsky 1994). Given the data that tend to survive at sites such as 41SR242, technological organization is among the most feasible research topics at similar sites, one that can be addressed through analysis of lithic assemblages and study of reduction stages.

In the regional literature, researchers have defined maritime, savannah, and desert adaptations among historic and prehistoric inhabitants in the far South Texas region. Most mobility models, grounded in ethnohistorical literature, depict inhabitants moving among habitats following seasonally available resources. The mobility, foraging strategies, and economic networks in these adaptations and models strongly link with lithic tool production, use, maintenance, and discard. As Ricklis and Cox (1993) note, technological organization is a subsystem of the larger culture, and the coastal inhabitants employed different strategies for different circumstances. Ricklis and Cox (1993) provide a model of lithic technological organization based on the Late Prehistoric archeological record along the central Texas coast. There are strong parallels between their study area and the setting of the La Joya sites.

Situated immediately adjacent to lithic sources, site 41SR242 primarily reflect Ricklis and Cox's Mode I, procurement, transport, and reduction of raw materials. The sites likely represent an embedded procurement locale where materials were acquired during the regular seasonal mobility schedule. Based on ethnohistorical descriptions, groups maintained large foraging territories that were generally not mutually exclusive (Campbell 1988:117). Multiple groups often overlapped, occupying the same territories and even sharing camps (Campbell 1988:117). Both residential and logistical mobility occurred on a seasonal basis, often exploiting intermittently available resources. Early accounts reported coastal groups moving inland during the summer to harvest the abundance of prickly pear fruit, which were found in great concentrations in Starr County (Campbell 1988:12). As part of these regular seasonal movements, site 41SR242 likely represents a short-term camp where retooling occurred, exploiting raw material outcrops that are immediately adjacent to the sites.

A strong component of activities occurring at 41SR242 included exploitation of relatively abundant local raw materials to produce tools. Occupational materials such as site furniture and ground stone are informal and unsubstantial, indicating low-intensity, short-term occupations. Consequently, the lithic activities perhaps reflect an embedded procurement strategy during short-term forays to exploit seasonal upland resources. In the vicinity of the tested sites, lithic raw material is abundant in downcut exposures. However, the Rio Grande delta, as well as the inland South Texas sandsheet to the north, is an exceedingly lithic-poor area. Assessing the discard patterns and reduction activities occurring on the site can contribute to a larger model of how the area occupants mapped onto the landscape. The model of technological organization suggests the Cornelio Alvarez site (41SR242) assemblages represents retooling in relatively lithic-rich areas on the margin of the lithic-poor areas, such as the Rio Grande Delta.

Based on the debitage analysis and assemblage, it appears bifacial production was a central focus in the technological organization on the site. To illustrate this point, the biface to core ratio is quite high on the Cornelio Alvarez site (41SR242), about 20 to 1 (61 bifaces excluding projectile points to 3 cores). In general, biface use increases with mobility, though Tomka (2001) identifies mitigating circumstances, and flake-core use increases with longer occupations. Comparing the biface-to-core ratios to other regional data, a four to one ratio is within reasonable expectations of hunter-gatherers according to North American data compiled by Parry and Kelly (1987) (Table 8.1). However, there may be a sampling bias - surface collection units at the Cornelio Alvarez site likely focused more on formal tools than cores. Nevertheless, the debitage analysis and the high numbers of brown bifaces shows an abundance of small 
biface production on site, and the important point is that as mobility increases, formal curated technology increases.

Table 8.1. Comparative Biface:Core Ratio Data from Parry and Kelly (1987)

\begin{tabular}{|c|c|c|}
\hline Archeological Group & Sedentism/Mobility Pattern & $\begin{array}{l}\text { Biface to Core ratio according to Parry } \\
\text { and Kelly (1987) }\end{array}$ \\
\hline Oaxaca Archaic & Quasi-sedentism & 1.09 \\
\hline Oaxaca Formative & Sedentism & 0.03 \\
\hline Black Mesa Archaic & Mobile hunter-gatherers & 5.75 \\
\hline Black Mesa BMII & Quasi-sedentism & 2.38 \\
\hline Black Mesa PI & Sedentism & 0.45 \\
\hline Black Mesa PII & Sedentism & 0.04 \\
\hline SW Colorado Archaic & Mobile hunter-gatherers & 5.75 \\
\hline SW Colorado BMII & Early quasi-sedentism & 2.83 \\
\hline SW Colorado BMIII & Quasi-sedentism & 0.71 \\
\hline SW Colorado PI & Sedentism & 0.95 \\
\hline SW Colorado PII & Sedentism & 0.70 \\
\hline Chaco Preceramic & Quasi-sedentism & 0.80 \\
\hline Chaco Puebloan & Sedentism & 0.13 \\
\hline Knife River ND Paleo/EA & Mobile hunter-gatherers & 3.52 \\
\hline Knife River ND Archaic & Mobile hunter-gatherers & 2.92 \\
\hline Knife River ND Plains Village & Sedentism & 1.34 \\
\hline Cornelio Alvarez Site & Mobile hunter-gatherers & 20.1 \\
\hline
\end{tabular}

Debitage is often a problematic artifact class, and analyses are often prone to simplistic or foregone conclusions. However, in discrete reduction features they can provide insight into not only the types of tools being produced but also post-depositional processes that affect sites, as explored on 41SR242.

\section{ELIGIBILITY RECOMMENDATIONS}

Evaluations of NRHP and SAL eligibility focused on two primary aspects of 41SR242: site integrity and potential data yield.

\section{Site Integrity}

Post-depositional processes at 41SR242 are generally not conducive to preservation of intact archeological surfaces, patterns, or other aspects of site structure. However, as the various investigative approaches to 41SR242 have demonstrated, there are some notable exceptions where isolated but informative data can be collected. The application of MAN analysis of the lithic debris, particularly in Feature 1, greatly assisted in identifying multiple biface thinning flakes from numerous Rio Grande nodules and determining the feature was a discrete behavioral event. Similarly, the combined use of traditional methods with newer approaches (i.e., CT analysis) offered unprecedented insights into the complex and varied natural post-depositional processes affecting the site. Effectively, these collaborative approaches have shed new light on previously disregarded data. 


\section{Potential Data Yield}

As discussed in the previous chapters, potential data yield addresses the aspect of significance, the ability of a site to yield important information related to one or more meaningful contexts or research issues. Based on the testing investigations, 41SR242 contains sufficient data to substantively and explicitly address specific local or regional contexts. Although, the site does have limited preservation for organic remains, several radiocarbon samples from mesquite (Prosopis sp.), acacia (Acacia sp.), and snakewood (Condalia sp.). were identified and examined. Therefore, some organic preservation is present.

The artifact content is moderately robust, and the investigations suggest that discrete behavioral events are present (e.g., Feature 1). Although some mixing of the site deposits has occurred, there is evidence to indicate that beneficial information can be discerned from the larger features, when identified. Further, buried cultural material is present throughout the profile of 41SR242, but dense clusters that appear to represent cultural activity loci are present, particularly at approximately $40-65 \mathrm{~cm}$. The radiocarbon data of 41SR242 indicates that the assemblage has a slightly mixed context. However, Bayesian analyses of the chronometric data indicates repeated activity over more than a thousand years during the Late Archaic, minimally from B.C. 1600-100.

\section{Site Eligibility and Recommendations}

Based on the considerations of integrity and potential data yield, 41SR242 is recommended as eligible for the NRHP and as an SAL. This recommendation pertains to the portions of the site within the APE. The site does extend beyond the APE, most notably to the north and south, and these areas have not been evaluated. Should additional work be required outside the current APE, additional assessment is warranted. 


\section{CHAPTER 9. REFERENCES CITED}

Abbott, J. T.

2001 Houston Area Geoarcheology: A Framework for Archeological Investigation, Interpretation, and Cultural Resources Management in the Houston Highway District. Texas Department of Transportation, Environmental Affairs Division, Archeological Studies Program.

Andrefsky, William

1994 Raw-material Availability and the Organization of Technology. American Antiquity 59(1):21-34.

1998 Lithics: Macroscopic Approaches to Analysis. Cambridge University Press, Cambridge.

2014 Lithics, Macroscopic Approaches to Analysis. Cambridge University Press, New York. $14^{\text {th }}$ edition.

Armour-Chelu, M., and P. Andrews

1994 Effects of Bioturbation by Earthworms (Oligochaeta) on Archeological Sites. Journal of Archeological Science 21(4):433-443.

Aveleyra Arroyo de Anda, Luis

1956 The Second Mammoth and Associated Artifacts at Santa Iztapan, Mexico. American Antiquity XXII(1):12-28

Bagnold, R. A.

1941 The Physics of Blown Sand and Desert Dunes. London: Chapman \& Hall.

Bagyaraj, D. J., C. J. Nethravathi, and K. S. Nitin

2016 Chapter 2: Soil biodiversity and arthropods: Role in soil fertility. In: Economic and Ecological Significance of Arthropods in Diversified Ecosystems, A. K. Chakravarthy and S. Sridhara (eds.), pp. 17-51. Hong Kong: Springer Science+Business Media.

Barker, T. L.

2002 The Exploration of Magnetic Susceptibility as an Indicator for Topsoil Loss in KwaZuluNatal. Unpublished Master's Thesis, School of Applied Environmental Sciences, University of Natal, South Africa.

Barnes, V. E.

1976 Geologic Atlas of Texas: The McAllen-Brownsville Sheet. Austin: Bureau of Economic Geology. The University of Texas at Austin.

Bastardie, F., Y. Capowietz, J. -R. de Dreuzy, and D. Cluzeau

2003 X-ray Tomographic and Hydraulic Characterization of Burrowing by Three Earthworm Species in Repacked Soil Cores. Applied Soil Ecology 24(1):3-16.

Bateman, M. D., C. H. Boulter, A. S. Carr, C. D. Frederick, D. Peter, and M. Wilder

2007 Detecting Postdepositional Sediment Disturbance in Sandy Deposits using Optical Luminescence. Quaternary Geochronology 2:57-64.

Bateman, M. D., C. D. Frederick, M.K. Jaiswal, and A. K. Singhvi

2003 Investigations into the Potential Effects of Pedoturbation on Luminescence Dating. Quaternary Science Reviews 22:1169-1176. 
Bates, R. L., and J. A. Jackson

1984 Dictionary of Geological Terms, Third Edition. Garden City, New York: Anchor/Doubleday.

Bement, L. C., E. L. Lundelius, Jr., and R. A. Ketcham

2005 Hoax or History: A Bison Skull with Embedded Calf Creek Projectile Point. Plains Anthropologist 50:221-226.

Black, Stephen L.

1986 The Clemente and Herminia Hinojosa Site, 41JW8: A Toyah Horizon Campsite in Southern Texas. Special Report 18. Center for Archeological Research, The University of Texas at San Antonio.

1989 Central Texas Plateau Prairie. In From the Gulf to the Rio Grande: Human Adaptation in Central, South, and Lower Pecos Texas, by Thomas R. Hester, Stephen L. Black, D. Gentry Steele, Ben W. Olive, Anne A. Fox, Karl J. Reinhard, and Leland C. Bement, pp. 17-38. Research Series No. 33. Arkansas Archeological Survey, Fayetteville.

Blair, W. F.

1950 The Biotic Provinces of Texas. Texas Journal of Science 2(1):93-117.

Brown, K. M.

1985 Three Caches of Guadalupe Tools from South Texas. Bulletin of the Texas Archeological Society 56:75-125.

Butler, D. R.

1995 Zoogeomorphology: Animals as Geomorphic Agents. Cambridge: Cambridge University Press.

Byrd, C. L.

1971 Origin and History of the Uvalde Gravel of Central Texas. Baylor Geological Studies Bulletin 20.

Callahan, E. C.

1974 A Guide for Flintworking: Stages of Manufacture. Experimental Archeology Papers 3:185192.

1979 The Basics of Flintknapping in the Eastern Fluted Point Tradition: A Manual for Flintknappers and Lithic Analysts. Archeology of Eastern North America 7(1):1-80.

Campbell, Eloise

2019 "La Sal Del Rey," Handbook of Texas Online Available at http://www.tshaonline.org/handbook/online/articles/gplpe. Accessed October 1, 2019. Uploaded on June 15, 2010. Published by the Texas State Historical Association.

Campbell, Thomas N.

1947 The Johnson Site: Type Site of the Aransas Focus of the Texas Coast. Bulletin of the Texas Archeological and Paleontological Society 18:40-75.

1952 The Kent-Crane site: a Shell Midden on the Texas Coast. Bulletin of the Texas Archeological and Paleontological Society 23:39-77. 
1988 The Indian of Southern Texas and Northeastern Mexico, Selected Writings of Thomas Nolan Campbell. The University of Texas at Austin.

Carlson, W. D., T. Rowe, R.A. Ketcham, and M. W. Colbert

2003 Applications of High-Resolution X-ray Computed Tomography in Petrology, Meteoritics and Palaeontology. Applications of X-ray Computed Tomography in the Geosciences. Geological Society, London, UK. Special Publications, No. 215, pp. 722.

Carpenter, Stephen M, Mercedes C. Cody, Ken Lawrence, Charles Frederick, and Christina Nielsen 2015 Significance Testing of Archaeological Sites 41HG240 and 41HG241 on the La Joya Outer Loop, Hidalgo County, Texas. SWCA Environmental Consultants and Texas Department of Transportation Archeological Studies Program Report No. 167, Austin.

Carpenter, Steve, and Pierre Paquin

2010 Towards a Genealogy of Texas Projectile Point. Bulletin of the Texas Archeological Society 81:153-176.

Crossley, R.

1986 Sedimentation by Termites in the Malawi Rift Valley. Geological Society, London, Special Publications, 25, pp. 191-199.

2008 A Review of the Role of Magnetic Susceptibility in Archaeologeophysical Studies in the USA: Recent Developments and Prospects. Archeological Prospection 15:1-31.

Dalan, Rinita A., and Subir K. Banerjee

1998 Solving Archeological Problems Using Techniques of Soil Magnetism. Geoarcheology 13:3-36.

Darwin, Charles

1881 The Formation of Vegetable Mould Through the Action of Worms. Reprint. Echo Library, Middlesex.

Dearing, J.

1999 Environmental Magnetic Susceptibility Using the Bartington MS2 System. http://www.gmw.com/magnetic_properties/MS2_support.html. Accessed December 2019.

Dearing, J. A., R. J. L. Dann, K. Hay, J. A. Lees, P. J. Loveland, B. A. Maher, and K. O’Grady 1996 Frequency-Dependent Susceptibility Measurements of Environmental Materials. Geophysical Journal International 124(1):228-240.

Derbeyshire, E., K. J. Gregory, and J. R. Hails

1979 Geomorphological Processes. Studies in Physical Geography. Boulder, CO: Westview Press.

Diamond. D. D., D. H. Riskind, and S. L. Orzell

1987 A Framework for Plant Community Classification and Conservation in Texas. Texas Journal of Science 39(3):203-221.

Dreimanis, A.

1962 Quantitative Gasometric Determination of Calcite and Dolomite using a Chittick Apparatus. Journal of Sedimentary Petrology 32(3):520-529. 
Epstein, Jeremiah F.

1969 The San Isidro site, an early man campsite in Nuevo Leon, Mexico. Anthropological Series, Department of Anthropology No. 7. The University of Texas at Austin.

Fisher, W.L.

1976 Geologic Atlas of Texas, McAllen-Brownsville Sheet. Bureau of Economic Geology, The University of Texas at Austin.

Fisher, W.L., C. V. Proctor, Jr., W. E. Galloway, and J. S. Nagle

1970 Depositional Systems in the Jackson Group of Texas. Bureau of Economic Geology Geologic Circular 70-4.

Frederick, Charles D.

1996 Section 8.5: Geoarcheological Results. In Archeology and Native American Religion at the Leon River Medicine Wheel. M. J. Quigg, C. D. Frederick, and D. Lippert, pp. 88-109. United States Army Fort Hood, Archeological Resource Management Series, Research Report No. 33.

Fritz, G. J.

1975 Matagorda Bay Area: A Survey of the Archeological and Historical Resources. Research Report 45. Texas Archeological Survey, The University of Texas at Austin.

Fox, A. A., and T. R. Hester

1976 An Archeological Survey of Coleto Creek, Victoria and Goliad Counties, Texas. Archeological Survey Report 18. San Antonio: Center for Archeological Research, The University of Texas at San Antonio.

Gale, Stephen J., and Peter G. Hoare

1991 Quaternary Sediments: Petrographic Methods for the Study of Unlithified Rocks. Halsted Press, John Wiley \& Sons, Inc., New York.

Genise, J. F.

2017 Ichnoentomology: Insect Traces in Soils and Paleosols. Topics in Geobiology 37. Switzerland: Springer.

Goodfriend, G. A.

1992 The Use of Land Snail Shells in Paleoenvironmental Reconstruction. Quaternary Science Reviews 11:665-685.

Goodfriend, G. A., G. L. Ellis, and L. J. Toolin

1999 Radiocarbon Age Anomalies in Land Snails from Texas: Ontogenetic, Individual, and Geographic Patterns of Variation. Radiocarbon 41(2):149-156.

Hainsworth, J. M., and Aylmore, L. A. G.

1983 The use of computer-assisted tomography to determine spatial distribution of soil water content. Australian Journal of Soil Research 21: 435-443.

Hall, Grant D.

1981 Allen's Creek: A Study in the Prehistory of the Lower Brazos River Valley, Texas. Research Report 61. Texas Archeological Research Laboratory, The University of Texas at Austin. 
2002 Archeology at the Crestmont Site. General Investigations Report 1, Archeology Laboratory, Texas Tech University, Lubbock.

Hall, G.D., M. B. Collins, and E. R. Prewitt

1987 Cultural Resources Investigations Along Drainage Improvements, Hidalgo and Willacy Counties, Texas: 1986 Investigations. Report of Investigations 59, Prewitt \& Associates Inc., Austin.

Hall, Grant. D., T. R. Hester, and S.L. Black

1986 The Prehistoric Sites at Choke Canyon Reservoir, Southern Texas: Results of the Phase II Archeological Investigations. Choke Canyon Series 10. Center for Archeological Research, The University of Texas at San Antonio.

Hester, Thomas R.

1969 The Floyd Morris and Ayala Sites: A Discussion of Burial Practices in the Rio Grande Valley and the Lower Texas Coast. Part III in Two Prehistoric Sites in the Lower Rio Grande Valley of Texas, by T.R. Hester M. B. Collins, Frank Weir, and Frederick Ruecking. Bulletin of the Texas Archeological Society 40:157-166.

2004 The Prehistory of South Texas. In Prehistory of Texas, edited by T. K. Perttula, pp. 127-155. Texas A\&M Press, College Station.

Hill, R.T.

1971 Notes on the Geology of the Southwest. American Geologist 7:254-255; 336-370.

Hoffman, G. O.

1975 Control and Management of Mesquite on Rangeland. Pamphlet produced by the Texas Agricultural Extension Service, the Texas A\&M University System, in cooperation with the United States Department of Agriculture.

Jahrsdoerfer, S. E., and D. M. Leslie, Jr.

1988 Tamaulipan Brushland of the Lower Rio Grande Valley of South Texas: Description, Human Impacts, and Management Options. U.S. Fish and Wildlife Service Biology Report 88(36).

Jégou, D., S. Schrader, H. Diestel, and D. Cluzeau

2001 Morphological, Physical and Biochemical Characteristics of Burrow Walls Formed by Earthworms. Applied Soil Ecology 17(2001):165-174

Johnson, M. O., S. M. Mudd, B. Pillans, N. A. Spooner, L. K. Fifield, M. J. Kirby, and M. Gloor

2014 Quantifying the Rate and Depth Dependence of Bioturbation Based on Optically-Stimulated Luminescence (OSL) Dates and Meteoric 10Be. Earth Surface Processes and Landforms 39:1188-1196.

Johnson, L., Jr., and G. T. Goode

1994 A New Try at Dating and Characterizing Holocene Climates, as well as Archeological Periods on the Eastern Edwards Plateau. Bulletin of the Texas Archeological Society 65:1-54.

Jongmans, A. G., M. M. Pulleman, M. Balabane, F. Van Ort, and J. C. Y. Marinissen

2003 Soil Structure and Characteristics of Organic Matter in Two Orchards Differing in Earthworm Activity. Applied Soil Ecology 24(3):219-232. 
Kelly, R. L.

1985 Hunter-Gatherer Mobility and Sedentism: A Great Basin Study. Ph.D. dissertation, Department of Anthropology, University of Michigan, Ann Arbor.

Ketcham, R. A., and W. D. Carlson

2001 Acquisition, Optimization and Interpretation of X-ray Computed Tomographic Imagery:

Applications to the Geosciences. Computers and Geosciences 27:381-400.

Kibler, K. W., and M. D. Freeman

1993 Preliminary Cultural Resources Investigations for the Pharr-Reynosa International Bridge, Hidalgo County, Texas. Reports of Investigations, No. 90. Prewitt and Associates, Inc., Austin, Texas.

King, Brian and Rachel Feit

2006 Archeological Survey of the Proposed US 83 Reliever Route from Roma to Rio Grande City in Starr County, Texas. Archeology Series 167. Hicks \& Company. Austin, Texas.

Kok J. F., Parteli E. J. R., Michaels T. I., and Bou Karam D.

2012 The Physics of Wind-blown Sand and Dust. Reports on Progress in Physics 75.

Lancaster, N., and W. G. Nickling

1994 Aeolian Sediment Transport. In Geomorphology of Desert Environments. Abrahms, A. D., and A. J. Parsons, eds. London: Chapman \& Hall, Ltd. pp. 447-473.

Larson, Mary Lou, and Marcel Kornfield

1997 Chipped Stone Nodules: Theory, Method, and Examples. Lithic Technology 22:4-18.

Lee, K. E., and R. C. Foster

1991 Soil Fauna and Soil Structure. Australian Journal of Soil Research 29(6):745-775.

Little, B., E. M. Seibert, J. Townsend, J. H. Sprinkle, and J. Knoerl

2000 Guidelines for Evaluating and Registering Archeological Properties. National Register

Bulletin, U.S. Department of the Interior, National Park Service.

Lohse, Jon C., David B. Madsen, Brendan J. Culleton, Douglas J. Kennett

2014 Isotope paleoecology of episodic mid-to-late Holocene bison population expansions in the Southern Plains, U.S.A. Quaternary Science Reviews 101:1-13.

McBrearty, S.

1990 Consider the Humble Termite: Termites as Agents of Post-Depositional Disturbance at African Archeological Sites. Journal of Archeological Science 17(2):111-143.

McMahan C. A., R. G. Frye, and K. L. Brown

1984 The Vegetation Types of Texas, including Cropland. Map and accompanying Illustrated Synopsis. Austin: Texas Parks and Wildlife Department.

MacNeish, 1958 Preliminary archaeological investigations in the Sierra de Tamaulipas, Mexico. Transactions of the American Philosophical Society 48 (6). 
Meltzer, D. J., and M. R. Bever

1995 Paleoindians of Texas: An Update on the Texas Clovis Fluted Point Survey. Bulletin of the Texas Archeological Society 66:47-81.

Miller, B. A., and J. Juilleret

2015 What is Colluvium? Poster presented at the 2015 Soil Science Society of America Annual Meeting, Minneapolis.

2016 Defining Colluvium and Alluvium: An Experiment to Discuss and Consolidate Perspectives. Poster presented at the 2016 European Geosciences Union General Assembly, Vienna.

Natural Resources Conservation Service (NRCS)

2012 NRCS Conservation Practice Standard, Brush Management, Code 314.

2019 Web Soil Survey. Available at http://websoilsurvey.nrcs.usda.gov/ app/WebSoilSurvey.aspx. United States Department of Agriculture, Washington, D.C. Accessed August 2019.

Odell, G. H.

2003 Lithic Analysis. Manuals in Archeological Method, Theory, and Technique Series. Springer, New York.

Olson, G. W. (compiler)

1976 Criteria for Making and Interpreting a Soil Profile Description: A Compilation of the Official USDA Procedure and Nomenclature for Describing Soils. Lawrence: University of Kansas Publications.

Patterson, Leland W.

1977 An Archeological Complex in Kendall County, Texas. La Tierra 4(2):6-16.

Petrovic, A. M., J. E. Siebert, and P. E. Rieke

1982 Soil Bulk Density Analysis in Three Dimensions by Computed Tomographic Scanning. Journal of the Soil Science Society of America 46:445-450.

Prewitt, E. R., S. V. Lisk, and M.A. Howard

1987 National Register Assessments of the Swan Lake Site, 41AS16, on the Copano Bay, Aransas County, Texas. Reports of Investigations No. 56, Prewitt and Associates, Austin.

Quigg, J. Michael, Chris Lintz, Grant Smith, and Scott Wilcox

2000 The Lino Site: A Stratified Late Archaic Campsite in a Terrae of the San Ildefonso Creek, Webb County, Southern Texas. Technical Report 23756, TRC Mariah Associates, Inc. Texas Department of Transportation Archeological Studies Program Report 20, Austin.

Resner, K., K. Yoo, C. Hale, A. Aufdenkampe, A. Blum, and S. Sebestyen

2011 Elemental and Mineralogical Changes in Soils due to Bioturbation along an Earthworm Invasion Chronosequence in Northern Minnesota. Applied Geochemistry 26:S127-S131.

Ricklis, R. A.

1988 Archeological Investigations at the McKenzie Site (41NU221), Nueces County, Texas: Description and Contextual Interpretations. Bulletin of the Texas Archeological Society 58:176. 
2004 The Archeology of the Native American Occupation of Southeast Texas. In The Prehistory of Texas, edited by T. K. Perttula, pp. 181-202. Texas A\&M Press, College Station.

2011 New Perspectives on the Archaic of the Texas Coastal Plain: The Buckeye Knoll Site (41VT98) on the Lower Guadalupe River near Victoria, Texas. Bulletin of the Texas Archeological Society 82:77-116.

Ricklis, Robert A., and Kim A. Cox

1993 Examining Lithic Technological Organization as a Dynamic Cultural Subsystem: The Advantages of an Explicitly Spatial Approach. American Antiquity 58(3):444-461.

Ringstaff, Chris

2014 Archeological Survey of the Proposed US 83 (La Joya) Loop, Hidalgo County, Texas. Report for Archeological Survey, Environmental Affairs Division, Texas Department of Transportation, Austin.

Ringstaff, Christopher W., and James T. Abbott

2017 Interim Testing Report for NRHP Testing at 41SR242, The Cornelio Alvarez Sr. Site, Starr County, Texas. Texas Antiquities Permit 7912. Environmental Affairs Division, Texas Department of Transportation, Austin.

Root, Matthew J.

2004 Technological analysis of Flake debris and the limitations of size-grade techniques. In Aggregate Analysis of Chipped Stone, edited by Christopher Hall and Mary Lou Larson, pp. 65-94. University of Utah Press, Salt Lake City

Salinas, Martin

1990 Indians of the Rio Grande Delta, Their Role in the History of Southern Texas and Northeastern Mexico. University of Texas Press, Austin.

Schiffer, M. B.

1983 Towards the identification of formation processes. American Antiquity 48:675-706.

Schoeneberger, P.J., D.A. Wysocki, E.C. Benham, and Soil Survey Staff

2012 Field Book for Describing and Sampling Soils, Version 3.0. Natural Resources Conservation Service, National Soil Survey Center, Lincoln, NE.

Schrader, S., and H. Zhang

1997 Earthworm casting: Stabilization or destabilization of soil structure? Soil Biology and Biochemistry 29(3/4):469-475.

Story, Dee Ann

1985 Adaptive Strategies of Archaic Cultures of the West Gulf Coastal Plain. In Prehistoric Food Production in North America, edited by R. I. Ford, pp. 19-56. Anthropological Papers 75. Museum of Anthropology, University of Michigan, Ann Arbor.

Suhm, D. A., A. D. Krieger, and E. B. Jelks

1954 An Introductory Handbook of Texas Archeology. Bulletin of the Texas Archeological Society, Vol. 25. 
Suhm, Raymond W.

1978 The La Paloma Mammoth Site, Kenedy County, Texas. Journal of Texas A\&I University, Kingsville 11(1):13-36.

1980 The La Paloma Mammoth Site, Kenedy County, Texas (with notes on the archaeology by Thomas R. Hester). In Papers on the Archaeology of the Texas Coast, edited by Lynn Highley and Thomas R. Hester, pp. 79-103. Special Report 11, Center for Archaeological Research, University of Texas, San Antonio.

Sullivan, A. P, and Kenneth C. Rozen

1985 Debitage Analysis and Archeological Interpretation. American Antiquity 50:755-779.

Taina, I. A., R. J. Heck, and T. R. Elliot

2008 Application of X-ray computed tomography to soil science: A literature review. Canadian Journal of Soil Science 88(1): 1-19.

Taylor, A. J., and C. L. Highley

1995 Archeological Investigations at the Loma Sandia Site (41LK28): A Prehistoric Cemetery and Campsite in Lone Oak County, Texas. Studies in Archeology 20, Texas Archeological Research Laboratory, The University of Texas at Austin.

Terneny, Tiffany $\mathrm{T}$.

2005 A Re-evaluation of Late Prehistoric and Archaic Chronology in the Rio Grande Delta of South Texas. PhD Dissertation, Department of Anthropology, The University of Texas at Austin.

Texas Department of Transportation (TxDOT)

2013 Chipped Stone Analytical Protocol. Version 2.4b. Archeological Studies Program, Texas Department of Transportation, Austin.

Texas Historical Commission (THC)

2019 Texas Archeological Sites Atlas restricted database, Texas Historical Commission. http://pedernales.thc. state.tx.us/. Accessed October 11, 2019.

Thompson, C. M., R. R. Sanders, and D. Williams

1972 Soil Survey of Starr County, Texas. USDA, Soil Conservation Service, in cooperation with the Texas Agricultural Experiment Station.

Thoms, A. V., and Patricia Clabaugh

2011 The Archaic Period at the Richard Beene Site: Six Thousand Years of Hunter-Gatherer Family Cookery in South-Central North America. Bulletin of the Texas Archeological Society 82:77-116.

Thoms, A. V., and R. D. Mandel (editors)

2007 Archeological and Paleoecological Investigations at the Richard Beene Site, South-Central Texas. Reports of Investigation No. 8. Center for Ecological Archeology, Texas A\&M University, College Station.

Toomey, Rickard S., III, M. D. Blum, and S. Valastro, Jr.

1993 Late Quaternary Climates and Environments of the Edwards Plateau, Texas. Global and Planetary Change 7:299-320. 
Turner, E. S., T. R. Hester, and R. McReynolds

2011 Stone Artifacts of Texas Indians. Taylor Trade Publishing, New York.

Turpin, S. A.

2004 The Lower Pecos River Region of Texas and Northern Mexico. In The Prehistory of Texas.

Edited by T. K. Perttula, pp. 266-280. Texas A\&M University Press, College Station.

Waters, M. R.

1992 Principles of Geoarcheology: A North American Perspective. Tucson: University of Arizona Press.

Webb, W.P. (Ed.)

1952 The Handbook of Texas. 2 Vols. Texas State Historical Association, Austin.

Weinstein, Richard A.

1992 Archeology and Paleogeography of the Lower Guadalupe River/San Antonio Bay Region: Cultural Resources Investigations Along the Channel to Victoria, Calhoun and Victoria Counties, Texas. Coastal Environments, Inc, Baton Rouge.

Weinstein, Richard A. (editor)

2002 Archeological Investigations at the Guadalupe Bay site (41 CL 2): Late Archaic through Historic Occupation along the Channel to Victoria, Calhoun County, Texas. Coastal Environments, Inc. Prepared for Galveston District, U.S. Army Corps of Engineers.

Whittaker, J. C.

1994 Flintknapping: Making and Understanding Stone Tools. University of Texas Press, Austin.

Whittow, J.

1984 The Penguin Dictionary of Physical Geography. New York: Penguin Books.

Wilkinson, M. T., P. J. Richards, and G. S. Humphreys

2009 Breaking ground: Pedological, geological, and ecological implications of soil bioturbation. Earth-Science Reviews 97(1-4):257-272.

Zaller, J. G., J. A. Arnone, and J. G. Zaller, 1997. Activity of surface-casting earthworms in a calcareous grassland under elevated atmospheric CO2. Oecologia 111(2):249-254. 
This page intentionally left blank. 


\section{APPENDIX A}

\section{Backhoe Trench Descriptions}

James T. Abbott 
This page intentionally left blank. 


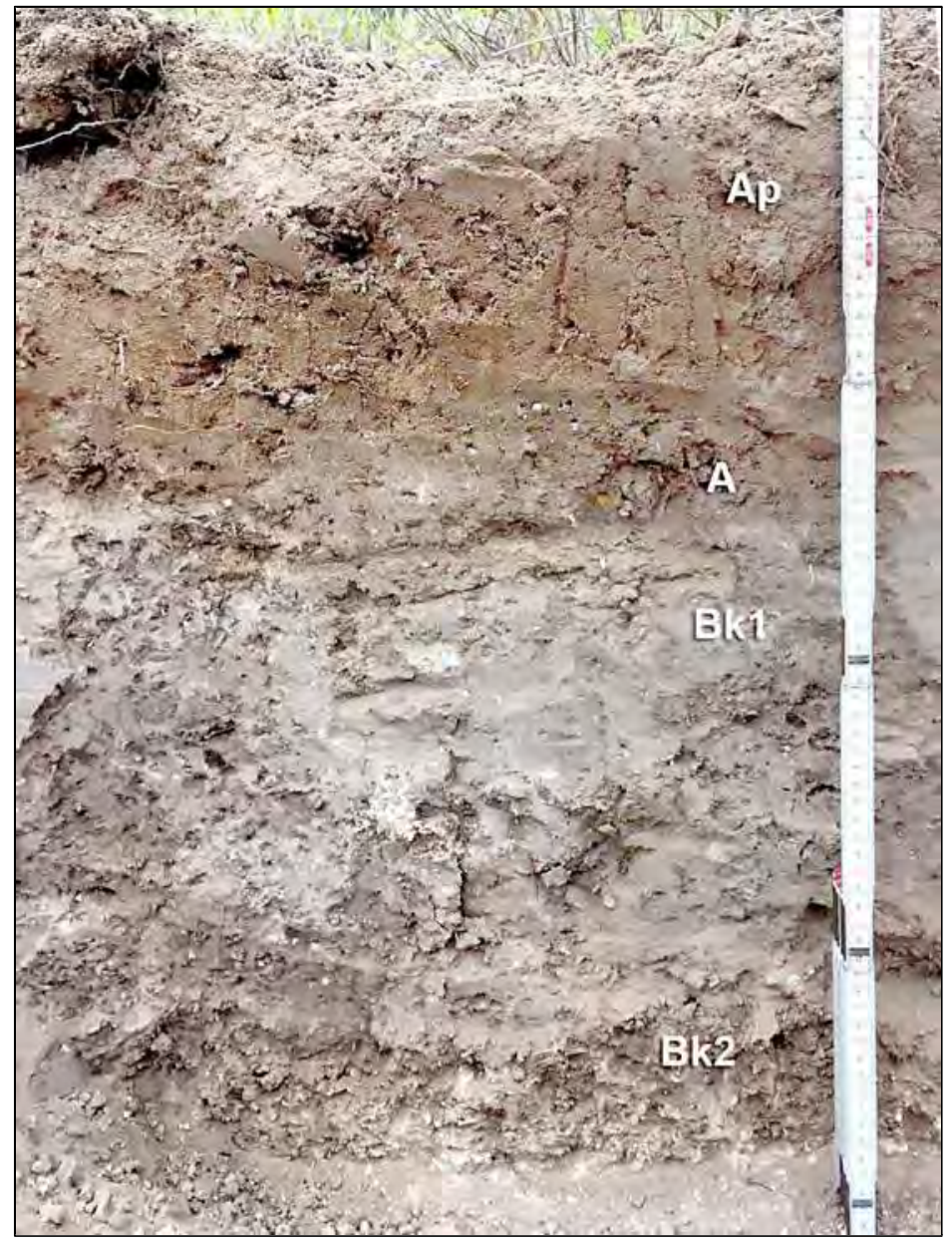

BT1:

0-13 cm: Ap horizon; sandy to silty loam; irregular platy structure superimposed on irregular biogenic granular structure; soft; 10YR 3/3 (dry); occasional roots; common fine pores and krotovina; clear boundary.

13-18 cm: A horizon; sandy to silty loam; irregular biogenic granular structure; soft; $10 Y R 3 / 2$ (dry); occasional roots; common crushed snail shell; few fine siliceous gravels; gradual boundary.

18-40 cm: Bk1 horizon; sandy to silty loam; massive to weak, irregular biogenic granular structure; 10YR $4 / 2$ to 5/2 (dry); many open pores and insect-scale krotovina; occasional fine roots; occasional flakes; few fine gravels; common crushed snail shell; few localized clusters of poorly bounded $\mathrm{CaCO}^{3}$ nodules; abundant diffuse matrix carbonate; clear boundary.

40-65 cm: Bk2 horizon; sandy to silty loam; prominent irregular biogenic granular structure; 10YR 5/2 (dry); many open pores and insect-scale krotovina; occasional fine roots; common flakes; few fine gravels; few localized clusters of poorly bounded $\mathrm{CaCO}^{3}$ nodules; abundant diffuse matrix carbonate; abundant whole and crushed snail shells (Rabdotus spp.); common to abundant lithic debitage.

Comments: From center of site. Base of exposed horizon contains a "feature" composed of hundreds of intact snail shells and dozens of flat-lying flakes (up to 3-4 cm maximum dimension) in physical contact or near contact. Excavated 12-14-16. 


\section{ВТ2:}

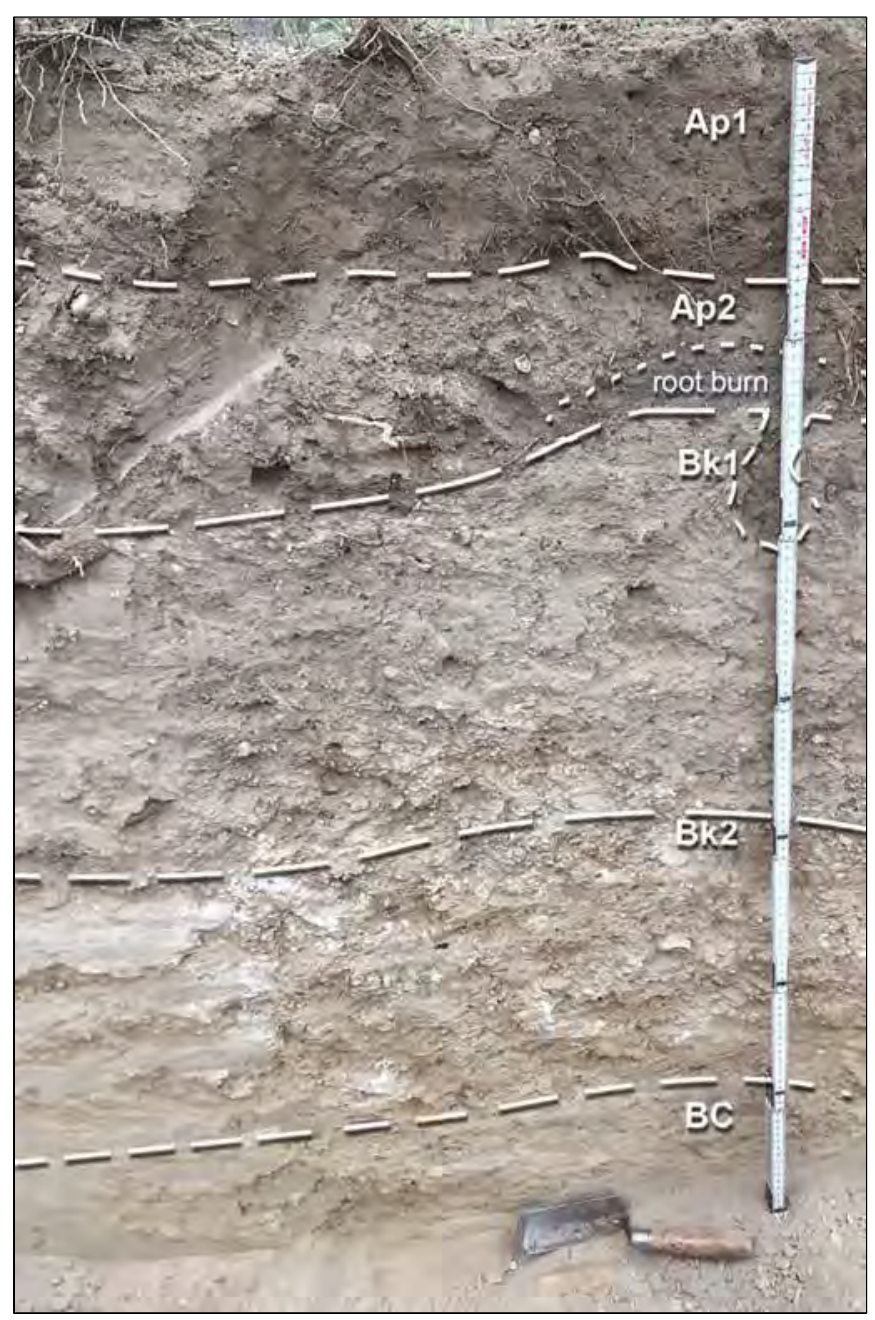

0-10 cm: Ap1 horizon; loamy fine sand; massive; soft; 10YR 4/3 (dry); occasional roots; common fine pores and krotovina; sparse debitage; clear boundary.

10-22 cm: Ap2 horizon; loamy fine sand; irregular biogenic granular structure; soft; 10YR 4/2 (dry); occasional roots; common crushed snail shell; few fine siliceous gravels; localized zone of charcoal representing irregular root burn; clear smooth boundary.

22-60 cm: Bk1 horizon; sandy to silty loam; massive to weak, irregular biogenic granular structure; slightly hard; 10YR 5/3 (dry); many open pores and insect-scale krotovina; occasional fine roots; occasional flakes; few fine gravels; common crushed snail shell; few localized clusters of poorly bounded $\mathrm{CaCO} 3$ nodules; abundant diffuse matrix carbonate; common dispersed intact snail shells (Rabdotus spp), lithic debitage, and small burned sandstone fragments; contains two thin subhorizontal concentrations of snail shell and debitage at approximately 40 and $55 \mathrm{cmbs}$; clear boundary.

60-95 cm: Bk2 horizon; sandy to silty loam; massive when cut; reveals irregular biogenic granular structure when brushed; slightly hard; 10YR 6/3 to 6/4 (dry); many open pores and insect-scale krotovina; few fine roots; common flakes; few fine gravels; few coarse masses of poorly bounded $\mathrm{CaCO} 3$; abundant diffuse matrix carbonate; common whole and crushed snail shells (Rabdotus spp.); gradual boundary. Excavated 12-14-16.

95-120 cm: BC horizon; sandy to silty loam; massive; slightly hard to ; 10YR 6/3 to 6/4 (dry); many open pores and insect-scale krotovina; abrupt wavy boundary.

$120 \mathrm{~cm}$ : $\quad$ Cr horizon; medium graysandstone. 
Comments: Cultural material, including flakes and burned sandstone, common through Ap and Bk1 horizon.

ВT3:

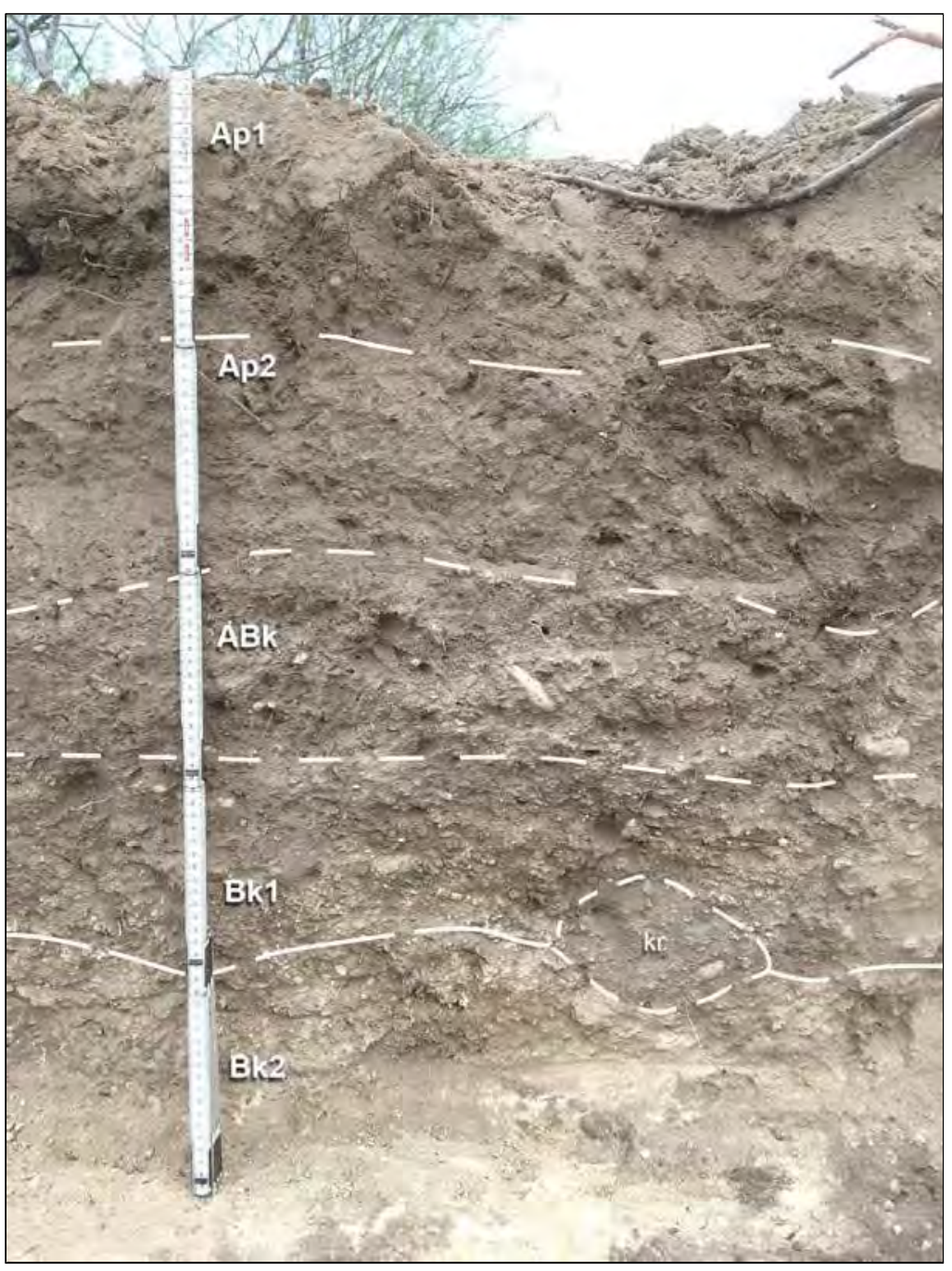

0-20 cm: Ap1 horizon; loamy fine sand to fine sandy loam; massive; soft; 10YR 5/2 (dry); occasional roots; common fine pores and krotovina; clear boundary.

20-38 cm: Ap2 horizon; loamy fine sand; irregular biogenic granular structure; soft; 10YR 5/2 (dry); occasional roots; common crushed snail shell; few fine siliceous gravels; clear smooth boundary marked by fine gravel stone line.

38-61 cm: ABk horizon; gravelly loamy fine sand; irregular biogenic granular structure; soft; 10YR 5/2 (dry); occasional roots; common crushed snail shell; common dispersed fine siliceous gravels; gradual boundary.

61-78 cm: Bk1 horizon; loamy fine sand to sandy loam; irregular biogenic granular structure; soft; 10YR 5/2 (dry); occasional roots; common crushed snail shell; occasional dispersed fine siliceous gravels; clear smooth boundary.

78-95 cm: Bk2 horizon; loamy fine sand to sandy loam; common fine siliceous gravels; irregular biogenic granular structure; soft; 10YR 5/2 (dry); few coarse, poorly-bounded masses of calcium carbonate; localized zones of matrix carbonate accumulation.

Comments: No artifacts were observed during recording, but a few were noted by monitor (Ringstaff) during excavation. Excavated 12-14-16. 


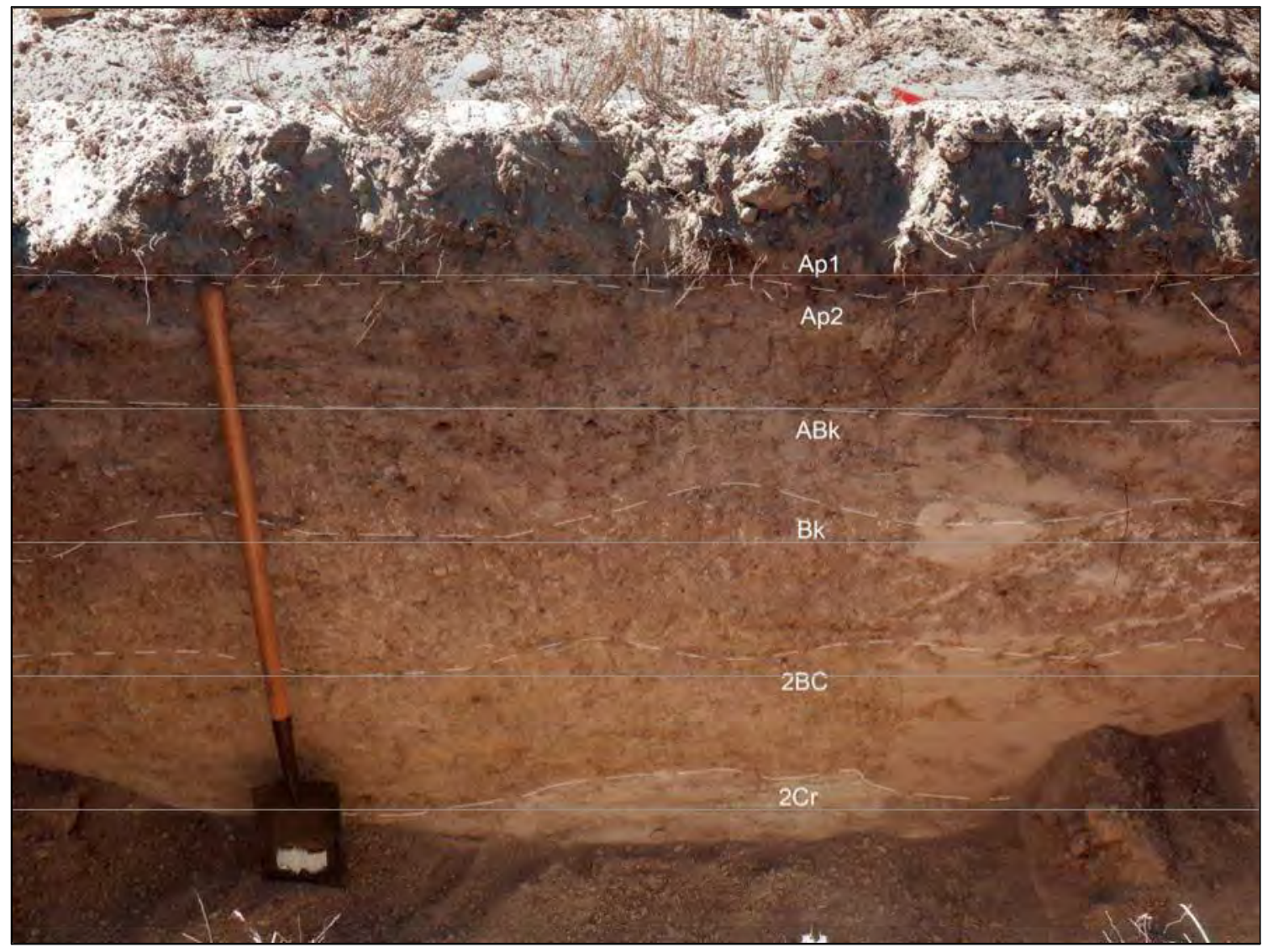

BT4:

0-8 cm: $\quad$ Ap1 horizon; sandy to silty loam; weak platy structure with superimposed irregular biogenic granular structure; soft; 10YR 5/2 to 5/3 (dry); occasional roots; common fine pores and krotovina; common snail shells (Rabdotus spp.) and lithic debitage; clear boundary.

8-36 cm: $\quad$ Ap2 horizon; gravelly fine sandy loam; weak subangular blocky structure with superimposed irregular biogenic granular structure; soft to slightly hard; 10YR 5/3 (dry); occasional roots; common crushed snail shell; common snail shells (Rabdotus spp.) and lithic debitage; clear boundary.

36-80 cm: $\quad$ ABk horizon; sandy to silty loam; massive to weak, irregular biogenic granular structure; slightly hard; 10YR 5/3 (dry); many open pores and insect-scale krotovina; occasional fine roots; few localized clusters of poorly bounded $\mathrm{CaCO} 3$ nodules; common dispersed intact snail shells (Rabdotus spp) and lithic debitage; contains burned rock feature (Fea. 2); clear boundary.

80-103 cm: Bk horizon; fine sandy loam; irregular biogenic granular structure; slightly hard; 10YR 6/3 (dry); occasional roots; occasional crushed snail shell; common soft, poorly bounded calcium carbonate masses; few crystals of gypsum; clear smooth boundary.

103-140 cm: 2BC horizon; fine sandy loam; massive; color varies from 2.5Y 7/3 to 10YR 7/4 (dry), with localized zones of 10YR 6/6 that appear to represent weak iron staining; occasional soft, poorly bounded masses of calcium carbonate; common crystals of gypsum, particularly in downwarddeflected pockets along lower boundary; clear to abrupt wavy boundary.

140-160 cm: 2Cr horizon; weathered sandstone.

Comments: Samples for sediment analysis were taken from this profile. See laboratory profile. Excavated 2-21-17. 


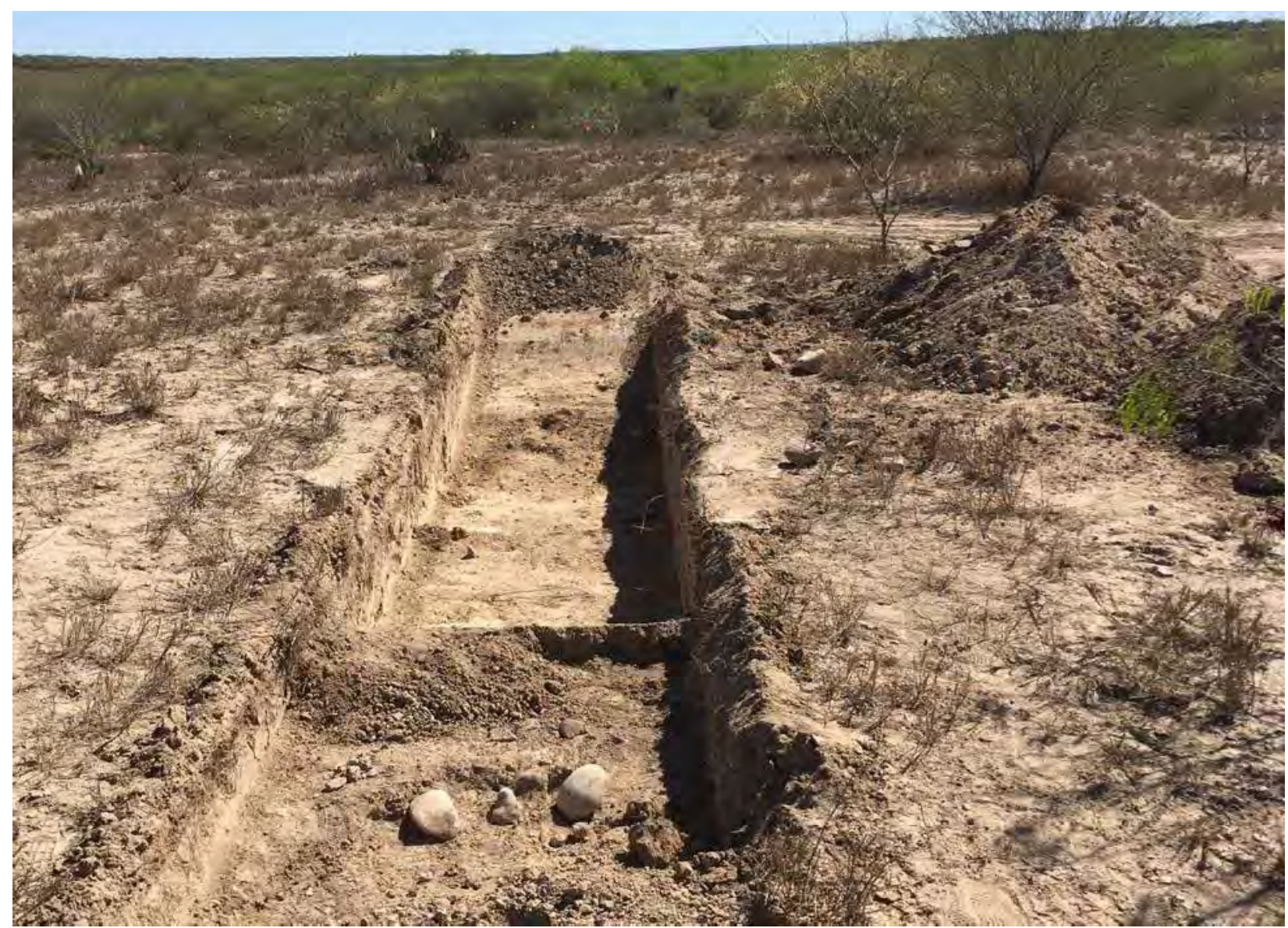

BT5:

0-15 cm: Ap horizon; sandy to silty loam; weak platy structure with superimposed irregular biogenic granular structure; soft; 10YR 4/3 (dry); occasional roots; common fine pores and krotovina; occasional fine siliceous gravels; clear boundary.

15-30 cm: AC1 horizon: gravelly loamy sand; most gravels are fine but contains pockets of cobbles to approx. $20 \mathrm{~cm}$ diameter; coarsens with depth (primarily due to gravel inclusions); 10YR 4/3 (dry); occasional roots; common fine pores and krotovina; gradual to clear boundary.

30-50 cm: AC2 horizon; grades from sandy loam to gravelly loamy sand with depth; 10YR 4/3 to 5/3 (dry); gravels to $10 \mathrm{~cm}$ diameter; fines are relatively hard and compact; carbonate filaments and some matrix carbonate; occasional roots; common fine pores and krotovina; clear boundary.

50-68 cm: Bk horizon; fine sandy loam; massive; slightly hard to hard; 10YR 6/3 (dry); occasional roots; occasional crushed snail shell; common soft, poorly bounded calcium carbonate masses.

Comment: Gravels and graded deposits indicate shallow channelized flow across surface here. Cluster of large cobbles was exposed by hand by J. Barrett and determined to be natural. No cultural material noted in profile. Trench terminated at compacted zone representing subsoil (BC or $C$ horizon). Excavated 2-22-17 (recorded 2-23-17). 


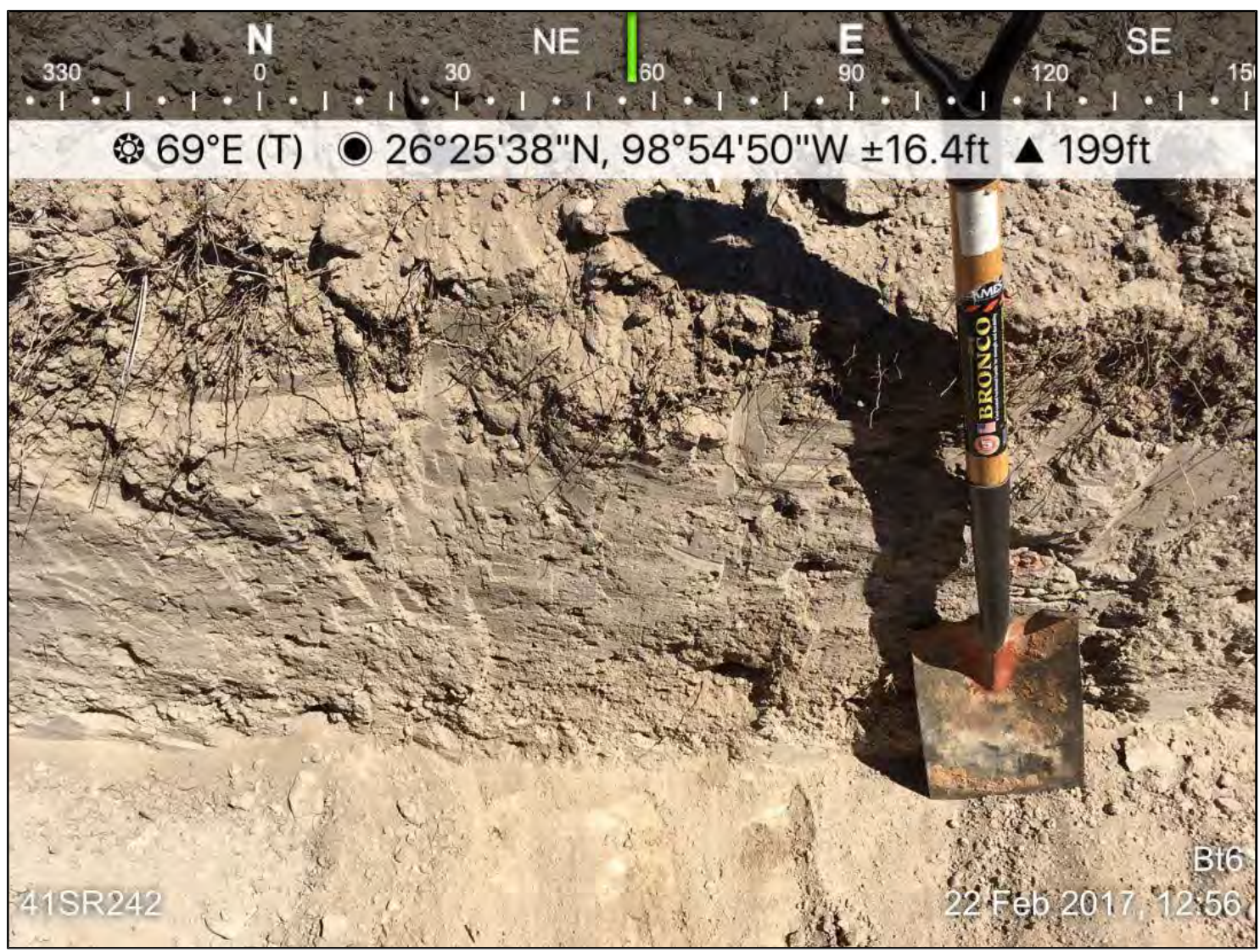

BT6:

0-12 cm: Ap horizon; sandy to silty loam; irregular platy structure superimposed on irregular biogenic granular structure; soft; 10YR 3/4 (dry); occasional roots; common fine pores and krotovina; clear boundary.

12-20: cm: A horizon; sandy to silty loam; irregular biogenic granular structure; soft; 10YR 3/4 (dry); occasional roots; common crushed snail shell; few fine siliceous gravels; gradual boundary.

20-50 cm: Bk1 horizon; sandy to silty loam; massive to weak, massive to irregular biogenic granular structure; 10YR 4/3 to 5/2 (dry); many open pores and insect-scale krotovina; occasional fine roots; few fine gravels; few localized clusters of poorly bounded $\mathrm{CaCO}^{3}$ nodules; abundant diffuse matrix carbonate; clearboundary.

50-70 cm: Bk2 horizon; sandy to silty loam; prominent irregular biogenic granular structure; 10YR 5/2 (dry); many open pores and insect-scale krotovina; occasional fine roots; few fine gravels; few localized clusters of poorly bounded $\mathrm{CaCO}^{3}$ nodules; abundant diffuse matrix carbonate.

Comments: No cultural material noted in profile. Trench terminated at compacted zone representing subsoil (BC or C horizon). Excavated 2-22-17 (recorded 2-23-17). 


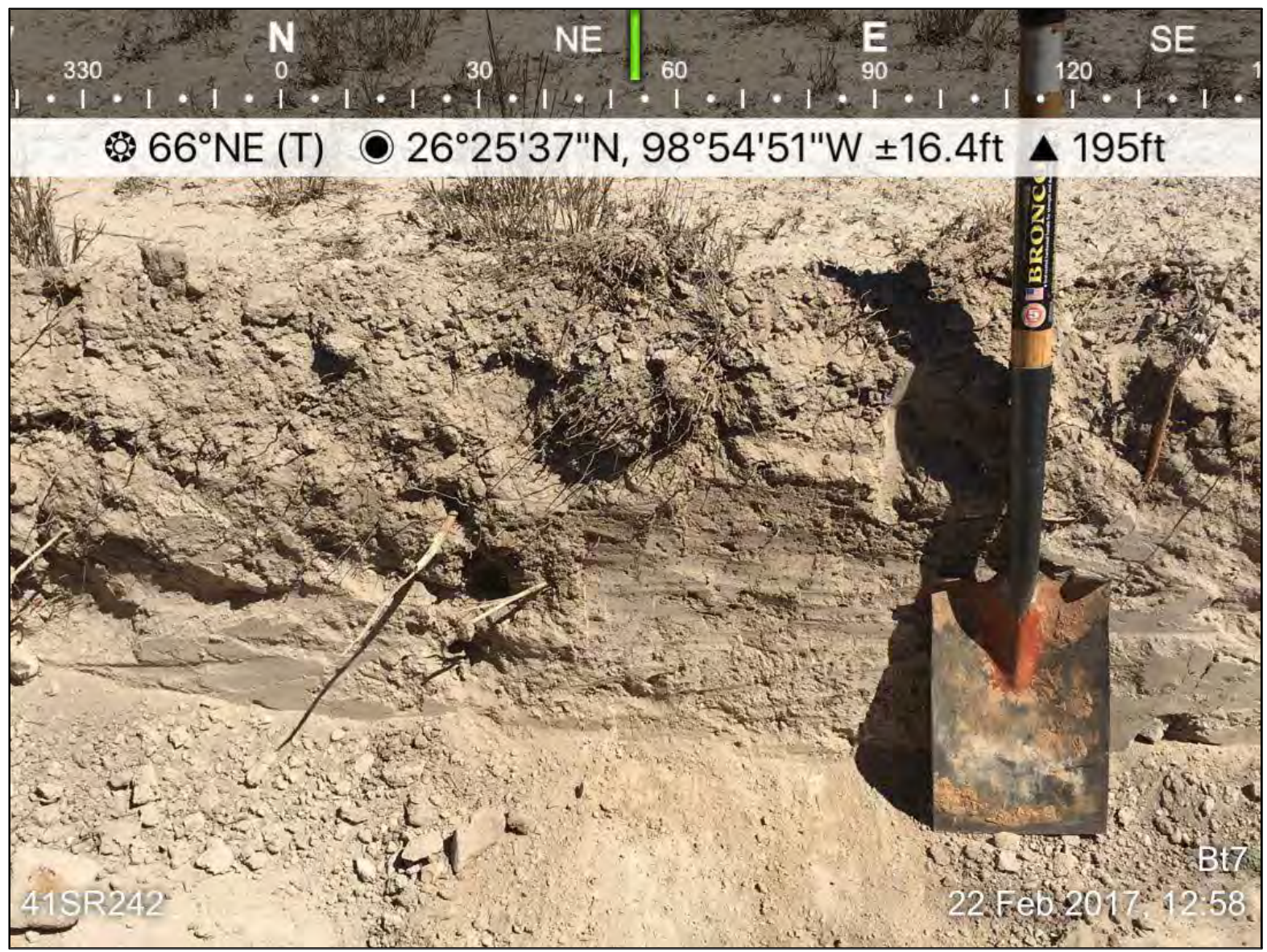

BT7:

0-15 cm: $\quad$ Ap horizon; sandy to silty loam; irregular platy structure superimposed on irregular biogenic granular structure; soft; 10YR 3/4 (dry); occasional roots; common fine pores and krotovina; clear boundary.

15-22: cm: A horizon; sandy to silty loam; irregular biogenic granular structure; soft; 10YR 3/4 (dry); occasional roots; common crushed snail shell; few fine siliceous gravels; gradual boundary.

22-50 cm: Bk horizon; sandy to silty loam; massive to weak, massive to irregular biogenic granular structure; 10YR 4/3 to 5/2 (dry); many open pores and insect-scale krotovina; occasional fine roots; few fine gravels; few carbonate filaments; abundant diffuse matrix carbonate; clear boundary.

Comments: $\quad$ Similar to BT1 \& BT6, but shallower. Trench terminated at compacted zone representing subsoil (BC or C horizon). No cultural material noted in profile. Excavated 2-22-17 (recorded 2-23-17). 


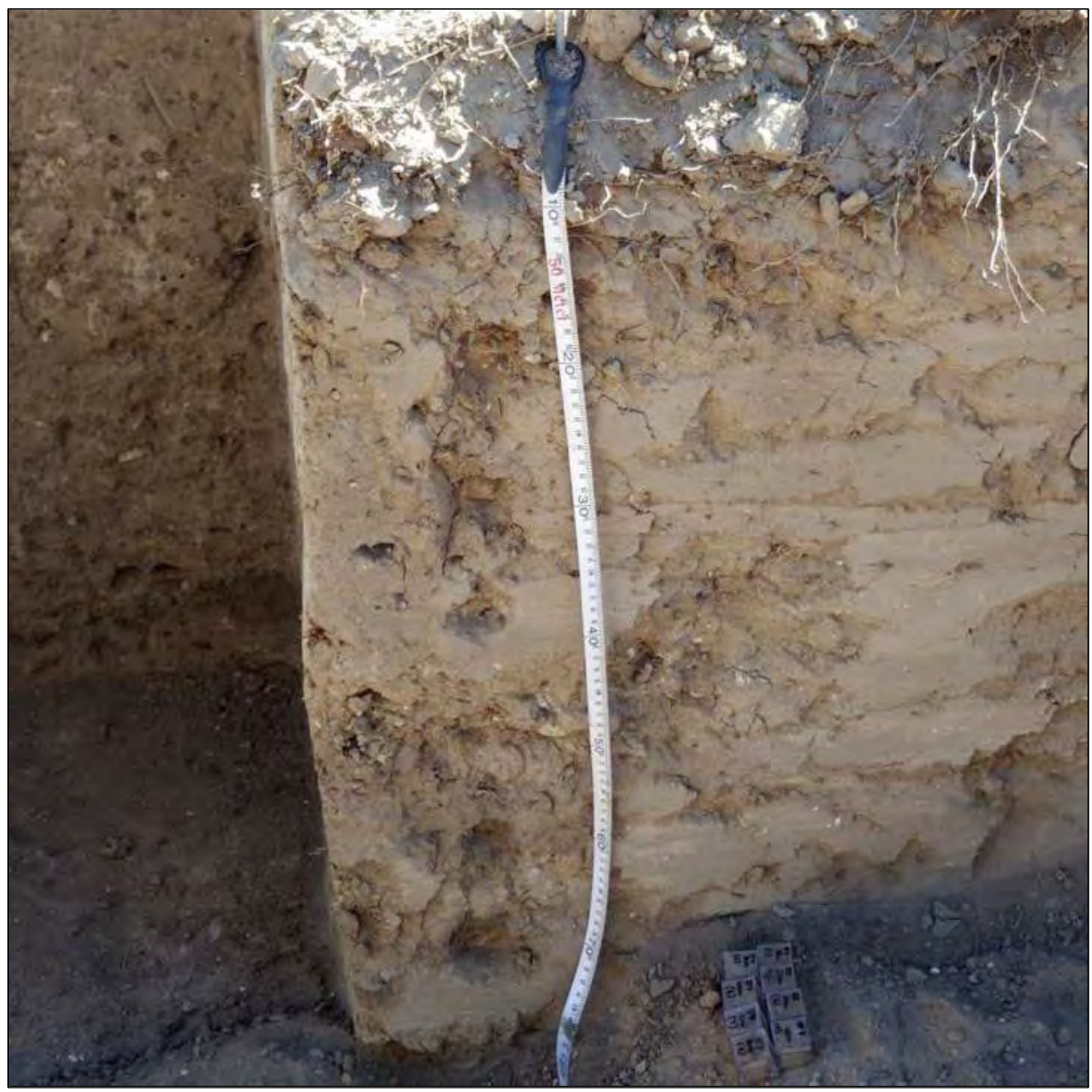

BT8:

0-9 cm: Ap horizon; sandy to silty loam; irregular platy structure superimposed on irregular biogenic granular structure; soft; 10YR 4/3 (dry); occasional roots; common fine pores and krotovina; clear boundary.

9-40: cm: A horizon; sandy to silty loam; irregular biogenic granular structure; soft; $10 \mathrm{YR} 4 / 3$ (dry); occasional roots; common crushed snail shell; sparse charcoal; occasional fragments of burned sandstone; dispersed lithic debitage few fine siliceous gravels; gradual boundary.

40-70 cm: Bk horizon; sandy to silty loam; massive to weak, massive to irregular biogenic granular structure; 10YR 4/3 to 5/2 (dry); many open pores and insect-scale krotovina; occasional fine roots; few fine gravels; few carbonate filaments; abundant diffuse matrix carbonate; clear boundary.

70-80 cm: Bk2 horizon; sandy to silty loam; weak subangular blocky with superimposed irregular biogenic granular structure; 10YR 5/2 (dry); many open pores and insect-scale krotovina; occasional fine roots; few fine gravels; few localized clusters of poorly bounded $\mathrm{CaCO}^{3}$ nodules; abundant diffuse matrix carbonate.

Comments: See laboratory profile. Samples for sediment analysis, thin section analysis, and CT analysis were taken from this profile. The depressions left by the small textural cube samples are visible, but the larger block samples had not yet been collected when the photo was taken. Tortugas point recovered from trench at approximately $50 \mathrm{cmbs}$. Trench terminated at compacted zone representing subsoil (BC or C horizon). Excavated 2-22-17 (recorded 2-23-17). 


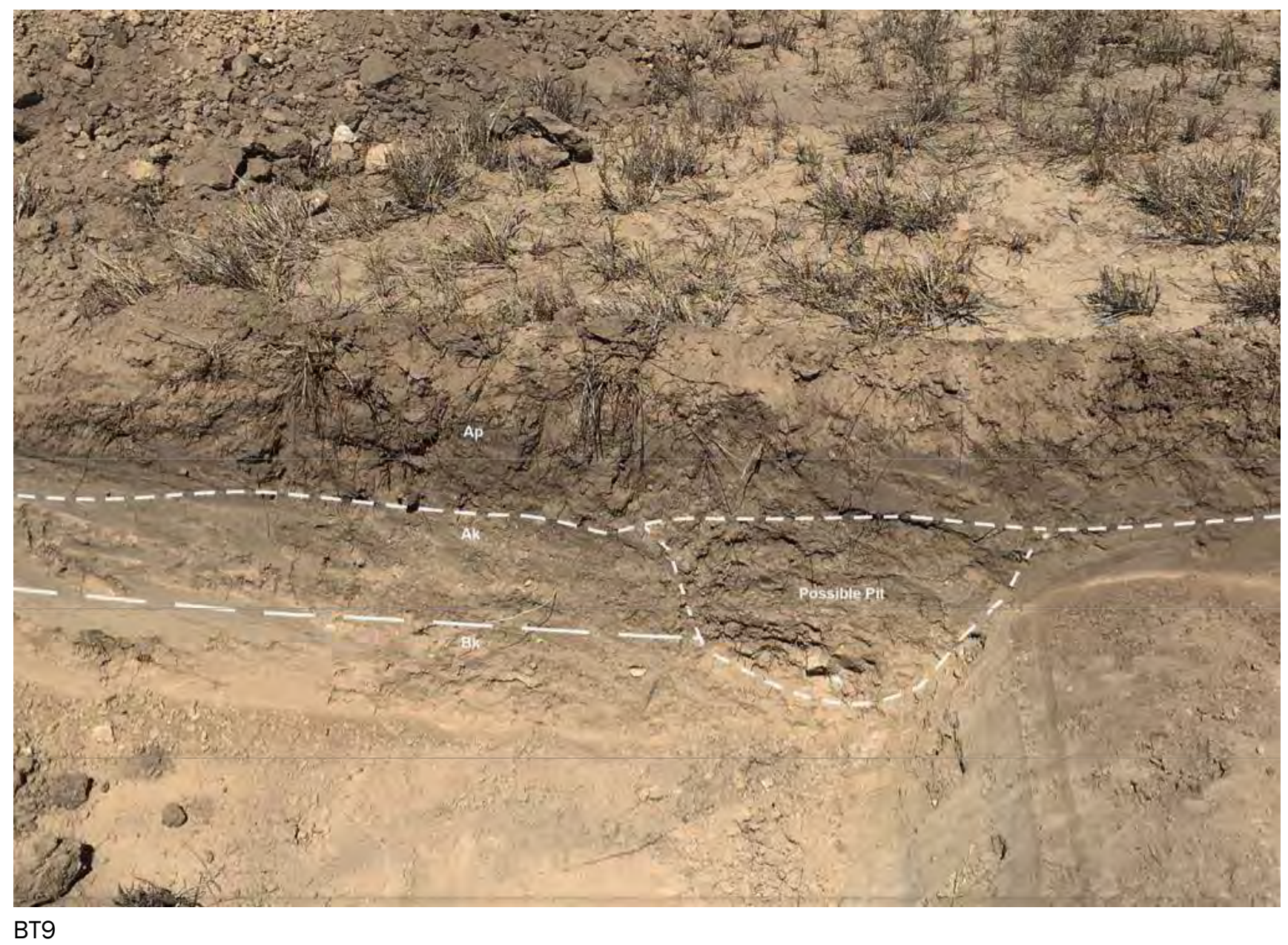

0-25 cm: $\quad$ Ap horizon; sandy to silty loam; irregular platy structure superimposed on irregular biogenic granular structure; soft; 10YR 4/2 (dry); occasional roots; common fine pores and krotovina; clear boundary.

25-60 cm: Ak horizon; sandy to silty loam; massive to weak, irregular biogenic granular structure; slightly hard; 10YR 4/3 (dry); many open pores and insect-scale krotovina; occasional fine roots; few localized clusters of poorly bounded $\mathrm{CaCO} 3$ nodules; common snail shell fragments; contains possible pit feature with burned rock in bottom; gradual boundary.

60-90 cm: Bk horizon; sandy to silty loam; massive to weak, massive to irregular biogenic granular structure; 10YR 5/2 to 6/3 (dry); common open pores and insect-scale krotovina; occasional fine roots;; few fine gravels; some diffuse matrix carbonate.

Comments: Possible pit was noted but not investigated. Trench terminated at compacted zone representing subsoil (BC or C horizon). Excavated 2-22-17 (recorded 2-23-17). 


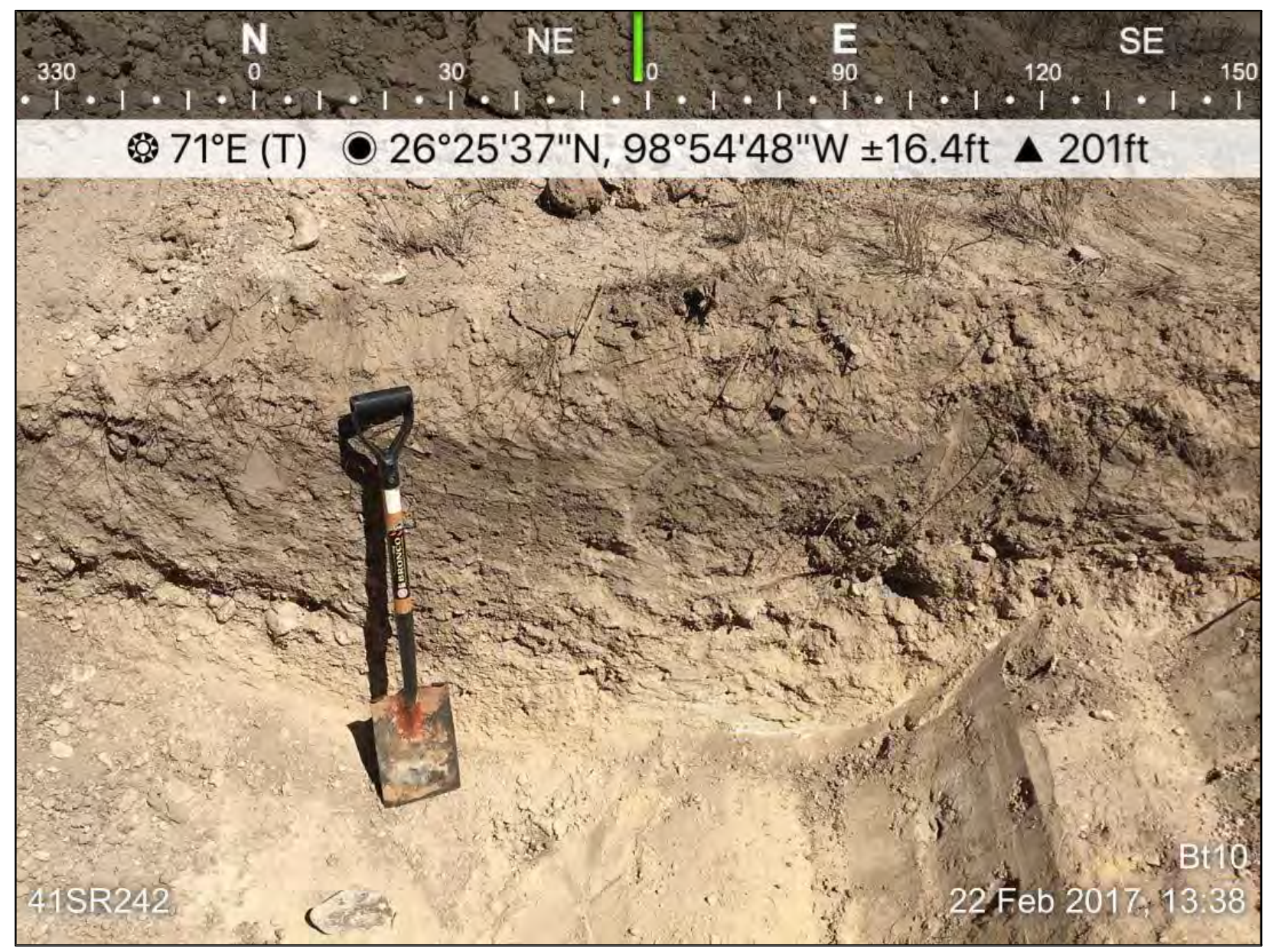

BT10:

0-6 cm: $\quad$ Ap1 horizon; sandy to silty loam; irregular platy structure superimposed on irregular biogenic granular structure; soft; 10YR 4/3 (dry); occasional roots; occasional siliceous gravels; common fine pores and krotovina; clearboundary.

6-40 cm: Ap2 horizon; gravelly fine sandy loam; weak subangular blocky structure with superimposed irregular biogenic granular structure; soft to slightly hard; 10YR 5/3 (dry); occasional roots; occasional small (thumb-sized) clasts of burned rock; common snail shells (Rabdotus spp); gradual boundary.

40-80 cm: $\quad$ C1 horizon; loamy gravel; very poorly sorted gravel to approx. $10 \mathrm{~cm}$ diameter; massive to crudely bedded; primarily rounded siliceous gravels, many with randomly oriented carbonate pendants; includes some possible burned rock clasts; 10YR 5/3 (dry); abrupt irregular boundary.

80-100 cm: 2 Bk horizon; sandy to silty loam; massive to weak, irregular biogenic granular structure; 10YR 6/3 (dry); common open pores and insect-scale krotovina; occasional fine roots; few fine gravels; occasional fine, poorly bounded carbonate masses; some diffuse matrix carbonate.

Comments: Trench contains only reworked burned rock mixed with many unburned rocks in a shallow, channelized deposit. Randomly oriented carbonate pendants on gravel clasts indicate that this represents short-distance reworking of older, calcified Rio Grande gravels. Trench terminated at compacted zone representing subsoil (BC or C horizon). Excavated 2-22-17 (recorded 2-23-17). 


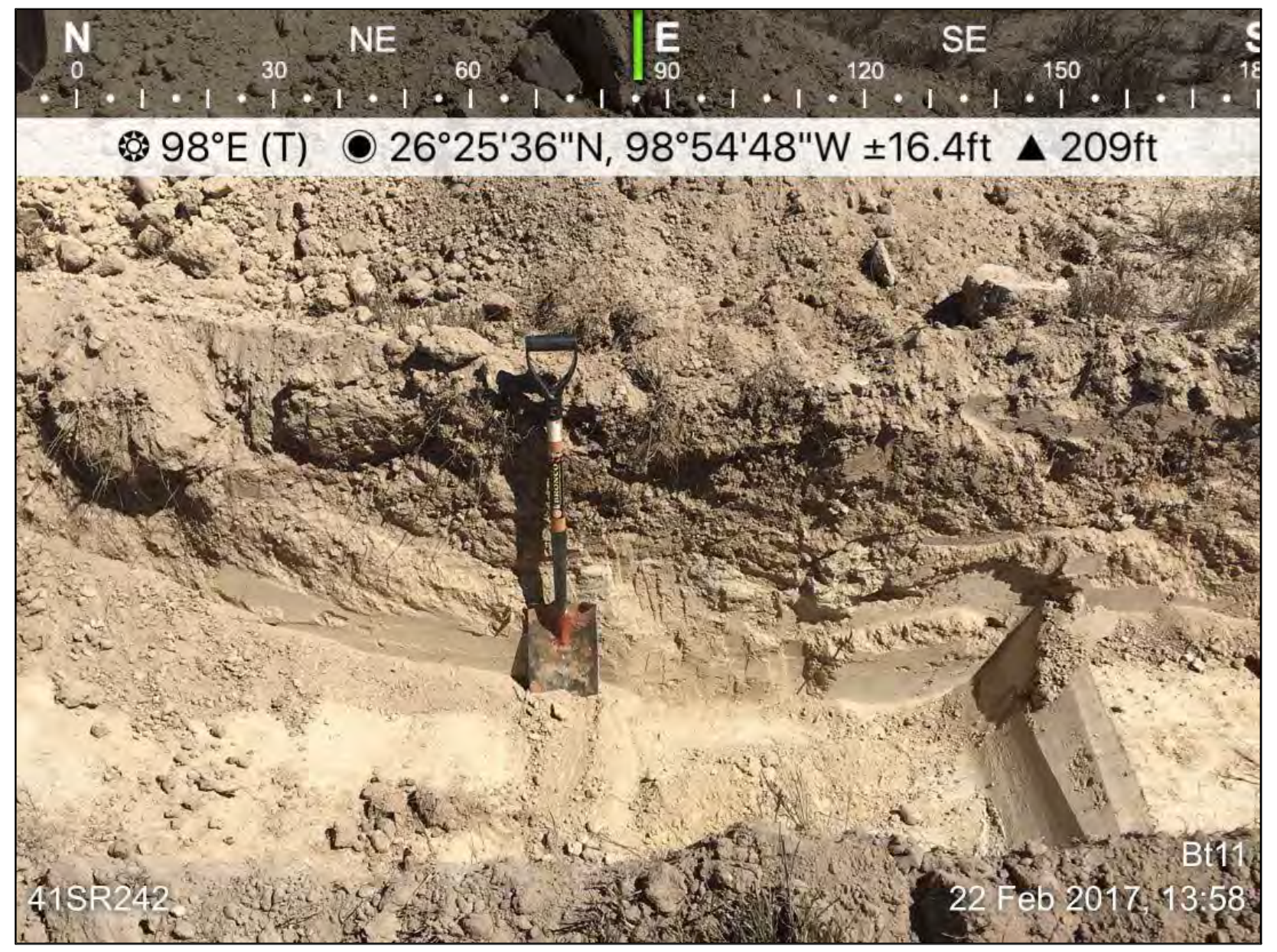

BT11:

0-10 cm: $\quad$ Ap1 horizon; sandy to silty loam; irregular platy structure superimposed on irregular biogenic granular structure; soft; 10YR 4/3 (dry); occasional roots; occasional siliceous gravels; common fine pores and krotovina; clearboundary.

10-35 cm: Ap/C horizon; gravelly fine sandy loam to loamy gravel; weak subangular blocky structure with superimposed irregular biogenic granular structure; soft to slightly hard; 10YR 5/3 (dry); occasional roots; occasional small (thumb-sized) clasts of burned rock; common snail shells (Rabdotus spp); gradual boundary.

35-80 cm: $\quad$ 2BCk horizon; sandy to silty loam; massive to weak, irregular biogenic granular structure; 10YR 6/3 (dry); common open pores and insect-scale krotovina; occasional fine roots; abundant crushed snail shell; occasional fine, poorly bounded carbonate masses; some diffuse matrix carbonate; contains large fragments of underlying sandstone.

80-82 cm: $\quad 2$ Cr horizon: Weathered, brecciated sandstone bedrock.

Comments: Trench contains only small reworked burned rock fragments mixed with many unburned clasts in a shallow, channelized deposit. As in BT10, this represents short-distance reworking of older, calcified Rio Grande gravels. Trench terminated in brecciated sandstone bedrock. Excavated 222-17 (recorded 2-23-17). 

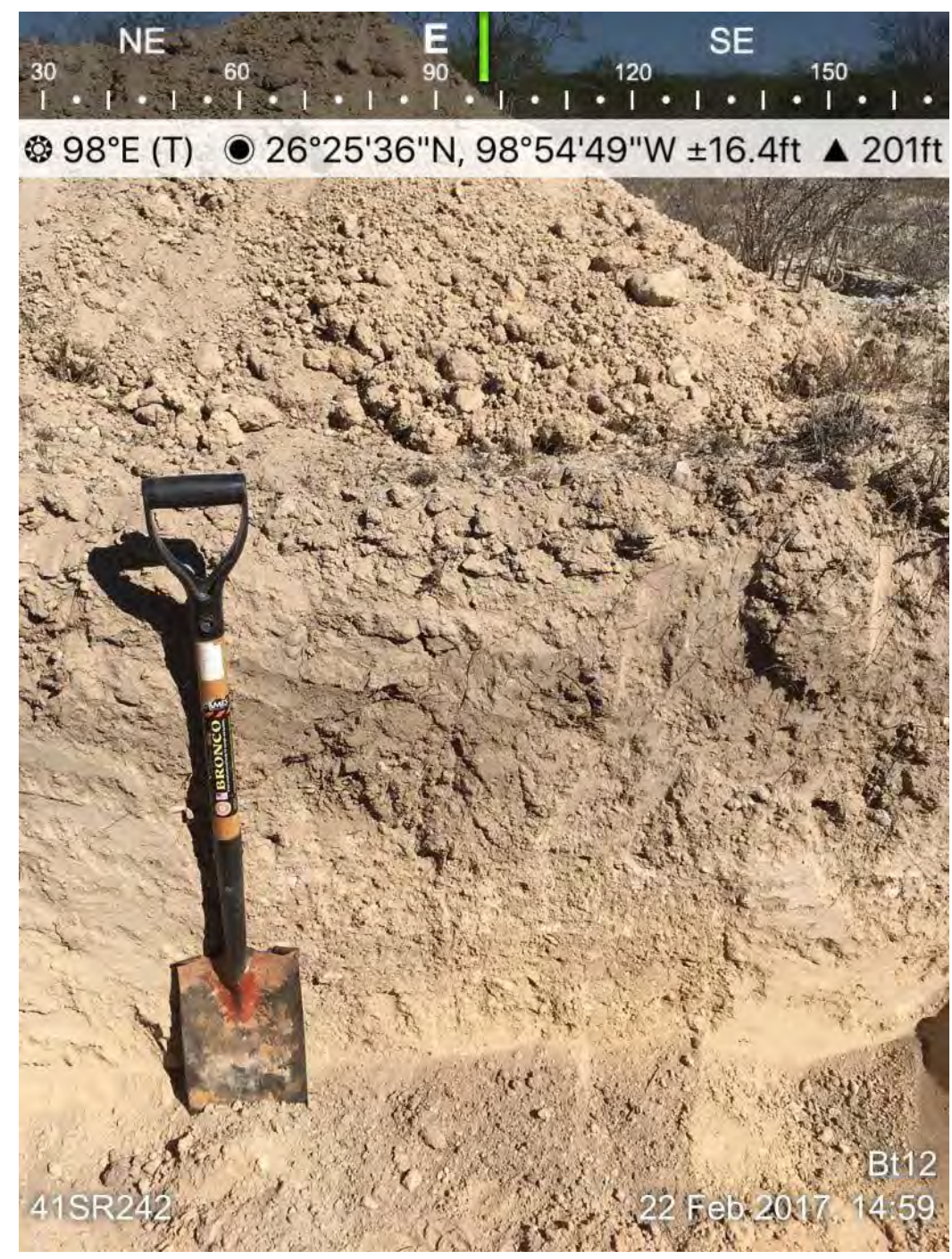

BT12:

0-8 cm: Ap1 horizon; sandy to silty loam; irregular platy structure superimposed on irregular biogenic granular structure; soft; 10YR 4/3 (dry); occasional roots; occasional siliceous gravels; common fine pores and krotovina; clearboundary.

8-42 cm: Ap2 horizon; gravelly fine sandy loam; weak subangular blocky structure with superimposed irregular biogenic granular structure; soft to slightly hard; 10YR 5/3 (dry); occasional roots; occasional small (thumb-sized) clasts of burned rock; common snail shells (Rabdotus spp) and crushed snail shell; gradualboundary.

42-80 cm: Bk horizon; sandy to silty loam; massive to weak, irregular biogenic granular structure; 10YR 6/3 (dry); common open pores and insect-scale krotovina; occasional fine roots; few fine gravels; common fine, poorly bounded carbonate masses; some diffuse matrix carbonate; occasional thumb-sized fragments of thermally-fractured siliceous rock; clear boundary.

80-100 cm 2BC horizon; fine sandy loam; massive; slightly hard; 10YR 7/4 (dry).

Comments: Trench terminated at compacted zone representing subsoil (BC horizon) 

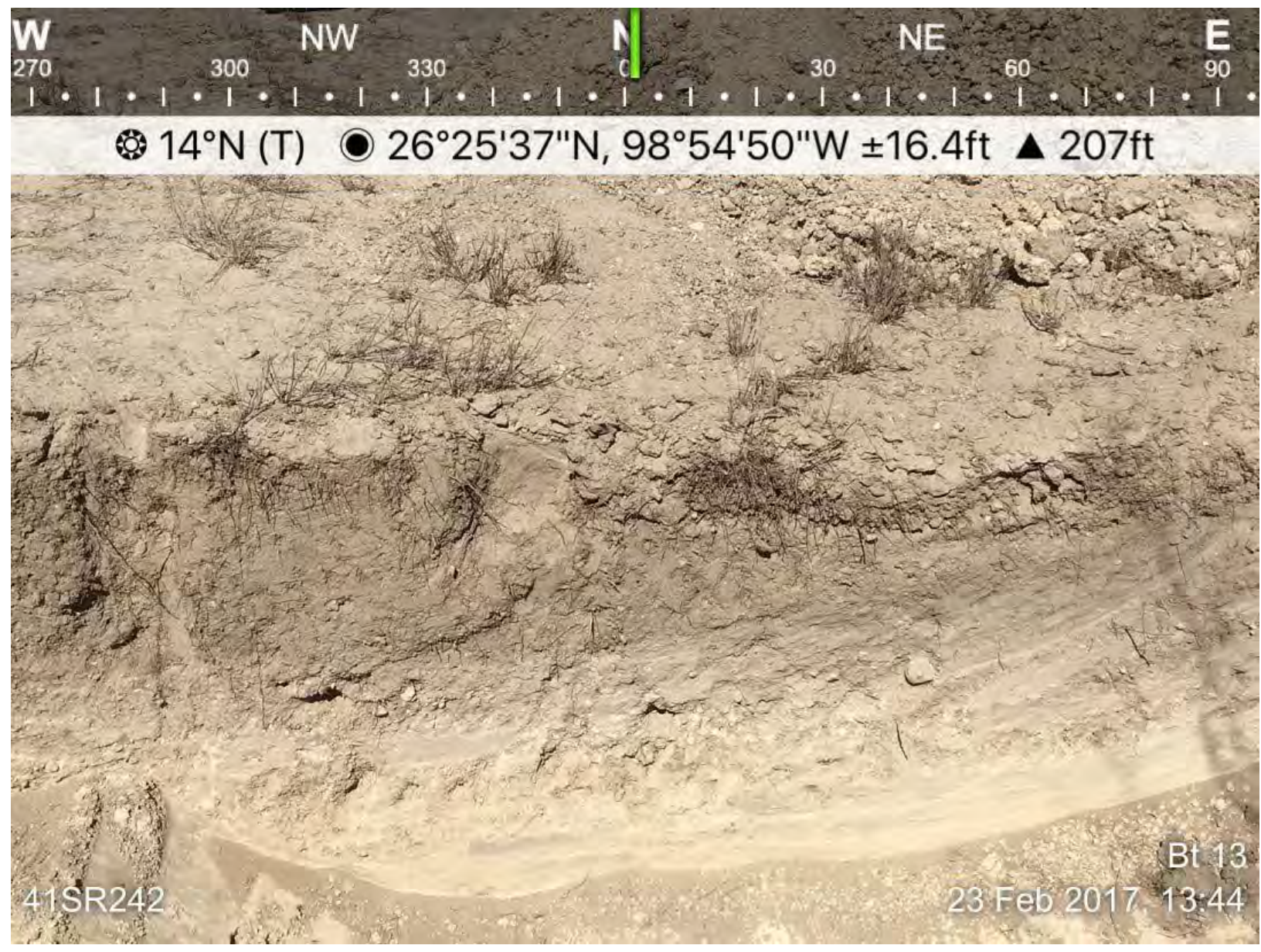

BT13:

0-15 cm: Ap1 horizon; sandy to silty loam; irregular platy structure superimposed on irregular biogenic granular structure; soft; 10YR 4/2 (dry); occasional roots; common fine pores and krotovina; clear boundary.

15-50 cm: Ap2 horizon; sandy to silty loam; irregular biogenic granular structure; soft; 10YR 4/2 (dry); occasional roots; common crushed snail shell; occasional siliceous gravels and cobbles; clear boundary.

50-95 cm: Bk horizon; sandy to silty loam; massive to weak, irregular biogenic granular structure; 10YR 5/2 (dry); common open pores and insect-scale krotovina; occasional fine roots; common fine gravels; common crushed snail shell; few localized clusters of poorly bounded $\mathrm{CaCO}^{3}$ nodules; clear boundary.

95-120 cm: BC horizon; sandy to silty loam; massive; compact; slightly hard to hard; $10 Y R$ 6/2 to $7 / 4$ (dry).

Comments: Trench situated between BT1 and BT4, but contained very little cultural material Trench terminated in compacted zone representing subsoil (BC or C horizon). Excavated 2-22-17 (recorded 2-23-17). 


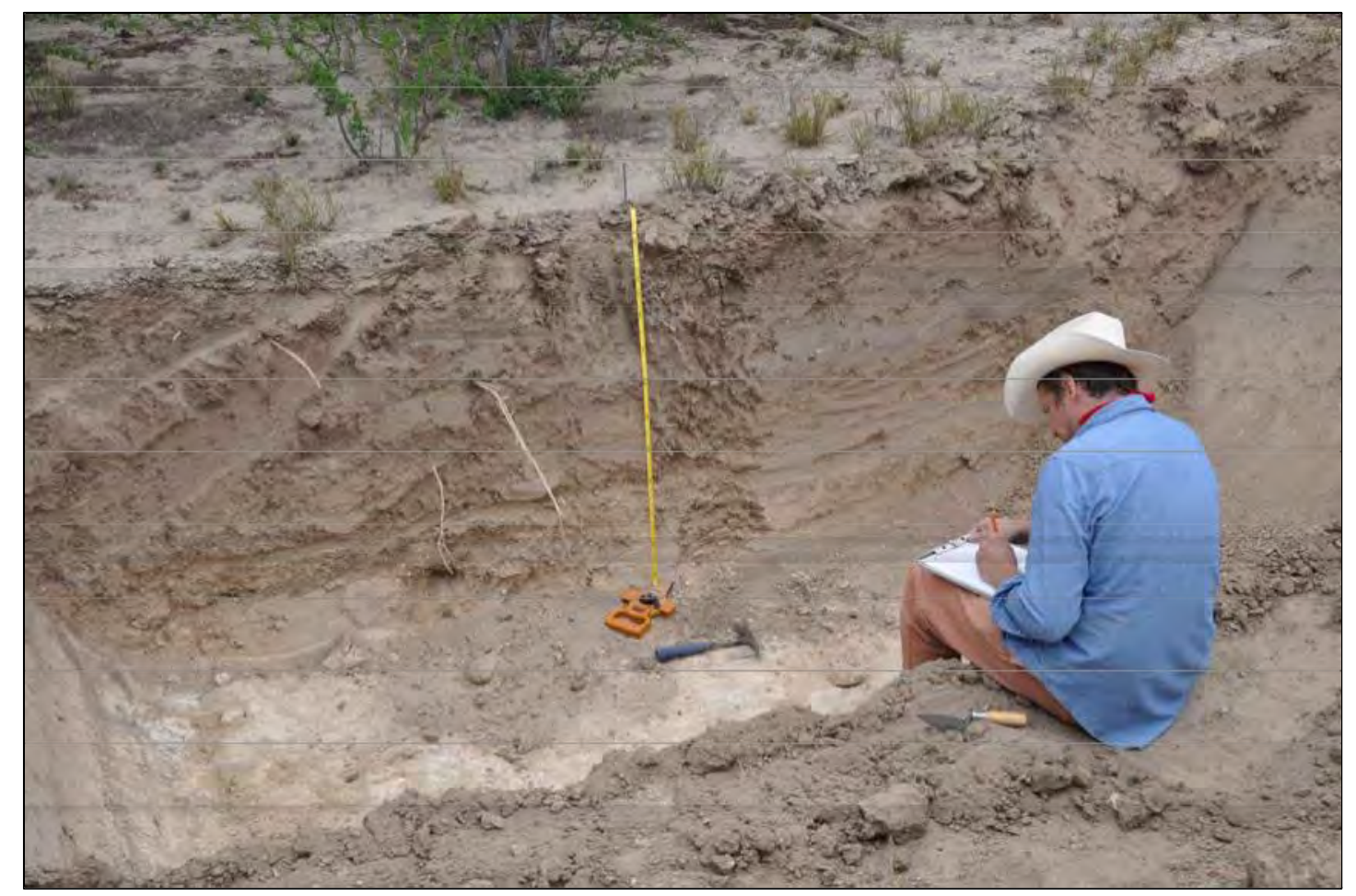

BT14:

0-42 cm: Ap horizon; sandy to silty loam; 10YR 5/3 (dry); disturbed scattered flakes and shell.

42-79 cm: B1 horizon; gravelly sandy to silty loam; 10YR 6/2 (dry); common fire cracked rock and flakes; $2 \%$ gravels $1-3 \mathrm{~cm}$ in size.

79-106 cm: B2 horizon; gravelly sandy to silty loam; $10 \mathrm{YR} 7 / 3$ (dry); $2 \%$ gravels $1-3 \mathrm{~cm}$ in size; $\mathrm{CaCO}^{3}$ nodules; clear boundary.

106-125 cm: C horizon; sandy to silty loam; weathered sandstone parent material; $2.5 \mathrm{Y} 8 / 2$ (dry); includes sandstone fragments.

Comments: Trench terminated in compacted zone representing subsoil (C horizon). Trench recorded by Corey Crawford. 


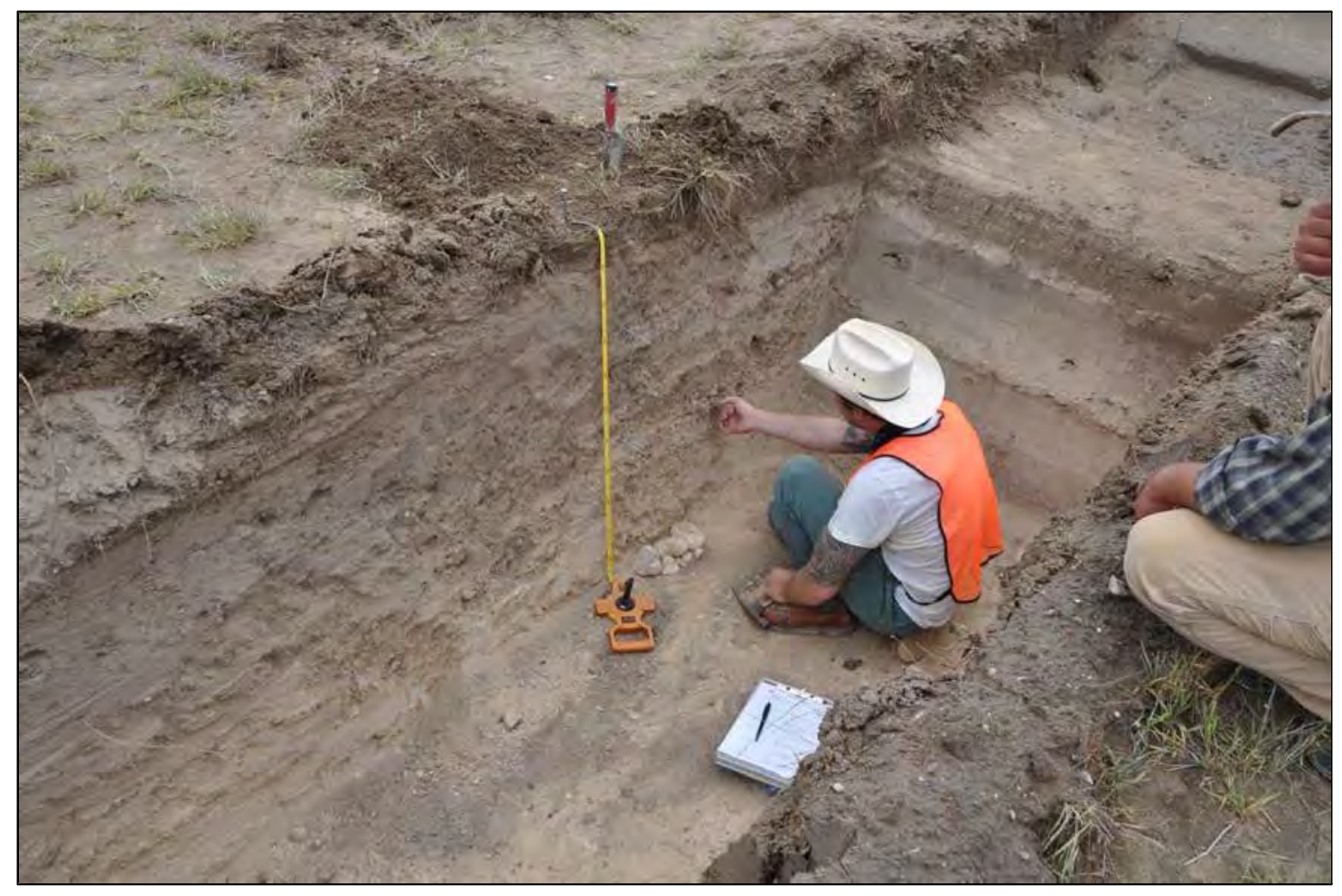

BT15:

0-43 cm: Ap horizon; sandy loam; 10YR 5/3 (dry); clear boundary.

443-77 cm: B horizon; sandy loam; 10YR 6/2 (dry); contains snail shell, fire cracked rock and flakes; clear boundary.

777-110 cm: Bk horizon; sandy loam; 10YR 7/3 (dry); common $\mathrm{CaCO}^{3}$ nodules; clear boundary.

$100-125 \mathrm{~cm}$ : C horizon; gravelly sandy loam; $2.5 \mathrm{Y} 8 / 2$ (dry); $30 \%$ gravels between $0.5 \mathrm{~cm}$ and $10 \mathrm{~cm}$ in diameter.

Comments: Trench terminated at compacted zone representing older alluvium (C horizon).Trench recorded by Corey Crawford. 
A-16 


\section{APPENDIX B \\ Soil Micromorphology}

Dr. Charles Frederick and Dr. James T. Abbott 
This page intentionally left blank. 
Soil Micromorphology and Micro CT Scanning of two Soil Blocks from 41SR242

by

Charles D. Frederick

ConsultingGeoarchaeologist

Dublin, TX

B-1 


\section{Introduction}

Two oriented soil blocks were collected from Trench 8 at site 41SR242 by Jim Abbott. One block was collected from a depth of $15-23 \mathrm{~cm}$ below the ground surface, in a portion of the profile that had been subjected to root plowing. The second sample was collected from a depth of $45-53 \mathrm{~cm}$ below the ground surface, in a portion of the profile where the dominant fabric appeared to be biogenic in nature, primarily associated with insect bioturbation. These blocks were wrapped in foil and tape in order to preserve their undisturbed fabrics.

\section{BT-8 15-23 cm}

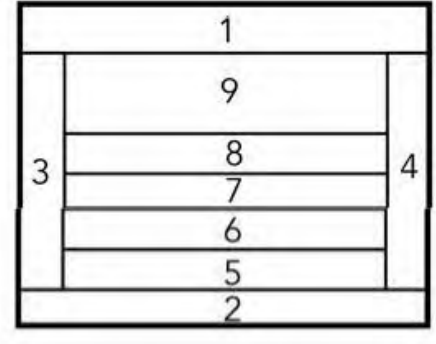

Plan View

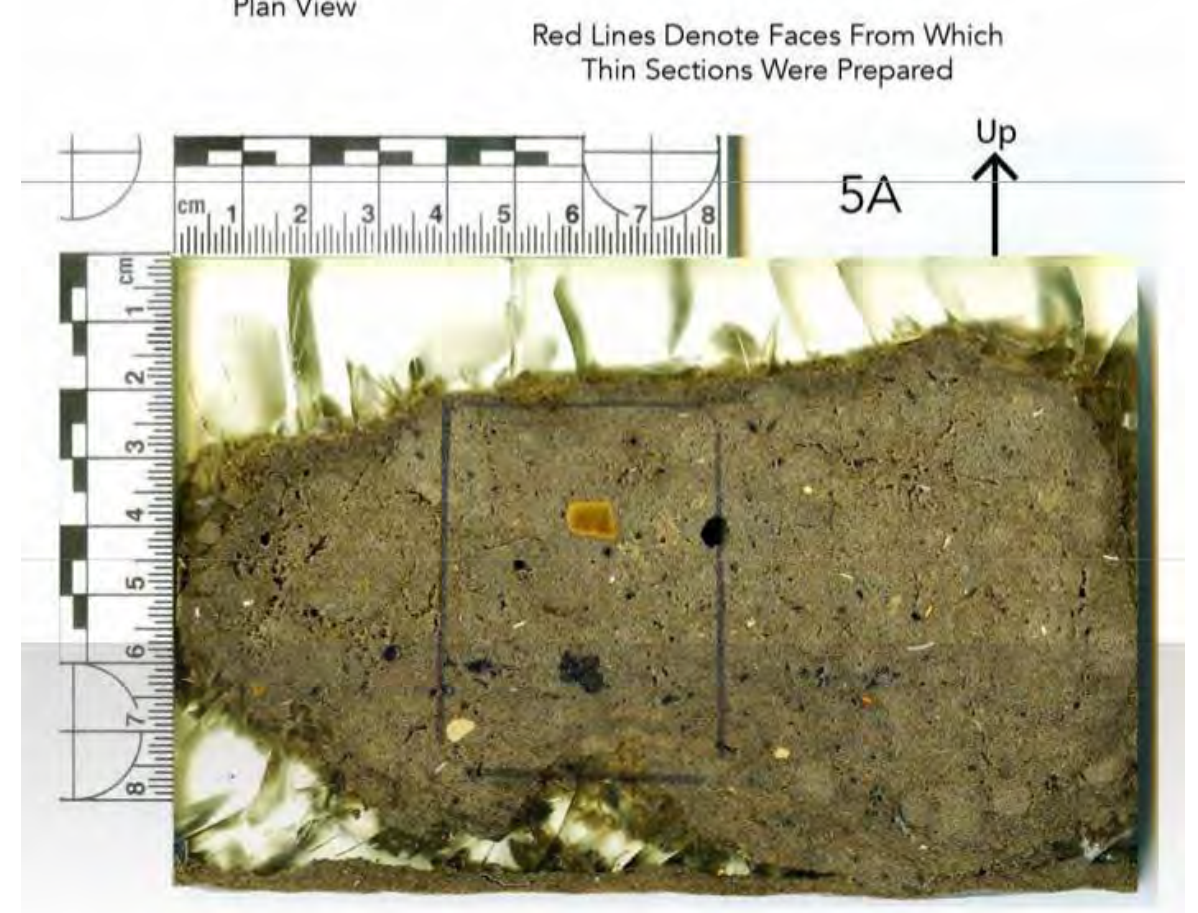

Figure B1: Top Left: Plan view of the soil block showing how it was slabbed on the rock saw. Top Right: An exploded view of the slabs for which two scans were ade, showing how they relate to each other, and the nomenclature used to designate them (A \& B). Bottom: Reflected light scan of slab 5a. Black rectangle shows the area from which the thinsection was prepared. 
The blocks were first submitted to the High-Resolution X-Ray Computed Tomography Facility at the University of Texas at Austin (UTCT; see http://www.ctlab.geo.utexas.edu) for CT scanning in order to provide a different view of the soil matrix. CT scanning has been done on soil before (cf. Huisman and Milek 2017; Hgan-Tillard and Huisman 2017) but is still a relatively novel process. After the CT scans were completed, the blocks were embedded in a polyester resin mixture (70\% non-promoted polyester resin, 30\% styrene, $<1 \%$ methyl ethyl ketone peroxide) and after the resin had polymerized, the block were placed in a low temperature oven overnight to cure. They were then slabbed on a rock saw in order to provide multiple cross sections that could be directly compared to the micro CT scans. Figure B1 and Figure B2 show a plan view of the original consolidated block and how it was slabbed. All cut faces were scanned, and where a slab had two cut faces (as did most of the interior slabs) one side was designated A and the other B. Each face was then scanned using reflected light on a flatbed scanner. Three slabs, one from the upper block $(15-23 \mathrm{~cm}$, slab 5a) and two from the lower block (45-53 cm, slabs $6 a$ and $8 \mathrm{~b})$ were selected for thin section preparation, specifically focusing on peofeatures associated with burrowing. Direct comparison of the reflected light scan and a cross-section derived from the 3D CT scan are provided on Figures B3, B4, and B5.

From each slab a single area, approximately $3 \mathrm{~cm} \times 5 \mathrm{~cm}$, was chosen for thin section manufacture, and the areas chosen are shown outlined in black ink on the lower portions of Figures B1 and B2. The selected areas were then trimmed on a tile saw, dried and then submitted to National Petrographic Service (Rosenberg, Texas) for the preparation of 2" x 3" thin sections. Upon receipt of the thin sections, each slide was scanned on a flat-bed scanner at a resolution of 1200 dpi using transmitted light, and using pseudo-darkfield conditions (reflected light with the scanner top open) which highlights different attributes of the deposits. Figure B6 shows the area of each slide in different states of preparation, specifically as viewed in transmitted light, pseudo darkfield, reflected light scan of slab, and approximate cross-section derived from the computed tomography.

These slide scans, which highlight different attributes of the materials, were then examined at various magnifications using a Zeiss AXIO Zoom v16 microscope under plane transmitted light, cross-polarized light, oblique incident light, and blue light epiflourescence in order to identify features associated with apparent biogenic activity. These features were then highlighted on the transmitted plane light scan using simple and dashed lines (see Figures B7, B9, and B11 ). Specific areas were then selected to highlight features of interest and photographed; the locations of these photos are shown on Figures B8, B10, and B12). For each thin section, a basic description was compiled of the overall slide. These descriptions are presented on Tables 1, 2 and3. 


\section{BT-8 $45-53 \mathrm{~cm}$}
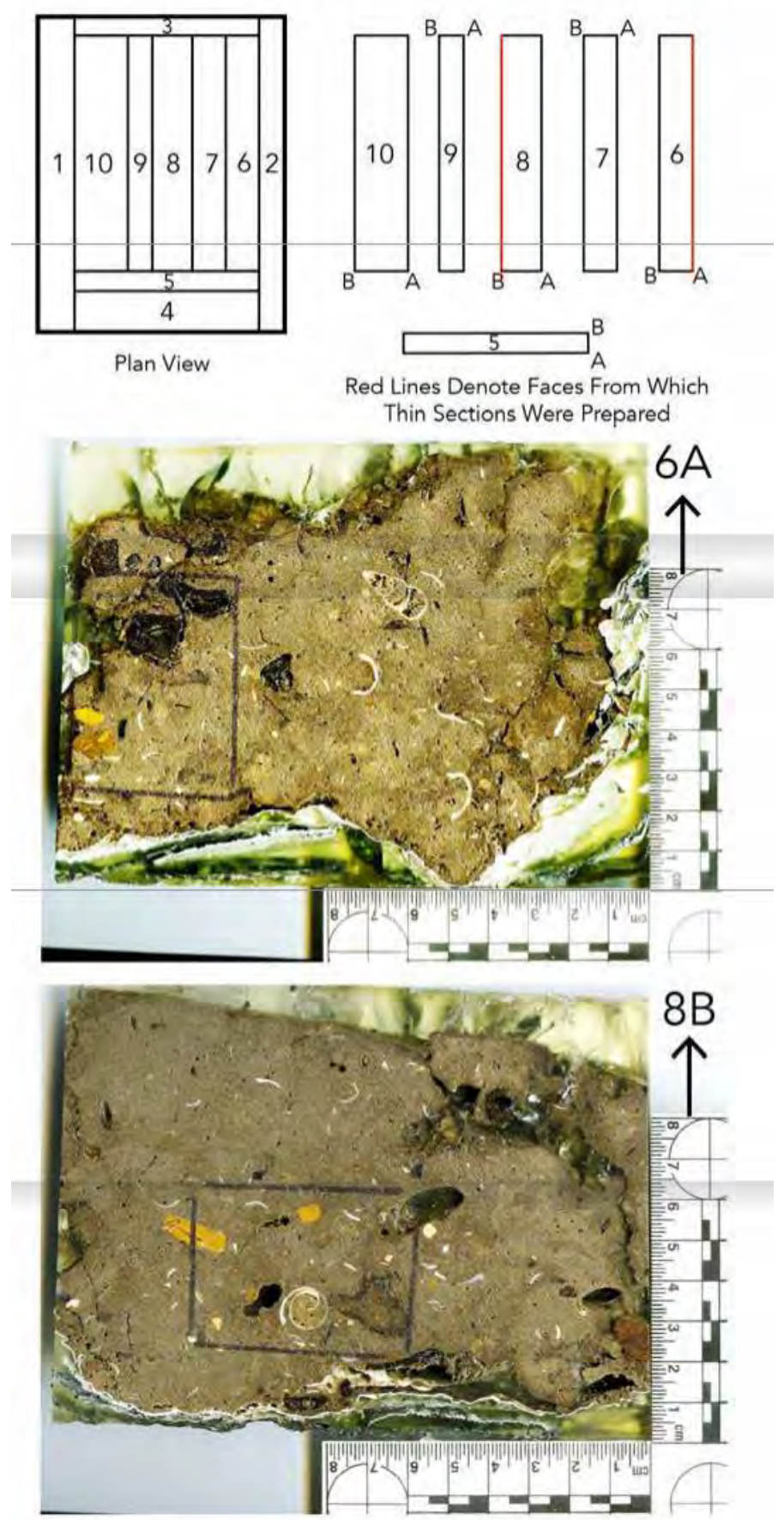

Figure B2: Top Left: Plan view of the block identifying the slabs created when the block was slabbed on the rock saw. Top Right: Both sides of each slab were scanned and this exploded view shows how the scanned slabs relate to each other. The red lines denote the scanned slabs used to prepare thin sections. Middle: Reflected light scan of slab $6 a$, with the black rectangle denoting the portion of the slab from which the thin section was prepared. Bottom: Reflected light scan of slab $8 \mathrm{~b}$. Black rectangle is the portion of the slab from which the thin section was prepared. 

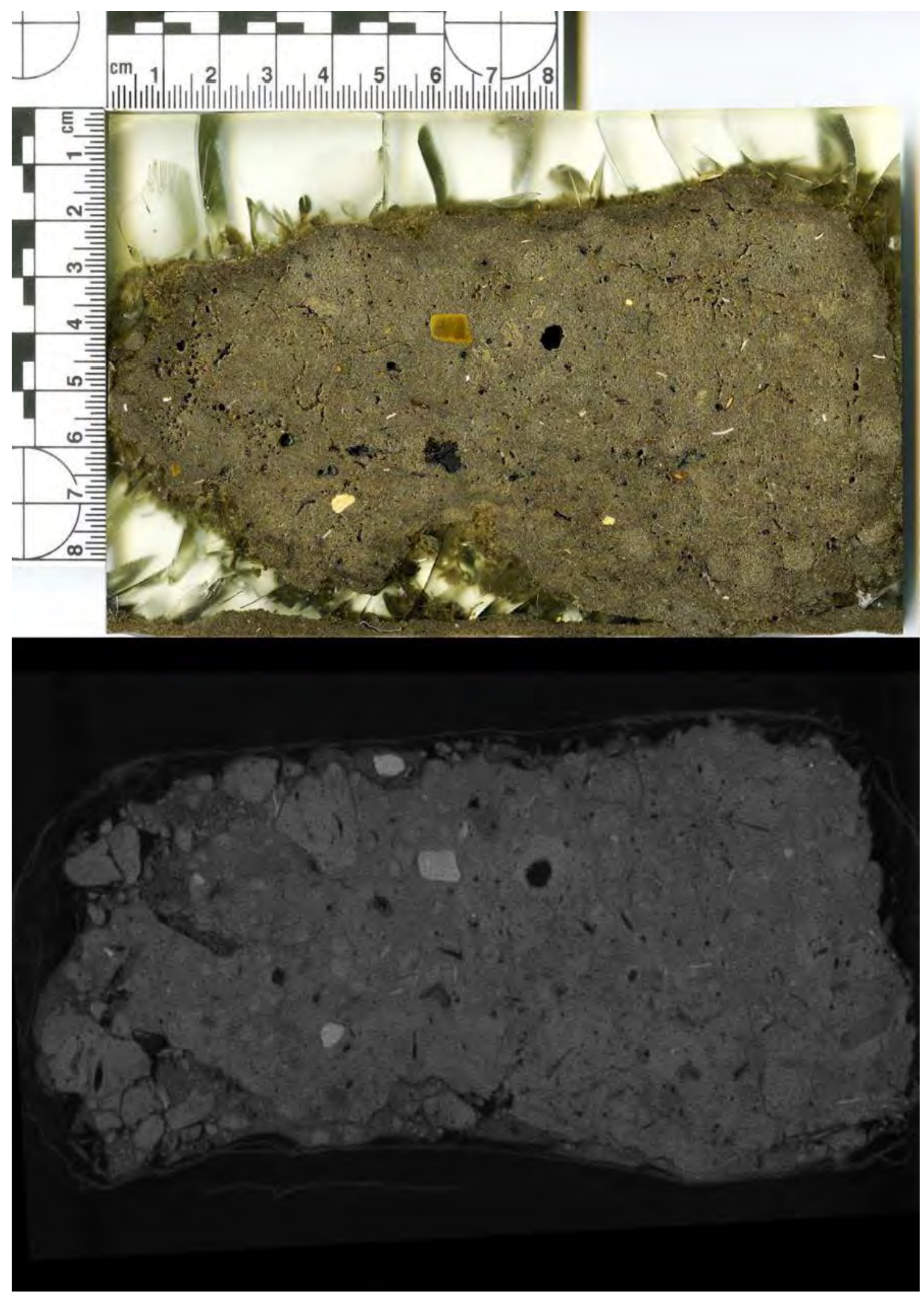

Figure B3: Top Half: Reflected light scan of slab $5 a$ from the $15-23 \mathrm{~cm}$ depth block from which the thin section was prepared. Bottom Half: Cross-section derived from the CT scan data of approximately the same section line as shown in the tophalf. 

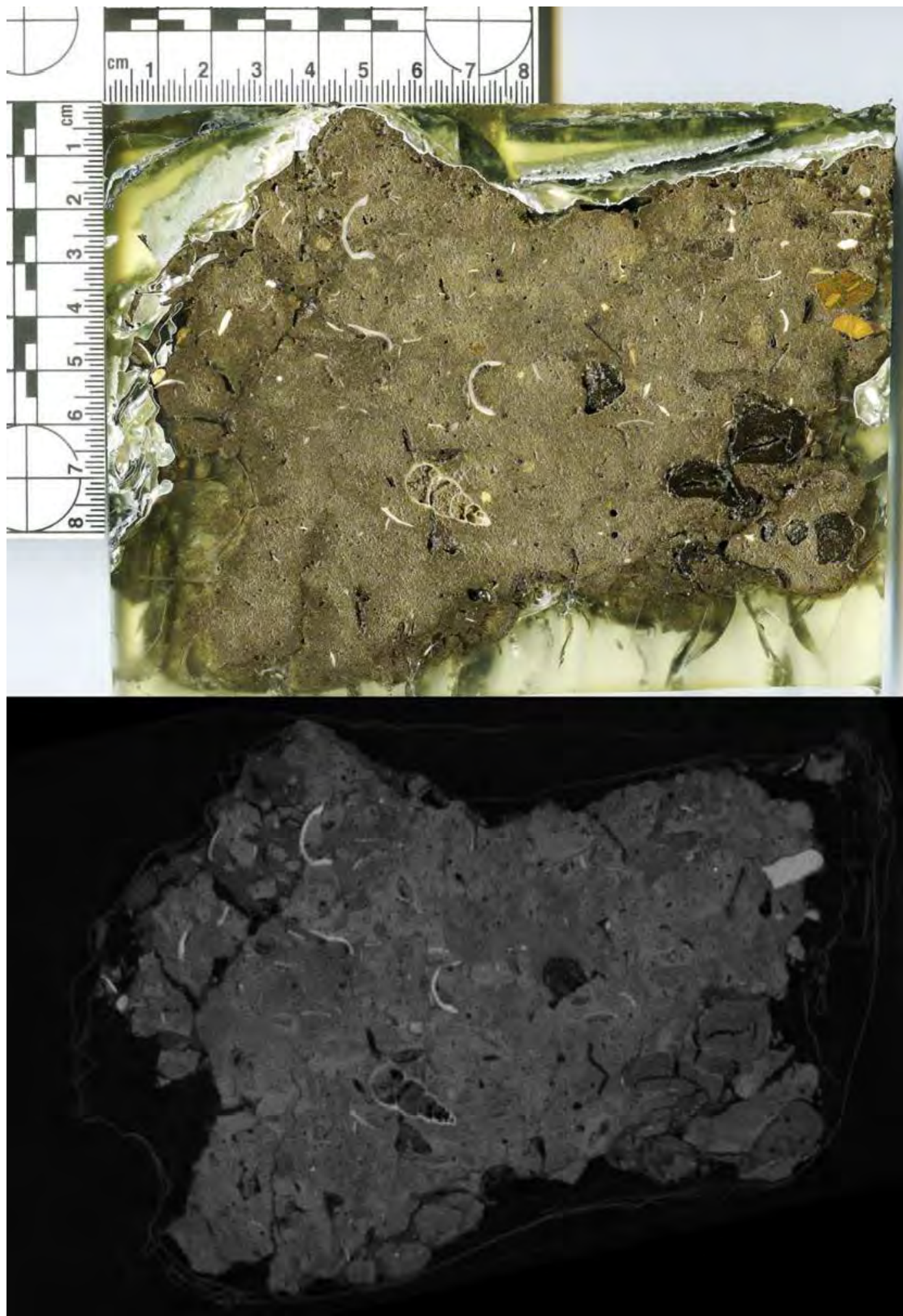

Figure B4: Top Half: Reflected light scan of slab $6 a$ cut from the $45-53 \mathrm{~cm}$ block. Bottom Half: A CT scan derived illustration of approximately the same section line as shown above. 

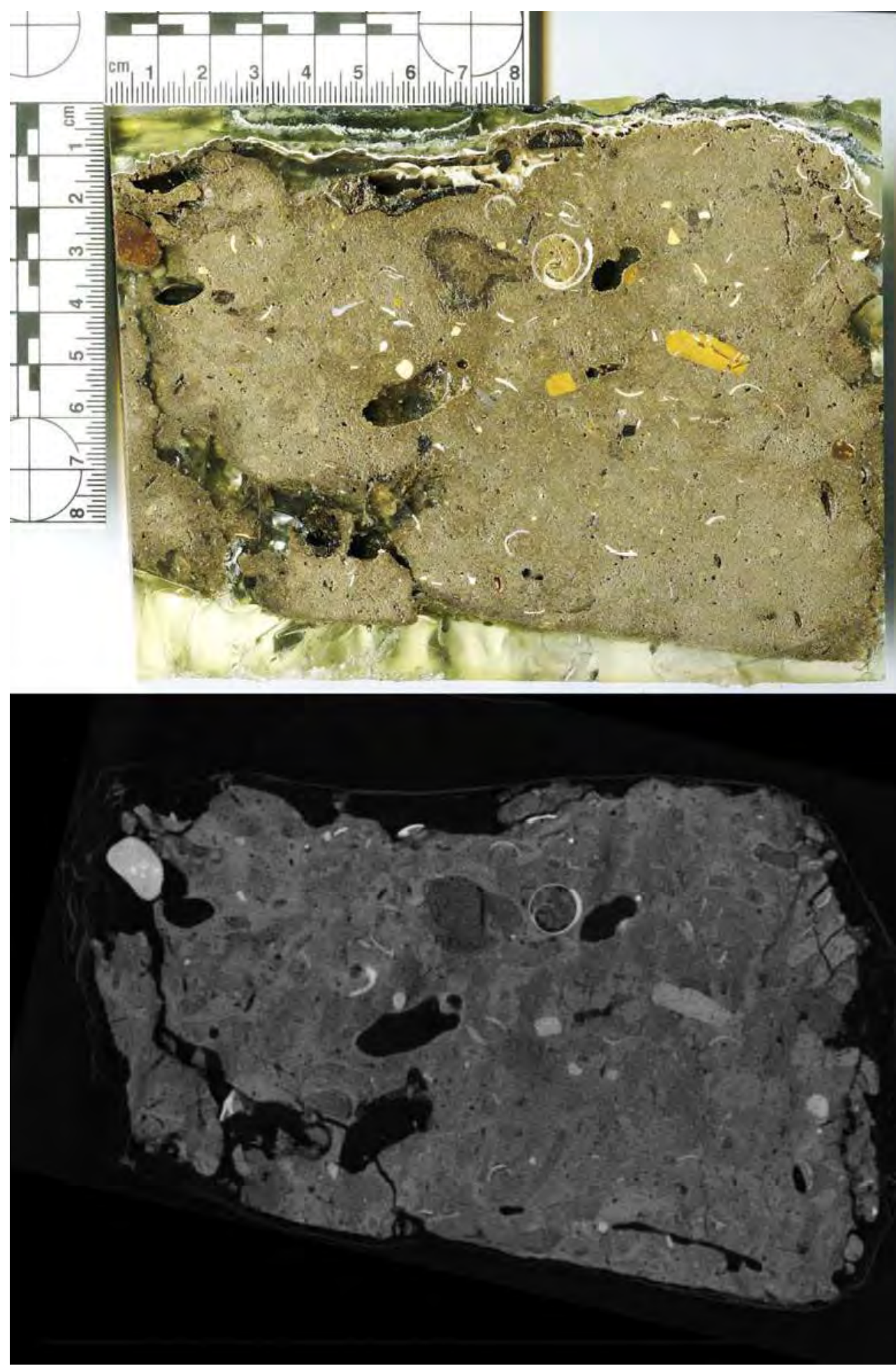

Figure B5: Top Half: Reflected light scan of slab $8 \mathrm{~b}$ cut from the polyester embedded $45-53 \mathrm{~cm}$ block sample. Bottom Half: A CT scan of approximately the same section line as shown above. 

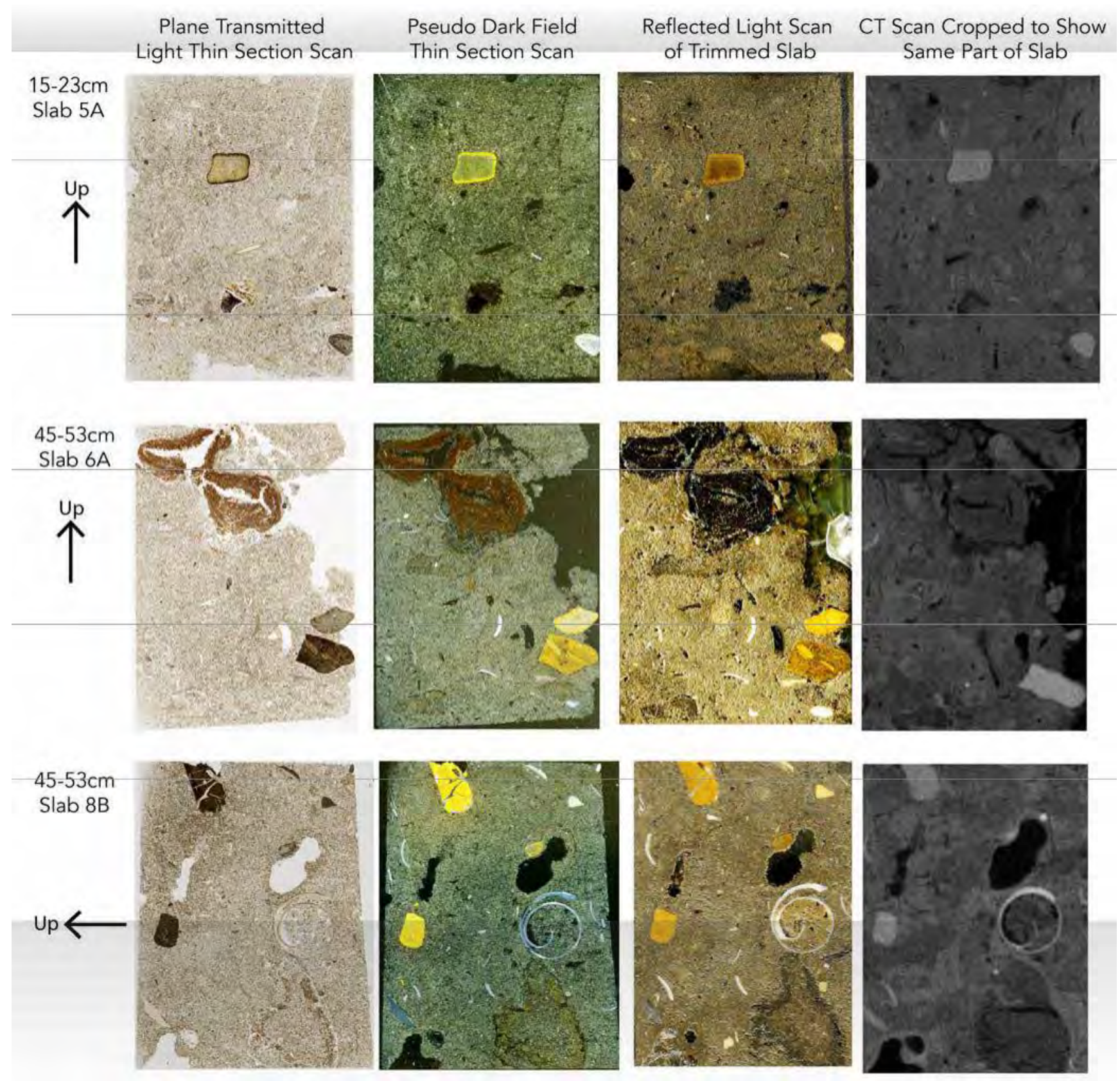

Figure B6: Four different views of the thin section slides (left two images) and source of the slides from which the three thin sections prepared from the embedded soil blocks(right two images). Top row is the single thin section made from the $15-23 \mathrm{~cm}$ depth block, while the lower two rows are the two thin sections made from the 45-53 cm depth block. The left column shows a transmitted light scan of each thin section. The second from left column shows each slide in pseudo-dark field, which highlights reflective mineral and biogenic mineral matter. The third column from the left shows a reflected light scan of the polyester embedded blank from which the slide was prepared. The fourth column is approximately the same field of view as seen from the CT scan, made before the block was impregnated with polyester resin. 


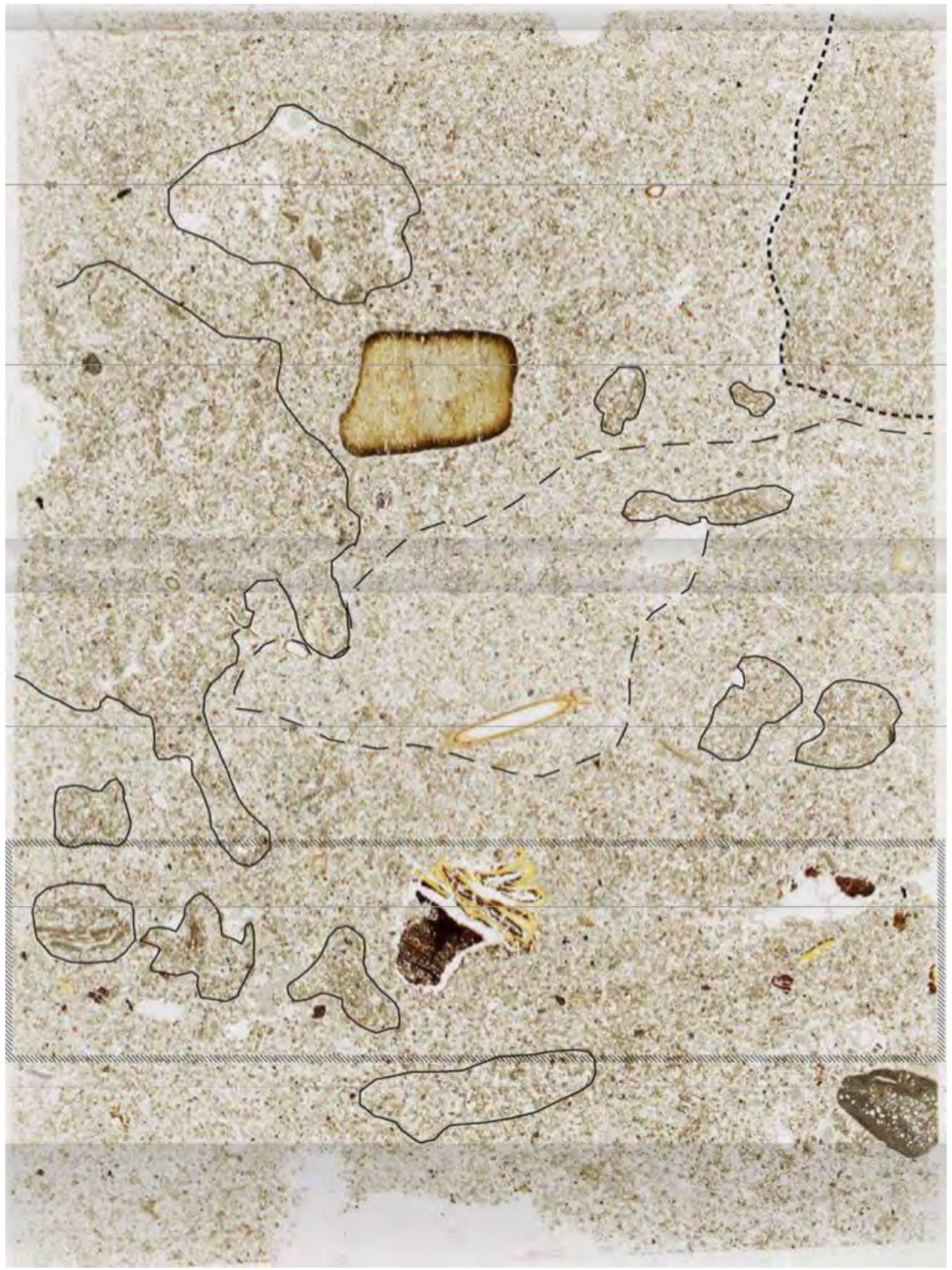

Figure B7: View of the transmitted light scan of the thin section of sample $15-23 \mathrm{~cm}$ slab $5 \mathrm{a}$ annotated to highlight relatively distinct bioturbation related textural/fabric pedofeatures. The heavy dashed line in the top right outlines a relict ped fragment (which is much more clearly visible on the CT scan of this slab; see Figure B3). The solid lines surround a variety of features which vary in degree of cohesion, density of fine matrix, and textural patterns. Some of these exhibit (bottom left) bow-like fine-textured fill which may be in fills of silt sized material, or compressed and collapsed wall linings (See Figure Textural Features.jpg) . Others are spatially discrete concentrations of more silty matrix within less silty matrix, which are most likely passage features, but with few diagnostic attributes to support this inference. The rectangular box with a diagonal hatch line, in the lower half of the image is a zone containing numerous fragments of undecomposed woody material, the largest of which is in the center of the box and has a presumed fungal body along the top half of the large woody fragment. 


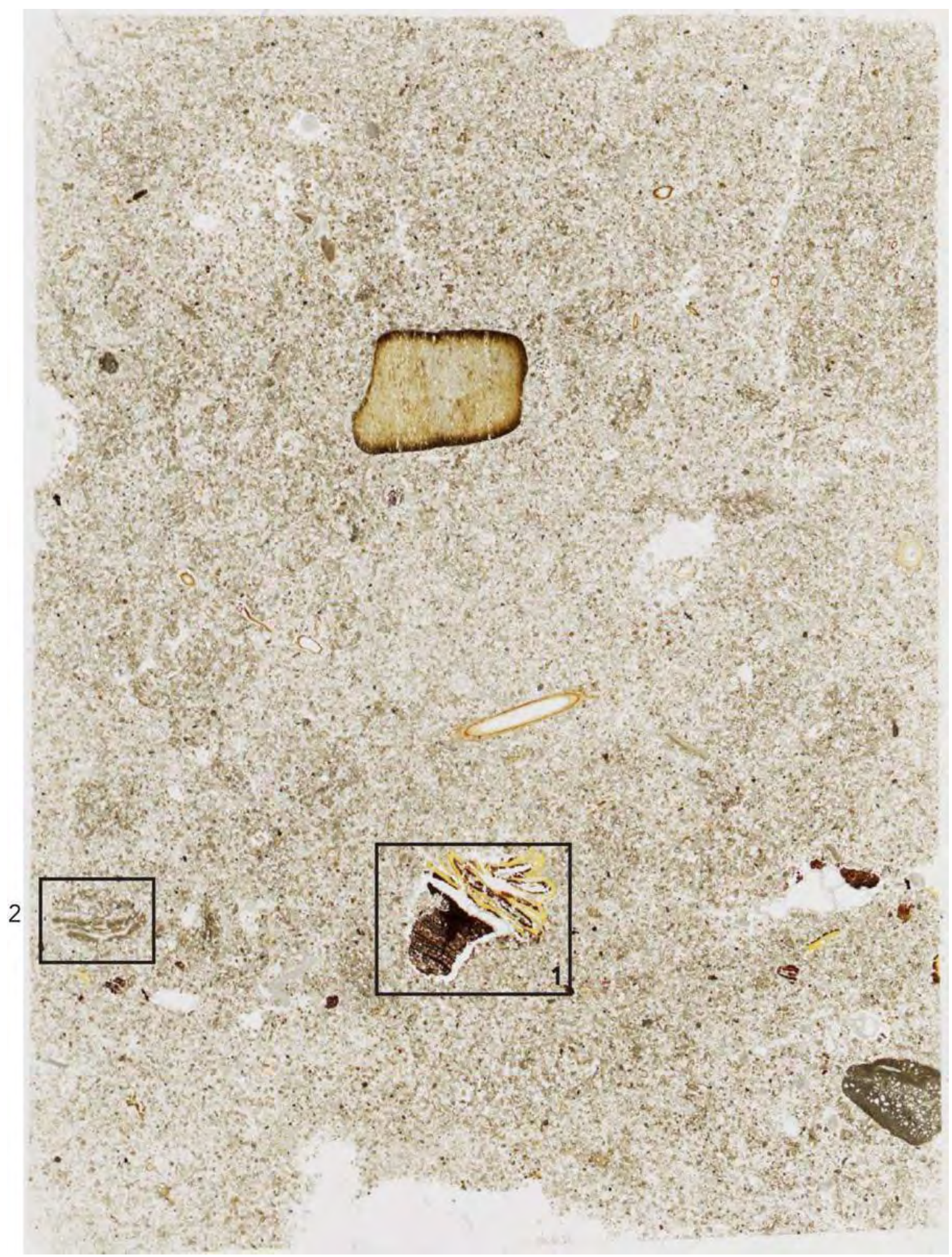

Figure: B8: Transmitted plane light image of slide $15-23 \mathrm{~cm}$ slab $5 \mathrm{a}$, showing the location of the two photomicrographs made from this thinsection. 


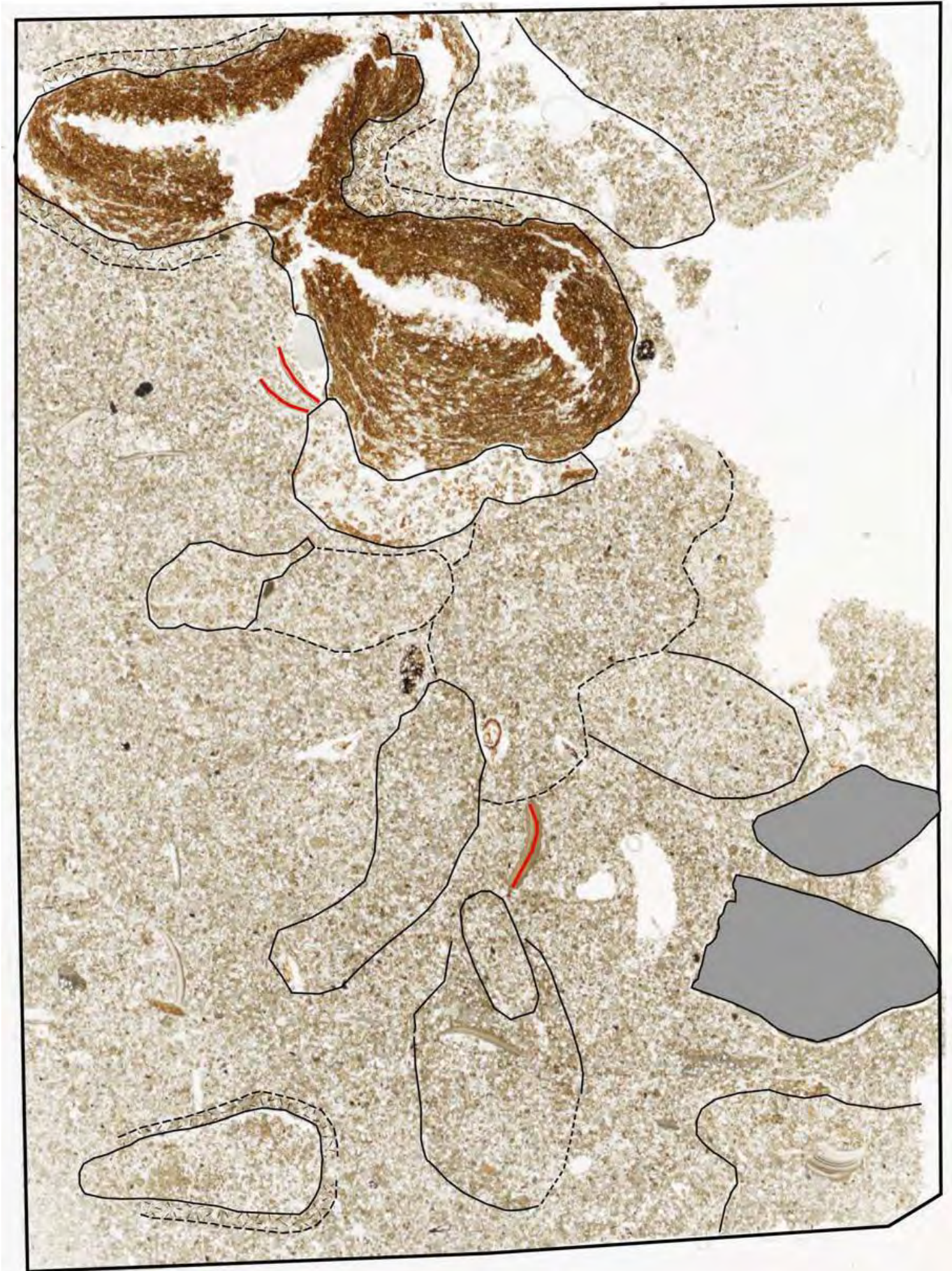

Figure B9: Transmitted light view of the thin section prepared from slab $6 a$ of the $45-53 \mathrm{~cm}$ block showing a variety of textural/fabric pedofeatures, most of which are thought to be associated with insect/mesofauna bioturbation. 


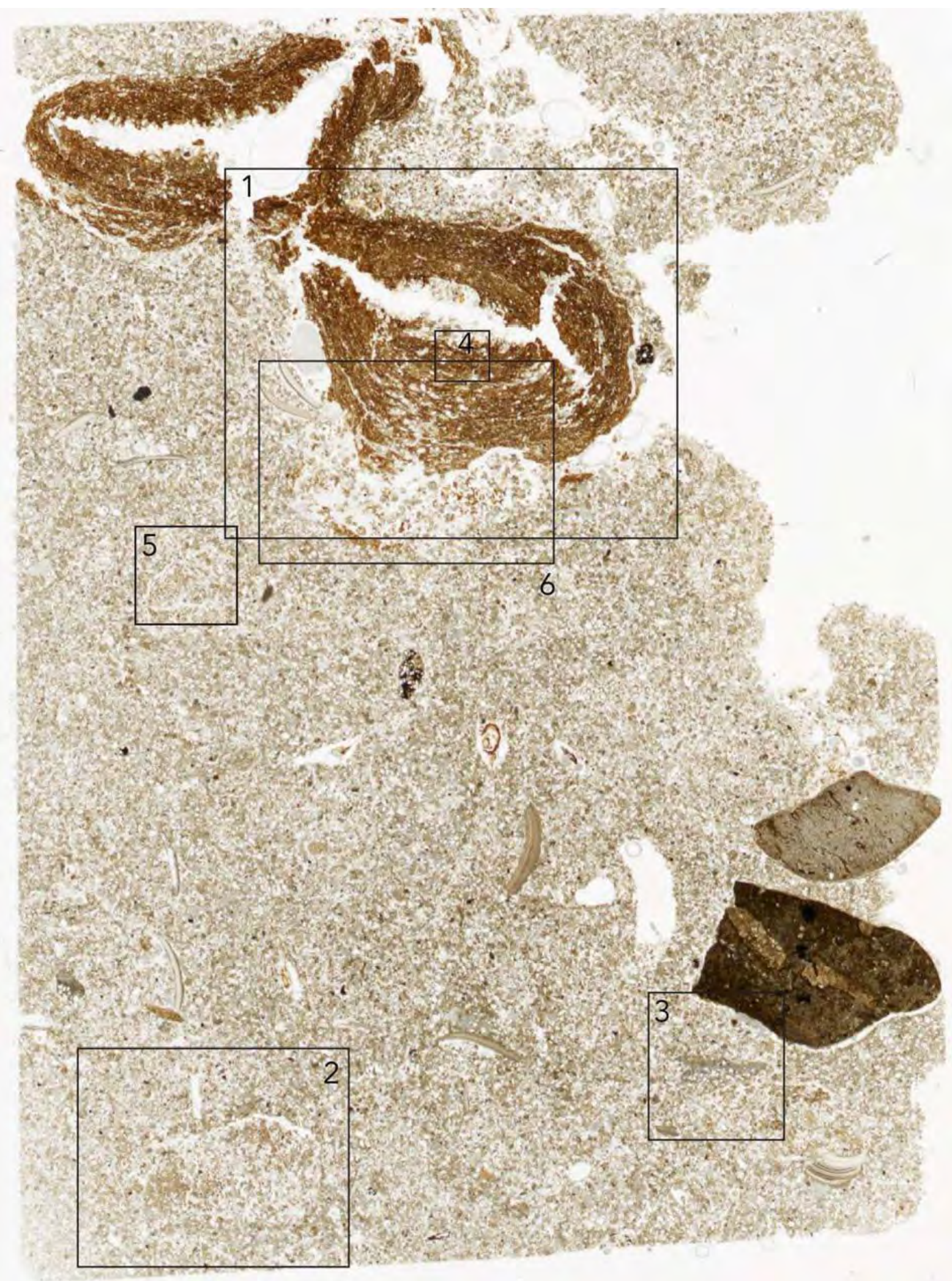

Figure B10: View of the plane light scan of the thin section prepared from slab $6 a$ of the $44-53 \mathrm{~cm}$ block, showing the location of various photomicrographs made of this slide. 


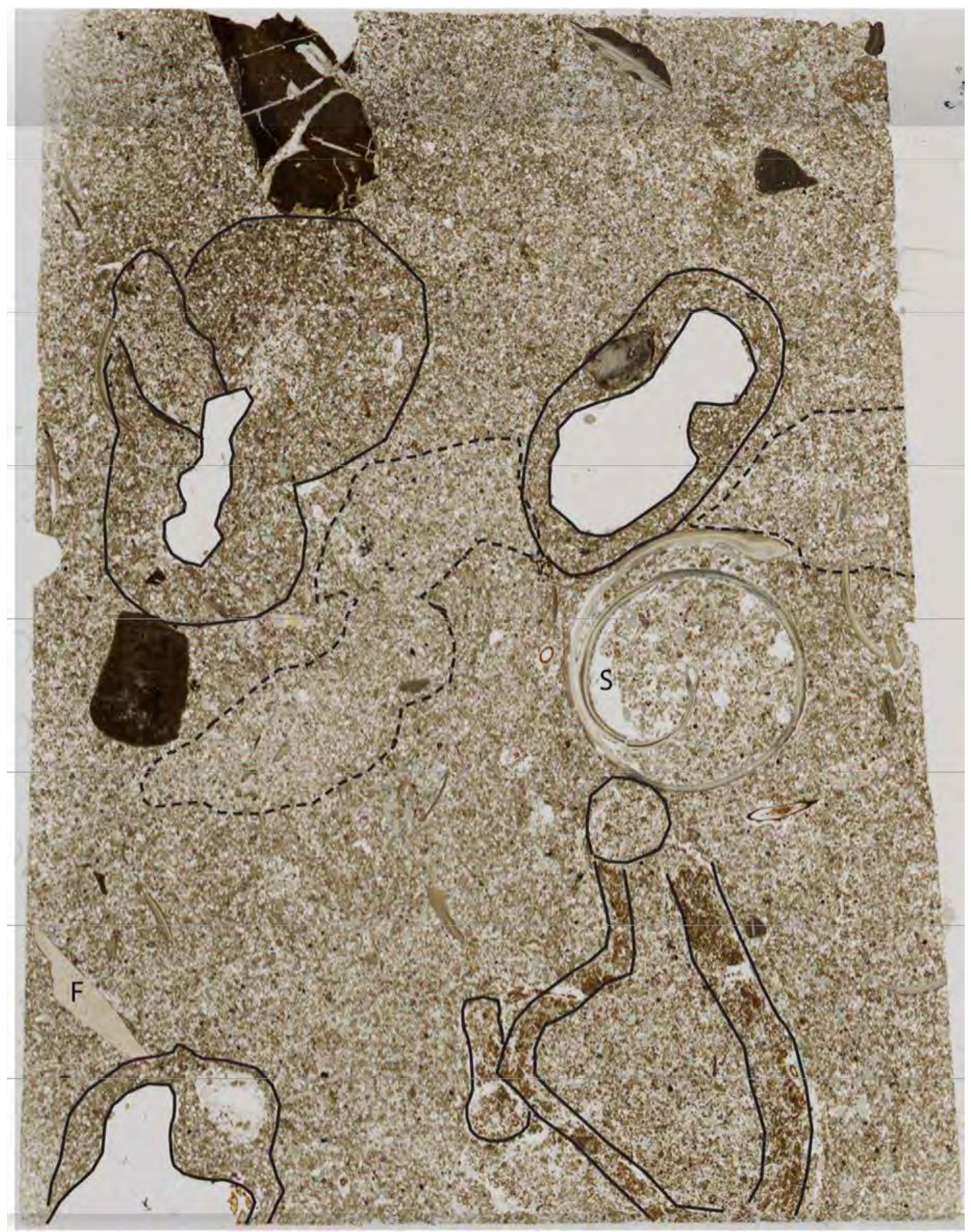

Figure B11: Annotated view of the transmitted light scan of the thin section made from slab $8 \mathrm{~b}$ of the 45-53 cm block. Most of the features outlined are either open chambers or filled chambers with a relatively thick coat of sediment that is more organic rich and/or finer textured than the surrounding sediment. Also highlighted are other textural/fabric pedofeatures that are associated with faunal activity which exhibit clear edges, internal features that clearly denote them as passages or filled chambers, or areas with less dense matrix that is probably a passage featue (dashed line) but does 
not exhibit any infill attributes that clearly support this interpretation. Also highlighted are a transverse section of a snail shell (S) and a chert flake (F).

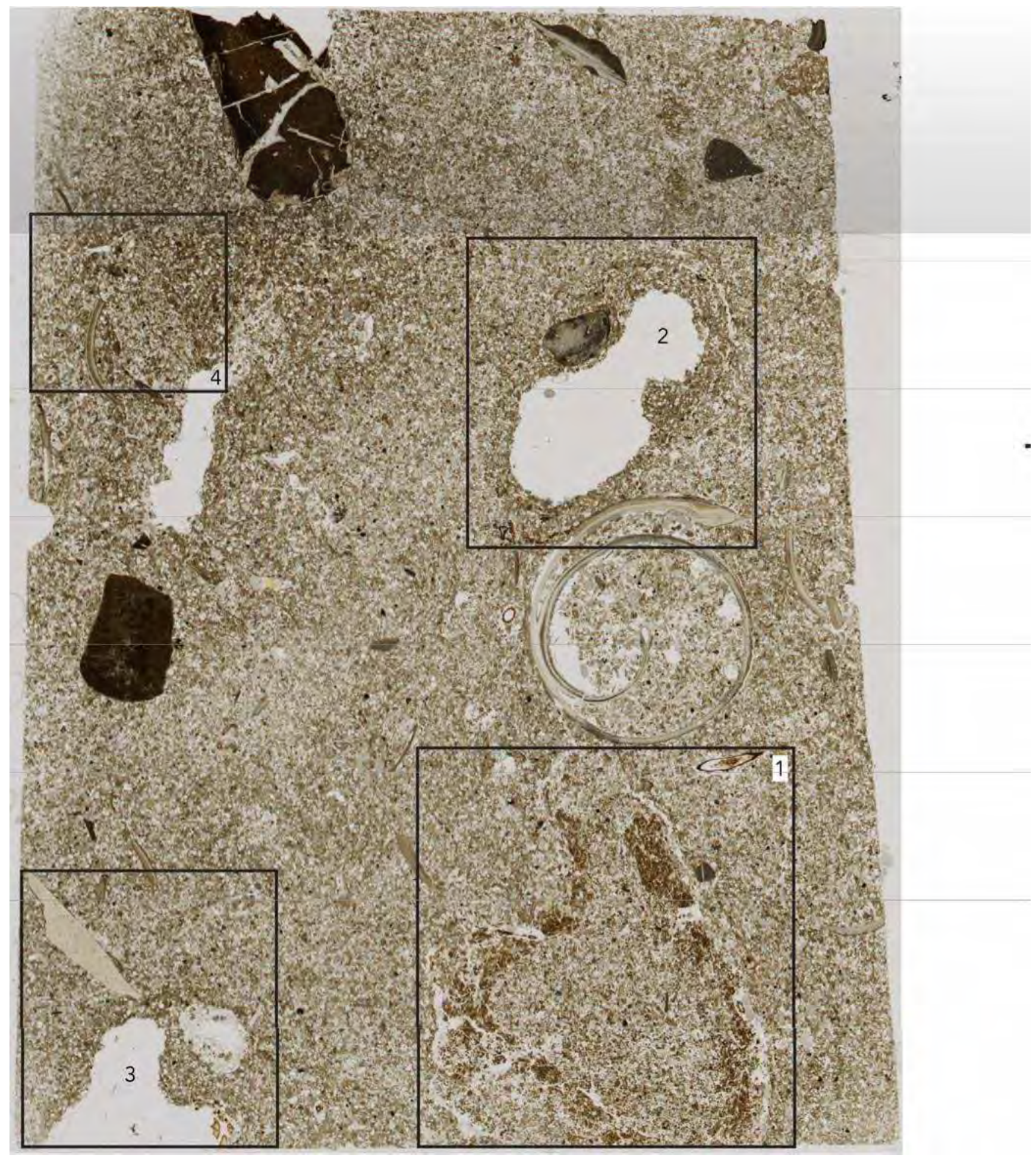

Figure B12: View of the transmitted light scan of the thin section prepared from slab $8 \mathrm{~b}$ of the $45-53$ $\mathrm{cm}$ block showing the location of photomicrographs made from this thin section. 
Analysis

The results of this work revealed significant differences between the two blocks, which are summarized below. For analysis of the faunal related features guidance was provided by Genise (2017), Kooistra and Pulleman (2010), Nicosia and Stoops (2017), Bullock et al., (1985).

\section{Sample $15-23 \mathrm{~cm}$}

This sample, as noted by Abbott in the field, contains numerous subrounded blocky fragments which presumably are portions of peds disturbed by the root plowing (see Figure B7). One of these was clearly visible in the top right of the thin section, but is even more distinct on the CT scan (see Figure B3). Although this sample exhibits numerous textural or fabric pedofeatures that are interpreted as associated with biogenic activity, unlike the lower block, most of these appear to be fragments, or very broad areas of similar fabric which contrasts with the surrounding matrix. The biogenic features here appear to be less common, less pervasive, and scattered throughout the block. In the lower third of this slidethere is a 1-2 cm thick zone (highlighted with a broad rectangular box on Figure B7) where there numerous scattered, disarticulated fragments of primarily lignified woody tissue (presumably roots) some of which appear to have either fungal or plant organ tissue associated (Figure B13).
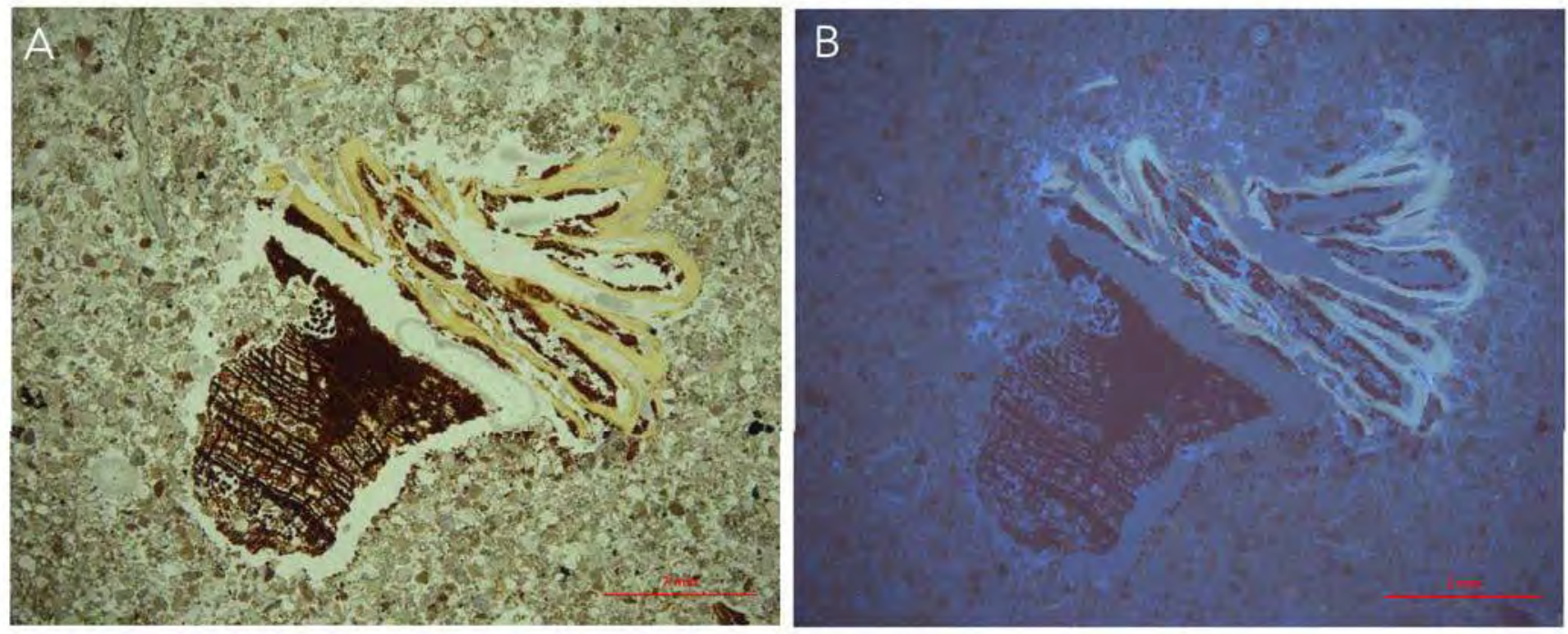

Figure B13: A. Plane light view of a large $(2 \times 3 \mathrm{~mm})$ blocky fragment of lignified tissue, presummably a root (blocky lower half), and a complex folded light yellow structure that is either plant organ tissue or fungal hyphae. Sample 15-23 cm, slab 5a, photomicrograph 1. B. Same view as at left, but in blue light epifluorescence. Note that the plant tissue that is pale yellow in plane light fluoresces under blue light.

\section{Sample $45-53 \mathrm{~cm}$}

This sample presents many more, clearly in situ, and most likely multiple generations of biogenic textural/fabric pedofeatures. The most distinct are centered on open vesicles/chambers than have various forms of linings, which range from dominantly organic matter with small amounts of mineralic material, to dominantly mineral 
material with traces of organic constituents, and various intergrades between these two end members. The features I have typically associated in the field with termite activity are like the large, open center vesicle with a thick laminated organic lining (slab 6a; Figure B14 panels A, B, C and D). I infer that features like that shown on Figure B14 panels $E$ and $F$, and Figure B15 panels A and B, are aged and infilled versions of the same type of feature, but it is possible that they are completely different.

In addition to these large vesicles with variable linings and infillings, there are other types of biogenic structures present here as well. Some, such as the two shown on Figure B15 panels C, D (in situ in the $45-53 \mathrm{~cm}$ block), E and F (and disarticulated in the $15-23 \mathrm{~cm}$ block), exhibit fine-grained linings that are principally finer textured mineralic material rather than organic material. There are also areas which are filled with pellets/excrements which range widely in size from large pellets with little evidence of coalescence (Figure B16, panels $C \& D$ ), to very small pellets/excrements that are smaller than the sand grains (Figure B16 panels $A \& B$ ).

There are also traces of passage features with weakly preserved traces of bow-like structures (center bottom of slide 6a, not shown separately).

Hence the evidence for the lower block, in thin section, is one of a more complete and intact fabric associated with biogenic activity. Much of this appears to be associated with termites, but the fecal pellets and bow-like structured infills are clearly some other agent. 

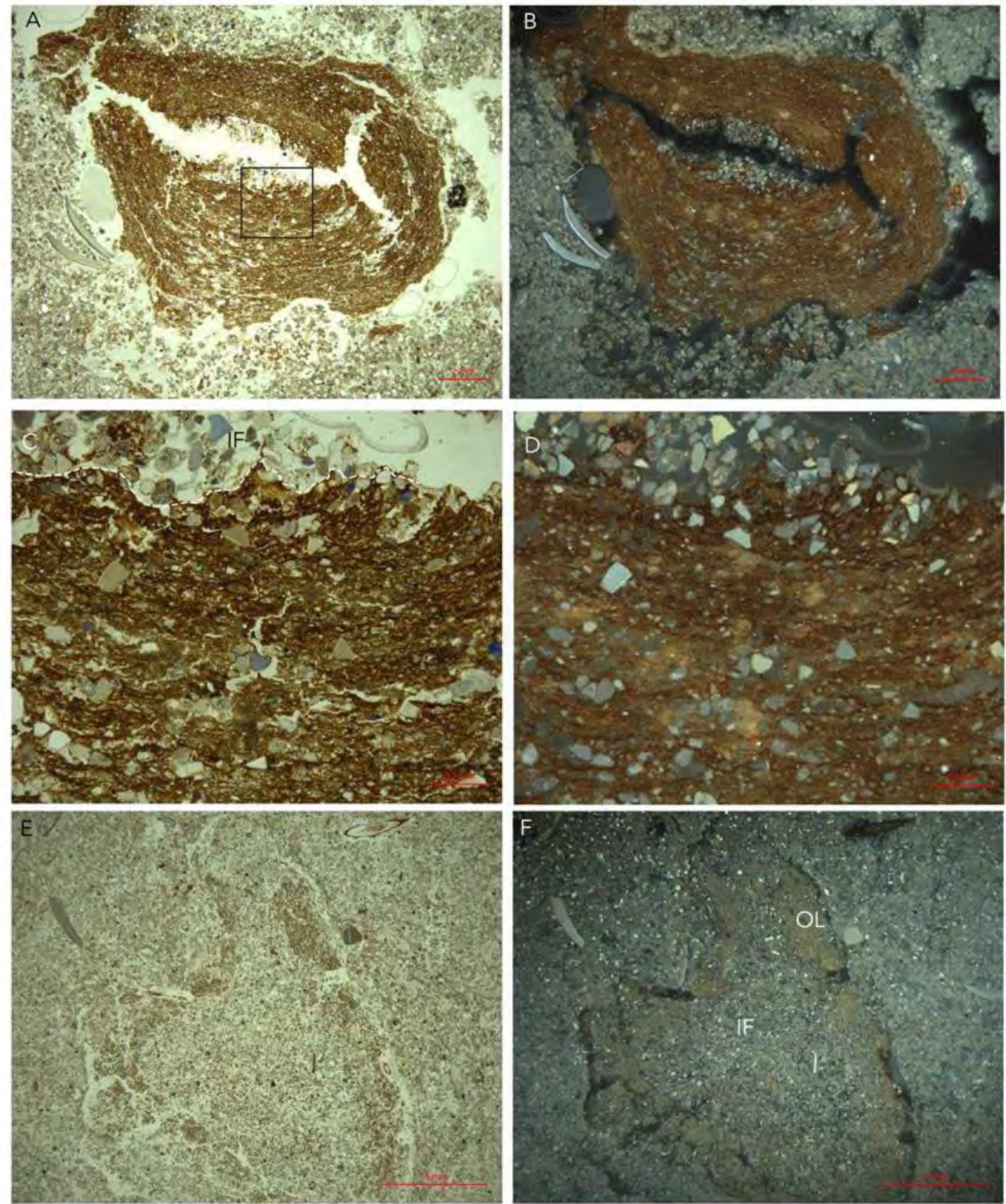

Figure B14: A. Multilayered dominantly organic lining with bow-like structure (compare to Genise 2017:53, Figure 3.14 b, example of termitic micromorphological features). Slab 45-53 6a-1, plane light. Square denotes area enlarged in panels $C$ and D. B. Same as A, oblique incident light. C. Close up of the multilayered organic lining, plane light. Note the start of dominantly mineralic infill at the top of the frame (IF) separated by the white dashed line. D. Same view as C, but in oblique incident light, which emphasizes the mineralic component. The lighter colored areas most likely contain more fine mineral matrix which is calcium carbonate rich. E. A completely infilled vessicly that originally contained a multilayered organic lining. This feature most likely looked like the vessicle shown in A, prior to abandonent and infilling. Subsequent bioturbation has reworked the original organic lining in several places, and some of it appears to have been dispersed into the infilling. F. Same view as $E$ but in oblique incident light. Here the organic lining is slightly more visible owing to its light brown reflection. 

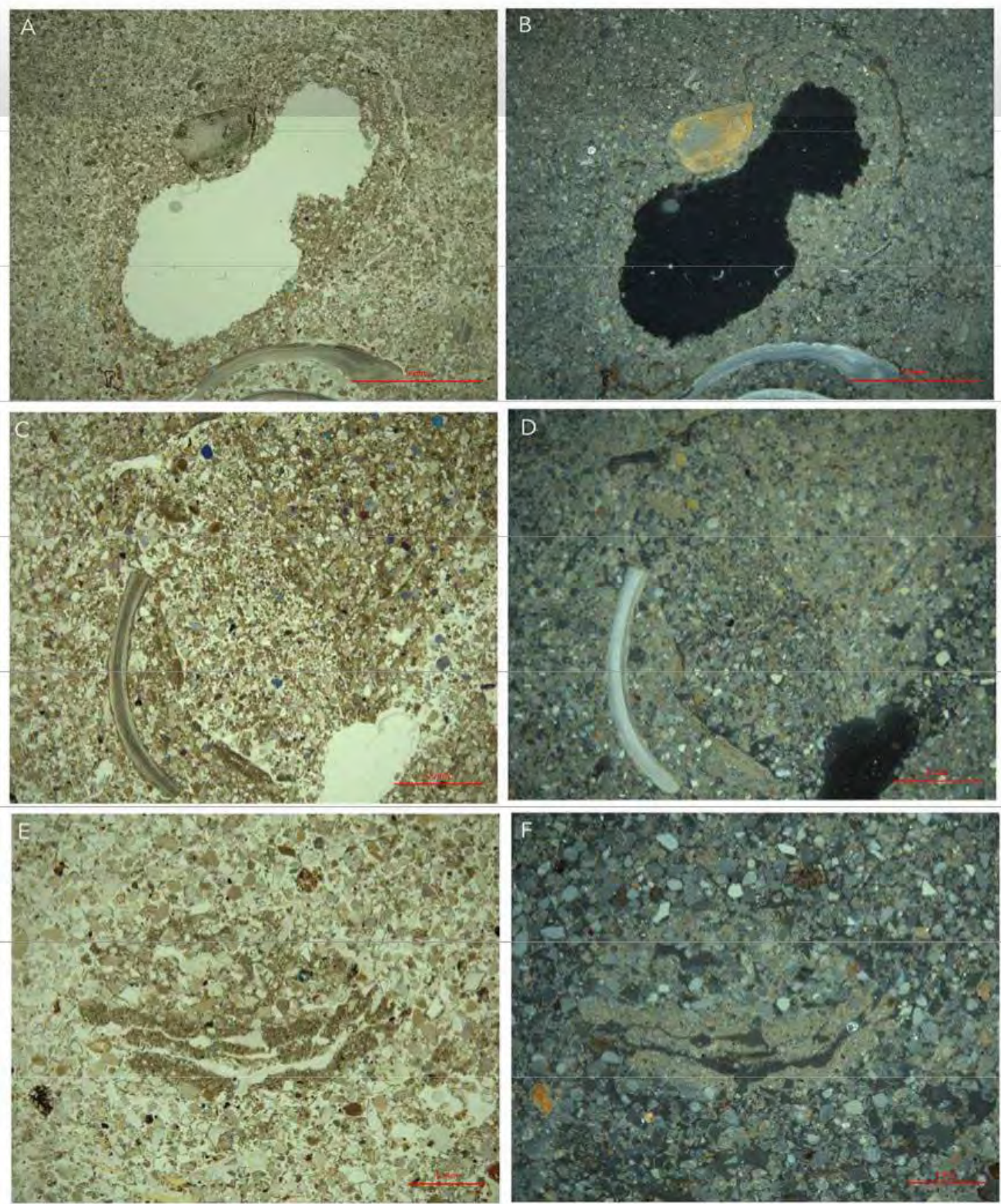

Figure B15: A. 45-53 slab 8B-2. An open vesicle with a stained lining approximately $1 \mathrm{~mm}$ thick. Compare with Genise 2017:17, Figure $2.9 \mathrm{~d}$. This lining is parting from the plasma along a thin organic coat in the top right, but the particles show no clear preferred orientation. Given the shape I suspect this is termite related, but it also somewhat resembles a pupation chamber Genise 2017:342, Figure 13.22. B. Same as A, but as viewed in oblique incident light. C. 45-53 8B-4. A burrow filled with pellets and sand grains, and which preserves traces of a fine-textured lining, some of which may have been applied in a fluidized state (there is some preferred orientation of mineral grains within this layer). D. Same as C, but as viewed in oblique incident light. E. 15-23 5A-2. Part of a burrow fill or lining, but it is difficult to say which. The dark bands are a mixture of organic matter and fine earth which is calcium carbonate rich (exhibits a crystallitic b-fabric in cross-polarized light). F. Same as E, but viewed in oblique incident light. 

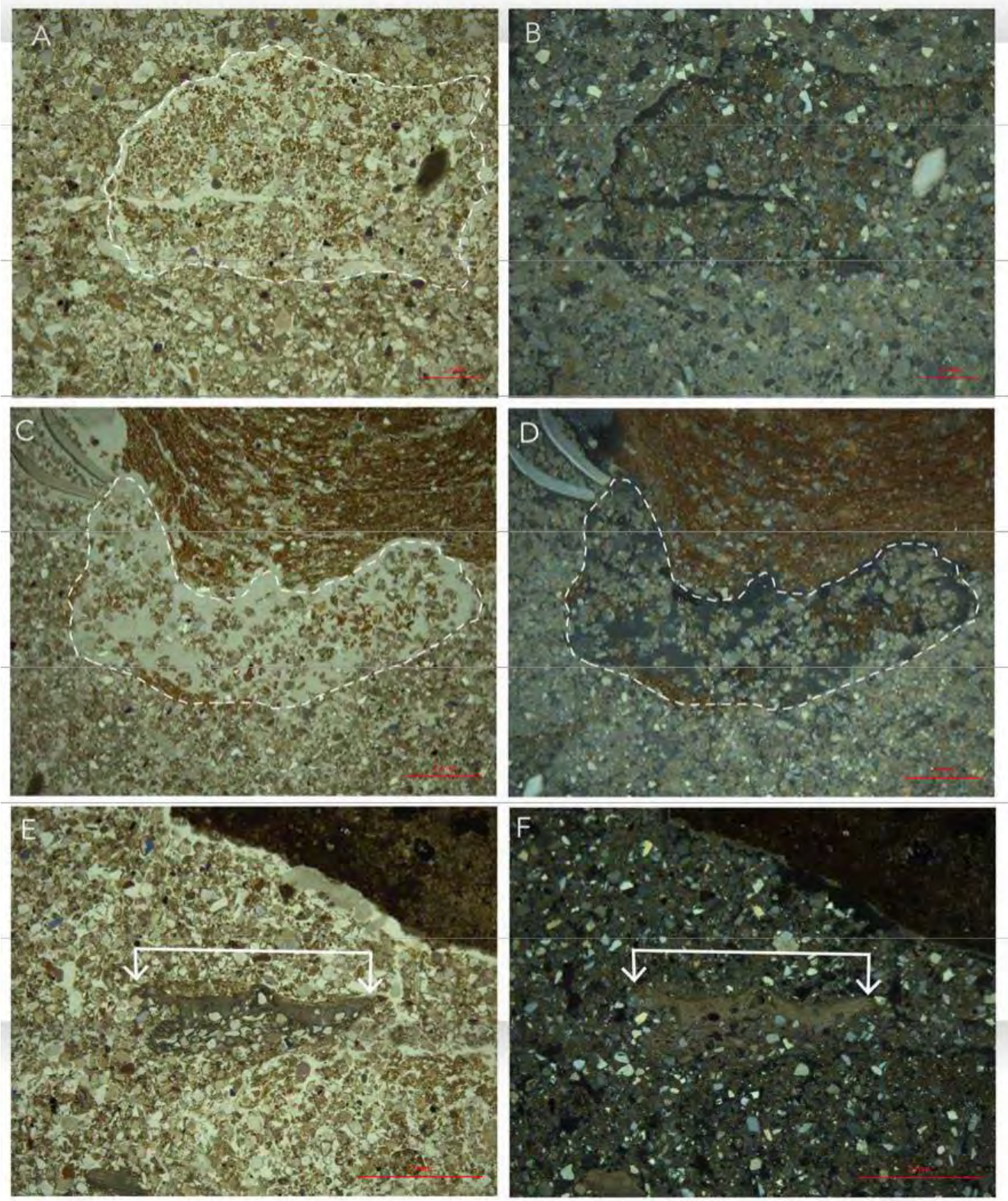

Figure B16: A. Plane light view of a wide passage feature/chamber (outlined in a dashed white line) filled with many very thin spherical pellets/excrements or organic mineralic material which are dark brown in plane light, and much smaller than the sand grains that are also present (sample 45-53 cm slab 6a photomicrograph 5). These pellets are weakly coalesced and porous. B. Same as previous photo, but view is in oblique incident light. Note how the chamber/passage is more clearly defined by the contrast between the organo-mineralic pellets (dark brown) and the more crystallitic b-fabric of the surrounding matrix (light yellow brown).C. An elongate passage feature filled with thin (200-500 micron) circular to ellipsoidal excrement/pellets, that ae weakly coalesced and very porous mineralic to organomineralic material. D. Same as previous photo but as seen in oblique incident light. E. A granule sized fragment of a calcium carbonate cemented sand (beneath and between the arrows), possibly a petrocalcic horizon, plane light. F. Same view as before but in crossed polarized light. 
Table 1. Basic Thin Section Description of Sample 15-23 cm Slab 5a

\begin{tabular}{|c|c|c|}
\hline Sample & 15-23 cm Slab 5A & Description \\
\hline \multirow[t]{2}{*}{ Structure } & Microstructucture & Intergrain channel to massive \\
\hline & Dominant Orientation & none \\
\hline \multirow[t]{7}{*}{ Porosity } & Planes & few \\
\hline & Simple Packing & many \\
\hline & Complex Packing & common \\
\hline & Vesicles & rare \\
\hline & Channels & few \\
\hline & Cracks & none \\
\hline & Vughs & none \\
\hline \multirow[t]{6}{*}{ Groundmass } & Grain Size & Ioam \\
\hline & $\begin{array}{l}\text { Coarse Material } \\
\text { Composition }\end{array}$ & $\begin{array}{l}\text { Quartz, } 0 / 1 \text { to } 0.4 \mathrm{~mm} \text {, subrounded, } 60-70 \% \\
\text { Plagioclase Feldspar, } 0.1 \text { to } 0.4 \mathrm{~mm} \text {, subrounded, } 10-15 \% \\
\text { Chert, } 0.1 \text { to } 0.4 \mathrm{~mm}, 5 \% \text { to } 10 \% \text {, subrounded to rounded } \\
\text { Traces: Microcline, petrocalcic horizon rock fragments, } \\
\text { volcanic rock fragments, }\end{array}$ \\
\hline & $c / f_{x}$ ratio & $80: 20$ (40 micron) to $70: 30$ (40 micron) \\
\hline & $\begin{array}{l}\mathrm{c} / \mathrm{f} \text { related } \\
\text { distribution }\end{array}$ & Chitonic to open porphyric, few areas with enaulic \\
\hline & b-fabric & speckled \\
\hline & Optical features & Pale brown \\
\hline \multirow[t]{3}{*}{ Biominerals } & Phytoliths & -- \\
\hline & Oxalates & -- \\
\hline & Fossils & Terrestrial snail, mostly fragments, $1-3 \mathrm{~mm}$ in length \\
\hline \multirow{4}{*}{$\begin{array}{l}\text { Organic } \\
\text { Matter }\end{array}$} & Opaque Dark & -- \\
\hline & & \\
\hline & Opaque Light & -- \\
\hline & Partly Decomposed & $\begin{array}{l}\text { Zone towards bottom of the slide with numerous fragments of } \\
\text { partly decomposed fragments of woody material (roots?) }\end{array}$ \\
\hline \multirow[t]{5}{*}{ Pedofeatures } & Coats & -- \\
\hline & Infillings & -- \\
\hline & Crystals & -- \\
\hline & Nodules & -- \\
\hline & Excrements & Numerous passage features of various kinds. \\
\hline
\end{tabular}


Table 2. Basic Thin Section Description of Sample 45-53 cm Slab 6b

\begin{tabular}{|c|c|c|}
\hline Sample & 45-53 cm Slab 6B & Description \\
\hline \multirow[t]{2}{*}{ Structure } & Microstructucture & spongy to vessicular \\
\hline & Dominant Orientation & none \\
\hline \multirow[t]{7}{*}{ Porosity } & Planes & none \\
\hline & Simple Packing & Many \\
\hline & Complex Packing & Common (10-20\%) \\
\hline & Vesicles & Few, $2 \mathrm{~mm}$ to $>2 \mathrm{~cm}$ \\
\hline & Channels & few \\
\hline & Cracks & none \\
\hline & Vughs & none \\
\hline \multirow[t]{6}{*}{ Groundmass } & Grain Size & Clay loam \\
\hline & $\begin{array}{l}\text { Coarse Material } \\
\text { Composition }\end{array}$ & $\begin{array}{l}\text { Quartz, } 0.05 \text { to } 0.2 \mathrm{~mm} \text {, subrounded, } 70 \% \\
\text { Plagioclase Feldspar, } 0.1 \text { to } 0.2 \mathrm{~mm} \text {, subrounded, } 5 \% \\
\text { Chert, } 0.05 \text { to } 0.2 \mathrm{~mm} \text {, rounded, } 10 \% \\
\text { Traces: Microcline, petrocalcic horizon fragments, Fe- } \\
\text { cemented sand (opaque), }\end{array}$ \\
\hline & $c / f_{x}$ ratio & 70:30 (40 micron) \\
\hline & $\begin{array}{l}\mathrm{c} / \mathrm{f} \text { related } \\
\text { distribution }\end{array}$ & Close porphyric to enaulic \\
\hline & b-fabric & Crystallitic to speckled \\
\hline & Optical features & Pale brown \\
\hline \multirow[t]{3}{*}{ Biominerals } & Phytoliths & - \\
\hline & Oxalates & - \\
\hline & Fossils & Terrestrial snail, mostly fragments, 0.5 to $4 \mathrm{~mm}$ in length \\
\hline \multirow{3}{*}{$\begin{array}{l}\text { Organic } \\
\text { Matter }\end{array}$} & Opaque Dark & - \\
\hline & Opaque Light & -- \\
\hline & Partly Decomposed & $\begin{array}{l}\text { Prominent laminated organic matter lining some vesicles, } \\
\text { includes some small sand to coarse silt grains. }\end{array}$ \\
\hline \multirow[t]{5}{*}{ Pedofeatures } & Coats & Few, 0.1 to $0.2 \mathrm{~mm}$, carbonate lining larger framework grains \\
\hline & Infillings & - \\
\hline & Crystals & - \\
\hline & Nodules & - \\
\hline & Excrements & Numerous passage features of various kinds. \\
\hline
\end{tabular}


Table 3. Basic Thin Section Description of Sample 45-53 cm Slab 8b

\begin{tabular}{|c|c|c|}
\hline Sample & 45-53 cm Slab 8B & Description \\
\hline \multirow[t]{2}{*}{ Structure } & Microstructucture & Massive to vesicular \\
\hline & Dominant Orientation & none \\
\hline \multirow[t]{7}{*}{ Porosity } & Planes & none \\
\hline & Simple Packing & Many \\
\hline & Complex Packing & Common (10-20\%) \\
\hline & Vessicles & Few, $2 \mathrm{~mm}$ to $>1.5 \mathrm{~cm}$ \\
\hline & Channels & none \\
\hline & Cracks & none \\
\hline & Vughs & none \\
\hline \multirow[t]{6}{*}{ Groundmass } & Grain Size & Clay loam to loam \\
\hline & $\begin{array}{l}\text { Coarse Material } \\
\text { Composition }\end{array}$ & $\begin{array}{l}\text { Quartz, } 0.1 \text { to } 0.4 \mathrm{~mm} \text {, subrounded, } 60-70 \% \\
\text { Plagioclase Feldspar, } 0.1 \text { to } 0.4 \mathrm{~mm} \text {, subrounded, } 10-15 \% \\
\text { Chert, } 0.1 \text { to } 0.4 \mathrm{~mm}, 5 \% \text { to } 10 \% \text {, subrounded to rounded } \\
\text { Volcanic rock fragments, } 0.2 \text { to } 0.4 \mathrm{~mm}, 1-2 \% \text {, rounded, } 1-2 \% \\
\text { Traces: Microcline, petrocalcic horizon fragments, }\end{array}$ \\
\hline & $\mathrm{c} / \mathrm{f}_{\mathrm{x}}$ ratio & 70:30 (40 micron) \\
\hline & $\begin{array}{l}\mathrm{c} / \mathrm{f} \text { related } \\
\text { distribution }\end{array}$ & Close porphyric to enaulic \\
\hline & b-fabric & Crystallitic to speckled \\
\hline & Optical features & Pale brown \\
\hline \multirow[t]{3}{*}{ Biominerals } & Phytoliths & -- \\
\hline & Oxalates & -- \\
\hline & Fossils & Terrestrial snail, mostly fragments, $0.5-3 \mathrm{~mm}$ in length \\
\hline \multirow[t]{3}{*}{$\begin{array}{l}\text { Organic } \\
\text { Matter }\end{array}$} & Opaque Dark & -- \\
\hline & Opaque Light & -- \\
\hline & Partly Decomposed & $\begin{array}{l}\text { One prominent filled chamber that has a thick, partially } \\
\text { preserved dominantly organic matter lining that itself has } \\
\text { been partly disturbed by bioturbation, which contains a } \\
\text { significant component of partially decomposed organic matter. }\end{array}$ \\
\hline \multirow[t]{5}{*}{ Pedofeatures } & Coats & Few, 0.1 to $0.2 \mathrm{~mm}$, carbonate lining larger framework grains \\
\hline & Infillings & -- \\
\hline & Crystals & -- \\
\hline & Nodules & -- \\
\hline & Excrements & Numerous passage features of various kinds. \\
\hline
\end{tabular}




\section{References Cited}

Bullock, P., N. Fedoroff, A. Jongerius, G. Stoops, T. Tursina, and U. Babel, 1985. Handbook for Soil Thin Section Description. Waine Research Publications, Wolverhampton,UK.

Genise, J. F., 2017. Ichnoentomology: Insect Traces in Soils and Paleosols. Springer International Publishing, Switzerland. DOI 10.1007/978-3-319-28210-7

Huisman, D. J., and K. B. Milek, 2017. Turf as a Construction Material. Chapter 12 in Archaeological Soil and Sediment Micromorphology, edited by C. Nicosia and G. Stoops, pp. 113-119. John Wiley \& Sons Ltd, Hoboken, NJ, USA.

Kooistra, M. J., and M. M. Pulleman, 2010. Features Related to Faunal Activity. Chapter 18 in: Interpretation of Micromorphological Features of Soils and Regolith, edited by G. Stoops, V. Marcelino, and F. Mees, pp. 397-418. Elsevier: Amsterdam, The Netherlands. ISBN: 78-0-444-53156-8

Ngan-Tillard, D. J. M., and D. J. Huisman, 2017. Micro CT Scanning. Chapter 42 in: Archaeological Soil and Sediment Micromorphology, edited by C. Nicosia and G. Stoops, pp. 441-449. John Wiley \& Sons Ltd, Hoboken, NJ, USA.

Nicosia, C., and G. Stoops, 2017. Archaeological Soil and Sediment Micromorphology. John Wiley \& Sons Ltd, Hoboken, NJ, USA. ISBN 9781118941058 
This page intentionally left blank. 


\section{APPENDIX C}

Radiocarbon Data 
This page intentionally left blank. 
July 03, 2017

Dr. Chris Dayton

Cox Mclain Environmental Consulting

8401 Shoal Creek Blvd.

No. 100

Austin, TX 78757

USA

RE: Radiocarbon Dating Results

Dear Dr. Dayton,

Enclosed are the radiocarbon dating results for seven samples recently sent to us. The report sheet contains the Conventional Radiocarbon Age (BP), the method used, material type, and applied pretreatments, any sample specific comments and, where applicable, the two-sigma calendar calibration range. The Conventional Radiocarbon ages have been corrected for total isotopic fractionation effects (natural and laboratory induced).

All results (excluding some inappropriate material types) which fall within the range of available calibration data are calibrated to calendar years (cal BC/AD) and calibrated radiocarbon years (cal BP). Calibration was calculated using one of the databases associated with the 2013 INTCAL program (cited in the references on the bottom of the calibration graph page provided for each sample.) Multiple probability ranges may appear in some cases, due to short-term variations in the atmospheric $14 \mathrm{C}$ contents at certain time periods. Looking closely at the calibration graph provided and where the BP sigma limits intercept the calibration curve will help you understand this phenomenon.

Conventional Radiocarbon Ages and sigmas are rounded to the nearest 10 years per the conventions of the 1977 International Radiocarbon Conference. When counting statistics produce sigmas lower than $+/-30$ years, a conservative $+/-30$ $\mathrm{BP}$ is cited for the result.

All work on these samples was performed in our laboratories in Miami under strict chain of custody and quality control under ISO/IEC 17025:2005 Testing Accreditation PJLA \#59423 accreditation protocols. Sample, modern and blanks were all analyzed in the same chemistry lines by qualified professional technicians using identical reagents and counting parameters within our own particle accelerators. A quality assurance report is posted to your directory for each result.

The cost of the analysis was charged to the credit card provided. Thank you. As always, if you have any questions or would like to discuss the results, don't hesitate to contact us.

Sincerely ,

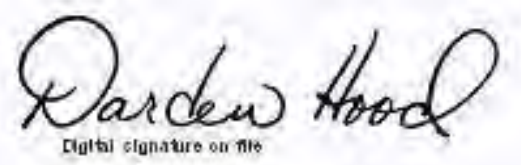




\section{REPORT OF RADIOCARBON DATING ANALYSES}

Dr. Chris Dayton

Cox Mclain Environmental Consulting

Cox Mclain Environmental Consulting

Sample Information and Data

Sample Code Number
Report Date: July 03, 2017

Material Received: June 26, 2017

Conventional Radiocarbon Age (BP) or

Percent Modern Carbon (pMC) \& Stable Isotopes

Calendar Calibrated Results: $95.4 \%$ Probability

High Probability Density Range Method (HPD)

SR242-6C

$2420+/-30$ BP

(74.8\%) $556-402$ cal BC

(15.5\%) $748-685 \mathrm{cal} \mathrm{BC}$

( $4.7 \%$ ) $666-642 \mathrm{cal} \mathrm{BC}$

( $0.4 \%) \quad 587-581 \mathrm{cal} \mathrm{BC}$

IRMS ס13C: -23.1 o/00

Submitter Material: Woody Material

Analyzed Material: Wood

Pretreatment: (charred material) acid/alkali/acid

Analysis Service: AMS-Standard delivery

Percent Modern Carbon: $73.99+/-0.28$ pMC

Fraction Modern Carbon: $0.7399+/-0.0028$

D14C: $-260.11+/-2.76$ o/oo

$\Delta$ 14C: $-266.09+/-2.76$ o/oo(1950:2017)

Measured Radiocarbon Age: (without d13C correction): 2390 +/- 30 BP

Calibration: BetaCal3.21: HPD method: INTCAL13

Results are ISO/IEC-17025:2005 accredited. No sub-contracting or student labor was used in the analyses. All work was done at Beta in 4 in-house NEC accelerator mass spectrometers and 4 Thermo IRMSs. The "Conventional Radiocarbon Age" was calculated using the Libby half-life (5568 years), is corrected for total isotopic fraction and was used for calendar calibration where applicable. The Age is rounded to the nearest 10 years and is reported as radiocarbon years before present (BP), "present" = AD 1950. Results greater than the modern reference are reported as percent modern carbon (pMC). The modern reference standard was 95\% the 14C signature of NIST SRM-4990C (oxalic acid). Quoted errors are 1 sigma counting statistics. Calculated sigmas less than $30 \mathrm{BP}$ on the Conventional Radiocarbon Age are conservatively rounded up to 30 . $d 13 \mathrm{C}$ values are on the material itself (not the $A M S$ d13C). $d 13 C$ and $d 15 \mathrm{~N}$ values are relative to VPDB-1. References for calendar calibrations are cited at the bottom of calibration graph pages. 


\section{REPORT OF RADIOCARBON DATING ANALYSES}

Dr. Chris Dayton

Cox Mclain Environmental Consulting

Cox Mclain Environmental Consulting

Sample Information and Data

Sample Code Number
Report Date: July 03, 2017

Material Received: June 26, 2017

Conventional Radiocarbon Age (BP) or

Percent Modern Carbon (pMC) \& Stable Isotopes

Calendar Calibrated Results: $95.4 \%$ Probability

High Probability Density Range Method (HPD)

SR242-7C

$2250+/-30$ BP

(64.1\%) $321-206 \mathrm{cal} \mathrm{BC}$

(31.3\%) $395-347$ cal BC
IRMS ס13C: -24.1 o/oo

(2270 - 2155 cal BP)

(2344 - 2296 cal BP)

Analyzed Material: Wood

Pretreatment: (charred material) acid/alkali/acid

Analysis Service: AMS-Standard delivery

Percent Modern Carbon: $75.57+/-0.28$ pMC

Fraction Modern Carbon: $0.7557+/-0.0028$

D14C: $-244.29+/-2.82$ o/oo

$\Delta$ 14C: $-250.39+/-2.82$ o/oo(1950:2017)

Measured Radiocarbon Age: (without d13C correction): 2240 +/- 30 BP

Calibration: BetaCal3.21: HPD method: INTCAL13

Results are ISO/IEC-17025:2005 accredited. No sub-contracting or student labor was used in the analyses. All work was done at Beta in 4 in-house NEC accelerator mass spectrometers and 4 Thermo IRMSs. The "Conventional Radiocarbon Age" was calculated using the Libby half-life (5568 years), is corrected for total isotopic fraction and was used for calendar calibration where applicable. The Age is rounded to the nearest 10 years and is reported as radiocarbon years before present (BP), "present" = AD 1950. Results greater than the modern reference are reported as percent modern carbon (pMC). The modern reference standard was 95\% the 14C signature of NIST SRM-4990C (oxalic acid). Quoted errors are 1 sigma counting statistics. Calculated sigmas less than $30 \mathrm{BP}$ on the Conventional Radiocarbon Age are conservatively rounded up to 30 . $d 13 \mathrm{C}$ values are on the material itself (not the $A M S$ d13C). $d 13 \mathrm{C}$ and $\mathrm{d} 15 \mathrm{~N}$ values are relative to VPDB-1. References for calendar calibrations are cited at the bottom of calibration graph pages. 


\section{REPORT OF RADIOCARBON DATING ANALYSES}

Dr. Chris Dayton

Cox Mclain Environmental Consulting

Cox Mclain Environmental Consulting

Sample Information and Data

Sample Code Number
Report Date: July 03, 2017

Material Received: June 26, 2017

Conventional Radiocarbon Age (BP) or

Percent Modern Carbon (pMC) \& Stable Isotopes

Calendar Calibrated Results: $95.4 \%$ Probability

High Probability Density Range Method (HPD)

SR242-5C

$3260+/-30$ BP

(87.8\%) $1616-1493 \mathrm{cal} \mathrm{BC}$

( $7.6 \%) \quad 1481-1454 \mathrm{cal} \mathrm{BC}$
IRMS ס13C: -24.1 o/00

(3565 - 3442 cal BP) (3430 - 3403 cal BP)

Analyzed Material: Wood

Pretreatment: (charred material) acid/alkali/acid

Analysis Service: AMS-Standard delivery

Percent Modern Carbon: $66.64+/-0.25$ pMC

Fraction Modern Carbon: $0.6664+/-0.0025$

D14C: $-333.58+/-2.49$ o/oo

$\Delta$ 14C: $-338.96+/-2.49$ o/oo(1950:2017)

Measured Radiocarbon Age: (without d13C correction): 3250 +/- 30 BP

Calibration: BetaCal3.21: HPD method: INTCAL13

Results are ISO/IEC-17025:2005 accredited. No sub-contracting or student labor was used in the analyses. All work was done at Beta in 4 in-house NEC accelerator mass spectrometers and 4 Thermo IRMSs. The "Conventional Radiocarbon Age" was calculated using the Libby half-life (5568 years), is corrected for total isotopic fraction and was used for calendar calibration where applicable. The Age is rounded to the nearest 10 years and is reported as radiocarbon years before present (BP), "present" = AD 1950. Results greater than the modern reference are reported as percent modern carbon (pMC). The modern reference standard was 95\% the 14C signature of NIST SRM-4990C (oxalic acid). Quoted errors are 1 sigma counting statistics. Calculated sigmas less than $30 \mathrm{BP}$ on the Conventional Radiocarbon Age are conservatively rounded up to 30 . $d 13 \mathrm{C}$ values are on the material itself (not the $A M S$ d13C). $d 13 \mathrm{C}$ and $\mathrm{d} 15 \mathrm{~N}$ values are relative to VPDB-1. References for calendar calibrations are cited at the bottom of calibration graph pages. 


\section{REPORT OF RADIOCARBON DATING ANALYSES}

Dr. Chris Dayton

Cox Mclain Environmental Consulting

Cox Mclain Environmental Consulting

Sample Information and Data

Sample Code Number
Report Date: July 03, 2017

Material Received: June 26, 2017

Conventional Radiocarbon Age (BP) or

Percent Modern Carbon (pMC) \& Stable Isotopes

Calendar Calibrated Results: $95.4 \%$ Probability

High Probability Density Range Method (HPD)

SR242-8C

$2160+/-30$ BP

(55.3\%) 259 - $108 \mathrm{cal} \mathrm{BC}$

(40.1\%) $358-279 \mathrm{cal}$ BC
IRMS ס13C: -23.4 o/oo
Submitter Material: Woody Material

Analyzed Material: Wood

Pretreatment: (charred material) acid/alkali/acid

Analysis Service: AMS-Standard delivery

Percent Modern Carbon: $76.42+/-0.29$ pMC

Fraction Modern Carbon: $0.7642+/-0.0029$

D14C: $-235.78+/-2.85$ o/oo

$\Delta$ 14C: $-241.94+/-2.85$ o/oo(1950:2017)

Measured Radiocarbon Age: (without d13C correction): 2130 +/- 30 BP

Calibration: BetaCal3.21: HPD method: INTCAL13
(2208 - 2057 cal BP)

(2307 - 2228 cal BP)

Results are ISO/IEC-17025:2005 accredited. No sub-contracting or student labor was used in the analyses. All work was done at Beta in 4 in-house NEC accelerator mass spectrometers and 4 Thermo IRMSs. The "Conventional Radiocarbon Age" was calculated using the Libby half-life (5568 years), is corrected for total isotopic fraction and was used for calendar calibration where applicable. The Age is rounded to the nearest 10 years and is reported as radiocarbon years before present (BP), "present" = AD 1950. Results greater than the modern reference are reported as percent modern carbon (pMC). The modern reference standard was 95\% the 14C signature of NIST SRM-4990C (oxalic acid). Quoted errors are 1 sigma counting statistics. Calculated sigmas less than $30 \mathrm{BP}$ on the Conventional Radiocarbon Age are conservatively rounded up to 30 . $d 13 \mathrm{C}$ values are on the material itself (not the $A M S$ d13C). $d 13 \mathrm{C}$ and $\mathrm{d} 15 \mathrm{~N}$ values are relative to VPDB-1. References for calendar calibrations are cited at the bottom of calibration graph pages. 


\section{REPORT OF RADIOCARBON DATING ANALYSES}

Dr. Chris Dayton

Cox Mclain Environmental Consulting

Cox Mclain Environmental Consulting

Sample Information and Data

Sample Code Number
Report Date: July 03, 2017

Material Received: June 26, 2017

Conventional Radiocarbon Age (BP) or

Percent Modern Carbon (pMC) \& Stable Isotopes

Calendar Calibrated Results: $95.4 \%$ Probability

High Probability Density Range Method (HPD)

SR242-9C

$3260+/-30$ BP

(87.8\%) $1616-1493 \mathrm{cal} \mathrm{BC}$

( $7.6 \%) \quad 1481-1454 \mathrm{cal} \mathrm{BC}$
IRMS ס13C: -22.5 o/00

(3565 - 3442 cal BP) (3430 - 3403 cal BP)

Analyzed Material: Wood

Pretreatment: (charred material) acid/alkali/acid

Analysis Service: AMS-Standard delivery

Percent Modern Carbon: $66.64+/-0.25$ pMC

Fraction Modern Carbon: $0.6664+/-0.0025$

D14C: $-333.58+/-2.49$ o/oo

$\Delta$ 14C: $-338.96+/-2.49$ o/oo(1950:2017)

Measured Radiocarbon Age: (without d13C correction): 3220 +/- 30 BP

Calibration: BetaCal3.21: HPD method: INTCAL13

Results are ISO/IEC-17025:2005 accredited. No sub-contracting or student labor was used in the analyses. All work was done at Beta in 4 in-house NEC accelerator mass spectrometers and 4 Thermo IRMSs. The "Conventional Radiocarbon Age" was calculated using the Libby half-life (5568 years), is corrected for total isotopic fraction and was used for calendar calibration where applicable. The Age is rounded to the nearest 10 years and is reported as radiocarbon years before present (BP), "present" = AD 1950. Results greater than the modern reference are reported as percent modern carbon (pMC). The modern reference standard was 95\% the 14C signature of NIST SRM-4990C (oxalic acid). Quoted errors are 1 sigma counting statistics. Calculated sigmas less than $30 \mathrm{BP}$ on the Conventional Radiocarbon Age are conservatively rounded up to 30 . $d 13 \mathrm{C}$ values are on the material itself (not the $A M S$ d13C). $d 13 \mathrm{C}$ and $\mathrm{d} 15 \mathrm{~N}$ values are relative to VPDB-1. References for calendar calibrations are cited at the bottom of calibration graph pages. 


\section{REPORT OF RADIOCARBON DATING ANALYSES}

Dr. Chris Dayton

Cox Mclain Environmental Consulting

Cox Mclain Environmental Consulting

Sample Information and Data

Sample Code Number
Report Date: July 03, 2017

Material Received: June 26, 2017

Conventional Radiocarbon Age (BP) or

Percent Modern Carbon (pMC) \& Stable Isotopes

Calendar Calibrated Results: $95.4 \%$ Probability

High Probability Density Range Method (HPD)

SR242-10C

$2450+/-30$ BP

(53.2\%) $595-411 \mathrm{cal} \mathrm{BC}$

(26.7\%) $754-681$ cal BC

(15.5\%) $670-609 \mathrm{cal} \mathrm{BC}$
IRMS ס13C: -23.6 o/oo
Submitter Material: Woody Material

Analyzed Material: Wood

Pretreatment: (charred material) acid/alkali/acid

Analysis Service: AMS-Standard delivery

Percent Modern Carbon: $73.71+/-0.28$ pMC

Fraction Modern Carbon: $0.7371+/-0.0028$

D14C: $-262.87+/-2.75$ o/oo

$\Delta 14 \mathrm{C}:-268.82+/-2.75$ o/oo(1950:2017)

Measured Radiocarbon Age: (without d13C correction): 2430 +/- $30 \mathrm{BP}$

Calibration: BetaCal3.21: HPD method: INTCAL13
(2544 - 2360 cal BP)

(2703 - 2630 cal BP)

(2619 - 2558 cal BP)

Results are ISO/IEC-17025:2005 accredited. No sub-contracting or student labor was used in the analyses. All work was done at Beta in 4 in-house NEC accelerator mass spectrometers and 4 Thermo IRMSs. The "Conventional Radiocarbon Age" was calculated using the Libby half-life (5568 years), is corrected for total isotopic fraction and was used for calendar calibration where applicable. The Age is rounded to the nearest 10 years and is reported as radiocarbon years before present (BP), "present" = AD 1950. Results greater than the modern reference are reported as percent modern carbon (pMC). The modern reference standard was 95\% the 14C signature of NIST SRM-4990C (oxalic acid). Quoted errors are 1 sigma counting statistics. Calculated sigmas less than $30 \mathrm{BP}$ on the Conventional Radiocarbon Age are conservatively rounded up to 30 . d13C values are on the material itself (not the AMS d13C). $d 13 \mathrm{C}$ and $\mathrm{d} 15 \mathrm{~N}$ values are relative to VPDB-1. References for calendar calibrations are cited at the bottom of calibration graph pages. 


\section{REPORT OF RADIOCARBON DATING ANALYSES}

Dr. Chris Dayton

Cox Mclain Environmental Consulting

Cox Mclain Environmental Consulting

Sample Information and Data

Sample Code Number
Report Date: July 03, 2017

Material Received: June 26, 2017

Conventional Radiocarbon Age (BP) or

Percent Modern Carbon (pMC) \& Stable Isotopes

Calendar Calibrated Results: $95.4 \%$ Probability

High Probability Density Range Method (HPD)

SR242-11C

$3020+/-30$ BP

(73.1\%) $1322-1191 \mathrm{cal} \mathrm{BC}$

(18.9\%) $1391-1337 \mathrm{cal} B C$

( $2.0 \%) \quad 1144-1131 \mathrm{cal} B C$

( $1.4 \%) \quad 1177-1164 \mathrm{cal} \mathrm{BC}$

IRMS ס13C: $\quad-23.0$ o/oo

Submitter Material: Woody Material

Analyzed Material: Wood

Pretreatment: (charred material) acid/alkali/acid

Analysis Service: AMS-Standard delivery

Percent Modern Carbon: $68.66+/-0.26$ pMC

Fraction Modern Carbon: $0.6866+/-0.0026$

D14C: $-313.37+/-2.56$ o/oo

$\Delta 14 \mathrm{C}:-318.91+/-2.56$ o/oo(1950:2017)

Measured Radiocarbon Age: (without d13C correction): 2990 +/- 30 BP

Calibration: BetaCal3.21: HPD method: INTCAL13
(3271 - 3140 cal BP)

(3340 - 3286 cal BP)

(3093 - 3080 cal BP)

(3126 - 3113 cal BP)

Results are ISO/IEC-17025:2005 accredited. No sub-contracting or student labor was used in the analyses. All work was done at Beta in 4 in-house NEC accelerator mass spectrometers and 4 Thermo IRMSs. The "Conventional Radiocarbon Age" was calculated using the Libby half-life (5568 years), is corrected for total isotopic fraction and was used for calendar calibration where applicable. The Age is rounded to the nearest 10 years and is reported as radiocarbon years before present (BP), "present" = AD 1950. Results greater than the modern reference are reported as percent modern carbon (pMC). The modern reference standard was $95 \%$ the $14 \mathrm{C}$ signature of NIST SRM-4990C (oxalic acid). Quoted errors are 1 sigma counting statistics. Calculated sigmas less than $30 \mathrm{BP}$ on the Conventional Radiocarbon Age are conservatively rounded up to 30 . d13C values are on the material itself (not the AMS d13C). $d 13 \mathrm{C}$ and $\mathrm{d} 15 \mathrm{~N}$ values are relative to VPDB-1. References for calendar calibrations are cited at the bottom of calibration graph pages. 


\section{Calibration of Radiocarbon Age to Calendar Years}

(High Probability Density Range Method (HPD): INTCAL13)

(Variables: $\mathrm{d} 13 \mathrm{C}=-23.1 \mathrm{o} / \mathrm{oo})$

\section{Laboratory number Beta-468115}

Conventional radiocarbon age $\quad 2420 \pm 30 \mathrm{BP}$

$95.4 \%$ probability

$\begin{array}{lll}(74.8 \%) & 556-402 \text { cal BC } & (2505-2351 \text { cal BP }) \\ (15.5 \%) & 748-685 \text { cal BC } & (2697-2634 \text { cal BP }) \\ (4.7 \%) & 666-642 \text { cal BC } & (2615-2591 \text { cal BP }) \\ (0.4 \%) & 587-581 \text { cal BC } & (2536-2530 \text { cal BP })\end{array}$

$68.2 \%$ probability

$(68.2 \%) \quad 536-411$ cal BC $\quad(2485-2360$ cal BP $)$

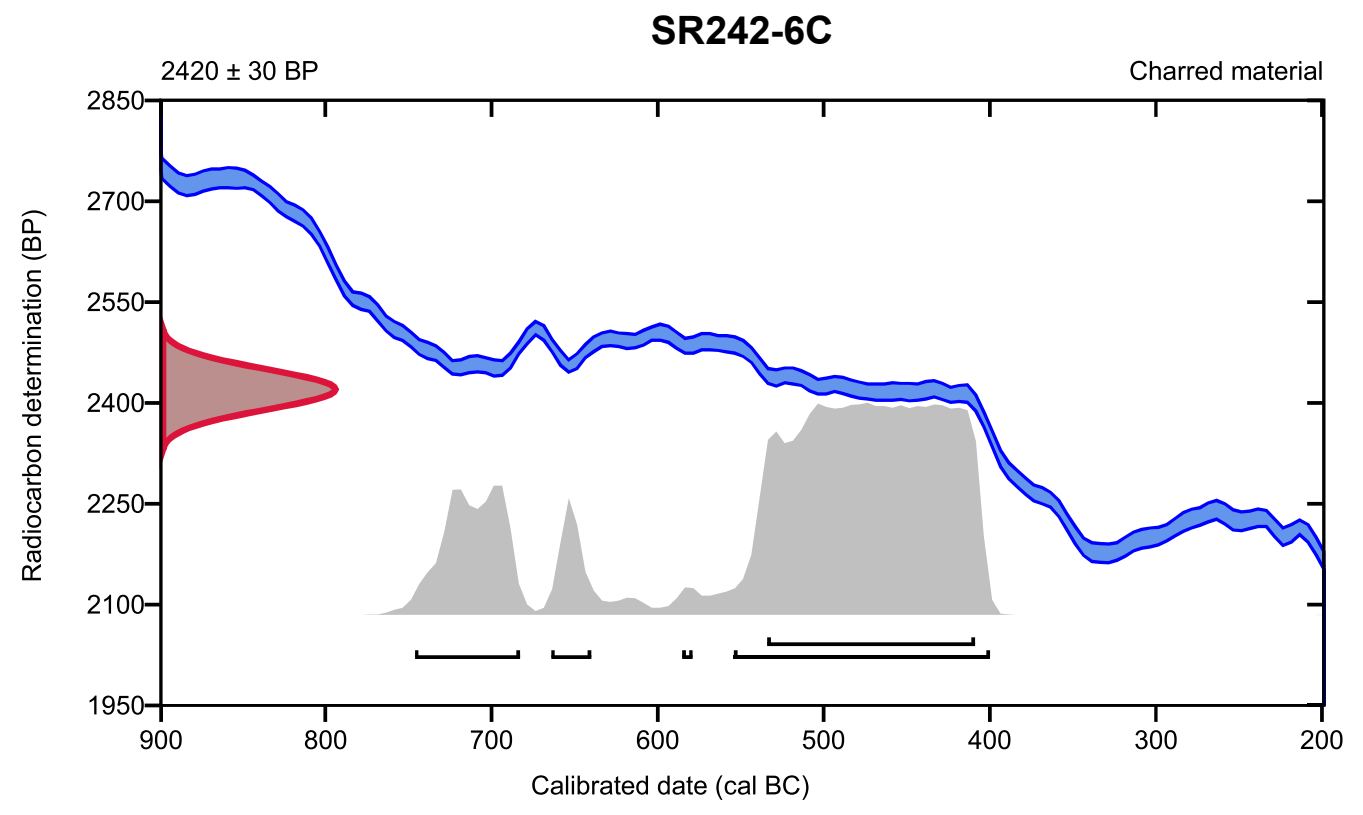

Database used

INTCAL13

\section{References}

References to Probability Method

Bronk Ramsey, C. (2009). Bayesian analysis of radiocarbon dates. Radiocarbon, 51(1), 337-360.

References to Database INTCAL13

Reimer, et.al., 2013, Radiocarbon55(4).

\section{Beta Analytic Radiocarbon Dating Laboratory}

4985 S.W. 74th Court, Miami, Florida 33155 - Tel: (305)667-5167 • Fax: (305)663-0964 • Email: beta@radiocarbon.com 


\section{Calibration of Radiocarbon Age to Calendar Years}

(High Probability Density Range Method (HPD): INTCAL13)

(Variables: $\mathrm{d} 13 \mathrm{C}=-24.1 \mathrm{o} / \mathrm{oo})$

\section{Laboratory number Beta-468116}

Conventional radiocarbon age $2250 \pm 30 \mathrm{BP}$

$95.4 \%$ probability
(64.1\%) $321-206$ cal BC
(2270 - 2155 cal BP)
$(31.3 \%) \quad 395-347$ cal BC
(2344 - 2296 cal BP)

$68.2 \%$ probability
$(43.7 \%) \quad 290-232$ cal BC
(2239 - 2181 cal BP)
$(24.5 \%) \quad 384-355$ cal BC
(2333 - 2304 cal BP)

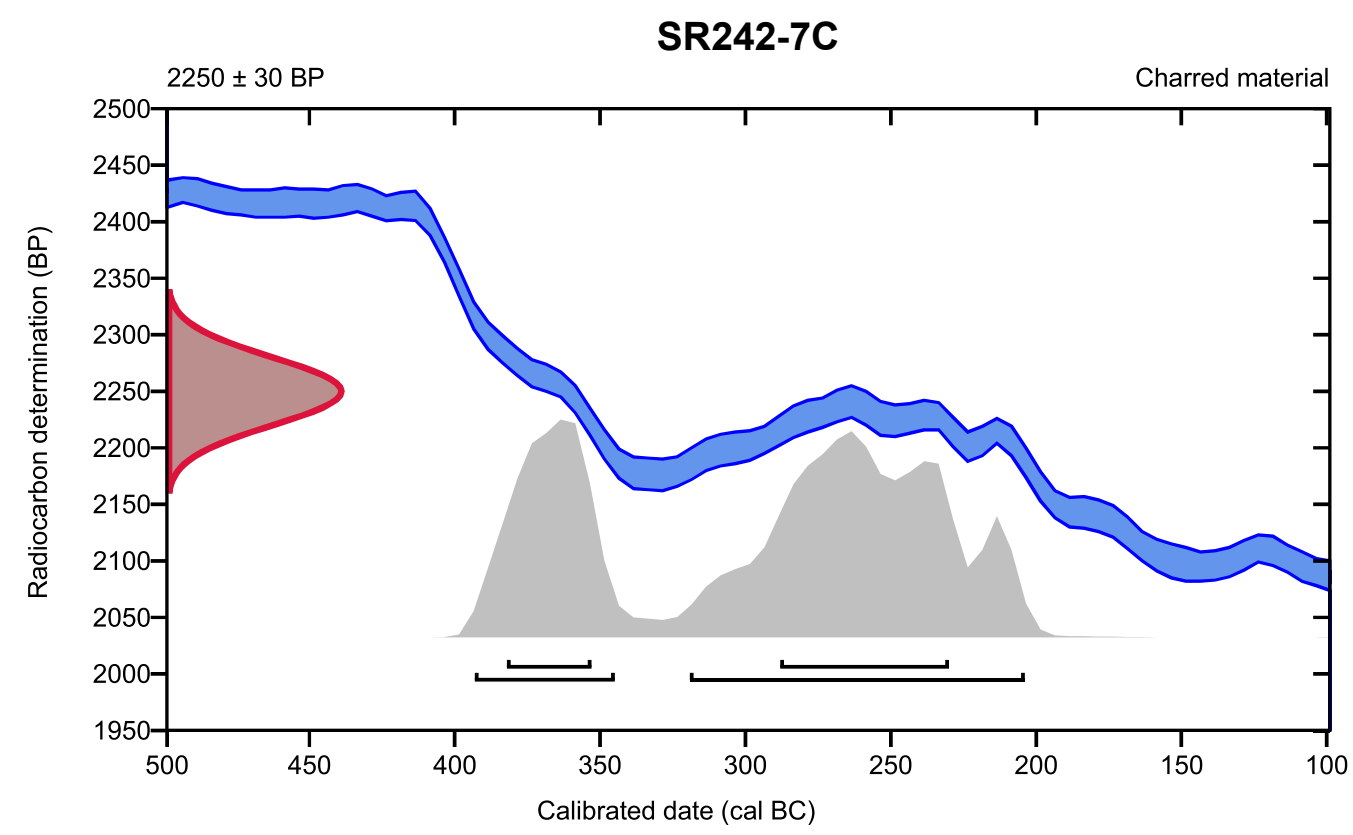

\section{Database used}

INTCAL13

\section{References}

References to Probability Method

Bronk Ramsey, C. (2009). Bayesian analysis of radiocarbon dates. Radiocarbon, 51(1), 337-360.

References to Database INTCAL13

Reimer, et.al., 2013, Radiocarbon55(4).

\section{Beta Analytic Radiocarbon Dating Laboratory}

4985 S.W. 74th Court, Miami, Florida 33155 • Tel: (305)667-5167 • Fax: (305)663-0964 • Email: beta@radiocarbon.com 
BetaCal 3.21

\section{Calibration of Radiocarbon Age to Calendar Years}

(High Probability Density Range Method (HPD): INTCAL13)

(Variables: $\mathrm{d} 13 \mathrm{C}=-24.1 \mathrm{o} / \mathrm{oo})$

Laboratory number Beta-468117

Conventional radiocarbon age $\quad 3260 \pm 30 \mathrm{BP}$

$95.4 \%$ probability

(87.8\%) $1616-1493$ cal BC

(3565 - 3442 cal BP)

$(7.6 \%) \quad 1481-1454 \mathrm{cal} \mathrm{BC}$

(3430 - 3403 cal BP)

$68.2 \%$ probability
(48.5\%) $\quad 1560-1500 \mathrm{cal} \mathrm{BC}$
(3509 - 3449 cal BP)
$(19.7 \%) \quad 1607-1582$ cal BC
(3556 - 3531 cal BP)

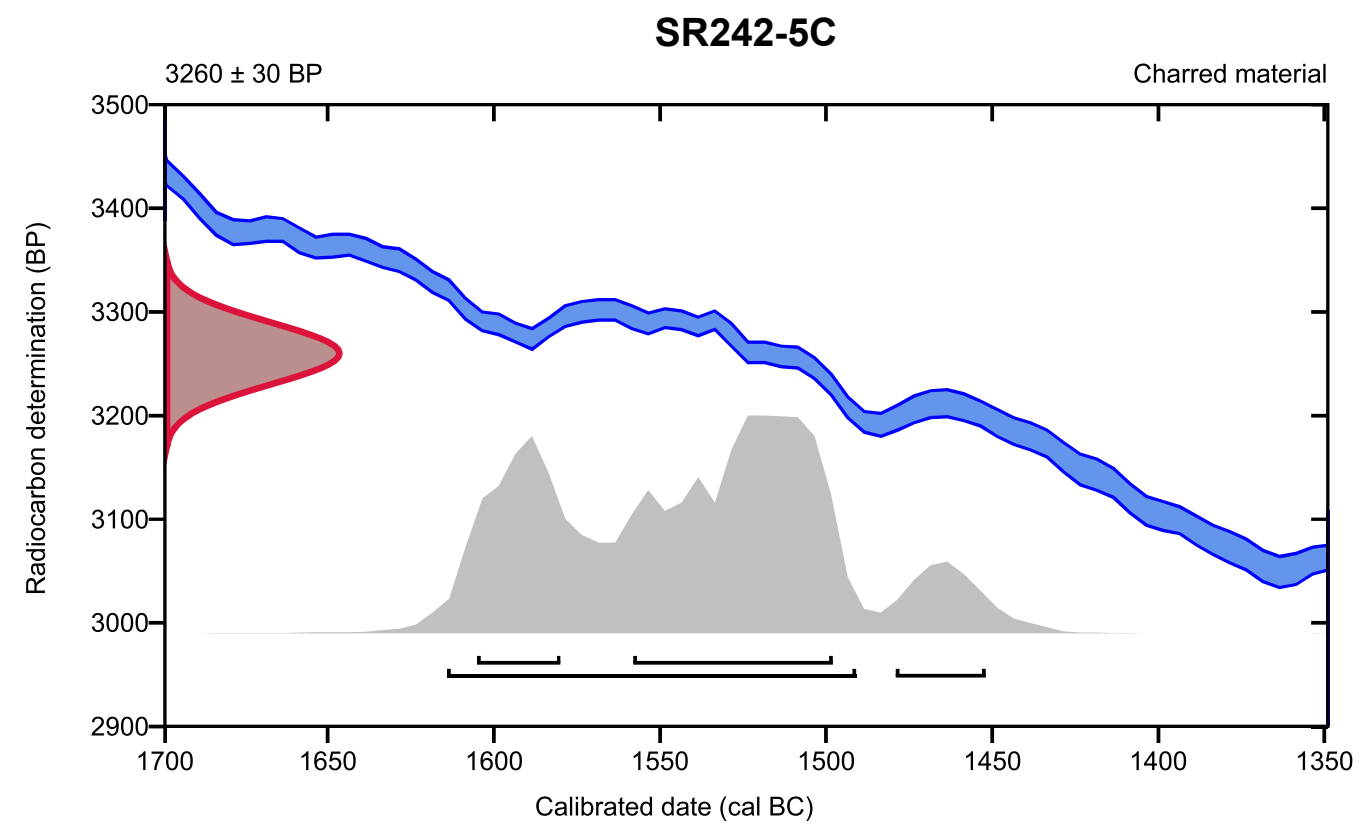

\section{Database used}

INTCAL13

\section{References}

References to Probability Method

Bronk Ramsey, C. (2009). Bayesian analysis of radiocarbon dates. Radiocarbon, 51(1), 337-360.

References to Database INTCAL13

Reimer, et.al., 2013, Radiocarbon55(4).

\section{Beta Analytic Radiocarbon Dating Laboratory}

4985 S.W. 74th Court, Miami, Florida 33155 • Tel: (305)667-5167 • Fax: (305)663-0964 • Email: beta@radiocarbon.com 


\section{Calibration of Radiocarbon Age to Calendar Years}

(High Probability Density Range Method (HPD): INTCAL13)

(Variables: $\mathrm{d} 13 \mathrm{C}=-23.4 \mathrm{o} / \mathrm{oo})$

\section{Laboratory number Beta-468118}

Conventional radiocarbon age $2160 \pm 30 \mathrm{BP}$

$95.4 \%$ probability
(55.3\%) $259-108$ cal BC
(2208 - 2057 cal BP)
$(40.1 \%) \quad 358-279$ cal BC
(2307 - 2228 cal BP)

$68.2 \%$ probability
(34\%) $352-299$ cal BC
(2301 - 2248 cal BP)
(32.4\%) $211-167$ cal BC
$(2160-2116$ cal BP)
$(1.9 \%) \quad 228-223 \mathrm{cal} \mathrm{BC}$
(2177 - 2172 cal BP)

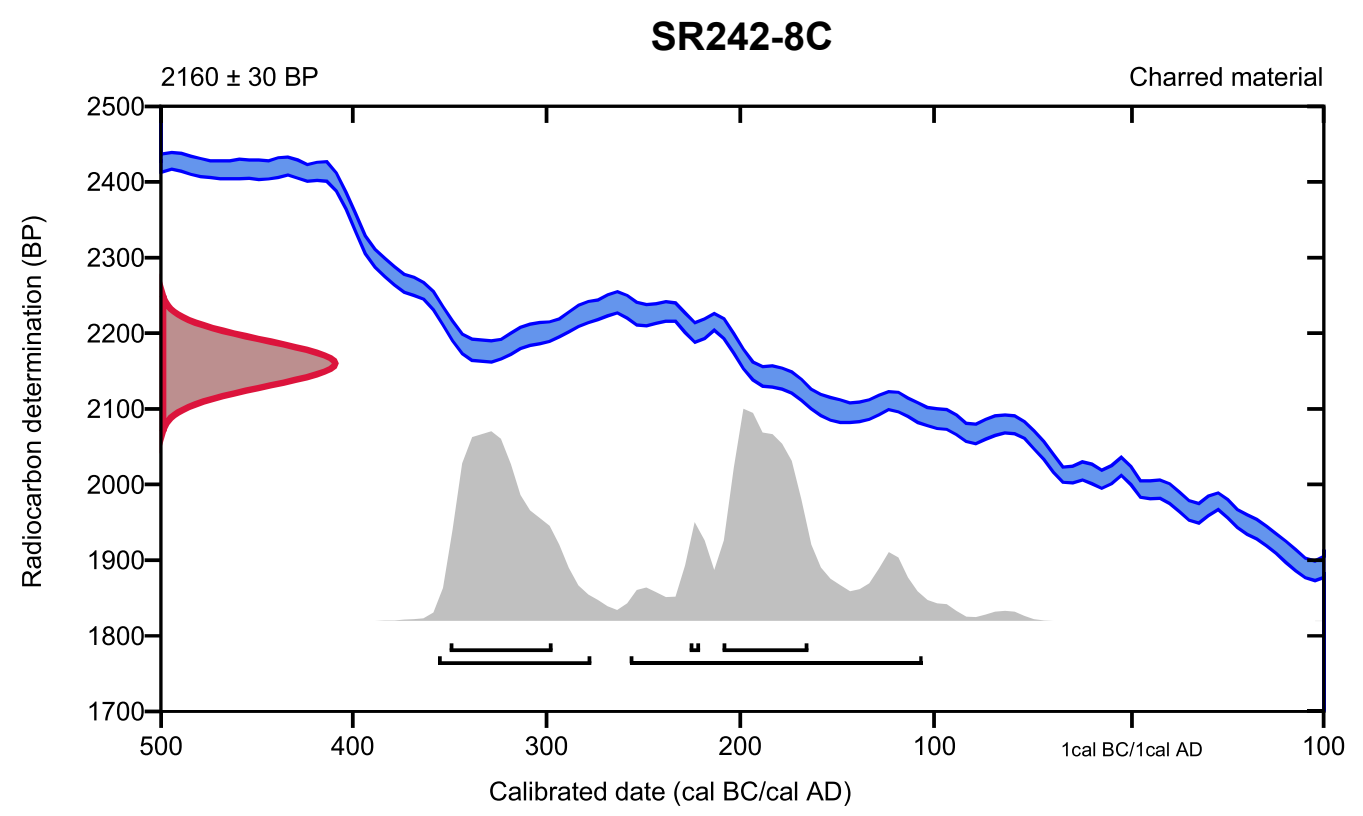

\section{Database used}

INTCAL13

\section{References}

References to Probability Method

Bronk Ramsey, C. (2009). Bayesian analysis of radiocarbon dates. Radiocarbon, 51(1), 337-360.

References to Database INTCAL13

Reimer, et.al., 2013, Radiocarbon55(4).

\section{Beta Analytic Radiocarbon Dating Laboratory}

4985 S.W. 74th Court, Miami, Florida 33155 • Tel: (305)667-5167 • Fax: (305)663-0964 • Email: beta@radiocarbon.com 
BetaCal 3.21

\section{Calibration of Radiocarbon Age to Calendar Years}

(High Probability Density Range Method (HPD): INTCAL13)

(Variables: $\mathrm{d} 13 \mathrm{C}=-22.5 \mathrm{o} / \mathrm{oo})$

Laboratory number Beta-468119

Conventional radiocarbon age $\quad 3260 \pm 30 \mathrm{BP}$

$95.4 \%$ probability

$(87.8 \%) \quad 1616-1493$ cal BC

(3565 - 3442 cal BP)

$(7.6 \%) \quad 1481-1454 \mathrm{cal} \mathrm{BC}$

(3430 - 3403 cal BP)

$68.2 \%$ probability
(48.5\%) $\quad 1560-1500 \mathrm{cal} \mathrm{BC}$
(3509 - 3449 cal BP)
$(19.7 \%) \quad 1607-1582$ cal BC
(3556 - 3531 cal BP)

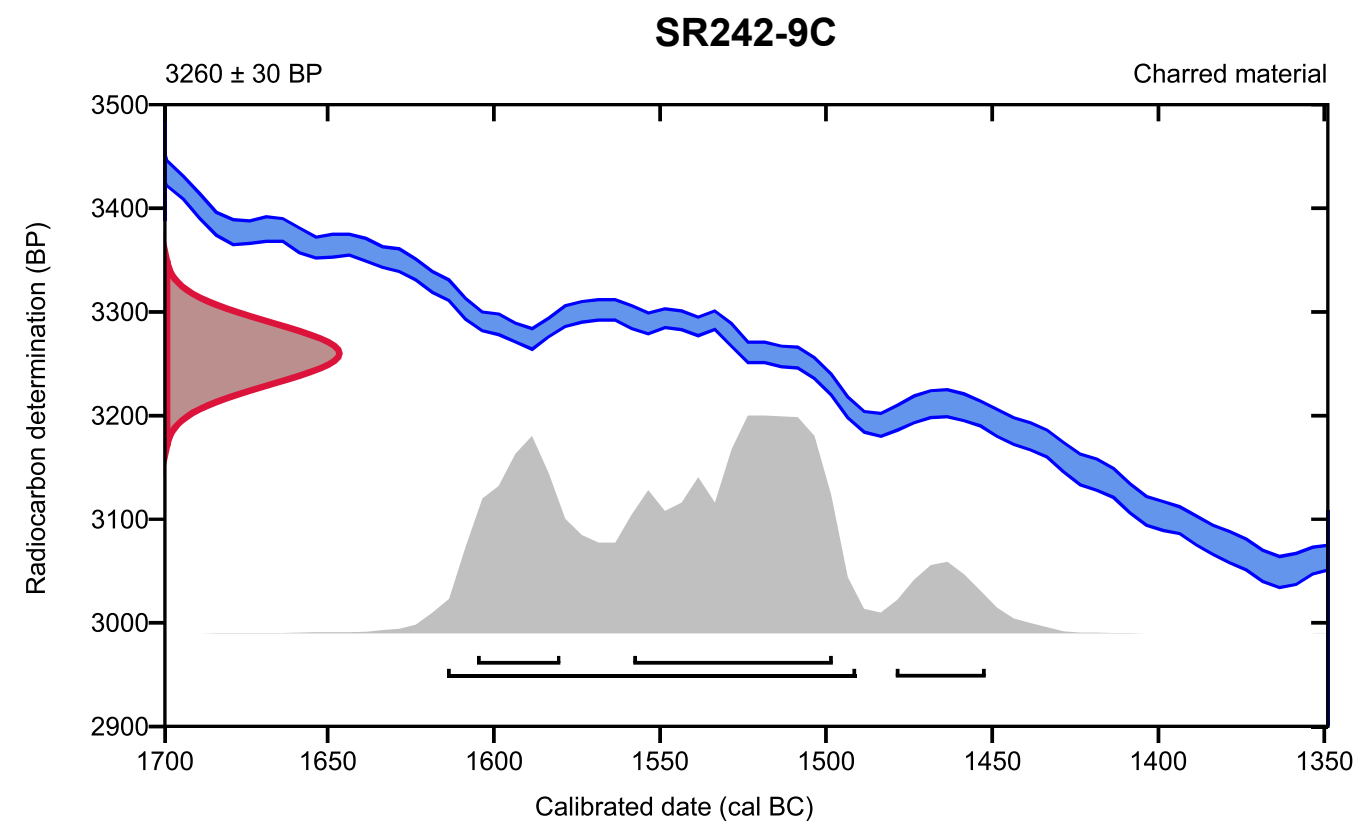

\section{Database used}

INTCAL13

\section{References}

References to Probability Method

Bronk Ramsey, C. (2009). Bayesian analysis of radiocarbon dates. Radiocarbon, 51(1), 337-360.

References to Database INTCAL13

Reimer, et.al., 2013, Radiocarbon55(4).

\section{Beta Analytic Radiocarbon Dating Laboratory}

4985 S.W. 74th Court, Miami, Florida 33155 • Tel: (305)667-5167 • Fax: (305)663-0964 • Email: beta@radiocarbon.com 


\title{
Calibration of Radiocarbon Age to Calendar Years
}

\section{(High Probability Density Range Method (HPD): INTCAL13)}

\author{
(Variables: $\mathrm{d} 13 \mathrm{C}=-23.6 \mathrm{o} / \mathrm{oo})$ \\ Laboratory number Beta-468120 \\ Conventional radiocarbon age $2450 \pm 30 \mathrm{BP}$
}

$95.4 \%$ probability

$\begin{array}{lll}(53.2 \%) & 595-411 \text { cal } \mathrm{BC} & (2544-2360 \mathrm{cal} \\ (26.7 \%) & 754-681 \mathrm{cal}) \\ (15.5 \%) & 670-609 \mathrm{cal} \text { BC } & (2703-2630 \mathrm{cal} \text { BP }) \\ & & (2619-2558 \text { cal BP })\end{array}$

$68.2 \%$ probability

$\begin{array}{lll}(28.8 \%) & 554-475 \text { cal BC } & (2503-2424 \text { cal BP }) \\ (24.6 \%) & 746-686 \text { cal BC } & (2695-2635 \text { cal BP }) \\ (8.6 \%) & 666-643 \text { cal BC } & (2615-2592 \text { cal BP }) \\ (4.1 \%) & 445-431 \text { cal BC } & (2394-2380 \text { cal BP }) \\ (2.1 \%) & 463-455 \text { cal BC } & (2412-2404 \text { cal BP })\end{array}$

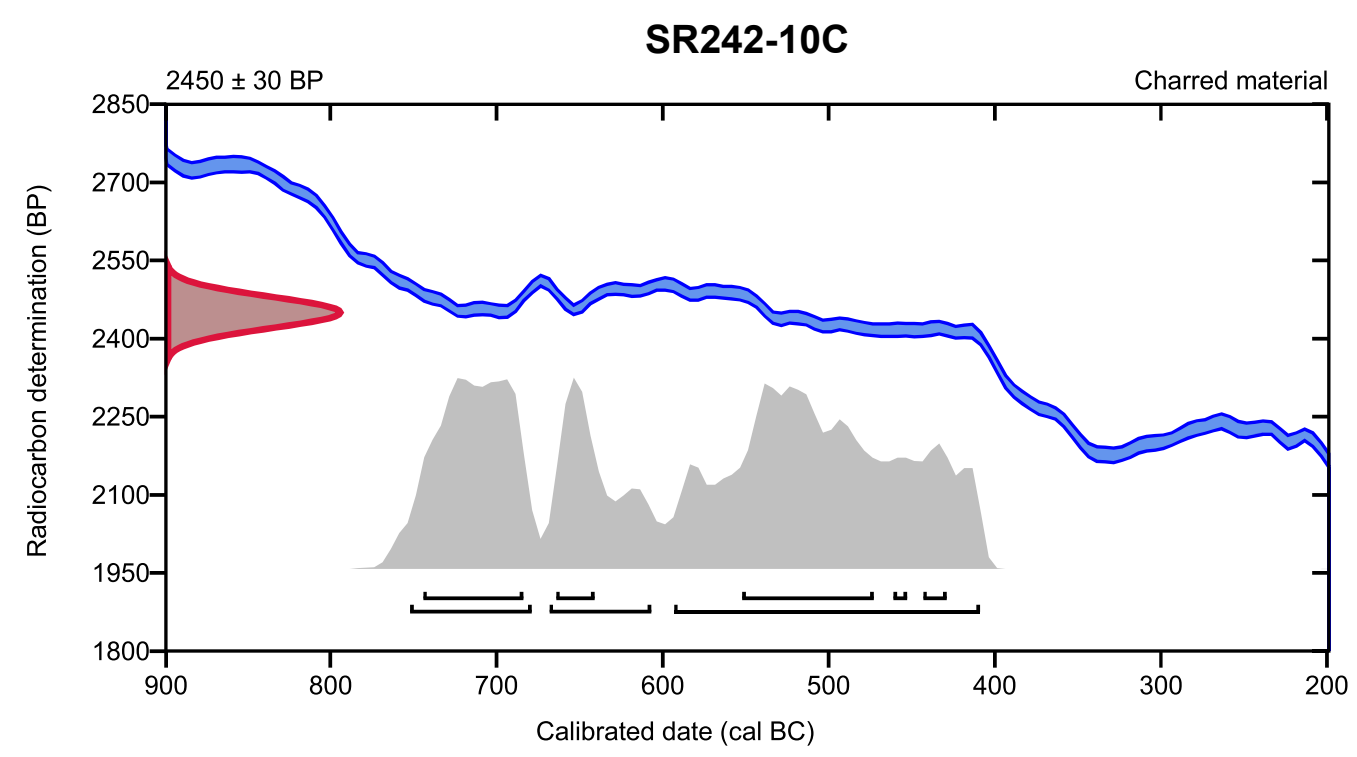

Database used

INTCAL13

\section{References}

References to Probability Method

Bronk Ramsey, C. (2009). Bayesian analysis of radiocarbon dates. Radiocarbon, 51(1), 337-360.

References to Database INTCAL13

Reimer, et.al., 2013, Radiocarbon55(4).

\section{Beta Analytic Radiocarbon Dating Laboratory}

4985 S.W. 74th Court, Miami, Florida 33155 • Tel: (305)667-5167 • Fax: (305)663-0964 • Email: beta@radiocarbon.com 


\title{
Calibration of Radiocarbon Age to Calendar Years
}

\section{(High Probability Density Range Method (HPD): INTCAL13)}

(Variables: $\mathrm{d} 13 \mathrm{C}=-23.0 \mathrm{o} / \mathrm{oo})$

\author{
Laboratory number Beta-468121 \\ Conventional radiocarbon age $\quad 3020 \pm 30 \mathrm{BP}$
}

$95.4 \%$ probability

$\begin{array}{lll}(73.1 \%) & 1322-1191 \text { cal } \mathrm{BC} & (3271-3140 \mathrm{cal} \text { BP }) \\ (18.9 \%) & 1391-1337 \mathrm{cal} \text { BC } & (3340-3286 \text { cal } \mathrm{BP}) \\ (2 \%) & 1144-1131 \mathrm{cal} \text { BC } & (3093-3080 \text { cal } \mathrm{BP}) \\ (1.4 \%) & 1177-1164 \mathrm{cal} \mathrm{BC} & (3126-3113 \mathrm{cal} \text { BP })\end{array}$

$68.2 \%$ probability
$(61.2 \%) \quad 1299-1217$ cal BC
(3248 - 3166 cal BP)
$(7 \%)$
$1372-1359$ cal BC
(3321 - 3308 cal BP)

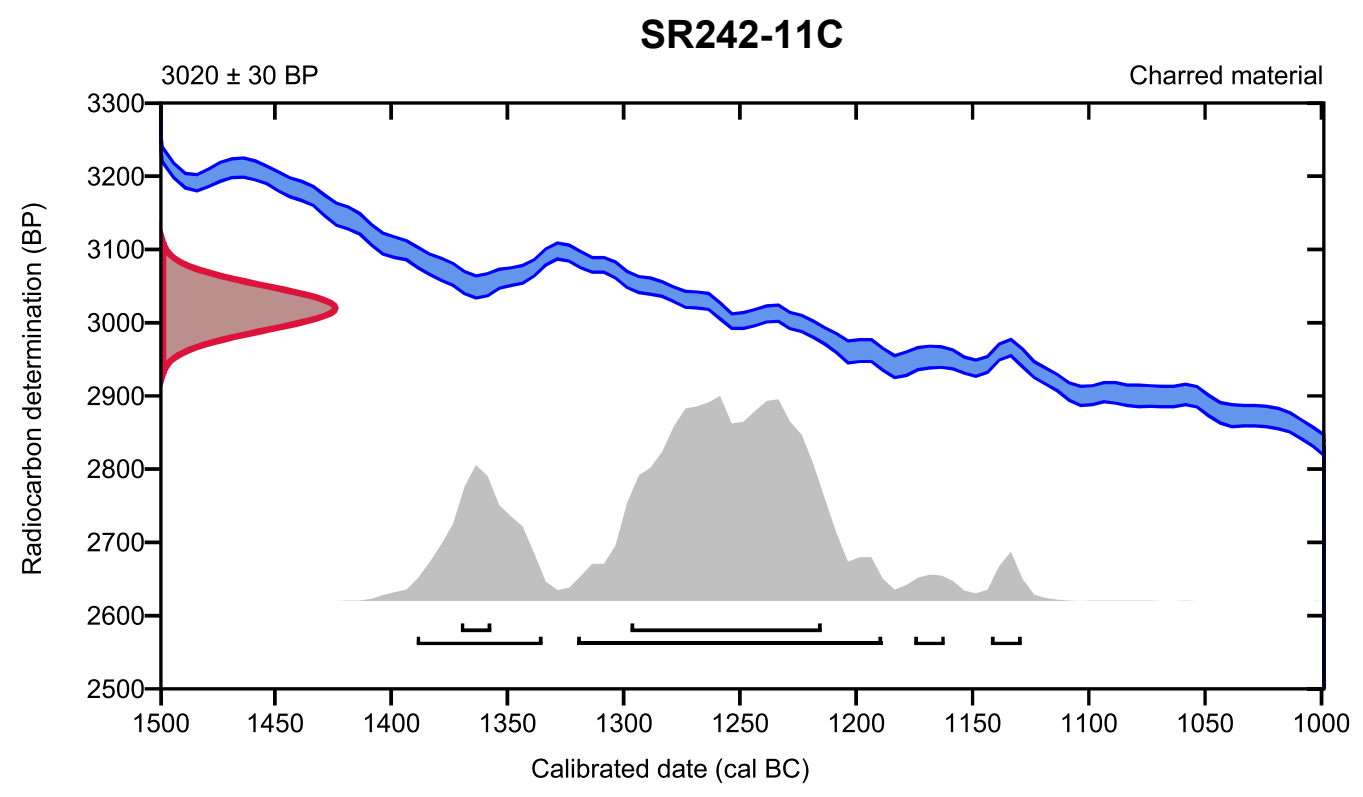

\section{Database used}

INTCAL13

\section{References}

References to Probability Method

Bronk Ramsey, C. (2009). Bayesian analysis of radiocarbon dates. Radiocarbon, 51(1), 337-360.

References to Database INTCAL13

Reimer, et.al., 2013, Radiocarbon55(4).

\section{Beta Analytic Radiocarbon Dating Laboratory}

4985 S.W. 74th Court, Miami, Florida 33155 • Tel: (305)667-5167 • Fax: (305)663-0964 • Email: beta@radiocarbon.com 
This page intentionally left blank. 


\section{APPENDIX D}

Lithic Analysis 
This page intentionally left blank. 


\begin{tabular}{|c|c|c|c|c|c|c|c|c|c|}
\hline $\begin{array}{l}\text { Lot } \\
\text { No. }\end{array}$ & $\begin{array}{l}\text { Specimen } \\
\text { No. } \\
\end{array}$ & Nodule No. & $\begin{array}{l}\text { Flake } \\
\text { Size } \\
\end{array}$ & $\begin{array}{l}\text { Percent } \\
\text { Cortex } \\
\end{array}$ & $\begin{array}{l}\text { Platform } \\
\text { Type } \\
\end{array}$ & $\begin{array}{c}\text { Thermal } \\
\text { Alteration }\end{array}$ & $\begin{array}{c}\text { Technological } \\
\text { Class } \\
\end{array}$ & Count & Comments \\
\hline 152 & 001 & 1.1 & 01 & 04 & CRT & ANO & PRI & 1 & None \\
\hline 152 & 002 & 1.2 & 01 & 04 & CRT & ANO & $\mathrm{PRI}$ & 1 & None \\
\hline 152 & 003 & 1.3 & 02 & 00 & MSG & ANO & $\mathrm{CMX}$ & 1 & None \\
\hline 152 & 004 & 1.4 & 02 & 00 & MSG & ANO & CMX & 1 & None \\
\hline 152 & 005 & 1.5 & 01 & 02 & MSG & ANO & SIM & 1 & None \\
\hline 152 & 006 & 1.6 & 03 & 00 & MSG & ANO & $\mathrm{CMX}$ & 1 & None \\
\hline 152 & 007 & 1.7 & 03 & 00 & FCT & ANO & $\mathrm{CMX}$ & 1 & None \\
\hline 152 & 008 & 1.8 & 01 & 01 & CRT & ANO & SIM & 1 & None \\
\hline 152 & 009 & 1.9 & 04 & 00 & MSG & ANO & $\mathrm{CMX}$ & 1 & None \\
\hline 152 & 010 & 1.10 & 03 & 00 & MSG & ANO & $\mathrm{CMX}$ & 1 & None \\
\hline 152 & 011 & 1.11 & 04 & 00 & MSG & ANO & $\mathrm{CMX}$ & 1 & None \\
\hline 152 & 012 & 1.12 & 02 & 00 & MSG & ANO & $\mathrm{CMX}$ & 1 & None \\
\hline 152 & 013 & 1.13 & 01 & 00 & MLT & ANO & BTF & 1 & None \\
\hline 152 & 014 & 2.1 & 04 & 00 & $\overline{M S G}$ & ANO & $\mathrm{CMX}$ & 1 & None \\
\hline 152 & 015 & 2.2 & 04 & 00 & MSG & ANO & CMX & 1 & None \\
\hline 152 & 016 & 2.3 & 04 & 00 & MSG & ANO & CMX & 1 & None \\
\hline 152 & 017 & 2.4 & 02 & 00 & FLA & ANO & CMX & 1 & None \\
\hline 152 & 018 & 3.1 & 01 & 04 & FCT & ANO & PRI & 1 & None \\
\hline 152 & 019 & 3.2 & 01 & 00 & CRT & ANO & $\mathrm{CMX}$ & 1 & None \\
\hline 152 & 020 & 3.3 & 04 & 00 & MSG & ANO & CMX & 1 & None \\
\hline 152 & 021 & 4.1 & 01 & 02 & MSG & ANO & SHA & 1 & None \\
\hline 152 & 022 & 4.2 & 01 & 00 & MSG & ANO & $\mathrm{SHA}$ & 1 & None \\
\hline 152 & 023 & 4.3 & 02 & 00 & MSG & ANO & SHA & 1 & None \\
\hline 152 & 024 & 5.1 & 01 & 00 & MSG & ANO & CMX & 1 & None \\
\hline 152 & 025 & 5.2 & 01 & 00 & MLT & ANO & BTF & 1 & None \\
\hline 152 & 026 & 5.3 & 04 & 00 & MLT & ANO & CMX & 1 & None \\
\hline 152 & 027 & 5.4 & 04 & 00 & MSG & ANO & CMX & 1 & None \\
\hline 152 & 028 & 5.5 & 04 & 00 & MSG & ANO & CMX & 1 & None \\
\hline 152 & 029 & 5.6 & 04 & 00 & MLT & ANO & CMX & 1 & None \\
\hline 152 & 030 & 5.7 & 03 & 00 & MLT & ANO & CMX & 1 & None \\
\hline 152 & 031 & 5.8 & 04 & 00 & MSG & ANO & CMX & 1 & None \\
\hline 152 & 032 & 5.9 & 01 & 00 & FLA & ANO & $\mathrm{CMX}$ & 1 & None \\
\hline 152 & 033 & 5.10 & 01 & 00 & $\overline{M L T}$ & ANO & BTF & 1 & None \\
\hline 152 & 034 & 5.11 & 02 & 00 & MSG & ANO & CMX & 1 & None \\
\hline 152 & 035 & 6.1 & 01 & 00 & $\mathrm{MLT}$ & ANO & BTF & 1 & None \\
\hline 152 & 036 & 6.2 & 02 & 00 & MSG & ANO & CMX & 1 & None \\
\hline 152 & 037 & 6.3 & 04 & 00 & MSG & ANO & CMX & 1 & None \\
\hline 152 & 038 & 7.1 & 01 & 02 & CRT & ANO & SIM & 1 & None \\
\hline 152 & 039 & 7.2 & 01 & 00 & MLT & ANO & BTF & 1 & None \\
\hline 152 & 040 & 7.3 & 01 & 00 & MSG & ANO & $\mathrm{CMX}$ & 1 & None \\
\hline 152 & 041 & 7.4 & 04 & 00 & MSG & ANO & $\overline{C M X}$ & 1 & None \\
\hline 152 & 042 & 7.5 & 01 & 00 & MLT & ANO & BTF & 1 & None \\
\hline 152 & 043 & 8.1 & 01 & 00 & MLT & ANO & BTF & 1 & None \\
\hline 152 & 044 & 8.2 & 01 & 04 & CRT & ANO & PRI & 1 & None \\
\hline 152 & 045 & 8.3 & 01 & 00 & FCT & ANO & CMX & 1 & None \\
\hline 152 & 046 & 9.1 & 04 & 00 & $\overline{M L T}$ & ANO & $\overline{C M X}$ & 1 & None \\
\hline 152 & 047 & 9.2 & 01 & 00 & $\mathrm{MLT}$ & ANO & BTF & 1 & None \\
\hline 152 & 048 & 9.3 & 03 & 00 & MSG & ANO & CMX & 1 & None \\
\hline 152 & 049 & 9.4 & 04 & 00 & MSG & ANO & CMX & 1 & None \\
\hline 152 & 050 & 9.5 & 03 & 00 & FLA & ANO & CMX & 1 & None \\
\hline 152 & 051 & 9.6 & 05 & 00 & MSG & ANO & CMX & 1 & None \\
\hline 152 & 052 & 9.7 & 01 & 00 & MSG & ANO & CMX & 1 & None \\
\hline 152 & 053 & 9.8 & 04 & 00 & MSG & ANO & CMX & 1 & None \\
\hline 152 & 054 & 9.9 & 03 & 00 & MSG & ANO & CMX & 1 & None \\
\hline 152 & 055 & 9.10 & 01 & 00 & MLT & ANO & BTF & 1 & None \\
\hline 152 & 056 & 9.11 & 02 & 00 & MSG & ANO & CMX & 1 & None \\
\hline 152 & 057 & 10.1 & 01 & 00 & MSG & ANO & $\mathrm{CMX}$ & 1 & None \\
\hline 152 & 058 & 10.2 & 01 & 00 & $\mathrm{MLT}$ & ANO & BTF & 1 & None \\
\hline 152 & 059 & 10.3 & 01 & 00 & FCT & ANO & BTF & 1 & None \\
\hline 152 & 060 & 10.4 & 01 & 00 & MSG & ANO & $\mathrm{CMX}$ & 1 & None \\
\hline 152 & 061 & 10.5 & 01 & 00 & MSG & ANO & CMX & 1 & None \\
\hline 152 & 062 & 10.6 & 03 & 00 & MSG & ANO & CMX & 1 & None \\
\hline 152 & 063 & 10.7 & 01 & 00 & FCT & ANO & CMX & 1 & None \\
\hline 152 & 064 & 10.8 & 01 & 00 & MSG & ANO & CMX & 1 & None \\
\hline 152 & 065 & 10.9 & 02 & 00 & MLT & ANO & CMX & 1 & None \\
\hline 152 & 066 & 10.10 & 01 & 00 & MLT & ANO & BTF & 1 & None \\
\hline
\end{tabular}




\begin{tabular}{|c|c|c|c|c|c|c|c|c|c|}
\hline $\begin{array}{l}\text { Lot } \\
\text { No. }\end{array}$ & $\begin{array}{l}\text { Specimen } \\
\text { No. } \\
\end{array}$ & Nodule No. & $\begin{array}{l}\text { Flake } \\
\text { Size }\end{array}$ & $\begin{array}{l}\text { Percent } \\
\text { Cortex } \\
\end{array}$ & $\begin{array}{l}\text { Platform } \\
\text { Type } \\
\end{array}$ & $\begin{array}{c}\text { Thermal } \\
\text { Alteration }\end{array}$ & $\begin{array}{c}\text { Technological } \\
\text { Class } \\
\end{array}$ & Count & Comments \\
\hline 152 & 067 & 10.11 & 01 & 00 & MLT & ANO & $\mathrm{CMX}$ & 1 & None \\
\hline 152 & 068 & 10.12 & 02 & 00 & MSG & ANO & CMX & 1 & None \\
\hline 152 & 069 & 10.13 & 03 & 00 & MSG & ANO & $\mathrm{CMX}$ & 1 & None \\
\hline 152 & 070 & 10.14 & 03 & 00 & MSG & ANO & CMX & 1 & None \\
\hline 152 & 071 & 10.15 & 04 & 00 & MSG & ANO & $\mathrm{CMX}$ & 1 & None \\
\hline 152 & 072 & 10.16 & 04 & 00 & MSG & ANO & $\mathrm{CMX}$ & 1 & None \\
\hline 152 & 073 & 10.17 & 04 & 00 & $\overline{M S G}$ & ANO & $\mathrm{CMX}$ & 1 & None \\
\hline 152 & 074 & 10.18 & 04 & 00 & MSG & ANO & CMX & 1 & None \\
\hline 152 & 075 & 10.19 & 04 & 00 & MSG & ANO & CMX & 1 & None \\
\hline 152 & 076 & 10.20 & 04 & 00 & MSG & ANO & $\mathrm{CMX}$ & 1 & None \\
\hline 152 & 077 & 10.21 & 04 & 00 & MSG & ANO & $\mathrm{CMX}$ & 1 & None \\
\hline 152 & 078 & 10.22 & 03 & 00 & $\overline{M L T}$ & ANO & CMX & 1 & None \\
\hline 152 & 079 & 10.23 & 04 & 00 & MSG & ANO & CMX & 1 & None \\
\hline 152 & 080 & 11.1 & 01 & 00 & CRT & ANO & CMX & 1 & None \\
\hline 152 & 081 & 11.2 & 01 & 00 & MLT & ANO & CMX & 1 & None \\
\hline 152 & 082 & 11.3 & 02 & 00 & FLA & ANO & CMX & 1 & None \\
\hline 152 & 083 & 11.4 & 05 & 00 & $\overline{M S G}$ & ANO & CMX & 1 & None \\
\hline 152 & 084 & 11.5 & 04 & 00 & MSG & ANO & CMX & 1 & None \\
\hline 152 & 085 & 11.6 & 01 & 00 & MLT & ANO & BTF & 1 & None \\
\hline 152 & 086 & 11.7 & 01 & 01 & $\overline{M L T}$ & ANO & BTF & 1 & None \\
\hline 152 & 087 & 11.8 & 01 & 04 & CRT & ANO & $\mathrm{PRI}$ & 1 & None \\
\hline 152 & 088 & 11.9 & 03 & 00 & MSG & ANO & CMX & 1 & None \\
\hline 152 & 089 & 11.10 & 03 & 02 & FLA & ANO & SIM & 1 & None \\
\hline 152 & 090 & 11.11 & 02 & 02 & MSG & ANO & SIM & 1 & None \\
\hline 152 & 091 & 12.1 & 03 & 00 & MLT & ANO & CMX & 1 & None \\
\hline 152 & 092 & 12.2 & 03 & 04 & MSG & ANO & PRI & 1 & None \\
\hline 152 & 093 & 12.3 & 02 & 00 & $\overline{M S G}$ & ANO & CMX & 1 & None \\
\hline 152 & 094 & 12.4 & 01 & 00 & MLT & ANO & CMX & 1 & None \\
\hline 152 & 095 & 12.5 & 01 & 00 & MLT & ANO & BTF & 1 & None \\
\hline 152 & 096 & 12.6 & 04 & 00 & $\overline{M S G}$ & ANO & CMX & 1 & None \\
\hline 152 & 097 & 12.7 & 04 & 00 & $\overline{M L T}$ & ANO & CMX & 1 & None \\
\hline 152 & 098 & 12.8 & 03 & 00 & MSG & ANO & CMX & 1 & None \\
\hline 152 & 099 & 12.9 & 01 & 00 & $\overline{M L T}$ & ANO & BTF & 1 & None \\
\hline 152 & 100 & 12.10 & 04 & 00 & MSG & ANO & CMX & 1 & None \\
\hline 152 & 101 & 12.11 & 03 & 01 & MSG & ANO & SIM & 1 & None \\
\hline 152 & 102 & 13.1 & 01 & 03 & CRT & ANO & SIM & 1 & None \\
\hline 152 & 103 & 13.2 & 01 & 01 & MLT & ANO & CMX & 1 & None \\
\hline 152 & 104 & 13.3 & 01 & 00 & MLT & ANO & BTF & 1 & None \\
\hline 152 & 105 & 13.4 & 04 & 00 & $\overline{M S G}$ & ANO & CMX & 1 & None \\
\hline 152 & 106 & 13.5 & 03 & 00 & MSG & ANO & CMX & 1 & None \\
\hline 152 & 107 & 13.6 & 03 & 00 & MSG & ANO & CMX & 1 & None \\
\hline 152 & 108 & 13.7 & 01 & 00 & MSG & ANO & CMX & 1 & None \\
\hline 152 & 109 & 13.8 & 04 & 00 & MSG & ANO & CMX & 1 & None \\
\hline 152 & 110 & 13.9 & 02 & 00 & MSG & ANO & CMX & 1 & None \\
\hline 152 & 111 & 13.10 & 02 & 01 & MSG & ANO & SIM & 1 & None \\
\hline 152 & 112 & 14.1 & 04 & 00 & $\overline{M S G}$ & ANO & CMX & 1 & None \\
\hline 152 & 113 & 14.2 & 02 & 00 & MSG & ANO & CMX & 1 & None \\
\hline 152 & 114 & 15.1 & 05 & NA & $\mathrm{NA}$ & NA & SG4 & 38 & Not Analyzed \\
\hline 153 & 001 & 1.1 & 01 & 04 & CRT & ANO & $\mathrm{PRI}$ & 1 & None \\
\hline 153 & 002 & 2.1 & 01 & 00 & MLT & ANO & CMX & 1 & None \\
\hline 153 & 003 & 3.1 & 01 & 02 & MSG & ANO & SIM & 1 & None \\
\hline 153 & 004 & 4.1 & 01 & 00 & $\overline{M L T}$ & ANO & BTF & 1 & None \\
\hline 153 & 005 & 4.2 & 03 & 00 & MSG & ANO & SIM & 1 & None \\
\hline 153 & 006 & 4.3 & 03 & 00 & MSG & ANO & CMX & 1 & None \\
\hline 153 & 007 & 5.1 & 01 & 00 & FLA & ANO & CMX & 1 & None \\
\hline 153 & 008 & 5.2 & 03 & 02 & MSG & ANO & SIM & 1 & None \\
\hline 153 & 009 & 6.1 & 03 & 00 & MSG & IND & SIM & 1 & None \\
\hline 153 & 010 & 6.2 & 03 & 02 & MSG & $\mathrm{AOB}$ & SIM & 1 & None \\
\hline 153 & 011 & 7.1 & 01 & 01 & MSG & ANO & BTF & 1 & None \\
\hline 153 & 012 & 7.2 & 02 & 00 & MSG & ANO & BTF & 1 & None \\
\hline 153 & 013 & 7.3 & 03 & 00 & MSG & ANO & CMX & 1 & None \\
\hline 153 & 014 & 7.4 & 02 & 00 & FCT & ANO & CMX & 1 & None \\
\hline 153 & 015 & 7.5 & 03 & 00 & MLT & ANO & CMX & 1 & None \\
\hline 153 & 016 & 7.6 & 03 & 00 & MLT & ANO & CMX & 1 & None \\
\hline 153 & 017 & 7.7 & 03 & 00 & MSG & ANO & SIM & 1 & None \\
\hline 153 & 018 & 7.8 & 03 & 00 & MLT & ANO & SIM & 1 & None \\
\hline
\end{tabular}




\begin{tabular}{|c|c|c|c|c|c|c|c|c|c|}
\hline $\begin{array}{l}\text { Lot } \\
\text { No. }\end{array}$ & $\begin{array}{l}\text { Specimen } \\
\text { No. } \\
\end{array}$ & Nodule No. & $\begin{array}{l}\text { Flake } \\
\text { Size }\end{array}$ & $\begin{array}{l}\text { Percent } \\
\text { Cortex } \\
\end{array}$ & $\begin{array}{l}\text { Platform } \\
\text { Type } \\
\end{array}$ & $\begin{array}{c}\text { Thermal } \\
\text { Alteration }\end{array}$ & $\begin{array}{c}\text { Technological } \\
\text { Class } \\
\end{array}$ & Count & Comments \\
\hline 153 & 019 & 7.9 & 03 & 00 & MLT & ANO & SIM & 1 & None \\
\hline 153 & 020 & 7.10 & 03 & 00 & MLT & ANO & CMX & 1 & None \\
\hline 153 & 021 & 7.11 & 03 & 00 & MSG & ANO & SIM & 1 & None \\
\hline 153 & 022 & 7.12 & 03 & 00 & IND & ANO & $\mathrm{CMX}$ & 1 & None \\
\hline 153 & 023 & 7.13 & 03 & 00 & MSG & ANO & SIM & 1 & None \\
\hline 153 & 024 & 7.14 & 03 & 00 & FLA & ANO & SIM & 1 & None \\
\hline 153 & 025 & 7.15 & 03 & 00 & MSG & ANO & SIM & 1 & None \\
\hline 153 & 026 & 7.16 & 03 & 00 & MSG & ANO & SIM & 1 & None \\
\hline 153 & 027 & 7.17 & 04 & 00 & MSG & ANO & $\mathrm{SHA}$ & 1 & None \\
\hline 153 & 028 & 7.18 & 04 & 00 & MSG & $\mathrm{AOB}$ & $\mathrm{SHA}$ & 1 & None \\
\hline 153 & 029 & 8.1 & 02 & 01 & CRT & $\mathrm{AOB}$ & SIM & 1 & None \\
\hline 153 & 030 & 8.2 & 02 & 00 & $\overline{F C T}$ & ANO & CMX & 1 & None \\
\hline 153 & 031 & 8.3 & 03 & 03 & FCT & ANO & SIM & 1 & None \\
\hline 153 & 032 & 8.4 & 04 & 02 & $\overline{M S G}$ & ANO & $\mathrm{SHA}$ & 1 & None \\
\hline 153 & 033 & 9.1 & 02 & 00 & MLT & ANO & CMX & 1 & None \\
\hline 153 & 034 & 10.1 & 02 & 00 & MLT & ANO & CMX & 1 & None \\
\hline 153 & 035 & 10.2 & 02 & 04 & $\overline{M S G}$ & ANO & BTF & 1 & None \\
\hline 153 & 036 & 11.1 & 02 & 04 & IND & ANO & BTF & 1 & None \\
\hline 153 & 037 & 11.2 & 03 & 04 & IND & ANO & SIM & 1 & None \\
\hline 153 & 038 & 11.3 & 03 & 01 & MSG & ANO & $\mathrm{SHA}$ & 1 & None \\
\hline 153 & 039 & 11.4 & 03 & 02 & MSG & ANO & SIM & 1 & None \\
\hline 153 & 040 & 11.5 & 04 & 00 & MSG & ANO & SIM & 1 & None \\
\hline 153 & 041 & 11.6 & 04 & 02 & MLT & ANO & SIM & 1 & None \\
\hline 153 & 042 & 12.1 & 02 & 00 & MSG & ANO & CMX & 1 & None \\
\hline 153 & 043 & 12.2 & 03 & 00 & MSG & ANO & CMX & 1 & None \\
\hline 153 & 044 & 12.3 & 03 & 00 & MSG & ANO & SIM & 1 & None \\
\hline 153 & 045 & 12.4 & 02 & 01 & CRT & ANO & SIM & 1 & None \\
\hline 153 & 046 & 12.5 & 04 & 00 & MSG & ANO & SG4 & 1 & None \\
\hline 153 & 047 & 13.1 & 02 & 01 & MSG & ANO & BTF & 1 & None \\
\hline 153 & 048 & 13.2 & 03 & 04 & FCT & ANO & PRI & 1 & None \\
\hline 153 & 049 & 13.3 & 03 & 01 & IND & ANO & SIM & 1 & None \\
\hline 153 & 050 & 13.4 & 03 & 04 & MSG & ANO & SIM & 1 & None \\
\hline 153 & 051 & 14.1 & 02 & 00 & CMP & AOB & CMX & 1 & None \\
\hline 153 & 052 & 14.2 & 03 & 02 & CRT & $\mathrm{AOB}$ & SIM & 1 & None \\
\hline 153 & 053 & 14.3 & 04 & 01 & MSG & ANO & SHA & 1 & None \\
\hline 153 & 054 & 15.1 & 03 & 04 & FLA & ANO & $\mathrm{PRI}$ & 1 & None \\
\hline 153 & 055 & 16.1 & 02 & 00 & FCT & ANO & CMX & 1 & None \\
\hline 153 & 056 & 17.1 & 02 & 00 & IND & ANO & SG4 & 1 & None \\
\hline 153 & 057 & 18.1 & 03 & 04 & MSG & ANO & SG4 & 1 & None \\
\hline 153 & 058 & 19.1 & 03 & 00 & FCT & ANO & CMX & 1 & None \\
\hline 153 & 059 & 19.2 & 04 & 00 & MSG & ANO & SIM & 1 & None \\
\hline 153 & 060 & 20.1 & 03 & 00 & MSG & ANO & CMX & 1 & None \\
\hline 153 & 061 & 20.2 & 03 & 02 & MSG & ANO & SIM & 1 & None \\
\hline 153 & 062 & 20.3 & 03 & 00 & MSG & ANO & SIM & 1 & None \\
\hline 153 & 063 & 20.4 & 03 & 00 & MSG & ANO & SIM & 1 & None \\
\hline 153 & 064 & 20.5 & 03 & 00 & MSG & ANO & SIM & 1 & None \\
\hline 153 & 065 & 20.6 & 04 & 00 & MSG & ANO & SIM & 1 & None \\
\hline 153 & 066 & 21.1 & 03 & 04 & MSG & ANO & PRI & 1 & None \\
\hline 153 & 067 & 21.2 & 03 & 01 & FCT & ANO & SIM & 1 & None \\
\hline 153 & 068 & 21.3 & 04 & 04 & IND & ANO & PRI & 1 & None \\
\hline 153 & 069 & 21.4 & 04 & 04 & MSG & ANO & SHA & 1 & None \\
\hline 153 & 070 & 22.1 & 02 & 01 & FCT & ANO & CMX & 1 & None \\
\hline 153 & 071 & 23.1 & 03 & 01 & MSG & $\mathrm{AOB}$ & SHA & 1 & None \\
\hline 153 & 072 & 24.1 & 04 & 04 & IND & ANO & SHA & 1 & None \\
\hline 153 & 073 & 25.1 & 03 & 00 & IND & ANO & CMX & 1 & None \\
\hline 153 & 074 & 26.1 & 04 & 00 & MSG & ANO & SG4 & 1 & None \\
\hline 153 & 075 & 27.1 & 04 & 00 & MSG & ANO & CMX & 1 & None \\
\hline 153 & 076 & 28.1 & 02 & 01 & IND & $\mathrm{AOB}$ & SIM & 1 & None \\
\hline 153 & 077 & 28.2 & 02 & 00 & MSG & ANO & CMX & 1 & None \\
\hline 153 & 078 & 28.3 & 02 & 04 & MSG & $\mathrm{AOB}$ & PRI & 1 & None \\
\hline 153 & 079 & 28.4 & 04 & 00 & MSG & ANO & SHA & 1 & None \\
\hline 153 & 080 & 29.1 & 02 & 00 & MLT & ANO & BTF & 1 & None \\
\hline 153 & 081 & 29.2 & 04 & 00 & MLT & ANO & SIM & 1 & None \\
\hline 153 & 082 & 30.1 & 03 & 01 & MLT & ANO & CMX & 1 & None \\
\hline 153 & 083 & 30.2 & 04 & 00 & MSG & $\mathrm{AOB}$ & SG4 & 1 & None \\
\hline 153 & 084 & 31.1 & 03 & 03 & MSG & ANO & SHA & 1 & None \\
\hline
\end{tabular}




\begin{tabular}{|c|c|c|c|c|c|c|c|c|c|}
\hline $\begin{array}{l}\text { Lot } \\
\text { No. }\end{array}$ & $\begin{array}{l}\text { Specimen } \\
\text { No. }\end{array}$ & Nodule No. & $\begin{array}{l}\text { Flake } \\
\text { Size }\end{array}$ & $\begin{array}{l}\text { Percent } \\
\text { Cortex }\end{array}$ & $\begin{array}{l}\text { Platform } \\
\text { Type }\end{array}$ & $\begin{array}{l}\text { Thermal } \\
\text { Alteration }\end{array}$ & $\begin{array}{c}\text { Technological } \\
\text { Class }\end{array}$ & Count & Comments \\
\hline 153 & 085 & 32.1 & 04 & 00 & FLA & ANO & SIM & 1 & None \\
\hline 153 & 086 & 32.2 & 04 & 00 & MSG & $\mathrm{AOB}$ & SIM & 1 & None \\
\hline 153 & 087 & 32.3 & 03 & 00 & $\mathrm{MLT}$ & ANO & CMX & 1 & None \\
\hline 153 & 088 & 32.4 & 03 & 00 & MSG & ANO & CMX & 1 & None \\
\hline 153 & 089 & 33.1 & 04 & 00 & MSG & ANO & SIM & 1 & None \\
\hline 153 & 090 & 33.2 & 04 & 00 & MSG & ANO & SHA & 1 & None \\
\hline 153 & 091 & 34.1 & 03 & 00 & MSG & ANO & SIM & 1 & None \\
\hline 153 & 092 & 35.1 & 04 & 00 & MSG & ANO & SIM & 1 & None \\
\hline 153 & 093 & 36.1 & 02 & 04 & CRT & ANO & $\mathrm{PRI}$ & 1 & None \\
\hline 153 & 094 & 36.2 & 02 & 00 & FLA & ANO & $\mathrm{CMX}$ & 1 & None \\
\hline 153 & 095 & 36.3 & 03 & 04 & IND & ANO & SIM & 1 & None \\
\hline 153 & 096 & 36.4 & 02 & 00 & IND & ANO & $\mathrm{CMX}$ & 1 & None \\
\hline 153 & 097 & 36.5 & 03 & 00 & MSG & ANO & $\mathrm{CMX}$ & 1 & None \\
\hline 153 & 098 & 36.6 & 03 & 04 & MSG & ANO & SIM & 1 & None \\
\hline 153 & 099 & 36.7 & 03 & 01 & MSG & ANO & SIM & 1 & None \\
\hline 153 & 100 & 36.8 & 04 & 00 & FLA & ANO & SIM & 1 & None \\
\hline 153 & 101 & 36.9 & 04 & 00 & FLA & $\mathrm{AOB}$ & SIM & 1 & None \\
\hline 153 & 102 & 37.1 & 01 & 00 & MSG & ANO & SHA & 1 & None \\
\hline 153 & 103 & 37.2 & 03 & 01 & MSG & ANO & SIM & 1 & None \\
\hline 153 & 104 & 38.1 & 03 & 02 & MSG & ANO & SIM & 1 & None \\
\hline 153 & 105 & 38.2 & 03 & 00 & MSG & ANO & SIM & 1 & None \\
\hline 153 & 106 & 39.1 & 04 & 00 & MSG & ANO & SIM & 1 & None \\
\hline 153 & 107 & 39.2 & 04 & 00 & MLT & ANO & SIM & 1 & None \\
\hline 153 & 108 & 39.3 & 04 & 00 & FLA & ANO & SIM & 1 & None \\
\hline 153 & 109 & 39.4 & 04 & 00 & MSG & ANO & SHA & 1 & None \\
\hline 153 & 110 & 40.1 & 02 & 00 & IND & ANO & SIM & 1 & None \\
\hline 153 & 111 & 40.2 & 03 & 04 & MLT & ANO & SIM & 1 & None \\
\hline 153 & 112 & 40.3 & 03 & 00 & MSG & ANO & SIM & 1 & None \\
\hline 153 & 113 & 40.4 & 03 & 00 & MSG & ANO & CMX & 1 & None \\
\hline 153 & 114 & 40.5 & 03 & 02 & MSG & ANO & SIM & 1 & None \\
\hline 153 & 115 & 40.6 & 04 & 00 & MLT & ANO & CMX & 1 & None \\
\hline 153 & 116 & 40.7 & 04 & 00 & FLA & ANO & $\mathrm{CMX}$ & 1 & None \\
\hline 153 & 117 & 40.8 & 03 & 00 & FLA & ANO & CMX & 1 & None \\
\hline 153 & 118 & 40.9 & 04 & 02 & MSG & ANO & SIM & 1 & None \\
\hline 153 & 119 & 40.10 & 03 & 00 & MSG & ANO & CMX & 1 & None \\
\hline 153 & 120 & 40.11 & 04 & 00 & MSG & ANO & SIM & 1 & None \\
\hline 153 & 121 & 40.12 & 04 & 01 & MSG & ANO & SIM & 1 & None \\
\hline 153 & 122 & 41.1 & 01 & 00 & $\mathrm{MLT}$ & ANO & BTF & 1 & None \\
\hline 153 & 123 & 41.2 & 03 & 00 & MSG & ANO & SIM & 1 & None \\
\hline 153 & 124 & 41.3 & 04 & 01 & MSG & ANO & SHA & 1 & None \\
\hline 153 & 125 & 41.4 & 03 & 03 & MSG & ANO & SIM & 1 & None \\
\hline 153 & 126 & 41.5 & 04 & 04 & MSG & ANO & SIM & 1 & None \\
\hline 153 & 127 & 41.6 & 04 & 00 & MSG & ANO & SIM & 1 & None \\
\hline 153 & 128 & 41.7 & 04 & 00 & MSG & ANO & SIM & 1 & None \\
\hline 153 & 129 & 41.8 & 04 & 04 & $\mathrm{FCT}$ & ANO & SIM & 1 & None \\
\hline 153 & 130 & 42.1 & 02 & 01 & MSG & ANO & SIM & 1 & None \\
\hline 153 & 131 & 42.2 & 03 & 01 & CRT & ANO & SIM & 1 & None \\
\hline 153 & 132 & 42.3 & 03 & 00 & IND & ANO & SIM & 1 & None \\
\hline 153 & 133 & 42.4 & 02 & 00 & MSG & ANO & BTF & 1 & None \\
\hline 153 & 134 & 42.5 & 03 & 00 & FCT & ANO & SIM & 1 & None \\
\hline 153 & 135 & 42.6 & 03 & 01 & CRT & ANO & SIM & 1 & None \\
\hline 153 & 136 & 42.7 & 03 & 00 & $\mathrm{MLT}$ & ANO & SIM & 1 & None \\
\hline 153 & 137 & 42.8 & 03 & 00 & MSG & ANO & SIM & 1 & None \\
\hline 153 & 138 & 42.9 & 04 & 00 & MLT & ANO & CMX & 1 & None \\
\hline 153 & 139 & 43.1 & 03 & 00 & MSG & ANO & CMX & 1 & None \\
\hline 153 & 140 & 43.2 & 03 & 00 & MLT & ANO & $\mathrm{CMX}$ & 1 & None \\
\hline 153 & 141 & 43.3 & 04 & 01 & MSG & ANO & SIM & 1 & None \\
\hline 153 & 142 & 43.4 & 02 & 03 & FLA & ANO & SIM & 1 & None \\
\hline 153 & 143 & 43.5 & 03 & 00 & MSG & ANO & SIM & 1 & None \\
\hline 153 & 144 & 43.6 & 04 & 00 & MSG & ANO & SIM & 1 & None \\
\hline 153 & 145 & 43.7 & 04 & 00 & MSG & ANO & SIM & 1 & None \\
\hline 153 & 146 & 44.1 & 04 & 01 & MSG & $\mathrm{AOB}$ & $\mathrm{SHA}$ & 1 & None \\
\hline 153 & 147 & 44.2 & 04 & 00 & MLT & ANO & CMX & 1 & None \\
\hline 154 & 001 & 1.1 & 03 & 00 & MSG & ANO & SHA & 1 & None \\
\hline 154 & 002 & 2.1 & 04 & 00 & FLA & ANO & SIM & 1 & None \\
\hline 154 & 003 & 3.1 & 05 & $\mathrm{~N} / \mathrm{A}$ & $\mathrm{N} / \mathrm{A}$ & ANO & $\mathrm{N} / \mathrm{A}$ & 1 & Not Analyzed \\
\hline
\end{tabular}




\begin{tabular}{|c|c|c|c|c|c|c|c|c|c|}
\hline $\begin{array}{l}\text { Lot } \\
\text { No. }\end{array}$ & $\begin{array}{l}\text { Specimen } \\
\text { No. } \\
\end{array}$ & Nodule No. & $\begin{array}{l}\text { Flake } \\
\text { Size }\end{array}$ & $\begin{array}{l}\text { Percent } \\
\text { Cortex } \\
\end{array}$ & $\begin{array}{l}\text { Platform } \\
\text { Type } \\
\end{array}$ & $\begin{array}{c}\text { Thermal } \\
\text { Alteration }\end{array}$ & $\begin{array}{c}\text { Technological } \\
\text { Class } \\
\end{array}$ & Count & Comments \\
\hline 154 & 004 & 4.1 & 03 & 01 & FCT & ANO & SIM & 1 & None \\
\hline 154 & 005 & 5.1 & 03 & 00 & MSG & ANO & CMX & 1 & None \\
\hline 154 & 006 & 6.1 & 04 & 00 & MLT & ANO & SIM & 1 & None \\
\hline 154 & 007 & 7.1 & 03 & 00 & MSG & ANO & SIM & 1 & None \\
\hline 154 & 008 & 8.1 & 04 & 00 & MSG & ANO & SIM & 1 & None \\
\hline 154 & 009 & 9.1 & 04 & 04 & CRT & ANO & PRI & 1 & None \\
\hline 154 & 010 & 10.1 & 04 & 00 & IND & ANO & SIM & 1 & None \\
\hline 154 & 011 & 11.1 & 04 & 00 & MSG & ANO & SIM & 1 & None \\
\hline 154 & 012 & 12.1 & 05 & $\mathrm{~N} / \mathrm{A}$ & $\mathrm{N} / \mathrm{A}$ & ANO & $\mathrm{N} / \mathrm{A}$ & 1 & Not Analyzed \\
\hline 154 & 013 & 13.1 & 04 & 00 & MSG & ANO & SIM & 1 & None \\
\hline 154 & 014 & 13.2 & 04 & 00 & MSG & ANO & SHA & 1 & None \\
\hline 154 & 015 & 13.3 & 04 & 00 & $\overline{M S G}$ & ANO & SIM & 1 & None \\
\hline 155 & 001 & 1.1 & 02 & 00 & MSG & AOB & CMX & 1 & None \\
\hline 155 & 002 & 1.2 & 02 & 00 & $\overline{M S G}$ & ANO & CMX & 1 & None \\
\hline 155 & 003 & 1.3 & 04 & 00 & MSG & ANO & SHA & 1 & None \\
\hline 155 & 004 & 1.4 & 02 & 02 & MSG & ANO & SIM & 1 & None \\
\hline 155 & 005 & 1.5 & 02 & 00 & MSG & ANO & $\mathrm{SHA}$ & 1 & None \\
\hline 155 & 006 & 1.6 & 03 & 03 & MSG & ANO & $\mathrm{SHA}$ & 1 & None \\
\hline 155 & 007 & 1.7 & 02 & 01 & CRT & ANO & CMX & 1 & None \\
\hline 155 & 008 & 2.1 & 01 & 00 & $\overline{M S G}$ & ANO & BTF & 1 & None \\
\hline 155 & 009 & 3.1 & 04 & 00 & IND & ANO & CMX & 1 & None \\
\hline 155 & 010 & 3.2 & 02 & 00 & MSG & ANO & CMX & 1 & None \\
\hline 155 & 011 & 4.1 & 04 & 00 & MSG & ANO & CMX & 1 & None \\
\hline 155 & 012 & 5.1 & 04 & 00 & MSG & $\mathrm{AOB}$ & CMX & 1 & None \\
\hline 155 & 013 & 6.1 & 04 & 00 & FCT & $\mathrm{AOB}$ & CMX & 1 & None \\
\hline 155 & 014 & 6.2 & 04 & 00 & MSG & $\mathrm{AOB}$ & CMX & 1 & Potlid \\
\hline 155 & 015 & 6.3 & 04 & 00 & MFT & ANO & CMX & 1 & None \\
\hline 155 & 016 & 7.1 & 03 & 02 & CRT & ANO & SIM & 1 & None \\
\hline 155 & 017 & 7.2 & 04 & 00 & MSG & ANO & CMX & 1 & None \\
\hline 155 & 018 & 7.3 & 04 & 00 & $\overline{M S G}$ & ANO & CMX & 1 & None \\
\hline 155 & 019 & 8.1 & 04 & 00 & $\overline{M L T}$ & ANO & CMX & 1 & None \\
\hline 155 & 020 & 8.2 & 04 & 00 & MSG & ANO & CMX & 1 & None \\
\hline 155 & 021 & 9.1 & 04 & 00 & $\overline{M L T}$ & ANO & CMX & 1 & None \\
\hline 155 & 022 & 9.2 & 04 & 00 & FCT & ANO & CMX & 1 & None \\
\hline 155 & 023 & 9.3 & 04 & 01 & MLT & ANO & SIM & 1 & None \\
\hline 155 & 024 & 10.1 & 04 & 00 & FCT & ANO & $\mathrm{CMX}$ & 1 & None \\
\hline 155 & 025 & 10.2 & 04 & 03 & MSG & ANO & PRI & 1 & None \\
\hline 155 & 026 & 11.1 & 04 & 00 & FLA & ANO & CMX & 1 & None \\
\hline 155 & 027 & 11.2 & 04 & 00 & IND & ANO & CMX & 1 & None \\
\hline 155 & 028 & 11.3 & 04 & 00 & FCT & ANO & CMX & 1 & None \\
\hline 155 & 029 & 12.1 & 03 & 00 & IND & ANO & CMX & 1 & None \\
\hline 155 & 030 & 12.2 & 03 & 00 & MSG & ANO & CMX & 1 & None \\
\hline 155 & 031 & 12.3 & 04 & 00 & FLA & ANO & CMX & 1 & None \\
\hline 155 & 032 & 13.1 & 01 & 00 & MLT & ANO & BTF & 1 & None \\
\hline 155 & 033 & 14.1 & 02 & 00 & MSG & ANO & CMX & 1 & None \\
\hline 155 & 034 & 15.1 & 02 & 00 & MSG & ANO & CMX & 1 & None \\
\hline 155 & 035 & 15.2 & 04 & 03 & MSG & ANO & CMX & 1 & None \\
\hline 155 & 036 & 15.3 & 04 & 00 & MSG & ANO & CMX & 1 & None \\
\hline 155 & 037 & 16.1 & 03 & 00 & MSG & ANO & CMX & 1 & None \\
\hline 155 & 038 & 17.1 & 04 & 00 & CRT & ANO & CMX & 1 & None \\
\hline 155 & 039 & 18.1 & 01 & 01 & MLT & ANO & BTF & 1 & None \\
\hline 155 & 040 & 18.2 & 04 & 00 & FCT & ANO & CMX & 1 & None \\
\hline 155 & 041 & 19.1 & 03 & 04 & CRT & ANO & PRI & 1 & None \\
\hline 155 & 042 & 20.1 & 04 & 00 & MSG & ANO & CMX & 1 & None \\
\hline 155 & 043 & 21.1 & 04 & 02 & FCT & ANO & SIM & 1 & None \\
\hline 155 & 044 & 22.1 & 04 & 00 & MSG & ANO & CMX & 1 & None \\
\hline 155 & 045 & 23.1 & 04 & 00 & MSG & ANO & CMX & 1 & None \\
\hline 155 & 046 & 23.2 & 04 & 00 & MSG & ANO & CMX & 1 & None \\
\hline 155 & 047 & 23.3 & 04 & 00 & MSG & ANO & CMX & 1 & None \\
\hline 155 & 048 & 23.4 & 04 & 00 & MSG & ANO & $\mathrm{CMX}$ & 1 & None \\
\hline 155 & 049 & 24.1 & 03 & 00 & MSG & ANO & CMX & 1 & None \\
\hline 155 & 050 & 25.1 & 03 & 01 & MSG & ANO & CMX & 1 & None \\
\hline 155 & 051 & 26.1 & 04 & 00 & FCT & ANO & CMX & 1 & None \\
\hline 155 & 052 & 27.1 & 04 & 00 & MSG & ANO & $\mathrm{CMX}$ & 1 & None \\
\hline 155 & 053 & 28.1 & 02 & 00 & MSG & ANO & CMX & 1 & None \\
\hline 155 & 054 & 28.2 & 04 & 00 & FLA & ANO & CMX & 1 & None \\
\hline
\end{tabular}




\begin{tabular}{|c|c|c|c|c|c|c|c|c|c|}
\hline $\begin{array}{l}\text { Lot } \\
\text { No. }\end{array}$ & $\begin{array}{l}\text { Specimen } \\
\text { No. } \\
\end{array}$ & Nodule No. & $\begin{array}{l}\text { Flake } \\
\text { Size } \\
\end{array}$ & $\begin{array}{l}\text { Percent } \\
\text { Cortex } \\
\end{array}$ & $\begin{array}{l}\text { Platform } \\
\text { Type } \\
\end{array}$ & $\begin{array}{c}\text { Thermal } \\
\text { Alteration }\end{array}$ & $\begin{array}{c}\text { Technological } \\
\text { Class } \\
\end{array}$ & Count & Comments \\
\hline 155 & 055 & 28.3 & 04 & 04 & CRT & ANO & PRI & 1 & None \\
\hline 155 & 056 & 28.4 & 04 & 00 & CRT & ANO & SIM & 1 & None \\
\hline 155 & 057 & 28.5 & 04 & 00 & MLT & ANO & $\mathrm{CMX}$ & 1 & None \\
\hline 155 & 058 & 29.1 & 04 & 00 & MSG & ANO & CMX & 1 & None \\
\hline 155 & 059 & 30.1 & 04 & 00 & MSG & ANO & CMX & 1 & None \\
\hline 155 & 060 & 30.2 & 04 & 00 & MSG & ANO & CMX & 1 & None \\
\hline 155 & 061 & 31.1 & 04 & 00 & MSG & ANO & $\mathrm{CMX}$ & 1 & None \\
\hline 155 & 062 & 32.1 & 04 & 00 & CRT & ANO & $\mathrm{CMX}$ & 1 & None \\
\hline 155 & 063 & 33.1 & 04 & 00 & MSG & ANO & $\mathrm{CMX}$ & 1 & None \\
\hline 155 & 064 & 34.1 & 05 & 00 & MSG & ANO & SG4 & 1 & None \\
\hline 155 & 065 & 35.1 & 05 & 00 & MSG & ANO & SG4 & 1 & None \\
\hline 156 & 001 & 1.1 & 03 & 00 & MSG & ANO & $\mathrm{SHA}$ & 1 & None \\
\hline 156 & 002 & 2.1 & 03 & 00 & MSG & ANO & $\mathrm{CMX}$ & 1 & None \\
\hline 156 & 003 & 2.2 & 03 & 03 & CRT & ANO & PRI & 1 & None \\
\hline 156 & 004 & 3.1 & 01 & 00 & MSG & ANO & CMX & 1 & None \\
\hline 156 & 005 & 4.1 & 01 & 02 & FLA & ANO & SIM & 1 & None \\
\hline 156 & 006 & 4.2 & 03 & 00 & MSG & ANO & CMX & 1 & None \\
\hline 156 & 007 & 4.3 & 04 & 04 & MSG & ANO & CMX & 1 & None \\
\hline 156 & 008 & 4.4 & 04 & 00 & MSG & ANO & SHA & 1 & None \\
\hline 156 & 009 & 4.5 & 05 & 00 & MSG & ANO & SG4 & 1 & None \\
\hline 156 & 010 & 5.1 & 02 & 00 & MLT & ANO & BTF & 1 & None \\
\hline 156 & 011 & 6.1 & 02 & 00 & FLA & ANO & CMX & 1 & None \\
\hline 156 & 012 & 7.1 & 03 & 02 & MSG & ANO & SIM & 1 & None \\
\hline 156 & 013 & 7.2 & 03 & 00 & MLT & ANO & CMX & 1 & None \\
\hline 156 & 014 & 7.3 & 03 & 00 & MSG & ANO & CMX & 1 & None \\
\hline 156 & 015 & 7.4 & 03 & 00 & MSG & ANO & CMX & 1 & None \\
\hline 156 & 016 & 7.5 & 04 & 00 & MSG & ANO & CMX & 1 & None \\
\hline 156 & 017 & 7.6 & 04 & 00 & $\mathrm{MLT}$ & ANO & $\mathrm{CMX}$ & 1 & None \\
\hline 156 & 018 & 7.7 & 04 & 00 & MSG & ANO & CMX & 1 & None \\
\hline 156 & 019 & 7.8 & 05 & 00 & MSG & ANO & SG4 & 1 & None \\
\hline 156 & 020 & 8.1 & 01 & 02 & CRT & ANO & SIM & 1 & None \\
\hline 156 & 021 & 8.2 & 04 & 00 & FCT & ANO & $\mathrm{CMX}$ & 1 & None \\
\hline 156 & 022 & 9.1 & 04 & 00 & $\overline{M S G}$ & ANO & $\mathrm{CMX}$ & 1 & None \\
\hline 156 & 023 & 9.2 & 05 & 00 & MSG & ANO & SG4 & 1 & None \\
\hline 156 & 024 & 10.1 & 02 & 00 & MLT & ANO & $\mathrm{CMX}$ & 1 & None \\
\hline 156 & 025 & 10.2 & 03 & 00 & FCT & ANO & CMX & 1 & None \\
\hline 156 & 026 & 11.1 & 04 & 00 & MSG & ANO & CMX & 1 & None \\
\hline 156 & 027 & 11.2 & 04 & 00 & MSG & ANO & CMX & 1 & None \\
\hline 156 & 028 & 11.3 & 04 & 00 & MSG & ANO & CMX & 1 & None \\
\hline 156 & 029 & 11.4 & 04 & 00 & MSG & ANO & CMX & 1 & None \\
\hline 156 & 030 & 11.5 & 04 & 00 & MSG & ANO & $\overline{C M X}$ & 1 & None \\
\hline 156 & 031 & 11.6 & 04 & 00 & MSG & ANO & CMX & 1 & None \\
\hline 156 & 032 & 11.7 & 05 & 00 & MSG & ANO & SG4 & 1 & None \\
\hline 156 & 033 & 12.1 & 01 & 01 & CRT & ANO & CMX & 1 & None \\
\hline 156 & 034 & 12.2 & 02 & 00 & MLT & ANO & CMX & 1 & None \\
\hline 156 & 035 & 12.3 & 03 & 00 & FLA & ANO & $\overline{C M X}$ & 1 & None \\
\hline 156 & 036 & 13.1 & 04 & 00 & MSG & ANO & CMX & 1 & None \\
\hline 156 & 037 & 13.2 & 03 & 00 & FCT & ANO & CMX & 1 & None \\
\hline 156 & 038 & 14.1 & 03 & 00 & MSG & ANO & CMX & 1 & None \\
\hline 156 & 039 & 15.1 & 05 & 00 & MSG & ANO & SG4 & 1 & None \\
\hline 156 & 040 & 16.1 & 04 & 00 & MSG & ANO & CMX & 1 & None \\
\hline 156 & 041 & 17.1 & 04 & 00 & MSG & ANO & CMX & 1 & None \\
\hline 156 & 042 & 18.1 & 03 & 00 & FCT & ANO & CMX & 1 & None \\
\hline 156 & 043 & 19.1 & 04 & 00 & MSG & ANO & CMX & 1 & None \\
\hline 156 & 044 & 20.1 & 04 & 00 & MSG & ANO & CMX & 1 & None \\
\hline 156 & 045 & 21.1 & 03 & 00 & MSG & ANO & CMX & 1 & None \\
\hline 156 & 046 & 21.2 & 04 & 00 & MSG & ANO & $\mathrm{CMX}$ & 1 & None \\
\hline 156 & 047 & 21.3 & 04 & 00 & MSG & ANO & CMX & 1 & None \\
\hline 156 & 048 & 21.4 & 05 & 00 & MSG & ANO & SG4 & 1 & None \\
\hline 156 & 049 & 22.1 & 02 & 03 & CRT & ANO & SIM & 1 & None \\
\hline 156 & 050 & 23.1 & 02 & 01 & MSG & ANO & SIM & 1 & None \\
\hline 156 & 051 & 24.1 & 02 & 03 & MSG & ANO & SIM & 1 & None \\
\hline 156 & 052 & 25.1 & 02 & 03 & CRT & ANO & SIM & 1 & None \\
\hline 156 & 053 & 25.2 & 03 & 00 & MSG & ANO & CMX & 1 & None \\
\hline 156 & 054 & 26.1 & 03 & 00 & MSG & ANO & CMX & 1 & None \\
\hline 156 & 055 & 27.1 & 03 & 03 & MSG & $\mathrm{AOB}$ & SIM & 1 & None \\
\hline
\end{tabular}




\begin{tabular}{|c|c|c|c|c|c|c|c|c|c|}
\hline $\begin{array}{l}\text { Lot } \\
\text { No. }\end{array}$ & $\begin{array}{l}\text { Specimen } \\
\text { No. } \\
\end{array}$ & Nodule No. & $\begin{array}{l}\text { Flake } \\
\text { Size } \\
\end{array}$ & $\begin{array}{l}\text { Percent } \\
\text { Cortex } \\
\end{array}$ & $\begin{array}{l}\text { Platform } \\
\text { Type } \\
\end{array}$ & $\begin{array}{c}\text { Thermal } \\
\text { Alteration }\end{array}$ & $\begin{array}{c}\text { Technological } \\
\text { Class } \\
\end{array}$ & Count & Comments \\
\hline 156 & 056 & 27.2 & 02 & 02 & CRT & ANO & SIM & 1 & None \\
\hline 156 & 057 & 27.3 & 03 & 01 & MSG & ANO & SIM & 1 & None \\
\hline 156 & 058 & 27.4 & 03 & 00 & $\mathrm{MLT}$ & ANO & $\mathrm{CMX}$ & 1 & None \\
\hline 156 & 059 & 27.5 & 03 & 01 & CRT & ANO & CMX & 1 & None \\
\hline 156 & 060 & 27.6 & 03 & 00 & MSG & ANO & CMX & 1 & None \\
\hline 156 & 061 & 27.7 & 03 & 00 & MSG & ANO & CMX & 1 & None \\
\hline 156 & 062 & 27.8 & 04 & 00 & $\mathrm{MLT}$ & ANO & $\mathrm{CMX}$ & 1 & None \\
\hline 156 & 063 & 27.9 & 04 & 00 & MSG & ANO & $\mathrm{CMX}$ & 1 & None \\
\hline 156 & 064 & 27.10 & 04 & 00 & MSG & ANO & $\mathrm{CMX}$ & 1 & None \\
\hline 156 & 065 & 27.11 & 05 & 00 & MSG & ANO & SG5 & 1 & None \\
\hline 156 & 066 & 28.1 & 03 & 00 & MSG & $\mathrm{AOB}$ & SHA & 1 & None \\
\hline 156 & 067 & 29.1 & 01 & 04 & CRT & ANO & $\mathrm{PRI}$ & 1 & None \\
\hline 156 & 068 & 30.1 & 05 & 00 & MSG & ANO & SG4 & 1 & None \\
\hline 156 & 069 & 31.1 & 03 & 00 & $\overline{M S G}$ & ANO & $\mathrm{CMX}$ & 1 & None \\
\hline 156 & 070 & 32.1 & 03 & 00 & MSG & ANO & CMX & 1 & None \\
\hline 156 & 071 & 33.1 & 04 & 00 & MSG & ANO & CMX & 1 & None \\
\hline 156 & 072 & 34.1 & 03 & 00 & $\mathrm{MLT}$ & ANO & CMX & 1 & None \\
\hline 156 & 073 & 35.1 & 03 & 00 & MSG & ANO & CMX & 1 & None \\
\hline 156 & 074 & 36.1 & 03 & 00 & FCT & ANO & $\mathrm{CMX}$ & 1 & None \\
\hline 156 & 075 & 37.1 & 04 & 00 & MSG & ANO & CMX & 1 & None \\
\hline 156 & 076 & 38.1 & 03 & 00 & MSG & ANO & CMX & 1 & None \\
\hline 156 & 077 & 39.1 & 05 & 00 & MSG & ANO & SG4 & 1 & None \\
\hline 156 & 078 & 40.1 & 04 & 00 & MSG & ANO & CMX & 1 & None \\
\hline 156 & 079 & 40.2 & 04 & 00 & MSG & ANO & CMX & 1 & None \\
\hline 156 & 080 & 41.1 & 04 & 00 & MSG & ANO & CMX & 1 & None \\
\hline 156 & 081 & 41.2 & 03 & 01 & CRT & ANO & SIM & 1 & None \\
\hline 156 & 082 & 42.1 & 04 & 00 & $\overline{M S G}$ & ANO & CMX & 1 & None \\
\hline 156 & 083 & 43.1 & 04 & 00 & MSG & ANO & CMX & 1 & None \\
\hline 156 & 084 & 43.2 & 04 & 01 & MSG & ANO & CMX & 1 & None \\
\hline 156 & 085 & 43.3 & 04 & 00 & MSG & ANO & CMX & 1 & None \\
\hline 156 & 086 & 44.1 & 04 & 00 & MSG & ANO & CMX & 1 & None \\
\hline 156 & 087 & 44.2 & 04 & 00 & MSG & ANO & $\mathrm{CMX}$ & 1 & None \\
\hline 156 & 088 & 44.3 & 05 & 00 & $\overline{M S G}$ & ANO & SG4 & 1 & None \\
\hline 156 & 089 & 45.1 & 04 & 00 & MSG & ANO & CMX & 1 & None \\
\hline 156 & 090 & 46.1 & 04 & 00 & MSG & ANO & $\mathrm{CMX}$ & 1 & None \\
\hline 156 & 091 & 46.2 & 04 & 00 & MSG & ANO & CMX & 1 & None \\
\hline 156 & 092 & 46.3 & 04 & 00 & MSG & ANO & CMX & 1 & None \\
\hline 156 & 093 & 47.1 & 04 & 00 & $\overline{M S G}$ & ANO & $\mathrm{PRI}$ & 1 & None \\
\hline 156 & 094 & 47.2 & 04 & 00 & MSG & ANO & CMX & 1 & None \\
\hline 156 & 095 & 48.1 & 03 & 01 & CRT & ANO & SIM & 1 & None \\
\hline 156 & 096 & 48.2 & 03 & 00 & MSG & ANO & $\overline{C M X}$ & 1 & None \\
\hline 156 & 097 & 49.1 & 02 & 03 & MSG & ANO & $\mathrm{PRI}$ & 1 & None \\
\hline 156 & 098 & 49.2 & 04 & 00 & MSG & ANO & SIM & 1 & None \\
\hline 156 & 099 & 49.3 & 03 & 00 & MSG & ANO & SIM & 1 & None \\
\hline 156 & 100 & 50.1 & 04 & 00 & MSG & AOB & CMX & 1 & None \\
\hline 156 & 101 & 50.2 & 04 & 00 & MSG & ANO & $\overline{C M X}$ & 1 & None \\
\hline 156 & 102 & 51.1 & 01 & 01 & MSG & ANO & SIM & 1 & None \\
\hline 156 & 103 & 51.2 & 01 & 01 & MSG & ANO & SIM & 1 & None \\
\hline 156 & 104 & 51.3 & 03 & 00 & MSG & ANO & CMX & 1 & None \\
\hline 156 & 105 & 51.4 & 03 & 01 & MSG & ANO & SIM & 1 & None \\
\hline 156 & 106 & 51.5 & 03 & 00 & MSG & $\mathrm{AOB}$ & SHA & 1 & Potlid \\
\hline 156 & 107 & 51.6 & 02 & 03 & MSG & ANO & SIM & 1 & None \\
\hline 156 & 108 & 51.7 & 03 & 04 & FCT & ANO & PRI & 1 & None \\
\hline 156 & 109 & 51.8 & 04 & 00 & MSG & ANO & CMX & 1 & None \\
\hline 156 & 110 & 51.9 & 04 & 01 & CRT & ANO & CMX & 1 & None \\
\hline 156 & 111 & 51.10 & 04 & 00 & MSG & ANO & CMX & 1 & None \\
\hline 156 & 112 & 51.11 & 04 & 00 & MSG & ANO & $\mathrm{CMX}$ & 1 & None \\
\hline 156 & 113 & 51.12 & 04 & 00 & MSG & ANO & CMX & 1 & None \\
\hline 156 & 114 & 51.13 & 04 & 00 & MSG & ANO & CMX & 1 & None \\
\hline 156 & 115 & 51.14 & 04 & 00 & MSG & ANO & $\mathrm{CMX}$ & 1 & None \\
\hline 156 & 116 & 51.15 & 04 & 00 & MSG & ANO & CMX & 1 & None \\
\hline 156 & 117 & 52.1 & 04 & 00 & MSG & ANO & CMX & 1 & None \\
\hline 156 & 118 & 53.1 & 03 & 00 & MSG & ANO & CMX & 1 & None \\
\hline 156 & 119 & 53.2 & 04 & 00 & MSG & ANO & CMX & 1 & None \\
\hline 156 & 120 & 53.3 & 04 & 00 & MSG & ANO & CMX & 1 & None \\
\hline 156 & 121 & 54.1 & 04 & 00 & MSG & ANO & CMX & 1 & None \\
\hline
\end{tabular}




\begin{tabular}{|c|c|c|c|c|c|c|c|c|c|}
\hline $\begin{array}{l}\text { Lot } \\
\text { No. }\end{array}$ & $\begin{array}{l}\text { Specimen } \\
\text { No. } \\
\end{array}$ & Nodule No. & $\begin{array}{l}\text { Flake } \\
\text { Size } \\
\end{array}$ & $\begin{array}{l}\text { Percent } \\
\text { Cortex } \\
\end{array}$ & $\begin{array}{l}\text { Platform } \\
\text { Type } \\
\end{array}$ & $\begin{array}{c}\text { Thermal } \\
\text { Alteration }\end{array}$ & $\begin{array}{c}\text { Technological } \\
\text { Class } \\
\end{array}$ & Count & Comments \\
\hline 156 & 122 & 54.2 & 04 & 00 & MSG & ANO & $\mathrm{CMX}$ & 1 & None \\
\hline 156 & 123 & 54.3 & 04 & 00 & FLA & ANO & $\mathrm{CMX}$ & 1 & None \\
\hline 156 & 124 & 55.1 & 04 & 00 & FCT & ANO & $\mathrm{CMX}$ & 1 & None \\
\hline 156 & 125 & 55.2 & 04 & 00 & MSG & ANO & CMX & 1 & None \\
\hline 156 & 126 & 55.3 & 04 & 01 & MSG & ANO & SIM & 1 & None \\
\hline 156 & 127 & 56.1 & 03 & 00 & MSG & ANO & CMX & 1 & None \\
\hline 156 & 128 & 57.1 & 01 & 00 & CRT & ANO & SIM & 1 & None \\
\hline 156 & 129 & 57.2 & 04 & 00 & MSG & ANO & $\mathrm{CMX}$ & 1 & None \\
\hline 156 & 130 & 57.3 & 04 & 03 & MSG & ANO & CMX & 1 & None \\
\hline 156 & 131 & 57.4 & 04 & 01 & MSG & ANO & $\mathrm{CMX}$ & 1 & None \\
\hline 156 & 132 & 58.1 & 02 & 04 & FLA & ANO & $\mathrm{PRI}$ & 1 & None \\
\hline 156 & 133 & 58.2 & 03 & 01 & CRT & ANO & SIM & 1 & None \\
\hline 156 & 134 & 58.3 & 04 & 00 & MSG & ANO & $\mathrm{CMX}$ & 1 & None \\
\hline 156 & 135 & 59.1 & 02 & 01 & CRT & ANO & SIM & 1 & None \\
\hline 156 & 136 & 59.2 & 03 & 00 & MSG & ANO & CMX & 1 & None \\
\hline 156 & 137 & 59.3 & 04 & 00 & MSG & ANO & SHA & 1 & None \\
\hline 156 & 138 & 59.4 & 04 & 00 & MSG & ANO & CMX & 1 & None \\
\hline 156 & 139 & 59.5 & 04 & 00 & MSG & AOB & SHA & 1 & Potlid \\
\hline 156 & 140 & 59.6 & 04 & 00 & MSG & $\mathrm{AOB}$ & SHA & 1 & None \\
\hline 156 & 141 & 60.1 & 02 & 00 & MSG & ANO & CMX & 1 & None \\
\hline 156 & 142 & 60.2 & 02 & 01 & MSG & ANO & CMX & 1 & None \\
\hline 156 & 143 & 60.3 & 02 & 00 & MLT & ANO & BTF & 1 & None \\
\hline 156 & 144 & 60.4 & 04 & 00 & MSG & ANO & CMX & 1 & None \\
\hline 156 & 145 & 60.5 & 04 & 00 & MSG & ANO & CMX & 1 & None \\
\hline 156 & 146 & 60.6 & 04 & 00 & MSG & ANO & CMX & 1 & None \\
\hline 156 & 147 & 60.7 & 05 & 00 & MSG & ANO & SG4 & 1 & None \\
\hline 156 & 148 & 61.1 & 03 & 04 & MSG & ANO & PRI & 1 & None \\
\hline 156 & 149 & 61.2 & 04 & 04 & FCT & ANO & $\mathrm{PRI}$ & 1 & None \\
\hline 156 & 150 & 61.3 & 04 & 00 & MSG & ANO & CMX & 1 & None \\
\hline 156 & 151 & 62.1 & 04 & 00 & MSG & ANO & CMX & 1 & None \\
\hline 156 & 152 & 62.2 & 03 & 00 & MSG & ANO & CMX & 1 & None \\
\hline 156 & 153 & 63.1 & 04 & 00 & MSG & ANO & $\mathrm{CMX}$ & 1 & None \\
\hline 156 & 154 & 64.1 & 04 & 00 & FCT & ANO & $\mathrm{CMX}$ & 1 & None \\
\hline 156 & 155 & 65.1 & 02 & 00 & CRT & ANO & CMX & 1 & None \\
\hline 156 & 156 & 65.2 & 03 & 01 & CRT & $\mathrm{AOB}$ & SIM & 1 & None \\
\hline 156 & 157 & 65.3 & 04 & 00 & MSG & ANO & CMX & 1 & None \\
\hline 156 & 158 & 65.4 & 04 & 00 & MSG & ANO & CMX & 1 & None \\
\hline 156 & 159 & 65.5 & 04 & 00 & MSG & ANO & CMX & 1 & None \\
\hline 156 & 160 & 66.1 & 04 & 02 & MSG & ANO & SIM & 1 & None \\
\hline 156 & 161 & 66.2 & 04 & 00 & MSG & ANO & CMX & 1 & None \\
\hline 156 & 162 & 66.3 & 04 & 00 & MSG & ANO & $\overline{C M X}$ & 1 & None \\
\hline 156 & 163 & 66.4 & 04 & 00 & MSG & ANO & CMX & 1 & None \\
\hline 156 & 164 & 66.5 & 04 & 01 & MSG & ANO & CMX & 1 & None \\
\hline 156 & 165 & 66.6 & 05 & 00 & MSG & ANO & SG4 & 1 & None \\
\hline 156 & 166 & 67.1 & 03 & 00 & MSG & ANO & CMX & 1 & None \\
\hline 156 & 167 & 67.2 & 03 & 01 & MSG & ANO & $\mathrm{SHA}$ & 1 & None \\
\hline 156 & 168 & 68.1 & 04 & 00 & MSG & ANO & SG4 & 1 & None \\
\hline 156 & 169 & 69.1 & 05 & 00 & MSG & ANO & NA & 1 & None \\
\hline 156 & 170 & 69.2 & 05 & 00 & MSG & ANO & NA & 1 & None \\
\hline 156 & 171 & 70.1 & 04 & 05 & MSG & ANO & PRI & 1 & None \\
\hline 156 & 172 & 70.2 & 04 & 00 & MSG & ANO & CMX & 1 & None \\
\hline 156 & 173 & 70.3 & 04 & 00 & $\overline{M S G}$ & ANO & CMX & 1 & None \\
\hline 157 & 001 & 1.1 & 03 & 00 & MSG & ANO & SHA & 1 & None \\
\hline 157 & 002 & 2.1 & 01 & 00 & MLT & ANO & CMX & 1 & None \\
\hline 157 & 003 & 3.1 & 02 & 03 & MSG & AOS & SIM & 1 & None \\
\hline 157 & 004 & 4.1 & 04 & 00 & FLA & ANO & CMX & 1 & None \\
\hline 157 & 005 & 5.1 & 02 & 01 & MSG & ANO & SIM & 1 & None \\
\hline 157 & 006 & 6.1 & 04 & 00 & MSG & ANO & SG4 & 1 & None \\
\hline 157 & 007 & 7.1 & 04 & 00 & MSG & ANO & SG4 & 1 & None \\
\hline 157 & 008 & 8.1 & 04 & 00 & $\overline{M L T}$ & ANO & $\overline{C M X}$ & 1 & None \\
\hline 157 & 009 & 8.2 & 04 & 00 & MLT & ANO & CMX & 1 & None \\
\hline 157 & 010 & 8.3 & 04 & 00 & MLT & ANO & CMX & 1 & None \\
\hline 157 & 011 & 9.1 & 04 & 00 & MSG & ANO & CMX & 1 & None \\
\hline 157 & 012 & 9.2 & 03 & 00 & IND & ANO & CMX & 1 & None \\
\hline 157 & 013 & 10.1 & 02 & 00 & $\overline{M L T}$ & ANO & BTF & 1 & None \\
\hline 157 & 014 & 11.1 & 01 & 00 & MLT & ANO & BTF & 1 & None \\
\hline
\end{tabular}




\begin{tabular}{|c|c|c|c|c|c|c|c|c|c|}
\hline Lot & $\begin{array}{l}\text { Specimen } \\
\text { No. } \\
\end{array}$ & Nodule No. & $\begin{array}{l}\text { Flake } \\
\text { Size } \\
\end{array}$ & $\begin{array}{l}\text { Percent } \\
\text { Cortex } \\
\end{array}$ & $\begin{array}{l}\text { Platform } \\
\text { Type } \\
\end{array}$ & $\begin{array}{c}\text { Thermal } \\
\text { Alteration }\end{array}$ & $\begin{array}{c}\text { Technological } \\
\text { Class } \\
\end{array}$ & Count & Comments \\
\hline 157 & 015 & 12.1 & 04 & 00 & MLT & ANO & $\mathrm{CMX}$ & 1 & None \\
\hline 157 & 016 & 13.1 & 04 & 00 & MSG & ANO & SG4 & 1 & None \\
\hline 157 & 017 & 13.2 & 03 & 01 & MSG & ANO & $\mathrm{SHA}$ & 1 & None \\
\hline 157 & 018 & 13.3 & 01 & 01 & MSG & ANO & SIM & 1 & None \\
\hline 157 & 019 & 14.1 & 03 & 02 & MSG & ANO & SIM & 1 & None \\
\hline 157 & 020 & 14.2 & 04 & 00 & MLT & ANO & CMX & 1 & None \\
\hline 157 & 021 & 15.1 & 04 & 00 & MSG & ANO & $\mathrm{CMX}$ & 1 & None \\
\hline 157 & 022 & 16.1 & 04 & 04 & MSG & ANO & $\mathrm{PRI}$ & 1 & None \\
\hline 157 & 023 & 17.1 & 03 & 00 & MLT & ANO & CMX & 1 & None \\
\hline 158 & 001 & 1.1 & 01 & 00 & MLT & ANO & BTF & 1 & None \\
\hline 158 & 002 & 1.2 & 02 & 00 & MLT & ANO & $\mathrm{CMX}$ & 1 & None \\
\hline 158 & 003 & 2.1 & 01 & 02 & CRT & ANO & SIM & 1 & None \\
\hline 158 & 004 & 3.1 & 01 & 04 & CRT & ANO & SIM & 1 & None \\
\hline 158 & 005 & 3.2 & 02 & 00 & $\overline{M S G}$ & ANO & $\mathrm{CMX}$ & 1 & None \\
\hline 158 & 006 & 3.3 & 02 & 01 & FLA & ANO & SIM & 1 & None \\
\hline 158 & 007 & 4.1 & 02 & 00 & MLT & ANO & BTF & 1 & None \\
\hline 158 & 008 & 4.2 & 03 & 00 & MSG & ANO & CMX & 1 & None \\
\hline 158 & 009 & 5.1 & 02 & 01 & MSG & ANO & SIM & 1 & None \\
\hline 158 & 010 & 5.2 & 03 & 01 & FLA & ANO & SIM & 1 & None \\
\hline 158 & 011 & 6.1 & 03 & 01 & MSG & ANO & CMX & 1 & None \\
\hline 158 & 012 & 6.2 & 03 & 01 & CRT & ANO & SIM & 1 & None \\
\hline 158 & 013 & 6.3 & 03 & 04 & MSG & ANO & PRI & 1 & None \\
\hline 158 & 014 & 7.1 & 02 & 04 & MSG & ANO & PRI & 1 & None \\
\hline 158 & 015 & 7.2 & 03 & 00 & FLA & ANO & CMX & 1 & None \\
\hline 158 & 016 & 8.1 & 02 & 00 & MSG & ANO & $\mathrm{CMX}$ & 1 & None \\
\hline 158 & 017 & 8.2 & 03 & 00 & MSG & ANO & CMX & 1 & None \\
\hline 158 & 018 & 8.3 & 03 & 00 & MLT & ANO & BPF & 1 & None \\
\hline 158 & 019 & 9.1 & 02 & 00 & MLT & ANO & BTF & 1 & None \\
\hline 158 & 020 & 9.2 & 02 & 02 & FLA & ANO & SIM & 1 & None \\
\hline 158 & 021 & 10.1 & 02 & 00 & MLT & ANO & CMX & 1 & None \\
\hline 158 & 022 & 10.2 & 04 & 00 & $\overline{M L T}$ & ANO & CMX & 1 & None \\
\hline 158 & 023 & 10.3 & 04 & 00 & MSG & ANO & $\mathrm{CMX}$ & 1 & None \\
\hline 158 & 024 & 10.4 & 04 & 00 & $\overline{M S G}$ & ANO & $\mathrm{CMX}$ & 1 & None \\
\hline 158 & 025 & 10.5 & 05 & 00 & MSG & ANO & CMX & 1 & None \\
\hline 158 & 026 & 11.1 & 04 & 00 & MLT & ANO & $\mathrm{CMX}$ & 1 & None \\
\hline 158 & 027 & 11.2 & 04 & 00 & MSG & ANO & CMX & 1 & None \\
\hline 158 & 028 & 12.1 & 03 & 00 & MLT & ANO & BTF & 1 & None \\
\hline 158 & 029 & 12.2 & 04 & 00 & MSG & ANO & $\mathrm{CMX}$ & 1 & None \\
\hline 158 & 030 & 13.1 & 03 & 00 & MSG & ANO & $\mathrm{CMX}$ & 1 & None \\
\hline 158 & 031 & 13.2 & 03 & 00 & MSG & ANO & $\mathrm{CMX}$ & 1 & None \\
\hline 158 & 032 & 14.1 & 04 & 00 & MSG & ANO & $\overline{C M X}$ & 1 & None \\
\hline 158 & 033 & 14.2 & 04 & 00 & MSG & ANO & $\mathrm{CMX}$ & 1 & None \\
\hline 158 & 034 & 14.3 & 04 & 00 & MSG & ANO & $\mathrm{CMX}$ & 1 & None \\
\hline 158 & 035 & 14.4 & 04 & 00 & MSG & ANO & $\mathrm{CMX}$ & 1 & None \\
\hline 158 & 036 & 14.5 & 04 & 00 & MSG & ANO & CMX & 1 & None \\
\hline 158 & 037 & 14.6 & 04 & 00 & MSG & ANO & $\overline{C M X}$ & 1 & None \\
\hline 158 & 038 & 14.7 & 04 & 00 & MSG & ANO & $\mathrm{CMX}$ & 1 & None \\
\hline 158 & 039 & 15.1 & 03 & 02 & CRT & ANO & SIM & 1 & None \\
\hline 158 & 040 & 15.2 & 05 & $\mathrm{~N} / \mathrm{A}$ & $\mathrm{N} / \mathrm{A}$ & ANO & SIM & 1 & Not Analyzed \\
\hline 158 & 041 & 15.3 & 05 & $\mathrm{~N} / \mathrm{A}$ & $\mathrm{N} / \mathrm{A}$ & ANO & $\mathrm{N} / \mathrm{A}$ & 1 & Not Analyzed \\
\hline 158 & 042 & 16.1 & 02 & 00 & MSG & ANO & $\mathrm{CMX}$ & 1 & None \\
\hline 158 & 043 & 17.1 & 02 & 02 & FLA & ANO & SIM & 1 & None \\
\hline 158 & 044 & 18.1 & 02 & 00 & MLT & ANO & BTF & 1 & None \\
\hline 158 & 045 & 19.1 & 03 & 04 & MSG & ANO & $\mathrm{PRI}$ & 1 & None \\
\hline 158 & 046 & 19.2 & 05 & $\mathrm{~N} / \mathrm{A}$ & $\mathrm{N} / \mathrm{A}$ & ANO & $\mathrm{CMX}$ & 1 & Not Analyzed \\
\hline 158 & 047 & 19.3 & 04 & 00 & MSG & ANO & $\mathrm{CMX}$ & 1 & None \\
\hline 158 & 048 & 20.1 & 04 & 04 & MSG & ANO & SIM & 1 & None \\
\hline 158 & 049 & 20.2 & 05 & $\mathrm{~N} / \mathrm{A}$ & $\mathrm{N} / \mathrm{A}$ & ANO & $\mathrm{N} / \mathrm{A}$ & 1 & Not Analyzed \\
\hline 158 & 050 & 20.3 & 04 & 00 & MSG & ANO & $\mathrm{CMX}$ & 1 & None \\
\hline 158 & 051 & 20.4 & 05 & $\mathrm{~N} / \mathrm{A}$ & $\mathrm{N} / \mathrm{A}$ & ANO & $\mathrm{N} / \mathrm{A}$ & 1 & Not Analyzed \\
\hline 158 & 052 & 20.5 & 05 & $\mathrm{~N} / \mathrm{A}$ & $\mathrm{N} / \mathrm{A}$ & ANO & $\mathrm{N} / \mathrm{A}$ & 1 & Not Analyzed \\
\hline 158 & 053 & 20.6 & 05 & $\mathrm{~N} / \mathrm{A}$ & $\mathrm{N} / \mathrm{A}$ & ANO & N/A & 1 & Not Analyzed \\
\hline 158 & 054 & 21.1 & 04 & 00 & MSG & ANO & SIM & 1 & None \\
\hline 158 & 055 & 21.2 & 04 & 00 & MSG & ANO & CMX & 1 & None \\
\hline 158 & 056 & 22.1 & 03 & 00 & CRT & ANO & CMX & 1 & None \\
\hline 158 & 057 & 22.2 & 04 & 00 & MSG & ANO & CMX & 1 & None \\
\hline
\end{tabular}




\begin{tabular}{|c|c|c|c|c|c|c|c|c|c|}
\hline $\begin{array}{l}\text { Lot } \\
\text { No. }\end{array}$ & $\begin{array}{l}\text { Specimen } \\
\text { No. }\end{array}$ & Nodule No. & $\begin{array}{l}\text { Flake } \\
\text { Size } \\
\end{array}$ & $\begin{array}{l}\text { Percent } \\
\text { Cortex } \\
\end{array}$ & $\begin{array}{l}\text { Platform } \\
\text { Type } \\
\end{array}$ & $\begin{array}{c}\text { Thermal } \\
\text { Alteration }\end{array}$ & $\begin{array}{c}\text { Technological } \\
\text { Class }\end{array}$ & Count & Comments \\
\hline 158 & 058 & 23.1 & 04 & 00 & MSG & ANO & SIM & 1 & None \\
\hline 158 & 059 & 23.2 & 04 & 03 & MSG & ANO & $\mathrm{CMX}$ & 1 & None \\
\hline 158 & 060 & 23.3 & 05 & $\mathrm{~N} / \mathrm{A}$ & $\mathrm{N} / \mathrm{A}$ & ANO & $\mathrm{N} / \mathrm{A}$ & 1 & Not Analyzed \\
\hline 158 & 061 & 23.4 & 05 & $\mathrm{~N} / \mathrm{A}$ & $\mathrm{N} / \mathrm{A}$ & ANO & $\mathrm{N} / \mathrm{A}$ & 1 & Not Analyzed \\
\hline 158 & 062 & 24.1 & 04 & 00 & MSG & ANO & $\mathrm{CMX}$ & 1 & None \\
\hline 158 & 063 & 24.2 & 04 & 00 & MSG & ANO & PRI & 1 & None \\
\hline 158 & 064 & 25.1 & 03 & 00 & MSG & $\mathrm{AOB}$ & $\mathrm{SHA}$ & 1 & None \\
\hline 158 & 065 & 26.1 & 03 & 00 & MSG & ANO & CMX & 1 & None \\
\hline 158 & 066 & 26.2 & 05 & $\mathrm{~N} / \mathrm{A}$ & $\mathrm{N} / \mathrm{A}$ & ANO & $\mathrm{N} / \mathrm{A}$ & 1 & Not Analyzed \\
\hline 158 & 067 & 26.3 & 05 & $\mathrm{~N} / \mathrm{A}$ & $\mathrm{N} / \mathrm{A}$ & ANO & $\mathrm{N} / \mathrm{A}$ & 1 & Not Analyzed \\
\hline 158 & 068 & 27.1 & 04 & 00 & MSG & ANO & CMX & 1 & None \\
\hline 158 & 069 & 27.2 & 05 & $\mathrm{~N} / \mathrm{A}$ & $\mathrm{N} / \mathrm{A}$ & ANO & $\mathrm{N} / \mathrm{A}$ & 1 & Not Analyzed \\
\hline 158 & 070 & 28.1 & 04 & 00 & MSG & ANO & $\mathrm{CMX}$ & 1 & None \\
\hline 158 & 071 & 29.1 & 04 & 00 & MSG & ANO & $\mathrm{CMX}$ & 1 & None \\
\hline 158 & 072 & 30.1 & 04 & 00 & MSG & ANO & CMX & 1 & None \\
\hline 158 & 073 & 31.1 & 04 & 00 & MSG & ANO & CMX & 1 & None \\
\hline 158 & 074 & 32.1 & 04 & 00 & MSG & ANO & $\mathrm{CMX}$ & 1 & None \\
\hline 158 & 075 & 32.2 & 05 & $\mathrm{~N} / \mathrm{A}$ & $\mathrm{N} / \mathrm{A}$ & ANO & $\mathrm{N} / \mathrm{A}$ & 1 & Not Analyzed \\
\hline 158 & 076 & 32.3 & 05 & $\mathrm{~N} / \mathrm{A}$ & $\mathrm{N} / \mathrm{A}$ & ANO & $\mathrm{N} / \mathrm{A}$ & 1 & Not Analyzed \\
\hline 158 & 077 & 33.1 & 05 & $\mathrm{~N} / \mathrm{A}$ & $\mathrm{N} / \mathrm{A}$ & ANO & $\mathrm{N} / \mathrm{A}$ & 1 & Not Analyzed \\
\hline 158 & 078 & 34.1 & 05 & $\mathrm{~N} / \mathrm{A}$ & $\mathrm{N} / \mathrm{A}$ & ANO & $\mathrm{N} / \mathrm{A}$ & 1 & Not Analyzed \\
\hline 158 & 079 & 35.1 & 05 & $\mathrm{~N} / \mathrm{A}$ & $\mathrm{N} / \mathrm{A}$ & ANO & $\mathrm{N} / \mathrm{A}$ & 1 & Not Analyzed \\
\hline 158 & 080 & 36.1 & 04 & 00 & MSG & ANO & $\mathrm{CMX}$ & 1 & None \\
\hline 158 & 081 & 37.1 & 05 & $\mathrm{~N} / \mathrm{A}$ & $\mathrm{N} / \mathrm{A}$ & ANO & $\mathrm{N} / \mathrm{A}$ & 1 & Not Analyzed \\
\hline 158 & 082 & 37.2 & 05 & $\mathrm{~N} / \mathrm{A}$ & $\mathrm{N} / \mathrm{A}$ & ANO & $\mathrm{N} / \mathrm{A}$ & 1 & Not Analyzed \\
\hline 158 & 083 & 38.1 & 05 & $\mathrm{~N} / \mathrm{A}$ & $\mathrm{N} / \mathrm{A}$ & ANO & $\mathrm{N} / \mathrm{A}$ & 1 & Not Analyzed \\
\hline 158 & 084 & 39.1 & 05 & $\mathrm{~N} / \mathrm{A}$ & $\mathrm{N} / \mathrm{A}$ & ANO & $\mathrm{N} / \mathrm{A}$ & 1 & Not Analyzed \\
\hline 159 & 001 & 1.1 & 01 & 00 & FLA & ANO & CMX & 1 & None \\
\hline 159 & 002 & 1.2 & 01 & 03 & MSG & ANO & SIM & 1 & None \\
\hline 159 & 003 & 1.3 & 01 & 02 & CRT & ANO & SIM & 1 & None \\
\hline 159 & 004 & 2.1 & 01 & 04 & MSG & ANO & SIM & 1 & None \\
\hline 159 & 005 & 2.2 & 04 & 00 & MSG & ANO & SG4 & 1 & None \\
\hline 159 & 006 & 3.1 & 01 & 04 & MSG & ANO & PRI & 1 & None \\
\hline 159 & 007 & 4.1 & 03 & 04 & CRT & ANO & PRI & 1 & None \\
\hline 159 & 008 & 4.2 & 02 & 02 & MSG & ANO & SIM & 1 & None \\
\hline 159 & 009 & 5.1 & 01 & 00 & FLA & ANO & CMX & 1 & None \\
\hline 159 & 010 & 6.1 & 01 & 02 & MSG & ANO & SIM & 1 & None \\
\hline 159 & 011 & 6.2 & 03 & 00 & MLT & ANO & CMX & 1 & None \\
\hline 159 & 012 & 7.1 & 01 & 04 & FLA & ANO & $\mathrm{CMX}$ & 1 & None \\
\hline 159 & 013 & 8.1 & 01 & 00 & MSG & ANO & CMX & 1 & None \\
\hline 159 & 014 & 8.2 & 04 & 00 & $\mathrm{MLT}$ & ANO & $\mathrm{CMX}$ & 1 & None \\
\hline 159 & 015 & 9.1 & 01 & 00 & MSG & ANO & BTF & 1 & None \\
\hline 159 & 016 & 10.1 & 01 & 01 & FLA & ANO & SIM & 1 & None \\
\hline 159 & 017 & 10.2 & 01 & 02 & MLT & ANO & BTF & 1 & None \\
\hline 159 & 018 & 11.1 & 03 & 00 & MSG & ANO & SHA & 1 & None \\
\hline 159 & 019 & 11.2 & 03 & 02 & MSG & ANO & SIM & 1 & None \\
\hline 159 & 020 & 12.1 & 01 & 00 & $\mathrm{MLT}$ & ANO & BTF & 1 & None \\
\hline 159 & 021 & 13.1 & 01 & 00 & FCT & ANO & CMX & 1 & None \\
\hline 159 & 022 & 14.1 & 01 & 00 & MSG & ANO & BTF & 1 & None \\
\hline 159 & 023 & 14.2 & 03 & 00 & MSG & ANO & $\mathrm{CMX}$ & 1 & None \\
\hline 159 & 024 & 15.1 & 01 & 00 & FLA & ANO & $\mathrm{CMX}$ & 1 & None \\
\hline 159 & 025 & 16.1 & 01 & 00 & MSG & ANO & BTF & 1 & None \\
\hline 159 & 026 & 17.1 & 03 & 00 & CRT & ANO & CMX & 1 & None \\
\hline 159 & 027 & 18.1 & 01 & 02 & MSG & ANO & SIM & 1 & None \\
\hline 159 & 028 & 19.1 & 02 & 00 & MSG & ANO & CMX & 1 & None \\
\hline 159 & 029 & 20.1 & 01 & 00 & MSG & ANO & $\mathrm{CMX}$ & 1 & None \\
\hline 159 & 030 & 20.2 & 04 & 00 & MSG & ANO & CMX & 1 & None \\
\hline 159 & 031 & 21.1 & 04 & 00 & BPF & ANO & CMX & 1 & None \\
\hline 159 & 032 & 21.2 & 04 & 00 & BPF & ANO & CMX & 1 & None \\
\hline 159 & 033 & 21.3 & 04 & 00 & MSG & ANO & $\mathrm{CMX}$ & 1 & None \\
\hline 159 & 034 & 21.4 & 04 & 00 & MSG & ANO & CMX & 1 & None \\
\hline 159 & 035 & 21.5 & 04 & 00 & BPF & ANO & CMX & 1 & None \\
\hline 159 & 036 & 21.6 & 04 & 00 & MSG & ANO & CMX & 1 & None \\
\hline 159 & 037 & 22.1 & 01 & 02 & CRT & ANO & SIM & 1 & None \\
\hline 159 & 038 & 22.2 & 03 & 00 & MSG & ANO & $\overline{C M X}$ & 1 & None \\
\hline 159 & 039 & 23.1 & 02 & 00 & MSG & ANO & CMX & 1 & None \\
\hline
\end{tabular}




\begin{tabular}{|c|c|c|c|c|c|c|c|c|c|}
\hline Lot & $\begin{array}{l}\text { Specimen } \\
\text { No. } \\
\end{array}$ & Nodule No. & $\begin{array}{l}\text { Flake } \\
\text { Size } \\
\end{array}$ & $\begin{array}{l}\text { Percent } \\
\text { Cortex } \\
\end{array}$ & $\begin{array}{l}\text { Platform } \\
\text { Type } \\
\end{array}$ & $\begin{array}{c}\text { Thermal } \\
\text { Alteration }\end{array}$ & $\begin{array}{c}\text { Technological } \\
\text { Class } \\
\end{array}$ & Count & Comments \\
\hline 159 & 040 & 23.2 & 02 & 00 & MSG & ANO & BTF & 1 & None \\
\hline 159 & 041 & 24.1 & 02 & 00 & $\mathrm{MLT}$ & ANO & $\mathrm{CMX}$ & 1 & None \\
\hline 159 & 042 & 24.2 & 04 & 00 & MSG & ANO & $\mathrm{CMX}$ & 1 & None \\
\hline 159 & 043 & 25.1 & 03 & 03 & MSG & ANO & SIM & 1 & None \\
\hline 159 & 044 & 25.2 & 04 & 00 & MSG & ANO & $\mathrm{CMX}$ & 1 & None \\
\hline 159 & 045 & 25.3 & 05 & 00 & MSG & ANO & CMX & 1 & None \\
\hline 159 & 046 & 26.1 & 03 & 00 & MSG & ANO & $\mathrm{CMX}$ & 1 & None \\
\hline 159 & 047 & 26.2 & 03 & 00 & MLT & ANO & $\mathrm{CMX}$ & 1 & None \\
\hline 159 & 048 & 27.1 & 02 & 00 & MSG & ANO & $\mathrm{CMX}$ & 1 & None \\
\hline 159 & 049 & 28.1 & 02 & 00 & MSG & ANO & $\mathrm{CMX}$ & 1 & None \\
\hline 159 & 050 & 28.2 & 03 & 00 & MSG & ANO & $\mathrm{CMX}$ & 1 & None \\
\hline 159 & 051 & 29.1 & 01 & 00 & $\mathrm{MLT}$ & ANO & $\mathrm{CMX}$ & 1 & None \\
\hline 159 & 052 & 30.1 & 03 & 00 & MSG & ANO & $\mathrm{CMX}$ & 1 & None \\
\hline 159 & 053 & 31.1 & 03 & 00 & $\overline{M S G}$ & ANO & $\mathrm{CMX}$ & 1 & None \\
\hline 159 & 054 & 31.2 & 03 & 00 & FCT & ANO & CMX & 1 & None \\
\hline 159 & 055 & 31.3 & 04 & 00 & CRT & ANO & CMX & 1 & None \\
\hline 159 & 056 & 32.1 & 02 & 00 & FLA & ANO & CMX & 1 & None \\
\hline 159 & 057 & 32.2 & 04 & 00 & MSG & ANO & CMX & 1 & None \\
\hline 159 & 058 & 33.1 & 03 & 00 & CRT & ANO & $\mathrm{CMX}$ & 1 & None \\
\hline 159 & 059 & 33.2 & 03 & 00 & MSG & ANO & SIM & 1 & None \\
\hline 159 & 060 & 34.1 & 03 & 00 & FCT & ANO & CMX & 1 & None \\
\hline 159 & 061 & 35.1 & 03 & 00 & MSG & ANO & CMX & 1 & None \\
\hline 159 & 062 & 36.1 & 03 & 00 & MSG & ANO & CMX & 1 & None \\
\hline 159 & 063 & 37.1 & 04 & 00 & MSG & ANO & CMX & 1 & None \\
\hline 159 & 064 & 37.2 & 04 & 00 & MSG & ANO & CMX & 1 & None \\
\hline 159 & 065 & 38.1 & 02 & 00 & MSG & ANO & CMX & 1 & None \\
\hline 159 & 066 & 38.2 & 04 & 00 & MSG & ANO & CMX & 1 & None \\
\hline 159 & 067 & 39.1 & 04 & 00 & MLT & ANO & CMX & 1 & None \\
\hline 159 & 068 & 40.1 & 04 & 00 & MSG & ANO & CMX & 1 & None \\
\hline 159 & 069 & 41.1 & 04 & 00 & MSG & ANO & CMX & 1 & None \\
\hline 159 & 070 & 42.1 & 04 & 00 & MSG & ANO & CMX & 1 & None \\
\hline 159 & 071 & 42.2 & 04 & 00 & MSG & ANO & $\mathrm{CMX}$ & 1 & None \\
\hline 159 & 072 & 43.1 & 04 & 02 & $\overline{M S G}$ & ANO & $\mathrm{SHA}$ & 1 & None \\
\hline 159 & 073 & 43.2 & 04 & 00 & MSG & ANO & CMX & 1 & None \\
\hline 159 & 074 & 43.3 & 05 & 00 & MSG & ANO & $\mathrm{CMX}$ & 1 & None \\
\hline 159 & 075 & 44.1 & 04 & 00 & FCT & ANO & CMX & 1 & None \\
\hline 159 & 076 & 44.2 & 05 & 00 & MSG & ANO & CMX & 1 & None \\
\hline 159 & 077 & 44.3 & 05 & 00 & CRT & ANO & CMX & 1 & None \\
\hline 159 & 078 & 45.1 & 04 & 00 & MSG & ANO & CMX & 1 & None \\
\hline 159 & 079 & 45.2 & 04 & 00 & FCT & ANO & CMX & 1 & None \\
\hline 159 & 080 & 46.1 & 04 & 00 & MSG & ANO & $\overline{C M X}$ & 1 & None \\
\hline 159 & 081 & 46.2 & 04 & 00 & MSG & ANO & CMX & 1 & None \\
\hline 159 & 082 & 47.1 & 04 & 00 & MLT & ANO & BPF & 1 & None \\
\hline 159 & 083 & 48.1 & 04 & 00 & MSG & ANO & CMX & 1 & None \\
\hline 159 & 084 & 48.2 & 04 & 00 & MSG & ANO & CMX & 1 & None \\
\hline 159 & 085 & 49.1 & 04 & 00 & MSG & ANO & CMX & 1 & None \\
\hline 159 & 086 & 50.1 & 04 & 00 & MSG & ANO & CMX & 1 & None \\
\hline 159 & 087 & 50.2 & 04 & 00 & MSG & ANO & CMX & 1 & None \\
\hline 159 & 088 & 51.1 & 04 & 00 & MSG & ANO & CMX & 1 & None \\
\hline 159 & 089 & 52.1 & 04 & 00 & MSG & ANO & CMX & 1 & None \\
\hline 159 & 090 & 52.2 & 05 & 00 & MSG & ANO & CMX & 1 & None \\
\hline 159 & 091 & 53.1 & 03 & 00 & MSG & ANO & CMX & 1 & None \\
\hline 159 & 092 & 54.1 & 04 & 00 & MSG & ANO & CMX & 1 & None \\
\hline 159 & 093 & 54.2 & 04 & 00 & MSG & ANO & CMX & 1 & None \\
\hline 159 & 094 & 55.1 & 04 & 00 & MLT & ANO & CMX & 1 & None \\
\hline 159 & 095 & 56.1 & 04 & 00 & MSG & ANO & CMX & 1 & None \\
\hline 159 & 096 & 57.1 & 04 & 00 & MSG & ANO & $\mathrm{CMX}$ & 1 & None \\
\hline 159 & 097 & 58.1 & 04 & 00 & MSG & ANO & CMX & 1 & None \\
\hline 159 & 098 & 59.1 & 04 & 00 & MSG & ANO & CMX & 1 & None \\
\hline 159 & 099 & 60.1 & 04 & 00 & MSG & ANO & CMX & 1 & None \\
\hline 159 & 100 & 61.1 & 04 & 00 & MSG & ANO & CMX & 1 & None \\
\hline 159 & 101 & 62.1 & 05 & 00 & MSG & ANO & CMX & 1 & None \\
\hline 160 & 001 & 1.1 & 02 & 00 & MLT & ANO & SIM & 1 & None \\
\hline 160 & 002 & 2.1 & 01 & 02 & CRT & ANO & SIM & 1 & None \\
\hline 160 & 003 & 3.1 & 01 & 00 & $\overline{M L T}$ & ANO & BTF & 1 & None \\
\hline 160 & 004 & 3.2 & 02 & 02 & MSG & ANO & SIM & 1 & None \\
\hline
\end{tabular}




\begin{tabular}{|c|c|c|c|c|c|c|c|c|c|}
\hline $\begin{array}{l}\text { Lot } \\
\text { No. }\end{array}$ & $\begin{array}{l}\text { Specimen } \\
\text { No. }\end{array}$ & Nodule No. & $\begin{array}{l}\text { Flake } \\
\text { Size }\end{array}$ & $\begin{array}{l}\text { Percent } \\
\text { Cortex }\end{array}$ & $\begin{array}{l}\text { Platform } \\
\text { Type }\end{array}$ & $\begin{array}{l}\text { Thermal } \\
\text { Alteration }\end{array}$ & $\begin{array}{c}\text { Technological } \\
\text { Class }\end{array}$ & Count & Comments \\
\hline 160 & 005 & 3.3 & 03 & 00 & MSG & $\mathrm{AOB}$ & SHA & 1 & None \\
\hline 160 & 006 & 4.1 & 01 & 00 & $\overline{M L T}$ & ANO & BTF & 1 & None \\
\hline 160 & 007 & 4.2 & 04 & 00 & FLA & ANO & $\mathrm{CMX}$ & 1 & None \\
\hline 160 & 008 & 4.3 & 04 & 00 & MSG & ANO & $\mathrm{CMX}$ & 1 & None \\
\hline 160 & 009 & 4.4 & 04 & 03 & MSG & ANO & SIM & 1 & None \\
\hline 160 & 010 & 4.5 & 05 & 00 & MSG & ANO & SG4 & 4 & None \\
\hline 160 & 011 & 5.1 & 04 & 00 & MSG & ANO & CMX & 1 & None \\
\hline 160 & 012 & 6.1 & 01 & 00 & FLA & ANO & CMX & 1 & None \\
\hline 160 & 013 & 6.2 & 01 & 00 & MSG & ANO & $\mathrm{CMX}$ & 1 & None \\
\hline 160 & 014 & 6.3 & 04 & 00 & MSG & ANO & $\overline{C M X}$ & 1 & None \\
\hline 160 & 015 & 7.1 & 04 & 00 & MLT & ANO & $\mathrm{CMX}$ & 1 & None \\
\hline 160 & 016 & 7.2 & 04 & 00 & MSG & ANO & $\mathrm{CMX}$ & 1 & None \\
\hline 160 & 017 & 7.3 & 04 & 00 & MSG & ANO & CMX & 1 & None \\
\hline 160 & 018 & 8.1 & 04 & 00 & MSG & ANO & CMX & 1 & None \\
\hline 160 & 019 & 9.1 & 04 & 00 & $\overline{M S G}$ & ANO & $\overline{C M X}$ & 1 & None \\
\hline 160 & 020 & 10.1 & 04 & 00 & $\overline{M S G}$ & ANO & BPF & 1 & None \\
\hline 160 & 021 & 10.2 & 04 & 00 & MSG & ANO & CMX & 1 & None \\
\hline 160 & 022 & 10.3 & 04 & 00 & $\overline{M S G}$ & AOB & $\mathrm{SHA}$ & 1 & None \\
\hline 160 & 023 & 10.4 & 04 & 00 & MSG & ANO & CMX & 1 & None \\
\hline 160 & 024 & 10.5 & 04 & 00 & MSG & ANO & CMX & 1 & None \\
\hline 160 & 025 & 11.1 & 03 & 01 & FLA & ANO & SIM & 1 & None \\
\hline 160 & 026 & 12.1 & 01 & 04 & FCT & ANO & SIM & 1 & None \\
\hline 160 & 027 & 13.1 & 01 & 00 & MSG & ANO & CMX & 1 & None \\
\hline 160 & 028 & 14.1 & 04 & 00 & $\overline{M S G}$ & ANO & CMX & 1 & None \\
\hline 160 & 029 & 14.2 & 04 & 00 & MSG & ANO & SIM & 1 & None \\
\hline 160 & 030 & 15.1 & 01 & 01 & FLA & ANO & CMX & 1 & None \\
\hline 160 & 031 & 15.2 & 01 & 00 & FLA & ANO & CMX & 1 & None \\
\hline 160 & 032 & 16.1 & 01 & 00 & MSG & ANO & CMX & 1 & None \\
\hline 160 & 033 & 17.1 & 01 & 01 & $\overline{M S G}$ & ANO & SIM & 1 & None \\
\hline 160 & 034 & 17.2 & 04 & 00 & CRT & ANO & CMX & 1 & None \\
\hline 160 & 035 & 18.1 & 01 & 00 & FLA & ANO & $\overline{C M X}$ & 1 & None \\
\hline 160 & 036 & 18.2 & 02 & 00 & FLA & ANO & CMX & 1 & None \\
\hline 160 & 037 & 18.3 & 01 & 01 & CRT & ANO & SIM & 1 & None \\
\hline 160 & 038 & 18.4 & 04 & 00 & $\overline{\mathrm{CRT}}$ & ANO & $\overline{C M X}$ & 1 & None \\
\hline 160 & 039 & 19.1 & 03 & 00 & FLA & ANO & $\mathrm{CMX}$ & 1 & None \\
\hline 160 & 040 & 19.2 & 03 & 00 & MSG & ANO & CMX & 1 & None \\
\hline 160 & 041 & 19.3 & 03 & 02 & CRT & ANO & SIM & 1 & None \\
\hline 160 & 042 & 20.1 & 04 & 00 & MSG & ANO & CMX & 1 & None \\
\hline 160 & 043 & 20.2 & 04 & 02 & MSG & ANO & SIM & 1 & None \\
\hline 160 & 044 & 20.3 & 05 & 00 & MSG & ANO & $\mathrm{CMX}$ & 1 & None \\
\hline 160 & 045 & 21.1 & 03 & 00 & MSG & ANO & CMX & 1 & None \\
\hline 160 & 046 & 21.2 & 04 & 00 & $\overline{M S G}$ & ANO & $\mathrm{CMX}$ & 1 & None \\
\hline 160 & 047 & 22.1 & 03 & 00 & MLT & ANO & $\mathrm{CMX}$ & 1 & None \\
\hline 160 & 048 & 22.2 & 04 & 00 & MSG & ANO & CMX & 1 & None \\
\hline 160 & 049 & 23.1 & 01 & 00 & CRT & ANO & $\mathrm{CMX}$ & 1 & None \\
\hline 160 & 050 & 23.2 & 04 & 00 & MSG & ANO & $\mathrm{CMX}$ & 1 & None \\
\hline 160 & 051 & 23.3 & 04 & 00 & MSG & ANO & SHA & 1 & None \\
\hline 160 & 052 & 23.4 & 05 & $\mathrm{~N} / \mathrm{A}$ & $\mathrm{N} / \mathrm{A}$ & ANO & $\mathrm{N} / \mathrm{A}$ & 1 & Not Analyzed \\
\hline 160 & 053 & 24.1 & 02 & 00 & MLT & ANO & BTF & 1 & None \\
\hline 160 & 054 & 24.2 & 04 & 00 & MLT & ANO & BTF & 1 & None \\
\hline 160 & 055 & 24.3 & 04 & 00 & MSG & ANO & CMX & 1 & None \\
\hline 160 & 056 & 24.4 & 04 & 00 & MSG & ANO & CMX & 1 & None \\
\hline 160 & 057 & 24.5 & 04 & 00 & MSG & ANO & $\overline{C M X}$ & 1 & None \\
\hline 160 & 058 & 24.6 & 04 & 00 & MSG & ANO & CMX & $\frac{1}{1}$ & None \\
\hline 160 & 059 & 24.7 & 04 & 00 & MSG & ANO & $\mathrm{CMX}$ & 1 & None \\
\hline 160 & 060 & 24.8 & 04 & 00 & MSG & ANO & CMX & 1 & None \\
\hline 160 & 061 & 24.9 & 04 & 00 & MSG & ANO & CMX & 1 & None \\
\hline 160 & 062 & 24.10 & 05 & $\mathrm{~N} / \mathrm{A}$ & $\mathrm{N} / \mathrm{A}$ & ANO & $\mathrm{N} / \mathrm{A}$ & 1 & Not Analyzed \\
\hline 160 & 063 & 25.1 & 04 & 00 & MSG & ANO & CMX & 1 & None \\
\hline 160 & 064 & 25.2 & 04 & 00 & MSG & ANO & $\overline{C M X}$ & 1 & None \\
\hline 160 & 065 & 25.3 & 04 & 00 & MSG & ANO & CMX & 1 & None \\
\hline 160 & 066 & 25.4 & 05 & $\mathrm{~N} / \mathrm{A}$ & $\mathrm{N} / \mathrm{A}$ & ANO & $\mathrm{N} / \mathrm{A}$ & 1 & Not Analyzed \\
\hline 160 & 067 & 26.1 & 03 & 00 & MSG & ANO & CMX & 1 & None \\
\hline 160 & 068 & 26.2 & 03 & 02 & MSG & ANO & $\mathrm{CMX}$ & 1 & None \\
\hline 160 & 069 & 27.1 & 03 & 00 & CRT & ANO & CMX & 1 & None \\
\hline 160 & 070 & 27.2 & 04 & 00 & MSG & ANO & CMX & 1 & None \\
\hline
\end{tabular}




\begin{tabular}{|c|c|c|c|c|c|c|c|c|c|}
\hline $\begin{array}{l}\text { Lot } \\
\text { No. }\end{array}$ & $\begin{array}{l}\text { Specimen } \\
\text { No. }\end{array}$ & Nodule No. & $\begin{array}{l}\text { Flake } \\
\text { Size }\end{array}$ & $\begin{array}{l}\text { Percent } \\
\text { Cortex }\end{array}$ & $\begin{array}{l}\text { Platform } \\
\text { Type }\end{array}$ & $\begin{array}{l}\text { Thermal } \\
\text { Alteration }\end{array}$ & $\begin{array}{c}\text { Technological } \\
\text { Class }\end{array}$ & Count & Comments \\
\hline 160 & 071 & 27.3 & 04 & 00 & MSG & ANO & CMX & 1 & None \\
\hline 160 & 072 & 27.4 & 04 & 00 & MSG & ANO & $\mathrm{CMX}$ & 1 & None \\
\hline 160 & 073 & 27.5 & 05 & $\mathrm{~N} / \mathrm{A}$ & $\mathrm{N} / \mathrm{A}$ & ANO & $\mathrm{N} / \mathrm{A}$ & 1 & Not Analyzed \\
\hline 160 & 074 & 28.1 & 04 & 00 & MSG & ANO & $\mathrm{CMX}$ & 1 & None \\
\hline 160 & 075 & 28.2 & 04 & 03 & MSG & ANO & SIM & 1 & None \\
\hline 160 & 076 & 28.3 & 05 & $\mathrm{~N} / \mathrm{A}$ & $\mathrm{N} / \mathrm{A}$ & ANO & $\mathrm{N} / \mathrm{A}$ & 1 & Not Analyzed \\
\hline 160 & 077 & 29.1 & 04 & 00 & MSG & ANO & CMX & 1 & None \\
\hline 160 & 078 & 29.2 & 03 & 00 & MSG & $\mathrm{AOB}$ & $\mathrm{SHA}$ & 1 & None \\
\hline 160 & 079 & 29.3 & 04 & 00 & MSG & ANO & CMX & 1 & None \\
\hline 160 & 080 & 30.1 & 03 & 01 & CRT & ANO & SIM & 1 & None \\
\hline 160 & 081 & 31.1 & 05 & $\mathrm{~N} / \mathrm{A}$ & $\mathrm{N} / \mathrm{A}$ & ANO & $\mathrm{N} / \mathrm{A}$ & 1 & Not Analyzed \\
\hline 160 & 082 & 31.2 & 05 & $\mathrm{~N} / \mathrm{A}$ & $\mathrm{N} / \mathrm{A}$ & ANO & $\mathrm{N} / \mathrm{A}$ & 1 & Not Analyzed \\
\hline 160 & 083 & 31.3 & 05 & $\mathrm{~N} / \mathrm{A}$ & $\mathrm{N} / \mathrm{A}$ & ANO & $\mathrm{N} / \mathrm{A}$ & 1 & Not Analyzed \\
\hline 160 & 084 & 32.1 & 04 & 00 & MSG & ANO & $\mathrm{CMX}$ & 1 & None \\
\hline 161 & 001 & 1.1 & 04 & 03 & CRT & ANO & SIM & 1 & None \\
\hline 161 & 002 & 2.1 & 05 & $\mathrm{~N} / \mathrm{A}$ & $\mathrm{N} / \mathrm{A}$ & ANO & $\mathrm{N} / \mathrm{A}$ & 1 & Not Analyzed \\
\hline 161 & 003 & 2.2 & 05 & $\mathrm{~N} / \mathrm{A}$ & $\mathrm{N} / \mathrm{A}$ & ANO & $\mathrm{N} / \mathrm{A}$ & 1 & Not Analyzed \\
\hline 161 & 004 & 3.1 & 02 & 00 & MSG & ANO & $\mathrm{CMX}$ & 1 & None \\
\hline 161 & 005 & 4.1 & 04 & 00 & $\mathrm{MLT}$ & ANO & $\mathrm{CMX}$ & 1 & None \\
\hline 161 & 006 & 4.2 & 05 & $\mathrm{~N} / \mathrm{A}$ & $\mathrm{N} / \mathrm{A}$ & ANO & $\mathrm{N} / \mathrm{A}$ & 1 & Not Analyzed \\
\hline 161 & 007 & 5.1 & 05 & N/A & $\mathrm{N} / \mathrm{A}$ & ANO & $\mathrm{N} / \mathrm{A}$ & 1 & Not Analyzed \\
\hline 161 & 008 & 6.1 & 05 & $\mathrm{~N} / \mathrm{A}$ & N/A & ANO & $\mathrm{N} / \mathrm{A}$ & 1 & Not Analyzed \\
\hline 161 & 009 & 7.1 & 05 & $\mathrm{~N} / \mathrm{A}$ & $\mathrm{N} / \mathrm{A}$ & ANO & $\mathrm{N} / \mathrm{A}$ & 1 & Not Analyzed \\
\hline 161 & 010 & 7.2 & 05 & $\mathrm{~N} / \mathrm{A}$ & $\mathrm{N} / \mathrm{A}$ & ANO & $\mathrm{N} / \mathrm{A}$ & 1 & Not Analyzed \\
\hline 161 & 011 & 8.1 & 05 & $\mathrm{~N} / \mathrm{A}$ & $\mathrm{N} / \mathrm{A}$ & ANO & $\mathrm{N} / \mathrm{A}$ & 1 & Not Analyzed \\
\hline 161 & 012 & 9.1 & 05 & $\mathrm{~N} / \mathrm{A}$ & $\mathrm{N} / \mathrm{A}$ & ANO & $\mathrm{N} / \mathrm{A}$ & 1 & Not Analyzed \\
\hline 161 & 013 & 10.1 & 04 & 00 & MSG & ANO & CMX & 1 & None \\
\hline 161 & 014 & 11.1 & 02 & 00 & FCT & ANO & CMX & 1 & None \\
\hline 161 & 015 & 12.1 & 05 & $\mathrm{~N} / \mathrm{A}$ & $\mathrm{N} / \mathrm{A}$ & ANO & $\mathrm{N} / \mathrm{A}$ & 1 & Not Analyzed \\
\hline 161 & 016 & 13.1 & 05 & $\mathrm{~N} / \mathrm{A}$ & $\mathrm{N} / \mathrm{A}$ & ANO & $\mathrm{N} / \mathrm{A}$ & 1 & Not Analyzed \\
\hline 161 & 017 & 14.1 & 05 & $\mathrm{~N} / \mathrm{A}$ & $\mathrm{N} / \mathrm{A}$ & ANO & $\mathrm{N} / \mathrm{A}$ & 1 & Not Analyzed \\
\hline 161 & 018 & 15.1 & 04 & 00 & MSG & ANO & $\mathrm{CMX}$ & 1 & None \\
\hline 161 & 019 & 15.2 & 05 & $\mathrm{~N} / \mathrm{A}$ & $\mathrm{N} / \mathrm{A}$ & ANO & $\mathrm{N} / \mathrm{A}$ & 1 & Not Analyzed \\
\hline 161 & 020 & 16.1 & 05 & $\mathrm{~N} / \mathrm{A}$ & $\mathrm{N} / \mathrm{A}$ & ANO & $\mathrm{N} / \mathrm{A}$ & 1 & Not Analyzed \\
\hline 161 & 021 & 17.1 & 05 & $\mathrm{~N} / \mathrm{A}$ & $\mathrm{N} / \mathrm{A}$ & ANO & $\mathrm{N} / \mathrm{A}$ & 1 & Not Analyzed \\
\hline 161 & 022 & 18.1 & 04 & 00 & MSG & ANO & CMX & 1 & None \\
\hline 161 & 023 & 19.1 & 05 & $\mathrm{~N} / \mathrm{A}$ & N/A & ANO & $\mathrm{N} / \mathrm{A}$ & 1 & Not Analyzed \\
\hline 161 & 024 & 20.1 & 03 & 00 & MSG & ANO & $\mathrm{CMX}$ & 1 & None \\
\hline 161 & 025 & 21.1 & 05 & $\mathrm{~N} / \mathrm{A}$ & N/A & ANO & $\mathrm{N} / \mathrm{A}$ & 1 & Not Analyzed \\
\hline 161 & 026 & 22.1 & 04 & 00 & MLT & ANO & $\mathrm{BPF}$ & 1 & None \\
\hline 161 & 027 & 22.2 & 04 & 00 & MSG & ANO & $\mathrm{CMX}$ & 1 & None \\
\hline 161 & 028 & 22.3 & 05 & $\mathrm{~N} / \mathrm{A}$ & $\mathrm{N} / \mathrm{A}$ & ANO & $\mathrm{N} / \mathrm{A}$ & 1 & Not Analyzed \\
\hline 161 & 029 & 23.1 & 04 & 00 & FLA & ANO & CMX & 1 & None \\
\hline 162 & 001 & 1.1 & 04 & 00 & $\mathrm{MLT}$ & ANO & BPF & 1 & None \\
\hline 162 & 002 & 2.1 & 04 & 00 & MSG & ANO & SIM & 1 & None \\
\hline 162 & 003 & 3.1 & 05 & 00 & MSG & ANO & $\overline{C M X}$ & 1 & None \\
\hline 162 & 004 & 3.2 & 03 & 00 & FCT & ANO & CMX & 1 & None \\
\hline 162 & 005 & 4.1 & 03 & 00 & MSG & ANO & CMX & 1 & None \\
\hline 162 & 006 & 4.2 & 05 & 00 & MSG & ANO & CMX & 1 & None \\
\hline 162 & 007 & 5.1 & 03 & 00 & MSG & ANO & $\mathrm{CMX}$ & 1 & None \\
\hline 162 & 008 & 6.1 & 02 & 00 & MSG & ANO & CMX & 1 & None \\
\hline 162 & 009 & 6.2 & 04 & 00 & MSG & ANO & $\mathrm{CMX}$ & 1 & None \\
\hline 162 & 010 & 7.1 & 05 & 00 & MSG & ANO & CMX & 1 & None \\
\hline 162 & 011 & 8.1 & 04 & 00 & MSG & ANO & CMX & 1 & None \\
\hline 162 & 012 & 9.1 & 02 & 04 & MSG & $\mathrm{AOB}$ & SHA & 1 & None \\
\hline 162 & 013 & 9.2 & 04 & 00 & MSG & $\mathrm{AOB}$ & SHA & 1 & Potlid \\
\hline 162 & 014 & 10.1 & 01 & 02 & CRT & ANO & SIM & 1 & None \\
\hline 162 & 015 & 10.2 & 03 & 00 & CRT & ANO & CMX & 1 & None \\
\hline 162 & 016 & 11.1 & 04 & 00 & MSG & $\mathrm{AOB}$ & $\mathrm{SHA}$ & 1 & None \\
\hline 162 & 017 & 12.1 & 03 & 00 & MSG & ANO & $\mathrm{CMX}$ & 1 & None \\
\hline 162 & 018 & 12.2 & 04 & 00 & MSG & ANO & CMX & 1 & None \\
\hline 162 & 019 & 13.1 & 05 & 00 & MSG & ANO & CMX & 1 & None \\
\hline 162 & 020 & 14.1 & 04 & 00 & MSG & ANO & CMX & 1 & None \\
\hline 162 & 021 & 15.1 & 04 & 00 & MSG & ANO & CMX & 1 & None \\
\hline 162 & 022 & 16.1 & 04 & 00 & MSG & ANO & $\mathrm{SHA}$ & 1 & None \\
\hline 162 & 023 & 16.2 & 04 & 00 & MSG & $\mathrm{AOB}$ & SHA & 1 & None \\
\hline
\end{tabular}




\begin{tabular}{|c|c|c|c|c|c|c|c|c|c|}
\hline $\begin{array}{l}\text { Lot } \\
\text { No. }\end{array}$ & $\begin{array}{l}\text { Specimen } \\
\text { No. }\end{array}$ & Nodule No. & $\begin{array}{l}\text { Flake } \\
\text { Size }\end{array}$ & $\begin{array}{l}\text { Percent } \\
\text { Cortex }\end{array}$ & $\begin{array}{l}\text { Platform } \\
\text { Type }\end{array}$ & $\begin{array}{l}\text { Thermal } \\
\text { Alteration }\end{array}$ & $\begin{array}{c}\text { Technological } \\
\text { Class }\end{array}$ & Count & Comments \\
\hline 162 & 024 & 17.1 & 02 & 01 & $\mathrm{FCT}$ & ANO & SIM & 1 & None \\
\hline 162 & 025 & 18.1 & 02 & 02 & MSG & ANO & SIM & 1 & None \\
\hline 163 & 001 & 1.1 & 01 & 00 & FCT & ANO & $\mathrm{CMX}$ & 1 & None \\
\hline 163 & 002 & 1.2 & 01 & 01 & $\mathrm{MLT}$ & ANO & SIM & 1 & None \\
\hline 163 & 003 & 2.1 & 01 & 01 & MSG & ANO & SIM & 1 & None \\
\hline 163 & 004 & 2.2 & 04 & 00 & MLT & ANO & CMX & 1 & None \\
\hline 163 & 005 & 2.3 & 04 & 00 & MSG & ANO & $\mathrm{CMX}$ & 1 & None \\
\hline 163 & 006 & 3.1 & 01 & 01 & CRT & ANO & SIM & 1 & None \\
\hline 163 & 007 & 4.1 & 01 & 04 & FLA & ANO & PRI & 1 & None \\
\hline 163 & 008 & 5.1 & 01 & 04 & MSG & ANO & PRI & 1 & None \\
\hline 163 & 009 & 6.1 & 01 & 00 & FLA & ANO & $\mathrm{CMX}$ & 1 & None \\
\hline 163 & 010 & 6.2 & 04 & 01 & CRT & ANO & SIM & 1 & None \\
\hline 163 & 011 & 6.3 & 04 & 00 & MSG & ANO & CMX & 1 & None \\
\hline 163 & 012 & 7.1 & 01 & 00 & MSG & ANO & CMX & 1 & None \\
\hline 163 & 013 & 7.2 & 02 & 00 & $\overline{\text { CRT }}$ & ANO & $\overline{C M X}$ & 1 & None \\
\hline 163 & 014 & 7.3 & 03 & 00 & FLA & ANO & $\mathrm{CMX}$ & 1 & None \\
\hline 163 & 015 & 7.4 & 03 & 00 & MSG & ANO & CMX & 1 & None \\
\hline 163 & 016 & 7.5 & 03 & 00 & $\mathrm{MLT}$ & ANO & $\mathrm{CMX}$ & 1 & None \\
\hline 163 & 017 & 7.6 & 04 & 00 & MSG & ANO & CMX & 1 & None \\
\hline 163 & 018 & 7.7 & 04 & 00 & MSG & ANO & $\mathrm{CMX}$ & 1 & None \\
\hline 163 & 019 & 7.8 & 05 & $\mathrm{~N} / \mathrm{A}$ & $\mathrm{N} / \mathrm{A}$ & ANO & $\mathrm{N} / \mathrm{A}$ & 1 & Not Analyzed \\
\hline 163 & 020 & 8.1 & 02 & 00 & MSG & ANO & CMX & 1 & None \\
\hline 163 & 021 & 9.1 & 01 & 00 & MSG & ANO & CMX & 1 & None \\
\hline 163 & 022 & 10.1 & 02 & 00 & FLA & ANO & $\mathrm{CMX}$ & 1 & None \\
\hline 163 & 023 & 11.1 & 03 & 00 & MSG & ANO & CMX & 1 & None \\
\hline 163 & 024 & 11.2 & 03 & 00 & MSG & ANO & $\mathrm{CMX}$ & 1 & None \\
\hline 163 & 025 & 12.1 & 04 & 00 & MSG & ANO & CMX & 1 & None \\
\hline 163 & 026 & 13.1 & 04 & 00 & MSG & ANO & CMX & 1 & None \\
\hline 163 & 027 & 14.1 & 02 & 01 & MSG & ANO & SIM & 1 & None \\
\hline 163 & 028 & 15.1 & 01 & 00 & MSG & ANO & CMX & 1 & None \\
\hline 163 & 029 & 15.2 & 02 & 00 & $\overline{F C T}$ & ANO & CMX & 1 & None \\
\hline 163 & 030 & 15.3 & 04 & 00 & MSG & ANO & CMX & 1 & None \\
\hline 163 & 031 & 15.4 & 04 & 00 & MSG & ANO & CMX & 1 & None \\
\hline 163 & 032 & 15.5 & 04 & 00 & MSG & ANO & $\mathrm{CMX}$ & 1 & None \\
\hline 163 & 033 & 15.6 & 05 & N/A & $\mathrm{N} / \mathrm{A}$ & ANO & $\mathrm{N} / \mathrm{A}$ & 1 & Not Analyzed \\
\hline 163 & 034 & 16.1 & 03 & 00 & MSG & ANO & CMX & 1 & None \\
\hline 163 & 035 & 16.2 & 03 & 00 & MLT & ANO & CMX & 1 & None \\
\hline 163 & 036 & 17.1 & 03 & 02 & MSG & ANO & $\mathrm{SHA}$ & 1 & None \\
\hline 163 & 037 & 18.1 & 01 & 00 & FCT & ANO & $\mathrm{CMX}$ & 1 & None \\
\hline 163 & 038 & 18.2 & 05 & $\mathrm{~N} / \mathrm{A}$ & $\mathrm{N} / \mathrm{A}$ & ANO & $\mathrm{N} / \mathrm{A}$ & 1 & Not Analyzed \\
\hline 163 & 039 & 19.1 & 04 & 00 & MSG & ANO & CMX & 1 & None \\
\hline 163 & 040 & 19.2 & 05 & $\mathrm{~N} / \mathrm{A}$ & $\mathrm{N} / \mathrm{A}$ & ANO & $\mathrm{N} / \mathrm{A}$ & 1 & Not Analyzed \\
\hline 163 & 041 & 20.1 & 04 & $\mathrm{~N} / \mathrm{A}$ & $\mathrm{N} / \mathrm{A}$ & ANO & $\mathrm{N} / \mathrm{A}$ & 1 & Not Analyzed \\
\hline 163 & 042 & 21.1 & 02 & 00 & $\mathrm{MLT}$ & ANO & CMX & 1 & None \\
\hline 163 & 043 & 21.2 & 04 & 00 & MSG & ANO & CMX & 1 & None \\
\hline 163 & 044 & 22.1 & 02 & 00 & MSG & ANO & BTF & 1 & None \\
\hline 163 & 045 & 22.2 & 04 & 00 & MSG & ANO & CMX & 1 & None \\
\hline 163 & 046 & 23.1 & 02 & 00 & $\mathrm{MLT}$ & ANO & BTF & 1 & None \\
\hline 163 & 047 & 24.1 & 02 & 02 & MLT & ANO & SIM & 1 & None \\
\hline 163 & 048 & 24.2 & 03 & 00 & MLT & ANO & CMX & 1 & None \\
\hline 163 & 049 & 25.1 & 03 & 00 & MSG & ANO & CMX & 1 & None \\
\hline 163 & 050 & 26.1 & 02 & 00 & MSG & ANO & $\mathrm{CMX}$ & 1 & None \\
\hline 163 & 051 & 26.2 & 04 & 00 & MSG & ANO & $\overline{C M X}$ & 1 & None \\
\hline 163 & 052 & 27.1 & 04 & 00 & $\mathrm{MLT}$ & ANO & CMX & 1 & None \\
\hline 163 & 053 & 27.2 & 04 & 00 & MSG & ANO & CMX & 1 & None \\
\hline 163 & 054 & 27.3 & 04 & 00 & MSG & ANO & CMX & 1 & None \\
\hline 163 & 055 & 28.1 & 04 & 00 & MSG & ANO & CMX & 1 & None \\
\hline 163 & 056 & 28.2 & 04 & 00 & $\overline{F C T}$ & ANO & CMX & 1 & None \\
\hline 163 & 057 & 28.3 & 05 & $\mathrm{~N} / \mathrm{A}$ & $\mathrm{N} / \mathrm{A}$ & ANO & $\mathrm{N} / \mathrm{A}$ & 1 & Not Analyzed \\
\hline 163 & 058 & 29.1 & 03 & 00 & MSG & ANO & CMX & 1 & None \\
\hline 163 & 059 & 30.1 & 04 & 00 & MSG & ANO & $\mathrm{CMX}$ & 1 & None \\
\hline 163 & 060 & 31.1 & 05 & $\mathrm{~N} / \mathrm{A}$ & $\mathrm{N} / \mathrm{A}$ & ANO & $\mathrm{N} / \mathrm{A}$ & 1 & Not Analyzed \\
\hline 163 & 061 & 32.1 & 04 & 00 & MSG & ANO & CMX & 1 & None \\
\hline 163 & 062 & 33.1 & 04 & 00 & MSG & ANO & CMX & 1 & None \\
\hline 163 & 063 & 34.1 & 05 & $\mathrm{~N} / \mathrm{A}$ & $\mathrm{N} / \mathrm{A}$ & ANO & $\mathrm{N} / \mathrm{A}$ & 1 & Not Analyzed \\
\hline 163 & 064 & 35.1 & 04 & 00 & MSG & ANO & CMX & 1 & None \\
\hline
\end{tabular}




\begin{tabular}{|c|c|c|c|c|c|c|c|c|c|}
\hline Lot & $\begin{array}{l}\text { Specimen } \\
\text { No. } \\
\end{array}$ & Nodule No. & $\begin{array}{l}\text { Flake } \\
\text { Size } \\
\end{array}$ & $\begin{array}{l}\text { Percent } \\
\text { Cortex } \\
\end{array}$ & $\begin{array}{l}\text { Platform } \\
\text { Type } \\
\end{array}$ & $\begin{array}{c}\text { Thermal } \\
\text { Alteration }\end{array}$ & $\begin{array}{c}\text { Technological } \\
\text { Class } \\
\end{array}$ & Count & Comments \\
\hline 163 & 065 & 35.2 & 04 & 00 & MSG & ANO & $\mathrm{CMX}$ & 1 & None \\
\hline 163 & 066 & 36.1 & 04 & 00 & MSG & ANO & $\mathrm{CMX}$ & 1 & None \\
\hline 163 & 067 & 37.1 & 04 & 00 & MSG & ANO & $\mathrm{SHA}$ & 1 & None \\
\hline 163 & 068 & 38.1 & 05 & $\mathrm{~N} / \mathrm{A}$ & $\mathrm{N} / \mathrm{A}$ & ANO & $\mathrm{N} / \mathrm{A}$ & 1 & Not Analyzed \\
\hline 163 & 069 & 38.2 & 05 & $\mathrm{~N} / \mathrm{A}$ & $\mathrm{N} / \mathrm{A}$ & ANO & $\mathrm{N} / \mathrm{A}$ & 1 & Not Analyzed \\
\hline 163 & 070 & 39.1 & 03 & 00 & MSG & ANO & CMX & 1 & None \\
\hline 163 & 071 & 39.2 & 04 & 00 & MSG & ANO & $\mathrm{CMX}$ & 1 & None \\
\hline 163 & 072 & 40.1 & 05 & $\mathrm{~N} / \mathrm{A}$ & $\mathrm{N} / \mathrm{A}$ & ANO & $\mathrm{N} / \mathrm{A}$ & 1 & Not Analyzed \\
\hline 163 & 073 & 41.1 & 05 & $\mathrm{~N} / \mathrm{A}$ & $\mathrm{N} / \mathrm{A}$ & ANO & $\mathrm{N} / \mathrm{A}$ & 1 & Not Analyzed \\
\hline 163 & 074 & 42.1 & 04 & 00 & MSG & ANO & CMX & 1 & None \\
\hline 163 & 075 & 42.2 & 04 & 00 & MSG & ANO & $\mathrm{CMX}$ & 1 & None \\
\hline 163 & 076 & 43.1 & 05 & $\mathrm{~N} / \mathrm{A}$ & $\mathrm{N} / \mathrm{A}$ & ANO & $\mathrm{N} / \mathrm{A}$ & 1 & Not Analyzed \\
\hline 164 & 001 & 1.1 & 01 & 00 & MLT & ANO & BTF & 1 & None \\
\hline 164 & 002 & 1.2 & 03 & 00 & $\overline{M S G}$ & ANO & $\mathrm{CMX}$ & 1 & None \\
\hline 164 & 003 & 2.1 & 04 & 00 & MSG & ANO & $\mathrm{CMX}$ & 1 & None \\
\hline 164 & 004 & 3.1 & 04 & 04 & MSG & ANO & $\mathrm{PRI}$ & 1 & None \\
\hline 164 & 005 & 4.1 & 04 & 00 & MSG & ANO & $\mathrm{CMX}$ & 1 & None \\
\hline 164 & 006 & 4.2 & 04 & 00 & MSG & ANO & $\mathrm{CMX}$ & 1 & None \\
\hline 164 & 007 & 4.3 & 04 & 00 & MSG & ANO & $\mathrm{CMX}$ & 1 & None \\
\hline 164 & 008 & 5.1 & 02 & 04 & MSG & ANO & $\mathrm{PRI}$ & 1 & None \\
\hline 164 & 009 & 6.1 & 04 & 00 & MLT & ANO & BPF & 1 & None \\
\hline 164 & 010 & 7.1 & 02 & 00 & FCT & ANO & $\mathrm{CMX}$ & 1 & None \\
\hline 164 & 011 & 8.1 & 04 & 00 & MSG & ANO & CMX & 1 & None \\
\hline 164 & 012 & 9.1 & 04 & 00 & MSG & ANO & $\mathrm{CMX}$ & 1 & None \\
\hline 164 & 013 & 9.2 & 04 & 00 & MSG & ANO & CMX & 1 & None \\
\hline 164 & 014 & 10.1 & 04 & 00 & MSG & ANO & CMX & 1 & None \\
\hline 164 & 015 & 11.1 & 05 & 00 & MSG & ANO & CMX & 1 & None \\
\hline 164 & 016 & 12.1 & 04 & 00 & MSG & ANO & CMX & 1 & None \\
\hline 164 & 017 & 12.2 & 04 & 00 & MSG & ANO & CMX & 1 & None \\
\hline 164 & 018 & 13.1 & 04 & 00 & MSG & ANO & CMX & 1 & None \\
\hline 164 & 019 & 13.2 & 04 & 00 & MSG & ANO & $\mathrm{SHA}$ & 1 & None \\
\hline 164 & 020 & 13.3 & 04 & 00 & MSG & ANO & $\mathrm{CMX}$ & 1 & None \\
\hline 164 & 021 & 13.4 & 04 & 00 & $\overline{M S G}$ & ANO & $\mathrm{CMX}$ & 1 & None \\
\hline 164 & 022 & 14.1 & 03 & 00 & CRT & ANO & CMX & 1 & None \\
\hline 164 & 023 & 15.1 & 04 & 00 & CRT & ANO & CMX & 1 & None \\
\hline 164 & 024 & 15.2 & 03 & 04 & MSG & ANO & PRI & 1 & None \\
\hline 164 & 025 & 15.3 & 04 & 00 & MSG & ANO & BPF & 1 & None \\
\hline 164 & 026 & 16.1 & 02 & 00 & MSG & ANO & $\mathrm{CMX}$ & 1 & None \\
\hline 164 & 027 & 17.1 & 02 & 00 & MLT & ANO & CMX & 1 & None \\
\hline 164 & 028 & 17.2 & 04 & 00 & MSG & $\mathrm{AOB}$ & CMX & 1 & None \\
\hline 164 & 029 & 18.1 & 01 & 04 & MSG & ANO & PRI & 1 & None \\
\hline 164 & 030 & 18.2 & 01 & 00 & MSG & ANO & CMX & 1 & None \\
\hline 164 & 031 & 18.3 & 02 & 00 & MSG & ANO & CMX & 1 & None \\
\hline 164 & 032 & 18.4 & 02 & 00 & MLT & ANO & CMX & 1 & None \\
\hline 164 & 033 & 18.5 & 04 & 00 & MSG & ANO & CMX & 1 & None \\
\hline 164 & 034 & 19.1 & 04 & 00 & MSG & ANO & $\overline{C M X}$ & 1 & None \\
\hline 164 & 035 & 19.2 & 05 & 00 & MSG & ANO & CMX & 1 & None \\
\hline 165 & 001 & 1.1 & 01 & 04 & MLT & ANO & $\mathrm{PRI}$ & 1 & None \\
\hline 165 & 002 & 2.1 & 03 & 04 & MSG & ANO & PRI & 1 & None \\
\hline 165 & 003 & 2.2 & 03 & 00 & MLT & ANO & CMX & 1 & None \\
\hline 165 & 004 & 3.1 & 01 & 02 & FLA & ANO & SIM & 1 & None \\
\hline 165 & 005 & 4.1 & 03 & 00 & $\overline{M L T}$ & ANO & CMX & 1 & None \\
\hline 165 & 006 & 5.1 & 03 & 01 & FLA & ANO & CMX & 1 & None \\
\hline 165 & 007 & 6.1 & 04 & 00 & MSG & ANO & CMX & 1 & None \\
\hline 165 & 008 & 6.2 & 02 & 00 & MLT & ANO & SIM & 1 & None \\
\hline 165 & 009 & 7.1 & 03 & 00 & MLT & ANO & CMX & 1 & None \\
\hline 165 & 010 & 8.1 & 04 & 00 & MSG & ANO & SHA & 1 & None \\
\hline 165 & 011 & 8.2 & 03 & 00 & $\mathrm{MLT}$ & ANO & CMX & 1 & None \\
\hline 165 & 012 & 9.1 & 02 & 00 & MLT & ANO & CMX & 1 & None \\
\hline 165 & 013 & 10.1 & 01 & 04 & FCT & ANO & PRI & 1 & None \\
\hline 165 & 014 & 11.1 & 03 & 01 & MSG & ANO & SHA & 1 & None \\
\hline 165 & 015 & 12.1 & 03 & 01 & IND & ANO & SIM & 1 & None \\
\hline 165 & 016 & 12.2 & 03 & 02 & MSG & ANO & SIM & 1 & None \\
\hline 165 & 017 & 13.1 & 03 & 00 & MSG & ANO & CMX & 1 & None \\
\hline 165 & 018 & 14.1 & 03 & 03 & MSG & ANO & SIM & 1 & None \\
\hline 165 & 019 & 15.1 & 01 & 00 & MSG & ANO & CMX & 1 & None \\
\hline
\end{tabular}




\begin{tabular}{|c|c|c|c|c|c|c|c|c|c|}
\hline $\begin{array}{l}\text { Lot } \\
\text { No. }\end{array}$ & $\begin{array}{l}\text { Specimen } \\
\text { No. } \\
\end{array}$ & Nodule No. & $\begin{array}{l}\text { Flake } \\
\text { Size }\end{array}$ & $\begin{array}{l}\text { Percent } \\
\text { Cortex } \\
\end{array}$ & $\begin{array}{l}\text { Platform } \\
\text { Type } \\
\end{array}$ & $\begin{array}{c}\text { Thermal } \\
\text { Alteration }\end{array}$ & $\begin{array}{c}\text { Technological } \\
\text { Class } \\
\end{array}$ & Count & Comments \\
\hline 165 & 020 & 16.1 & 01 & 01 & MLT & ANO & SIM & 1 & None \\
\hline 165 & 021 & 17.1 & 01 & 01 & CRT & ANO & SIM & 1 & None \\
\hline 166 & 001 & 1.1 & 05 & $\mathrm{~N} / \mathrm{A}$ & $\mathrm{N} / \mathrm{A}$ & ANO & $\mathrm{N} / \mathrm{A}$ & 1 & Not Analyzed \\
\hline 166 & 002 & 2.1 & 05 & $\mathrm{~N} / \mathrm{A}$ & $\mathrm{N} / \mathrm{A}$ & ANO & $\mathrm{N} / \mathrm{A}$ & 1 & Not Analyzed \\
\hline 166 & 003 & 3.1 & 05 & $\mathrm{~N} / \mathrm{A}$ & $\mathrm{N} / \mathrm{A}$ & ANO & $\mathrm{N} / \mathrm{A}$ & 1 & Not Analyzed \\
\hline 166 & 004 & 4.1 & 05 & $\mathrm{~N} / \mathrm{A}$ & $\mathrm{N} / \mathrm{A}$ & ANO & $\mathrm{N} / \mathrm{A}$ & 1 & Not Analyzed \\
\hline 166 & 005 & 5.1 & 05 & $\mathrm{~N} / \mathrm{A}$ & $\mathrm{N} / \mathrm{A}$ & ANO & $\mathrm{N} / \mathrm{A}$ & 1 & Not Analyzed \\
\hline 166 & 006 & 6.1 & 05 & $\mathrm{~N} / \mathrm{A}$ & $\mathrm{N} / \mathrm{A}$ & ANO & $\mathrm{N} / \mathrm{A}$ & 1 & Not Analyzed \\
\hline 166 & 007 & 7.1 & 05 & $\mathrm{~N} / \mathrm{A}$ & $\mathrm{N} / \mathrm{A}$ & ANO & $\mathrm{N} / \mathrm{A}$ & 1 & Not Analyzed \\
\hline 166 & 008 & 8.1 & 05 & $\mathrm{~N} / \mathrm{A}$ & $\mathrm{N} / \mathrm{A}$ & ANO & $\mathrm{N} / \mathrm{A}$ & 1 & Not Analyzed \\
\hline 166 & 009 & 9.1 & 05 & $\mathrm{~N} / \mathrm{A}$ & $\mathrm{N} / \mathrm{A}$ & ANO & $\mathrm{N} / \mathrm{A}$ & 1 & Not Analyzed \\
\hline 166 & 010 & 10.1 & 05 & $\mathrm{~N} / \mathrm{A}$ & $\mathrm{N} / \mathrm{A}$ & ANO & $\mathrm{N} / \mathrm{A}$ & 1 & Not Analyzed \\
\hline 166 & 011 & 11.1 & 05 & $\mathrm{~N} / \mathrm{A}$ & $\mathrm{N} / \mathrm{A}$ & ANO & $\mathrm{N} / \mathrm{A}$ & 1 & Not Analyzed \\
\hline 166 & 012 & 12.1 & 05 & $\mathrm{~N} / \mathrm{A}$ & $\mathrm{N} / \mathrm{A}$ & ANO & $\mathrm{N} / \mathrm{A}$ & 1 & Not Analyzed \\
\hline 166 & 013 & 13.1 & 05 & $\mathrm{~N} / \mathrm{A}$ & $\mathrm{N} / \mathrm{A}$ & ANO & $\mathrm{N} / \mathrm{A}$ & 1 & Not Analyzed \\
\hline 166 & 014 & 14.1 & 05 & $\mathrm{~N} / \mathrm{A}$ & $\mathrm{N} / \mathrm{A}$ & ANO & $\mathrm{N} / \mathrm{A}$ & 1 & Not Analyzed \\
\hline 166 & 015 & 14.2 & 05 & $\mathrm{~N} / \mathrm{A}$ & $\mathrm{N} / \mathrm{A}$ & ANO & $\mathrm{N} / \mathrm{A}$ & 1 & Not Analyzed \\
\hline 166 & 016 & 15.1 & 05 & $\mathrm{~N} / \mathrm{A}$ & $\mathrm{N} / \mathrm{A}$ & ANO & $\mathrm{N} / \mathrm{A}$ & 1 & Not Analyzed \\
\hline 166 & 017 & 15.2 & 05 & $\mathrm{~N} / \mathrm{A}$ & $\mathrm{N} / \mathrm{A}$ & ANO & $\mathrm{N} / \mathrm{A}$ & 1 & Not Analyzed \\
\hline 166 & 018 & 16.1 & 05 & $\mathrm{~N} / \mathrm{A}$ & $\mathrm{N} / \mathrm{A}$ & ANO & $\mathrm{N} / \mathrm{A}$ & 1 & Not Analyzed \\
\hline 166 & 019 & 16.2 & 05 & N/A & $\mathrm{N} / \mathrm{A}$ & ANO & $\mathrm{N} / \mathrm{A}$ & 1 & Not Analyzed \\
\hline 166 & 020 & 17.1 & 05 & $\mathrm{~N} / \mathrm{A}$ & $\mathrm{N} / \mathrm{A}$ & ANO & $\mathrm{N} / \mathrm{A}$ & 1 & Not Analyzed \\
\hline 166 & 021 & 17.2 & 05 & $\mathrm{~N} / \mathrm{A}$ & $\mathrm{N} / \mathrm{A}$ & ANO & $\mathrm{N} / \mathrm{A}$ & 1 & Not Analyzed \\
\hline 166 & 022 & 18.1 & 05 & N/A & N/A & ANO & $\mathrm{N} / \mathrm{A}$ & 1 & Not Analyzed \\
\hline 166 & 023 & 18.2 & 05 & $\mathrm{~N} / \mathrm{A}$ & $\mathrm{N} / \mathrm{A}$ & ANO & $\mathrm{N} / \mathrm{A}$ & 1 & Not Analyzed \\
\hline 166 & 024 & 18.3 & 05 & $\mathrm{~N} / \mathrm{A}$ & $\mathrm{N} / \mathrm{A}$ & ANO & $\mathrm{N} / \mathrm{A}$ & 1 & Not Analyzed \\
\hline 166 & 025 & 19.1 & 05 & $\mathrm{~N} / \mathrm{A}$ & $\mathrm{N} / \mathrm{A}$ & ANO & $\mathrm{N} / \mathrm{A}$ & 1 & Not Analyzed \\
\hline 166 & 026 & 19.2 & 05 & $\mathrm{~N} / \mathrm{A}$ & $\mathrm{N} / \mathrm{A}$ & ANO & $\mathrm{N} / \mathrm{A}$ & 1 & Not Analyzed \\
\hline 166 & 027 & 20.1 & 05 & $\mathrm{~N} / \mathrm{A}$ & $\mathrm{N} / \mathrm{A}$ & ANO & $\mathrm{N} / \mathrm{A}$ & 1 & Not Analyzed \\
\hline 166 & 028 & 20.2 & 05 & $\mathrm{~N} / \mathrm{A}$ & $\mathrm{N} / \mathrm{A}$ & ANO & $\mathrm{N} / \mathrm{A}$ & 1 & Not Analyzed \\
\hline 166 & 029 & 21.1 & 05 & $\mathrm{~N} / \mathrm{A}$ & $\mathrm{N} / \mathrm{A}$ & ANO & $\mathrm{N} / \mathrm{A}$ & 1 & Not Analyzed \\
\hline 166 & 030 & 21.2 & 05 & $\mathrm{~N} / \mathrm{A}$ & $\mathrm{N} / \mathrm{A}$ & ANO & $\mathrm{N} / \mathrm{A}$ & 1 & Not Analyzed \\
\hline 166 & 031 & 22.1 & 05 & $\mathrm{~N} / \mathrm{A}$ & $\mathrm{N} / \mathrm{A}$ & ANO & $\mathrm{N} / \mathrm{A}$ & 1 & Not Analyzed \\
\hline 166 & 032 & 23.1 & 05 & N/A & $\mathrm{N} / \mathrm{A}$ & ANO & $\mathrm{N} / \mathrm{A}$ & 1 & Not Analyzed \\
\hline 166 & 033 & 23.2 & 05 & $\mathrm{~N} / \mathrm{A}$ & $\mathrm{N} / \mathrm{A}$ & ANO & $\mathrm{N} / \mathrm{A}$ & 1 & Not Analyzed \\
\hline 166 & 034 & 23.3 & 05 & $\mathrm{~N} / \mathrm{A}$ & $\mathrm{N} / \mathrm{A}$ & ANO & $\mathrm{N} / \mathrm{A}$ & 1 & Not Analyzed \\
\hline 166 & 035 & 24.1 & 05 & $\mathrm{~N} / \mathrm{A}$ & $\mathrm{N} / \mathrm{A}$ & ANO & $\mathrm{N} / \mathrm{A}$ & 1 & Not Analyzed \\
\hline 166 & 036 & 24.2 & 05 & $\mathrm{~N} / \mathrm{A}$ & $\mathrm{N} / \mathrm{A}$ & ANO & $\mathrm{N} / \mathrm{A}$ & 1 & Not Analyzed \\
\hline 166 & 037 & 25.1 & 05 & $\mathrm{~N} / \mathrm{A}$ & $\mathrm{N} / \mathrm{A}$ & ANO & $\mathrm{N} / \mathrm{A}$ & 1 & Not Analyzed \\
\hline 166 & 038 & 25.2 & 05 & N/A & N/A & ANO & $\mathrm{N} / \mathrm{A}$ & 1 & Not Analyzed \\
\hline 166 & 039 & 26.1 & 05 & $\mathrm{~N} / \mathrm{A}$ & $\mathrm{N} / \mathrm{A}$ & ANO & $\mathrm{N} / \mathrm{A}$ & 1 & Not Analyzed \\
\hline 166 & 040 & 26.2 & 05 & $\mathrm{~N} / \mathrm{A}$ & $\mathrm{N} / \mathrm{A}$ & ANO & $\mathrm{N} / \mathrm{A}$ & 1 & Not Analyzed \\
\hline 166 & 041 & 26.3 & 05 & N/A & N/A & ANO & $\mathrm{N} / \mathrm{A}$ & 1 & Not Analyzed \\
\hline 166 & 042 & 27.1 & 05 & $\mathrm{~N} / \mathrm{A}$ & $\mathrm{N} / \mathrm{A}$ & ANO & $\mathrm{N} / \mathrm{A}$ & 1 & Not Analyzed \\
\hline 166 & 043 & 27.2 & 05 & $\mathrm{~N} / \mathrm{A}$ & $\mathrm{N} / \mathrm{A}$ & ANO & $\mathrm{N} / \mathrm{A}$ & 1 & Not Analyzed \\
\hline 166 & 044 & 28.1 & 05 & $\mathrm{~N} / \mathrm{A}$ & $\mathrm{N} / \mathrm{A}$ & ANO & $\mathrm{N} / \mathrm{A}$ & 1 & Not Analyzed \\
\hline 166 & 045 & 28.2 & 05 & N/A & N/A & ANO & $\mathrm{N} / \mathrm{A}$ & 1 & Not Analyzed \\
\hline 166 & 046 & 29.1 & 05 & $\mathrm{~N} / \mathrm{A}$ & $\mathrm{N} / \mathrm{A}$ & ANO & $\mathrm{N} / \mathrm{A}$ & 1 & Not Analyzed \\
\hline 166 & 047 & 29.2 & 05 & $\mathrm{~N} / \mathrm{A}$ & $\mathrm{N} / \mathrm{A}$ & ANO & $\mathrm{N} / \mathrm{A}$ & 1 & Not Analyzed \\
\hline 166 & 048 & 30.1 & 05 & $\mathrm{~N} / \mathrm{A}$ & $\mathrm{N} / \mathrm{A}$ & ANO & $\mathrm{N} / \mathrm{A}$ & 1 & Not Analyzed \\
\hline 166 & 049 & 30.2 & 05 & $\mathrm{~N} / \mathrm{A}$ & $\mathrm{N} / \mathrm{A}$ & ANO & $\mathrm{N} / \mathrm{A}$ & 1 & Not Analyzed \\
\hline 166 & 050 & 30.3 & 05 & $\mathrm{~N} / \mathrm{A}$ & $\mathrm{N} / \mathrm{A}$ & ANO & $\mathrm{N} / \mathrm{A}$ & 1 & Not Analyzed \\
\hline 166 & 051 & 31.1 & 05 & N/A & N/A & ANO & $\mathrm{N} / \mathrm{A}$ & 1 & Not Analyzed \\
\hline 166 & 052 & 31.2 & 05 & $\mathrm{~N} / \mathrm{A}$ & $\mathrm{N} / \mathrm{A}$ & ANO & $\mathrm{N} / \mathrm{A}$ & 1 & Not Analyzed \\
\hline 166 & 053 & 31.3 & 05 & $\mathrm{~N} / \mathrm{A}$ & $\mathrm{N} / \mathrm{A}$ & ANO & $\mathrm{N} / \mathrm{A}$ & 1 & Not Analyzed \\
\hline 166 & 054 & 31.4 & 05 & N/A & N/A & ANO & $\mathrm{N} / \mathrm{A}$ & 1 & Not Analyzed \\
\hline 167 & 001 & 1.1 & 01 & 03 & FLA & ANO & SIM & 1 & None \\
\hline 167 & 002 & 2.1 & 01 & 01 & MSG & ANO & SIM & 1 & None \\
\hline 167 & 003 & 3.1 & 02 & 04 & MSG & ANO & PRI & 1 & None \\
\hline 167 & 004 & 4.1 & 01 & 00 & FLA & ANO & $\mathrm{CMX}$ & 1 & None \\
\hline 167 & 005 & 5.1 & 01 & 00 & MSG & ANO & CMX & 1 & None \\
\hline 167 & 006 & 6.1 & 03 & 00 & MSG & ANO & CMX & 1 & None \\
\hline 167 & 007 & 7.1 & 01 & 00 & FCT & ANO & BTF & 1 & None \\
\hline 167 & 008 & 8.1 & 04 & 00 & CRT & ANO & CMX & 1 & None \\
\hline 167 & 009 & 9.1 & 05 & 00 & MSG & ANO & SG4 & 1 & None \\
\hline 167 & 010 & 10.1 & 01 & 01 & CRT & ANO & SIM & 1 & None \\
\hline
\end{tabular}




\begin{tabular}{|c|c|c|c|c|c|c|c|c|c|}
\hline $\begin{array}{l}\text { Lot } \\
\text { No. }\end{array}$ & $\begin{array}{l}\text { Specimen } \\
\text { No. } \\
\end{array}$ & Nodule No. & $\begin{array}{l}\text { Flake } \\
\text { Size } \\
\end{array}$ & $\begin{array}{l}\text { Percent } \\
\text { Cortex } \\
\end{array}$ & $\begin{array}{l}\text { Platform } \\
\text { Type } \\
\end{array}$ & $\begin{array}{c}\text { Thermal } \\
\text { Alteration }\end{array}$ & $\begin{array}{c}\text { Technological } \\
\text { Class } \\
\end{array}$ & Count & Comments \\
\hline 167 & 011 & 10.2 & 03 & 00 & MSG & ANO & CMX & 1 & None \\
\hline 167 & 012 & 11.1 & 02 & 00 & MSG & ANO & $\mathrm{CMX}$ & 1 & None \\
\hline 167 & 013 & 11.2 & 01 & 00 & $\mathrm{MLT}$ & ANO & BTF & 1 & None \\
\hline 167 & 014 & 12.1 & 04 & 00 & MSG & ANO & CMX & 1 & None \\
\hline 167 & 015 & 13.1 & 05 & 00 & MSG & ANO & SG4 & 1 & None \\
\hline 171 & 001 & 1.1 & 01 & 01 & CRT & ANO & SIM & 1 & None \\
\hline 171 & 002 & 2.1 & 02 & 00 & FLA & ANO & CMX & 1 & None \\
\hline 171 & 003 & 3.1 & 01 & 01 & CRT & ANO & SIM & 1 & None \\
\hline 171 & 004 & 4.1 & 02 & 04 & MSG & ANO & $\mathrm{PRI}$ & 1 & None \\
\hline 171 & 005 & 5.1 & 03 & 00 & MSG & ANO & CMX & 1 & None \\
\hline 171 & 006 & 6.1 & 03 & 00 & MSG & ANO & $\mathrm{CMX}$ & 1 & None \\
\hline 171 & 007 & 7.1 & 03 & 02 & FLA & ANO & SIM & 1 & None \\
\hline 171 & 008 & 8.1 & 03 & 00 & MSG & ANO & CMX & 1 & None \\
\hline 171 & 009 & 9.1 & 01 & 01 & CRT & ANO & $\mathrm{CMX}$ & 1 & None \\
\hline 171 & 010 & 9.2 & 05 & 00 & MSG & ANO & CMX & 1 & None \\
\hline 171 & 011 & 10.1 & 03 & 00 & MSG & ANO & CMX & 1 & None \\
\hline 171 & 012 & 11.1 & 04 & 00 & CRT & ANO & $\mathrm{CMX}$ & 1 & None \\
\hline 171 & 013 & 11.2 & 04 & 00 & CRT & ANO & $\mathrm{CMX}$ & 1 & None \\
\hline 172 & 001 & 1.1 & 02 & 00 & MSG & ANO & CMX & 1 & None \\
\hline 172 & 002 & 1.2 & 04 & 04 & MSG & ANO & PRI & 1 & None \\
\hline 172 & 003 & 2.1 & 01 & 00 & FCT & ANO & CMX & 1 & None \\
\hline 172 & 004 & 3.1 & 02 & 00 & MSG & ANO & CMX & 1 & None \\
\hline 172 & 005 & 4.1 & 03 & 00 & MSG & ANO & CMX & 1 & None \\
\hline 172 & 006 & 4.2 & 03 & 00 & FLA & ANO & CMX & 1 & None \\
\hline 172 & 007 & 5.1 & 03 & 00 & MSG & ANO & CMX & 1 & None \\
\hline 172 & 008 & 5.2 & 04 & 04 & MSG & ANO & PRI & 1 & None \\
\hline 172 & 009 & 6.1 & 01 & 00 & MSG & ANO & CMX & 1 & None \\
\hline 172 & 010 & 7.1 & 01 & 00 & FLA & ANO & CMX & 1 & None \\
\hline 172 & 011 & 8.1 & 05 & $\mathrm{~N} / \mathrm{A}$ & $\mathrm{N} / \mathrm{A}$ & ANO & $\mathrm{N} / \mathrm{A}$ & 1 & Not Analyzed \\
\hline 172 & 012 & 9.1 & 04 & 04 & MSG & ANO & $\mathrm{PRI}$ & 1 & None \\
\hline 172 & 013 & 10.1 & 02 & 02 & MSG & ANO & SIM & 1 & None \\
\hline 172 & 014 & 10.2 & 04 & 00 & MSG & ANO & CMX & 1 & None \\
\hline 172 & 015 & 11.1 & 03 & 04 & MSG & ANO & PRI & 1 & None \\
\hline 172 & 016 & 12.1 & 02 & 01 & CRT & ANO & SIM & 1 & None \\
\hline 172 & 017 & 12.2 & 02 & 00 & $\mathrm{MLT}$ & ANO & CMX & 1 & None \\
\hline 172 & 018 & 12.3 & 03 & 00 & MSG & ANO & CMX & 1 & None \\
\hline 172 & 019 & 13.1 & 04 & 00 & MLT & ANO & BTF & 1 & None \\
\hline 172 & 020 & 13.2 & 02 & 00 & MSG & ANO & CMX & 1 & None \\
\hline 172 & 021 & 13.3 & 04 & 00 & MSG & ANO & $\mathrm{CMX}$ & 1 & None \\
\hline 172 & 022 & 14.1 & 05 & $\mathrm{~N} / \mathrm{A}$ & $\mathrm{N} / \mathrm{A}$ & ANO & $\mathrm{N} / \mathrm{A}$ & 1 & Not Analyzed \\
\hline 172 & 023 & 15.1 & 04 & 00 & MSG & ANO & CMX & 1 & None \\
\hline 172 & 024 & 15.2 & 05 & $\mathrm{~N} / \mathrm{A}$ & $\mathrm{N} / \mathrm{A}$ & ANO & $\mathrm{N} / \mathrm{A}$ & 1 & Not Analyzed \\
\hline 172 & 025 & 16.1 & 04 & 00 & MSG & ANO & CMX & 1 & None \\
\hline 172 & 026 & 16.2 & 04 & 00 & MSG & ANO & $\mathrm{CMX}$ & 1 & None \\
\hline 172 & 027 & 16.3 & 05 & $\mathrm{~N} / \mathrm{A}$ & N/A & ANO & $\mathrm{N} / \mathrm{A}$ & 1 & Not Analyzed \\
\hline 172 & 028 & 16.4 & 05 & $\mathrm{~N} / \mathrm{A}$ & $\mathrm{N} / \mathrm{A}$ & ANO & $\mathrm{N} / \mathrm{A}$ & 1 & Not Analyzed \\
\hline 172 & 029 & 17.1 & 04 & 00 & MSG & ANO & $\mathrm{CMX}$ & 1 & None \\
\hline 172 & 030 & 18.1 & 02 & 02 & FLA & $\mathrm{AOB}$ & SIM & 1 & None \\
\hline 172 & 031 & 18.2 & 04 & 04 & MSG & ANO & PRI & 1 & None \\
\hline 172 & 032 & 18.3 & 04 & 00 & MSG & ANO & $\mathrm{CMX}$ & 1 & None \\
\hline 172 & 033 & 18.4 & 05 & $\mathrm{~N} / \mathrm{A}$ & $\mathrm{N} / \mathrm{A}$ & ANO & $\mathrm{N} / \mathrm{A}$ & 1 & Not Analyzed \\
\hline 172 & 034 & 19.1 & 04 & 00 & MSG & ANO & $\mathrm{CMX}$ & 1 & None \\
\hline 172 & 035 & 20.1 & 03 & 00 & MSG & ANO & CMX & 1 & None \\
\hline 172 & 036 & 20.2 & 04 & 00 & FLA & ANO & CMX & 1 & None \\
\hline 172 & 037 & 20.3 & 04 & 00 & MSG & ANO & $\mathrm{CMX}$ & 1 & None \\
\hline 172 & 038 & 20.4 & 04 & 00 & MSG & ANO & $\mathrm{CMX}$ & 1 & None \\
\hline 172 & 039 & 20.5 & 05 & $\mathrm{~N} / \mathrm{A}$ & $\mathrm{N} / \mathrm{A}$ & ANO & $\mathrm{N} / \mathrm{A}$ & 1 & Not Analyzed \\
\hline 172 & 040 & 20.6 & 05 & $\mathrm{~N} / \mathrm{A}$ & $\mathrm{N} / \mathrm{A}$ & ANO & $\mathrm{N} / \mathrm{A}$ & 1 & Not Analyzed \\
\hline 172 & 041 & 21.1 & 03 & 00 & MSG & ANO & CMX & 1 & None \\
\hline 172 & 042 & 21.2 & 04 & 00 & MSG & ANO & $\mathrm{CMX}$ & 1 & None \\
\hline 172 & 043 & 22.1 & 02 & 00 & MSG & ANO & $\mathrm{CMX}$ & 1 & None \\
\hline 172 & 044 & 22.2 & 03 & 00 & MSG & ANO & $\mathrm{CMX}$ & 1 & None \\
\hline 172 & 045 & 22.3 & 05 & $\mathrm{~N} / \mathrm{A}$ & $\mathrm{N} / \mathrm{A}$ & ANO & $\mathrm{N} / \mathrm{A}$ & 1 & Not Analyzed \\
\hline 172 & 046 & 22.4 & 05 & $\mathrm{~N} / \mathrm{A}$ & $\mathrm{N} / \mathrm{A}$ & ANO & $\mathrm{N} / \mathrm{A}$ & 1 & Not Analyzed \\
\hline 172 & 047 & 23.1 & 04 & 00 & MSG & ANO & CMX & 1 & None \\
\hline 172 & 048 & 23.2 & 04 & 00 & MSG & ANO & CMX & 1 & None \\
\hline
\end{tabular}




\begin{tabular}{|c|c|c|c|c|c|c|c|c|c|}
\hline $\begin{array}{l}\text { Lot } \\
\text { No. }\end{array}$ & $\begin{array}{l}\text { Specimen } \\
\text { No. } \\
\end{array}$ & Nodule No. & $\begin{array}{l}\text { Flake } \\
\text { Size } \\
\end{array}$ & $\begin{array}{l}\text { Percent } \\
\text { Cortex } \\
\end{array}$ & $\begin{array}{l}\text { Platform } \\
\text { Type } \\
\end{array}$ & $\begin{array}{c}\text { Thermal } \\
\text { Alteration }\end{array}$ & $\begin{array}{c}\text { Technological } \\
\text { Class } \\
\end{array}$ & Count & Comments \\
\hline 172 & 049 & 23.3 & 04 & 00 & MSG & ANO & CMX & 1 & None \\
\hline 172 & 050 & 24.1 & 01 & 00 & MLT & ANO & $\mathrm{CMX}$ & 1 & None \\
\hline 172 & 051 & 25.1 & 01 & 02 & CRT & ANO & SIM & 1 & None \\
\hline 172 & 052 & 25.2 & 04 & 00 & MSG & ANO & CMX & 1 & None \\
\hline 172 & 053 & 25.3 & 05 & $\mathrm{~N} / \mathrm{A}$ & $\mathrm{N} / \mathrm{A}$ & ANO & $\mathrm{N} / \mathrm{A}$ & 1 & Not Analyzed \\
\hline 172 & 054 & 25.4 & 05 & $\mathrm{~N} / \mathrm{A}$ & $\mathrm{N} / \mathrm{A}$ & ANO & $\mathrm{N} / \mathrm{A}$ & 1 & Not Analyzed \\
\hline 172 & 055 & 25.5 & 05 & $\mathrm{~N} / \mathrm{A}$ & $\mathrm{N} / \mathrm{A}$ & ANO & $\mathrm{N} / \mathrm{A}$ & 1 & Not Analyzed \\
\hline 172 & 056 & 26.1 & 04 & 00 & MSG & ANO & $\mathrm{CMX}$ & 1 & None \\
\hline 172 & 057 & 26.2 & 04 & 00 & MSG & ANO & $\mathrm{CMX}$ & 1 & None \\
\hline 172 & 058 & 26.3 & 04 & 00 & MSG & ANO & CMX & 1 & None \\
\hline 172 & 059 & 26.4 & 05 & $\mathrm{~N} / \mathrm{A}$ & $\mathrm{N} / \mathrm{A}$ & ANO & $\mathrm{N} / \mathrm{A}$ & 1 & Not Analyzed \\
\hline 172 & 060 & 26.5 & 05 & $\mathrm{~N} / \mathrm{A}$ & $\mathrm{N} / \mathrm{A}$ & ANO & $\mathrm{N} / \mathrm{A}$ & 1 & Not Analyzed \\
\hline 172 & 061 & 27.1 & 04 & 00 & MSG & ANO & $\mathrm{CMX}$ & 1 & None \\
\hline 172 & 062 & 28.1 & 05 & $\mathrm{~N} / \mathrm{A}$ & $\mathrm{N} / \mathrm{A}$ & ANO & $\mathrm{N} / \mathrm{A}$ & 1 & Not Analyzed \\
\hline 172 & 063 & 29.1 & 05 & N/A & $\mathrm{N} / \mathrm{A}$ & ANO & $\mathrm{N} / \mathrm{A}$ & 1 & Not Analyzed \\
\hline 172 & 064 & 30.1 & 04 & 02 & CRT & ANO & SIM & 1 & None \\
\hline 172 & 065 & 30.2 & 04 & 00 & $\overline{M L T}$ & ANO & $\mathrm{CMX}$ & 1 & None \\
\hline 172 & 066 & 30.3 & 04 & 00 & MSG & ANO & $\mathrm{CMX}$ & 1 & None \\
\hline 172 & 067 & 30.4 & 04 & 00 & MSG & ANO & $\mathrm{CMX}$ & 1 & None \\
\hline 172 & 068 & 30.5 & 04 & 00 & MSG & ANO & $\mathrm{CMX}$ & 1 & None \\
\hline 172 & 069 & 30.6 & 05 & $\mathrm{~N} / \mathrm{A}$ & $\mathrm{N} / \mathrm{A}$ & ANO & $\mathrm{N} / \mathrm{A}$ & 1 & Not Analyzed \\
\hline 173 & 001 & 1.1 & 01 & 00 & FLA & ANO & MSG & 1 & None \\
\hline 173 & 002 & 1.2 & 01 & 03 & MSG & ANO & SIM & 1 & None \\
\hline 173 & 003 & 2.1 & 01 & 00 & $\mathrm{MLT}$ & ANO & BTF & 1 & None \\
\hline 173 & 004 & 2.2 & 04 & 00 & MLT & ANO & MSG & 1 & None \\
\hline 173 & 005 & 3.1 & 02 & 00 & FCT & $\mathrm{AOB}$ & MSG & 1 & None \\
\hline 173 & 006 & 4.1 & 01 & 00 & MSG & ANO & BTF & 1 & None \\
\hline 173 & 007 & 5.1 & 01 & 00 & MSG & ANO & MSG & 1 & None \\
\hline 173 & 008 & 6.1 & 02 & 00 & $\mathrm{MLT}$ & ANO & MSG & 1 & None \\
\hline 173 & 009 & 7.1 & 02 & 00 & CRT & ANO & MSG & 1 & None \\
\hline 173 & 010 & 8.1 & 02 & 00 & FLA & ANO & MSG & 1 & None \\
\hline 173 & 011 & 9.1 & 02 & 00 & MLT & ANO & BTF & 1 & None \\
\hline 173 & 012 & 10.1 & 03 & 00 & $\mathrm{MLT}$ & ANO & BTF & 1 & None \\
\hline 173 & 013 & 10.2 & 04 & 00 & MSG & ANO & MSG & 1 & None \\
\hline 173 & 014 & 11.1 & 02 & 03 & MSG & $\mathrm{AOB}$ & SHA & 1 & None \\
\hline 173 & 015 & 11.2 & 04 & 00 & MSG & ANO & MSG & 1 & None \\
\hline 173 & 016 & 11.3 & 04 & 00 & MSG & ANO & MSG & 1 & None \\
\hline 173 & 017 & 11.4 & 04 & 00 & FLA & ANO & MSG & 1 & None \\
\hline 173 & 018 & 11.5 & 04 & 00 & MSG & ANO & MSG & 1 & None \\
\hline 173 & 019 & 11.6 & 05 & $\mathrm{~N} / \mathrm{A}$ & $\mathrm{N} / \mathrm{A}$ & ANO & $\mathrm{N} / \mathrm{A}$ & 5 & Not Analyzed \\
\hline 173 & 020 & 12.1 & 01 & 01 & CRT & ANO & SIM & 1 & None \\
\hline 173 & 021 & 12.2 & 03 & 01 & CRT & $\mathrm{AOB}$ & SIM & 1 & None \\
\hline 173 & 022 & 12.3 & 04 & 02 & CRT & ANO & MSG & 1 & None \\
\hline 173 & 023 & 12.4 & 04 & 00 & MSG & ANO & MSG & 1 & None \\
\hline 173 & 024 & 12.5 & 04 & 00 & MSG & ANO & MSG & 1 & None \\
\hline 173 & 025 & 12.6 & 05 & $\mathrm{~N} / \mathrm{A}$ & $\mathrm{N} / \mathrm{A}$ & ANO & $\mathrm{N} / \mathrm{A}$ & 2 & Not Analyzed \\
\hline 173 & 026 & 13.1 & 03 & 00 & CRT & ANO & MSG & 1 & None \\
\hline 173 & 027 & 13.2 & 04 & 00 & CRT & ANO & MSG & 1 & None \\
\hline 173 & 028 & 13.3 & 04 & 00 & MSG & ANO & MSG & 1 & None \\
\hline 173 & 029 & 13.4 & 04 & 00 & MSG & ANO & $\mathrm{SHA}$ & 1 & Potlid \\
\hline 173 & 030 & 14.1 & 01 & 01 & CRT & ANO & SIM & 1 & None \\
\hline 173 & 031 & 14.2 & 03 & 00 & FCT & ANO & MSG & 1 & None \\
\hline 173 & 032 & 14.3 & 04 & 00 & FLA & ANO & MSG & 1 & None \\
\hline 173 & 033 & 14.4 & 03 & 00 & MSG & ANO & MSG & 1 & None \\
\hline 173 & 034 & 14.5 & 04 & 00 & MSG & ANO & MSG & 1 & None \\
\hline 173 & 035 & 14.6 & 04 & 00 & MSG & ANO & MSG & 1 & None \\
\hline 173 & 036 & 14.7 & 04 & 00 & MSG & ANO & MSG & 1 & None \\
\hline 173 & 037 & 14.8 & 05 & $\mathrm{~N} / \mathrm{A}$ & $\mathrm{N} / \mathrm{A}$ & ANO & $\mathrm{N} / \mathrm{A}$ & 1 & Not Analyzed \\
\hline 173 & 038 & 15.1 & 02 & 02 & CRT & ANO & SIM & 1 & None \\
\hline 173 & 039 & 16.1 & 03 & 00 & MSG & ANO & MSG & 1 & None \\
\hline 173 & 040 & 17.1 & 02 & 00 & MSG & ANO & MSG & 1 & None \\
\hline 173 & 041 & 18.1 & 02 & 02 & CRT & ANO & SIM & 1 & None \\
\hline 173 & 042 & 18.2 & 03 & 00 & FLA & ANO & MSG & 1 & None \\
\hline 173 & 043 & 18.3 & 03 & 00 & CRT & ANO & MSG & 1 & None \\
\hline 173 & 044 & 18.4 & 04 & 00 & MSG & ANO & BPF & 1 & None \\
\hline 173 & 045 & 19.1 & 04 & 00 & MSG & ANO & MSG & 1 & None \\
\hline
\end{tabular}




\begin{tabular}{|c|c|c|c|c|c|c|c|c|c|}
\hline Lot & $\begin{array}{l}\text { Specimen } \\
\text { No. } \\
\end{array}$ & Nodule No. & $\begin{array}{l}\text { Flake } \\
\text { Size } \\
\end{array}$ & $\begin{array}{l}\text { Percent } \\
\text { Cortex } \\
\end{array}$ & $\begin{array}{l}\text { Platform } \\
\text { Type } \\
\end{array}$ & $\begin{array}{c}\text { Thermal } \\
\text { Alteration }\end{array}$ & $\begin{array}{c}\text { Technological } \\
\text { Class } \\
\end{array}$ & Count & Comments \\
\hline 173 & 046 & 19.2 & 05 & N/A & $\mathrm{N} / \mathrm{A}$ & ANO & $\mathrm{N} / \mathrm{A}$ & 1 & Not Analyzed \\
\hline 173 & 047 & 20.1 & 01 & 02 & MSG & ANO & SIM & 1 & None \\
\hline 173 & 048 & 20.2 & 02 & 00 & MSG & ANO & MSG & 1 & None \\
\hline 173 & 049 & 20.3 & 03 & 00 & MSG & ANO & MSG & 1 & None \\
\hline 173 & 050 & 20.4 & 04 & 00 & MSG & ANO & MSG & 1 & None \\
\hline 173 & 051 & 20.5 & 04 & 00 & MSG & ANO & MSG & 1 & None \\
\hline 173 & 052 & 20.6 & 04 & 00 & MSG & ANO & MSG & 1 & None \\
\hline 173 & 053 & 20.7 & 04 & 00 & MSG & ANO & MSG & 1 & None \\
\hline 173 & 054 & 20.8 & 04 & 00 & MSG & ANO & MSG & 1 & None \\
\hline 173 & 055 & 20.9 & 04 & 00 & MSG & ANO & MSG & 1 & None \\
\hline 173 & 056 & 20.10 & 04 & 00 & CRT & ANO & MSG & 1 & None \\
\hline 173 & 057 & 21.1 & 03 & 04 & MSG & ANO & PRI & 1 & None \\
\hline 173 & 058 & 21.2 & 04 & 00 & FLA & ANO & MSG & 1 & None \\
\hline 173 & 059 & 22.1 & 01 & 03 & $\overline{M S G}$ & ANO & SIM & 1 & None \\
\hline 173 & 060 & 22.2 & 03 & 00 & MSG & ANO & MSG & 1 & None \\
\hline 173 & 061 & 22.3 & 03 & 00 & MSG & ANO & MSG & 1 & None \\
\hline 173 & 062 & 22.4 & 03 & 00 & MSG & ANO & MSG & 1 & None \\
\hline 173 & 063 & 22.5 & 04 & 00 & MSG & ANO & MSG & 1 & None \\
\hline 173 & 064 & 22.6 & 04 & 00 & MSG & ANO & MSG & 1 & None \\
\hline 173 & 065 & 22.7 & 04 & 00 & MSG & ANO & MSG & 1 & None \\
\hline 173 & 066 & 22.8 & 04 & 00 & MSG & ANO & MSG & 1 & None \\
\hline 173 & 067 & 22.9 & 04 & 00 & MSG & ANO & MSG & 1 & None \\
\hline 173 & 068 & 22.10 & 04 & 00 & MSG & ANO & MSG & 1 & None \\
\hline 173 & 069 & 22.11 & 04 & 00 & MSG & ANO & MSG & 1 & None \\
\hline 173 & 070 & 22.12 & 04 & 00 & MSG & ANO & MSG & 1 & None \\
\hline 173 & 071 & 22.13 & 05 & $\mathrm{~N} / \mathrm{A}$ & $\mathrm{N} / \mathrm{A}$ & ANO & $\mathrm{N} / \mathrm{A}$ & 3 & Not Analyzed \\
\hline 173 & 072 & 23.1 & 02 & 01 & CRT & ANO & SIM & 1 & None \\
\hline 173 & 073 & 24.1 & 02 & 00 & MSG & ANO & MSG & 1 & None \\
\hline 173 & 074 & 25.1 & 03 & 00 & MSG & ANO & MSG & 1 & None \\
\hline 173 & 075 & 26.1 & 03 & 00 & MSG & ANO & $\mathrm{CMX}$ & 1 & None \\
\hline 173 & 076 & 26.2 & 03 & 00 & MSG & ANO & $\mathrm{CMX}$ & 1 & None \\
\hline 173 & 077 & 26.3 & 04 & 00 & MSG & $\mathrm{AOB}$ & $\mathrm{SHA}$ & 1 & Potlid \\
\hline 173 & 078 & 26.4 & 04 & 00 & $\overline{M S G}$ & ANO & $\mathrm{SHA}$ & 1 & None \\
\hline 173 & 079 & 26.5 & 04 & 00 & MSG & ANO & $\mathrm{CMX}$ & 1 & None \\
\hline 173 & 080 & 26.6 & 04 & 00 & MSG & ANO & $\mathrm{CMX}$ & 1 & None \\
\hline 173 & 081 & 26.7 & 04 & 00 & MSG & ANO & $\mathrm{CMX}$ & 1 & None \\
\hline 173 & 082 & 26.8 & 04 & 00 & MSG & ANO & $\mathrm{CMX}$ & 1 & None \\
\hline 173 & 083 & 26.9 & 05 & 00 & $\mathrm{NA}$ & ANO & SG4 & 1 & None \\
\hline 173 & 084 & 27.1 & 02 & 01 & CRT & ANO & CMX & 4 & None \\
\hline 173 & 085 & 27.2 & 04 & 00 & MSG & ANO & CMX & 1 & None \\
\hline 173 & 086 & 27.3 & 05 & 00 & NA & ANO & SG4 & 1 & None \\
\hline 173 & 087 & 27.4 & 05 & 00 & NA & ANO & SG4 & 1 & None \\
\hline 173 & 088 & 27.5 & 04 & 00 & MSG & ANO & CMX & 1 & None \\
\hline 173 & 089 & 27.6 & 05 & 00 & NA & ANO & SG4 & 1 & None \\
\hline 173 & 090 & 28.1 & 03 & 03 & MSG & AOB & CMX & 1 & None \\
\hline 173 & 091 & 28.2 & 04 & 01 & MSG & AOB & SHA & 1 & None \\
\hline 173 & 092 & 28.3 & 04 & 02 & MSG & ANO & SHA & 1 & Potlid \\
\hline 173 & 093 & 28.4 & 04 & 00 & MSG & ANO & CMX & 1 & None \\
\hline 173 & 094 & 28.5 & 05 & 00 & NA & ANO & SG4 & 1 & None \\
\hline 173 & 095 & 29.1 & 02 & 00 & MSG & ANO & CMX & 1 & None \\
\hline 173 & 096 & 29.2 & 04 & 00 & MSG & ANO & $\mathrm{CMX}$ & 1 & None \\
\hline 173 & 097 & 30.1 & 04 & 00 & MSG & ANO & CMX & 1 & None \\
\hline 173 & 098 & 31.1 & 04 & 00 & MSG & ANO & CMX & 1 & None \\
\hline 173 & 099 & 32.1 & 04 & 00 & MSG & ANO & CMX & 1 & None \\
\hline 173 & 100 & 33.1 & 04 & 00 & MSG & ANO & CMX & 1 & None \\
\hline 173 & 101 & 34.1 & 04 & 00 & MSG & ANO & CMX & 1 & None \\
\hline 173 & 102 & 35.1 & 04 & 00 & MSG & ANO & CMX & 1 & None \\
\hline 173 & 103 & 35.2 & 04 & 00 & MSG & ANO & CMX & 1 & None \\
\hline 173 & 104 & 36.1 & 04 & 00 & MSG & ANO & CMX & 1 & None \\
\hline 173 & 105 & 36.2 & 04 & 00 & MSG & ANO & CMX & 1 & None \\
\hline 173 & 106 & 36.3 & 04 & 00 & MSG & ANO & CMX & 1 & None \\
\hline 173 & 107 & 37.1 & 04 & 00 & MSG & ANO & CMX & 1 & None \\
\hline 173 & 108 & 37.2 & 04 & 00 & MSG & ANO & CMX & 1 & None \\
\hline 173 & 109 & 38.1 & 04 & 00 & MSG & ANO & CMX & 1 & None \\
\hline 173 & 110 & 38.2 & 04 & 00 & MSG & ANO & CMX & 1 & None \\
\hline 173 & 111 & 38.3 & 04 & 00 & MSG & ANO & CMX & 1 & None \\
\hline
\end{tabular}




\begin{tabular}{|c|c|c|c|c|c|c|c|c|c|}
\hline $\begin{array}{l}\text { Lot } \\
\text { No. }\end{array}$ & $\begin{array}{l}\text { Specimen } \\
\text { No. }\end{array}$ & Nodule No. & $\begin{array}{l}\text { Flake } \\
\text { Size }\end{array}$ & $\begin{array}{l}\text { Percent } \\
\text { Cortex }\end{array}$ & $\begin{array}{l}\text { Platform } \\
\text { Type }\end{array}$ & $\begin{array}{l}\text { Thermal } \\
\text { Alteration }\end{array}$ & $\begin{array}{c}\text { Technological } \\
\text { Class }\end{array}$ & Count & Comments \\
\hline 173 & 112 & 39.1 & 04 & 00 & MSG & ANO & $\mathrm{CMX}$ & 1 & None \\
\hline 173 & 113 & 40.1 & 04 & 00 & MSG & ANO & CMX & 1 & None \\
\hline 173 & 114 & 40.2 & 04 & 00 & MSG & ANO & $\mathrm{CMX}$ & 1 & None \\
\hline 173 & 115 & 40.3 & 04 & 00 & MSG & ANO & CMX & 1 & None \\
\hline 173 & 116 & 40.4 & 04 & 00 & MSG & ANO & $\mathrm{CMX}$ & 1 & None \\
\hline 173 & 117 & 41.1 & 04 & 00 & MSG & ANO & CMX & 1 & None \\
\hline 173 & 118 & 41.2 & 04 & 00 & MSG & ANO & $\mathrm{CMX}$ & 1 & None \\
\hline 173 & 119 & 41.3 & 05 & 00 & NA & ANO & SG4 & 1 & None \\
\hline 173 & 120 & 42.1 & 05 & 00 & NA & ANO & SG4 & 1 & None \\
\hline 173 & 121 & 42.2 & 05 & 00 & $\mathrm{NA}$ & ANO & SG4 & 1 & None \\
\hline 173 & 122 & 43.1 & 05 & 00 & $\mathrm{NA}$ & ANO & SG4 & 1 & None \\
\hline 173 & 123 & 44.1 & 05 & 00 & NA & ANO & SG4 & 1 & None \\
\hline 173 & 124 & 45.1 & 05 & 00 & $\mathrm{NA}$ & ANO & SG4 & 1 & None \\
\hline 173 & 125 & 46.1 & 05 & 00 & $\mathrm{NA}$ & ANO & SG4 & 1 & None \\
\hline 173 & 126 & 47.1 & 05 & 00 & $\mathrm{NA}$ & ANO & SG4 & 1 & None \\
\hline 173 & 127 & 48.1 & 05 & 00 & NA & ANO & SG4 & 1 & None \\
\hline 173 & 128 & 49.1 & 05 & 00 & $\mathrm{NA}$ & ANO & SG4 & 1 & None \\
\hline 173 & 129 & 50.1 & 05 & 00 & $\mathrm{NA}$ & ANO & SG4 & 1 & None \\
\hline 173 & 130 & 50.2 & 05 & 00 & $\mathrm{NA}$ & ANO & SG4 & 1 & None \\
\hline 173 & 131 & 51.1 & 05 & 00 & $\mathrm{NA}$ & ANO & SG4 & 1 & None \\
\hline 173 & 132 & 51.2 & 05 & 00 & $\mathrm{NA}$ & ANO & SG4 & 1 & None \\
\hline 173 & 133 & 52.1 & 05 & 00 & NA & ANO & SG4 & 1 & None \\
\hline 173 & 134 & 53.1 & 05 & 00 & $\mathrm{NA}$ & ANO & SG4 & 1 & None \\
\hline 173 & 135 & 54.1 & 05 & 00 & $\mathrm{NA}$ & ANO & SG4 & 1 & None \\
\hline 173 & 136 & 55.1 & 05 & 00 & NA & ANO & SG4 & 1 & None \\
\hline 173 & 137 & 56.1 & 04 & 00 & CRT & ANO & $\overline{C M X}$ & 1 & None \\
\hline 173 & 138 & 56.2 & 05 & 00 & NA & ANO & SG4 & 1 & None \\
\hline 173 & 139 & 57.1 & 05 & 00 & NA & ANO & SG4 & 1 & None \\
\hline 173 & 140 & 57.2 & 05 & 00 & $\mathrm{NA}$ & ANO & SG4 & 1 & None \\
\hline 173 & 141 & 57.3 & 05 & 00 & NA & ANO & SG4 & 1 & None \\
\hline 173 & 142 & 58.1 & 04 & 00 & MSG & ANO & $\overline{C M X}$ & 1 & None \\
\hline 173 & 143 & 58.2 & 05 & 00 & NA & ANO & SG4 & 1 & None \\
\hline 173 & 144 & 58.3 & 05 & 00 & $\mathrm{NA}$ & ANO & SG4 & 1 & None \\
\hline 173 & 145 & 58.4 & 05 & 00 & $\mathrm{NA}$ & ANO & SG4 & 1 & None \\
\hline 173 & 146 & 58.5 & 05 & 00 & NA & ANO & SG4 & 1 & None \\
\hline 173 & 147 & 59.1 & 05 & 00 & NA & ANO & SG4 & 1 & None \\
\hline 173 & 148 & 59.2 & 05 & 00 & NA & ANO & SG4 & 1 & None \\
\hline 173 & 149 & 59.3 & 05 & 00 & NA & ANO & SG4 & 1 & None \\
\hline 173 & 150 & 60.1 & 04 & 00 & MSG & ANO & CMX & 1 & None \\
\hline 173 & 151 & 60.2 & 05 & 00 & NA & ANO & SG4 & 1 & None \\
\hline 173 & 152 & 60.3 & 05 & 00 & NA & ANO & SG4 & 1 & None \\
\hline 173 & 153 & 60.4 & 05 & 00 & $\mathrm{NA}$ & ANO & SG4 & 1 & None \\
\hline 173 & 154 & 61.1 & 05 & 00 & NA & ANO & SG4 & 1 & None \\
\hline 173 & 155 & 61.2 & 05 & 00 & NA & ANO & SG4 & 1 & None \\
\hline 173 & 156 & 61.3 & 05 & 00 & $\mathrm{NA}$ & ANO & SG4 & 1 & None \\
\hline 173 & 157 & 61.4 & 05 & 00 & $\mathrm{NA}$ & ANO & SG4 & 1 & None \\
\hline 173 & 158 & 61.5 & 05 & 00 & NA & ANO & SG4 & 1 & None \\
\hline 173 & 159 & 62.1 & 04 & 00 & MSG & ANO & CMX & 1 & None \\
\hline 173 & 160 & 62.2 & 05 & 00 & NA & ANO & SG4 & 1 & None \\
\hline 173 & 161 & 62.3 & 05 & 00 & NA & ANO & SG4 & 1 & None \\
\hline 173 & 162 & 62.4 & 05 & 00 & $\mathrm{NA}$ & ANO & SG4 & 1 & None \\
\hline 173 & 163 & 62.5 & 05 & 00 & NA & ANO & SG4 & 1 & None \\
\hline 173 & 164 & 62.6 & 04 & 00 & $\overline{M L T}$ & ANO & $\mathrm{BPF}$ & 1 & None \\
\hline 173 & 165 & 63.1 & 04 & 00 & MSG & ANO & CMX & 1 & None \\
\hline 173 & 166 & 64.1 & 04 & 00 & $\mathrm{MLT}$ & ANO & CMX & 1 & None \\
\hline 173 & 167 & 65.1 & 05 & 00 & NA & ANO & SG4 & 1 & None \\
\hline 173 & 168 & 65.2 & 05 & 00 & $\mathrm{NA}$ & ANO & SG4 & 1 & None \\
\hline 173 & 169 & 66.1 & 05 & 00 & $\overline{N A}$ & ANO & SG4 & 1 & None \\
\hline 173 & 170 & 66.2 & 05 & 00 & $\mathrm{NA}$ & ANO & SG4 & 1 & None \\
\hline 173 & 171 & 67.1 & 05 & 00 & NA & ANO & SG4 & 1 & None \\
\hline 173 & 172 & 67.2 & 05 & 00 & NA & ANO & SG4 & 1 & None \\
\hline 173 & 173 & 68.1 & 04 & 00 & MSG & ANO & CMX & 1 & None \\
\hline 173 & 174 & 68.2 & 05 & 00 & NA & ANO & SG4 & 1 & None \\
\hline 173 & 175 & 69.1 & 05 & 00 & $\mathrm{NA}$ & ANO & SG4 & 1 & None \\
\hline 173 & 176 & 69.2 & 05 & 00 & $\mathrm{NA}$ & ANO & SG4 & 1 & None \\
\hline 173 & 177 & 69.3 & 05 & 00 & NA & ANO & SG4 & 1 & None \\
\hline
\end{tabular}




\begin{tabular}{|c|c|c|c|c|c|c|c|c|c|}
\hline $\begin{array}{l}\text { Lot } \\
\text { No. }\end{array}$ & $\begin{array}{l}\text { Specimen } \\
\text { No. } \\
\end{array}$ & Nodule No. & $\begin{array}{l}\text { Flake } \\
\text { Size }\end{array}$ & $\begin{array}{l}\text { Percent } \\
\text { Cortex } \\
\end{array}$ & $\begin{array}{l}\text { Platform } \\
\text { Type } \\
\end{array}$ & $\begin{array}{c}\text { Thermal } \\
\text { Alteration }\end{array}$ & $\begin{array}{c}\text { Technological } \\
\text { Class } \\
\end{array}$ & Count & Comments \\
\hline 173 & 178 & 69.4 & 05 & 00 & NA & ANO & SG4 & 1 & None \\
\hline 173 & 179 & 69.5 & 05 & 00 & NA & ANO & SG4 & 1 & None \\
\hline 173 & 180 & 70.1 & 05 & 00 & NA & ANO & SG4 & 1 & None \\
\hline 173 & 181 & 71.1 & 05 & 00 & NA & ANO & SG4 & 1 & None \\
\hline 174 & 001 & 1.1 & 01 & 04 & CRT & ANO & $\mathrm{PRI}$ & 1 & None \\
\hline 174 & 002 & 2.1 & 01 & 00 & $\overline{M L T}$ & ANO & CMX & 1 & None \\
\hline 174 & 003 & 2.2 & 01 & 00 & MLT & ANO & BTF & 1 & None \\
\hline 174 & 004 & 2.3 & 02 & 00 & MSG & ANO & $\mathrm{SHA}$ & 1 & None \\
\hline 174 & 005 & 2.4 & 04 & 00 & MSG & ANO & $\mathrm{CMX}$ & 1 & None \\
\hline 174 & 006 & 3.1 & 01 & 00 & MLT & ANO & BTF & 1 & None \\
\hline 174 & 007 & 3.2 & 02 & 00 & MSG & ANO & $\mathrm{CMX}$ & 1 & None \\
\hline 174 & 008 & 3.3 & 04 & 00 & MLT & ANO & CMX & 1 & None \\
\hline 174 & 009 & 3.4 & 04 & 00 & MSG & ANO & CMX & 1 & None \\
\hline 174 & 010 & 3.5 & 05 & 00 & $\overline{M S G}$ & ANO & SG4 & 1 & None \\
\hline 174 & 011 & 4.1 & 01 & 00 & MSG & ANO & CMX & 1 & None \\
\hline 174 & 012 & 5.1 & 01 & 00 & MSG & ANO & CMX & 1 & None \\
\hline 174 & 013 & 6.1 & 01 & 02 & CRT & ANO & SIM & 1 & None \\
\hline 174 & 014 & 6.2 & 01 & 00 & $\mathrm{MLT}$ & ANO & BTF & 1 & None \\
\hline 174 & 015 & 6.3 & 02 & 00 & MLT & ANO & CMX & 1 & None \\
\hline 174 & 016 & 6.4 & 04 & 00 & FLA & ANO & CMX & 1 & None \\
\hline 174 & 017 & 6.5 & 04 & 00 & MSG & ANO & CMX & 1 & None \\
\hline 174 & 018 & 6.6 & 05 & 00 & MSG & ANO & SG4 & 2 & None \\
\hline 174 & 019 & 7.1 & 01 & 01 & MSG & ANO & SIM & 1 & None \\
\hline 174 & 020 & 7.2 & 04 & 02 & MSG & ANO & SIM & 1 & None \\
\hline 174 & 021 & 8.1 & 01 & 03 & FLA & ANO & PRI & 1 & None \\
\hline 174 & 022 & 9.1 & 01 & 00 & MLT & ANO & BTF & 1 & None \\
\hline 174 & 023 & 9.2 & 04 & 00 & $\overline{M S G}$ & ANO & PRI & 1 & None \\
\hline 174 & 024 & 10.1 & 01 & 00 & MSG & ANO & CMX & 1 & None \\
\hline 174 & 025 & 11.1 & 01 & 00 & MSG & ANO & CMX & 1 & None \\
\hline 174 & 026 & 12.1 & 01 & 00 & MLT & ANO & CMX & 1 & None \\
\hline 174 & 027 & 12.2 & 02 & 02 & MSG & ANO & SIM & 1 & None \\
\hline 174 & 028 & 12.3 & 04 & 00 & MSG & ANO & CMX & 1 & None \\
\hline 174 & 029 & 12.4 & 04 & 00 & $\overline{M S G}$ & ANO & CMX & 1 & None \\
\hline 174 & 030 & 12.5 & 05 & 00 & MSG & ANO & SG4 & 1 & None \\
\hline 174 & 031 & 12.6 & 05 & 00 & MSG & ANO & SG4 & 1 & None \\
\hline 174 & 032 & 12.7 & 05 & 00 & MSG & ANO & SG4 & 1 & None \\
\hline 174 & 033 & 12.8 & 05 & 00 & MSG & ANO & SG4 & 1 & None \\
\hline 174 & 034 & 12.9 & 05 & 00 & MSG & ANO & SG4 & 1 & None \\
\hline 174 & 035 & 13.1 & 02 & 00 & MLT & ANO & BTF & 1 & None \\
\hline 174 & 036 & 13.2 & 03 & 00 & MSG & ANO & CMX & 1 & None \\
\hline 174 & 037 & 13.3 & 04 & 04 & MSG & ANO & PRI & 1 & None \\
\hline 174 & 038 & 13.4 & 04 & 00 & CRT & ANO & CMX & 1 & None \\
\hline 174 & 039 & 13.5 & 04 & 00 & MSG & ANO & CMX & 1 & None \\
\hline 174 & 040 & 13.6 & 04 & 00 & MLT & ANO & BPF & 1 & None \\
\hline 174 & 041 & 13.7 & 04 & 04 & MSG & ANO & PRI & 1 & None \\
\hline 174 & 042 & 13.8 & 04 & 00 & $\mathrm{MLT}$ & ANO & BPF & 1 & None \\
\hline 174 & 043 & 14.1 & 02 & 04 & MSG & ANO & PRI & 1 & None \\
\hline 174 & 044 & 15.1 & 04 & 04 & MSG & ANO & PRI & 1 & None \\
\hline 174 & 045 & 16.1 & 02 & 04 & CRT & ANO & PRI & 1 & None \\
\hline 174 & 046 & 16.2 & 05 & 00 & MSG & ANO & SG4 & 1 & None \\
\hline 174 & 047 & 16.3 & 05 & 00 & MSG & ANO & SG4 & 1 & None \\
\hline 174 & 048 & 17.1 & 02 & 00 & $\overline{M L T}$ & ANO & BTF & 1 & None \\
\hline 174 & 049 & 18.1 & 02 & 00 & MLT & ANO & CMX & 1 & None \\
\hline 174 & 050 & 18.2 & 02 & 00 & FLA & ANO & CMX & 1 & None \\
\hline 174 & 051 & 18.3 & 03 & 00 & MLT & ANO & CMX & 1 & None \\
\hline 174 & 052 & 18.4 & 03 & 00 & MSG & ANO & CMX & 1 & None \\
\hline 174 & 053 & 18.5 & 03 & 00 & MSG & ANO & CMX & 1 & None \\
\hline 174 & 054 & 18.6 & 04 & 00 & MSG & ANO & CMX & 1 & None \\
\hline 174 & 055 & 18.7 & 04 & 00 & MSG & ANO & CMX & 1 & None \\
\hline 174 & 056 & 18.8 & 05 & 00 & MSG & ANO & SG4 & 1 & None \\
\hline 174 & 057 & 18.9 & 05 & 00 & MSG & ANO & SG4 & 1 & None \\
\hline 174 & 058 & 18.10 & 05 & 00 & MSG & ANO & SG4 & 2 & None \\
\hline 174 & 059 & 19.1 & 02 & 00 & MLT & ANO & BTF & 1 & None \\
\hline 174 & 060 & 20.1 & 04 & 00 & MSG & AOB & SHA & 1 & Potlid \\
\hline 174 & 061 & 21.1 & 01 & 00 & MSG & ANO & CMX & 1 & None \\
\hline 174 & 062 & 21.2 & 02 & 00 & FLA & ANO & CMX & 1 & None \\
\hline
\end{tabular}




\begin{tabular}{|c|c|c|c|c|c|c|c|c|c|}
\hline $\begin{array}{l}\text { Lot } \\
\text { No. }\end{array}$ & $\begin{array}{l}\text { Specimen } \\
\text { No. } \\
\end{array}$ & Nodule No. & $\begin{array}{l}\text { Flake } \\
\text { Size } \\
\end{array}$ & $\begin{array}{l}\text { Percent } \\
\text { Cortex } \\
\end{array}$ & $\begin{array}{l}\text { Platform } \\
\text { Type } \\
\end{array}$ & $\begin{array}{c}\text { Thermal } \\
\text { Alteration }\end{array}$ & $\begin{array}{c}\text { Technological } \\
\text { Class } \\
\end{array}$ & Count & Comments \\
\hline 174 & 063 & 21.3 & 03 & 00 & MSG & ANO & CMX & 1 & None \\
\hline 174 & 064 & 21.4 & 03 & 00 & MSG & ANO & $\mathrm{CMX}$ & 1 & None \\
\hline 174 & 065 & 21.5 & 03 & 00 & MSG & ANO & CMX & 1 & None \\
\hline 174 & 066 & 21.6 & 04 & 00 & MSG & ANO & CMX & 1 & None \\
\hline 174 & 067 & 21.7 & 04 & 00 & MSG & ANO & $\mathrm{CMX}$ & 1 & None \\
\hline 174 & 068 & 22.1 & 02 & 01 & MSG & ANO & SIM & 1 & None \\
\hline 174 & 069 & 22.2 & 04 & 00 & MSG & ANO & CMX & 1 & None \\
\hline 174 & 070 & 22.3 & 05 & 00 & CRT & ANO & SG4 & 1 & None \\
\hline 174 & 071 & 23.1 & 01 & 02 & CRT & ANO & SIM & 1 & None \\
\hline 174 & 072 & 23.2 & 04 & 01 & CRT & ANO & SIM & 1 & None \\
\hline 174 & 073 & 23.3 & 04 & 00 & MSG & ANO & CMX & 1 & None \\
\hline 174 & 074 & 23.4 & 04 & 00 & MSG & ANO & $\mathrm{CMX}$ & 1 & None \\
\hline 174 & 075 & 23.5 & 05 & 00 & MSG & $\mathrm{AOB}$ & SG4 & 1 & Potlid \\
\hline 174 & 076 & 24.1 & 01 & 01 & CRT & ANO & SIM & 1 & None \\
\hline 174 & 077 & 24.2 & 04 & 00 & MSG & ANO & CMX & 1 & None \\
\hline 174 & 078 & 25.1 & 02 & 00 & CRT & ANO & CMX & 1 & None \\
\hline 174 & 079 & 26.1 & 01 & 04 & MSG & ANO & CMX & 1 & None \\
\hline 174 & 080 & 26.2 & 03 & 00 & FLA & ANO & PRI & 1 & None \\
\hline 174 & 081 & 27.1 & 01 & 00 & FLA & ANO & BTF & 1 & None \\
\hline 174 & 082 & 27.2 & 02 & 00 & FLA & ANO & CMX & 1 & None \\
\hline 174 & 083 & 27.3 & 04 & 00 & MSG & ANO & CMX & 1 & None \\
\hline 174 & 084 & 28.1 & 01 & 00 & FLA & ANO & CMX & 1 & None \\
\hline 174 & 085 & 28.2 & 01 & 01 & CRT & ANO & SIM & 1 & None \\
\hline 174 & 086 & 28.3 & 02 & 00 & MSG & ANO & CMX & 1 & None \\
\hline 174 & 087 & 28.4 & 03 & 00 & MSG & ANO & CMX & 1 & None \\
\hline 174 & 088 & 28.5 & 03 & 00 & CRT & ANO & CMX & 1 & None \\
\hline 174 & 089 & 29.1 & 03 & 04 & CRT & ANO & PRI & 1 & None \\
\hline 174 & 090 & 30.1 & 01 & 00 & FLA & ANO & CMX & 1 & None \\
\hline 174 & 091 & 30.2 & 04 & 00 & MSG & ANO & CMX & 1 & None \\
\hline 174 & 092 & 30.3 & 03 & 00 & FLA & ANO & CMX & 1 & None \\
\hline 174 & 093 & 30.4 & 04 & 00 & FLA & ANO & CMX & 1 & None \\
\hline 174 & 094 & 30.5 & 04 & 00 & MSG & ANO & CMX & 1 & None \\
\hline 174 & 095 & 31.1 & 02 & 00 & FLA & ANO & CMX & 1 & None \\
\hline 174 & 096 & 31.2 & 04 & 00 & MLT & ANO & CMX & 1 & None \\
\hline 174 & 097 & 31.3 & 04 & 00 & FCT & ANO & CMX & 1 & None \\
\hline 174 & 098 & 31.4 & 03 & 00 & MLT & ANO & BTF & 1 & None \\
\hline 174 & 099 & 31.5 & 04 & 00 & MSG & ANO & $\mathrm{CMX}$ & 1 & None \\
\hline 174 & 100 & 31.6 & 04 & 00 & FCT & ANO & CMX & 1 & None \\
\hline 174 & 101 & 31.7 & 04 & 00 & MSG & ANO & CMX & 1 & None \\
\hline 174 & 102 & 32.1 & 02 & 00 & MSG & ANO & CMX & 1 & None \\
\hline 174 & 103 & 32.2 & 04 & 00 & MSG & ANO & CMX & 1 & None \\
\hline 174 & 104 & 32.3 & 05 & 00 & MSG & ANO & CMX & 1 & None \\
\hline 174 & 105 & 33.1 & 04 & 04 & MSG & ANO & PRI & 1 & None \\
\hline 174 & 106 & 33.2 & 04 & 00 & MSG & ANO & $\mathrm{CMX}$ & 1 & None \\
\hline 174 & 107 & 34.1 & 01 & 01 & CRT & ANO & SIM & 1 & None \\
\hline 174 & 108 & 34.2 & 03 & 00 & NA & $\mathrm{AOB}$ & $\mathrm{SHA}$ & 1 & Potlid \\
\hline 174 & 109 & 34.3 & 04 & 00 & NA & ANO & SHA & 1 & None \\
\hline 174 & 110 & 34.4 & 04 & 00 & MSG & ANO & $\mathrm{SHA}$ & 1 & None \\
\hline 174 & 111 & 34.5 & 04 & 00 & MSG & ANO & SHA & 1 & None \\
\hline 174 & 112 & 34.6 & 05 & 00 & MSG & ANO & CMX & 1 & None \\
\hline 174 & 113 & 35.1 & 02 & 00 & FLA & ANO & CMX & 1 & None \\
\hline 174 & 114 & 35.2 & 03 & 00 & MLT & ANO & CMX & 1 & None \\
\hline 174 & 115 & 36.1 & 02 & 00 & MLT & ANO & CMX & 1 & None \\
\hline 174 & 116 & 36.2 & 03 & 00 & MSG & ANO & CMX & 1 & None \\
\hline 174 & 117 & 36.3 & 05 & 00 & NA & ANO & SG4 & 1 & None \\
\hline 174 & 118 & 37.1 & 04 & 00 & MSG & ANO & CMX & 1 & None \\
\hline 174 & 119 & 38.1 & 04 & 00 & MSG & ANO & BPF & 1 & None \\
\hline 174 & 120 & 38.2 & 04 & 00 & MSG & ANO & CMX & 1 & None \\
\hline 174 & 121 & 38.3 & 05 & 00 & NA & ANO & SG4 & 1 & None \\
\hline 174 & 122 & 39.1 & 02 & 00 & FLA & ANO & $\mathrm{CMX}$ & 1 & None \\
\hline 174 & 123 & 40.1 & 02 & 00 & MSG & ANO & CMX & 1 & None \\
\hline 174 & 124 & 41.1 & 01 & 00 & CRT & ANO & CMX & 1 & None \\
\hline 174 & 125 & 41.2 & 02 & 00 & MSG & ANO & CMX & 1 & None \\
\hline 174 & 126 & 41.3 & 02 & 00 & MSG & ANO & CMX & 1 & None \\
\hline 174 & 127 & 41.4 & 04 & 00 & MSG & ANO & $\overline{C M X}$ & 1 & None \\
\hline 174 & 128 & 41.5 & 04 & 00 & MSG & ANO & CMX & 1 & None \\
\hline
\end{tabular}




\begin{tabular}{|c|c|c|c|c|c|c|c|c|c|}
\hline $\begin{array}{l}\text { Lot } \\
\text { No. }\end{array}$ & $\begin{array}{l}\text { Specimen } \\
\text { No. }\end{array}$ & Nodule No. & $\begin{array}{l}\text { Flake } \\
\text { Size }\end{array}$ & $\begin{array}{l}\text { Percent } \\
\text { Cortex }\end{array}$ & $\begin{array}{l}\text { Platform } \\
\text { Type }\end{array}$ & $\begin{array}{l}\text { Thermal } \\
\text { Alteration }\end{array}$ & $\begin{array}{c}\text { Technological } \\
\text { Class }\end{array}$ & Count & Comments \\
\hline 174 & 129 & 41.6 & 05 & 00 & NA & ANO & SG4 & 1 & None \\
\hline 174 & 130 & 41.7 & 05 & 00 & NA & ANO & SG4 & 1 & None \\
\hline 174 & 131 & 41.8 & 05 & 00 & NA & ANO & SG4 & 1 & None \\
\hline 174 & 132 & 42.1 & 03 & 00 & MSG & ANO & CMX & 1 & None \\
\hline 174 & 133 & 42.2 & 04 & 00 & MSG & ANO & $\mathrm{CMX}$ & 1 & None \\
\hline 174 & 134 & 43.1 & 04 & 00 & MLT & ANO & CMX & 1 & None \\
\hline 174 & 135 & 44.1 & 03 & 00 & MSG & ANO & CMX & 1 & None \\
\hline 174 & 136 & 45.1 & 04 & 00 & MSG & ANO & $\mathrm{SHA}$ & 1 & None \\
\hline 174 & 137 & 45.2 & 04 & 00 & MSG & ANO & CMX & 1 & None \\
\hline 174 & 138 & 45.3 & 04 & 00 & MSG & ANO & CMX & 1 & None \\
\hline 174 & 139 & 46.1 & 04 & 00 & MSG & ANO & $\mathrm{CMX}$ & 1 & None \\
\hline 174 & 140 & 47.1 & 04 & 00 & MSG & ANO & SHA & 1 & None \\
\hline 174 & 141 & 48.1 & 05 & 00 & NA & ANO & SG4 & 1 & None \\
\hline 174 & 142 & 49.1 & 04 & 00 & MSG & ANO & CMX & 1 & None \\
\hline 174 & 143 & 49.2 & 05 & 00 & NA & ANO & SG4 & 1 & None \\
\hline 174 & 144 & 49.3 & 05 & 00 & MSG & ANO & CMX & 1 & None \\
\hline 174 & 145 & 50.1 & 03 & 00 & $\mathrm{MLT}$ & ANO & BTF & 1 & None \\
\hline 174 & 146 & 51.1 & 03 & 00 & MSG & ANO & CMX & 1 & None \\
\hline 174 & 147 & 51.2 & 04 & 01 & MSG & ANO & SIM & 1 & None \\
\hline 174 & 148 & 52.1 & 04 & 00 & MSG & ANO & $\mathrm{CMX}$ & 1 & None \\
\hline 174 & 149 & 52.2 & 04 & 00 & MLT & ANO & BPF & 1 & None \\
\hline 174 & 150 & 52.3 & 04 & 00 & MSG & ANO & CMX & 1 & None \\
\hline 174 & 151 & 53.1 & 05 & 00 & NA & ANO & SG4 & 1 & None \\
\hline 174 & 152 & 54.1 & 04 & 00 & MSG & ANO & $\overline{C M X}$ & 1 & None \\
\hline 174 & 153 & 54.2 & 04 & 00 & MSG & ANO & SHA & 1 & None \\
\hline 174 & 154 & 54.3 & 05 & 00 & NA & ANO & SG4 & 1 & None \\
\hline 174 & 155 & 55.1 & 05 & 00 & NA & ANO & SG4 & 1 & None \\
\hline 174 & 156 & 56.1 & 04 & 00 & MSG & ANO & CMX & 1 & None \\
\hline 174 & 157 & 57.1 & 03 & 00 & FLA & ANO & $\overline{C M X}$ & 1 & None \\
\hline 174 & 158 & 58.1 & 03 & 00 & MSG & ANO & CMX & 1 & None \\
\hline 174 & 159 & 59.1 & 04 & 00 & FLA & ANO & $\overline{C M X}$ & 1 & None \\
\hline 174 & 160 & 60.1 & 01 & 00 & FCT & ANO & CMX & 1 & None \\
\hline 174 & 161 & 60.2 & 04 & 00 & MSG & ANO & CMX & 1 & None \\
\hline 174 & 162 & 60.3 & 04 & 00 & MSG & ANO & $\overline{C M X}$ & 1 & None \\
\hline 174 & 163 & 60.4 & 04 & 00 & MSG & ANO & $\mathrm{CMX}$ & 1 & None \\
\hline 174 & 164 & 60.5 & 04 & 00 & FLA & ANO & CMX & 1 & None \\
\hline 174 & 165 & 60.6 & 04 & 00 & MSG & ANO & CMX & 1 & None \\
\hline 174 & 166 & 60.7 & 05 & 00 & NA & ANO & SG4 & 1 & None \\
\hline 174 & 167 & 60.8 & 05 & 00 & $\mathrm{NA}$ & ANO & SG4 & 1 & None \\
\hline 174 & 168 & 60.9 & 05 & 00 & NA & ANO & SG4 & 1 & None \\
\hline 174 & 169 & 60.10 & 05 & 00 & NA & ANO & SG4 & 1 & None \\
\hline 174 & 170 & 60.11 & 05 & 00 & NA & ANO & SG4 & 2 & None \\
\hline 174 & 171 & 61.1 & 02 & 04 & MSG & ANO & PRI & 1 & None \\
\hline 174 & 172 & 62.1 & 04 & 00 & MSG & ANO & CMX & 1 & None \\
\hline 174 & 173 & 63.1 & 04 & 00 & MSG & ANO & CMX & 1 & None \\
\hline 174 & 174 & 64.1 & 04 & 00 & MSG & ANO & $\mathrm{SHA}$ & 1 & None \\
\hline 174 & 175 & 64.2 & 04 & 00 & MSG & ANO & SIM & 1 & None \\
\hline 174 & 176 & 65.1 & 04 & 04 & MSG & ANO & PRI & 1 & None \\
\hline 174 & 177 & 66.1 & 01 & 01 & CRT & ANO & SIM & 1 & None \\
\hline 174 & 178 & 66.2 & 02 & 00 & MSG & ANO & CMX & 1 & None \\
\hline 174 & 179 & 66.3 & 04 & 00 & MSG & ANO & CMX & 1 & None \\
\hline 174 & 180 & 66.4 & 04 & 00 & MSG & ANO & $\mathrm{CMX}$ & 1 & None \\
\hline 174 & 181 & 66.5 & 04 & 00 & FLA & ANO & $\overline{C M X}$ & 1 & None \\
\hline 174 & 182 & 66.6 & 05 & NA & NA & ANO & SG4 & 1 & None \\
\hline 174 & 183 & 66.7 & 05 & $\mathrm{NA}$ & $\mathrm{NA}$ & ANO & SG4 & 1 & None \\
\hline 174 & 184 & 66.8 & 05 & NA & $\mathrm{NA}$ & ANO & SG4 & 1 & None \\
\hline 174 & 185 & 66.9 & 05 & NA & NA & ANO & SG4 & 1 & None \\
\hline 174 & 186 & 67.1 & 02 & 04 & FLA & ANO & PRI & 1 & None \\
\hline 174 & 187 & 67.2 & 03 & 00 & MSG & ANO & CMX & 1 & None \\
\hline 174 & 188 & 67.3 & 04 & 03 & MSG & ANO & SIM & 1 & None \\
\hline 174 & 189 & 67.4 & 05 & $\mathrm{NA}$ & NA & ANO & SG4 & 1 & None \\
\hline 174 & 190 & 67.5 & 05 & NA & NA & ANO & SG4 & 1 & None \\
\hline 174 & 191 & 68.1 & 04 & 00 & MSG & ANO & CMX & 1 & None \\
\hline 174 & 192 & 68.2 & 04 & 01 & MSG & ANO & SIM & 1 & None \\
\hline 174 & 193 & 68.3 & 04 & 00 & MSG & ANO & CMX & 1 & None \\
\hline 174 & 194 & 69.1 & 05 & NA & NA & ANO & SG4 & 1 & None \\
\hline
\end{tabular}




\begin{tabular}{|c|c|c|c|c|c|c|c|c|c|}
\hline Lot & $\begin{array}{l}\text { Specimen } \\
\text { No. }\end{array}$ & Nodule No. & $\begin{array}{l}\text { Flake } \\
\text { Size } \\
\end{array}$ & $\begin{array}{l}\text { Percent } \\
\text { Cortex } \\
\end{array}$ & $\begin{array}{l}\text { Platform } \\
\text { Type } \\
\end{array}$ & $\begin{array}{c}\text { Thermal } \\
\text { Alteration }\end{array}$ & $\begin{array}{c}\text { Technological } \\
\text { Class }\end{array}$ & Count & Comments \\
\hline 174 & 195 & 70.1 & 03 & 04 & MSG & ANO & PRI & 1 & None \\
\hline 174 & 196 & 70.2 & 04 & 03 & MSG & ANO & SIM & 1 & None \\
\hline 174 & 197 & 70.3 & 04 & 04 & MSG & ANO & $\mathrm{PRI}$ & 1 & None \\
\hline 174 & 198 & 70.4 & 04 & 00 & MSG & ANO & $\mathrm{CMX}$ & 1 & None \\
\hline 174 & 199 & 70.5 & 04 & 00 & MSG & ANO & $\mathrm{CMX}$ & 1 & None \\
\hline 174 & 200 & 70.6 & 04 & 00 & MSG & ANO & CMX & 1 & None \\
\hline 174 & 201 & 70.7 & 04 & 00 & MSG & ANO & CMX & 1 & None \\
\hline 174 & 202 & 70.8 & 04 & 04 & MSG & ANO & PRI & 1 & None \\
\hline 174 & 203 & 70.9 & 04 & 00 & MSG & $\mathrm{AOB}$ & $\mathrm{SHA}$ & 1 & None \\
\hline 174 & 204 & 70.10 & 04 & 00 & MSG & $\mathrm{AOB}$ & $\mathrm{SHA}$ & 1 & None \\
\hline 174 & 205 & 70.11 & 04 & 00 & MSG & $\mathrm{AOB}$ & SHA & 1 & None \\
\hline 174 & 206 & 70.12 & 05 & $\mathrm{NA}$ & NA & ANO & SG4 & 1 & None \\
\hline 174 & 207 & 71.1 & 04 & 00 & FLA & ANO & $\mathrm{CMX}$ & 1 & None \\
\hline 174 & 208 & 71.2 & 04 & 00 & FLA & ANO & CMX & 1 & None \\
\hline 174 & 209 & 71.3 & 05 & $\mathrm{NA}$ & NA & ANO & SG4 & 1 & None \\
\hline 174 & 210 & 72.1 & 04 & 00 & MSG & $\mathrm{AOB}$ & SHA & 1 & Potlid \\
\hline 174 & 211 & 72.2 & 04 & 00 & MSG & ANO & CMX & 1 & None \\
\hline 174 & 212 & 73.1 & 05 & $\mathrm{NA}$ & NA & ANO & SG4 & 1 & None \\
\hline 174 & 213 & 74.1 & 03 & 03 & MSG & ANO & SIM & 1 & None \\
\hline 174 & 214 & 75.1 & 05 & $\mathrm{NA}$ & NA & ANO & SG4 & 1 & None \\
\hline 174 & 215 & 76.1 & 04 & 00 & MSG & ANO & CMX & 1 & None \\
\hline 174 & 216 & 76.2 & 04 & 00 & MSG & ANO & SHA & 1 & None \\
\hline 174 & 217 & 76.3 & 05 & $\mathrm{NA}$ & NA & ANO & SG4 & 1 & None \\
\hline 174 & 218 & 76.4 & 05 & NA & NA & ANO & SG4 & 1 & None \\
\hline 174 & 219 & 76.5 & 05 & $\mathrm{NA}$ & NA & ANO & SG4 & 1 & None \\
\hline 174 & 220 & 77.1 & 03 & 00 & MSG & ANO & CMX & 1 & None \\
\hline 174 & 221 & 77.2 & 04 & 00 & CRT & ANO & CMX & 1 & None \\
\hline 174 & 222 & 77.3 & 04 & 00 & MSG & ANO & CMX & 1 & None \\
\hline 174 & 223 & 77.4 & 04 & 00 & MSG & ANO & CMX & 1 & None \\
\hline 174 & 224 & 77.5 & 04 & 00 & MSG & ANO & CMX & 1 & None \\
\hline 174 & 225 & 78.1 & 05 & $\mathrm{NA}$ & NA & ANO & SG4 & 1 & None \\
\hline 174 & 226 & 79.1 & 04 & 00 & MSG & ANO & CMX & 1 & None \\
\hline 174 & 227 & 79.2 & 04 & 00 & MSG & ANO & CMX & 1 & None \\
\hline 174 & 228 & 79.3 & 04 & 00 & MSG & ANO & CMX & 1 & None \\
\hline 174 & 229 & 79.4 & 04 & 00 & MSG & ANO & CMX & 1 & None \\
\hline 174 & 230 & 79.5 & 05 & $\mathrm{NA}$ & NA & ANO & SG4 & 1 & None \\
\hline 174 & 231 & 79.6 & 05 & $\mathrm{NA}$ & NA & ANO & SG4 & 1 & None \\
\hline 174 & 232 & 80.1 & 04 & 02 & MSG & ANO & SIM & 1 & None \\
\hline 174 & 233 & 80.2 & 04 & 00 & MSG & ANO & CMX & 1 & None \\
\hline 174 & 234 & 81.1 & 04 & 00 & MSG & ANO & CMX & 1 & None \\
\hline 174 & 235 & 81.2 & 04 & 00 & MSG & ANO & CMX & 1 & None \\
\hline 174 & 236 & 82.1 & 04 & 00 & MSG & ANO & CMX & 1 & None \\
\hline 174 & 237 & 83.1 & 05 & NA & NA & ANO & SG4 & 1 & None \\
\hline 174 & 238 & 84.1 & 04 & 00 & MLT & ANO & CMX & 1 & None \\
\hline 174 & 239 & 84.2 & 04 & 00 & MLT & ANO & BPF & 1 & None \\
\hline 174 & 240 & 85.1 & 05 & $\mathrm{NA}$ & NA & ANO & SG4 & 1 & None \\
\hline 174 & 241 & 86.1 & 05 & NA & NA & ANO & SG4 & 1 & None \\
\hline 175 & 001 & 1.1 & 01 & 01 & CRT & ANO & SIM & 1 & None \\
\hline 175 & 002 & 2.1 & 03 & 01 & MLT & $\mathrm{AOB}$ & CMX & 1 & None \\
\hline 175 & 003 & 2.2 & 04 & 01 & MLT & $\mathrm{AOB}$ & SG4 & 1 & None \\
\hline 175 & 004 & 3.1 & 04 & 00 & IND & ANO & $\mathrm{CMX}$ & 1 & None \\
\hline 175 & 005 & 3.2 & 04 & 00 & MSG & ANO & SG4 & 1 & None \\
\hline 175 & 006 & 4.1 & 03 & 00 & MSG & $\mathrm{AOB}$ & CMX & 1 & None \\
\hline 175 & 007 & 5.1 & 01 & 00 & $\mathrm{MLT}$ & ANO & CMX & 1 & None \\
\hline 175 & 008 & 5.2 & 01 & 04 & MSG & ANO & PRI & 1 & None \\
\hline 175 & 009 & 5.3 & 04 & 01 & MSG & ANO & SG4 & 1 & None \\
\hline 175 & 010 & 6.1 & 01 & 02 & MLT & $\mathrm{AOB}$ & SIM & 1 & None \\
\hline 175 & 011 & 6.2 & 02 & 00 & MLT & $\mathrm{AOB}$ & SIM & 1 & None \\
\hline 175 & 012 & 7.1 & 03 & 00 & MSG & ANO & $\mathrm{SHA}$ & 1 & None \\
\hline 175 & 013 & 7.2 & 03 & 00 & MSG & ANO & CMX & 1 & None \\
\hline 175 & 014 & 7.3 & 04 & 00 & MSG & ANO & SG4 & 1 & None \\
\hline 175 & 015 & 8.1 & 01 & 01 & FLA & ANO & SIM & 1 & None \\
\hline 175 & 016 & 8.2 & 03 & 00 & MSG & ANO & CMX & 1 & None \\
\hline 175 & 017 & 8.3 & 04 & 00 & MSG & ANO & SG4 & 1 & None \\
\hline 175 & 018 & 9.1 & 02 & 04 & MSG & ANO & PRI & 1 & None \\
\hline 175 & 019 & 9.2 & 03 & 04 & $\mathrm{MLT}$ & ANO & PRI & 1 & None \\
\hline
\end{tabular}


Appendix D.1. TxDOT 41SR242 Feature 1 Debitage Analysis

\begin{tabular}{|c|c|c|c|c|c|c|c|c|c|}
\hline $\begin{array}{l}\text { Lot } \\
\text { No. }\end{array}$ & $\begin{array}{l}\text { Specimen } \\
\text { No. }\end{array}$ & Nodule No. & $\begin{array}{l}\text { Flake } \\
\text { Size }\end{array}$ & $\begin{array}{l}\text { Percent } \\
\text { Cortex }\end{array}$ & $\begin{array}{l}\text { Platform } \\
\text { Type }\end{array}$ & $\begin{array}{l}\text { Thermal } \\
\text { Alteration }\end{array}$ & $\begin{array}{c}\text { Technological } \\
\text { Class }\end{array}$ & Count & Comments \\
\hline 175 & 020 & 10.1 & 03 & 00 & MSG & $\mathrm{AOB}$ & SHA & 1 & None \\
\hline 175 & 021 & 10.2 & 03 & 00 & $\overline{M L T}$ & AOB & $\mathrm{CMX}$ & 1 & None \\
\hline 175 & 022 & 10.3 & 03 & 04 & MSG & $\mathrm{AOB}$ & $\mathrm{PRI}$ & 1 & None \\
\hline 175 & 023 & 11.1 & 01 & 00 & $\mathrm{MLT}$ & ANO & BTF & 1 & None \\
\hline 175 & 024 & 11.2 & 03 & 04 & MSG & ANO & PRI & 1 & None \\
\hline 175 & 025 & 11.3 & 03 & 00 & MSG & ANO & CMX & 1 & None \\
\hline 175 & 026 & 11.4 & 03 & 00 & IND & ANO & $\overline{C M X}$ & 1 & None \\
\hline 175 & 027 & 11.5 & 04 & 00 & FLA & ANO & CMX & 1 & None \\
\hline 175 & 028 & 12.1 & 02 & 01 & MSG & $\mathrm{AOB}$ & SIM & 1 & None \\
\hline 175 & 029 & 13.1 & 01 & 00 & FCT & ANO & BTF & 1 & None \\
\hline 175 & 030 & 14.1 & 02 & 04 & MSG & AOB & $\mathrm{SHA}$ & 1 & None \\
\hline 175 & 031 & 15.1 & 03 & 01 & MSG & ANO & SIM & 1 & None \\
\hline 175 & 032 & 16.1 & 02 & 01 & FLA & AOB & SIM & 1 & None \\
\hline 175 & 033 & 17.1 & 01 & 02 & $\mathrm{MLT}$ & ANO & SIM & 1 & None \\
\hline 175 & 034 & 18.1 & 03 & 01 & $\overline{M S G}$ & AOB & SIM & 1 & None \\
\hline 175 & 035 & 19.1 & 01 & 00 & MSG & ANO & SHA & 1 & None \\
\hline 175 & 036 & 19.2 & 04 & 00 & MSG & $\mathrm{AOB}$ & SG4 & 1 & None \\
\hline 175 & 037 & 20.1 & 03 & 01 & CMP & AOB & SIM & 1 & None \\
\hline 175 & 038 & 20.2 & 04 & 00 & IND & AOB & SG4 & 1 & None \\
\hline 175 & 039 & 20.3 & 04 & 00 & FCT & AOB & CMX & 1 & None \\
\hline 175 & 040 & 21.1 & 02 & 04 & $\overline{M S G}$ & ANO & PRI & 1 & None \\
\hline 175 & 041 & 21.2 & 02 & 01 & MSG & $\mathrm{AOB}$ & SIM & 1 & None \\
\hline 175 & 042 & 21.3 & 04 & 04 & MSG & AOB & PRI & 1 & None \\
\hline 175 & 043 & 22.1 & 04 & 00 & FCT & ANO & $\overline{C M X}$ & 1 & None \\
\hline 175 & 044 & 23.1 & 01 & 01 & FLA & $\mathrm{AOB}$ & SIM & 1 & None \\
\hline 175 & 045 & 24.1 & 04 & 00 & FLA & AOB & SIM & 1 & None \\
\hline 175 & 046 & 24.2 & 03 & 00 & MSG & $\mathrm{AOB}$ & CMX & 1 & None \\
\hline 175 & 047 & 25.1 & 03 & 00 & IND & ANO & CMX & 1 & None \\
\hline 175 & 048 & 26.1 & 04 & 00 & MSG & ANO & SG4 & 1 & None \\
\hline 175 & 049 & 27.1 & 03 & 04 & FCT & ANO & PRI & 1 & None \\
\hline 175 & 050 & 28.1 & 03 & 02 & MSG & ANO & SIM & 1 & None \\
\hline 175 & 051 & 28.2 & 04 & 00 & FCT & ANO & CMX & 1 & None \\
\hline 175 & 052 & 29.1 & 02 & 00 & IND & ANO & CMX & 1 & None \\
\hline 175 & 053 & 30.1 & 03 & 00 & $\overline{M L T}$ & ANO & CMX & 1 & None \\
\hline 175 & 054 & 31.1 & 02 & 00 & MSG & $\mathrm{AOB}$ & CMX & 1 & None \\
\hline 175 & 055 & 32.1 & 02 & 00 & MLT & ANO & CMX & 1 & None \\
\hline 175 & 056 & 32.2 & 03 & 00 & MSG & ANO & SIM & 1 & None \\
\hline 175 & 057 & 33.1 & 05 & NA & NA & NA & NA & 2 & Not Analyzed \\
\hline 175 & 058 & 34.1 & 03 & 00 & MLT & ANO & CMX & 1 & None \\
\hline 175 & 059 & 35.1 & 03 & 00 & MSG & ANO & CMX & 1 & None \\
\hline 175 & 060 & 36.1 & 03 & 00 & IND & ANO & SIM & 1 & None \\
\hline 175 & 061 & 37.1 & 03 & 00 & MSG & ANO & SHA & 1 & None \\
\hline 175 & 062 & 38.1 & 04 & 00 & MSG & $\mathrm{AOB}$ & $\mathrm{SHA}$ & 1 & None \\
\hline 175 & 063 & 39.1 & 04 & 04 & MSG & ANO & PRI & 1 & None \\
\hline 175 & 064 & 39.2 & 05 & NA & NA & NA & NA & 1 & Not Analyzed \\
\hline
\end{tabular}




\begin{tabular}{|c|c|c|c|c|c|c|c|c|c|}
\hline Lot & $\begin{array}{l}\text { Specimen } \\
\text { No. }\end{array}$ & Nodule No. & $\begin{array}{l}\text { Flake } \\
\text { Size } \\
\end{array}$ & $\begin{array}{l}\text { Percent } \\
\text { Cortex } \\
\end{array}$ & $\begin{array}{l}\text { Platform } \\
\text { Type } \\
\end{array}$ & $\begin{array}{c}\text { Thermal } \\
\text { Alteration }\end{array}$ & $\begin{array}{c}\text { Technological } \\
\text { Class }\end{array}$ & Count & Comments \\
\hline 194 & 001 & 1.1 & 01 & 01 & CRT & ANO & SIM & 1 & None \\
\hline 194 & 002 & 2.1 & 01 & 04 & IND & $\mathrm{AOB}$ & $\mathrm{PRI}$ & 1 & None \\
\hline 194 & 003 & 2.2 & 03 & 04 & FCT & $\mathrm{AOB}$ & $\mathrm{PRI}$ & 1 & None \\
\hline 194 & 004 & 2.3 & 03 & 02 & MSG & $\mathrm{AOB}$ & SIM & 1 & None \\
\hline 194 & 005 & 2.4 & 03 & 00 & MSG & $\mathrm{AOB}$ & SIM & 1 & None \\
\hline 194 & 006 & 2.5 & 03 & 04 & MSG & $\mathrm{AOB}$ & PRI & 1 & None \\
\hline 194 & 007 & 2.6 & 04 & 00 & FCT & $\mathrm{AOB}$ & SIM & 1 & None \\
\hline 194 & 008 & 3.1 & 01 & 00 & $\mathrm{MLT}$ & ANO & BTF & 1 & None \\
\hline 194 & 009 & 4.1 & 01 & 04 & IND & ANO & SIM & 1 & None \\
\hline 194 & 010 & 4.2 & 04 & 00 & MSG & ANO & SG4 & 1 & None \\
\hline 194 & 011 & 5.1 & 01 & 04 & MSG & ANO & $\mathrm{PRI}$ & 1 & None \\
\hline 194 & 012 & 6.1 & 01 & 03 & MSG & ANO & SIM & 1 & None \\
\hline 194 & 013 & 6.2 & 03 & 01 & FLA & ANO & SIM & 1 & None \\
\hline 194 & 014 & 7.1 & 01 & 00 & $\mathrm{MLT}$ & ANO & BTF & 1 & None \\
\hline 194 & 015 & 7.2 & 02 & 00 & MSG & ANO & BTF & 1 & None \\
\hline 194 & 016 & 7.3 & 01 & 00 & MLT & ANO & BTF & 1 & None \\
\hline 194 & 017 & 7.4 & 01 & 00 & MLT & ANO & BTF & 1 & None \\
\hline 194 & 018 & 7.5 & 02 & 00 & IND & ANO & CMX & 1 & None \\
\hline 194 & 019 & 7.6 & 02 & 01 & MSG & ANO & SIM & 1 & None \\
\hline 194 & 020 & 7.7 & 02 & 00 & MSG & ANO & SIM & 1 & None \\
\hline 194 & 021 & 7.8 & 02 & 00 & MSG & ANO & CMX & 1 & None \\
\hline 194 & 022 & 7.9 & 03 & 00 & MSG & ANO & SIM & 1 & None \\
\hline 194 & 023 & 7.10 & 04 & 00 & MSG & ANO & CMX & 1 & None \\
\hline 194 & 024 & 7.11 & 04 & 00 & MLT & ANO & CMX & 1 & None \\
\hline 194 & 025 & 8.1 & 01 & 03 & MLT & ANO & SIM & 1 & None \\
\hline 194 & 026 & 8.2 & 03 & 00 & MSG & ANO & CMX & 1 & None \\
\hline 194 & 027 & 8.3 & 04 & 01 & MSG & ANO & $\mathrm{SHA}$ & 1 & None \\
\hline 194 & 028 & 8.4 & 04 & 01 & CRT & ANO & SIM & 1 & None \\
\hline 194 & 029 & 9.1 & 01 & 04 & IND & ANO & $\mathrm{PRI}$ & 1 & None \\
\hline 194 & 030 & 9.2 & 01 & 01 & CRT & ANO & CMX & 1 & None \\
\hline 194 & 031 & 9.3 & 02 & 01 & CRT & ANO & SIM & 1 & None \\
\hline 194 & 032 & 9.4 & 03 & 00 & MSG & ANO & $\mathrm{CMX}$ & 1 & None \\
\hline 194 & 033 & 9.5 & 03 & 04 & FLA & ANO & PRI & 1 & None \\
\hline 194 & 034 & 9.6 & 04 & 01 & FLA & ANO & SIM & 1 & None \\
\hline 194 & 035 & 10.1 & 01 & 04 & CRT & ANO & $\mathrm{PRI}$ & 1 & None \\
\hline 194 & 036 & 11.1 & 01 & 00 & MLT & ANO & BTF & 1 & None \\
\hline 194 & 037 & 11.2 & 03 & 00 & MSG & ANO & $\mathrm{CMX}$ & 1 & None \\
\hline 194 & 038 & 11.3 & 04 & 00 & MLT & ANO & CMX & 1 & None \\
\hline 194 & 039 & 12.1 & 01 & 04 & MSG & ANO & SIM & 1 & None \\
\hline 194 & 040 & 12.2 & 04 & 04 & MSG & ANO & SIM & 1 & None \\
\hline 194 & 041 & 13.1 & 02 & 01 & MSG & ANO & SIM & 1 & None \\
\hline 194 & 042 & 13.2 & 03 & 01 & MSG & ANO & SIM & 1 & None \\
\hline 194 & 043 & 14.1 & 02 & 00 & MLT & ANO & CMX & 1 & None \\
\hline 194 & 044 & 14.2 & 03 & 02 & FCT & ANO & SIM & 1 & None \\
\hline 194 & 045 & 14.3 & 02 & 00 & MSG & ANO & SHA & 1 & None \\
\hline 194 & 046 & 14.4 & 03 & 00 & MSG & ANO & SIM & 1 & None \\
\hline 194 & 047 & 14.5 & 03 & 02 & $\mathrm{MLT}$ & ANO & SIM & 1 & None \\
\hline 194 & 048 & 14.6 & 03 & 00 & MSG & ANO & CMX & 1 & None \\
\hline 194 & 049 & 14.7 & 04 & 00 & MSG & ANO & SG4 & 1 & None \\
\hline 194 & 050 & 15.1 & 01 & 00 & MLT & ANO & BTF & 1 & None \\
\hline 194 & 051 & 15.2 & 02 & 01 & MSG & ANO & SIM & 1 & None \\
\hline 194 & 052 & 15.3 & 04 & 00 & MSG & ANO & $\mathrm{CMX}$ & 1 & None \\
\hline 194 & 053 & 16.1 & 02 & 00 & MSG & ANO & SHA & 1 & None \\
\hline 194 & 054 & 17.1 & 01 & 00 & MLT & ANO & CMX & 1 & None \\
\hline 194 & 055 & 17.2 & 03 & 00 & MLT & ANO & BTF & 1 & None \\
\hline 194 & 056 & 17.3 & 03 & 01 & MSG & ANO & SIM & 1 & None \\
\hline 194 & 057 & 17.4 & 04 & 00 & MLT & ANO & $\mathrm{CMX}$ & 1 & None \\
\hline 194 & 058 & 17.5 & 03 & 01 & FLA & ANO & SIM & 1 & None \\
\hline 194 & 059 & 18.1 & 02 & 00 & MSG & ANO & CMX & 1 & None \\
\hline 194 & 060 & 19.1 & 04 & 00 & $\mathrm{MLT}$ & ANO & $\mathrm{CMX}$ & 1 & None \\
\hline 194 & 061 & 19.2 & 04 & 00 & MLT & ANO & CMX & 1 & None \\
\hline 194 & 062 & 19.3 & 04 & 00 & MLT & ANO & CMX & 1 & None \\
\hline 194 & 063 & 20.1 & 02 & 00 & MSG & ANO & $\mathrm{CMX}$ & 1 & None \\
\hline 194 & 064 & 20.2 & 02 & 04 & FLA & ANO & PRI & 1 & None \\
\hline 194 & 065 & 21.1 & 04 & 00 & $\overline{M L T}$ & ANO & $\overline{C M X}$ & 1 & None \\
\hline 194 & 066 & 22.1 & 02 & 00 & MSG & ANO & CMX & 1 & None \\
\hline
\end{tabular}




\begin{tabular}{|c|c|c|c|c|c|c|c|c|c|}
\hline $\begin{array}{l}\text { Lot } \\
\text { No. }\end{array}$ & $\begin{array}{l}\text { Specimen } \\
\text { No. } \\
\end{array}$ & Nodule No. & $\begin{array}{l}\text { Flake } \\
\text { Size }\end{array}$ & $\begin{array}{l}\text { Percent } \\
\text { Cortex } \\
\end{array}$ & $\begin{array}{l}\text { Platform } \\
\text { Type } \\
\end{array}$ & $\begin{array}{c}\text { Thermal } \\
\text { Alteration }\end{array}$ & $\begin{array}{c}\text { Technological } \\
\text { Class } \\
\end{array}$ & Count & Comments \\
\hline 194 & 067 & 22.2 & 03 & 01 & MSG & ANO & SHA & 1 & None \\
\hline 194 & 068 & 22.3 & 03 & 04 & MSG & ANO & $\mathrm{PRI}$ & 1 & None \\
\hline 194 & 069 & 22.4 & 04 & 04 & MSG & ANO & PRI & 1 & None \\
\hline 194 & 070 & 23.1 & 02 & 00 & MLT & ANO & BFT & 1 & None \\
\hline 194 & 071 & 23.2 & 04 & 00 & MSG & ANO & CMX & 1 & None \\
\hline 194 & 072 & 24.1 & 03 & 04 & MSG & ANO & PRI & 1 & None \\
\hline 194 & 073 & 24.2 & 03 & 01 & FCT & ANO & SIM & 1 & None \\
\hline 194 & 074 & 25.1 & 04 & 04 & MSG & ANO & PRI & 1 & None \\
\hline 194 & 075 & 26.1 & 03 & 04 & MSG & ANO & $\mathrm{SHA}$ & 1 & None \\
\hline 194 & 076 & 26.2 & 04 & 04 & MSG & ANO & $\mathrm{PRI}$ & 1 & None \\
\hline 194 & 077 & 26.3 & 04 & 00 & MSG & ANO & SHA & 1 & None \\
\hline 194 & 078 & 27.1 & 03 & 00 & MSG & ANO & CMX & 1 & None \\
\hline 194 & 079 & 27.2 & 03 & 00 & MSG & ANO & CMX & 1 & None \\
\hline 194 & 080 & 28.1 & 03 & 00 & $\overline{M L T}$ & ANO & CMX & 1 & None \\
\hline 194 & 081 & 29.1 & 03 & 01 & CRT & ANO & SIM & 1 & None \\
\hline 194 & 082 & 29.2 & 04 & 00 & MLT & ANO & CMX & 1 & None \\
\hline 194 & 083 & 30.1 & 03 & 00 & $\overline{M L T}$ & ANO & CMX & 1 & None \\
\hline 195 & 001 & 1.1 & 03 & 01 & FLA & ANO & SIM & 1 & None \\
\hline 195 & 002 & 1.2 & 04 & 00 & MSG & ANO & CMX & 1 & None \\
\hline 195 & 003 & 1.3 & 04 & 00 & $\overline{M S G}$ & ANO & SHA & 1 & None \\
\hline 195 & 004 & 2.1 & 02 & 01 & CRT & ANO & SIM & 1 & None \\
\hline 195 & 005 & 2.2 & 03 & 00 & FLA & ANO & SIM & 1 & None \\
\hline 195 & 006 & 2.3 & 04 & 00 & MSG & ANO & IND & 1 & None \\
\hline 195 & 007 & 3.1 & 01 & 00 & MSG & ANO & SIM & 1 & None \\
\hline 195 & 008 & 4.1 & 01 & 04 & MSG & ANO & PRI & 1 & None \\
\hline 195 & 009 & 4.2 & 03 & 00 & MSG & ANO & SHA & 1 & None \\
\hline 195 & 010 & 4.3 & 04 & 00 & $\overline{M S G}$ & ANO & IND & 1 & None \\
\hline 195 & 011 & 4.4 & 04 & 00 & CRT & ANO & IND & 1 & None \\
\hline 195 & 012 & 5.1 & 04 & 00 & MLT & ANO & CMX & 1 & None \\
\hline 195 & 013 & 6.1 & 04 & 04 & CRT & ANO & PRI & 1 & None \\
\hline 195 & 014 & 7.1 & 01 & 02 & CRT & ANO & SIM & 1 & None \\
\hline 195 & 015 & 7.2 & 02 & 00 & MLT & ANO & BTF & 1 & None \\
\hline 195 & 016 & 7.3 & 02 & 00 & MLT & ANO & CMX & 1 & None \\
\hline 195 & 017 & 7.4 & 02 & 00 & MSG & ANO & SIM & 1 & None \\
\hline 195 & 018 & 7.5 & 03 & 00 & MSG & ANO & CMX & 1 & None \\
\hline 195 & 019 & 7.6 & 03 & 01 & CRT & ANO & $\mathrm{CMX}$ & 1 & None \\
\hline 195 & 020 & 7.7 & 03 & 00 & FCT & ANO & CMX & 1 & None \\
\hline 195 & 021 & 7.8 & 03 & 00 & MSG & ANO & CMX & 1 & None \\
\hline 195 & 022 & 7.9 & 04 & 00 & MSG & ANO & IND & 1 & None \\
\hline 195 & 023 & 7.10 & 04 & 00 & MSG & ANO & IND & 1 & None \\
\hline 195 & 024 & 7.11 & 04 & 00 & MSG & ANO & IND & 1 & None \\
\hline 195 & 025 & 8.1 & 02 & 00 & MSG & ANO & CMX & 1 & None \\
\hline 195 & 026 & 8.2 & 03 & 00 & MLT & ANO & CMX & 1 & None \\
\hline 195 & 027 & 8.3 & 03 & 00 & MSG & ANO & IND & 1 & None \\
\hline 195 & 028 & 9.1 & 03 & 00 & MSG & ANO & CMX & 1 & None \\
\hline 195 & 029 & 10.1 & 04 & 00 & CRT & ANO & IND & 1 & None \\
\hline 195 & 030 & 11.1 & 02 & 03 & MSG & ANO & SIM & 1 & None \\
\hline 195 & 031 & 12.1 & 02 & 03 & MSG & ANO & SIM & 1 & None \\
\hline 195 & 032 & 12.2 & 04 & 00 & MSG & ANO & IND & 1 & None \\
\hline 195 & 033 & 12.3 & 04 & 03 & MSG & ANO & IND & 1 & None \\
\hline 195 & 034 & 13.1 & 03 & 00 & MLT & ANO & CMX & 1 & None \\
\hline 195 & 035 & 13.2 & 02 & 00 & MSG & ANO & BTF & 1 & None \\
\hline 195 & 036 & 13.3 & 02 & 00 & MSG & ANO & BTF & 1 & None \\
\hline 195 & 037 & 13.4 & 03 & 00 & MLT & ANO & BTF & 1 & None \\
\hline 195 & 038 & 14.1 & 02 & 03 & MSG & $\mathrm{AOB}$ & SIM & 1 & None \\
\hline 195 & 039 & 14.2 & 02 & 04 & CRT & ANO & PRI & 1 & None \\
\hline 195 & 040 & 15.1 & 02 & 03 & CRT & ANO & SIM & 1 & None \\
\hline 195 & 041 & 15.2 & 02 & 03 & $\overline{M S G}$ & ANO & SIM & 1 & None \\
\hline 195 & 042 & 15.3 & 04 & 04 & MSG & ANO & SIM & 1 & None \\
\hline 195 & 043 & 16.1 & 02 & 00 & FCT & ANO & $\mathrm{CMX}$ & 1 & None \\
\hline 195 & 044 & 17.1 & 04 & 00 & MSG & ANO & IND & 1 & None \\
\hline 195 & 045 & 18.1 & 03 & 00 & MSG & ANO & IND & 1 & None \\
\hline 195 & 046 & 19.1 & 02 & 00 & MLT & ANO & BTF & 1 & None \\
\hline 195 & 047 & 19.2 & 04 & 00 & MSG & ANO & IND & 1 & None \\
\hline 195 & 048 & 19.3 & 04 & 00 & MSG & ANO & IND & 1 & None \\
\hline 195 & 049 & 19.4 & 04 & 00 & MSG & ANO & IND & 1 & None \\
\hline
\end{tabular}




\begin{tabular}{|c|c|c|c|c|c|c|c|c|c|}
\hline $\begin{array}{l}\text { Lot } \\
\text { No. }\end{array}$ & $\begin{array}{l}\text { Specimen } \\
\text { No. }\end{array}$ & Nodule No. & $\begin{array}{l}\text { Flake } \\
\text { Size }\end{array}$ & $\begin{array}{l}\text { Percent } \\
\text { Cortex }\end{array}$ & $\begin{array}{l}\text { Platform } \\
\text { Type }\end{array}$ & $\begin{array}{l}\text { Thermal } \\
\text { Alteration }\end{array}$ & $\begin{array}{c}\text { Technological } \\
\text { Class }\end{array}$ & Count & Comments \\
\hline 195 & 050 & 20.1 & 03 & 00 & MSG & ANO & IND & 1 & None \\
\hline 195 & 051 & 20.2 & 04 & 00 & $\mathrm{MLT}$ & ANO & IND & 1 & None \\
\hline 195 & 052 & 20.3 & 04 & 00 & $\mathrm{MLT}$ & $\mathrm{AOB}$ & IND & 1 & None \\
\hline 195 & 053 & 21.1 & 02 & 01 & CRT & $\mathrm{AOB}$ & SIM & 1 & None \\
\hline 195 & 054 & 21.2 & 04 & 00 & MSG & ANO & IND & 1 & None \\
\hline 195 & 055 & 21.3 & 04 & 00 & MSG & ANO & IND & 1 & None \\
\hline 195 & 056 & 22.1 & 04 & 00 & MSG & ANO & IND & 1 & None \\
\hline 195 & 057 & 23.1 & 03 & 00 & MLT & ANO & CMX & 1 & None \\
\hline 195 & 058 & 23.2 & 04 & 00 & MSG & ANO & SIM & 1 & None \\
\hline 195 & 059 & 23.3 & 04 & 00 & FLA & ANO & IND & 1 & None \\
\hline 198 & 001 & 1.1 & 01 & 01 & FLT & ANO & CMX & 1 & None \\
\hline 198 & 002 & 1.2 & 02 & 01 & $\mathrm{MLT}$ & ANO & CMX & 1 & None \\
\hline 198 & 003 & 1.3 & 01 & 01 & FCT & ANO & SIM & 1 & None \\
\hline 198 & 004 & 2.1 & 01 & 01 & CRT & ANO & SIM & 1 & None \\
\hline 198 & 005 & 2.2 & 01 & 00 & $\overline{M S G}$ & ANO & SIM & 1 & None \\
\hline 198 & 006 & 3.1 & 04 & 00 & MSG & ANO & SG4 & 1 & None \\
\hline 198 & 007 & 3.2 & 03 & 00 & MSG & ANO & CMX & 1 & None \\
\hline 198 & 008 & 3.3 & 03 & 00 & IND & ANO & CMX & 1 & None \\
\hline 198 & 009 & 3.4 & 02 & 00 & MSG & ANO & SIM & 1 & None \\
\hline 198 & 010 & 3.5 & 01 & 01 & MSG & ANO & SIM & 1 & None \\
\hline 198 & 011 & 3.6 & 01 & 00 & MSG & ANO & SHA & 1 & None \\
\hline 198 & 012 & 3.7 & 01 & 01 & $\mathrm{MLT}$ & ANO & BTF & 1 & None \\
\hline 198 & 013 & 4.1 & 02 & 00 & MSG & ANO & $\mathrm{SHA}$ & 1 & None \\
\hline 198 & 014 & 4.2 & 01 & 01 & MSG & ANO & SIM & 1 & None \\
\hline 198 & 015 & 5.1 & 01 & 01 & CRT & ANO & SIM & 1 & None \\
\hline 198 & 016 & 6.1 & 04 & 00 & IND & ANO & SIM & 1 & None \\
\hline 198 & 017 & 6.2 & 03 & 02 & IND & ANO & PRI & 1 & None \\
\hline 198 & 018 & 6.3 & 03 & 00 & MSG & ANO & SHA & 1 & None \\
\hline 198 & 019 & 6.4 & 03 & 00 & MSG & ANO & SIM & 1 & None \\
\hline 198 & 020 & 6.5 & 03 & 00 & MSG & ANO & SIM & 1 & None \\
\hline 198 & 021 & 6.6 & 02 & 00 & $\mathrm{MLT}$ & ANO & CMX & 1 & None \\
\hline 198 & 022 & 6.7 & 02 & 00 & MSG & ANO & SIM & 1 & None \\
\hline 198 & 023 & 6.8 & 02 & 00 & FLA & ANO & SIM & 1 & None \\
\hline 198 & 024 & 6.9 & 02 & 01 & $\overline{\mathrm{CRT}}$ & ANO & $\overline{\mathrm{SIM}}$ & 1 & None \\
\hline 198 & 025 & 6.10 & 01 & 04 & CRT & ANO & PRI & 1 & None \\
\hline 198 & 026 & 7.1 & 02 & 00 & MLT & ANO & BTF & 1 & None \\
\hline 198 & 027 & 8.1 & 03 & 01 & CRT & ANO & SIM & 1 & None \\
\hline 198 & 028 & 8.2 & 04 & 04 & IND & ANO & PRI & 1 & None \\
\hline 198 & 029 & 8.3 & 03 & 01 & IND & ANO & SIM & 1 & None \\
\hline 198 & 030 & 8.4 & 01 & 02 & IND & ANO & SIM & 1 & None \\
\hline 198 & 031 & 8.5 & 01 & 01 & FLA & ANO & CMX & 1 & None \\
\hline 198 & 032 & 9.1 & 03 & 00 & MSG & ANO & SIM & 1 & None \\
\hline 198 & 033 & 9.2 & 04 & 00 & MSG & ANO & SIM & 1 & None \\
\hline 198 & 034 & 9.3 & 03 & 00 & MSG & ANO & SIM & 1 & None \\
\hline 198 & 035 & 9.4 & 03 & 01 & $\mathrm{FCT}$ & ANO & SIM & 1 & None \\
\hline 198 & 036 & 9.5 & 03 & 00 & MSG & ANO & $\mathrm{CMX}$ & 1 & None \\
\hline 198 & 037 & 9.6 & 02 & 00 & MSG & ANO & SIM & 1 & None \\
\hline 198 & 038 & 9.7 & 02 & 00 & IND & ANO & SIM & 1 & None \\
\hline 198 & 039 & 9.8 & 03 & 00 & MSG & ANO & SIM & 1 & None \\
\hline 198 & 040 & 9.9 & 03 & 00 & MSG & ANO & SIM & 1 & None \\
\hline 198 & 041 & 9.10 & 03 & 00 & FLA & ANO & SIM & 1 & None \\
\hline 198 & 042 & 9.11 & 03 & 00 & MLT & ANO & $\mathrm{CMX}$ & 1 & None \\
\hline 198 & 043 & 9.12 & 03 & 00 & IND & ANO & SIM & 1 & None \\
\hline 198 & 044 & 9.13 & 03 & 00 & MSG & ANO & SIM & 1 & None \\
\hline 198 & 045 & 9.14 & 03 & 00 & MSG & ANO & CMX & 1 & None \\
\hline 198 & 046 & 9.15 & 02 & 00 & IND & ANO & CMX & 1 & None \\
\hline 198 & 047 & 9.16 & 03 & 00 & $\mathrm{MLT}$ & ANO & CMX & 1 & None \\
\hline 198 & 048 & 9.17 & 02 & 00 & MSG & ANO & SIM & 1 & None \\
\hline 198 & 049 & 9.18 & 02 & 00 & MLT & ANO & BTF & 1 & None \\
\hline 198 & 050 & 9.19 & 02 & 00 & IND & ANO & CMX & 1 & None \\
\hline 198 & 051 & 9.20 & 02 & 00 & $\mathrm{MLT}$ & ANO & CMX & $\frac{1}{1}$ & None \\
\hline 198 & 052 & 9.21 & 02 & 00 & MSG & ANO & SIM & 1 & None \\
\hline 198 & 053 & 9.22 & 02 & 00 & MSG & ANO & SIM & 1 & None \\
\hline 198 & 054 & 9.23 & 01 & 00 & MLT & ANO & BTF & 1 & None \\
\hline 198 & 055 & 9.24 & 02 & 01 & MSG & ANO & SIM & 1 & None \\
\hline 198 & 056 & 9.25 & 02 & 00 & MLT & ANO & CMX & 1 & None \\
\hline
\end{tabular}




\begin{tabular}{|c|c|c|c|c|c|c|c|c|c|}
\hline $\begin{array}{l}\text { Lot } \\
\text { No. }\end{array}$ & $\begin{array}{l}\text { Specimen } \\
\text { No. } \\
\end{array}$ & Nodule No. & $\begin{array}{l}\text { Flake } \\
\text { Size }\end{array}$ & $\begin{array}{l}\text { Percent } \\
\text { Cortex } \\
\end{array}$ & $\begin{array}{l}\text { Platform } \\
\text { Type } \\
\end{array}$ & $\begin{array}{c}\text { Thermal } \\
\text { Alteration }\end{array}$ & $\begin{array}{c}\text { Technological } \\
\text { Class } \\
\end{array}$ & Count & Comments \\
\hline 198 & 057 & 9.26 & 02 & 04 & IND & ANO & PRI & 1 & None \\
\hline 198 & 058 & 9.27 & 01 & 00 & MSG & ANO & BTF & 1 & None \\
\hline 198 & 059 & 9.28 & 01 & 00 & IND & ANO & $\mathrm{CMX}$ & 1 & None \\
\hline 198 & 060 & 9.29 & 01 & 00 & MSG & ANO & CMX & 1 & None \\
\hline 198 & 061 & 9.30 & 01 & 00 & MSG & ANO & SIM & 1 & None \\
\hline 198 & 062 & 9.31 & 01 & 00 & MLT & ANO & CMX & 1 & None \\
\hline 198 & 063 & 9.32 & 01 & 00 & $\overline{M L T}$ & ANO & BTF & 1 & None \\
\hline 198 & 064 & 9.33 & 01 & 01 & CRT & ANO & SIM & 1 & None \\
\hline 198 & 065 & 9.34 & 01 & 01 & MLT & ANO & BTF & 1 & None \\
\hline 198 & 066 & 9.35 & 01 & 00 & MLT & ANO & BTF & 1 & None \\
\hline 198 & 067 & 10.1 & 02 & 01 & FLT & ANO & SIM & 1 & None \\
\hline 198 & 068 & 10.2 & 02 & 01 & CRT & ANO & SIM & 1 & None \\
\hline 198 & 069 & 10.3 & 01 & 00 & MLT & ANO & CMX & 1 & None \\
\hline 198 & 070 & 11.1 & 02 & 00 & $\overline{M S G}$ & ANO & CMX & 1 & None \\
\hline 198 & 071 & 11.2 & 03 & 00 & MSG & ANO & SIM & 1 & None \\
\hline 198 & 072 & 12.1 & 01 & 01 & CRT & ANO & SIM & 1 & None \\
\hline 198 & 073 & 13.1 & 03 & 02 & $\overline{M S G}$ & ANO & SIM & 1 & None \\
\hline 198 & 074 & 13.2 & 03 & 01 & MSG & ANO & SIM & 1 & None \\
\hline 198 & 075 & 13.3 & 03 & 01 & MSG & ANO & SIM & 1 & None \\
\hline 198 & 076 & 13.4 & 04 & 02 & IND & ANO & SIM & 1 & None \\
\hline 198 & 077 & 13.5 & 04 & 04 & MSG & ANO & PRI & 1 & None \\
\hline 198 & 078 & 14.1 & 01 & 01 & FCT & ANO & SIM & 1 & None \\
\hline 198 & 079 & 15.1 & 03 & 00 & MLT & ANO & BTF & 1 & None \\
\hline 198 & 080 & 15.2 & 03 & 00 & MSG & ANO & CMX & 1 & None \\
\hline 198 & 081 & 15.3 & 03 & 00 & MLT & ANO & CMX & 1 & None \\
\hline 198 & 082 & 16.1 & 03 & 00 & MLT & ANO & CMX & 1 & None \\
\hline 198 & 083 & 16.2 & 04 & 00 & MSG & ANO & SG4 & 1 & None \\
\hline 198 & 084 & 17.1 & 03 & 00 & IND & ANO & CMX & 1 & None \\
\hline 198 & 085 & 17.2 & 03 & 00 & MSG & ANO & CMX & 1 & None \\
\hline 198 & 086 & 18.1 & 03 & 00 & MSG & ANO & SIM & 1 & None \\
\hline 198 & 087 & 19.1 & 01 & 01 & IND & AOB & CMX & 1 & None \\
\hline 198 & 088 & 19.2 & 02 & 00 & IND & ANO & CMX & 1 & None \\
\hline 198 & 089 & 20.1 & 03 & 00 & MSG & ANO & SIM & 1 & None \\
\hline 198 & 090 & 21.1 & 02 & 01 & MSG & ANO & SIM & 1 & None \\
\hline 198 & 091 & 21.2 & 04 & 00 & IND & ANO & SG4 & 1 & None \\
\hline 198 & 092 & 21.3 & 04 & 00 & MSG & ANO & SG4 & 1 & None \\
\hline 198 & 093 & 22.1 & 01 & 00 & IND & ANO & CMX & 1 & None \\
\hline 198 & 094 & 23.1 & 01 & 04 & MSG & $\mathrm{AOB}$ & $\begin{array}{l}\mathrm{PRI} \\
\end{array}$ & 1 & None \\
\hline 198 & 095 & 24.1 & 03 & 02 & FCT & ANO & SIM & 1 & None \\
\hline 198 & 096 & 24.2 & 03 & 02 & MSG & ANO & SIM & 1 & None \\
\hline 198 & 097 & 24.3 & 03 & 01 & $\overline{F C T}$ & ANO & SIM & 1 & None \\
\hline 198 & 098 & 24.4 & 03 & 00 & MSG & ANO & SIM & 1 & None \\
\hline 198 & 099 & 25.1 & 01 & 00 & MLT & ANO & BTF & 1 & None \\
\hline 198 & 100 & 26.1 & 01 & 00 & MSG & ANO & SIM & 1 & None \\
\hline 198 & 101 & 26.2 & 03 & 00 & MSG & ANO & SIM & 1 & None \\
\hline 198 & 102 & 27.1 & 03 & 01 & $\overline{F C T}$ & ANO & SIM & 1 & None \\
\hline 198 & 103 & 27.2 & 04 & 00 & IND & ANO & SG4 & 1 & None \\
\hline 198 & 104 & 28.1 & 02 & 02 & FLA & ANO & SIM & 1 & None \\
\hline 198 & 105 & 28.2 & 02 & 01 & CRT & ANO & SIM & 1 & None \\
\hline 198 & 106 & 28.3 & 03 & 00 & MSG & ANO & SHA & 1 & None \\
\hline 198 & 107 & 28.4 & 04 & 00 & MSG & ANO & SG4 & 1 & None \\
\hline 198 & 108 & 29.1 & 03 & 04 & FCT & ANO & PRI & 1 & None \\
\hline 198 & 109 & 30.1 & 02 & 01 & FLA & ANO & SIM & 1 & None \\
\hline 198 & 110 & 30.2 & 03 & 03 & FCT & ANO & SIM & 1 & None \\
\hline 198 & 111 & 30.3 & 03 & 01 & MSG & ANO & SIM & 1 & None \\
\hline 198 & 112 & 30.4 & 03 & 00 & FCT & ANO & CMX & 1 & None \\
\hline 198 & 113 & 31.1 & 04 & 00 & FCT & ANO & CMX & 1 & None \\
\hline 198 & 114 & 31.2 & 04 & 00 & $\overline{M L T}$ & ANO & SG4 & 1 & None \\
\hline 198 & 115 & 31.3 & 04 & 00 & MLT & ANO & SG4 & 1 & None \\
\hline 198 & 116 & 32.1 & 04 & 00 & $\mathrm{MLT}$ & ANO & SG4 & 1 & None \\
\hline 198 & 117 & 32.2 & 04 & 00 & MSG & ANO & SG4 & 1 & None \\
\hline 198 & 118 & 33.1 & 04 & 00 & IND & ANO & SG4 & 1 & None \\
\hline 198 & 119 & 33.2 & 04 & 04 & MSG & ANO & PRI & 1 & None \\
\hline 198 & 120 & 33.3 & 03 & 01 & MSG & ANO & SIM & 1 & None \\
\hline 198 & 121 & 34.1 & 03 & 01 & $\overline{F C T}$ & ANO & SIM & 1 & None \\
\hline 198 & 122 & 34.2 & 03 & 04 & IND & ANO & PRI & 1 & None \\
\hline
\end{tabular}




\begin{tabular}{|c|c|c|c|c|c|c|c|c|c|}
\hline $\begin{array}{l}\text { Lot } \\
\text { No. }\end{array}$ & $\begin{array}{l}\text { Specimen } \\
\text { No. } \\
\end{array}$ & Nodule No. & $\begin{array}{l}\text { Flake } \\
\text { Size } \\
\end{array}$ & $\begin{array}{l}\text { Percent } \\
\text { Cortex } \\
\end{array}$ & $\begin{array}{l}\text { Platform } \\
\text { Type } \\
\end{array}$ & $\begin{array}{c}\text { Thermal } \\
\text { Alteration }\end{array}$ & $\begin{array}{c}\text { Technological } \\
\text { Class } \\
\end{array}$ & Count & Comments \\
\hline 198 & 123 & 34.3 & 04 & 00 & MSG & ANO & SG4 & 1 & None \\
\hline 198 & 124 & 35.1 & 03 & 01 & MSG & ANO & SIM & 1 & None \\
\hline 198 & 125 & 35.2 & 04 & 00 & MSG & ANO & SG4 & 1 & None \\
\hline 198 & 126 & 36.1 & 03 & 00 & MSG & ANO & SIM & 1 & None \\
\hline 198 & 127 & 37.1 & 03 & 00 & FCT & ANO & SIM & 1 & None \\
\hline 198 & 128 & 37.2 & 04 & 00 & MSG & ANO & SG4 & 1 & None \\
\hline 198 & 129 & 38.1 & 03 & 04 & FCT & ANO & $\mathrm{PRI}$ & 1 & None \\
\hline 198 & 130 & 39.1 & 04 & 00 & IND & ANO & SG4 & 1 & None \\
\hline 198 & 131 & 39.2 & 04 & 00 & MSG & ANO & SG4 & 1 & None \\
\hline 199 & 001 & 1.1 & 01 & 04 & CRT & ANO & $\mathrm{PRI}$ & 1 & None \\
\hline 199 & 002 & 1.2 & 01 & 02 & FCT & ANO & SIM & 1 & None \\
\hline 199 & 003 & 2.1 & 01 & 00 & $\overline{M L T}$ & ANO & $\mathrm{CMX}$ & 1 & None \\
\hline 199 & 004 & 3.1 & 01 & 00 & FCT & ANO & BTF & 1 & None \\
\hline 199 & 005 & 3.2 & 02 & 00 & MSG & ANO & SIM & 1 & None \\
\hline 199 & 006 & 3.3 & 04 & 00 & MSG & $\mathrm{AOB}$ & IND & 1 & None \\
\hline 199 & 007 & 4.1 & 02 & 00 & MSG & ANO & CMX & 1 & None \\
\hline 199 & 008 & 4.2 & 02 & 00 & MSG & $\mathrm{AOB}$ & $\mathrm{SHA}$ & 1 & None \\
\hline 199 & 009 & 5.1 & 01 & 00 & MSG & ANO & $\mathrm{SHA}$ & 1 & None \\
\hline 199 & 010 & 5.2 & 03 & 00 & FCT & ANO & SHA & 1 & None \\
\hline 199 & 011 & 6.1 & 03 & 00 & MLT & ANO & BTF & 1 & None \\
\hline 199 & 012 & 7.1 & 04 & 00 & MLT & ANO & BPF & 1 & None \\
\hline 199 & 013 & 8.1 & 02 & 04 & MSG & ANO & SIM & 1 & None \\
\hline 199 & 014 & 8.2 & 02 & 04 & MSG & ANO & $\mathrm{PRI}$ & 1 & None \\
\hline 199 & 015 & 8.3 & 03 & 04 & $\mathrm{FCT}$ & ANO & SIM & 1 & None \\
\hline 199 & 016 & 8.4 & 03 & 02 & CRT & ANO & SIM & 1 & None \\
\hline 199 & 017 & 8.5 & 04 & 00 & MSG & ANO & SIM & 1 & None \\
\hline 199 & 018 & 8.6 & 03 & 02 & FLA & ANO & CMX & 1 & None \\
\hline 199 & 019 & 8.7 & 03 & 00 & MLT & ANO & SIM & 1 & None \\
\hline 199 & 020 & 8.8 & 03 & 00 & MLT & ANO & CMX & 1 & None \\
\hline 199 & 021 & 8.9 & 04 & 00 & MSG & ANO & SIM & 1 & None \\
\hline 199 & 022 & 8.10 & 04 & 00 & MSG & ANO & CMX & 1 & None \\
\hline 199 & 023 & 8.11 & 04 & 00 & $\mathrm{MLT}$ & ANO & SG4 & 1 & None \\
\hline 199 & 024 & 9.1 & 02 & 00 & MSG & ANO & CMX & 1 & None \\
\hline 199 & 025 & 10.1 & 02 & 00 & FCT & ANO & CMX & 1 & None \\
\hline 199 & 026 & 10.2 & 03 & 00 & MSG & ANO & CMX & 1 & None \\
\hline 199 & 027 & 11.1 & 02 & 00 & MSG & ANO & SIM & 1 & None \\
\hline 199 & 028 & 11.2 & 03 & 01 & CRT & ANO & SIM & 1 & None \\
\hline 199 & 029 & 11.3 & 04 & 00 & MSG & ANO & SHA & 1 & None \\
\hline 199 & 030 & 12.1 & 02 & 00 & CRT & ANO & SIM & 1 & None \\
\hline 199 & 031 & 12.2 & 02 & 00 & MSG & ANO & SHA & 1 & None \\
\hline 199 & 032 & 12.3 & 03 & 00 & MSG & ANO & $\mathrm{SHA}$ & 1 & None \\
\hline 199 & 033 & 12.4 & 03 & 01 & CRT & ANO & SIM & 1 & None \\
\hline 199 & 034 & 12.5 & 03 & 00 & MSG & ANO & SHA & 1 & None \\
\hline 199 & 035 & 12.6 & 03 & 00 & MSG & ANO & SHA & 1 & None \\
\hline 199 & 036 & 13.1 & 03 & 00 & MLT & ANO & $\mathrm{CMX}$ & 1 & None \\
\hline 199 & 037 & 14.1 & 03 & 00 & $\overline{M S G}$ & ANO & IND & 1 & None \\
\hline 199 & 038 & 15.1 & 02 & 00 & $\mathrm{MLT}$ & ANO & BTF & 1 & None \\
\hline 199 & 039 & 15.2 & 03 & 00 & MLT & ANO & BTF & 1 & None \\
\hline 199 & 040 & 16.1 & 01 & 00 & FCT & ANO & CMX & 1 & None \\
\hline 199 & 041 & 16.2 & 04 & 00 & MSG & ANO & $\mathrm{CMX}$ & 1 & None \\
\hline 199 & 042 & 16.3 & 04 & 00 & $\mathrm{FCT}$ & ANO & $\mathrm{CMX}$ & 1 & None \\
\hline 199 & 043 & 16.4 & 04 & 00 & MSG & ANO & $\mathrm{CMX}$ & 1 & None \\
\hline 199 & 044 & 17.1 & 04 & 00 & FCT & ANO & CMX & 1 & None \\
\hline 199 & 045 & 18.1 & 04 & 01 & FLA & ANO & SIM & 1 & None \\
\hline 199 & 046 & 19.1 & 02 & 00 & MSG & ANO & CMX & 1 & None \\
\hline 199 & 047 & 19.2 & 03 & 00 & MSG & ANO & $\mathrm{CMX}$ & 1 & None \\
\hline 199 & 048 & 19.3 & 04 & 00 & MSG & ANO & $\mathrm{CMX}$ & 1 & None \\
\hline 199 & 049 & 19.4 & 04 & 00 & MLT & ANO & CMX & 1 & None \\
\hline 199 & 050 & 19.5 & 04 & 00 & MSG & ANO & SG4 & 1 & None \\
\hline 199 & 051 & 20.1 & 04 & 00 & MSG & ANO & $\mathrm{CMX}$ & 1 & None \\
\hline 199 & 052 & 20.2 & 04 & 00 & MSG & ANO & CMX & 1 & None \\
\hline 199 & 053 & 20.3 & 04 & 00 & MLT & ANO & CMX & 1 & None \\
\hline 199 & 054 & 20.4 & 04 & 00 & MSG & ANO & CMX & 1 & None \\
\hline 199 & 055 & 20.5 & 04 & 00 & MSG & ANO & CMX & 1 & None \\
\hline 199 & 056 & 21.1 & 04 & 00 & MSG & ANO & $\overline{C M X}$ & 1 & None \\
\hline 199 & 057 & 22.1 & 04 & 00 & $\mathrm{MLT}$ & ANO & CMX & 1 & None \\
\hline
\end{tabular}




\begin{tabular}{|c|c|c|c|c|c|c|c|c|c|}
\hline $\begin{array}{l}\text { Lot } \\
\text { No. }\end{array}$ & $\begin{array}{l}\text { Specimen } \\
\text { No. }\end{array}$ & Nodule No. & $\begin{array}{l}\text { Flake } \\
\text { Size }\end{array}$ & $\begin{array}{l}\text { Percent } \\
\text { Cortex }\end{array}$ & $\begin{array}{l}\text { Platform } \\
\text { Type }\end{array}$ & $\begin{array}{l}\text { Thermal } \\
\text { Alteration }\end{array}$ & $\begin{array}{c}\text { Technological } \\
\text { Class }\end{array}$ & Count & Comments \\
\hline 199 & 058 & 23.1 & 02 & 01 & MLT & ANO & $\mathrm{CMX}$ & 1 & None \\
\hline 199 & 059 & 24.1 & 03 & 00 & MSG & ANO & PRI & 1 & None \\
\hline 199 & 060 & 24.2 & 03 & 00 & MSG & ANO & $\mathrm{CMX}$ & 1 & None \\
\hline 199 & 061 & 24.3 & 04 & 00 & MSG & ANO & $\mathrm{CMX}$ & 1 & None \\
\hline 199 & 062 & 24.4 & 04 & 00 & $\overline{M L T}$ & ANO & SG4 & 1 & None \\
\hline 199 & 063 & 24.5 & 04 & 00 & FLA & ANO & SG4 & 1 & None \\
\hline 199 & 064 & 24.6 & 04 & 00 & MSG & ANO & SG4 & 1 & None \\
\hline 199 & 065 & 25.1 & 04 & 00 & MSG & ANO & SG4 & 1 & None \\
\hline 199 & 066 & 26.1 & 04 & 00 & MSG & ANO & SG4 & 1 & None \\
\hline 199 & 067 & 26.2 & 04 & 00 & $\overline{M S G}$ & ANO & SG4 & 1 & None \\
\hline 199 & 068 & 26.3 & 04 & 00 & MSG & ANO & SG4 & 1 & None \\
\hline 199 & 069 & 26.4 & 04 & 00 & MSG & ANO & SG4 & 1 & None \\
\hline 199 & 070 & 26.5 & 04 & 00 & MSG & ANO & SG4 & 1 & None \\
\hline 199 & 071 & 26.6 & 04 & 00 & CRT & ANO & SG4 & 1 & None \\
\hline 199 & 072 & 26.7 & 04 & 00 & $\overline{M S G}$ & ANO & SG4 & 1 & None \\
\hline 199 & 073 & 26.8 & 04 & 00 & $\overline{M S G}$ & ANO & SG4 & 1 & None \\
\hline 199 & 074 & 26.9 & 04 & 00 & MSG & ANO & SG4 & 1 & None \\
\hline 199 & 075 & 26.10 & 05 & 00 & $\mathrm{~N} / \mathrm{A}$ & $\mathrm{N} / \mathrm{A}$ & $\mathrm{N} / \mathrm{A}$ & 2 & Not Analyzed \\
\hline 199 & 076 & 27.1 & 04 & 00 & MSG & ANO & $\mathrm{SHA}$ & 1 & None \\
\hline 199 & 077 & 27.2 & 03 & 01 & CRT & ANO & SIM & 1 & None \\
\hline 199 & 078 & 28.1 & 04 & 00 & $\overline{M S G}$ & ANO & SG4 & 1 & None \\
\hline 199 & 079 & 28.2 & 04 & 00 & MSG & ANO & SG4 & 1 & None \\
\hline 199 & 080 & 29.1 & 04 & 00 & MSG & ANO & SG4 & 1 & None \\
\hline 199 & 081 & 30.1 & 04 & 00 & FCT & ANO & SG4 & 1 & None \\
\hline 199 & 082 & 30.2 & 04 & 04 & MSG & ANO & SG4 & 1 & None \\
\hline 199 & 083 & 31.1 & 04 & 00 & MSG & ANO & SG4 & 1 & None \\
\hline 199 & 084 & 31.2 & 05 & 00 & MSG & ANO & SG4 & 1 & None \\
\hline 199 & 085 & 32.1 & 04 & 00 & MSG & ANO & BPF & 1 & None \\
\hline 199 & 086 & 32.2 & 04 & 00 & $\overline{M S G}$ & ANO & SG4 & 1 & None \\
\hline 199 & 087 & 33.1 & 04 & 00 & MSG & ANO & SG4 & 1 & None \\
\hline 199 & 088 & 33.2 & 04 & 00 & $\overline{M S G}$ & ANO & SG4 & 1 & None \\
\hline 199 & 089 & 33.3 & 04 & 00 & CRT & ANO & SG4 & 1 & None \\
\hline 199 & 090 & 33.4 & 04 & 00 & MSG & ANO & SG4 & 1 & None \\
\hline 199 & 091 & 33.5 & 04 & 00 & $\overline{M S G}$ & ANO & SG4 & 1 & None \\
\hline 199 & 092 & 33.6 & 04 & 00 & $\overline{M S G}$ & ANO & SG4 & 1 & None \\
\hline 199 & 093 & 33.7 & 05 & 00 & MSG & ANO & SG4 & 1 & None \\
\hline 199 & 094 & 34.1 & 04 & 00 & MSG & ANO & SG4 & 1 & None \\
\hline 199 & 095 & 35.1 & 04 & 00 & MSG & ANO & SG4 & 1 & None \\
\hline 199 & 096 & 35.2 & 04 & 00 & MSG & ANO & SG4 & 1 & None \\
\hline 199 & 097 & 35.3 & 04 & 00 & $\overline{M L T}$ & ANO & SG4 & 1 & None \\
\hline 199 & 098 & 35.4 & 04 & 00 & MSG & ANO & SG4 & 1 & None \\
\hline 199 & 099 & 35.5 & 04 & 00 & MLT & ANO & SG4 & 1 & Possible notching \\
\hline 199 & 100 & 35.6 & 04 & 00 & MSG & ANO & SG4 & 1 & None \\
\hline 199 & 101 & 36.1 & 04 & 00 & MSG & ANO & SG4 & 1 & None \\
\hline 199 & 102 & 36.2 & 04 & 00 & MSG & ANO & SG4 & 1 & None \\
\hline 199 & 103 & 37.1 & 04 & 00 & MSG & ANO & SG4 & 1 & None \\
\hline 199 & 104 & 37.2 & 05 & 00 & MSG & ANO & SG4 & 1 & None \\
\hline 199 & 105 & 38.1 & 04 & 00 & $\overline{M L T}$ & ANO & $\mathrm{BPF}$ & 1 & None \\
\hline 199 & 106 & 38.2 & 04 & 00 & MLT & ANO & SG4 & 1 & None \\
\hline 199 & 107 & 39.1 & 04 & 00 & MSG & ANO & SG4 & 1 & None \\
\hline 199 & 108 & 39.2 & 04 & 00 & MSG & ANO & SG4 & 1 & None \\
\hline 199 & 109 & 39.3 & 04 & 00 & MLT & ANO & SG4 & 1 & None \\
\hline 199 & 110 & 39.4 & 04 & 00 & MSG & ANO & SG4 & 1 & None \\
\hline 199 & 111 & 39.5 & 04 & 00 & MSG & ANO & SG4 & 1 & None \\
\hline 199 & 112 & 39.6 & 04 & 00 & MSG & ANO & SG4 & 1 & None \\
\hline 199 & 113 & 39.7 & 04 & 00 & MSG & ANO & SG4 & 1 & None \\
\hline 199 & 114 & 40.1 & 04 & 00 & MSG & ANO & SG4 & 1 & None \\
\hline 199 & 115 & 40.2 & 04 & 00 & MSG & ANO & SG4 & 1 & None \\
\hline 199 & 116 & 40.3 & 05 & 00 & MSG & ANO & SG4 & 1 & None \\
\hline 199 & 117 & 40.4 & 05 & 00 & $\overline{M S G}$ & ANO & SG4 & 1 & None \\
\hline 199 & 118 & 41.1 & 04 & 00 & MLT & ANO & SG4 & 1 & None \\
\hline 199 & 119 & 41.2 & 05 & 00 & MSG & ANO & SG4 & 1 & None \\
\hline 199 & 120 & 42.1 & 05 & 00 & MSG & ANO & SG4 & 1 & None \\
\hline 199 & 121 & 43.1 & 01 & 00 & CRT & ANO & SIM & 1 & None \\
\hline 199 & 122 & 43.2 & 03 & 00 & CRT & ANO & CMX & 1 & None \\
\hline 199 & 123 & 43.3 & 03 & 00 & MSG & ANO & CMX & 1 & None \\
\hline
\end{tabular}




\begin{tabular}{|c|c|c|c|c|c|c|c|c|c|}
\hline $\begin{array}{l}\text { Lot } \\
\text { No. }\end{array}$ & $\begin{array}{l}\text { Specimen } \\
\text { No. }\end{array}$ & Nodule No. & $\begin{array}{l}\text { Flake } \\
\text { Size }\end{array}$ & $\begin{array}{l}\text { Percent } \\
\text { Cortex }\end{array}$ & $\begin{array}{l}\text { Platform } \\
\text { Type }\end{array}$ & $\begin{array}{l}\text { Thermal } \\
\text { Alteration }\end{array}$ & $\begin{array}{l}\text { Technological } \\
\text { Class }\end{array}$ & Count & Comments \\
\hline 199 & 124 & 44.1 & 01 & 00 & FLA & ANO & $\mathrm{CMX}$ & 1 & None \\
\hline 199 & 125 & 45.1 & 01 & 01 & FCT & ANO & $\mathrm{CMX}$ & 1 & None \\
\hline 199 & 126 & 46.1 & 01 & 00 & MLT & ANO & BTF & 1 & None \\
\hline 199 & 127 & 46.2 & 01 & 00 & MLT & ANO & BTF & 1 & None \\
\hline 199 & 128 & 46.3 & 02 & 00 & MSG & ANO & BTF & 1 & None \\
\hline 199 & 129 & 46.4 & 02 & 00 & FCT & ANO & CMX & 1 & None \\
\hline 199 & 130 & 47.1 & 04 & 00 & FCT & ANO & CMX & 1 & None \\
\hline 199 & 131 & 48.1 & 02 & 00 & MLT & ANO & BTF & 1 & None \\
\hline 199 & 132 & 49.1 & 02 & 00 & FCT & ANO & $\mathrm{CMX}$ & 1 & None \\
\hline 199 & 133 & 50.1 & 01 & 00 & $\overline{M L T}$ & ANO & BTF & 1 & None \\
\hline 199 & 134 & 50.2 & 04 & 00 & MLT & ANO & CMX & 1 & None \\
\hline 199 & 135 & 51.1 & 04 & 00 & MLT & ANO & CMX & 1 & None \\
\hline 199 & 136 & 52.1 & 01 & 04 & FLAT & ANO & $\mathrm{PRI}$ & 1 & None \\
\hline 199 & 137 & 52.2 & 02 & 00 & MSG & ANO & CMX & 1 & None \\
\hline 199 & 138 & 52.3 & 04 & 00 & $\overline{F C T}$ & ANO & $\overline{C M X}$ & 1 & None \\
\hline 199 & 139 & 53.1 & 02 & 00 & $\overline{M S G}$ & ANO & $\mathrm{SHA}$ & 1 & None \\
\hline 199 & 140 & 53.2 & 02 & 00 & MSG & ANO & $\mathrm{SHA}$ & 1 & None \\
\hline 199 & 141 & 54.1 & 03 & 00 & MSG & ANO & CMX & 1 & None \\
\hline 199 & 142 & 55.1 & 03 & 00 & MSG & ANO & CMX & 1 & None \\
\hline 199 & 143 & 55.2 & 03 & 04 & MSG & ANO & PRI & 1 & None \\
\hline 199 & 144 & 55.3 & 03 & 00 & $\overline{M S G}$ & ANO & $\mathrm{CMX}$ & 1 & None \\
\hline 199 & 145 & 55.4 & 04 & 00 & MSG & ANO & CMX & 1 & None \\
\hline 199 & 146 & 55.5 & 04 & 00 & MLT & ANO & CMX & 1 & None \\
\hline 199 & 147 & 55.6 & 04 & 00 & MSG & ANO & CMX & 1 & None \\
\hline 199 & 148 & 55.7 & 05 & 00 & MSG & ANO & CMX & 1 & None \\
\hline 199 & 149 & 56.1 & 04 & 00 & CRT & ANO & CMX & 1 & None \\
\hline 199 & 150 & 57.1 & 04 & 00 & MSG & ANO & CMX & 1 & None \\
\hline 199 & 151 & 57.2 & 04 & 00 & MSG & ANO & $\mathrm{CMX}$ & 1 & None \\
\hline 199 & 152 & 58.1 & 03 & 00 & $\overline{M S G}$ & ANO & $\overline{C M X}$ & 1 & None \\
\hline 199 & 153 & 59.1 & 03 & 04 & MSG & ANO & SIM & 1 & None \\
\hline 199 & 154 & 59.2 & 04 & 03 & $\overline{C R T}$ & ANO & $\overline{C M X}$ & 1 & None \\
\hline 199 & 155 & 59.3 & 04 & 00 & MSG & ANO & CMX & 1 & None \\
\hline 199 & 156 & 60.1 & 04 & 00 & MSG & ANO & CMX & 1 & None \\
\hline 199 & 157 & 60.2 & 04 & 00 & $\overline{M S G}$ & ANO & $\overline{C M X}$ & 1 & None \\
\hline 201 & 001 & 1.1 & 01 & 03 & CRT & ANO & SIM & 1 & None \\
\hline 201 & 002 & 1.2 & 03 & 04 & MSG & ANO & PRI & 1 & None \\
\hline 201 & 003 & 1.3 & 03 & 03 & MSG & ANO & SIM & 1 & None \\
\hline 201 & 004 & 1.4 & 04 & 03 & MSG & ANO & SHA & 1 & None \\
\hline 201 & 005 & 2.1 & 01 & 00 & MLT & ANO & BTF & 1 & None \\
\hline 201 & 006 & 3.1 & 03 & 01 & CRT & ANO & SIM & 1 & None \\
\hline 201 & 007 & 3.2 & 02 & 00 & MSG & ANO & BTF & 1 & None \\
\hline 201 & 008 & 3.3 & 03 & 00 & $\overline{M S G}$ & ANO & SIM & 1 & None \\
\hline 201 & 009 & 3.4 & 03 & 00 & MSG & ANO & CMX & 1 & None \\
\hline 201 & 010 & 4.1 & 01 & 03 & CRT & ANO & SIM & 1 & None \\
\hline 201 & 011 & 5.1 & 01 & 01 & MLT & ANO & SIM & 1 & None \\
\hline 201 & 012 & 6.1 & 01 & 00 & FLA & ANO & CMX & 1 & None \\
\hline 201 & 013 & 6.2 & 03 & 00 & FLA & ANO & SHA & 1 & None \\
\hline 201 & 014 & 6.3 & 03 & 00 & MSG & ANO & $\overline{C M X}$ & 1 & None \\
\hline 201 & 015 & 7.1 & 01 & 03 & FLA & ANO & SIM & 1 & None \\
\hline 201 & 016 & 7.2 & 02 & 01 & CRT & ANO & SIM & 1 & None \\
\hline 201 & 017 & 8.1 & 02 & 01 & MSG & ANO & SIM & 1 & None \\
\hline 201 & 018 & 8.2 & 04 & 00 & MSG & ANO & SG4 & 1 & None \\
\hline 201 & 019 & 8.3 & 04 & 00 & MSG & ANO & $\mathrm{SHA}$ & 1 & None \\
\hline 201 & 020 & 8.4 & 03 & 00 & MSG & ANO & CMX & 1 & None \\
\hline 201 & 021 & 9.1 & 01 & 03 & MLT & ANO & SIM & 1 & None \\
\hline 201 & 022 & 9.2 & 03 & 01 & MSG & ANO & SIM & 1 & None \\
\hline 201 & 023 & 10.1 & 04 & 01 & MSG & $\mathrm{AOB}$ & SG4 & 1 & None \\
\hline 201 & 024 & 11.1 & 03 & 00 & MSG & ANO & $\overline{C M X}$ & 1 & None \\
\hline 201 & 025 & 11.2 & 03 & 00 & MSG & ANO & CMX & 1 & None \\
\hline 201 & 026 & 11.3 & 04 & 00 & MSG & ANO & SG4 & 1 & None \\
\hline 201 & 027 & 11.4 & 03 & 01 & MSG & ANO & SIM & 1 & None \\
\hline 201 & 028 & 12.1 & 03 & 00 & MSG & ANO & CMX & 1 & None \\
\hline 201 & 029 & 12.2 & 03 & 01 & CRT & ANO & SIM & 1 & None \\
\hline 201 & 030 & 12.3 & 03 & 01 & MLT & ANO & SIM & 1 & None \\
\hline 201 & 031 & 13.1 & 02 & 00 & MSG & ANO & SIM & 1 & None \\
\hline 201 & 032 & 14.1 & 03 & 00 & $\mathrm{MLT}$ & ANO & CMX & 1 & None \\
\hline
\end{tabular}




\begin{tabular}{|c|c|c|c|c|c|c|c|c|c|}
\hline $\begin{array}{l}\text { Lot } \\
\text { No. }\end{array}$ & $\begin{array}{l}\text { Specimen } \\
\text { No. }\end{array}$ & Nodule No. & $\begin{array}{l}\text { Flake } \\
\text { Size }\end{array}$ & $\begin{array}{l}\text { Percent } \\
\text { Cortex }\end{array}$ & $\begin{array}{l}\text { Platform } \\
\text { Type }\end{array}$ & $\begin{array}{l}\text { Thermal } \\
\text { Alteration }\end{array}$ & $\begin{array}{c}\text { Technological } \\
\text { Class }\end{array}$ & Count & Comments \\
\hline 201 & 033 & 14.2 & 04 & 00 & MLT & ANO & $\mathrm{CMX}$ & 1 & None \\
\hline 201 & 034 & 14.3 & 04 & 00 & FLA & ANO & $\mathrm{CMX}$ & 1 & None \\
\hline 201 & 035 & 15.1 & 04 & 03 & FLA & ANO & SIM & 1 & None \\
\hline 201 & 036 & 15.2 & 04 & 00 & MSG & ANO & $\mathrm{PRI}$ & 1 & None \\
\hline 201 & 037 & 16.1 & 03 & 00 & $\overline{M L T}$ & ANO & CMX & 1 & None \\
\hline 201 & 038 & 17.1 & 03 & 00 & MSG & ANO & CMX & 1 & None \\
\hline 201 & 039 & 18.1 & 04 & 00 & MSG & $\mathrm{AOB}$ & CMX & 1 & None \\
\hline 201 & 040 & 18.2 & 04 & 00 & MSG & AOB & SG4 & 1 & None \\
\hline 201 & 041 & 18.3 & 04 & 01 & MSG & ANO & SIM & 1 & None \\
\hline 201 & 042 & 19.1 & 03 & 00 & $\overline{M L T}$ & ANO & SIM & 1 & None \\
\hline 201 & 043 & 19.2 & 04 & 00 & MSG & ANO & SG4 & 1 & None \\
\hline 201 & 044 & 19.3 & 04 & 00 & MSG & ANO & SG4 & 1 & None \\
\hline 201 & 045 & 19.4 & 04 & 00 & MSG & ANO & CMX & 1 & None \\
\hline 201 & 046 & 19.5 & 04 & 00 & MSG & ANO & SG4 & 1 & None \\
\hline 201 & 047 & 20.1 & 04 & 00 & $\overline{M L T}$ & ANO & $\overline{C M X}$ & 1 & None \\
\hline 201 & 048 & 20.2 & 04 & 00 & $\overline{M S G}$ & ANO & SG4 & 1 & None \\
\hline 201 & 049 & 20.3 & 04 & 00 & MSG & ANO & SG4 & 1 & None \\
\hline 201 & 050 & 20.4 & 04 & 00 & MSG & ANO & SG4 & 1 & None \\
\hline 201 & 051 & 20.5 & 04 & 00 & MSG & ANO & SG4 & 1 & None \\
\hline 201 & 052 & 20.6 & 04 & 00 & MSG & ANO & SG4 & 1 & None \\
\hline 201 & 053 & 21.1 & 04 & 00 & $\overline{M S G}$ & ANO & $\mathrm{CMX}$ & 1 & None \\
\hline 201 & 054 & 22.1 & 03 & 00 & $\mathrm{MLT}$ & ANO & BTF & 1 & None \\
\hline 201 & 055 & 22.2 & 04 & 00 & MSG & ANO & SG4 & 1 & None \\
\hline 201 & 056 & 23.1 & 02 & 00 & $\overline{M S G}$ & ANO & CMX & 1 & None \\
\hline 201 & 057 & 23.2 & 04 & 00 & MSG & ANO & CMX & 1 & None \\
\hline 201 & 058 & 23.3 & 04 & 00 & $\overline{M L T}$ & ANO & SG4 & 1 & None \\
\hline 201 & 059 & 23.4 & 04 & 00 & MSG & ANO & CMX & 1 & None \\
\hline 201 & 060 & 24.1 & 04 & 00 & MSG & ANO & SG4 & 1 & None \\
\hline 201 & 061 & 25.1 & 04 & $\overline{01}$ & $\overline{M S G}$ & ANO & SIM & 1 & None \\
\hline 201 & 062 & 26.1 & 04 & 00 & MSG & ANO & SG4 & 1 & None \\
\hline 201 & 063 & 26.2 & 04 & 00 & $\overline{C R T}$ & ANO & SIM & 1 & None \\
\hline 201 & 064 & 26.3 & 04 & 01 & CRT & ANO & SIM & 1 & None \\
\hline 201 & 065 & 27.1 & 04 & 01 & MSG & AOB & SIM & 1 & None \\
\hline 201 & 066 & 27.2 & 04 & 02 & $\overline{M S G}$ & AOB & $\overline{C M X}$ & 1 & None \\
\hline 201 & 067 & 28.1 & 04 & 00 & IND & ANO & $\mathrm{CMX}$ & 1 & None \\
\hline 201 & 068 & 29.1 & 03 & 02 & MSG & $\mathrm{AOB}$ & SIM & 1 & None \\
\hline 202 & 001 & 202.1 .1 & 1 & 4 & MSG & ANO & PRI & 1 & None \\
\hline 202 & 002 & 202.1 .2 & 3 & 0 & MSG & ANO & CMX & 1 & None \\
\hline 202 & 003 & 202.2 .1 & 1 & 0 & FLA & ANO & $\mathrm{CMX}$ & 1 & None \\
\hline 202 & 004 & 202.2 .2 & 3 & 2 & IND & ANO & SIM & 1 & None \\
\hline 202 & 005 & 202.2 .3 & 3 & 3 & MSG & ANO & SIM & 1 & None \\
\hline 202 & 006 & 202.2 .4 & 4 & 0 & $\overline{M S G}$ & ANO & SG4 & 1 & None \\
\hline 202 & 007 & 202.3 .1 & 2 & 3 & FLA & ANO & SIM & 1 & None \\
\hline 202 & 008 & 202.3 .2 & 3 & 0 & MLT & ANO & CMX & 1 & None \\
\hline 202 & 009 & 202.3 .3 & 4 & 0 & MSG & ANO & $\mathrm{CMX}$ & 1 & None \\
\hline 202 & 010 & 202.3 .4 & 4 & 0 & MSG & ANO & CMX & 1 & None \\
\hline 202 & 011 & 202.3 .5 & 4 & 0 & MLT & ANO & $\mathrm{CMX}$ & 1 & None \\
\hline 202 & 012 & 202.3 .6 & 4 & 0 & FLA & ANO & CMX & 1 & None \\
\hline 202 & 013 & 202.3 .7 & 4 & 0 & MSG & ANO & CMX & 1 & None \\
\hline 202 & 014 & 202.3 .8 & 3 & 3 & MSG & ANO & CMX & 1 & None \\
\hline 202 & 015 & 202.3 .9 & 4 & 0 & MLT & ANO & CMX & 1 & None \\
\hline 202 & 016 & 202.3 .10 & 4 & 0 & MSG & ANO & SG4 & 1 & None \\
\hline 202 & 017 & 202.3 .11 & 4 & 0 & MSG & ANO & SG4 & 1 & None \\
\hline 202 & 018 & 202.4 .1 & 2 & 4 & CRT & ANO & PRI & 1 & None \\
\hline 202 & 019 & 202.4 .2 & 3 & 2 & MSG & ANO & $\mathrm{CMX}$ & 1 & None \\
\hline 202 & 020 & 202.4 .3 & 3 & 1 & MSG & ANO & SIM & 1 & None \\
\hline 202 & 021 & 202.4 .4 & 3 & 0 & MSG & ANO & BTF & 1 & None \\
\hline 202 & 022 & 202.4 .5 & 4 & 0 & IND & ANO & $\overline{C M X}$ & 1 & None \\
\hline 202 & 023 & 202.5 .1 & 3 & 0 & MSG & ANO & CMX & 1 & None \\
\hline 202 & 024 & 202.5 .2 & 3 & 1 & CRT & ANO & $\overline{C M X}$ & 1 & None \\
\hline 202 & 025 & 202.5 .3 & 2 & 0 & FLA & ANO & SIM & 1 & None \\
\hline 202 & 026 & 202.5 .4 & 3 & 0 & MSG & ANO & CMX & 1 & None \\
\hline 202 & 027 & 202.6 .1 & 2 & 0 & MSG & ANO & BTF & 1 & None \\
\hline 202 & 028 & 202.6 .2 & 3 & 0 & MLT & ANO & BTF & 1 & None \\
\hline 202 & 029 & 202.6 .3 & 3 & 0 & MSG & ANO & CMX & 1 & None \\
\hline 202 & 030 & 202.6 .4 & 3 & 0 & MSG & ANO & CMX & 1 & None \\
\hline
\end{tabular}




\begin{tabular}{|c|c|c|c|c|c|c|c|c|c|}
\hline $\begin{array}{l}\text { Lot } \\
\text { No. }\end{array}$ & $\begin{array}{l}\text { Specimen } \\
\text { No. }\end{array}$ & Nodule No. & $\begin{array}{l}\text { Flake } \\
\text { Size }\end{array}$ & $\begin{array}{l}\text { Percent } \\
\text { Cortex }\end{array}$ & $\begin{array}{l}\text { Platform } \\
\text { Type }\end{array}$ & $\begin{array}{l}\text { Thermal } \\
\text { Alteration }\end{array}$ & $\begin{array}{c}\text { Technological } \\
\text { Class }\end{array}$ & Count & Comments \\
\hline 202 & 031 & 202.7 .1 & 3 & 0 & MLT & ANO & $\mathrm{CMX}$ & 1 & None \\
\hline 202 & 032 & 202.7 .2 & 3 & 0 & $\overline{M S G}$ & ANO & $\mathrm{CMX}$ & 1 & None \\
\hline 202 & 033 & 202.8 .1 & 1 & 2 & FLA & ANO & SIM & 1 & None \\
\hline 202 & 034 & 202.8 .2 & 1 & 1 & FLA & ANO & $\mathrm{CMX}$ & 1 & None \\
\hline 202 & 035 & 202.8 .3 & 4 & 0 & MSG & ANO & $\overline{C M X}$ & 1 & None \\
\hline 202 & 036 & 202.8 .4 & 3 & 1 & FCT & ANO & CMX & 1 & None \\
\hline 202 & 037 & 202.8 .5 & 4 & 0 & MLT & ANO & CMX & 1 & None \\
\hline 202 & 038 & 202.8 .6 & 3 & 3 & MSG & ANO & CMX & 1 & None \\
\hline 202 & 039 & 202.8 .7 & 3 & 0 & $\mathrm{MLT}$ & ANO & $\mathrm{CMX}$ & 1 & None \\
\hline 202 & 040 & 202.8 .8 & 3 & 1 & $\overline{M S G}$ & ANO & $\overline{C M X}$ & 1 & None \\
\hline 202 & 041 & 202.9 .1 & 3 & 4 & MSG & ANO & $\mathrm{PRI}$ & 1 & None \\
\hline 202 & 042 & 202.9 .2 & 3 & 0 & FCT & ANO & $\mathrm{CMX}$ & 1 & None \\
\hline 202 & 043 & 202.9 .3 & 4 & 0 & MSG & ANO & $\mathrm{CMX}$ & 1 & None \\
\hline 202 & 044 & 202.9 .4 & 4 & 4 & MSG & ANO & CMX & 1 & None \\
\hline 202 & 045 & 202.9 .5 & 4 & 0 & $\overline{M S G}$ & ANO & $\overline{C M X}$ & 1 & None \\
\hline 202 & 046 & 202.9 .6 & 4 & 1 & $\overline{M S G}$ & ANO & $\mathrm{CMX}$ & 1 & None \\
\hline 202 & 047 & 202.9 .7 & 4 & 4 & MSG & ANO & $\mathrm{CMX}$ & 1 & None \\
\hline 202 & 048 & 202.9 .8 & 4 & 0 & MSG & ANO & SG4 & 1 & None \\
\hline 202 & 049 & 202.10 .1 & 1 & 0 & $\mathrm{MLT}$ & ANO & BTF & 1 & None \\
\hline 202 & 050 & 202.10 .2 & 1 & 4 & CRT & ANO & PRI & 1 & None \\
\hline 202 & 051 & 202.10 .3 & 3 & 0 & FLA & ANO & $\mathrm{CMX}$ & 1 & None \\
\hline 202 & 052 & 202.10 .4 & 3 & 0 & MSG & ANO & $\mathrm{CMX}$ & 1 & None \\
\hline 202 & 053 & 202.10 .5 & 3 & 0 & MSG & ANO & $\mathrm{CMX}$ & 1 & None \\
\hline 202 & 054 & 202.10 .6 & 4 & 0 & $\overline{M L T}$ & ANO & CMX & 1 & None \\
\hline 202 & 055 & 202.10 .7 & 4 & 3 & MSG & ANO & SHA & 1 & None \\
\hline 202 & 056 & 202.10 .8 & 4 & 0 & $\overline{M S G}$ & ANO & SG4 & 1 & None \\
\hline 202 & 057 & 202.10 .9 & 4 & 0 & MSG & ANO & SG4 & 1 & None \\
\hline 202 & 058 & 202.11 .1 & 1 & 2 & FLA & ANO & SIM & 1 & None \\
\hline 202 & 059 & 202.11 .2 & 4 & 0 & $\overline{M S G}$ & ANO & $\overline{C M X}$ & 1 & None \\
\hline 202 & 060 & 202.11 .3 & 4 & 0 & MSG & ANO & $\mathrm{CMX}$ & 1 & None \\
\hline 202 & 061 & 202.11 .4 & 4 & 0 & IND & ANO & $\overline{C M X}$ & 1 & None \\
\hline 202 & 062 & 202.11 .5 & 4 & 0 & MSG & ANO & CMX & 1 & None \\
\hline 202 & 063 & 202.11 .6 & 4 & 0 & MSG & ANO & CMX & 1 & None \\
\hline 202 & 064 & 202.12 .1 & 2 & 0 & $\overline{M L T}$ & ANO & BTF & 1 & None \\
\hline 202 & 065 & 202.12 .2 & 4 & 2 & CRT & ANO & $\mathrm{CMX}$ & 1 & None \\
\hline 202 & 066 & 202.12 .3 & 2 & 3 & MSG & ANO & SIM & 1 & None \\
\hline 202 & 067 & 202.12 .4 & 4 & 0 & MLT & ANO & SIM & 1 & None \\
\hline 202 & 068 & 202.12 .5 & 4 & 1 & CRT & ANO & CMX & 1 & None \\
\hline 202 & 069 & 202.13 .1 & 3 & 1 & MSG & ANO & $\mathrm{CMX}$ & 1 & None \\
\hline 202 & 070 & 202.13 .2 & 4 & 0 & MSG & ANO & $\mathrm{CMX}$ & 1 & None \\
\hline 202 & 071 & 202.13 .3 & 5 & 0 & MSG & ANO & SG4 & 1 & None \\
\hline 202 & 072 & 202.14 .1 & 3 & 0 & MLT & ANO & BTF & 1 & None \\
\hline 202 & 073 & 202.14 .2 & 4 & 0 & MLT & ANO & CMX & 1 & None \\
\hline 202 & 074 & 202.14 .3 & 4 & 0 & FLA & ANO & SG4 & 1 & None \\
\hline 202 & 075 & 202.15 .1 & 4 & 0 & IND & ANO & SG4 & 1 & None \\
\hline 202 & 076 & 202.16 .1 & 4 & 1 & CRT & ANO & $\mathrm{CMX}$ & 1 & None \\
\hline 202 & 077 & 202.16 .2 & 3 & 1 & CRT & ANO & $\mathrm{CMX}$ & 1 & None \\
\hline 202 & 078 & 202.16 .3 & 4 & 0 & $\overline{M S G}$ & ANO & $\overline{C M X}$ & 1 & None \\
\hline 202 & 079 & 202.17 .1 & 2 & 0 & MSG & ANO & BTF & 1 & None \\
\hline 202 & 080 & 202.17 .2 & 3 & 0 & FLA & ANO & CMX & 1 & None \\
\hline 202 & 081 & 202.17 .3 & 3 & 0 & MSG & ANO & CMX & 1 & None \\
\hline 202 & 082 & 202.17 .4 & 4 & 0 & MSG & ANO & CMX & 1 & None \\
\hline 202 & 083 & 202.17 .5 & 4 & 0 & MSG & ANO & $\overline{C M X}$ & 1 & None \\
\hline 202 & 084 & 202.17 .6 & 4 & 0 & MSG & ANO & CMX & 1 & None \\
\hline 202 & 085 & 202.17 .7 & 4 & 0 & $\overline{M L T}$ & ANO & $\overline{C M X}$ & 1 & None \\
\hline 202 & 086 & 202.17 .8 & 4 & 0 & MLT & ANO & SG4 & 1 & None \\
\hline 202 & 087 & 202.17 .9 & 4 & 0 & MLT & ANO & SG4 & 1 & None \\
\hline 202 & 088 & 202.18 .1 & 3 & 4 & $\overline{\mathrm{CRT}}$ & ANO & PRI & 1 & None \\
\hline 202 & 089 & 202.18 .2 & 3 & 2 & CRT & ANO & SIM & 1 & None \\
\hline 202 & 090 & 202.18 .3 & 4 & 0 & $\overline{M S G}$ & AOB & SHA & 1 & None \\
\hline 202 & 091 & 202.18 .4 & 4 & 0 & CRT & ANO & SG4 & 1 & None \\
\hline 202 & 092 & 202.18 .5 & 4 & 0 & CRT & ANO & CMX & 1 & None \\
\hline 202 & 093 & 202.18 .6 & 4 & 0 & MLT & ANO & CMX & 1 & None \\
\hline 202 & 094 & 202.18 .7 & 3 & 0 & MLT & ANO & CMX & 1 & None \\
\hline 202 & 095 & 202.18 .8 & 4 & 0 & $\overline{M L T}$ & ANO & $\mathrm{CMX}$ & 1 & None \\
\hline 202 & 096 & 202.19 .1 & 1 & 1 & CRT & ANO & SIM & 1 & None \\
\hline
\end{tabular}




\begin{tabular}{|c|c|c|c|c|c|c|c|c|c|}
\hline $\begin{array}{l}\text { Lot } \\
\text { No. }\end{array}$ & $\begin{array}{l}\text { Specimen } \\
\text { No. }\end{array}$ & Nodule No. & $\begin{array}{l}\text { Flake } \\
\text { Size }\end{array}$ & $\begin{array}{l}\text { Percent } \\
\text { Cortex }\end{array}$ & $\begin{array}{l}\text { Platform } \\
\text { Type }\end{array}$ & $\begin{array}{l}\text { Thermal } \\
\text { Alteration }\end{array}$ & $\begin{array}{c}\text { Technological } \\
\text { Class }\end{array}$ & Count & Comments \\
\hline 202 & 097 & 202.19 .2 & 4 & 0 & MSG & ANO & $\mathrm{CMX}$ & 1 & None \\
\hline 202 & 098 & 202.19 .3 & 4 & 0 & MSG & ANO & CMX & 1 & None \\
\hline 202 & 099 & 202.19 .4 & 4 & 3 & MSG & ANO & SHA & 1 & None \\
\hline 202 & 100 & 202.19 .5 & 4 & 0 & MSG & ANO & CMX & 1 & None \\
\hline 202 & 101 & 202.20 .1 & 2 & 0 & MSG & ANO & $\mathrm{CMX}$ & 1 & None \\
\hline 202 & 102 & 202.20 .2 & 2 & 0 & MSG & ANO & BTF & 1 & None \\
\hline 202 & 103 & 202.21 .1 & 3 & 0 & MSG & ANO & $\mathrm{CMX}$ & 1 & None \\
\hline 202 & 104 & 202.21 .2 & 3 & 0 & MSG & ANO & CMX & 1 & None \\
\hline 202 & 105 & 202.22 .1 & 1 & 0 & MSG & ANO & BTF & 1 & None \\
\hline 202 & 106 & 202.22 .2 & 3 & 0 & MLT & ANO & BTF & 1 & None \\
\hline 202 & 107 & 202.22 .3 & 3 & 0 & MSG & ANO & SIM & 1 & None \\
\hline 202 & 108 & 202.22 .4 & 4 & 0 & MSG & ANO & CMX & 1 & None \\
\hline 202 & 109 & 202.22 .5 & 4 & 0 & MLT & ANO & CMX & 1 & None \\
\hline 202 & 110 & 202.23 .1 & 4 & 0 & MSG & ANO & CMX & 1 & None \\
\hline 202 & 111 & 202.24 .1 & 3 & 1 & $\overline{\text { CRT }}$ & ANO & SIM & 1 & None \\
\hline 202 & 112 & 202.25 .1 & 4 & 1 & MSG & ANO & CMX & 1 & None \\
\hline 202 & 113 & 202.25 .2 & 4 & 0 & MSG & ANO & CMX & 1 & None \\
\hline 202 & 114 & 202.25 .3 & 4 & 1 & CRT & ANO & $\mathrm{CMX}$ & 1 & None \\
\hline 202 & 115 & 202.25 .4 & 4 & 0 & $\overline{M L T}$ & ANO & CMX & 1 & None \\
\hline 202 & 116 & 202.25 .5 & 4 & 0 & MSG & ANO & SG4 & 1 & None \\
\hline 202 & 117 & 202.25 .6 & 4 & 2 & $\overline{M L T}$ & ANO & CMX & 1 & None \\
\hline 202 & 118 & 202.25 .7 & 4 & 0 & MLT & ANO & CMX & 1 & None \\
\hline 202 & 119 & 202.25 .8 & 4 & 0 & MSG & ANO & CMX & 1 & None \\
\hline 202 & 120 & 202.25 .9 & 4 & 2 & MSG & ANO & CMX & 1 & None \\
\hline 202 & 121 & 202.25 .10 & 4 & 0 & MSG & ANO & CMX & 1 & None \\
\hline 202 & 122 & 202.26 .1 & 4 & 4 & CRT & ANO & PRI & 1 & None \\
\hline 202 & 123 & 202.26 .2 & 4 & 2 & MSG & ANO & SIM & 1 & None \\
\hline 202 & 124 & 202.26 .3 & 4 & 4 & MSG & ANO & SG4 & 1 & None \\
\hline 202 & 125 & 202.26 .4 & 4 & 0 & MSG & ANO & SG4 & 1 & None \\
\hline 202 & 126 & 202.27 .1 & 4 & 0 & MLT & ANO & CMX & 1 & None \\
\hline 202 & 127 & 202.27 .2 & 4 & 0 & MSG & ANO & CMX & 1 & None \\
\hline 202 & 128 & 202.28 .1 & 4 & 0 & MSG & ANO & CMX & 1 & None \\
\hline 202 & 129 & 202.29 .1 & 2 & 0 & MLT & ANO & CMX & 1 & None \\
\hline 202 & 130 & 202.29 .2 & 4 & 0 & $\overline{M L T}$ & ANO & $\overline{C M X}$ & 1 & None \\
\hline 202 & 131 & 202.29 .3 & 2 & 0 & MSG & ANO & SIM & 1 & None \\
\hline 202 & 132 & 202.30 .1 & 4 & 0 & MSG & ANO & CMX & 1 & None \\
\hline 202 & 133 & 202.30 .2 & 4 & 0 & MSG & ANO & CMX & 1 & None \\
\hline 202 & 134 & 202.30 .3 & 5 & 0 & MSG & ANO & SG4 & 1 & None \\
\hline 202 & 135 & 202.30 .4 & 4 & 0 & MSG & ANO & CMX & 1 & None \\
\hline 202 & 136 & 202.31 .1 & 4 & 0 & MSG & ANO & CMX & 1 & None \\
\hline 202 & 137 & 202.31 .2 & 4 & 0 & MSG & ANO & CMX & 1 & None \\
\hline 202 & 138 & 202.31 .3 & 4 & 0 & MSG & ANO & CMX & 1 & None \\
\hline 202 & 139 & 202.32 .1 & 4 & 0 & MSG & ANO & $\mathrm{CMX}$ & 1 & None \\
\hline 202 & 140 & 202.33 .1 & 3 & 0 & MSG & ANO & BTF & 1 & None \\
\hline 202 & 141 & 202.34 .1 & 4 & 0 & MLT & ANO & CMX & 1 & None \\
\hline 202 & 142 & 202.35 .1 & 4 & 0 & MSG & ANO & CMX & 1 & None \\
\hline 202 & 143 & 202.35 .2 & 5 & 0 & MSG & ANO & SG4 & 1 & None \\
\hline 202 & 144 & 202.36 .1 & 2 & 0 & FLA & ANO & CMX & 1 & None \\
\hline 202 & 145 & 202.36 .2 & 4 & 0 & MSG & ANO & SHA & 1 & None \\
\hline 202 & 146 & 202.37 .1 & 4 & 0 & MSG & ANO & CMX & 1 & None \\
\hline 202 & 147 & 202.38 .1 & 4 & 0 & MSG & ANO & CMX & 1 & None \\
\hline 202 & 148 & 202.38 .2 & 4 & 0 & MSG & ANO & CMX & 1 & None \\
\hline 202 & 149 & 202.38 .3 & 4 & 0 & $\overline{M S G}$ & ANO & $\mathrm{CMX}$ & 1 & None \\
\hline 202 & 150 & 202.39 .1 & 3 & 4 & CRT & ANO & PRI & 1 & None \\
\hline 202 & 151 & 202.40 .1 & 4 & 4 & CRT & ANO & $\mathrm{PRI}$ & 1 & None \\
\hline 202 & 152 & 202.40 .2 & 4 & 0 & MLT & ANO & CMX & 1 & None \\
\hline 202 & 153 & 202.40 .3 & 4 & 0 & MSG & ANO & SG4 & 1 & None \\
\hline 202 & 154 & 202.40 .4 & 4 & 0 & $\overline{\text { CRT }}$ & ANO & SG4 & 1 & None \\
\hline 202 & 155 & 202.41 .1 & 4 & 2 & MSG & $\mathrm{AOB}$ & SHA & 1 & None \\
\hline 202 & 156 & 202.41 .2 & 4 & 0 & $\overline{M S G}$ & $\mathrm{AOB}$ & SHA & 1 & None \\
\hline 202 & 157 & 202.41 .3 & 4 & 0 & $\mathrm{MLT}$ & ANO & CMX & $\frac{1}{1}$ & None \\
\hline 202 & 158 & 202.41 .4 & 4 & 0 & MLT & ANO & SG4 & 1 & None \\
\hline 202 & 159 & 202.41 .5 & 4 & 0 & FCT & ANO & CMX & 1 & None \\
\hline 202 & 160 & 202.42 .1 & 3 & 0 & MSG & ANO & BTF & 1 & None \\
\hline 202 & 161 & 202.42 .2 & 4 & 0 & MSG & ANO & SG4 & 1 & None \\
\hline 202 & 162 & 202.43 .1 & 4 & 0 & MSG & ANO & SG4 & 1 & None \\
\hline
\end{tabular}




\begin{tabular}{|c|c|c|c|c|c|c|c|c|c|}
\hline $\begin{array}{l}\text { Lot } \\
\text { No. }\end{array}$ & $\begin{array}{l}\text { Specimen } \\
\text { No. }\end{array}$ & Nodule No. & $\begin{array}{l}\text { Flake } \\
\text { Size }\end{array}$ & $\begin{array}{l}\text { Percent } \\
\text { Cortex }\end{array}$ & $\begin{array}{l}\text { Platform } \\
\text { Type }\end{array}$ & $\begin{array}{l}\text { Thermal } \\
\text { Alteration }\end{array}$ & $\begin{array}{c}\text { Technological } \\
\text { Class }\end{array}$ & Count & Comments \\
\hline 202 & 163 & 202.43 .2 & 4 & 0 & MSG & ANO & SG4 & 1 & None \\
\hline 202 & 164 & 202.43 .3 & 4 & 0 & MSG & ANO & SG4 & 1 & None \\
\hline 202 & 165 & 202.44 .1 & 4 & 0 & MSG & ANO & SG4 & 1 & None \\
\hline 202 & 166 & 202.44 .2 & 4 & 0 & MSG & ANO & SG4 & 1 & None \\
\hline 202 & 167 & 202.44 .3 & 4 & 0 & MSG & ANO & $\mathrm{SHA}$ & 1 & None \\
\hline 202 & 168 & 202.45 .1 & 4 & 0 & MSG & ANO & CMX & 1 & None \\
\hline 202 & 169 & 202.45 .2 & 4 & 0 & MSG & ANO & SG4 & 1 & None \\
\hline 202 & 170 & 202.46 .1 & 4 & 0 & MSG & ANO & CMX & 1 & None \\
\hline 202 & 171 & 202.47 .1 & 4 & 0 & MSG & ANO & CMX & 1 & None \\
\hline 202 & 172 & 202.48 .1 & 4 & 0 & MSG & ANO & SG4 & 1 & None \\
\hline 202 & 173 & 202.48 .2 & 4 & 0 & MSG & ANO & SG4 & 1 & None \\
\hline 202 & 174 & 202.49 .1 & 4 & 0 & MSG & ANO & $\mathrm{CMX}$ & 1 & None \\
\hline 202 & 175 & 202.50 .1 & 4 & 0 & IND & ANO & CMX & 1 & None \\
\hline 202 & 176 & 202.51 .1 & 4 & 0 & MSG & ANO & CMX & 1 & None \\
\hline 202 & 177 & 202.51 .2 & 4 & 4 & FLA & ANO & PRI & 1 & None \\
\hline 202 & 178 & 202.51 .3 & 4 & 0 & MSG & ANO & SG4 & 1 & None \\
\hline 202 & 179 & 202.52 .1 & 4 & 0 & MSG & ANO & BTF & 1 & None \\
\hline 202 & 180 & 202.52 .2 & 4 & 0 & MLT & ANO & SG4 & 1 & None \\
\hline 202 & 181 & 202.53 .1 & 4 & 0 & MSG & ANO & SG4 & 1 & None \\
\hline 202 & 182 & 202.53 .2 & 4 & 0 & MSG & ANO & SG4 & 1 & None \\
\hline 202 & 183 & 202.54 .1 & 4 & 0 & $\mathrm{MLT}$ & ANO & SG4 & 1 & None \\
\hline 202 & 184 & 202.54 .2 & 4 & 0 & MSG & ANO & SG4 & 1 & None \\
\hline 202 & 185 & 202.55 .1 & 4 & 0 & MSG & ANO & SG4 & 1 & None \\
\hline 202 & 186 & 202.55 .2 & 4 & 0 & MSG & ANO & SG4 & 1 & None \\
\hline 202 & 187 & 202.56 .1 & 4 & 0 & MSG & ANO & SG4 & 1 & None \\
\hline 202 & 188 & 202.56 .2 & 4 & 0 & MSG & ANO & CMX & 1 & None \\
\hline 202 & 189 & 202.57 .1 & 4 & 0 & MSG & ANO & SG4 & 1 & None \\
\hline 202 & 190 & 202.57 .2 & 4 & 0 & MSG & ANO & SG4 & 1 & None \\
\hline 202 & 191 & 202.58 .1 & 1 & 0 & MSG & ANO & BTF & 1 & None \\
\hline 202 & 192 & 202.59 .1 & 3 & 4 & MSG & ANO & $\mathrm{PRI}$ & 1 & None \\
\hline 203 & 1 & 1.1 & 1 & 04 & MSG & ANO & $\mathrm{PRI}$ & 1 & None \\
\hline 203 & 2 & 1.2 & 1 & 04 & CRT & ANO & PRI & 1 & None \\
\hline 203 & 3 & 1.3 & 2 & 02 & FLA & ANO & $\mathrm{SHA}$ & 1 & None \\
\hline 203 & 4 & 2.1 & 2 & 00 & MLT & ANO & BTF & 1 & None \\
\hline 203 & 5 & 2.2 & 2 & 00 & FLA & ANO & SIM & 1 & None \\
\hline 203 & 6 & 2.3 & 3 & 00 & MSG & ANO & CMX & 1 & None \\
\hline 203 & 7 & 3.1 & 2 & 03 & MSG & ANO & SIM & 1 & None \\
\hline 203 & 8 & 3.2 & 3 & 04 & FLA & ANO & PRI & 1 & None \\
\hline 203 & 9 & 3.3 & 3 & 00 & MSG & ANO & CMX & 1 & None \\
\hline 203 & 10 & 3.4 & 3 & 00 & FCT & ANO & CMX & 1 & None \\
\hline 203 & 11 & 3.5 & 4 & 00 & MSG & ANO & CMX & 1 & None \\
\hline 203 & 12 & 3.6 & 4 & 03 & CRT & ANO & SIM & 1 & None \\
\hline 203 & 13 & 4.1 & 2 & 00 & $\mathrm{MLT}$ & ANO & $\mathrm{CMX}$ & 1 & None \\
\hline 203 & 14 & 4.2 & 2 & 00 & CRT & ANO & CMX & 1 & None \\
\hline 203 & 15 & 4.3 & 3 & 00 & MSG & ANO & CMX & 1 & None \\
\hline 203 & 16 & 4.4 & 4 & 04 & CRT & ANO & PRI & 1 & None \\
\hline 203 & 17 & 5.1 & 1 & 04 & MLT & ANO & BTF & 1 & None \\
\hline 203 & 18 & 5.2 & 1 & 00 & FCT & ANO & CMX & 1 & None \\
\hline 203 & 19 & 6.1 & 3 & 04 & MSG & ANO & SHA & 1 & None \\
\hline 203 & 20 & 6.2 & 4 & 03 & FLA & ANO & CMX & 1 & None \\
\hline 203 & 21 & 7.1 & 1 & 00 & CRT & ANO & SIM & 1 & None \\
\hline 203 & 22 & 8.1 & 4 & 02 & MSG & ANO & SIM & 1 & None \\
\hline 203 & 23 & 9.1 & 4 & 00 & MSG & ANO & CMX & 1 & None \\
\hline 203 & 24 & 10.1 & 2 & 00 & MSG & ANO & CMX & 1 & None \\
\hline 203 & 25 & 10.2 & 2 & 00 & FCT & ANO & CMX & 1 & None \\
\hline 203 & 26 & 10.3 & 2 & 02 & FCT & ANO & SIM & 1 & None \\
\hline 203 & 27 & 10.4 & 3 & 00 & MSG & ANO & CMX & 1 & None \\
\hline 203 & 28 & 11.1 & 3 & 00 & FCT & ANO & CMX & 1 & None \\
\hline 203 & 29 & 11.2 & 4 & 00 & FCT & ANO & CMX & 1 & None \\
\hline 203 & 30 & 11.3 & 4 & 00 & MSG & ANO & CMX & 1 & None \\
\hline 203 & 31 & 11.4 & 4 & 00 & MLT & ANO & CMX & 1 & None \\
\hline 203 & 32 & 11.5 & 4 & 00 & MSG & $\mathrm{AOB}$ & SHA & 1 & None \\
\hline 203 & 33 & 11.6 & 5 & 00 & MSG & ANO & CMX & 1 & None \\
\hline 203 & 34 & 12.1 & 3 & 00 & MSG & ANO & CMX & 1 & None \\
\hline 203 & 35 & 13.1 & 3 & 00 & FCT & ANO & CMX & 1 & None \\
\hline 203 & 36 & 13.2 & 3 & 00 & FLA & ANO & $\mathrm{CMX}$ & 1 & None \\
\hline
\end{tabular}




\begin{tabular}{|c|c|c|c|c|c|c|c|c|c|}
\hline $\begin{array}{l}\text { Lot } \\
\text { No. }\end{array}$ & $\begin{array}{l}\text { Specimen } \\
\text { No. }\end{array}$ & Nodule No. & $\begin{array}{l}\text { Flake } \\
\text { Size }\end{array}$ & $\begin{array}{l}\text { Percent } \\
\text { Cortex }\end{array}$ & $\begin{array}{l}\text { Platform } \\
\text { Type }\end{array}$ & $\begin{array}{l}\text { Thermal } \\
\text { Alteration }\end{array}$ & $\begin{array}{c}\text { Technological } \\
\text { Class }\end{array}$ & Count & Comments \\
\hline 203 & 37 & 13.3 & 4 & 00 & MLT & ANO & $\mathrm{CMX}$ & 1 & None \\
\hline 203 & 38 & 13.4 & 3 & 03 & FCT & ANO & SIM & 1 & None \\
\hline 203 & 39 & 13.5 & 4 & 00 & MLT & ANO & CMX & 1 & None \\
\hline 203 & 40 & 13.6 & 4 & 00 & MSG & ANO & $\mathrm{CMX}$ & 1 & None \\
\hline 203 & 41 & 13.7 & 4 & 00 & MSG & ANO & $\overline{C M X}$ & 1 & None \\
\hline 203 & 42 & 13.8 & 4 & 00 & MSG & ANO & CMX & 1 & None \\
\hline 203 & 43 & 13.9 & 4 & 00 & MSG & ANO & $\mathrm{CMX}$ & 1 & None \\
\hline 203 & 44 & 13.10 & 4 & 00 & MSG & ANO & $\mathrm{CMX}$ & 1 & None \\
\hline 203 & 45 & 13.11 & 4 & & MSG & ANO & CMX & 1 & None \\
\hline 203 & 46 & 13.12 & 4 & 01 & MSG & ANO & CMX & 1 & None \\
\hline 203 & 47 & 13.13 & 4 & 00 & MSG & ANO & CMX & 1 & None \\
\hline 203 & 48 & 13.14 & 5 & $\mathrm{NA}$ & $\mathrm{N} / \mathrm{A}$ & $\mathrm{N} / \mathrm{A}$ & $\mathrm{N} / \mathrm{A}$ & 1 & None \\
\hline 203 & 49 & 13.15 & 4 & 00 & MLT & ANO & CMX & 1 & None \\
\hline 203 & 50 & 13.16 & 5 & NA & $\mathrm{N} / \mathrm{A}$ & $\mathrm{N} / \mathrm{A}$ & $\mathrm{N} / \mathrm{A}$ & 1 & None \\
\hline 203 & 51 & 13.17 & 4 & 00 & MSG & ANO & CMX & 1 & None \\
\hline 203 & 52 & 13.18 & 4 & 00 & MSG & ANO & CMX & 1 & None \\
\hline 203 & 53 & 13.19 & 4 & 00 & MSG & ANO & CMX & 1 & None \\
\hline 203 & 54 & 13.20 & 4 & 00 & MSG & ANO & CMX & 1 & None \\
\hline 203 & 55 & 13.21 & 5 & $\overline{N A}$ & $\mathrm{~N} / \mathrm{A}$ & $\mathrm{N} / \mathrm{A}$ & $\mathrm{N} / \mathrm{A}$ & 1 & None \\
\hline 203 & 56 & 13.22 & 5 & $\mathrm{NA}$ & $\mathrm{N} / \mathrm{A}$ & $\mathrm{N} / \mathrm{A}$ & BPR & 1 & None \\
\hline 203 & 57 & 13.23 & 5 & $\mathrm{NA}$ & $\mathrm{N} / \mathrm{A}$ & $\mathrm{N} / \mathrm{A}$ & $\mathrm{N} / \mathrm{A}$ & 1 & None \\
\hline 203 & 58 & 14.1 & 4 & 03 & MSG & AOB & CMX & 1 & None \\
\hline 203 & 59 & 14.2 & 4 & 00 & MSG & ANO & CMX & 1 & None \\
\hline 203 & 60 & 14.3 & 4 & 00 & MSG & ANO & CMX & 1 & None \\
\hline 203 & 61 & 14.4 & 5 & NA & $\mathrm{N} / \mathrm{A}$ & $\mathrm{N} / \mathrm{A}$ & BPR & 1 & None \\
\hline 203 & 62 & 14.5 & 4 & 00 & MSG & ANO & CMX & 1 & None \\
\hline 203 & 63 & 14.6 & 5 & NA & $\mathrm{N} / \mathrm{A}$ & $\mathrm{N} / \mathrm{A}$ & $\mathrm{N} / \mathrm{A}$ & 1 & None \\
\hline 203 & 64 & 15.1 & 4 & 00 & $\overline{M L T}$ & ANO & CMX & 1 & None \\
\hline 203 & 65 & 15.2 & 4 & 00 & MSG & ANO & CMX & 1 & None \\
\hline 203 & 66 & 15.3 & 4 & 00 & MSG & ANO & $\mathrm{CMX}$ & 1 & None \\
\hline 203 & 67 & 15.4 & 4 & 00 & MSG & ANO & CMX & 1 & None \\
\hline 203 & 68 & 15.5 & 4 & 00 & MSG & ANO & CMX & 1 & None \\
\hline 203 & 69 & 15.6 & 4 & 00 & MSG & ANO & $\overline{C M X}$ & 1 & None \\
\hline 203 & 70 & 15.7 & 4 & 00 & MSG & ANO & CMX & 1 & None \\
\hline 203 & 71 & 16.1 & 4 & 00 & MSG & ANO & CMX & 1 & None \\
\hline 203 & 72 & 16.2 & 4 & 00 & $\overline{M S G}$ & ANO & $\overline{C M X}$ & 1 & None \\
\hline 203 & 73 & 16.3 & 4 & 00 & MSG & ANO & CMX & 1 & None \\
\hline 203 & 74 & 16.4 & 4 & 00 & MSG & ANO & CMX & 1 & None \\
\hline 203 & 75 & 17.1 & 4 & 04 & MSG & ANO & CMX & 1 & None \\
\hline 203 & 76 & 18.1 & 1 & 02 & MSG & ANO & SIM & 1 & None \\
\hline 203 & 77 & 18.2 & 1 & 03 & MSG & ANO & SIM & 1 & None \\
\hline 203 & 78 & 18.3 & 2 & 00 & $\mathrm{MLT}$ & ANO & CMX & 1 & None \\
\hline 203 & 79 & 18.4 & 2 & 00 & MLT & ANO & CMX & 1 & None \\
\hline 203 & 80 & 18.5 & 3 & 02 & MSG & ANO & SIM & 1 & None \\
\hline 203 & 81 & 18.6 & 4 & 00 & MSG & ANO & CMX & 1 & None \\
\hline 203 & 82 & 19.1 & 3 & 00 & MLT & ANO & CMX & 1 & None \\
\hline 203 & 83 & 19.2 & 3 & 00 & MSG & ANO & CMX & 1 & None \\
\hline 203 & 84 & 19B.1 & 3 & 00 & FCT & ANO & CMX & 1 & None \\
\hline 203 & 85 & 19B.2 & 3 & 00 & MSG & ANO & CMX & 1 & None \\
\hline 203 & 86 & 19B.3 & 4 & 00 & MSG & ANO & CMX & 1 & None \\
\hline 203 & 87 & 20.1 & 2 & 04 & CRT & ANO & PRI & 1 & None \\
\hline 203 & 88 & 20.2 & 3 & 00 & MLT & ANO & $\overline{C M X}$ & 1 & None \\
\hline 203 & 89 & 21.1 & 2 & 00 & CRT & ANO & CMX & 1 & None \\
\hline 203 & 90 & 21.2 & 3 & 00 & FLA & ANO & CMX & 1 & None \\
\hline 203 & 91 & 21.3 & 4 & 00 & $\mathrm{MLT}$ & ANO & CMX & $\frac{1}{1}$ & None \\
\hline 203 & 92 & 21.4 & 4 & 00 & MSG & ANO & CMX & 1 & None \\
\hline 203 & 93 & 21.5 & 4 & 04 & CRT & ANO & CMX & 1 & None \\
\hline 203 & 94 & 21.6 & 4 & 00 & FLA & ANO & CMX & 1 & None \\
\hline 203 & 95 & 22.1 & 3 & 00 & MLT & ANO & CMX & 1 & None \\
\hline 203 & 96 & 22.2 & 3 & 00 & MSG & ANO & $\overline{C M X}$ & 1 & None \\
\hline 203 & 97 & 22.3 & 5 & NA & N/A & $\mathrm{N} / \mathrm{A}$ & $\mathrm{N} / \mathrm{A}$ & 1 & None \\
\hline 203 & 98 & 22.4 & 4 & 00 & MLT & ANO & BPR & 1 & None \\
\hline 203 & 99 & 23.1 & 1 & 03 & MSG & ANO & SIM & 1 & None \\
\hline 203 & 100 & 23.2 & 2 & 00 & FLA & ANO & CMX & 1 & None \\
\hline 203 & 101 & 23.3 & 3 & 00 & MSG & ANO & CMX & 1 & None \\
\hline 203 & 102 & 23.4 & 4 & 00 & MSG & ANO & CMX & 1 & None \\
\hline
\end{tabular}


Appendix D.2. TxDOT 41SR242 Feature 4 Debitage Analysis

\begin{tabular}{|c|c|c|c|c|c|c|c|c|c|}
\hline $\begin{array}{l}\text { Lot } \\
\text { No. }\end{array}$ & $\begin{array}{c}\text { Specimen } \\
\text { No. }\end{array}$ & Nodule No. & $\begin{array}{l}\text { Flake } \\
\text { Size }\end{array}$ & $\begin{array}{l}\text { Percent } \\
\text { Cortex } \\
\end{array}$ & $\begin{array}{l}\text { Platform } \\
\text { Type } \\
\end{array}$ & $\begin{array}{l}\text { Thermal } \\
\text { Alteration }\end{array}$ & $\begin{array}{c}\text { Technological } \\
\text { Class }\end{array}$ & Count & Comments \\
\hline 203 & 103 & 24.1 & 2 & 00 & MSG & ANO & $\mathrm{CMX}$ & 1 & None \\
\hline 203 & 104 & 24.2 & 2 & 00 & MSG & ANO & CMX & 1 & None \\
\hline 203 & 105 & 24.3 & 4 & 00 & MSG & ANO & CMX & 1 & None \\
\hline 203 & 106 & 24.4 & 4 & 00 & MLT & ANO & CMX & 1 & None \\
\hline 203 & 107 & 25.1 & 4 & 00 & MLT & ANO & CMX & 1 & None \\
\hline 203 & 108 & 25.2 & 4 & 00 & MSG & ANO & CMX & 1 & None \\
\hline 203 & 109 & 25.3 & 5 & NA & N/A & $\mathrm{N} / \mathrm{A}$ & $\mathrm{N} / \mathrm{A}$ & 1 & None \\
\hline 203 & 110 & 25.4 & 5 & NA & $\mathrm{N} / \mathrm{A}$ & $\mathrm{N} / \mathrm{A}$ & BPR & 1 & None \\
\hline 203 & 111 & 26.1 & 3 & 00 & MSG & ANO & CMX & 1 & None \\
\hline 203 & 112 & 26.2 & 4 & 00 & MSG & ANO & CMX & 1 & None \\
\hline 203 & 113 & 26.3 & 4 & 04 & CRT & ANO & PRI & 1 & None \\
\hline 203 & 114 & 27.1 & 4 & 00 & MSG & ANO & $\mathrm{CMX}$ & 1 & None \\
\hline 203 & 115 & 27.2 & 4 & 00 & MSG & ANO & SHA & 1 & None \\
\hline 203 & 117 & 27.4 & 4 & 00 & MSG & ANO & CMX & 1 & None \\
\hline 203 & 118 & 27.5 & 4 & 00 & MSG & ANO & CMX & 1 & None \\
\hline 203 & 119 & 27.6 & 4 & 00 & MSG & ANO & CMX & 1 & None \\
\hline 203 & 120 & 28.1 & 4 & 00 & MLT & ANO & CMX & 1 & None \\
\hline 203 & 121 & 28B.1 & 4 & 00 & MSG & ANO & SHA & 1 & None \\
\hline 203 & 122 & 29.1 & 4 & 00 & MSG & ANO & CMX & 1 & None \\
\hline 203 & 123 & 29.2 & 5 & NA & $\mathrm{N} / \mathrm{A}$ & $\mathrm{N} / \mathrm{A}$ & $\mathrm{N} / \mathrm{A}$ & 1 & None \\
\hline 203 & 124 & 30.1 & 3 & 01 & MLT & ANO & CMX & 1 & None \\
\hline 203 & 125 & 30.2 & 4 & 00 & MSG & ANO & CMX & 1 & None \\
\hline 203 & 126 & 31.1 & 2 & 00 & FCT & ANO & CMX & 1 & None \\
\hline 203 & 127 & 32.1 & 3 & 04 & MSG & ANO & CMX & 1 & None \\
\hline 203 & 128 & 32.2 & 3 & 00 & MSG & ANO & CMX & 1 & None \\
\hline 203 & 129 & 33.1 & 3 & 00 & CRT & ANO & CMX & 1 & None \\
\hline 203 & 130 & 34.1 & 4 & 04 & MSG & ANO & PRI & 1 & None \\
\hline 203 & 131 & 34.2 & 5 & NA & N/A & N/A & $\mathrm{N} / \mathrm{A}$ & 1 & None \\
\hline 203 & 134 & 35.3 & 5 & NA & $\mathrm{N} / \mathrm{A}$ & $\mathrm{N} / \mathrm{A}$ & $\mathrm{N} / \mathrm{A}$ & 1 & None \\
\hline 203 & 135 & 36.1 & 5 & NA & $\mathrm{N} / \mathrm{A}$ & $\mathrm{N} / \mathrm{A}$ & $\mathrm{N} / \mathrm{A}$ & 1 & None \\
\hline 203 & 136 & 36.2 & 5 & NA & N/A & N/A & $\mathrm{N} / \mathrm{A}$ & 1 & None \\
\hline 203 & 137 & 36.3 & 5 & NA & $\mathrm{N} / \mathrm{A}$ & $\mathrm{N} / \mathrm{A}$ & $\mathrm{N} / \mathrm{A}$ & 1 & None \\
\hline
\end{tabular}




\begin{tabular}{|c|c|c|c|c|c|c|c|c|c|c|c|c|c|c|c|c|c|c|c|c|c|c|c|c|c|c|c|c|c|c|c|c|c|c|}
\hline to & & $\begin{array}{l}\text { Fs } \\
\text { No. }\end{array}$ & 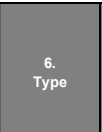 & $\begin{array}{c}\text { Subtypeal } \\
\text { Identity }\end{array}$ & Count & 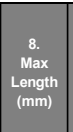 & 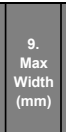 & 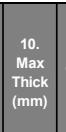 & $\left|\begin{array}{c}11 . \\
\text { Weight } \\
\text { (g) }\end{array}\right|$ & \begin{tabular}{|c|c|} 
Edgeg \\
Angle
\end{tabular} & $\begin{array}{c}13 . \\
\text { stage }\end{array}$ & $\begin{array}{c}14 . \\
\text { Portion }\end{array}$ & 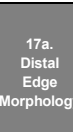 & 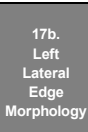 & 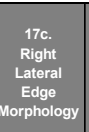 & 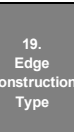 & $\begin{array}{l}\text { Filakng } \\
\text { Atartition }\end{array}$ & Lithology & 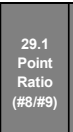 & 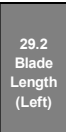 & 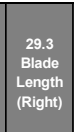 & \begin{tabular}{|cc} 
Based \\
Base Stem \\
LLongth \\
or \\
Basal \\
Inflection
\end{tabular} & 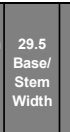 & $\begin{array}{c}29.11 \\
\text { Base to } \\
\text { Baded } \\
\text { Ratio } \\
\text { (Leagth) }\end{array}$ & 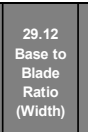 & $\begin{array}{l}20.13 \\
\text { Basel } \\
\text { setem } \\
\text { Ratio }\end{array}$ & \begin{tabular}{|l|l}
20.14 \\
Baso \\
Form
\end{tabular} \mid & 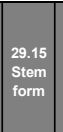 & 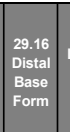 & 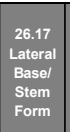 & 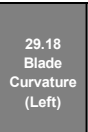 & 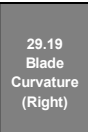 & 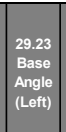 & 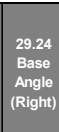 \\
\hline & 001 sc & col.1.11 & Bifiace & Earty-Stage & & 39.11 & \begin{tabular}{|l|l|}
22.84 \\
\end{tabular} & \begin{tabular}{|l|}
21.05 \\
\end{tabular} & 42.2 & 65 & INR & PRX & IND & $\operatorname{cvx}$ & $\mathrm{cvx}$ & $\mathrm{BFB}$ & NPR & CRT & NAP & NAP & NAP & NAP & NAP & NAP & NAP & NAP & \begin{tabular}{|l|} 
NAP \\
\end{tabular} & \begin{tabular}{|l|} 
NAP \\
\end{tabular} & \begin{tabular}{|l|} 
NAP \\
\end{tabular} & NAP & NAP & NAP & NAP & NAP \\
\hline 001 & \begin{tabular}{l|l}
002 & sc
\end{tabular} & sc 01.02 & Biface & Late-Stage & & 20.69 & 13.31 & \begin{tabular}{|l|}
7.06 \\
\end{tabular} & 9.6 & 35 & PRF & $\begin{array}{l}\mathrm{PRX} \\
\end{array}$ & IND & $\mathrm{cvx}$ & cvx & BFB & NPR & CRT & NAP & NAP & NAP & NAP & NAP & NAP & NAP & NAP & \begin{tabular}{|l|} 
NAP \\
\end{tabular} & \begin{tabular}{|l|} 
NAP \\
\end{tabular} & \begin{tabular}{|l|l|} 
NAP \\
\end{tabular} & NAP & NAP & NAP & NAP & \begin{tabular}{|l|l} 
NAP \\
\end{tabular} \\
\hline 001 & \begin{tabular}{l|l}
003 & sc
\end{tabular} & co 01.03 & Biface & Eary-Slage & 1 & 32.99 & \begin{tabular}{|l|}
29.40 \\
\end{tabular} & \begin{tabular}{|l|l|}
10.62 \\
\end{tabular} & 10.8 & 35 & \begin{tabular}{|l|l|} 
NRR \\
\end{tabular} & PRX & IND & cvx & $c v x$ & BFB & NPR & CRT & NAP & NAP & NAP & NAP & NAP & NAP & NAP & NAP & \begin{tabular}{|l|l|} 
NAP \\
\end{tabular} & \begin{tabular}{|l|l|} 
NAP \\
\end{tabular} & \begin{tabular}{|l|} 
NAP \\
\end{tabular} & NAP & NAP & NAP & NAP & NAP \\
\hline 001 & 004 & co 01.04 & dge-Modified & Utilized & 1 & \begin{tabular}{l|l}
37.87 &
\end{tabular} & 63.28 & \begin{tabular}{|l|l|} 
& 15.74 \\
\end{tabular} & 18.9 & 43 & NAP & PME & IND & cvx & $\operatorname{cov} x$ & NAP & UFU & CRT & NAP & NAP & NAP & NAP & NAP & NAP & NAP & NAP & \begin{tabular}{|l|} 
NAP \\
\end{tabular} & \begin{tabular}{|l|l|} 
NAP \\
\end{tabular} & \begin{tabular}{|l|} 
NAP \\
\end{tabular} & NAP & NAP & NAP & NAP & NAP \\
\hline 001 & 005 & sc 01 & & Utilized & 1 & 52.78 & \begin{tabular}{|l|l|} 
& 58.94 \\
\end{tabular} & \begin{tabular}{|l|l|}
15.74 \\
\end{tabular} & 20.5 & 63 & NAP & СMP & NAP & NAP & $\mathrm{cvdx}$ & NAP & BFU & CRT & NAP & NAP & NAP & NAP & NAP & NAP & NAP & NAP & \begin{tabular}{|l|} 
NAP \\
\end{tabular} & \begin{tabular}{|l|} 
NAP \\
\end{tabular} & NAP & NAP & NAP & NAP & NAP & NAP \\
\hline 002 & \begin{tabular}{l|l}
001 & sc
\end{tabular} & co 02.01 & Biface & Late-Stage & 1 & 60.18 & \begin{tabular}{|l|l|} 
& 38.09 \\
\end{tabular} & \begin{tabular}{|l|l|}
7.80 \\
\end{tabular} & 15.2 & 40 & PRF & IND & IND & cvx & $\operatorname{cvv} x$ & BFB & NPR & CRT & NAP & NAP & NAP & NAP & NAP & NAP & NAP & NAP & NAP & \begin{tabular}{|l|l|} 
NAP \\
\end{tabular} & \begin{tabular}{|l|} 
NAP \\
\end{tabular} & NAP & NAP & NAP & NAP & NAP \\
\hline 025 & \begin{tabular}{c|cc}
02 & sc
\end{tabular} & c 02.02 & Biface & -Stage & & 73.83 & 50.66 & \begin{tabular}{|l|l|}
27.99 \\
\end{tabular} & \begin{tabular}{|l|l|}
106.9 \\
\end{tabular} & 70 & INR & CMP & $\mathrm{cvx}$ & $c v x$ & cv. & BFC & NPR & CRT & NAP & NAP & NAP & NAP & NAP & NAP & NAP & \begin{tabular}{|l|} 
NAP \\
\end{tabular} & \begin{tabular}{|l|} 
NAP \\
\end{tabular} & \begin{tabular}{|l|l|} 
NAP \\
\end{tabular} & \begin{tabular}{|l|l|} 
NAP \\
\end{tabular} & NAP & NAP & NAP & NAP & NAP \\
\hline 002 & \begin{tabular}{l|l}
003 & sc
\end{tabular} & c 02.03 & Biface & Early-Slage & 1 & 66.77 & \begin{tabular}{|l|l|l|} 
\\
\end{tabular} & \begin{tabular}{|l|l|}
22.59 \\
\end{tabular} & \begin{tabular}{|l|l|}
73.9 \\
\end{tabular} & 50 & INR & MED & IND & $\mathrm{cvx}$ & $\mathrm{cvv}$ & BFB & NPR & CRT & NAP & NAP & NAP & NAP & NAP & NAP & NAP & NAP & \begin{tabular}{|l|l|} 
NAP \\
\end{tabular} & \begin{tabular}{|l|l|} 
NAP \\
\end{tabular} & \begin{tabular}{|l|} 
NAP \\
\end{tabular} & NAP & NAP & NAP & NAP & NAP \\
\hline 003 & \begin{tabular}{l|l}
001 & sc
\end{tabular} & 803.01 & Biface & Mid-Stage & 1 & 61.77 & \begin{tabular}{|l|l|l|}
42.34 \\
\end{tabular} & \begin{tabular}{|l|l|}
15.34 \\
\end{tabular} & \begin{tabular}{|l|l|}
41.9 \\
\end{tabular} & 50 & BLK & CMP & $\mathrm{cvx}$ & $\mathrm{cvx}$ & $\mathrm{cvx}$ & $\mathrm{BFC}$ & NPR & SLM & NAP & NAP & NAP & NAP & NAP & NAP & NAP & NAP & \begin{tabular}{|l|l|} 
NAP \\
\end{tabular} & \begin{tabular}{|l|l|} 
NAP \\
\end{tabular} & \begin{tabular}{|l|l|} 
NAP \\
\end{tabular} & NAP & NAP & NAP & \begin{tabular}{|l|} 
NAP \\
\end{tabular} & NAP \\
\hline 003 & \begin{tabular}{l|l}
002 & sc
\end{tabular} & 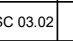 & Biface & $\begin{array}{l}\text { Lat-Stage } \\
\end{array}$ & 1 & 40.70 & \begin{tabular}{|l|l|}
39.93 \\
\end{tabular} & \begin{tabular}{|l|}
9.43 \\
\end{tabular} & \begin{tabular}{|l|l}
15.3 \\
\end{tabular} & $\begin{array}{l}45 \\
\end{array}$ & PRF & CMP & $\mathrm{cvx}$ & $\mathrm{cvx}$ & $c \mathrm{cvx}$ & BFC & NPR & $\begin{array}{ll}\text { CRT } \\
\end{array}$ & NAP & NAP & NAP & NAP & NAP & NAP & NAP & \begin{tabular}{|l|} 
NAP \\
\end{tabular} & \begin{tabular}{|l|l|} 
NAP \\
\end{tabular} & \begin{tabular}{|l|} 
NAP \\
\end{tabular} & NAP & NAP & NAP & NAP & NAP & NAP \\
\hline 003 & \begin{tabular}{l|l}
003 & sc
\end{tabular} & 300.03 & 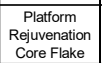 & NAP & 1 & 67.12 & 62.17 & \begin{tabular}{|l|}
25.38 \\
\end{tabular} & \begin{tabular}{|l|l|}
81.3 \\
\end{tabular} & 45 & NAP & NAP & NAP & NAP & NAP & NAP & NPR & CHL & NAP & NAP & NAP & NAP & NAP & NAP & NAP & NAP & \begin{tabular}{|l|} 
NAP \\
\end{tabular} & \begin{tabular}{|l|l|} 
NAP \\
\end{tabular} & \begin{tabular}{|l|} 
NAP \\
\end{tabular} & NAP & NAP & NAP & NAP & NAP \\
\hline 004 & \begin{tabular}{l|l}
001 & sc
\end{tabular} & c 04.01 & \begin{tabular}{|l|l|} 
Bifice \\
\end{tabular} & Mid-stage & 1 & 64.08 & \begin{tabular}{|l|l|} 
& \\
\end{tabular} & \begin{tabular}{|l|}
17.52 \\
\end{tabular} & 52.5 & 50 & BLK & СMP & cvx & cvx & $\mathrm{cvx}$ & $\mathrm{BFC}$ & NPR & CRT & NAP & NAP & NAP & NAP & NAP & NAP & NAP & NAP & \begin{tabular}{|l|} 
NAP \\
\end{tabular} & \begin{tabular}{|l|} 
NAP \\
\end{tabular} & \begin{tabular}{|l|l|} 
NAP \\
\end{tabular} & NAP & NAP & NAP & NAP & NAP \\
\hline 004 & \begin{tabular}{l|l}
002 & sc
\end{tabular} & 04,02 & Dart & Dessmuke Base & 1 & 43.22 & \begin{tabular}{|l|l|}
29.83 \\
\end{tabular} & \begin{tabular}{l|l|}
8.52 \\
\end{tabular} & 9.9 & 40 & FST & \begin{tabular}{|l|l|} 
DIS \\
\end{tabular} & $\mathrm{cvx}$ & $\mathrm{cvx}$ & cvx & BFD & NPR & $\mathrm{CHH}$ & 1.45 & 43.66 & 37.41 & NAP & NAP & NAP & NAP & NAP & \begin{tabular}{|l|l|} 
NAP \\
\end{tabular} & \begin{tabular}{|l|l|} 
NAP \\
\end{tabular} & 2 & NAP & 2 & 2 & \begin{tabular}{|l|l|} 
NAP \\
\end{tabular} & \begin{tabular}{|l|l|} 
NAP \\
\end{tabular} \\
\hline 005 & \begin{tabular}{l|l}
001 & sc
\end{tabular} & 05.01 & Dart & Totugas & 1 & 29.67 & 35.66 & \begin{tabular}{|l|l|}
8.96 \\
\end{tabular} & 11.2 & 40 & FST & \begin{tabular}{|l|l|}
$P R X$ \\
\end{tabular} & IND & cvx & $c \mathrm{cvx}$ & BFB & NPR & 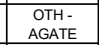 & 0.83 & 25.35 & 25.47 & 3.17 & 34.42 & 0.11 & 0.97 & NAP & \begin{tabular}{|l|}
1 \\
\end{tabular} & \begin{tabular}{|l|l|} 
NAP \\
\end{tabular} & \begin{tabular}{|l|l|} 
NAP \\
\end{tabular} & NAP & 2 & 2 & 48 & \begin{tabular}{|l|l|}
51 &
\end{tabular} \\
\hline 005 & \begin{tabular}{l|l}
002 & sc
\end{tabular} & co 05.02 & Biface & $\begin{array}{l}\text { Late-Stage } \\
\end{array}$ & 1 & 43.18 & \begin{tabular}{|l|l|}
35.57 \\
\end{tabular} & $\begin{array}{l}7.86 \\
\end{array}$ & \begin{tabular}{|l|l|}
11.4 \\
\end{tabular} & 35 & PRF & MED & IND & $\mathrm{cvx}$ & $\mathrm{cov}$ & BFB & NPR & CRT & NAP & NAP & NAP & NAP & NAP & NAP & NAP & NAP & \begin{tabular}{|l|l|} 
NAP \\
\end{tabular} & \begin{tabular}{|l|l|} 
NAP \\
\end{tabular} & \begin{tabular}{|l|l|} 
NAP \\
\end{tabular} & NAP & NAP & NAP & NAP & NAP \\
\hline 005 & \begin{tabular}{l|l}
003 & sc
\end{tabular} & co5.03 & Biface & Earry-Stage & 1 & 68.55 & \begin{tabular}{|l|l|}
43.22 \\
\end{tabular} & 22.51 & \begin{tabular}{|l|l|}
61.7 \\
\end{tabular} & 50 & INR & CMP & $\mathrm{cvx}$ & cr & $\mathrm{cr}$ & $\mathrm{BF}$ & NPR & $\mathrm{CF}$ & ${ }^{N}$ & NAP & NAP & & NAP & NAP & NAP & NAP & \begin{tabular}{|l|l|} 
NAP \\
\end{tabular} & \begin{tabular}{|l|l|} 
NAP \\
\end{tabular} & \begin{tabular}{|l|l|} 
NAP \\
\end{tabular} & NAP & NAP & NAP & NAP & NAP \\
\hline 0006 & \begin{tabular}{l|l}
001 & sc
\end{tabular} & 00.01 & Dart & Tortugas & 1 & 60.99 & \begin{tabular}{|l|l|}
28.75 \\
\end{tabular} & \begin{tabular}{|l|l|}
8.37 \\
\end{tabular} & 11.6 & 40 & FST & CMP & $\mathrm{cvx}$ & $\mathrm{ccv}$ & cvx & $\mathrm{BFC}$ & NPR & CRT & 2.12 & 57.92 & 60.98 & 4.84 & 28.96 & 0.08 & 1.01 & NAP & 1 & \begin{tabular}{|l|l|} 
NAP \\
\end{tabular} & 1 & NAP & 4 & 2 & 42 & 43 \\
\hline 006 & \begin{tabular}{l|l}
002 & sc \\
\end{tabular} & c 0.02 & Biface & Earty-Stage & 1 & 63.34 & 56.71 & \begin{tabular}{|l|l|}
26.89 \\
\end{tabular} & \begin{tabular}{|l|l|}
85.9 \\
\end{tabular} & 60 & INR & \begin{tabular}{|l|} 
IND \\
\end{tabular} & IND & $\mathrm{cvx}$ & cvx & BFB & NPR & CRT & NAP & NAP & NAP & NAP & NAP & NAP & NAP & NAP & \begin{tabular}{|l|l|} 
NAP \\
\end{tabular} & \begin{tabular}{|l|l|} 
NAP \\
\end{tabular} & \begin{tabular}{|l|l|} 
NAP \\
\end{tabular} & NAP & NAP & NAP & NAP & \begin{tabular}{|l} 
NAP \\
\end{tabular} \\
\hline 007 & \begin{tabular}{l|l}
001 & $\mathrm{~s}$ \\
\end{tabular} & SD 1 & Dart & \begin{tabular}{|l|l|} 
Totugas \\
\end{tabular} & 1 & 38.90 & \begin{tabular}{|l|l|}
24.37 \\
\end{tabular} & \begin{tabular}{|l|l|}
7.97 \\
\end{tabular} & \begin{tabular}{|l|}
8.6 \\
\end{tabular} & 60 & FST & PME & NND & $\operatorname{cvs}$ & $\mathrm{cvv}$ & BFB & บво & CRT & 1.60 & 37.24 & 38.75 & 2.93 & 24.18 & 0.08 & 0.99 & NAP & & \begin{tabular}{|l|} 
NAP \\
\end{tabular} & \begin{tabular}{|l|} 
NAP \\
\end{tabular} & NAP & 2 & 2 & 45 & 41 \\
\hline 008 & \begin{tabular}{l|l}
001 \\
\end{tabular} & SD 2 & Dart & & 1 & 39.75 & 33.12 & \begin{tabular}{|l|l|}
7.44 \\
\end{tabular} & 10.7 & 55 & FST & PME & IND & $\mathrm{cvx}$ & cvx & BFB & NPR & CRT & 1.20 & 36.80 & 37.12 & ${ }_{4.53}$ & 33.05 & 0.11 & 1.00 & NAP & 2 & \begin{tabular}{|l|l|} 
NAP \\
\end{tabular} & \begin{tabular}{|l|l|} 
NAP \\
\end{tabular} & NAP & 2 & $2^{2}$ & 41 & 46 \\
\hline 009 & 001 & SD 3 & Scraper & $\begin{array}{l}\text { Distilly } \\
\text { Beveled } \\
\text { Sccraer }\end{array}$ & 1 & 39.40 & \begin{tabular}{|l|}
29.52 \\
\end{tabular} & 6.67 & 10.1 & 50 & REJ & PRX & IND & $\operatorname{cvx}$ & $\mathrm{cvx}$ & $\mathrm{BFC}$ & UFD & CRT & NAP & NAP & NAP & NAP & NAP & NAP & NAP & NAP & NAP & NAP & NAP & NAP & NAP & NAP & \begin{tabular}{|l|l|} 
NAP \\
\end{tabular} & NAP \\
\hline 010 & 001 & SD 4 & Biface & Late-Stage & 1 & 36.15 & 26.99 & \begin{tabular}{|l|l|} 
\\
\end{tabular} & 6.8 & 60 & PRF & DIS & cvx & cux & $\operatorname{cvx}$ & BFD & NPR & CRT & NAP & NAP & NAP & NAP & NAP & NAP & NAP & NAP & NAP & \begin{tabular}{|l|l|} 
NAP \\
\end{tabular} & \begin{tabular}{|l|l|} 
NAP \\
\end{tabular} & NAP & NAP & NAP & NAP & NAP \\
\hline 01 & 001 & SD 5 & Dart Preform & 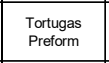 & 1 & 36.82 & 36.42 & 8.49 & 13.1 & 55 & PRF & PRX & IND & cux & $\operatorname{cvx}$ & BFB & NPR & \begin{tabular}{|l|} 
OTH- \\
METAMOR \\
SAALE
\end{tabular} & 1.01 & 36.16 & 30.48 & 3.04 & 34.52 & 0.08 & 0.95 & NAP & 2 & NAP & NAP & NAP & 2 & 2 & 43 & 47 \\
\hline 012 & 001 & SD 6 & Dart Preform & $\begin{array}{l}\text { Totugas } \\
\text { Preform }\end{array}$ & 1 & 68.20 & \begin{tabular}{|l|l|}
34.16 \\
\end{tabular} & \begin{tabular}{|l|l|l|} 
\\
\end{tabular} & 37.0 & 80 & PRF & CMP & $\operatorname{cvx}$ & $\mathrm{cvx}$ & $c \mathrm{crx}$ & $\mathrm{BFC}$ & NPR & CRT & 2.00 & 68.53 & 67.36 & 6.65 & 28.08 & 0.10 & 0.82 & NAP & & NAP & 1 & NAP & 2 & 2 & 54 & 56 \\
\hline $\begin{array}{lll}013 & \\
\end{array}$ & 001 & SD 7 & Dart & Tortugas & 1 & 40.90 & \begin{tabular}{|l|}
26.26 \\
\end{tabular} & \begin{tabular}{|l|l|}
5.64 \\
\end{tabular} & 7.7 & 60 & FST & PME & IND & $\mathrm{cvx}$ & $\mathrm{cvx}$ & BFB & BFB & SST & 1.56 & 40.20 & 41.49 & 5.40 & 26.26 & 0.13 & 1.00 & NAP & & \begin{tabular}{|l|} 
NAP \\
\end{tabular} & \begin{tabular}{|l|} 
NAP \\
\end{tabular} & NAP & 2 & 2 & 42 & 46 \\
\hline 014 & 001 & $\begin{array}{l}\text { SD } 8 \\
\end{array}$ & Bifice & & & 36.45 & \begin{tabular}{|l|}
25.54 \\
\end{tabular} & \begin{tabular}{|l|l|}
6.84 \\
\end{tabular} & 4.9 & 50 & \begin{tabular}{ll|} 
PRF \\
\end{tabular} & DIS & $\mathrm{cvx}$ & $\mathrm{cvx}$ & $\mathrm{crv}$ & BFD & $\begin{array}{l}\text { NPR } \\
\end{array}$ & & NAP & NAP & NAP & NAP & NAP & NAP & NAP & NAP & \begin{tabular}{|l|l|} 
NAP \\
\end{tabular} & \begin{tabular}{|l|l|} 
NAP \\
\end{tabular} & NAP & NAP & NAP & NAP & \begin{tabular}{|l|l|} 
NAP \\
\end{tabular} & \begin{tabular}{|l|l|} 
NAP \\
\end{tabular} \\
\hline is & 001 & SD 9 & Dart & 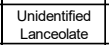 & 1 & 41.01 & \begin{tabular}{|l|l|}
27.94 \\
\end{tabular} & \begin{tabular}{|l}
6.20 \\
\end{tabular} & 6.9 & 40 & FST & \begin{tabular}{|l} 
PME \\
\end{tabular} & IND & $\mathrm{cvx}$ & cvx & BFB & NPR & $\begin{array}{l}\text { STH. } \\
\text { SLATE }\end{array}$ & 1.47 & 27.75 & 33.49 & 3.51 & 16.13 & 0.09 & 0.58 & NAP & \begin{tabular}{|l|}
0 \\
\end{tabular} & \begin{tabular}{|l|l|} 
NAP \\
\end{tabular} & \begin{tabular}{|l|} 
NAP \\
\end{tabular} & NAP & & & \begin{tabular}{|l|} 
NAP \\
\end{tabular} & 42 \\
\hline $\begin{array}{lll}016 \\
\end{array}$ & \begin{tabular}{l|l}
001 & $\mathrm{~s}$ \\
\end{tabular} & SD 10 & Dart & $\begin{array}{l}\text { Catan } \\
\end{array}$ & 1 & 35.77 & \begin{tabular}{|l|l|}
24.50 \\
\end{tabular} & 5.85 & 5.3 & 55 & FST & CMP & $c v x$ & $\operatorname{cvs} x$ & cvx & BFC & UFB & CRT & 1.46 & 29.42 & 28.32 & 7.46 & 15.27 & 0.21 & 0.62 & NAP & 2 & \begin{tabular}{|l|} 
NAP \\
\end{tabular} & 1 & NAP & 2 & 2 & 41 & 43 \\
\hline & \begin{tabular}{l|l}
001 \\
\end{tabular} & SB 1 & Bifiace & Mid-Siage & 1 & 49.4.43 & \begin{tabular}{|l|l|}
56.76 \\
\end{tabular} & \begin{tabular}{|l|}
11.77 \\
\end{tabular} & 33.9 & 60 & BLK & PRX & IND & $\mathrm{cvx}$ & $\mathrm{ccv} x$ & BFB & NPR & CRT & NAP & NAP & NAP & NAP & NAP & NAP & NAP & NAP & \begin{tabular}{|l|l|} 
NAP \\
\end{tabular} & \begin{tabular}{|l|} 
NAP \\
\end{tabular} & \begin{tabular}{|l|} 
NAP \\
\end{tabular} & NAP & NAP & NAP & \begin{tabular}{|l|l|} 
NAP \\
\end{tabular} & \begin{tabular}{|l|l|} 
NAP \\
\end{tabular} \\
\hline & 001 & SB 2 & Perforator & & 1 & 38.75 & & \begin{tabular}{|l|}
9.40 \\
\end{tabular} & 7.6 & \begin{tabular}{ll|}
70 \\
\end{tabular} & \begin{tabular}{|l|} 
IND \\
\end{tabular} & $\mathbb{N}$ & $\mathbb{N N}$ & o & $\mathrm{cr}$ & & $N$ & & $\mathrm{~N}$ & NAP & $\begin{array}{l}\text { NAP } \\
\end{array}$ & & NAP & & P & \begin{tabular}{|l|} 
NAP \\
\end{tabular} & \begin{tabular}{|l|l|} 
NAP \\
\end{tabular} & \begin{tabular}{|l|l|} 
NAP \\
\end{tabular} & \begin{tabular}{|l|} 
NAP \\
\end{tabular} & NAP & & NAP & \begin{tabular}{|l|} 
NAP \\
\end{tabular} & \begin{tabular}{|l|l|} 
NAP \\
\end{tabular} \\
\hline & 001 & SB 3 & Bifice & Mid-Stage & 1 & 58.60 & \begin{tabular}{|l|l|}
46.23 \\
\end{tabular} & \begin{tabular}{|l|l|}
15.45 \\
\end{tabular} & 39.0 & 65 & BLK & СMP & $\mathrm{cv} x$ & $\mathrm{cvx}$ & $\mathrm{cvx}$ & BFC & NPR & CRT & NAP & NAP & NAP & NAP & NAP & NAP & NAP & NAP & \begin{tabular}{|l|l|} 
NAP \\
\end{tabular} & \begin{tabular}{|l|} 
NAP \\
\end{tabular} & NAP & NAP & NAP & NAP & \begin{tabular}{|l|l|} 
NAP \\
\end{tabular} & \begin{tabular}{|l|l|} 
NAP \\
\end{tabular} \\
\hline $\begin{array}{l}020 \\
020 \\
\end{array}$ & 001 & SB 4 & Unitiace & $\begin{array}{l}\text { Disisold } \\
\text { Unniface }\end{array}$ & 1 & 38.52 & \begin{tabular}{|l|}
34.21 \\
\end{tabular} & \begin{tabular}{|l|l|}
14.91 \\
\end{tabular} & \begin{tabular}{|l|l|}
177.6 \\
\end{tabular} & 65 & NAP & CMP & $\operatorname{cvx}$ & cux & $\mathrm{cvx}$ & unc & NPR & $\begin{array}{ll}\text { CRT } \\
\end{array}$ & NAP & NAP & NAP & NAP & NAP & NAP & NAP & NAP & \begin{tabular}{|l|l|} 
NAP \\
\end{tabular} & \begin{tabular}{|l|l|} 
NAP \\
\end{tabular} & \begin{tabular}{|l|l|} 
NAP \\
\end{tabular} & NAP & NAP & NAP & NAP & \begin{tabular}{|l|l|} 
NAP \\
\end{tabular} \\
\hline & 001 & SB 5 & Bifiace & Late-Stage & 1 & \begin{tabular}{|c|}
36.16 \\
\end{tabular} & 31.66 & \begin{tabular}{|l|l|}
7.69 \\
\end{tabular} & 8.8 & 40 & PRF & IND & IND & $\operatorname{cvv} x$ & $c v x$ & $\mathrm{BFE}$ & NPR & CRT & NAP & NAP & NAP & NAP & NAP & NAP & NAP & NAP & \begin{tabular}{|l|l|} 
NAP \\
\end{tabular} & \begin{tabular}{|l|l|} 
NAP \\
\end{tabular} & \begin{tabular}{|l|} 
NAP \\
\end{tabular} & NAP & NAP & NAP & \begin{tabular}{|l|} 
NAP \\
\end{tabular} & NAP \\
\hline & 001 & $\mathrm{SB} B$ & Bifiace & Mid- & 1 & \begin{tabular}{l|l|}
49.67 \\
\end{tabular} & \begin{tabular}{|l|l|}
41.07 \\
\end{tabular} & $\begin{array}{ll}9.7 \\
\end{array}$ & 16.8 & \begin{tabular}{l|l|}
45 \\
\end{tabular} & BLK & D & $\mathrm{cv}$ & & $\mathrm{c}$ & & & & & $\mathrm{N}$ & & & NAF & & & NAP & \begin{tabular}{|l|l|} 
NAP \\
\end{tabular} & \begin{tabular}{|l|} 
NAP \\
\end{tabular} & \begin{tabular}{|l|} 
NAP \\
\end{tabular} & NAP & & AP & NAP & NAP \\
\hline $\begin{array}{lll}0233 & \\
\end{array}$ & 001 & SB7 & Biface & $\begin{array}{l}\text { Mid-Stage } \\
\text { e }\end{array}$ & 1 & 33.51 & \begin{tabular}{|l|l|}
44.11 \\
\end{tabular} & \begin{tabular}{|l|l|}
9.57 \\
\end{tabular} & 15.8 & 55 & BLK & PRX & IND & $\mathrm{cvx}$ & $\mathrm{crx}$ & BFB & NPR & $\mathrm{CHL}$ & NAP & NAP & NAP & NAP & NAP & NAP & NAP & \begin{tabular}{|l|} 
NAP \\
\end{tabular} & \begin{tabular}{|l|l|} 
NAP \\
\end{tabular} & \begin{tabular}{|l|} 
NAP \\
\end{tabular} & \begin{tabular}{|l|} 
NAP \\
\end{tabular} & NAP & NAP & NAP & \begin{tabular}{|l|} 
NAP \\
\end{tabular} & \begin{tabular}{|l|l|} 
NAP \\
\end{tabular} \\
\hline & 001 & SB8 & Bifice & Mid-stage & 1 & 74.81 & \begin{tabular}{|l|l|}
45.97 \\
\end{tabular} & \begin{tabular}{|l|l|}
14.87 \\
\end{tabular} & \begin{tabular}{|l}
48.2 \\
\end{tabular} & 60 & BLK & DME & $\mathrm{cvx}$ & cvx & $\mathrm{cvx}$ & $B F D$ & NPR & CRT & NAP & NAP & NAP & NAP & NAP & NAP & NAP & NAP & \begin{tabular}{|l|} 
NAP \\
\end{tabular} & \begin{tabular}{|l|l|} 
NAP \\
\end{tabular} & \begin{tabular}{|l|} 
NAP \\
\end{tabular} & NAP & NAP & NAP & \begin{tabular}{|l|} 
NAP \\
\end{tabular} & \begin{tabular}{|l|} 
NAP \\
\end{tabular} \\
\hline & 001 & SB9 & Bifice & -Stage & 1 & 75.49 & \begin{tabular}{|l|l|l|}
51.43 \\
\end{tabular} & \begin{tabular}{|l|l|}
22.65 \\
\end{tabular} & 84.9 & 60 & INR & СMP & $\mathrm{cvx}$ & $\mathrm{cv}$ & $\mathrm{cr}$ & & $\mathrm{NF}$ & CF & NAP & NAP & NAP & & NAP & $\mathrm{NAF}$ & NAP & NAP & \begin{tabular}{|l|} 
NAP \\
\end{tabular} & \begin{tabular}{|l|} 
NAP \\
\end{tabular} & \begin{tabular}{|l|} 
NAP \\
\end{tabular} & NAP & 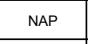 & NAP & \begin{tabular}{|l|} 
NAP \\
\end{tabular} & NAP \\
\hline & 001 & SB 10 & & & 1 & 86 & & & \begin{tabular}{|l|l|}
147. \\
\end{tabular} & 70 & \begin{tabular}{l|l|} 
INR \\
\end{tabular} & CN & $\mathrm{cr}$ & & c) & & & & $\mathrm{N}$ & $\mathrm{N}$ & $\mathrm{Nat}$ & & $\mathrm{NA}$ & $\mathrm{NA}$ & & NAP & \begin{tabular}{|l|l|} 
NAP \\
\end{tabular} & \begin{tabular}{|l|} 
NAP \\
\end{tabular} & \begin{tabular}{|l|} 
NAP \\
\end{tabular} & N & & & NAP & $A P$ \\
\hline & 001 & SB 11 & Unifice & Nueces Tool & 1 & 54.89 & \begin{tabular}{|l|l|}
46.91 \\
\end{tabular} & \begin{tabular}{|l|l|}
12.62 \\
\end{tabular} & \begin{tabular}{|l|l|}
39.4 \\
\end{tabular} & 65 & FST & СMP & ccV & cvx & $\mathrm{cvx}$ & पOB & UFD & $\begin{array}{l}\text { OTH - } \\
\text { MUDSTONE }\end{array}$ & NAP & NAP & NAP & NAP & NAP & NAP & NAP & NAP & \begin{tabular}{|l|l|} 
NAP \\
\end{tabular} & \begin{tabular}{|l|l|} 
NAP \\
\end{tabular} & \begin{tabular}{|l|} 
NAP \\
\end{tabular} & NAP & NAP & NAP & NAP & NAP \\
\hline is & \begin{tabular}{l|l}
001 & $\mathrm{~s}$
\end{tabular} & SB 12 & Bifice & Earty-Stage & 1 & \begin{tabular}{|l|l|}
65.13 \\
\end{tabular} & \begin{tabular}{|l|l|}
59.06 \\
\end{tabular} & \begin{tabular}{|l|l|}
30.80 \\
\end{tabular} & \begin{tabular}{|l|l|}
111.9 \\
\end{tabular} & \begin{tabular}{|l|}
85 \\
\end{tabular} & $\mathbb{N} \mid \mathbb{N D}$ & CMP & $\operatorname{cvx}$ & cvx & $\operatorname{cvs}$ & $\mathrm{BFC}$ & NPR & CRT & NAP & NAP & NAP & NAP & NAP & NAP & NAP & \begin{tabular}{|l|} 
NAP \\
\end{tabular} & \begin{tabular}{|l|} 
NAP \\
\end{tabular} & \begin{tabular}{|l|l|} 
NAP \\
\end{tabular} & \begin{tabular}{|l|l|} 
NAP \\
\end{tabular} & NAP & NAP & NAP & \begin{tabular}{|l|} 
NAP \\
\end{tabular} & NAP \\
\hline
\end{tabular}




\begin{tabular}{|c|c|c|c|c|c|c|c|c|c|c|c|c|c|c|c|c|c|c|c|c|c|c|c|c|c|c|c|c|c|c|c|c|c|c|}
\hline & $\begin{array}{l}\text { Spece. } \\
\text { No. }\end{array}$ & $\begin{array}{l}\text { Fs } \\
\text { No. }\end{array}$ & $\begin{array}{c}\text { C. } \\
\text { Type }\end{array}$ & $\begin{array}{l}\text { Subloppel } \\
\text { tientity }\end{array}$ & Count & 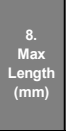 & 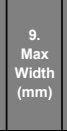 & 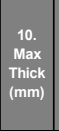 & $\begin{array}{c}\text { 11. } \\
\text { Weight } \\
\text { (g) }\end{array}$ & $\mid \begin{array}{c}\text { 每age } \\
\text { Angle }\end{array}$ & $\left|\begin{array}{c}13 \\
\text { stage }\end{array}\right|$ & $\begin{array}{c}14 . \\
\text { Portion }\end{array}$ & $\begin{array}{c}\text { 17tat } \\
\text { Distal } \\
\text { Morphol } \\
\text { Morphoogy }\end{array}$ & 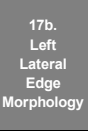 & $\begin{array}{l}\text { 17.c. } \\
\text { Right } \\
\text { Lateral } \\
\text { Edege } \\
\text { Morphology }\end{array}$ & 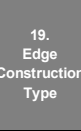 & $\begin{array}{c}\text { Fiaking } \\
\text { Attrition }\end{array}$ & $\begin{array}{l}27 . \\
\text { Lithology }\end{array}$ & 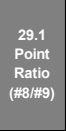 & \begin{tabular}{|c|c}
29.2 \\
Blade \\
Lengntit \\
(Lefit)
\end{tabular} & 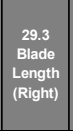 & 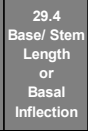 & 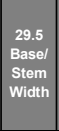 & 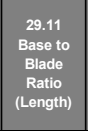 & 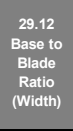 & 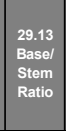 & 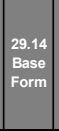 & $\mid \begin{array}{l}\text { 20.15 } \\
\text { stem } \\
\text { torm } \\
\mid\end{array}$ & 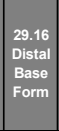 & 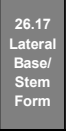 & 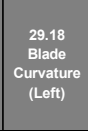 & $\begin{array}{c}\text { 20.19.19 } \\
\text { Bilded } \\
\text { Curvature } \\
\text { (Right) }\end{array}$ & $\mid \begin{array}{l}2.9 .93 \\
\text { Base } \\
\text { Angle } \\
\text { Lefoft) }\end{array}$ & 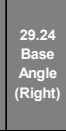 \\
\hline & 001 & SB 13 & Biface & $\begin{array}{l}\text { Late-Stage } \\
\end{array}$ & 1 & 59.77 & \begin{tabular}{|l|l|}
42.24 \\
\end{tabular} & \begin{tabular}{|l|l|} 
& 8.55 \\
\end{tabular} & 19.5 & 60 & PRF & LEM & IND & IND & $\mathrm{cvx}$ & BFB & NPR & CHL & NAP & NAP & NAP & NAP & NAP & NAP & NAP & NAP & \begin{tabular}{|l|} 
NAP \\
\end{tabular} & \begin{tabular}{|l|} 
NAP \\
\end{tabular} & \begin{tabular}{|l|} 
NAP \\
\end{tabular} & NAP & NAP & NAP & NAP & NAP \\
\hline 30 & 001 & SB 14 & Bifiace & Mid-Stage & 1 & 29.22 & \begin{tabular}{|l|l|}
54,60 \\
\end{tabular} & \begin{tabular}{|l|}
11.34 \\
\end{tabular} & 20.5 & 60 & BLK & PRX & IND & $\mathrm{cvx}$ & $\mathrm{cux}$ & $\mathrm{BFB}$ & NPR & CHL & NAP & NAP & NAP & NAP & NAP & NAP & NAP & NAP & NAP & NAP & \begin{tabular}{|l|} 
NAP \\
\end{tabular} & NAP & NAP & NAP & NAP & \begin{tabular}{|l|l} 
NAP \\
\end{tabular} \\
\hline & 001 & SB 15 & Scraper & $\begin{array}{l}\text { Distily } \\
\text { seveled } \\
\text { Scrcaper }\end{array}$ & 1 & 40.74 & \begin{tabular}{|l|l|} 
& 35.08 \\
\end{tabular} & 7.05 & 12.9 & 45 & REJ & PRX & IND & $\operatorname{cvx} x$ & $c v x$ & $\mathrm{BFB}$ & UFD & CRT & NAP & NAP & NAP & NAP & NAP & NAP & NAP & NAP & NAP & NAP & NAP & NAP & NAP & NAP & NAP & NAP \\
\hline & 001 & SB 16 & Bifrace & $\begin{array}{l}\text { Lat-Stage } \\
\end{array}$ & 1 & 35.69 & 23.62 & 7.99 & 4.3 & 65 & PRF & Dis & $\mathrm{cvv}$ & $c v x$ & $c v x$ & BFD & NPR & CRT & NAP & NAP & NAP & NAP & NAP & NAP & NAP & NAP & NAP & \begin{tabular}{|l|} 
NAP \\
\end{tabular} & \begin{tabular}{|l|} 
NAP \\
\end{tabular} & NAP & NAP & NAP & NAP & NAP \\
\hline & 001 & SB 17 & Biface & $\begin{array}{l}\text { Late-Stage } \\
\end{array}$ & 1 & 34.67 & \begin{tabular}{|l|l|} 
\\
\end{tabular} & \begin{tabular}{|l|}
8.27 \\
\end{tabular} & 12.6 & 45 & PRF & PRX & IND & $\mathrm{cvv}$ & cux & $\mathrm{BFB}$ & NPR & CRT & NAP & NAP & NAP & NAP & NAP & NAP & NAP & NAP & \begin{tabular}{|l|l|} 
NAP \\
\end{tabular} & \begin{tabular}{|l|} 
NAP \\
\end{tabular} & \begin{tabular}{|l|l|} 
NAP \\
\end{tabular} & NAP & NAP & NAP & NAP & NAP \\
\hline 34 & 001 & SB 18 & Bifice & $\begin{array}{l}\text { Late-Stage } \\
\end{array}$ & 1 & 33.82 & \begin{tabular}{|l|}
29.95 \\
\end{tabular} & \begin{tabular}{|l|}
8.22 \\
\end{tabular} & 9.4 & 55 & PRF & PRX & IND & $\mathrm{cvx}$ & $\mathrm{cvx}$ & BFB & NPR & CRT & NAP & NAP & NAP & NAP & NAP & NAP & NAP & NAP & \begin{tabular}{|l|l|} 
NAP \\
\end{tabular} & \begin{tabular}{|l|} 
NAP \\
\end{tabular} & \begin{tabular}{|l|} 
NAP \\
\end{tabular} & NAP & NAP & NAP & NAP & NAP \\
\hline & 001 & SB 19 & Side Scraper & NAP & 1 & 111.80 & \begin{tabular}{|l|}
82.55 \\
\end{tabular} & \begin{tabular}{|l|l|} 
\\
\end{tabular} & 408.3 & 80 & IND & CMP & cvx & $c v x$ & $c v x$ & BDU & $\mathrm{BFU}$ & CHL & NAP & NAP & NAP & NAP & NAP & NAP & NAP & NAP & NAP & \begin{tabular}{|l|} 
NAP \\
\end{tabular} & \begin{tabular}{|l|} 
NAP \\
\end{tabular} & NAP & NAP & NAP & NAP & \begin{tabular}{|l|} 
NAP \\
\end{tabular} \\
\hline 6 & 001 & 201 & \begin{tabular}{|l|l} 
Arrow \\
\end{tabular} & Matamoros & 1 & 32.61 & \begin{tabular}{|l|}
20.31 \\
\end{tabular} & \begin{tabular}{|l|l}
5.58 \\
\end{tabular} & 4.0 & 60 & FST & CMP & $\mathrm{cvx}$ & $c v x$ & $c v x$ & BFC & BFB & CRT & 1.61 & 33.27 & 32.67 & 2.85 & 20.31 & 0.09 & 1.00 & NAP & \begin{tabular}{|l|} 
\\
\end{tabular} & \begin{tabular}{|l|} 
NAP \\
\end{tabular} & 1 & NAP & & & 36 & 39 \\
\hline & 001 & 202 & Dart & $\begin{array}{l}\text { Totutuass } \\
\end{array}$ & 1 & 49,70 & \begin{tabular}{|l|}
25.50 \\
\end{tabular} & \begin{tabular}{|l|l|}
8.73 \\
\end{tabular} & 10.1 & 60 & FST & CMP & cvx & $\mathrm{cvx}$ & $\mathrm{cvx}$ & $\mathrm{BFC}$ & $B F B$ & CRT & 1.95 & 48.80 & 51.09 & 5.36 & 24.70 & 0.11 & 0.97 & NAP & 1 & \begin{tabular}{|l|} 
NAP \\
\end{tabular} & 1 & NAP & 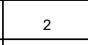 & & 50 & 49 \\
\hline & 001 & SD20 03 & Dart & Tortugas & 1 & 24.11 & \begin{tabular}{|l|}
26.03 \\
\end{tabular} & \begin{tabular}{|l|l}
5.85 \\
\end{tabular} & 4.9 & 55 & FST & PRX & IND & $\mathrm{cvx}$ & cvx & ВFВ & NPR & CRT & 0.93 & 21.64 & \begin{tabular}{|l|}
22.77 \\
\end{tabular} & 5.05 & 26.07 & 0.21 & 1.00 & NAP & 1 & \begin{tabular}{|l|} 
NAP \\
\end{tabular} & \begin{tabular}{|l|l|} 
NAP \\
\end{tabular} & NAP & & & 46 & 41 \\
\hline${ }^{99}$ & 001 & 2004 & Arrow & Matamoros & 1 & 35.26 & \begin{tabular}{|l|}
26.06 \\
\end{tabular} & \begin{tabular}{|l|l|}
4.87 \\
\end{tabular} & 4.0 & 40 & FST & СMP & cvx & $\mathrm{cvx}$ & $\mathrm{cvx}$ & $\mathrm{BFC}$ & BFB & CRT & 1.35 & 38.22 & \begin{tabular}{|l|}
35.13 \\
\end{tabular} & 4.32 & 26.03 & 0.12 & 1.00 & NAP & 1 & \begin{tabular}{|l|} 
NAP \\
\end{tabular} & \begin{tabular}{|l} 
\\
\end{tabular} & NAP & 2 & 2 & 40 & 37 \\
\hline & 001 & & Dart & Retugio & 1 & 70.00 & \begin{tabular}{|l|}
23.57 \\
\end{tabular} & \begin{tabular}{|l|}
10.24 \\
\end{tabular} & 19.6 & 70 & FST & СMP & cvx & $\mathrm{cvx}$ & $c v x$ & $\mathrm{BFC}$ & $\mathrm{BFB}$ & SST & 2.97 & 67.59 & \begin{tabular}{|l}
68.86 \\
\end{tabular} & 9.74 & 21.08 & 0.14 & 0.89 & NAP & 1 & \begin{tabular}{|l|} 
NAP \\
\end{tabular} & 1 & NAP & 2 & & 52 & 48 \\
\hline & 001 & S0206 & Dart & Tottugas & 1 & 39.62 & \begin{tabular}{|l|l|}
27.79 \\
\end{tabular} & \begin{tabular}{|l|}
6.93 \\
\end{tabular} & 8.8 & 55 & FST & PME & IND & $\mathrm{cvx}$ & $\mathrm{cvx}$ & BFB & ВFB & CRT & 1.43 & 39.11 & \begin{tabular}{|l|}
36.27 \\
\end{tabular} & 4.57 & 27.48 & 0.12 & 0.99 & NAP & 1 & \begin{tabular}{|l|} 
NAP \\
\end{tabular} & \begin{tabular}{|l|l|} 
NAP \\
\end{tabular} & NAP & 2 & & 46 & 39 \\
\hline 42 & 001 & SD207 & Dat Preform & 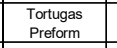 & 1 & $\begin{array}{ll}73.38 \\
\end{array}$ & \begin{tabular}{|l|l|}
30.95 \\
\end{tabular} & \begin{tabular}{|l|}
17.51 \\
\end{tabular} & 34.3 & 70 & FST & CMP & $\mathrm{cvx}$ & $\mathrm{cvv}$ & $\mathrm{cvx}$ & BFC & NPR & CRT & 2.37 & 73.15 & 73.13 & 10.88 & 29.42 & 0.15 & 0.95 & NAP & 1 & \begin{tabular}{|l|} 
NAP \\
\end{tabular} & 1 & NAP & & & 48 & 52 \\
\hline 433 & 001 & SB201 & \begin{tabular}{|l|} 
Dart \\
\end{tabular} & \begin{tabular}{|l|} 
Dessmuke Base \\
\end{tabular} & 1 & 33.47 & \begin{tabular}{|l|l|}
30.83 \\
\end{tabular} & \begin{tabular}{ll|}
7.16 \\
\end{tabular} & 7.5 & 55 & FST & PRX & IND & $\mathrm{cvx}$ & $\mathrm{cux}$ & ВFВ & NPR & чмм & 1.09 & 35.75 & \begin{tabular}{|l}
34.54 \\
\end{tabular} & NAP & NAP & NAP & NAP & NAP & \begin{tabular}{|l|l|} 
NAP \\
\end{tabular} & \begin{tabular}{|l|l|} 
NAP \\
\end{tabular} & \begin{tabular}{|l|l|} 
NAP \\
\end{tabular} & NAP & & 2 & NAP & NAP \\
\hline & 001 & & & $\begin{array}{l}\text { Late-Stage } \\
\text { Let }\end{array}$ & 1 & $\begin{array}{ll}52.65 \\
\end{array}$ & 31.65 & \begin{tabular}{|l|l|}
9.74 \\
\end{tabular} & 12.5 & 45 & PRF & СMP & cvx & $\mathrm{cvx}$ & $\mathrm{cvx}$ & $\mathrm{BFC}$ & NPR & CH. & NAP & NAP & NAP & NAP & NAP & AP & NAP & NAP & \begin{tabular}{|l|l|} 
NAP \\
\end{tabular} & \begin{tabular}{|l|l|} 
NAP \\
\end{tabular} & \begin{tabular}{|l|l|} 
NAP \\
\end{tabular} & NAP & NAP & NAP & NAP & NAP \\
\hline${ }_{45}$ & 001 & $\mathrm{SB}_{\mathrm{S} O 03}$ & Biface & $\begin{array}{l}\text { Late-Stage } \\
\end{array}$ & 1 & 38.64 & \begin{tabular}{|l|}
29.59 \\
\end{tabular} & \begin{tabular}{|l|l|} 
& \\
\end{tabular} & 8.5 & 55 & PRF & DIS & $\mathrm{cvx}$ & $\mathrm{cvx}$ & $\mathrm{cvx}$ & $\mathrm{BFD}$ & NPR & CRT & NAP & NAP & NAP & NAP & NAP & NAP & NAP & NAP & NAP & \begin{tabular}{|l|l|} 
NAP \\
\end{tabular} & NAP & NAP & NAP & NAP & NAP & NAP \\
\hline 46 & 001 & SB2 04 & Biface & $\begin{array}{l}\text { Late-Stage } \\
\end{array}$ & 1 & 36.82 & \begin{tabular}{|l|l|}
34.82 \\
\end{tabular} & \begin{tabular}{l|l|}
8.88 \\
\end{tabular} & 13.5 & 55 & PRF & PRX & IND & $\mathrm{cvx}$ & $\mathrm{cvx}$ & $\mathrm{BFB}$ & NPR & CHL & NAP & NAP & NAP & NAP & NAP & NAP & NAP & NAP & \begin{tabular}{|l|l|} 
NAP \\
\end{tabular} & \begin{tabular}{|l|} 
NAP \\
\end{tabular} & \begin{tabular}{|l|l|} 
NAP \\
\end{tabular} & NAP & NAP & NAP & NAP & NAP \\
\hline 4 & 001 & & Bitac & $\begin{array}{l}\text { Late-Stage } \\
\end{array}$ & 1 & 50.37 & \begin{tabular}{|l|}
39.22 \\
\end{tabular} & \begin{tabular}{ll|}
7.06 \\
\end{tabular} & 11.6 & 50 & PRF & PME & $\mathbb{N}$ & $\mathrm{cvx}$ & & $\mathrm{BFE}$ & NPR & CRT & NAP & NAP & NAP & NAP & NAP & NAP & NAP & NAP & \begin{tabular}{|l|l|} 
NAP \\
\end{tabular} & \begin{tabular}{|l|l|} 
NAP \\
\end{tabular} & \begin{tabular}{|l|l|} 
NAP \\
\end{tabular} & NAP & NAP & NAP & NAP & NAP \\
\hline & 001 & SB206 & Bitac & Mid-stage & 1 & 36.90 & \begin{tabular}{|l|l|}
45.69 \\
\end{tabular} & \begin{tabular}{|l|l|}
9.77 \\
\end{tabular} & 21.1 & 55 & BLK & PRX & IND & $\mathrm{cvx}$ & $\mathrm{cvx}$ & BFB & NPR & CRT & NAP & NAP & NAP & NAP & NAP & NAP & 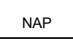 & NAP & \begin{tabular}{|l|l|} 
NAP \\
\end{tabular} & NAP & \begin{tabular}{|l|l|} 
NAP \\
\end{tabular} & NAP & TAPT & NAP & NAP & NAP \\
\hline 499 & 001 & S8207 & Bifiace & Mid-Slage & 1 & 49.51 & \begin{tabular}{|l|l|} 
& 50.93 \\
\end{tabular} & \begin{tabular}{|l|l|}
13.42 \\
\end{tabular} & 32.4 & 50 & BLK & DIS & $\mathrm{cvx}$ & $\mathrm{cvx}$ & $\mathrm{cvx}$ & BFD & NPR & CRT & NAP & NAP & NAP & NAP & NAP & NAP & NAP & NAP & \begin{tabular}{|l|l|} 
NAP \\
\end{tabular} & NAP & \begin{tabular}{|l|l|} 
NAP \\
\end{tabular} & NAP & NAP & NAP & NAP & NAP \\
\hline 050 & 001 & SB208 & Bitace & Mid-slage & 1 & $\begin{array}{lll}44.18 \\
\end{array}$ & \begin{tabular}{|l|l|l|} 
& \\
\end{tabular} & 10.77 & 30.0 & 60 & BLK & PRX & 1NO & $\mathrm{cvx}$ & $\operatorname{cvs}$ & BFB & NPR & $\mathrm{CHL}$ & NAP & NAP & NAP & NAP & NAP & NAP & NAP & NAP & NAP & NAP & \begin{tabular}{|l|l|} 
NAP \\
\end{tabular} & NAP & NAP & NAP & NAP & NAP \\
\hline 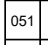 & 001 & & & Early-Stage & 1 & 77.36 & \begin{tabular}{|l|l|}
45.06 \\
\end{tabular} & 20.72 & 59.5 & 65 & INR & CMP & c & $\mathrm{cv}$ & & $\mathrm{BFC}$ & NPR & c & NAP & $\mathrm{N}$ & NAP & NAP & NAP & & NAP & NAP & \begin{tabular}{|l|l|} 
NAP \\
\end{tabular} & NAP & \begin{tabular}{|l|l|} 
NAP \\
\end{tabular} & NAP & NAP & NAP & NAP & NAP \\
\hline 52 & 001 & S82 10 & Dart & Desmuke Base & 1 & 32.53 & \begin{tabular}{|l|l|}
28.06 \\
\end{tabular} & \begin{tabular}{|l|l|}
6.13 \\
\end{tabular} & 5.7 & 50 & FST & PRX & IND & $\mathrm{cvx}$ & $c v x$ & $\mathrm{BFB}$ & NPR & CRT & 1.16 & 34.46 & 35.37 & NAP & NAP & NAP & IAP & NAP & \begin{tabular}{|l|l|} 
NAP \\
\end{tabular} & NAP & \begin{tabular}{|l|} 
NAP \\
\end{tabular} & NAP & & & NAP & NAP \\
\hline 53 & 001 & SB211 & Biface & Earty-Stage & 1 & 71.62 & \begin{tabular}{|l|}
75.22 \\
\end{tabular} & \begin{tabular}{|l|}
27.42 \\
\end{tabular} & 114.8 & 65 & INR & $P R X$ & IND & $\mathrm{cvx}$ & $\mathrm{cvx}$ & BFB & NPR & CRT & NAP & NAP & NAP & NAP & NAP & NAP & NAP & NAP & \begin{tabular}{|l|l|} 
NAP \\
\end{tabular} & \begin{tabular}{|l|} 
NAP \\
\end{tabular} & \begin{tabular}{|l|} 
NAP \\
\end{tabular} & NAP & NAP & NAP & NAP & NAP \\
\hline 054 & 001 & SB2 12 & Bifa & Mid-Stage & 1 & 68.32 & \begin{tabular}{|l|l|}
3229 \\
\end{tabular} & \begin{tabular}{|l|l|}
16.78 \\
\end{tabular} & 34.8 & 70 & BLK & СMP & cv & $\mathrm{cvx}$ & cr & $\mathrm{BFC}$ & NPR & имм & NAP & NAP & NAP & NAP & NAP & NAP & NAP & NAP & \begin{tabular}{|l|} 
NAP \\
\end{tabular} & NAP & \begin{tabular}{|l|} 
NAP \\
\end{tabular} & NAP & NAP & NAP & NAP & \begin{tabular}{|l|l} 
NAP \\
\end{tabular} \\
\hline & 001 & S82 13 & Unifica & NAP & 1 & 60.8 & \begin{tabular}{|l|l|}
31.73 \\
\end{tabular} & \begin{tabular}{|l|}
11.21 \\
\end{tabular} & 21.8 & 55 & IND & \begin{tabular}{|l|} 
INDD \\
\end{tabular} & & $\mathrm{Cr}_{2}$ & & $\mathrm{BD}$ & UFB & $T$ & NAP & $\mathrm{N}$ & NAP & NAP & NAP & , & & NAP & \begin{tabular}{|l|l|} 
NAP \\
\end{tabular} & NAP & \begin{tabular}{|l|l|} 
NAP \\
\end{tabular} & NAP & NAP & NAP & NAP & NAP \\
\hline 56 & 001 & SB2 14 & Biface & Earty-Slage & 1 & 48.63 & \begin{tabular}{|l|l|}
59.03 \\
\end{tabular} & \begin{tabular}{|l|l|}
19.30 \\
\end{tabular} & 45.6 & 65 & INR & DIS & $\mathrm{cvx}$ & $\mathrm{cvx}$ & $\mathrm{cvx}$ & BFD & NPR & CRT & NAP & NAP & NAP & NAP & NAP & NAP & NAP & NAP & \begin{tabular}{|l|l|} 
NAP \\
\end{tabular} & NAP & \begin{tabular}{|l|l|} 
NAP \\
\end{tabular} & NAP & NAP & NAP & NAP & NAP \\
\hline 057 & 001 & SB2 15 & Biface & Mid-Stage & 1 & 70.29 & \begin{tabular}{|l|l|} 
& 0.41 \\
\end{tabular} & \begin{tabular}{|l|l|}
18.60 \\
\end{tabular} & 45.4 & 65 & BLK & CMP & $\mathrm{cvx}$ & $\mathrm{cvx}$ & $\mathrm{cvx}$ & $\mathrm{BFC}$ & NPR & CRT & NAP & NAP & NAP & NAP & NAP & NAP & NAP & NAP & \begin{tabular}{|l|l|} 
NAP \\
\end{tabular} & NAP & \begin{tabular}{|l|l|} 
NAP \\
\end{tabular} & NAP & NAP & NAP & NAP & \begin{tabular}{|l} 
NAP \\
\end{tabular} \\
\hline 058 & 001 & SB216 & Bifice & $\begin{array}{l}\text { Late-Stage } \\
\end{array}$ & 1 & 43.45 & \begin{tabular}{|l|}
27.82 \\
\end{tabular} & \begin{tabular}{|l|}
6.62 \\
\end{tabular} & 8.1 & 50 & PRF & DIS & cvx & $c v x$ & $c v x$ & BFD & BFB & CRT & NAP & NAP & NAP & NAP & NAP & NAP & NAP & NAP & \begin{tabular}{|l|l|} 
NAP \\
\end{tabular} & NAP & \begin{tabular}{|l|l|} 
NAP \\
\end{tabular} & NAP & NAP & NAP & NAP & NAP \\
\hline 059 & 001 & SB217 & t Pretorm & $\begin{array}{l}\text { Tothtogas } \\
\text { Preferom }\end{array}$ & 1 & 34.64 & \begin{tabular}{|l|}
34,02 \\
\end{tabular} & \begin{tabular}{|l|}
11.23 \\
\end{tabular} & 14.6 & 60 & PRF & PRX & IND & $\mathrm{cvx}$ & $\mathrm{cvx}$ & $\mathrm{BFB}$ & NPR & & 1.02 & 33.56 & 32.21 & 7.44 & 33.90 & 4 & 1.00 & NAP & \begin{tabular}{|l|}
1 \\
\end{tabular} & NAP & \begin{tabular}{|l|} 
NAP \\
\end{tabular} & NAP & & & 43 & 45 \\
\hline 060 & 001 & SB2 18 & Bifiace & Mid-Stage & 1 & 41.97 & 35.96 & 12.26 & 20.5 & 50 & BLK & PRX & IND & $c v x$ & $\operatorname{cvdx}$ & $\mathrm{BFB}$ & NPR & 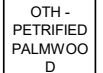 & NAP & NAP & NAP & NAP & NAP & NAP & NAP & NAP & NAP & NAP & NAP & NAP & NAP & NAP & NAP & NAP \\
\hline 061 & 001 & SB2 19 & Adze & Olmos Bificece & 1 & 35.30 & \begin{tabular}{|l|}
28.61 \\
\end{tabular} & \begin{tabular}{|l|l|} 
& 8.02 \\
\end{tabular} & 7.9 & 60 & FST & СMP & $\mathrm{cvx}$ & $\mathrm{CVx}$ & $c v x$ & $\mathrm{BFC}$ & UFC & CRT & NAP & NAP & NAP & NAP & NAP & NAP & NAP & NAP & NAP & NAP & \begin{tabular}{|l|} 
NAP \\
\end{tabular} & NAP & NAP & NAP & NAP & NAP \\
\hline 062 & 001 & SB2 20 & Bifiace & Eary-Slage & 1 & 94.61 & 78.01 & 24.18 & 152.9 & 60 & INR & СMP & $c v x$ & $c v x$ & $c v x$ & $\mathrm{BFC}$ & NPR & $\mathrm{RHY}$ & NAP & NAP & NAP & NAP & NAP & NAP & NAP & NAP & NAP & NAP & \begin{tabular}{|l|} 
NAP \\
\end{tabular} & NAP & NAP & NAP & NAP & NAP \\
\hline 159 & 102 & 8.001 & Edge-Modified & Utilized & 1 & 38.29 & 23.67 & 13.01 & 8.3 & 45 & NA & NA & cvx & NAP & NAP & NAP & BFU & CRT & NAP & NAP & NAP & NAP & NAP & NAP & NAP & NAP & NAP & NAP & NAP & NAP & NAP & NAP & NAP & NAP \\
\hline \begin{tabular}{|l|l|}
164 \\
\end{tabular} & 036 & 13.001 & Flake & NAP & 1 & 86.95 & \begin{tabular}{|l|l|} 
\\
\end{tabular} & \begin{tabular}{|l|l|}
4.22 \\
\end{tabular} & 239.4 & 85 & NAP & NAP & NAP & NAP & NAP & NAP & NPR & CRT & NAP & NAP & NAP & NAP & NAP & NAP & NAP & NAP & NAP & NAP & \begin{tabular}{|l|l|} 
NAP \\
\end{tabular} & NAP & NAP & NAP & NAP & NAP \\
\hline 167 & 016 & 16.001 & Biface & Late-Stage & 1 & 39.39 & \begin{tabular}{|l|l|}
41.65 \\
\end{tabular} & \begin{tabular}{|l|}
9.40 \\
\end{tabular} & 18.7 & 55 & PRF & PME & IND & $\mathrm{cvx}$ & $\mathrm{cvx}$ & BFB & NPR & $\mathrm{CHL}$ & NAP & NAP & NAP & NAP & NAP & NAP & NAP & NAP & \begin{tabular}{|l|l|} 
NAP \\
\end{tabular} & NAP & \begin{tabular}{|l|} 
NAP \\
\end{tabular} & NAP & NAP & NAP & NAP & NAP \\
\hline 169 & 005 & 99.001 & Bifiace & Mid-stage & 1 & 29.91 & \begin{tabular}{|l|l|}
33.98 \\
\end{tabular} & \begin{tabular}{|l|}
13.16 \\
\end{tabular} & 14.4 & 60 & BLK & MED & NND & $c v x$ & cv. & $B \mathrm{BFE}$ & NPR & CRT & NAP & NAP & NAP & NAP & NAP & NAP & NAP & NAP & NAP & NAP & \begin{tabular}{|l|} 
NAP \\
\end{tabular} & NAP & NAP & NAP & NAP & NAP \\
\hline & $\begin{array}{ll}006 \\
\end{array}$ & 19.0 & & Late-Sigage & 1 & 27.36 & \begin{tabular}{|l|}
32.53 \\
\end{tabular} & \begin{tabular}{l|l|}
7.85 \\
\end{tabular} & 9.0 & 60 & PRF & $\mathrm{Pr}$ & in & $\mathrm{Crv}$ & & $\mathrm{BFE}$ & NPF & 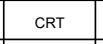 & $\mathrm{NA}$ & NAP & NAP & NAP & NAP & & NAP & NAP & \begin{tabular}{|l|l|} 
NAP \\
\end{tabular} & NAP & \begin{tabular}{|l|} 
NAP \\
\end{tabular} & NAP & & & NAP & NAP \\
\hline 171 & \begin{tabular}{l|l|l|}
014 & \\
\end{tabular} & 21.001 & Biface & Late-Stage & 1 & 35.10 & \begin{tabular}{|l|}
25.11 \\
\end{tabular} & \begin{tabular}{|l|l|}
8.78 \\
\end{tabular} & 10.7 & 60 & PRF & MED & IND & cvx & $c v x$ & BFB & BFB & CRT & NAP & NAP & NAP & NAP & NAP & NAP & NAP & NAP & \begin{tabular}{|l|l|} 
NAP \\
\end{tabular} & NAP & \begin{tabular}{|l|} 
NAP \\
\end{tabular} & NAP & NAP & NAP & NAP & NAP \\
\hline
\end{tabular}




\begin{tabular}{|c|c|c|c|c|c|c|c|c|c|c|c|c|c|c|c|c|c|c|c|c|c|c|c|c|c|c|c|c|c|c|c|c|c|c|}
\hline $\begin{array}{l}\text { Lot } \\
\text { No. }\end{array}$ & $\begin{array}{l}\text { Spec. } \\
\text { No. }\end{array}$ & $\begin{array}{l}\text { Fs } \\
\text { No. }\end{array}$ & $\begin{array}{c}6 \\
\text { Type }\end{array}$ & 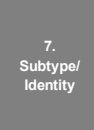 & Count & $\left|\begin{array}{c|}8 . \\
\text { Max } \\
\text { Length } \\
(\mathrm{mm})\end{array}\right|$ & $\mid$\begin{tabular}{c|}
9. \\
Max \\
Width \\
$(\mathrm{mm})$
\end{tabular} & $\mid$\begin{tabular}{c|}
10. \\
Max \\
Thick \\
$(\mathrm{mm})$
\end{tabular} & $\left|\begin{array}{c}11 . \\
\text { Weight } \\
(\mathrm{g})\end{array}\right|$ & $\mid \begin{array}{c}12 . \\
\text { Edge } \\
\text { Angle }\end{array}$ & $\begin{array}{c}13 . \\
\text { Stage }\end{array}$ & $\left|\begin{array}{c}14 . \\
\text { Portion }\end{array}\right|$ & $\mid \begin{array}{c}\text { 17a. } \\
\text { Distal } \\
\text { Edge } \\
\text { Morphology }\end{array}$ & $\mid \begin{array}{c}176 . \\
\text { Left } \\
\text { Lateral } \\
\text { Edgel } \\
\text { Morphology }\end{array}$ & $\begin{array}{c}\text { 17c. } \\
\text { Right } \\
\text { Lataral } \\
\text { Edge } \\
\text { Morphology }\end{array}$ & $\left|\begin{array}{c|}19 . \\
\text { Edge } \\
\text { Construction } \\
\text { Type }\end{array}\right|$ & $\left|\begin{array}{c}21 . \\
\text { Filaing } \\
\text { Atatrition }\end{array}\right|$ & Lithology & $\mid$\begin{tabular}{c|}
29.1 \\
Point \\
Ratio \\
$(\# 8 / * 39)$
\end{tabular} & \begin{tabular}{c|}
29.2 \\
Blade \\
Length \\
(Lefit)
\end{tabular} & $\mid$\begin{tabular}{c|}
29.3 \\
Blade \\
Length \\
(Right)
\end{tabular} & \begin{tabular}{|c|}
29.4 \\
Basel Stem \\
Length \\
or \\
Basal \\
Inflection
\end{tabular} & $\left|\begin{array}{l}29.5 \\
\text { Basel } \\
\text { Stem } \\
\text { Width }\end{array}\right|$ & \begin{tabular}{|c|c}
29.11 \\
Base to \\
Blade \\
Ratio \\
(Length)
\end{tabular} & $\mid$\begin{tabular}{|c|}
29.12 \\
Base to \\
Blade \\
Ratio \\
(Width)
\end{tabular} & \begin{tabular}{l|}
29.13 \\
Basel \\
Stem \\
Ratio
\end{tabular} & $\begin{array}{l}29.14 \\
\text { Base } \\
\text { Form }\end{array}$ & $\mid \begin{array}{l}29,15 \\
\text { stem } \\
\text { form }\end{array}$ & $\left|\begin{array}{l}29.16 \\
\text { Distal } \\
\text { Base } \\
\text { Form }\end{array}\right|$ & $\mid$\begin{tabular}{c|}
26.17 \\
Lateral \\
Basel \\
Stem \\
Form
\end{tabular} & $\begin{array}{c}29.18 \\
\text { Blade } \\
\text { Curvature } \\
\text { (Lefit) }\end{array}$ & \begin{tabular}{|c}
29.19 \\
Blade \\
Curvature \\
(Right)
\end{tabular} & $\mid \begin{array}{c}29.23 \\
\text { Base } \\
\text { Angle } \\
\text { (Lefit) }\end{array}$ & \begin{tabular}{|l|l}
29.24 \\
Base \\
Angle \\
(Right)
\end{tabular} \\
\hline 173 & 182 & \begin{tabular}{|l|}
23.001 \\
\end{tabular} & Flake & NAP & 1 & 69.26 & \begin{tabular}{|l|l|}
49.68 \\
\end{tabular} & \begin{tabular}{|l|}
22.53 \\
\end{tabular} & 59.2 & 65 & NAP & NAP & NAP & NAP & NAP & NAP & NPR & RHY & NAP & NAP & NAP & NAP & NAP & NAP & NAP & NAP & \begin{tabular}{|l|} 
NAP \\
\end{tabular} & \begin{tabular}{|l|} 
NAP \\
\end{tabular} & NAP & NAP & NAP & NAP & NAP & NAP \\
\hline 175 & 065 & 25.001 & Dart & $\begin{array}{l}\text { Unidentified } \\
\text { Base }\end{array}$ & 1 & 17.12 & 25.40 & 5.96 & 2.8 & 45 & FST & PRX & IND & $\mathrm{cvx}$ & $c v x$ & BFB & NPR & CRT & 0.67 & NAP & NAP & 0.98 & NAP & 0.06 & NAP & NAP & NAP & NAP & 3 & 1 & 0 & 0 & NAP & NAP \\
\hline \begin{tabular}{|l|}
178 \\
\end{tabular} & 001 & \begin{tabular}{|l|}
28.001 \\
\end{tabular} & Bifiace & Late-Stage & 1 & 46.28 & \begin{tabular}{|l|l|}
43.71 \\
\end{tabular} & \begin{tabular}{|l|l|} 
& 9.75 \\
\end{tabular} & 14.5 & 40 & PRF & PME & IND & cvx & cvx & BFB & NPR & SST & NAP & NAP & NAP & NAP & NAP & NAP & NAP & NAP & \begin{tabular}{|l|} 
NAP \\
\end{tabular} & \begin{tabular}{|l|} 
NAP \\
\end{tabular} & NAP & NAP & NAP & NAP & NAP & NAP \\
\hline 180 & 001 & \begin{tabular}{|l|}
29.002 \\
\end{tabular} & Bifiace & Early-Stage & 1 & 60.53 & \begin{tabular}{|l|l|}
49.86 \\
\end{tabular} & \begin{tabular}{|l|}
21.41 \\
\end{tabular} & 53.0 & 60 & INR & CMP & $\mathrm{cvx}$ & $\mathrm{cvx}$ & $c v x$ & BFC & NPR & $\mathrm{CHL}$ & NAP & NAP & NAP & NAP & NAP & NAP & NAP & NAP & \begin{tabular}{|l|} 
NAP \\
\end{tabular} & NAP & \begin{tabular}{|l|} 
NAP \\
\end{tabular} & NAP & NAP & NAP & NAP & NAP \\
\hline \begin{tabular}{|l|l|}
187 \\
\end{tabular} & 005 & 30.001 & Flake & NAP & 1 & 55.21 & \begin{tabular}{|l|}
35.70 \\
\end{tabular} & \begin{tabular}{|l|}
32.79 \\
\end{tabular} & 57.4 & 75 & NAP & NAP & NAP & NAP & NAP & NAP & NPR & CRT & NAP & NAP & NAP & NAP & NAP & NAP & NAP & NAP & NAP & \begin{tabular}{|l|} 
NAP \\
\end{tabular} & NAP & NAP & NAP & NAP & NAP & NAP \\
\hline \begin{tabular}{|l|}
189 \\
\end{tabular} & 005 & 32.001 & Bifice & Late-Stage & 1 & 48.77 & 25.42 & \begin{tabular}{|l|}
10.18 \\
\end{tabular} & 13.1 & 55 & PRF & IND & $c v x$ & $\mathrm{cvx}$ & $\mathrm{cvx}$ & $\mathrm{BFC}$ & NPR & CRT & NAP & NAP & NAP & NAP & NAP & NAP & NAP & NAP & NAP & \begin{tabular}{|l|} 
NAP \\
\end{tabular} & NAP & NAP & NAP & NAP & NAP & NAP \\
\hline 190 & 006 & 33.001 & Edge-Modified & Utilized & 1 & 25.43 & 20.75 & 7.59 & 3.3 & 40 & N/A & N/A & IND & $c v x$ & IND & NAP & UFU & CRT & NAP & NAP & NAP & NAP & NAP & NAP & NAP & NAP & NAP & NAP & NAP & NAP & NAP & NAP & NAP & NAP \\
\hline \begin{tabular}{|l|l|}
196 \\
\end{tabular} & 001 & 40.001 & Dart Preform & $\begin{array}{l}\begin{array}{c}\text { Tortugas } \\
\text { Preform }\end{array} \\
\end{array}$ & 1 & 44.37 & 35.20 & \begin{tabular}{|l|}
8.75 \\
\end{tabular} & 15.7 & 50 & PRF & PME & IND & $c v x$ & $\mathrm{cvx}$ & BFB & NPR & CRT & NAP & NAP & NAP & 7.39 & 33.43 & NAP & 0.95 & NAP & 1 & NAP & NAP & NAP & 2 & 2 & 46 & 42 \\
\hline \begin{tabular}{|l|l|}
197 \\
\end{tabular} & 001 & 41.001 & Bifiace & Mid-Stage & 1 & 82.40 & 50.30 & \begin{tabular}{|l|}
19.49 \\
\end{tabular} & 71.1 & 60 & BLK & СMP & $c v x$ & $\mathrm{cvx}$ & $c v x$ & BFC & NPR & CRT & NAP & NAP & NAP & NAP & NAP & NAP & NAP & NAP & NAP & \begin{tabular}{|l|} 
NAP \\
\end{tabular} & NAP & NAP & NAP & NAP & NAP & NAP \\
\hline 199 & 158 & 43.001 & Bifiace & Mid-Stage & 1 & 31.19 & 41.80 & \begin{tabular}{|l|}
12.31 \\
\end{tabular} & 16.0 & 60 & BLK & DIS & $c v x$ & $\mathrm{cvx}$ & $\mathrm{cvx}$ & BFD & NPR & CRT & NAP & NAP & NAP & NAP & NAP & NAP & NAP & NAP & NAP & NAP & NAP & NAP & NAP & NAP & NAP & NAP \\
\hline \begin{tabular}{|l|}
199 \\
\end{tabular} & 159 & \begin{tabular}{|l|}
43.002 \\
\end{tabular} & Dart & $\begin{array}{c}\text { Unidentified } \\
\text { Base }\end{array}$ & 1 & 28.46 & 21.78 & \begin{tabular}{|l|}
9.50 \\
\end{tabular} & 5.4 & 55 & FST & PME & IND & $c v x$ & $c v x$ & BFB & NPR & $\begin{array}{l}\text { OTH- } \\
\text { MUDSTONE }\end{array}$ & NAP & NAP & NAP & 14.41 & 15.91 & 0.51 & 0.73 & 0.91 & 1 & 1 & NAP & 1 & 2 & 2 & 50 & 56 \\
\hline 200 & 001 & 45.001 & Arrow & Fresno & 1 & 28.80 & 23.59 & 6.45 & 5.4 & 45 & FST & PME & IND & $\mathrm{cvx}$ & $\mathrm{cvx}$ & $B F B$ & NPR & CRT & NAP & 28.57 & 28.91 & 5.76 & 23.09 & 0.20 & 0.98 & NAP & 2 & NAP & NAP & NAP & 2 & 2 & 36 & 38 \\
\hline \begin{tabular}{|l|l|}
201 \\
\end{tabular} & 069 & 46.001 & Biface & Early-Stage & 1 & 38.29 & \begin{tabular}{|l|}
42.72 \\
\end{tabular} & 14.21 & 27.1 & 60 & INR & IND & $\mathrm{cvx}$ & $c v x$ & $\mathrm{cvx}$ & IND & NPR & CRT & NAP & NAP & NAP & NAP & NAP & NAP & NAP & NAP & \begin{tabular}{|l|} 
NAP \\
\end{tabular} & \begin{tabular}{|l|} 
NAP \\
\end{tabular} & NAP & NAP & NAP & NAP & NAP & NAP \\
\hline \begin{tabular}{|l|}
203 \\
\end{tabular} & 138 & \begin{tabular}{ll|}
48.001 \\
\end{tabular} & Biface & Early-Stage & 1 & 45.36 & \begin{tabular}{|l|}
44.93 \\
\end{tabular} & 15.44 & 31.8 & 65 & INR & IND & $\mathrm{cvx}$ & $\mathrm{cvx}$ & $\mathrm{cvx}$ & $\mathrm{BFC}$ & NPR & CRT & NAP & NAP & NAP & NAP & NAP & NAP & NAP & NAP & \begin{tabular}{|l|} 
NAP \\
\end{tabular} & \begin{tabular}{|l|} 
NAP \\
\end{tabular} & NAP & NAP & NAP & NAP & NAP & NAP \\
\hline \begin{tabular}{|l|}
203 \\
\end{tabular} & 139 & 48.002 & Bifiace & Early-Stage & 1 & 54.10 & \begin{tabular}{|l|}
52.32 \\
\end{tabular} & 27.65 & 64.8 & 70 & INR & CMP & $\mathrm{cvx}$ & $\mathrm{cvx}$ & $\mathrm{cvx}$ & $\mathrm{BFC}$ & NPR & CRT & NAP & NAP & NAP & NAP & NAP & NAP & NAP & \begin{tabular}{l|l} 
NAP \\
\end{tabular} & NAP & \begin{tabular}{|l|} 
NAP \\
\end{tabular} & NAP & NAP & NAP & NAP & NAP & NAP \\
\hline 203 & 140 & 48.003 & Edge-Modified & Utilized & 1 & 83.77 & 69.82 & 23.38 & 182.3 & 80 & N/A & CMP & $\mathrm{cvx}$ & NAP & NAP & NAP & NPR & CRT & NAP & NAP & NAP & NAP & NAP & NAP & NAP & NAP & NAP & NAP & NAP & NAP & NAP & NAP & NAP & NAP \\
\hline \begin{tabular}{|l|}
210 \\
\end{tabular} & 005 & \begin{tabular}{|l|l|}
54.001 \\
\end{tabular} & Dart & Tortugas & 1 & 58.27 & 27.13 & \begin{tabular}{|l|l|}
9.81 \\
\end{tabular} & 12.9 & 60 & FST & CMP & $\mathrm{cvx}$ & cvx & cvx & $\mathrm{BFC}$ & NPR & CRT & NAP & 58.73 & 60.75 & 11.79 & 26.58 & 0.20 & 0.98 & NAP & 1 & NAP & 1 & NAP & 2 & 2 & 47 & 50 \\
\hline \begin{tabular}{|l|}
210 \\
\end{tabular} & 006 & 54.002 & Bifiace & Late-Stage & 1 & 36.20 & 38.43 & 9.12 & 13.0 & 50 & PRF & IND & IND & $\mathrm{cvx}$ & $\mathrm{cvx}$ & BFB & NPR & CRT & NAP & NAP & NAP & NAP & NAP & NAP & NAP & NAP & NAP & \begin{tabular}{|l|} 
NAP \\
\end{tabular} & NAP & NAP & NAP & NAP & NAP & NAP \\
\hline \begin{tabular}{|l|}
210 \\
\end{tabular} & 007 & 54.003 & Bifiace & Mid-Stage & 1 & 31.46 & \begin{tabular}{|l|}
46.83 \\
\end{tabular} & \begin{tabular}{|l|}
15.55 \\
\end{tabular} & 21.4 & 65 & BLK & IND & IND & $\mathrm{cvx}$ & $\mathrm{cvx}$ & BFB & NPR & CRT & NAP & NAP & NAP & NAP & NAP & NAP & NAP & NAP & NAP & \begin{tabular}{|l|} 
NAP \\
\end{tabular} & NAP & NAP & NAP & NAP & NAP & NAP \\
\hline 210 & 008 & \begin{tabular}{|l|l|}
54.004 \\
\end{tabular} & Biface & Mid-Stage & 1 & 62.02 & \begin{tabular}{|l|l|}
37.62 \\
\end{tabular} & \begin{tabular}{|l|l|}
16.31 \\
\end{tabular} & 33.6 & 55 & BLK & CMP & $c v x$ & $c v x$ & $c v x$ & $\mathrm{BFC}$ & NPR & CRT & NAP & NAP & NAP & NAP & NAP & NAP & NAP & NAP & \begin{tabular}{|l|} 
NAP \\
\end{tabular} & \begin{tabular}{|l|} 
NAP \\
\end{tabular} & NAP & NAP & NAP & NAP & NAP & NAP \\
\hline \begin{tabular}{|l|}
210 \\
\end{tabular} & 009 & 54.005 & Biface & Early-Stage & 1 & 80.52 & 43.92 & 30.69 & 100.7 & 75 & INR & CMP & $\operatorname{cvx}$ & $\mathrm{crx}$ & $c v x$ & $\mathrm{BFC}$ & NPR & CRT & NAP & NAP & NAP & NAP & NAP & NAP & NAP & NAP & NAP & NAP & NAP & NAP & NAP & NAP & NAP & NAP \\
\hline 215 & 001 & 59 & Biface & Mid-Stage & 1 & 79.36 & \begin{tabular}{|l|}
44.05 \\
\end{tabular} & 19.75 & 48.0 & 60 & BLK & СMP & $c v x$ & $\mathrm{cvx}$ & $c v x$ & $\mathrm{BFC}$ & NPR & CRT & NAP & NAP & NAP & NAP & NAP & NAP & NAP & NAP & NAP & \begin{tabular}{|l|} 
NAP \\
\end{tabular} & NAP & NAP & NAP & NAP & NAP & NAP \\
\hline \begin{tabular}{|l|l|}
216 \\
\end{tabular} & 001 & 60 & Bifiace & Early-Stage & 1 & 90.91 & \begin{tabular}{|l|}
45.10 \\
\end{tabular} & 21.92 & 100.8 & 65 & INR & CMP & $c v x$ & $c v x$ & $c v x$ & $\mathrm{BFC}$ & NPR & FWD & NAP & NAP & NAP & NAP & NAP & NAP & NAP & NAP & NAP & NAP & NAP & NAP & NAP & NAP & NAP & NAP \\
\hline 219 & 001 & 63 & Edge-Modified & Utilized & 1 & 39.77 & 32.37 & 7.91 & 10.2 & 45 & N/A & N/A & NAP & NAP & STR & NAP & UFU & $\mathrm{OQZ}$ & NAP & NAP & NAP & NAP & NAP & NAP & NAP & NAP & NAP & NAP & NAP & NAP & NAP & NAP & NAP & NAP \\
\hline 220 & 001 & 64 & Edge-Modified & Utilized & 1 & 52.30 & 26.50 & 23.39 & 21.7 & 55 & N/A & $N / A$ & NAP & $\mathrm{cvx}$ & NAP & NAP & UFU & CRT & NAP & NAP & NAP & NAP & NAP & NAP & NAP & NAP & NAP & NAP & NAP & NAP & NAP & NAP & NAP & NAP \\
\hline
\end{tabular}


This page intentionally left blank. 


\section{APPENDIX E}

Faunal Analysis 
This page intentionally left blank. 


\begin{tabular}{|c|c|c|c|c|c|c|c|c|c|c|c|c|c|c|c|c|c|c|c|c|c|c|c|c|}
\hline $\begin{array}{l}\text { Lot } \\
\text { No. }\end{array}$ & $\begin{array}{l}\text { Spec. } \\
\text { No. }\end{array}$ & $\begin{array}{l}\text { FS } \\
\text { No. }\end{array}$ & $\begin{array}{c}\text { Proveni } \\
\text { ence }\end{array}$ & Ftr. & $\left|\begin{array}{c}\text { Lev } \\
\text { el }\end{array}\right|$ & \begin{tabular}{|l} 
Depth \\
(cmbs)
\end{tabular} & $\begin{array}{c}\text { Presen } \\
\text { ce }\end{array} \mid$ & $\begin{array}{l}\text { Weatheri } \\
\text { ng Stage }\end{array}$ & $\left|\begin{array}{l}\text { Surface } \\
\text { Visibility }\end{array}\right|$ & $\begin{array}{l}\text { Surface } \\
\text { Present }\end{array}$ & $\begin{array}{l}\text { Skeletal } \\
\text { Element }\end{array}$ & Side & $\begin{array}{l}\text { Fragment } \\
\text { Type }\end{array}$ & Taxon & $\begin{array}{c}\text { Common } \\
\text { Name }\end{array}$ & $\begin{array}{l}\text { Body } \\
\text { Size }\end{array}$ & $\begin{array}{c}\text { Adult/l } \\
\text { Subadult }\end{array}$ & Burned & $\begin{array}{c}\text { Margin } \\
\text { Angle }\end{array}$ & $\begin{array}{c}\text { Max } \\
\text { Length }\end{array}$ & \begin{tabular}{|c|} 
Max \\
Width
\end{tabular} & $\mid \begin{array}{c}\text { Max } \\
\text { Thickness }\end{array}$ & $\begin{array}{c}\text { Weight } \\
(\mathrm{g})\end{array}$ & Comments \\
\hline 152 & 115 & 1 & BHT1 & 1 & & & Frag & 0 & 100 & 100 & Humerus & Distal, right & $\begin{array}{c}\text { Distal } \\
\text { epiphysis }\end{array}$ & Microfauna & Unknown & Micro & Adult & No & Oblique & 21.8 & 7.9 & 3.3 & $<0.1$ & $\begin{array}{l}\text { Microfauna distal humerus. } \\
\text { Possible small rodent. }\end{array}$ \\
\hline 152 & 116 & 1 & BHT1 & 1 & & & Frag & 2 & 100 & $>50$ & Carapace & Unknown & Carapace & Testudines & Turtle/Tortoise & 1 & Adult & No & Right & 16.2 & 12.9 & 8.3 & 0.6 & $\begin{array}{l}\text { Edge fragment of a large } \\
\text { carapace. }\end{array}$ \\
\hline 152 & 117 & 1 & BHT1 & 1 & & & Frag & 2 & 100 & $>50$ & Carapace & Unknown & Carapace & Testudines & Turtle/Tortoise & 1 & Adult & No & Right & 14.3 & 9.4 & 5.4 & 0.2 & $\begin{array}{l}\text { Ventral fragment of a } \\
\text { carapace. Refits with .002. }\end{array}$ \\
\hline 152 & 118 & 1 & BHT1 & 1 & & & Frag & 2 & 100 & $>50$ & Unknown & Unknown & Unknown & Unknown & Unknown & $\mathrm{N} / \mathrm{A}$ & Unknown & No & Fresh & 7.4 & 6.5 & 2.7 & $<0.1$ & $\begin{array}{l}\text { Very small, unidentifiable } \\
\text { bone fragment. }\end{array}$ \\
\hline 158 & 085 & 7 & TU1 & 1 & 3 & $50-60$ & Frag & 1 & 100 & $<50$ & Long bone & N/A & Unknown & mammal & Unknown & 1 & Unknown & No & Fresh & 106.5 & 6.4 & 6.3 & 3.5 & $\begin{array}{l}\text { Small long bone. Has been } \\
\text { rodent gnawed beyond } \\
\text { recognition. Refits with } .002 . \\
\text { Possibly a tibia. }\end{array}$ \\
\hline 158 & 086 & 7 & TU1 & 1 & 3 & $50-60$ & Frag & 1 & 100 & $<50$ & Long bone & $\mathrm{N} / \mathrm{A}$ & Unknown & mammal & Unknown & 1 & Unknown & No & Fresh & 45.6 & 8.3 & 4.4 & 0.6 & $\begin{array}{l}\text { Small long bone. Has been } \\
\text { rodent gnawed beyond } \\
\text { recognition. Refits with . } 001 . \\
\text { Possibly a tibia. }\end{array}$ \\
\hline 158 & 087 & 7 & TU1 & 1 & 3 & $50-60$ & Frag & 1 & 100 & 100 & Carapace & $\mathrm{N} / \mathrm{A}$ & Carapace & Testudines & Turtle/Tortoise & 1 & Unknown & No & $N / A$ & 34.6 & 29.9 & 3.5 & 2.0 & $\begin{array}{l}\text { Carapace fragment. Has a } \\
\text { hole in the top. The area is } \\
\text { thin and the margins might be } \\
\text { unbroken, but the whole could } \\
\text { be a tooth puncture. }\end{array}$ \\
\hline 162 & 026 & 11 & TU1N & 1 & 3 & $50-60$ & Frag & 1 & 100 & 100 & Plastron & Unknown & Plastron & Testudines & Turtle/Tortoise & 1 & Unknown & No & N/A & 23.3 & 16.6 & 2.1 & 0.4 & Plastron fragment. \\
\hline 162 & 027 & 11 & TU1N & 1 & 3 & $50-60$ & Frag & 1 & 100 & 100 & $\begin{array}{c}\text { Plastron/Carap } \\
\text { ace }\end{array}$ & Unknown & $\begin{array}{c}\text { Plastron/Car } \\
\text { apace }\end{array}$ & Testudines & Turtle/Tortoise & 1 & Unknown & No & N/A & 36.1 & 12.3 & 3.2 & 0.8 & $\begin{array}{l}\text { Either a plastron or carapace } \\
\text { fragment. Likely plastron }\end{array}$ \\
\hline 162 & 028 & 11 & TU1N & 1 & 3 & $50-60$ & Whole & 0 & 100 & 100 & Tooth & Unknown & Unknown & Rodentia & Rodent & \begin{tabular}{|l|} 
Micro \\
\end{tabular} & Adult & No & $\mathrm{N} / \mathrm{A}$ & 19.0 & 5.7 & 2.1 & 0.2 & Rodent canine tooth. \\
\hline 162 & 029 & 11 & TU1N & 1 & 3 & $50-60$ & Frag & 1 & 100 & 100 & Unknown & Unknown & Unknown & Unknown & Unknown & N/A & Unknown & No & Right & 11.6 & 4.2 & 2.0 & $<0.1$ & $\begin{array}{l}\text { Small cortical fragment. Not } \\
\text { enough to make any } \\
\text { determinations. }\end{array}$ \\
\hline 162 & 030 & 11 & TU1N & 1 & 3 & $50-60$ & Frag & 0 & 100 & 100 & Humerus & Distal, Left & $\begin{array}{l}\text { Distal } \\
\text { epiphysis }\end{array}$ & Rodentia & Rodent & Micro & Adult & No & Oblique & 15.7 & 7.4 & 3.5 & $<0.1$ & $\begin{array}{l}\text { Left distal humerus of a } \\
\text { rodent. More robust than the } \\
\text { previous } 1.001 .\end{array}$ \\
\hline 162 & 031 & 11 & TU1N & 1 & 3 & $50-60$ & Frag & $\mathrm{N} / \mathrm{A}$ & $\mathrm{N} / \mathrm{A}$ & $\mathrm{N} / \mathrm{A}$ & Unknown & Unknown & Unknown & Unknown & Unknown & $\mathrm{N} / \mathrm{A}$ & Unknown & No & $\mathrm{N} / \mathrm{A}$ & 10.1 & 7.0 & 5.2 & $<0.1$ & Small, trabecular fragment. \\
\hline 162 & 032 & 11 & TU1N & 1 & 3 & $50-60$ & Frag & 0 & 100 & 100 & Unknown & Unknown & Unknown & Unknown & Unknown & N/A & Unknown & No & Spiral & 26.0 & 8.8 & 4.7 & 0.2 & $\begin{array}{l}\text { Large cortical fragment of a } \\
\text { small animal. Extensive } \\
\text { rodent tooth drag marks on } \\
\text { the margins. }\end{array}$ \\
\hline 162 & 033 & 11 & TU1N & 1 & 3 & $50-60$ & Whole & 0 & 100 & 100 & Ischium & right & N/A & Unknown & Unknown & $1-2$ & subadult & No & $\mathrm{N} / \mathrm{A}$ & 20.7 & 16.2 & 3.1 & 0.4 & $\begin{array}{l}\text { Unfused ischium. Unsure of } \\
\text { what animal. }\end{array}$ \\
\hline 162 & 034 & 11 & TU1N & 1 & 3 & $50-60$ & Frag & 0 & 100 & 100 & Tibia & Right & $\begin{array}{l}\text { Proximal } \\
\text { Epiphysis }\end{array}$ & Unknown & Unknown & Micro & Adult & No & Oblique & 13.1 & 4.7 & 3.0 & $<0.1$ & $\begin{array}{l}\text { Proximal tibia. Epiphysis is } \\
\text { worn off. Micro fauna. }\end{array}$ \\
\hline 162 & 035 & 11 & TU1N & 1 & 3 & $50-60$ & Frag & N/A & N/A & $\mathrm{N} / \mathrm{A}$ & Unknown & Unknown & Trabecula & Unknown & Unknown & N/A & Unknown & Yes & N/A & 19.3 & 7.7 & 8.2 & 0.4 & $\begin{array}{l}\text { Trabecular fragment. Burned } \\
\text { to black but not calcined. }\end{array}$ \\
\hline 162 & 036 & 11 & TU1N & 1 & 3 & $50-60$ & Frag & N/A & N/A & $\mathrm{N} / \mathrm{A}$ & Unknown & Unknown & Trabecula & Unknown & Unknown & N/A & Unknown & Yes & N/A & 13.7 & 10.6 & 9.6 & 0.4 & $\begin{array}{l}\text { Trabecular fragment. Burn } \\
\text { coloration from black to } \\
\text { unburned. }\end{array}$ \\
\hline 162 & 037 & 11 & TU1N & 1 & 3 & $50-60$ & Frag & 3 & N/A & N/A & Unknown & Unknown & Trabecula & Unknown & Unknown & N/A & Unknown & No & $\mathrm{N} / \mathrm{A}$ & 13.7 & 10.7 & 10.1 & 0.8 & $\begin{array}{l}\text { Trabeculae fragment. No sign } \\
\text { of burning. One very small } \\
\text { patch of cortical surface, } \\
\text { appeared very weathered. }\end{array}$ \\
\hline 162 & 038 & 11 & TU1N & 1 & 3 & $50-60$ & Frag & N/A & N/A & N/A & Unknown & Unknown & Trabecula & Unknown & Unknown & N/A & Unknown & No & $\mathrm{N} / \mathrm{A}$ & 10.4 & 9.9 & 7.5 & 0.1 & $\begin{array}{l}\text { Trabeculae fragment. No sign } \\
\text { of burning. }\end{array}$ \\
\hline
\end{tabular}




\begin{tabular}{|c|c|c|c|c|c|c|c|c|c|c|c|c|c|c|c|c|c|c|c|c|c|c|c|c|}
\hline $\begin{array}{l}\text { Lot } \\
\text { No. }\end{array}$ & $\begin{array}{l}\text { Spec. } \\
\text { No. }\end{array}$ & $\begin{array}{l}\text { FS } \\
\text { No. }\end{array}$ & $\begin{array}{c}\text { Proveni } \\
\text { ence }\end{array}$ & Ftr. & $\begin{array}{c}\text { Lev } \\
\text { el }\end{array}$ & \begin{tabular}{|l|} 
Depth \\
(cmbs)
\end{tabular} & $\begin{array}{c}\text { Presen } \\
\text { ce }\end{array}$ & $\begin{array}{l}\text { Weatheri } \\
\text { ng Stage }\end{array}$ & $\left|\begin{array}{l}\text { Surface } \\
\text { Visibility }\end{array}\right|$ & $\begin{array}{l}\text { Surface } \\
\text { Present }\end{array}$ & $\begin{array}{l}\text { Skeletal } \\
\text { Element }\end{array}$ & Side & $\begin{array}{l}\text { Fragment } \\
\text { Type }\end{array}$ & Taxon & $\begin{array}{l}\text { Common } \\
\text { Name }\end{array}$ & \begin{tabular}{|c|} 
Body \\
Size
\end{tabular} & $\mid \begin{array}{c}\text { Adult/ } \\
\text { Subadult }\end{array}$ & Burned & $\begin{array}{c}\text { Margin } \\
\text { Angle }\end{array}$ & $\begin{array}{l}\text { Max } \\
\text { Length }\end{array}$ & $\left|\begin{array}{c}\text { Max } \\
\text { Width }\end{array}\right|$ & \begin{tabular}{|l} 
Max \\
Thickness
\end{tabular} & $\begin{array}{c}\text { Weight } \\
\text { (g) }\end{array}$ & Comments \\
\hline 162 & 039 & 11 & TU1N & 1 & 3 & $50-60$ & Frag & 3 & 100 & $<50$ & Unknown & Unknown & Unknown & Mammal & Unknown & $2-3$ & Unknown & No & Fresh & 21.0 & 14.5 & 10.2 & 1.1 & \begin{tabular}{|l|} 
Large fragment. Mostly \\
trabecular with some cortex. \\
Likely from a size 2 or 3 \\
mammal.
\end{tabular} \\
\hline 162 & 040 & 11 & TU1N & 1 & 3 & $50-60$ & Frag & 3 & N/A & N/A & Unknown & Unknown & Trabecula & Unknown & Unknown & $\mathrm{N} / \mathrm{A}$ & Unknown & No & $\mathrm{N} / \mathrm{A}$ & 14.4 & 9.9 & 7.7 & 0.3 & $\begin{array}{l}\text { Trabeculae fragment. No sign } \\
\text { of burning. One very small } \\
\text { patch of cortical surface, } \\
\text { appeared very weathered. }\end{array}$ \\
\hline 162 & 041 & 11 & TU1N & 1 & 3 & $50-60$ & Frag & N/A & N/A & N/A & Unknown & Unknown & Trabecula & Unknown & Unknown & $N / A$ & Unknown & Yes & N/A & 12.1 & 10.3 & 7.2 & 0.2 & $\begin{array}{l}\text { Trabecular fragment. Burn } \\
\text { coloration from black to } \\
\text { unburned. }\end{array}$ \\
\hline 162 & 042 & 11 & TU1N & 1 & 3 & $50-60$ & Frag & $N / A$ & $\mathrm{~N} / \mathrm{A}$ & $\mathrm{N} / \mathrm{A}$ & Unknown & Unknown & Trabecula & Unknown & Unknown & $N / A$ & Unknown & Yes & $\mathrm{N} / \mathrm{A}$ & 9.4 & 7.5 & 5.7 & $<0.1$ & $\begin{array}{l}\text { Trabecular fragment. Burn } \\
\text { coloration from black to } \\
\text { unburned. Very small piece of } \\
\text { cortical surface. }\end{array}$ \\
\hline 162 & 043 & 11 & TU1N & 1 & 3 & $50-60$ & Frag & 4 & N/A & N/A & Unknown & Unknown & Trabecula & Unknown & Unknown & $N / A$ & Unknown & Yes & $\mathrm{N} / \mathrm{A}$ & 16.5 & 10.5 & 8.3 & 0.6 & $\begin{array}{l}\text { Mostly trabecular. The part } \\
\text { that is cortical has been } \\
\text { obliterated by weathering and } \\
\text { heat modification. Gradient of } \\
\text { heat color changes from black } \\
\text { to unburned. }\end{array}$ \\
\hline 162 & 044 & 11 & TU1N & 1 & 3 & $50-60$ & Frag & 1 & N/A & $\mathrm{N} / \mathrm{A}$ & Unknown & Unknown & Unknown & Unknown & Unknown & N/A & Unknown & Yes & $N / A$ & 9.2 & 6.4 & 2.8 & $<0.1$ & $\begin{array}{l}\text { Mostly trabecular. Gradient of } \\
\text { heat color changes from black } \\
\text { to unburned. }\end{array}$ \\
\hline 162 & 045 & 11 & TU1N & 1 & 3 & $50-60$ & Frag & 3 & 100 & $>50$ & Unknown & Unknown & Unknown & mammal & Unknown & $2-3$ & Unknown & Yes & $N / A$ & 29.6 & 20.5 & 19.2 & 3.9 & $\begin{array}{l}\text { Large bone fragment from a } \\
\text { large mammal. Appears to be } \\
\text { an articulating surface, but not } \\
\text { enough to determine element. } \\
\text { Small patches of black burn } \\
\text { marks. The rest is unburned. }\end{array}$ \\
\hline 174 & 242 & 24 & TU3 & 1 & 3 & 55 & Frag & 0 & 100 & 100 & Mandible & right & $\mathrm{N} / \mathrm{A}$ & Rodentia & Rodent & Micro & Adult & No & $\mathrm{N} / \mathrm{A}$ & 13.5 & 8.7 & 3.2 & $<0.1$ & $\begin{array}{l}\text { Proximal portion of a rodent } \\
\text { mandible, right side. Includes } \\
\text { two molars. }\end{array}$ \\
\hline 174 & 243 & 24 & TU3 & 1 & 3 & 55 & Whole & 0 & 100 & 100 & Tooth & Unknown & $\mathrm{N} / \mathrm{A}$ & Rodentia & Rodent & Micro & Adult & No & N/A & 7.1 & 1.8 & 1.8 & $<0.1$ & $\begin{array}{l}\text { Appears to be a molar M1 } \\
\text { (possibly from .001). }\end{array}$ \\
\hline 174 & 244 & 24 & TU3 & 1 & 3 & 55 & Whole & 0 & 100 & 100 & Vertebra & N/A & $\mathrm{N} / \mathrm{A}$ & Unknown & Unknown & Micro & Unknown & No & N/A & 7.5 & 5.2 & 4.3 & $<0.1$ & Microfauna cervical vertebra. \\
\hline 174 & 245 & 24 & TU3 & 1 & 3 & 55 & Frag & 2 & $\mathrm{~N} / \mathrm{A}$ & $\mathrm{N} / \mathrm{A}$ & Unknown & Unknown & Unknown & Unknown & Unknown & N/A & Unknown & No & N/A & 8.7 & 4.5 & 1.4 & $<0.1$ & $\begin{array}{l}\text { Cortical bone fragment, } \\
\text { Probably flaked off of a larger } \\
\text { piece. }\end{array}$ \\
\hline 174 & 246 & 24 & TU3 & 1 & 3 & 55 & Frag & $\mathrm{N} / \mathrm{A}$ & 100 & 100 & Tooth & Unknown & Enamel & mammal & Unknown & $2-3$ & Unknown & No & $\mathrm{N} / \mathrm{A}$ & 12.6 & 8.9 & 2.0 & 0.3 & $\begin{array}{l}\text { Large piece of tooth enamel. } \\
\text { Cannot tell if it is cervid or } \\
\text { bovid. }\end{array}$ \\
\hline 174 & 247 & 24 & TU3 & 1 & 3 & 55 & Frag & 3 & 100 & $<50$ & Unknown & Unknown & Unknown & Unknown & Unknown & $\mathrm{N} / \mathrm{A}$ & Unknown & No & Oblique & 18.9 & 9.5 & 2.3 & 0.5 & $\begin{array}{l}\text { Unidentifiable cortical } \\
\text { fragment. Weathering has } \\
\text { obliterated the surface. }\end{array}$ \\
\hline 175 & 066 & 25 & TU3 & 1 & 4 & & Frag & 1 & 100 & 100 & Unknown & Unknown & Unknown & Unknown & Unknown & $\mathrm{N} / \mathrm{A}$ & Unknown & No & \begin{tabular}{|l|} 
Oblique \\
\end{tabular} & 10.8 & 2.8 & 1.7 & $<0.1$ & Small cortical splinter. \\
\hline 175 & 067 & 25 & TU3 & 1 & 4 & & Whole & 1 & 100 & 100 & Vertebra & N/A & $\mathrm{N} / \mathrm{A}$ & Reptile & Snake & 1 & Adult & No & $\mathrm{N} / \mathrm{A}$ & 14.5 & 7.9 & 7.3 & 0.5 & $\begin{array}{l}\text { Small snake vertebra. Cannot } \\
\text { identify to species. Not a } \\
\text { viper. Possibly a small rat } \\
\text { snake. }\end{array}$ \\
\hline 176 & 006 & 26 & TU4 & 3 & 1 & & Frag & 1 & 100 & 100 & Long bone & Unknown & Unknown & Unknown & Unknown & 1 & Unknown & Yes & Oblique & 8.7 & 6 & 3.4 & $<0.1$ & \begin{tabular}{|l|} 
Long bone, possibly \\
metapodial. Small fragment, \\
Burned, nearly calcined. \\
\end{tabular} \\
\hline
\end{tabular}




\begin{tabular}{|c|c|c|c|c|c|c|c|c|c|c|c|c|c|c|c|c|c|c|c|c|c|c|c|c|}
\hline $\begin{array}{l}\text { Lot } \\
\text { No. }\end{array}$ & $\begin{array}{l}\text { Spec. } \\
\text { No. }\end{array}$ & $\begin{array}{l}\text { FS } \\
\text { No. }\end{array}$ & $\begin{array}{c}\text { Proveni } \\
\text { ence }\end{array} \mid$ & Ftr. & $\begin{array}{c}\text { Lev } \\
\text { el }\end{array}$ & \begin{tabular}{|l|} 
Depth \\
(cmbs)
\end{tabular} & $\begin{array}{l}\text { Presen } \\
\text { ce }\end{array}$ & $\begin{array}{l}\text { Weatheri } \\
\text { ng Stage }\end{array}$ & $\begin{array}{l}\text { Surface } \\
\text { Visibility }\end{array} \mid$ & $\begin{array}{l}\text { Surface } \\
\text { Present }\end{array}$ & $\begin{array}{l}\text { Skeletal } \\
\text { Element }\end{array}$ & Side & $\begin{array}{c}\text { Fragment } \\
\text { Type }\end{array}$ & Taxon & $\begin{array}{l}\text { Common } \\
\text { Name }\end{array}$ & \begin{tabular}{|l|} 
Body \\
Size
\end{tabular} & $\mid \begin{array}{c}\text { Adult/ } \\
\text { Subadult }\end{array}$ & Burned & $\begin{array}{c}\text { Margin } \\
\text { Angle }\end{array}$ & $\begin{array}{c}\text { Max } \\
\text { Length }\end{array}$ & $\left|\begin{array}{c}\text { Max } \\
\text { Width }\end{array}\right|$ & \begin{tabular}{|c|} 
Max \\
Thickness
\end{tabular} & \begin{tabular}{|c} 
Weight \\
(g)
\end{tabular} & Comments \\
\hline 176 & 007 & 26 & TU4 & 3 & 1 & & Frag & 1 & 100 & 100 & Unknown & Unknown & Unknown & Unknown & Unknown & N/A & Unknown & No & Fresh & 26.1 & 10.1 & 1.8 & 0.6 & $\begin{array}{l}\text { Unknown bone fragment with } \\
\text { thin cortex and no trabeculae. } \\
\text { Possibly from a large bird. }\end{array}$ \\
\hline 176 & 008 & 26 & TU4 & 3 & 1 & & Frag & 0 & 100 & 100 & Unknown & Unknown & Unknown & Microfauna & Unknown & Micro & Unknown & No & Oblique & 11.6 & 5.5 & 3.2 & $<0.1$ & $\begin{array}{l}\text { Microfaunal fragment, } \\
\text { possibly part of the inominant. }\end{array}$ \\
\hline 176 & 009 & 26 & TU4 & 3 & 1 & & Frag & 0 & 100 & 100 & Unknown & Unknown & Epiphysis & Microfauna & Unknown & Micro & Adult & No & Right & 8.7 & 3.9 & 2.2 & $<0.1$ & \begin{tabular}{|l|} 
Microfaunal fragment, \\
possibly part of the Ulina. \\
Micro mammal or small bird
\end{tabular} \\
\hline 177 & 005 & 27 & TU4 & 3 & 2 & $40-50$ & Frag & 4 & 100 & 0 & Unknown & Unknown & Unknown & Unknown & Unknown & N/A & Unknown & No & N/A & 10.9 & 6.8 & 2.5 & $<0.1$ & $\begin{array}{l}\text { Heavily weathered, small } \\
\text { cortical fragment. }\end{array}$ \\
\hline 177 & 006 & 27 & TU4 & 3 & 2 & $40-50$ & Frag & 4 & 100 & 0 & Unknown & Unknown & Unknown & Unknown & Unknown & N/A & Unknown & No & $N / A$ & 5.6 & 5.0 & 1.4 & $<0.1$ & $\begin{array}{l}\text { Heavily weathered, small } \\
\text { cortical fragment. }\end{array}$ \\
\hline 177 & 007 & 27 & TU4 & 3 & 2 & $40-50$ & Frag & 4 & 100 & 0 & Unknown & Unknown & Unknown & Unknown & Unknown & N/A & Unknown & No & $N / A$ & 5.2 & 5.1 & 1.9 & $<0.1$ & $\begin{array}{l}\text { Heavily weathered, small } \\
\text { cortical fragment. }\end{array}$ \\
\hline 191 & 005 & 35 & TU5 & 3 & 3 & $50-60$ & Frag & 4 & 100 & 0 & Unknown & Unknown & Unknown & Unknown & Unknown & N/A & Unknown & No & N/A & 11.5 & 10.3 & 1.9 & $<0.1$ & $\begin{array}{l}\text { Heavily weathered, small } \\
\text { cortical fragment. }\end{array}$ \\
\hline 205 & 004 & 50 & BHT8 & - & 2 & $10-20$ & Frag & 3 & 100 & $<50$ & Unknown & Unknown & Unknown & Unknown & Unknown & $\mathrm{N} / \mathrm{A}$ & Unknown & No & \begin{tabular}{|c} 
Oblique/ \\
Fresh
\end{tabular} & 15.0 & 11.1 & 2.4 & $<0.1$ & $\begin{array}{l}\text { Small cortical fragment. } \\
\text { Heavily weathered. Appears } \\
\text { to have a recent cut on the } \\
\text { surface, probably a trowel } \\
\text { mark. }\end{array}$ \\
\hline 205 & 005 & 50 & ВНт8 & - & 2 & $10-20$ & Frag & 1 & 100 & 100 & Tooth & Unknown & Enamel & Mammal & Unknown & $2-3$ & Unknown & No & N/A & 15.5 & 7.7 & 4.4 & 0.3 & $\begin{array}{l}\text { Probably cervid. Cannot say } \\
\text { for certain. }\end{array}$ \\
\hline 211 & 004 & 55 & ВНT8 & - & & 68 & Frag & 4 & 100 & 0 & Long Bone & Unknown & Metaphysis & Mammal & Unknown & 1 & Unknown & No & \begin{tabular}{|c} 
Oblique/ \\
Fresh
\end{tabular} & 42.5 & 9.6 & 10.1 & 2.5 & \begin{tabular}{|l|} 
Extreme weathering and \\
rodent gnawing have \\
obliterated the surface.
\end{tabular} \\
\hline 213 & 001 & 57 & TU4 & 3 & & 50 & Frag & 1 & 50 & 100 & $\begin{array}{l}\text { Mandible } \\
\text { fragment }\end{array}$ & Left & \begin{tabular}{|c|} 
Mandible \\
with 2 molars
\end{tabular} & Pecari tajacu & $\begin{array}{c}\text { Peccary/Javale } \\
\text { na }\end{array}$ & 2 & Adult & No & & & & & & $\begin{array}{l}\text { Mandible fragment with the } \\
\mathrm{m} 2 \text { and } \mathrm{m} 3 \text { in socket. The } \mathrm{m} 3 \\
\text { is fully erupted, but there is } \\
\text { little wear on the cusps, } \\
\text { probably a young adult. Tooth } \\
\text { morphology would indicate a } \\
\text { peccary. The bone fragment } \\
\text { was removed in a block of } \\
\text { surrounding matrix. The bone } \\
\text { is so fragmentile, that I left it in } \\
\text { the matrix after uncovering } \\
\text { the occlusal surface of the } \\
\text { teeth. }\end{array}$ \\
\hline
\end{tabular}




\begin{tabular}{|c|c|c|c|c|c|c|c|c|c|c|c|c|c|c|c|c|c|c|c|c|c|c|c|c|}
\hline \begin{tabular}{l|l} 
Lot & \\
No. &
\end{tabular} & $\begin{array}{l}\text { Spec. } \\
\text { No. }\end{array}$ & $\begin{array}{l}\text { FS } \\
\text { No. }\end{array}$ & $\begin{array}{c}\text { Proveni } \\
\text { ence }\end{array}$ & Ftr. & $\begin{array}{c}\text { Lev } \\
\text { el }\end{array}$ & \begin{tabular}{|l} 
Depth \\
(cmbs)
\end{tabular} & $\begin{array}{l}\text { Presen } \\
\text { ce }\end{array}$ & $\begin{array}{l}\text { Weatheri } \\
\text { ng Stage }\end{array}$ & $\mid \begin{array}{l}\text { Surface } \\
\text { Visibility }\end{array}$ & $\begin{array}{l}\text { Surface } \\
\text { Present }\end{array}$ & $\begin{array}{l}\text { Skeletal } \\
\text { Element }\end{array}$ & Side & $\begin{array}{c}\text { Fragment } \\
\text { Type }\end{array}$ & Taxon & $\begin{array}{l}\text { Common } \\
\text { Name }\end{array}$ & $\begin{array}{l}\text { Body } \\
\text { Size }\end{array}$ & $\mid \begin{array}{c}\text { Adult/ } \\
\text { Subadult }\end{array}$ & Burned & $\begin{array}{c}\text { Margin } \\
\text { Angle }\end{array}$ & $\begin{array}{c}\text { Max } \\
\text { Length }\end{array}$ & $\left|\begin{array}{c}\text { Max } \\
\text { Width }\end{array}\right|$ & $\begin{array}{c}\text { Max } \\
\text { Thickness }\end{array}$ & $\begin{array}{c}\text { Weight } \\
\text { (g) }\end{array}$ & Comments \\
\hline 214 & 001 & 58 & BHT1 & 1 & & $40-45$ & Frag & 3 & 100 & 50 & Phalange & Unknown & Epiphysis & mammal & Bovid & 2 & Adult & No & Oblique & 55.1 & 17.0 & 12.4 & 7.0 & $\begin{array}{l}\text { Fragment piece fits with } \\
\text { Specimen } 214.002, \text { forming } \\
\text { part of a phalange. The } \\
\text { animal is cow sized but given } \\
\text { the context is surmised to be } \\
\text { bison. Cortical bone is quite } \\
\text { thick. Weathering on surface } \\
\text { is high, and the surface shows } \\
\text { signs of extensive rodent } \\
\text { gnawing and tooth drags. } \\
\text { Cortex is } 7 \mathrm{~mm} \text { thick. } \\
\text { Weathering on surface is } \\
\text { high, and the surface shows } \\
\text { signs of extensive rodent } \\
\text { gnawing and tooth drags. } \\
\text { Fragment margins have been } \\
\text { recently broken. }\end{array}$ \\
\hline 214 & 002 & 58 & BHT1 & 1 & & $40-45$ & Frag & 3 & 100 & $>50$ & Phalange & Unknown & Epiphysis & mammal & Bovid & 2 & Adult & No & Fresh & 44.3 & 14.4 & 8.5 & 2.5 & $\begin{array}{l}\text { Fragment piece fits with } \\
\text { Specimen } 214.002, \text { forming } \\
\text { part of a phalange. The } \\
\text { animal is cow sized but given } \\
\text { the context is surmised to be } \\
\text { bison. Cortical bone is quite } \\
\text { thick. Weathering on surface } \\
\text { is high, and the surface shows } \\
\text { signs of extensive rodent } \\
\text { gnawing and tooth drags. } \\
\text { Cortex is } 7 \mathrm{~mm} \text { thick. } \\
\text { Weathering on surface is } \\
\text { high, and the surface shows } \\
\text { signs of extensive rodent } \\
\text { gnawing and tooth drags. } \\
\text { Fragment margins have been } \\
\text { recently broken. }\end{array}$ \\
\hline 214 & 003 & 58 & BHT1 & 1 & & $40-45$ & Frag & 2 & 100 & $<50$ & Unknown & Unknown & Unknown & mammal & Unknown & 2 & Unknown & No & Fresh & 15.4 & 12.9 & 5.7 & 0.5 & $\begin{array}{l}\text { Unidentifiable bone fragment. } \\
\text { Possible muscle } \\
\text { attachments/landmarks on } \\
\text { surface, but not enough to } \\
\text { identify. Surface has been } \\
\text { weathered. One possible } \\
\text { tooth puncture. }\end{array}$ \\
\hline 214 & 004 & 58 & BHT1 & 1 & & $40-45$ & Frag & 3 & 100 & $<50$ & Unknown & Unknown & Unknown & mammal & Unknown & 2 & Unknown & No & Fresh & 14.8 & 11.3 & 5.6 & 0.5 & $\begin{array}{l}\text { Unidenfiable bone fragment. } \\
\text { Surface has been heavily } \\
\text { weathered. }\end{array}$ \\
\hline 214 & 005 & 58 & BHT1 & 1 & & $40-45$ & Frag & 3 & 100 & $<50$ & Unknown & Unknown & Unknown & Unknown & Unknown & N/A & Unknown & No & Oblique & 18.4 & 8.4 & 6.2 & 0.5 & $\begin{array}{l}\text { Nearly all trabecular bone. } \\
\text { Small patch of cortical is very } \\
\text { thin and heavily weathered. } \\
\text { Unable to determine animal } \\
\text { size. }\end{array}$ \\
\hline
\end{tabular}




\section{APPENDIX F}

Historic Artifacts 
This page intentionally left blank. 


\begin{tabular}{|c|c|c|c|c|c|c|c|c|c|c|c|c|c|c|c|c|}
\hline $\begin{array}{l}\text { Lot } \\
\text { No. }\end{array}$ & $\begin{array}{l}\text { Spec. } \\
\text { No. }\end{array}$ & $\begin{array}{l}\text { FS } \\
\text { No. }\end{array}$ & Provenience & Level & $\begin{array}{l}\text { Elevation } \\
\text { (cmbs) }\end{array}$ & \begin{tabular}{|c} 
Feature \\
No.
\end{tabular} & $\begin{array}{l}\text { Artifact } \\
\text { Class }\end{array}$ & $\begin{array}{l}\text { Artifact } \\
\text { Subclass }\end{array}$ & $\begin{array}{l}\text { Artifact } \\
\text { Type }\end{array}$ & $\begin{array}{l}\text { Artifact } \\
\text { Subtypel } \\
\text { Identity }\end{array}$ & $\begin{array}{c}\text { Artifact } \\
\text { Description }\end{array}$ & Count & \begin{tabular}{|l} 
Weight \\
(g)
\end{tabular} & Material & Completeness & Comments \\
\hline 063 & 001 & H 01-1 & $\begin{array}{c}\text { Controlled Surface } \\
\text { Collection }\end{array}$ & Surface & Surface & - & $\begin{array}{l}\text { Historic } \\
\text { Ceramic }\end{array}$ & Historic & $\begin{array}{l}\text { Historic } \\
\text { Ceramic }\end{array}$ & - & $\begin{array}{c}\text { Earthenware } \\
\text { Slip Glazed-Brown } \\
\text { Ceramic } \\
\end{array}$ & 1 & 8.5 & Ceramic & Fragment-Indet & None \\
\hline 064 & 001 & H 01-2 & $\begin{array}{c}\text { Controlled Surface } \\
\text { Collection }\end{array}$ & Surface & Surface & - & $\begin{array}{l}\text { Historic } \\
\text { Ceramic }\end{array}$ & Historic & $\begin{array}{l}\text { Historic } \\
\text { Ceramic }\end{array}$ & - & $\begin{array}{c}\text { Undecorated } \\
\text { Whiteware Ceramic }\end{array}$ & 1 & 58.0 & Ceramic & Fragment-Base & Burned \\
\hline 065 & 001 & H 01-3 & $\begin{array}{c}\text { Controlled Surface } \\
\text { Collection }\end{array}$ & Surface & Surface & - & Glass & Historic & Glass & - & Manganese Glass & 1 & 2.5 & Glass & Fragment-Indet & None \\
\hline 066 & 001 & $\mathrm{H}$ 02-1 & $\begin{array}{c}\text { Controlled Surface } \\
\text { Collection }\end{array}$ & Surface & Surface & - & Glass & Historic & Glass & - & Manganese Glass & 1 & 11.5 & Glass & Fragment-Indet & Patinated \\
\hline 067 & 001 & $\mathrm{H}$ 02-2 & $\begin{array}{c}\text { Controlled Surface } \\
\text { Collection }\end{array}$ & Surface & Surface & - & Glass & Historic & Glass & - & Manganese Glass & 1 & 8.0 & Glass & Fragment-Indet & Patinated \\
\hline 068 & 001 & $\mathrm{H} 02-3$ & $\begin{array}{c}\text { Controlled Surface } \\
\text { Collection }\end{array}$ & Surface & Surface & - & Glass & Historic & Glass & - & Manganese Glass & 1 & 4.0 & Glass & Fragment-Indet & Patinated \\
\hline 069 & 001 & $\mathrm{H}$ 02-4 & $\begin{array}{c}\text { Controlled Surface } \\
\text { Collection }\end{array}$ & Surface & Surface & - & $\begin{array}{l}\text { Historic } \\
\text { Ceramic }\end{array}$ & Historic & $\begin{array}{l}\text { Historic } \\
\text { Ceramic }\end{array}$ & - & $\begin{array}{c}\text { Undecorated } \\
\text { Whiteware Ceramic }\end{array}$ & 1 & 5.0 & Ceramic & Fragment-Base & $\begin{array}{l}\text { Partial back stamp only very } \\
\text { small sliver of image no wording } \\
\text { visible }\end{array}$ \\
\hline 070 & 001 & $\mathrm{H} 03$ & $\begin{array}{c}\text { Controlled Surface } \\
\text { Collection }\end{array}$ & Surface & Surface & - & Glass & Historic & Glass & - & Manganese Glass & 1 & 2.5 & Glass & Fragment-Indet & None \\
\hline 071 & 001 & H 04-1 & $\begin{array}{c}\text { Controlled Surface } \\
\text { Collection }\end{array}$ & Surface & Surface & - & $\begin{array}{l}\text { Historic } \\
\text { Ceramic }\end{array}$ & Historic & $\begin{array}{l}\text { Historic } \\
\text { Ceramic }\end{array}$ & - & $\begin{array}{c}\text { Earthenware } \\
\text { Slip Glazed-Brown } \\
\text { Ceramic } \\
\end{array}$ & 1 & 7.0 & Ceramic & Fragment-Indet & None \\
\hline 072 & 001 & $\mathrm{H}$ 04-2 & $\begin{array}{c}\text { Controlled Surface } \\
\text { Collection }\end{array}$ & Surface & Surface & - & Glass & Historic & Glass & - & Aqua Glass & 1 & 1.5 & Glass & Fragment-Indet & None \\
\hline 073 & 001 & $\mathrm{H}$ 05-1 & $\begin{array}{c}\text { Controlled Surface } \\
\text { collection }\end{array}$ & Surface & Surface & - & $\begin{array}{l}\text { Historic } \\
\text { Ceramic } \\
\end{array}$ & Historic & $\begin{array}{l}\text { Historic } \\
\text { Ceramic } \\
\end{array}$ & - & $\begin{array}{c}\text { Undecorated } \\
\text { Whiteware Ceramic }\end{array}$ & 1 & 5.0 & Ceramic & Fragment-Indet & None \\
\hline 074 & 001 & H 05-2 & $\begin{array}{c}\text { Controlled Surface } \\
\text { Collection }\end{array}$ & Surface & Surface & - & Glass & Historic & Glass & - & Colorless Glass & 1 & 2.5 & Glass & Fragment-Indet & None \\
\hline 075 & 001 & H 06-1 & $\begin{array}{c}\text { Controlled Surface } \\
\text { Collection }\end{array}$ & Surface & Surface & - & $\begin{array}{l}\text { Historic } \\
\text { Ceramic }\end{array}$ & Historic & $\begin{array}{l}\text { Historic } \\
\text { Ceramic }\end{array}$ & - & $\begin{array}{c}\text { Earthenware } \\
\text { Slip Glazed-Green } \\
\text { Ceramic } \\
\end{array}$ & 1 & 8.0 & Ceramic & Fragment-Base & None \\
\hline 076 & 001 & H 06-2 & $\begin{array}{c}\text { Controlled Surface } \\
\text { Collection }\end{array}$ & Surface & Surface & - & Glass & Historic & Glass & - & Brown Glass & 1 & 1.5 & Glass & Fragment-Indet & None \\
\hline 077 & 001 & H 06-3 & $\begin{array}{c}\text { Controlled Surface } \\
\text { Collection }\end{array}$ & Surface & Surface & - & Glass & Historic & Glass & - & Colorless Glass & 1 & 1.0 & Glass & Fragment-Indet & Slightly patinated \\
\hline 078 & 001 & H 07-1 & $\begin{array}{c}\text { Controlled Surface } \\
\text { Collection }\end{array}$ & Surface & Surface & - & Cartridge & Historic & Cartridge & - & Pistol Cartridge & 1 & 3.5 & Metal & Complete & Unknown caliber \\
\hline 079 & 001 & $\mathrm{H} 07-2$ & $\begin{array}{c}\text { Controlled Surface } \\
\text { Collection }\end{array}$ & Surface & Surface & - & Glass & Historic & Glass & - & Colorless Glass & 1 & 3.5 & Glass & Fragment-Indet & Patinated \\
\hline 080 & 001 & $\mathrm{H}$ 07-3 & $\begin{array}{c}\text { Controlled Surface } \\
\text { Collection }\end{array}$ & Surface & Surface & - & Glass & Historic & Glass & - & Colorless Glass & 1 & 1.5 & Glass & Fragment-Indet & Slightly patinated \\
\hline 081 & 001 & $\mathrm{H}$ 07-4 & $\begin{array}{c}\text { Controlled Surface } \\
\text { Collection }\end{array}$ & Surface & Surface & - & Sparkplug & Historic & Sparkplug & - & AC Sparkplug & 1 & 40.0 & $\begin{array}{l}\text { Metal and } \\
\text { Plastic }\end{array}$ & Fragment-Indet & Oxidized \\
\hline 082 & 001 & $\mathrm{H}$ 08-1 & $\begin{array}{c}\text { Controlled Surface } \\
\text { Collection }\end{array}$ & Surface & Surface & - & Wire & Historic & Wire & - & Bailing Wire & 1 & 1.0 & Metal & Fragment-Indet & Oxidized \\
\hline 083 & 001 & $\mathrm{H}$ 08-2 & $\begin{array}{c}\text { Controlled Surface } \\
\text { collection }\end{array}$ & Surface & Surface & - & Glass & Historic & Glass & - & Colorless Glass & 1 & $<0.5$ & Glass & Fragment-Indet & Patinated \\
\hline 084 & 001 & H 09-1 & $\begin{array}{c}\text { Controlled Surface } \\
\text { Collection }\end{array}$ & Surface & Surface & - & Metal & Historic & Metal & - & Metal Bracket & 1 & 342.5 & Metal & Complete & Oxidized \\
\hline 085 & 001 & H 09-2 & $\begin{array}{c}\text { Controlled Surface } \\
\text { Collection }\end{array}$ & Surface & Surface & - & Metal & Historic & Metal & - & Sheet Metal & 1 & 52.0 & Metal & Fragment-Indet & Oxidized \\
\hline 086 & 001 & H 09-3 & $\begin{array}{c}\text { Controlled Surface } \\
\text { Collection }\end{array}$ & Surface & Surface & - & Metal & Historic & Metal & - & Metal Perforated Strap & 2 & 20.5 & Metal & Fragment-Indet & Oxidized \\
\hline 087 & 001 & H 09-4 & $\begin{array}{c}\text { Controlled Surface } \\
\text { Collection }\end{array}$ & Surface & Surface & - & Metal & Historic & Metal & - & Metal Perforated Strap & 1 & 31.5 & Metal & Fragment-Indet & Oxidized \\
\hline
\end{tabular}




\begin{tabular}{|c|c|c|c|c|c|c|c|c|c|c|c|c|c|c|c|c|}
\hline $\begin{array}{l}\text { Lot } \\
\text { No. }\end{array}$ & $\begin{array}{l}\text { Spec. } \\
\text { No. }\end{array}$ & $\begin{array}{l}\text { FS } \\
\text { No. }\end{array}$ & Provenience & Level & $\begin{array}{l}\text { Elevation } \\
\text { (cmbs) }\end{array}$ & \begin{tabular}{|l} 
Feature \\
No.
\end{tabular} & $\begin{array}{l}\text { Artifact } \\
\text { Class }\end{array}$ & $\begin{array}{l}\text { Artifact } \\
\text { Subclass }\end{array}$ & $\begin{array}{l}\text { Artifact } \\
\text { Type }\end{array}$ & $\begin{array}{l}\text { Artifact } \\
\text { Subtype/ } \\
\text { Identity } \\
\end{array}$ & $\begin{array}{c}\text { Artifact } \\
\text { Description } \\
\end{array}$ & Count & \begin{tabular}{|l} 
Weight \\
(g)
\end{tabular} & Material & Completeness & Comments \\
\hline 088 & 001 & H 10-1 & $\begin{array}{c}\text { Controlled Surface } \\
\text { Collection }\end{array}$ & Surface & Surface & - & $\begin{array}{l}\text { Historic } \\
\text { Ceramic }\end{array}$ & Historic & $\begin{array}{l}\text { Historic } \\
\text { Ceramic }\end{array}$ & - & $\begin{array}{c}\text { Earthenware } \\
\text { Slip Glazed-Brown } \\
\text { Ceramic } \\
\end{array}$ & 1 & 1.5 & Ceramic & Fragment-Indet & None \\
\hline 089 & 001 & $\mathrm{H} 10-2$ & $\begin{array}{c}\text { Controlled Surface } \\
\text { Collection }\end{array}$ & Surface & Surface & - & $\begin{array}{l}\text { Historic } \\
\text { Ceramic }\end{array}$ & Historic & $\begin{array}{l}\text { Historic } \\
\text { Ceramic }\end{array}$ & - & $\begin{array}{c}\text { Earthenware } \\
\text { Slip Glazed-Brown } \\
\text { Ceramic } \\
\end{array}$ & 1 & 1.0 & Ceramic & Fragment-Indet & None \\
\hline 090 & 001 & H 10-3 & $\begin{array}{c}\text { Controlled Surface } \\
\text { Collection }\end{array}$ & Surface & Surface & - & Glass & Historic & Glass & - & Colorless Glass & 1 & 6.5 & Glass & Fragment-Indet & None \\
\hline 091 & 001 & H 11-1 & \begin{tabular}{|c|}
$\begin{array}{c}\text { Controlled Surface } \\
\text { Collection }\end{array}$ \\
\end{tabular} & Surface & Surface & - & $\begin{array}{l}\text { Historic } \\
\text { Ceramic }\end{array}$ & Historic & $\begin{array}{l}\text { Historic } \\
\text { Ceramic }\end{array}$ & - & $\begin{array}{c}\text { Earthenware } \\
\text { Slip Glazed -Brown } \\
\text { Ceramic } \\
\end{array}$ & 1 & 1.0 & Ceramic & Fragment-Rim & None \\
\hline 092 & 001 & H 11-2 & $\begin{array}{c}\text { Controlled Surface } \\
\text { Collection }\end{array}$ & Surface & Surface & - & Glass & Historic & Glass & - & Colorless Glass & 1 & 3.5 & Glass & Fragment-Indet & None \\
\hline 093 & 001 & H 11-3 & $\begin{array}{c}\begin{array}{c}\text { Controlled Surface } \\
\text { Collection }\end{array} \\
\end{array}$ & Surface & Surface & - & Glass & Historic & Glass & - & Aqua Glass & 1 & 1.0 & Glass & Fragment-Indet & None \\
\hline 094 & 001 & H 11-4 & $\begin{array}{c}\text { Controlled Surface } \\
\text { Collection }\end{array}$ & Surface & Surface & - & Glass & Historic & Glass & - & Colorless Glass & 1 & 3.0 & Glass & Fragment-Rim & None \\
\hline 095 & 001 & H 11-5 & $\begin{array}{c}\text { Controlled Surface } \\
\text { Collection }\end{array}$ & Surface & Surface & - & Glass & Historic & Glass & - & Colorless Glass & 1 & 1.0 & Glass & Fragment-Indet & None \\
\hline 096 & 001 & H 12-1 & $\begin{array}{c}\text { Controlled Surface } \\
\text { Collection }\end{array}$ & Surface & Surface & - & $\begin{array}{l}\text { Historic } \\
\text { Ceramic } \\
\end{array}$ & Historic & $\begin{array}{l}\text { Historic } \\
\text { Ceramic } \\
\end{array}$ & - & $\begin{array}{c}\text { Undecorated } \\
\text { Whiteware Ceramic }\end{array}$ & 1 & 0.5 & Ceramic & Fragment-Indet & None \\
\hline 097 & 001 & $\mathrm{H} 12-2$ & $\begin{array}{c}\text { Controlled Surface } \\
\text { Collection }\end{array}$ & Surface & Surface & - & $\begin{array}{l}\text { Historic } \\
\text { Ceramic } \\
\end{array}$ & Historic & $\begin{array}{l}\text { Historic } \\
\text { Ceramic } \\
\end{array}$ & - & $\begin{array}{c}\text { Undecorated } \\
\text { Whiteware Ceramic }\end{array}$ & 1 & 0.5 & Ceramic & Fragment-Indet & None \\
\hline 098 & 001 & $\mathrm{H} 12-3$ & $\begin{array}{c}\text { Controlled Surface } \\
\text { Collection }\end{array}$ & Surface & Surface & - & Glass & Historic & Glass & - & Aqua Glass & 1 & 6.5 & Glass & Fragment-Indet & Patinated \\
\hline 099 & 001 & H 12-4 & $\begin{array}{c}\text { Controlled Surface } \\
\text { Collection }\end{array}$ & Surface & Surface & - & Glass & Historic & Glass & - & Aqua Glass & 1 & 1.5 & Glass & Fragment-Indet & Patinated \\
\hline 100 & 001 & $\mathrm{H} 13$ & $\begin{array}{c}\text { Controlled Surface } \\
\text { Collection }\end{array}$ & Surface & Surface & - & Glass & Historic & Glass & - & Manganese Glass & 1 & 1.0 & Glass & Fragment-Indet & None \\
\hline 101 & 001 & H 14-1 & $\begin{array}{c}\text { Controlled Surface } \\
\text { Collection }\end{array}$ & Surface & Surface & - & Glass & Historic & Glass & - & Colorless Glass & 1 & 1.0 & Glass & Fragment-Indet & None \\
\hline 102 & 001 & $\mathrm{H} 14-2$ & $\begin{array}{c}\text { Controlled Surface } \\
\text { Collection }\end{array}$ & Surface & Surface & - & Glass & Historic & Glass & - & Manganese Glass & 1 & 2.5 & Glass & Fragment-Indet & None \\
\hline 103 & 001 & H 14-3 & \begin{tabular}{|c|}
$\begin{array}{c}\text { Controlled Surface } \\
\text { Collection }\end{array}$ \\
\end{tabular} & Surface & Surface & - & Glass & Historic & Glass & - & Manganese Glass & 1 & 7.0 & Glass & Fragment-Indet & Patinated \\
\hline 104 & 001 & H 15 & $\begin{array}{c}\text { Controlled Surface } \\
\text { Collection }\end{array}$ & Surface & Surface & - & $\begin{array}{l}\text { Historic } \\
\text { Ceramic }\end{array}$ & Historic & $\begin{array}{l}\text { Historic } \\
\text { Ceramic }\end{array}$ & - & $\begin{array}{c}\text { Undecorated } \\
\text { Whiteware Ceramic }\end{array}$ & 1 & 2.0 & Ceramic & Fragment-Rim & None \\
\hline 105 & 001 & H 16-1 & $\begin{array}{c}\text { Controlled Surface } \\
\text { Collection }\end{array}$ & Surface & Surface & - & $\begin{array}{l}\text { Historic } \\
\text { Ceramic } \\
\end{array}$ & Historic & $\begin{array}{l}\text { Historic } \\
\text { Ceramic } \\
\end{array}$ & - & $\begin{array}{c}\text { Undecorated } \\
\text { Whiteware Ceramic }\end{array}$ & 1 & 3.5 & Ceramic & Fragment-Indet & None \\
\hline 106 & 001 & H 16-2 & $\begin{array}{c}\text { Controlled Surface } \\
\text { Collection }\end{array}$ & Surface & Surface & - & $\begin{array}{l}\text { Historic } \\
\text { Ceramic } \\
\end{array}$ & Historic & $\begin{array}{l}\text { Historic } \\
\text { Ceramic } \\
\end{array}$ & - & $\begin{array}{c}\text { Undecorated } \\
\text { Whiteware Ceramic }\end{array}$ & 1 & 4.0 & Ceramic & Fragment-Indet & None \\
\hline 107 & 001 & H 17-1 & $\begin{array}{c}\text { Controlled Surface } \\
\text { Collection }\end{array}$ & Surface & Surface & - & $\begin{array}{l}\text { Historic } \\
\text { Ceramic } \\
\end{array}$ & Historic & $\begin{array}{l}\text { Historic } \\
\text { Ceramic } \\
\end{array}$ & - & $\begin{array}{c}\text { Undecorated } \\
\text { Whiteware Ceramic }\end{array}$ & 1 & 1.5 & Ceramic & Fragment-Indet & None \\
\hline 108 & 001 & H $17-2$ & $\begin{array}{c}\text { Controlled Surface } \\
\text { Collection }\end{array}$ & Surface & Surface & - & $\begin{array}{l}\text { Historic } \\
\text { Ceramic }\end{array}$ & Historic & $\begin{array}{l}\text { Historic } \\
\text { Ceramic }\end{array}$ & - & $\begin{array}{c}\text { Undecorated } \\
\text { Whiteware Ceramic }\end{array}$ & 1 & 1.5 & Ceramic & Fragment-Rim & None \\
\hline 109 & 001 & $\mathrm{H}$ 17-3 & $\begin{array}{c}\text { Controlled Surface } \\
\text { Collection }\end{array}$ & Surface & Surface & - & Metal & Historic & Metal & - & Heavy Gauge Wire & 1 & 31.5 & Metal & Fragment-Indet & None \\
\hline 110 & 001 & H 17-4 & $\begin{array}{c}\text { Controlled Surface } \\
\text { Collection }\end{array}$ & Surface & Surface & - & Metal & Historic & Metal & - & Heavy Gauge Wire & 1 & 11.0 & Metal & Fragment-Indet & None \\
\hline 111 & 001 & H 18-1 & $\begin{array}{c}\text { Controlled Surface } \\
\text { Collection }\end{array}$ & Surface & Surface & - & Glass & Historic & Glass & - & Aqua Glass & 1 & 2.0 & Glass & Fragment-Indet & Patinated \\
\hline 112 & 001 & H 18-2 & $\begin{array}{c}\text { Controlled Surface } \\
\text { Collection }\end{array}$ & Surface & Surface & - & Glass & Historic & Glass & - & Manganese Glass & 1 & $<0.5$ & Glass & Fragment-Indet & None \\
\hline
\end{tabular}




\begin{tabular}{|c|c|c|c|c|c|c|c|c|c|c|c|c|c|c|c|c|}
\hline $\begin{array}{l}\text { Lot } \\
\text { No. }\end{array}$ & $\begin{array}{l}\text { Spec. } \\
\text { No. }\end{array}$ & $\begin{array}{l}\text { FS } \\
\text { No. }\end{array}$ & Provenience & Level & $\begin{array}{l}\text { Elevation } \\
\text { (cmbs) }\end{array}$ & \begin{tabular}{|c} 
Feature \\
No.
\end{tabular} & $\begin{array}{l}\text { Artifact } \\
\text { Class }\end{array}$ & $\begin{array}{l}\text { Artifact } \\
\text { Subclass }\end{array}$ & $\begin{array}{l}\text { Artifact } \\
\text { Type }\end{array}$ & $\begin{array}{l}\text { Artifact } \\
\text { Subtype/ } \\
\text { Identity } \\
\end{array}$ & $\begin{array}{c}\text { Artifact } \\
\text { Description }\end{array}$ & Count & $\begin{array}{l}\text { Weight } \\
\text { (g) }\end{array}$ & Material & Completeness & Comments \\
\hline 113 & 001 & H 18-3 & $\begin{array}{c}\text { Controlled Surface } \\
\text { Collection }\end{array}$ & Surface & Surface & - & Metal & Historic & Metal & - & Fence Staple & 1 & 2.5 & Metal & Complete & Oxidized \\
\hline 114 & 001 & H 19-1 & $\begin{array}{c}\text { Controlled Surface } \\
\text { Collection }\end{array}$ & Surface & Surface & - & Glass & Historic & Glass & - & Manganese Glass & 1 & 2.5 & Glass & Fragment-Indet & Patinated \\
\hline 115 & 001 & H 19-2 & $\begin{array}{c}\text { Controlled Surface } \\
\text { Collection }\end{array}$ & Surface & Surface & - & Glass & Historic & Glass & - & Manganese Glass & 1 & 1.5 & Glass & Fragment-Indet & tPatinated \\
\hline 116 & 001 & H 19-3 & $\begin{array}{c}\text { Controlled Surface } \\
\text { Collection }\end{array}$ & Surface & Surface & - & Glass & Historic & Glass & - & Manganese Glass & 1 & 1.5 & Glass & Fragment-Rim & Patinated \\
\hline 117 & 001 & H 19-4 & $\begin{array}{c}\text { Controlled Surface } \\
\text { Collection }\end{array}$ & Surface & Surface & - & $\begin{array}{l}\text { Historic } \\
\text { Ceramic } \\
\end{array}$ & Historic & $\begin{array}{l}\text { Historic } \\
\text { Ceramic } \\
\end{array}$ & - & $\begin{array}{c}\text { Undecorated } \\
\text { Whiteware Ceramic }\end{array}$ & 1 & 0.5 & Ceramic & Fragment-Indet & None \\
\hline 118 & 001 & H 19-5 & $\begin{array}{c}\text { Controlled Surface } \\
\text { collection }\end{array}$ & Surface & Surface & - & $\begin{array}{l}\text { Historic } \\
\text { Ceramic } \\
\end{array}$ & Historic & $\begin{array}{l}\text { Historic } \\
\text { Ceramic } \\
\end{array}$ & - & $\begin{array}{c}\text { Undecorated } \\
\text { Whiteware Ceramic } \\
\end{array}$ & 1 & 1.5 & Ceramic & Fragment-Indet & None \\
\hline 119 & 001 & H 19-6 & $\begin{array}{c}\text { Controlled Surface } \\
\text { Collection }\end{array}$ & Surface & Surface & - & $\begin{array}{l}\text { Historic } \\
\text { Ceramic }\end{array}$ & Historic & $\begin{array}{l}\text { Historic } \\
\text { Ceramic }\end{array}$ & - & $\begin{array}{c}\text { Blue Transfer Ware } \\
\text { Ceramic }\end{array}$ & 1 & $<0.5$ & Ceramic & Fragment-Rim & None \\
\hline 120 & 001 & $\mathrm{H} 20-1$ & $\begin{array}{c}\text { Controlled Surface } \\
\text { Collection }\end{array}$ & Surface & Surface & - & Glass & Historic & Glass & - & Manganese Glass & 1 & 3.0 & Glass & Fragment-Indet & None \\
\hline 121 & 001 & $\mathrm{H} 20-2$ & $\begin{array}{c}\text { Controlled Surface } \\
\text { Collection }\end{array}$ & Surface & Surface & - & Glass & Historic & Glass & - & Colorless Glass & 1 & 3.5 & Glass & Fragment-Indet & tPatinated \\
\hline 122 & 001 & H 20-3 & $\begin{array}{c}\text { Controlled Surface } \\
\text { collection }\end{array}$ & Surface & Surface & - & $\begin{array}{l}\text { Historic } \\
\text { Ceramic } \\
\end{array}$ & Historic & $\begin{array}{l}\text { Historic } \\
\text { Ceramic } \\
\end{array}$ & - & $\begin{array}{c}\text { Undecorated } \\
\text { Whiteware Ceramic }\end{array}$ & 1 & 2.0 & Ceramic & Fragment-Indet & None \\
\hline 123 & 001 & H 20-4 & $\begin{array}{c}\text { Controlled Surface } \\
\text { Collection }\end{array}$ & Surface & Surface & - & $\begin{array}{l}\text { Historic } \\
\text { Ceramic } \\
\end{array}$ & Historic & $\begin{array}{l}\text { Historic } \\
\text { Ceramic } \\
\end{array}$ & - & $\begin{array}{c}\text { Undecorated } \\
\text { Whiteware Ceramic }\end{array}$ & 1 & - & Ceramic & Fragment-Indet & Missing \\
\hline 124 & 001 & H 21-1 & $\begin{array}{c}\text { Controlled Surface } \\
\text { Collection }\end{array}$ & Surface & Surface & - & Glass & Historic & Glass & - & Colorless Glass & 1 & 1.0 & Glass & Fragment-Indet & Slightly patinated \\
\hline 125 & 001 & H 21-2 & $\begin{array}{c}\text { Controlled Surface } \\
\text { Collection }\end{array}$ & Surface & Surface & - & Glass & Historic & Glass & - & Manganese Glass & 1 & 0.5 & Glass & Fragment-Indet & None \\
\hline 126 & 001 & $\mathrm{H} 22$ & $\begin{array}{c}\begin{array}{c}\text { Controlled Surface } \\
\text { Collection }\end{array} \\
\end{array}$ & Surface & Surface & - & $\begin{array}{l}\text { Historic } \\
\text { Ceramic } \\
\end{array}$ & Historic & $\begin{array}{l}\text { Historic } \\
\text { Ceramic }\end{array}$ & - & $\begin{array}{c}\text { Earthenware } \\
\text { Slip Glazed-Brown } \\
\text { Ceramic } \\
\end{array}$ & 1 & 6.5 & Ceramic & Fragment-Indet & None \\
\hline 127 & 001 & $\mathrm{H} 23$ & $\begin{array}{c}\text { Controlled Surface } \\
\text { Collection }\end{array}$ & Surface & Surface & - & $\begin{array}{l}\text { Historic } \\
\text { Ceramic } \\
\end{array}$ & Historic & $\begin{array}{l}\text { Historic } \\
\text { Ceramic } \\
\end{array}$ & - & $\begin{array}{c}\text { Undecorated } \\
\text { Whiteware Ceramic } \\
\end{array}$ & 1 & 3.0 & Ceramic & Fragment-Indet & None \\
\hline 128 & 001 & $\mathrm{H} 24$ & $\begin{array}{c}\text { Controlled Surface } \\
\text { Collection }\end{array}$ & Surface & Surface & - & Glass & Historic & Glass & - & Colorless Glass & 1 & 4.0 & Glass & Fragment-Indet & Slightly patinated \\
\hline 129 & 001 & $\mathrm{H} 25$ & $\begin{array}{c}\text { Controlled Surface } \\
\text { Collection }\end{array}$ & Surface & Surface & - & $\begin{array}{l}\text { Historic } \\
\text { Ceramic }\end{array}$ & Historic & $\begin{array}{l}\text { Historic } \\
\text { Ceramic }\end{array}$ & - & $\begin{array}{c}\text { Undecorated } \\
\text { Whiteware Ceramic }\end{array}$ & 1 & 3.5 & Ceramic & Fragment-Base & None \\
\hline 130 & 001 & H 26-1 & $\begin{array}{c}\text { Controlled Surface } \\
\text { Collection }\end{array}$ & Surface & Surface & - & Glass & Historic & Glass & - & Manganese Glass & 1 & 6.0 & Glass & Fragment-Indet & None \\
\hline 131 & 001 & H 26-2 & $\begin{array}{c}\text { Controlled Surface } \\
\text { Collection }\end{array}$ & Surface & Surface & - & Glass & Historic & Glass & - & Manganese Glass & 1 & 2.0 & Glass & Fragment-Indet & None \\
\hline 132 & 001 & $\mathrm{H}$ 26-3 & $\begin{array}{c}\text { Controlled Surface } \\
\text { Collection }\end{array}$ & Surface & Surface & - & Glass & Historic & Glass & - & Manganese Glass & 1 & 3.0 & Glass & Fragment-Indet & None \\
\hline 133 & 001 & H 26-4 & $\begin{array}{c}\text { Controlled Surface } \\
\text { Collection }\end{array}$ & Surface & Surface & - & Glass & Historic & Glass & - & Manganese Glass & 1 & 0.5 & Glass & Fragment-Indet & None \\
\hline 134 & 001 & $\mathrm{H} 27$ & $\begin{array}{c}\text { Controlled Surface } \\
\text { Collection }\end{array}$ & Surface & Surface & - & Glass & Historic & Glass & - & Aqua Glass & 1 & 10.5 & Glass & Fragment-Base & Patinated \\
\hline 135 & 001 & H 28 & $\begin{array}{c}\begin{array}{c}\text { Controlled Surface } \\
\text { Collection }\end{array} \\
\end{array}$ & Surface & Surface & - & Metal & Historic & Metal & - & Bailing Wire & 1 & 28.0 & Metal & Fragment-Indet & Oxidized \\
\hline 136 & 001 & H 29 & $\begin{array}{c}\text { Controlled Surface } \\
\text { Collection }\end{array}$ & Surface & Surface & - & Metal & Historic & Metal & - & Cookware & 1 & 283.0 & Metal & Fragment-Rim & Oxidized \\
\hline 137 & 001 & H 30 & $\begin{array}{c}\text { Controlled Surface } \\
\text { Collection }\end{array}$ & Surface & Surface & - & Glass & Historic & Glass & - & Colorless Glass & 1 & 26.0 & Glass & Fragment-Indet & Highly patinated \\
\hline
\end{tabular}




\begin{tabular}{|c|c|c|c|c|c|c|c|c|c|c|c|c|c|c|c|c|}
\hline $\begin{array}{l}\text { Lot } \\
\text { No. }\end{array}$ & $\begin{array}{l}\text { Spec. } \\
\text { No. }\end{array}$ & $\begin{array}{l}\text { FS } \\
\text { No. }\end{array}$ & Provenience & Level & $\begin{array}{c}\text { Elevation } \\
\text { (cmbs) }\end{array}$ & \begin{tabular}{c|c} 
Feature \\
No.
\end{tabular} & $\begin{array}{l}\text { Artifact } \\
\text { Class }\end{array}$ & $\begin{array}{l}\text { Artifact } \\
\text { Subclass }\end{array}$ & $\begin{array}{l}\text { Artifact } \\
\text { Type }\end{array}$ & $\begin{array}{l}\text { Artifact } \\
\text { Subtypel } \\
\text { Identity } \\
\end{array}$ & $\begin{array}{c}\text { Artifact } \\
\text { Description }\end{array}$ & Count $\mid$ & $\begin{array}{l}\text { Weight } \\
\text { (g) }\end{array}$ & Material & Completeness & Comments \\
\hline 138 & 001 & H 31-1 & \begin{tabular}{|c|} 
Controlled Surface \\
Collection
\end{tabular} & Surface & Surface & - & Glass & Historic & Glass & - & Colorless Glass & 1 & 4.5 & Glass & Fragment-Indet & Slightly patinated \\
\hline 139 & 001 & H 31-2 & $\begin{array}{c}\text { Controlled Surface } \\
\text { Collection }\end{array}$ & Surface & Surface & - & Glass & Historic & Glass & - & Colorless Glass & 1 & 4.5 & Glass & Fragment-Indet & Slightly patinated \\
\hline 140 & 001 & H 31-3 & $\begin{array}{c}\text { Controlled Surface } \\
\text { Collection }\end{array}$ & Surface & Surface & - & Glass & Historic & Glass & - & Colorless Glass & 1 & 2.5 & Glass & Fragment-Indet & Slightly patinated \\
\hline 141 & 001 & H 31-4 & $\begin{array}{c}\text { Controlled Surface } \\
\text { Collection }\end{array}$ & Surface & Surface & - & Glass & Historic & Glass & - & Colorless Glass & 1 & 1.5 & Glass & Fragment-Indet & Slightly patinated \\
\hline 142 & 001 & H 31-5 & $\begin{array}{c}\text { Controlled Surface } \\
\text { Collection }\end{array}$ & Surface & Surface & - & $\begin{array}{l}\text { Historic } \\
\text { Ceramic } \\
\end{array}$ & Historic & $\begin{array}{l}\text { Historic } \\
\text { Ceramic }\end{array}$ & - & $\begin{array}{c}\text { Earthenware } \\
\text { Slip Glazed-Tan }\end{array}$ & 1 & 18.0 & Ceramic & Fragment-Indet & Painted line designs \\
\hline 143 & 001 & H 31-6 & $\begin{array}{c}\text { Controlled Surface } \\
\text { Collection }\end{array}$ & Surface & Surface & - & $\begin{array}{l}\text { Historic } \\
\text { Ceramic } \\
\end{array}$ & Historic & $\begin{array}{l}\text { Historic } \\
\text { Ceramic } \\
\end{array}$ & - & $\begin{array}{l}\text { Porcelain Ceramic } \\
\text { Figurine Fragment } \\
\end{array}$ & 1 & 1.0 & Ceramic & Fragment-Indet & None \\
\hline 144 & 001 & H 32-1 & $\begin{array}{c}\text { Controlled Surface } \\
\text { Collection }\end{array}$ & Surface & Surface & - & $\begin{array}{l}\text { Historic } \\
\text { Ceramic }\end{array}$ & Historic & $\begin{array}{l}\text { Historic } \\
\text { Ceramic }\end{array}$ & - & $\begin{array}{c}\text { Undecorated } \\
\text { Whiteware Ceramic }\end{array}$ & 1 & 4.5 & Ceramic & Fragment-Rim & None \\
\hline 145 & 001 & H 32-2 & $\begin{array}{c}\begin{array}{c}\text { Controlled Surface } \\
\text { Collection }\end{array} \\
\end{array}$ & Surface & Surface & - & Glass & Historic & Glass & - & Aqua Glass & 1 & 2.0 & Glass & Fragment-Indet & Patinated \\
\hline 146 & 001 & H 33 & $\begin{array}{c}\text { Controlled Surface } \\
\text { Collection }\end{array}$ & Surface & Surface & - & $\begin{array}{l}\text { Historic } \\
\text { Ceramic }\end{array}$ & Historic & $\begin{array}{l}\text { Historic } \\
\text { Ceramic }\end{array}$ & - & $\begin{array}{c}\text { Undecorated } \\
\text { Whiteware Ceramic }\end{array}$ & 1 & 6.0 & Ceramic & Fragment-Rim & None \\
\hline 147 & 001 & H 35-1 & $\begin{array}{c}\text { Controlled Surface } \\
\text { Collection }\end{array}$ & Surface & Surface & - & $\begin{array}{l}\text { Historic } \\
\text { Ceramic }\end{array}$ & Historic & $\begin{array}{l}\text { Historic } \\
\text { Ceramic }\end{array}$ & - & Undecorated Ironstone & 1 & 8.0 & Ceramic & Fragment-Base & $\begin{array}{l}\text { Partial Backstamp "...ONSTONE } \\
\text { CHINA" }\end{array}$ \\
\hline 148 & 001 & H 35-2 & $\begin{array}{c}\text { Controlled Surface } \\
\text { Collection }\end{array}$ & Surface & Surface & - & $\begin{array}{l}\text { Historic } \\
\text { Ceramic }\end{array}$ & Historic & $\begin{array}{l}\text { Historic } \\
\text { Ceramic }\end{array}$ & - & $\begin{array}{c}\text { Undecorated } \\
\text { Whiteware Ceramic }\end{array}$ & 1 & 10.0 & Ceramic & Fragment-Base & None \\
\hline 149 & 001 & H 35-3 & $\begin{array}{c}\text { Controlled Surface } \\
\text { Collection }\end{array}$ & Surface & Surface & - & Wire & Historic & Wire & - & Wire & 1 & - & Ceramic & Fragment-Rim & Missing \\
\hline 150 & 001 & H 36 & $\begin{array}{c}\text { Controlled Surface } \\
\text { Collection }\end{array}$ & Surface & Surface & - & $\begin{array}{l}\text { Historic } \\
\text { Ceramic }\end{array}$ & Historic & $\begin{array}{l}\text { Historic } \\
\text { Ceramic }\end{array}$ & - & $\begin{array}{c}\text { Earthenware } \\
\text { Slip Glazed-Brown } \\
\text { Ceramic } \\
\end{array}$ & 1 & 3.5 & Ceramic & Fragment-Indet & Green stripe decoration \\
\hline 151 & 001 & $\mathrm{H} 37$ & $\begin{array}{c}\text { Controlled Surface } \\
\text { Collection }\end{array}$ & Surface & Surface & - & $\begin{array}{l}\text { Historic } \\
\text { Ceramic }\end{array}$ & Historic & $\begin{array}{l}\text { Historic } \\
\text { Ceramic }\end{array}$ & - & \begin{tabular}{|c|} 
Earthenware \\
Slip Glazed-Brown \\
Ceramic
\end{tabular} & 1 & 0.5 & Ceramic & Fragment-Indet & None \\
\hline 169 & 008 & 19 & TU2 & Lvl 2 & $30-40 \mathrm{~cm}$ & 2 & $\begin{array}{l}\text { Historic } \\
\text { Ceramic } \\
\end{array}$ & Historic & $\begin{array}{l}\text { Earthenware } \\
\text { Slip Glazed }\end{array}$ & & $\begin{array}{c}\text { Earthenware Slip } \\
\text { Glazed Brown Ceramic } \\
\end{array}$ & 1 & 0.5 & Ceramic & Fragment-Indet & None \\
\hline 176 & 011 & 26 & TU4 & Lvl 1 & $30-40 \mathrm{~cm}$ & 3 & $\begin{array}{l}\text { Historic } \\
\text { Ceramic } \\
\end{array}$ & Historic & $\begin{array}{l}\text { Earthenware } \\
\text { Slip Glazed }\end{array}$ & & $\begin{array}{c}\text { Earthenware Slip } \\
\text { Glazed Brown Ceramic } \\
\end{array}$ & 1 & $<0.5$ & Ceramic & Fragment-Indet & None \\
\hline 177 & 008 & 27 & TU4 & LVl 2 & $40-50 \mathrm{~cm}$ & 3 & Glass & & Glass & & \begin{tabular}{|l|} 
Colorless Glass \\
\end{tabular} & 1 & 0.5 & Glass & & Heavily patinated \\
\hline 205 & 006 & 50 & BHT 8 & LVl 2 & $10-20 \mathrm{~cm}$ & - & $\begin{array}{l}\text { Historic } \\
\text { Ceramic }\end{array}$ & Historic & $\begin{array}{l}\text { Historic } \\
\text { Ceramic }\end{array}$ & - & $\begin{array}{c}\text { Undecorated } \\
\text { Whiteware Ceramic }\end{array}$ & 2 & 4.5 & Ceramic & Fragment-Indet & 2 changed from 1 \\
\hline
\end{tabular}

